\title{
Ökonomische Aspekte der dezentralen Dreiecksmietenkompostierung von Bioabfällen aus Haushalten in landwirtschaftlichen Low-Tech-Anlagen und der landbaulichen Kompostverwertung
}

\author{
Dissertation \\ zur Erlangung des Doktorgrades \\ der Fakultät für Agrarwissenschaften \\ der Georg-August-Universität Göttingen
}

vorgelegt von
Joachim Kasten
geboren in Hamburg

Göttingen, den 16.09.1999 
1. Referent: Prof. Dr. R. Marggraf

Institut für Agrarökonomie

2. Korreferent: Prof. Dr. W. Lücke

Institut für Agrartechnik

Tag der mündlichen Prüfung: 4.11.1999 
Gefördert durch

das Stipendienprogramm

der

Deutschen Bundesstiftung Umwelt 


\section{Danksagung}

Die vorliegende Arbeit wurde im Arbeitsbereich Umwelt- und Ressourcenökonomik am Institut für Agrarökonomie der Georg-August-Universität Göttingen durchgeführt.

Mein besonderer Dank gilt Herrn Prof. Dr. R. Marggraf für die wissenschaftliche Betreuung sowie das stetige Interesse am Fortgang dieser Arbeit.

Herrn Prof. W. Lücke danke ich für die Übernahme des Korreferats sowie des Zweitgutachtens.

Den Betriebsleitern der am Modellversuch zur dezentralen Kompostierung im Landkreis Demmin beteiligten Landwirtschaftsbetriebe, Herrn Ziel und Herrn Bahll, möchte ich für die stete Auskunfts- und Diskussionsbereitschaft, die wesentlich zum Gelingen dieser Arbeit beigetragen hat, meinen Dank aussprechen.

Dem Umweltamtsleiter des Landkreises Demmin, Herrn Dr. Thürkow, sowie den hinsichtlich des genannten Modellversuchs zuständigen Mitarbeitern (Herr Nagel, Herr Anders und Frau Schrader) gilt ebenso mein Dank für die notwendigen Auskünfte und Gespräche wie auch Herrn Kröhan vom Umweltministerium Mecklenburg-Vorpommern.

Der LUFA Rostock danke ich für die Durchführung der Schwermetallanalysen und Herrn Wiese von der LMS (Landwirtschaftsberatung Mecklenburg-Vorpommern / SchleswigHolstein $\mathrm{GmbH}$ ) für die angenehme Zusammenarbeit zu Beginn meiner Arbeit.

Der Deutschen Bundesstiftung Umwelt danke ich für die finanzielle und fachliche Förderung dieser Arbeit im Rahmen ihres Stipendienprogramms.

Mein besonderer Dank gilt meinen Eltern für die finanzielle Unterstützung während des Studiums sowie für Verständnis und Aufmunterung zu jeder Zeit. 
Anhang 


\section{$1 \quad$ Einleitung und Zielsetzung}

\subsection{Einleitung}

Um die zu deponierenden Abfallmengen zu reduzieren, wurde im Abfallrecht eine verstärkte Trennung der Abfallströme verankert. Gemäß den Vorgaben der TA Siedlungsabfall wird vielfach die organische Fraktion des Hausmülls durch die entsorgungspflichtigen Körperschaften getrennt gesammelt und gesondert behandelt, um diese Stoffe in aufbereiteter Form einer Verwertung zuzuführen. Als häufigste Form der Aufbereitung werden die Bioabfälle aus Haushalten zusammen mit dem erforderlichen Strukturmaterial kompostiert, um diese anschließend in den Stoffkreislauf zurückführen zu können.

Aus dem Einstieg der entsorgungspflichtigen Körperschaften in die flächendeckende Bioabfallsammlung resultieren immer größere Mengen zu verwertender Bioabfälle. Die Vermarktung der erzeugten Komposte in den herkömmlichen Abnehmerkreisen, wie z.B. den Kleingärtnern und dem Garten- und Landschaftsbau, scheint jedoch angesichts des beständig wachsenden Bioabfallaufkommens nur noch teilweise möglich zu sein. Insbesondere durch den Trend der Errichtung von zentralen Kompostierungsanlagen mit hohen Verarbeitungskapazitäten werden regionale Märkte für die Abnahme der produzierten Kompostmengen zukünftig nicht mehr ausreichen (Wintzer et.al. 1996: 156).

Aus diesem Grund erhält die landwirtschaftliche Verwertung der Bioabfallkomposte einen zunehmenden Stellenwert: durch langfristige vertragliche Bindung von Landwirten für die Abnahme der erzeugten Komposte können die Kommunen den Nachweis über deren gesicherte Verwertung, der in der TA Siedlungsabfall bzw. in Form von jährlich fortzuschreibenden Entsorgungsvorsorgenachweisen gemäß dem Abfallrecht der einzelen Bundesländer gefordert wird, führen.

Die Landwirtschaft ist als größter Flächeninhaber Deutschlands auch unter Beachtung der Konkurrenz anderer organischer Stoffe, die ebenfalls zu einer landbaulichen Verwertung geeignet sind, in der Lage, die erzeugten Bioabfallkomposte abzunehmen (vgl. Kluge/Embert 1996: 217). Dennoch ist keine uneingeschränkte Bereitschaft der Landwirte zur Verwertung von Bioabfallkomposten erkennbar. Vielmehr ist die landbauliche Abfallverwertung weniger von den vorhandenen landwirtschaftlichen Flächen als von einer häufig emotional belasteten öffentlichen 
Diskussion um diese Stoffe geprägt (Kluge/Embert 1996: 216), woraus eine Verunsicherung der Landwirte gegenüber der landbaulichen Kompostverwertung resultiert.

Unter Beachtung dieser Entwicklung ist absehbar, daß zukünftig ein großer Teil der erzeugten Komposte entweder kostenlos oder mit Zuzahlung (quasi als Aufbringungsprämie) an die Landwirtschaft abgegeben werden wird (Kasten/Marggraf 1999: 275).

Um die Bereitschaft der Landwirte zur landwirtschaftlichen Verwertung von Erzeugnissen auf der Basis behandelter Bioabfälle zu erhöhen, ist zu prüfen, ob Landwirte unter den heutigen Bedingungen auf dem Entsorgungsmarkt für biogene Stoffe in der Lage sind, neben der erwünschten Verwertung auch die Bioabfallbehandlung, z.B. als Betreiber einer Kompostierungsanlage, zu übernehmen.

Dieses Konzept bietet einige Vorteile: dadurch, daß der Verwerterbetrieb gleichzeitig die Kompostierung betreibt und überwacht, kann dieser direkt Einfluß auf die Kompostqualität nehmen. Dies ist deshalb erwähnenswert, da die Landwirte selbst das größte Interesse an einem langfristigen Erhalt ihrer Produktionsgrundlage „Boden“ haben (Popp et.al.1993: 358).

Zudem haben Landwirte Erfahrung im Umgang mit biologischen Prozessen und für den Fall der Verwertung auf betriebszugehörigen Flächen können Stoffkreisläufe regional geschlossen werden (Helm 1997: 171). Gleichzeitig bietet die Durchführung auch der Bioabfallbehandlung Landwirten die Möglichkeit, sich eine neue Einkommensquelle zu erschließen.

Die Dienstleistung der Kompostierung organischer Haushaltsabfälle wird überwiegend von überregional agierenden Unternehmen bedient, die zentrale Großanlagen mit großem Einzugsgebiet errichtet haben. Landwirte als Bioabfallbehandler bevorzugen jedoch offene Kleinanlagen (sog. Low-Tech-Anlagen), weil der Investitionsbedarf relativ gering ist und sich die produzierten Komposte im eigenen Betrieb verwerten lassen (Helm 1997:175). Solche Anlagen können wegen geringer Durchsatzleistungen, die insbesondere aus Emissionsschutzgründen begrenzt sind, nur im Rahmen dezentraler Entsorgungskonzepte für Bioabfälle betrieben werden. Die Preisentwicklung für die Bioabfallbehandlung in den letzten Jahren hat jedoch dazu geführt, daß ,dezentrale Lösungen mit Kleinanlagen aus Kostengründen häufig nicht konkurrenzfähig sind“ (Helm 1997: 175).

\subsection{Zielsetzung}

Ziel dieser Arbeit ist es, die Bedingungen darzustellen, unter denen dezentrale Konzepte der Bioabfallkompostierung in landwirtschaftlichen Low-Tech-Anlagen und der anschließenden 
landbaulichen Verwertung der produzierten Komposte konkurrenzfähig sind. Dazu werden die ökonomischen Aspekte dieses Verwertungswegs untersucht, wobei als verbreitetes Verfahren der Behandlung von Bioabfällen aus Haushalten und dem notwendigen Strukturmaterial die Kompostierung in offenen Dreiecksmieten zugrundegelegt wird.

Die genannten ökonomischen Aspekte beinhalten die Kosten, die den Landwirten durch die Bioabfallbehandlung und Kompostausbringung auf landwirtschaftlicher Nutzfläche entstehen, die Risiken in Zusammenhang mit dem Anlagenbetrieb und der landbaulichen Kompostverwertung sowie den Nutzen, der mit den (positiven) Kompostwirkungen verbunden ist (Tab.1.1).

Tab.1.1: Ökonomische Aspekte der Bioabfallkompostierung in landwirtschaftlichen Low-TechAnlagen und der landbaulichen Kompostverwertung

\begin{tabular}{|c|c|c|}
\hline & Betrieb der Kompostierungsanlage & $\begin{array}{l}\text { Landwirtschaftliche } \\
\text { Kompostverwertung }\end{array}$ \\
\hline Kosten & $\begin{array}{ll}\text { - } & \text { Maschinenkosten } \\
\text { - } & \text { Kosten der baulichen Einrichtungen } \\
\text { - } & \text { Personalkosten } \\
\text { - } & \text { Fremdleistungskosten } \\
\end{array}$ & $\begin{array}{ll}\text { - } & \text { Maschinenkosten } \\
\text { - } & \text { Personalkosten } \\
\text { - } & \text { Fremdleistungskosten } \\
\text { - } & \text { Gemeinkosten }\end{array}$ \\
\hline Risiko & \begin{tabular}{|l|} 
Sach- und Personenschäden durch \\
Einwirkungen, die durch den \\
Anlagenbetrieb hervorgerufen und über \\
Boden, Wasser oder Luft verbreitet \\
wurden \\
\end{tabular} & $\begin{array}{ll}\text { - } & \text { Wertminderung oder Wertverlust } \\
\text { - } & \text { Ertragsausfälle } \\
\text { - } & \text { Wertminderung oder Ablehnung von } \\
& \text { Ernteprodukten } \\
\end{array}$ \\
\hline Nutzen & $\begin{array}{l}\text { Vergütung für die Dienstleistung der } \\
\text { Bioabfallbehandlung durch die } \\
\text { entsorgungspflichtige Körperschaft }\end{array}$ & $\begin{array}{l}\text { - Wertgebende Kompostinhaltsstoffe } \\
\text { - } \begin{array}{l}\text { Bodenverbessernde Eigenschaften } \\
\text { von Kompost }\end{array} \\
\end{array}$ \\
\hline
\end{tabular}

\subsection{Vorgehensweise}

Nach Darstellung der rechtlichen Rahmenbedingungen für den Betrieb einer Kompostierungsanlage und der landbaulichen Kompostverwertung sowie der Grundlagen der Kompostierung werden die Kosten der dezentralen Behandlung von Bioabfällen aus Haushalten und dem notwendigen Strukturmaterial durch Landwirte, die neu errichtete Kompostierungsanlagen bzw. für die 
Kompostierung umgenutzte Altsiloanlagen betreiben (sog. „Betreibermodell“ ${ }^{1}$ ), für verschiedene Durchsätze ermittelt. Es wird davon ausgegangen, daß diese Landwirte als Bioabfallbehandler den produzierten Kompost auf betriebszugehöriger Fläche verwerten. Daher werden z.B. Kosten der Konfektionierung für die Kompostvermarktung nicht berïcksichtigt. Aus der Kompostgabe entstehende Nutzen und Risiken sind dem kompostherstellenden Landwirtschaftsbetrieb zuzurechnen. Zur Kostenermittlung wird beispielhaft ein bereits abgeschlossener Modellversuch in Mecklenburg-Vorpommern zur dezentralen Bioabfallkompostierung in Altsiloanlagen herangezogen. Um Ergebnisse zu erhalten, die über diesen Modellversuch hinaus Interpretationen zulassen, werden Besonderheiten in den untersuchten Betrieben hinsichtlich der einzelnen Verfahrensschritte nicht berücksichtigt bzw. erfaßt und hiervon abstrahiert.

Anschließend werden die Umweltbeeinträchtigungen dargestellt, die durch den Betrieb einer Kompostierungsanlage und durch die landwirtschaftliche Verwertung von Bioabfallkomposten entstehen können. Hieraus kann dem Landwirt ein unternehmerisches Risiko erwachsen, sofern er für deren Auswirkungen haftet oder Einkommenseinbußen bzw. Vermögensschäden zu befürchten hat. Daher haben Landwirte als Bioabfallbehandler diese Risiken in ihrer Preiskalkulation für die angebotenen Entsorgungsleistungen zu berücksichtigen, so daß in dieser Arbeit Ansätze zur monetären Bewertung dieser Risiken dargestellt werden.

Zudem sollen Nutzwirkungen der landbaulichen Kompostverwertung ökonomisch bewertet werden. Der (monetäre) Wert des Komposts hängt jedoch von vielen Einflußfaktoren $a b$, die in Modellrechnungen nicht vollständig erfaßt werden können (Kuhlmann et.al.1996: 32), zumal nicht alle Kompostwirkungen im System Boden-Pflanze hinreichend genau bekannt sind. Deshalb werden im Rahmen dieser Arbeit die aus betriebswirtschaftlicher Sicht wichtigsten nützlichen

\footnotetext{
${ }^{1}$ Ein Landwirt bzw. ein landwirtschaftlicher Betrieb bewirkt im einvernehmlichen Handeln mit der Kommune als entsorgungspflichtige Körperschaft die für die Errichtung neuer bzw. Sanierung bestehender Anlagen erforderlichen Leistungen. Er hat dabei die Bauherreneigenschaft, trägt das wirtschaftliche Risiko und übernimmt den Betrieb der Kompostierungsanlage. „Die an den Betreiber zu zahlende Vergütung geht als Entgelt für Fremddienstleistungen in die Berechnung der kommunalen Gebühren ein“ (Döhler et.al.1999: 184). Es sind auch andere Modelle denkbar, bei denen die Kommune eine Kompostierungsanlage auf eigene Kosten erstellen und diese z.B. durch einen Landwirtschaftsbetrieb oder Maschinenring betreiben läßt. Eine derartige Verschiebung des wirtschaftlichen Risikos bewirkt jedoch keine Veränderung der spezifischen Gesamtkosten für den Bereich der Bioabfallbehandlung, so daß durch eine Gegenüberstellung solcher unterschiedlicher Modelle keine zusätzlichen Erkenntnisse bezüglich der Konkurrenzfähigkeit des untersuchten Verwertungswegs gegenüber alternativen Verfahren der Bioabfallbehandlung gewonnen werden könnten. Daher wird diese Untersuchung auf das genannte Modell beschränkt.
} 
Komposteigenschaften ökonomisch bewertet, so daß eine Annäherung an den tatsächlichen monetären Wert der untersuchten Bioabfallkomposte erreicht wird (vgl. Kuhlmann et.al.1996: 32).

Im Ergebnis wird aufgezeigt, inwieweit das dargestellte Konzept der Bioabfallkompostierung mit anschließender landbaulicher Kompostverwertung bei dem derzeitigen Preisniveau für die Abnahme insbesondere von Bioabfällen aus Haushalten konkurrenzfähig ist.

Hierzu werden die einzelnen Teilergebnisse, nämlich die ermittelten Kosten und die monetär bewerteten Risiko- und Nutzeffekte des untersuchten Verwertungswegs, in Form spezifischer Größen gegenübergestellt. Danach werden durch eine vergleichende Betrachtung der ökonomischen Kenngrößen alternativer Verwertungswege Schlußfolgerungen über die Konkurrenzfähigkeit des gesamten Verwertungskonzepts gezogen. 


\section{Grundlagen der Kompostierung}

\section{$2.1 \quad$ Kompostienungsprozeß}

Die Kompostierung pflanzlicher Pflegerïckstände und Küchenabfälle ist ein natürlich ablaufendes Verfahren, das traditionell zur Behandlung organischer Abfälle eingesetzt wird (Wintzer et.al.1996: 93).

Beim Kompostierungsprozeß bauen Mikroorganismen in Anwesenheit von Sauerstoff und Wasser organische Verbindungen zu Wasser und Kohlendioxid ab, wobei von den unter den bestimmten Milieubedingungen aktiven Mikroorganismen Wärme freigesetzt wird. Bei der Mietenkompostierung führt diese zur Selbsterhitzung (mit Temperaturen bis zu $75^{\circ} \mathrm{C}$ ), wenn die Abstrahlungsverluste der Miete geringer sind als die nachgelieferte Wärmemenge (Schuchardt 1995: 8).

Die Population der mikrobiologischen Flora unterliegt in Abhängigkeit des Milieus während des Kompostierungsprozesses einer ständigen Veränderung: in Abhängigkeit von der Temperatur im Rottegut überwiegen bestimmte Gruppen, die jeweils spezifische Substrate abbauen, wie z.B. Pilze und säurebildende Bakterien im mesophilen Bereich bis etwa $40^{\circ} \mathrm{C}$, thermophile Bakterien, Actinomyceten und Pilze im thermophilen Bereich bis etwa $70{ }^{\circ} \mathrm{C}$ sowie sporenbildende Bakterien bei Temperaturen über $70{ }^{\circ} \mathrm{C}$. Die Temperatur hat damit wesentlichen Einfluß auf die mikrobielle Aktivität und daher auf den Abbau der einzelnen Bestandteile der organischen Substanz, wie z.B. Cellulose, Lignin, Proteine und Fette (Helm 1995: 24-25).

Neben einem ausreichenden Wassergehalt benötigen die Mikroorganismen im Substrat ein C/NVerhältnis von etwa 25. Bei einem engeren $\mathrm{C} / \mathrm{N}-$ Verhältnis besteht die Gefahr von Stickstoffverlusten durch abgasendes Ammoniak, bei einem weiteren $\mathrm{C} / \mathrm{N}-$ Verhältnis verlängert sich die erforderliche Rottedauer (Schuchardt 1995: 11).

Beim Kompostierungsprozeß ist ein charakteristischer Temperaturverlauf zu beobachten, anhand dessen dieser in verschiedene Phasen eingeteilt wird.

Die erste Phase der Kompostierung wird als Vorrotte bezeichnet, in der der Abbau der leicht abbaubaren organischen Substanz erfolgt. Zu Beginn der Vorrotte hat das Ausgangsmaterial etwa Umgebungstemperatur und ist meistens schwach sauer (Döhler et.al.1999: 165). Während der 
Vorrotte steigen die Temperaturen nach einer kurzen Anlaufphase exponentiell auf bis zu $75{ }^{\circ} \mathrm{C}$ an, wobei es durch Umstellung der Mikroorganismenpopulation von den Mesophilen zu den Thermophilen bei etwa $40{ }^{\circ} \mathrm{C} \mathrm{zu}$ einer zeitlichen Verzögerung kommt (Schuchardt 1995: 12). Im Zuge des Temperaturanstiegs werden auch die schwerer abbaubaren organischen Bestandteile zersetzt, wobei der $\mathrm{pH}$-Wert auf 7 bis 8 ansteigt. Bei Temperaturen über $60{ }^{\circ} \mathrm{C}$ findet eine Elimination unerwünschter Keime und Bakterien (human-sowie tier- und pflanzenpathogene Mikrofauna und -flora) statt, die als Hygienisierung bezeichnet wird. Diese Phase wird Intensiv- oder Heißrotte genannt (Döhler et.al.1999 166). In dieser Phase der Rotte, die bis zum Absinken der Temperatur auf etwa $60{ }^{\circ} \mathrm{C}$ andauert, findet eine Reduzierung des Volumens, des Wassergehalts und damit des Gewichts der Rotteeingangsmaterialien statt (Schuchardt 1995: 12-13). Aus den Kompostrohstoffen entsteht ein Frischkompost mit den Rottegraden II und III (s. Abschnitt 2.2).

Es schließt sich hieran die Reifephase, auch als Nachrotte bezeichnet, an, in der der Aufbau der Huminstoffe und stabilen Humusfraktionen stattfindet und Fertigkomposte der Rottegrade IV und V (s. Abschnitt 2.2) vorzufinden sind (Döhler et.al.1999:166). Die Temperatur des Rottematerials sinkt schließlich auf das Niveau der Umgebung ab (Schuchardt 1995: 12)

\subsection{Rottegrad, Strukturmaterialanteil und Umsetzintervall}

Komposte werden in sogenannte Rottegrade eingestuft. Der Rottegrad gilt als Maß für den Gehalt an biologisch abbaubaren Stoffen und kennzeichnet somit den aktuellen Stand des Abbaugeschehens der organischen Substanz. Dieser kann mittels Messung der Selbsterhitzung des Rotteguts bestimmt werden, indem die erzielte Maximaltemperatur für die Einteilung der Rottegrade herangezogen wird (Tab.2.1) (Klages-Haberkern 1993: 76; Döhler et.al.1999: 164-165).

Frischkompost ist ein „hygienisiertes, in intensiver Rotte befindliches oder zur intensiven Rotte befähigtes Rottegut mit höheren Gehalten an leicht abbaubarer organischer Substanz und besitzt den Rottegrad II oder III“ (Klages-Haberkern 1993: 76). Fertigkompost ist dagegen das Endprodukt der Kompostierung, bei dem insbesondere die leicht abbaubare organische Substanz weitgehend biologisch umgesetzt ist. Bei der pflanzenbaulichen Anwendung von Fertigkomposten soll die Mineralisierung der im Kompost enthaltenen organischen Substanz schon soweit fortgeschritten sein, „daß von einer Stickstoffimmobilisierung zunächst nicht ausgegangen werden muß“ (KlagesHaberkern 1993: 77). 
Tab.2.1: Einteilung der Rottegrade entsprechend den Maximaltemperaturen im Selbsterhitzungsversuch [LAGA M 10 (1995)]

\begin{tabular}{|c|c|c|}
\hline Rottegrad & $\begin{array}{c}\text { Maximale Temperatur } \\
\left({ }^{\circ} \mathbf{C}\right)\end{array}$ & Produktbezeichnung \\
\hline I & $>60$ & Kompostrohstoff \\
\hline II & 50 bis 60 & Frischkompost \\
\hline III & 40 bis 50 & Frischkompost \\
\hline IV & 30 bis 40 & Fertigkompost \\
\hline V & $<30$ & Fertigkompost \\
\hline
\end{tabular}

Der Durchsatz einer Kompostierungsanlage ist umso höher, je geringer die Verweildauer des Rotteguts ist. Eine Verkürzung der Verweildauer wird durch kurze Umsetzintervalle erreicht, da häufig umgesetzte Mieten relativ schnell hohe Rottegrade erreichen. Gleichzeitig erfolgt die Reifeentwicklung, gemessen am Rottegrad, umso langsamer, je niedriger der Strukturmaterialanteil ist (vgl. Helm 1995: 49).

Die Höhe des Strukturmaterialanteils hat einen wesentlichen Einfluß auf den Kompostierungsprozeß, das Emissionspotential und die Verfahrensleistung bei der Dreiecksmietenkompostierung von Bioabfällen. Bei keinem oder geringem Strukturmaterialanteil treten insbesondere in der Anfangsphase leicht anaerobe Verhältnisse auf. Zudem sind hinsichtlich des Rotteverlaufs bei niedrigen Strukturmaterialanteilen im Vergleich zu hohen Mischungsanteilen von Grüngut in der Kompostmiete Verzögerungen zu beobachten (Helm 1995: 123). „Unter diesen Aspekten liegt der Optimalbereich bei einem Strukturmaterialanteil von 20 bis 40 Vol.-\%.“ (Helm/Gronauer 1995: 34).

In offenen Dreiecksmieten mit einem Strukturmaterialanteil von 60 Vol.-\% wurde in einem Sommerversuch bei einem 7-tägigen Umsetzintervall nach 22 Tagen Frischkompost des Rottegrades III und nach weiteren 2 Wochen Fertigkompost (Rottegrad V) erzeugt (Helm 1995: 101). Im Herbstversuch hatte die Variante mit 7-tägigem Umsetzintervall nach 53 Tagen Rottegrad V erreicht. Beim Winterversuch zeigte sich insbesondere in der ersten Rottephase eine geringfügige Verzögerung der Reifeentwicklung. Nach etwa 8 Wochen wurde Rottegrad V erreicht (Helm 1995: 103). 
Die Rottedauer zur Herstellung von Fertigkompost (Rottegrad V) und damit die Verweildauer des zu Mieten aufgesetzten Materials im Rottebereich der Kompostierungsanlagen wird im Sommer mit 6 Wochen und im Winter mit 12 Wochen angegeben (LUFA Rostock 1996a: 2).

Im Pilotbetrieb einer dezentralen Low-Tech-Anlage im Landkreis Sigmaringen wurde zur Herstellung von Fertigkompost eine durchschnittliche Rottedauer von 7 bis 10 Wochen beobachtet (Spangenberg 1998: 70). Im Landkreis Ebersberg (Bayern), in dem ebenfalls die Kompostierung von Küchen- und Grünabfällen in dezentralen landwirtschaftlichen Kompostierungsanlagen betrieben wird, werden für den Kompostierungsvorgang in Abhängigkeit von der Jahreszeit 8 bis 18 Wochen benötigt (Wintzer et. al. 1996: 121).

Für die Kalkulation wird von einer durchschnittlichen Rottedauer von 12 Wochen ausgegangen (vgl. Gronauer et. al. 1993: 165 und Döhler et.al. 1999: 187 Tab.5).

Zudem wird hierbei von 7-tägigen Umsetzintervallen ausgegangen. Eine Verlängerung wurde nicht in Betracht gezogen, da bei Umsetzintervallen über sieben Tage die Hygienisierung der Randbereiche nicht gesichert ist (Helm/Gronauer 1995: 34).

\section{$\underline{2.3 \quad \text { Kompostienungsverfahren }}$}

Entsprechend ihrer Rottetechniken werden die praktizierbaren Kompostierungsverfahren in drei Gruppen eingeteilt: Flächenkompostierung, Mietenkompostierung und Reaktor-kompostierung (Reloe / Schuchardt 1993: 185).

Bei der Flächenkompostierung finden die Umsetzungs- und Mineralisationsprozesse in einer dünnen Schicht an der Oberfläche statt. Aufgrund der großen Grenzfläche zwischen Rottegut und Umgebung kommt es hierbei zu keiner Erwärmung des Rotteguts und damit nicht zur notwendigen Hygienisierung (dlz 1992: 48). Die Flächenkompostierung ist deshalb für organische Haushalts- und Küchenabfälle ungeeignet (Helm 1995: 54).

Bei der Mietenkompostierung wird das Material zu Mieten aufgesetzt. Hierdurch verringert sich die Grenzfläche zwischen dem Rottegut und der Umgebung, so daß der Wärmestrom vom Rottegut zur Außenluft abnimmt. Die hierdurch bedingte Erwärmung des Mietenmaterials auf bis $\mathrm{zu} 75^{\circ} \mathrm{C}$ im Mietenkern trägt zur erforderlichen Hygienisierung des Rotteguts bei (dlz 1992: 48). 
Hinsichtlich des Mietenquerschnitts lassen sich verschiedene Formen unterscheiden: eine spitz zulaufende Mietenoberfläche entspricht einer Dreiecksmiete, eine gewölbte einer Walmmiete und eine geglättete einer Trapezmiete (dlz 1992: 48-49). „Die Dreiecksmieten bieten durch das günstige Oberflächen-/Volumenverhältnis relativ gute Voraussetzungen für aerobe Rotteverhältnisse. Durch einfache und wikungsvolle Umsetztechniken werden günstige Voraussetzungen für einen schnellen Rotteverlauf geschaffen“ (Helm 1995: 57).

Dreiecksmietenverfahren werden häufig bei kleinen offenen Anlagen eingesetzt (Gronauer et. al. 1995: 19). Das Verfahren zeichnet sich durch einfache Anlagentechnik aus, die im wesentlichen aus einer Bodenplatte und einem Umsetzgerät besteht. Diese Geräte werden für den Schlepperanbau oder selbstfahrend angeboten.

Trapezmieten werden ebenfalls mit selbstfahrenden oder schlepperangebauten Umsetzgeräten behandelt. Das Verfahren findet bei offenen Anlagen, bei überdachten Anlagen oder, wegen des relativ geringen Flächenbedarfs, auch in geschlossenen Anlagen Anwendung ( Gonauer / Helm / Schön 1995: 20).

Die offene Mietenkompostierung ist die Urform der Kompostierung. Bei unbelüfteten Systemen erfolgt der Sauerstoffeintrag durch Diffusion, Thermik oder durch Umsetzen der Mieten (Kern 1999: 302).

Bei der Reaktorkompostierung läuft der Rotteprozeß gesteuert in einem abgegrenzten Behälter oder Raum, dem Reaktor, ab. Hierbei wird das Material z.B. in durch Seitenwände begrenzte Silos gefüllt. Bei mehreren nebeneinanderliegenden Silos ergibt sich im Prinzip eine Tafelmiete, die durch die jeweiligen Silowände unterbrochen wird.

Vorteile des Verfahrens liegen in der Geruchsminderung sowie der Reduzierung der erforderlichen Rottefläche. Die Belüftung der Mieten erfolgt i.d.R. durch eine Zwangsbelüftung. „Beim Umsetzen wird das Rottgut von Schaufelrädern aufgenommen und einige Meter nach hinten versetzt wieder abgelegt oder mittels einer Schneckenfräswelle aufgelockert (Kern/Funda/Mayer 1998: 695). Insbesondere bei der Zeilenkompostierung wird das Ausgangsmaterial in nach oben hin offenen Rottezeilen abgelegt, die durch feste Zwischenwände voneinander getrennt sind und die, jeweils separat belüftet, durch ein spezielles Umsetzgerät zeilenweise umgesetzt werden. Bei der sog. Tunnelkompostierung sind die beschriebenen Zeilen oben verschlossen, um das Abluftvolumen zu reduzieren (Kern 1999: 303). 
Die Verfahren der Reaktorkompostierung eignen sich vor allem für eingehauste Systeme (Helm 1995: 58). Verfahren der Reaktorkompostierung sind aufgrund der hohen Investitionskosten für landwirtschaftliche Betriebe nicht attraktiv. Diese Verfahren sind erst bei hohen Durchsatzleistungen ab etwa $5000 \mathrm{Mg}$ /a konkurrenzfähig, bei denen offene Verfahren aus Emissionsschutzgründen nicht mehr genehmigungsfähig sind. (vgl. Helm 1995: 60; vgl. Abschnitt 3).

Erfolgt die Intensivrotte in einem abgeschlossenen, zwangsbelüfteten Raum mit vollständiger Ablufterfassung, so bezeichnet man die entsprechenden Verfahren als Boxen- oder Containerkompostierung (Kern/Funda/Mayer 1998: 695).

Bei dem sog. Brikollare-Verfahren wird das Ausgangsmaterial zerkleinert, zu Formlingen gepreßt und auf Paletten in einer Rottehalle untergebracht. Im folgenden kommt es zu einer starken Verpilzung und Erwärmung des Rotteguts auf annähernd $70^{\circ} \mathrm{C}$. „Biologischer Abbau und Austrocknung verlaufen simultan und führen nach ca. drei bis sechs Wochen zu einem trockenstabilen, wasserabweisenden Produkt mit etwa $20 \%$ Restfeuchte“ (Kern/Funda/Mayer 1998: 695).

Die Verfahren der Trommelkompostierung nutzen die Drehbewegung einer Rottetrommel zu einer guten Durchmischung und Zerkleinerung des Rotteguts bei gleichzeitig kontinuierlicher Belüftung. Diesem Vorgang, der zwischen einem und sieben Tagen dauert, folgt i.d.R. eine Rotte in Form der Mietenkompostierung, in der die Hygienisierung des Materials stattfindet (Kern 1999: 304).

Die Auswahl eines Kompostierungsverfahrens für den konkreten Einzelfall erfolgt nach verschiedenen Kriterien, wie z.B. Verfahrensreife, Betriebssicherheit und Emissionsverhalten. „Der Einfluß von Investitions- und Betriebskosten sollte in angemessener Weise hinter die zuvor genannten Kriterien zurücktreten, ist jedoch bei der Verfahrenswahl erfahrungsgemäß von grundlegender Bedeutung“ (Kern/Wiemer 1990: 7). Auf die Kompostqualität hat die Auswahl des Kompostierungsverfahrens hingegen nur geringen Einfluß (Helm/Gronauer 1995: 35).

Dieser Untersuchung liegt das Verfahren der offenen Kompostierung in Dreiecksmieten zugrunde. Dieses Verfahren zeichnet sich bei Ausnutzung von Synergieeffekten mit dem landwirtschaftlichen Betrieb für den Landwirt durch relativ geringen Investitionsbedarf und einfache Anlagentechnik aus. 
Zudem lassen sich offene Kleinanlagen sinnvoll in den landwirtschaftlichen Betrieb und den betrieblichen Nährstoffkreislauf integrieren (Helm 1997: 175).

\subsection{Verfahrensschritte der offenen Mietenkompostienung}

Die Bioabfallkompostierungsanlagen arbeiten im wesentlichen nach demselben Verfahrensablauf, der sich in die Bereiche

- Materialanlieferung, -annahme und Zwischenlagerung,

- Materialaufbereitung, mechanische Zerkleinerung und Homogenisierung,

- Rotte sowie

- Konfektionierung und Lagerung des Komposts

unterteilen läßt.

(vgl. Wintzer et.al.1996: 111 und Ministerium für Bau, Landesentwicklung und Umwelt M-V 1998: 4).

Den Ablauf der einzelnen Arbeitsschritte bei der dezentralen Mietenkompostierung zeigt schematisch die Abb.2.1. 


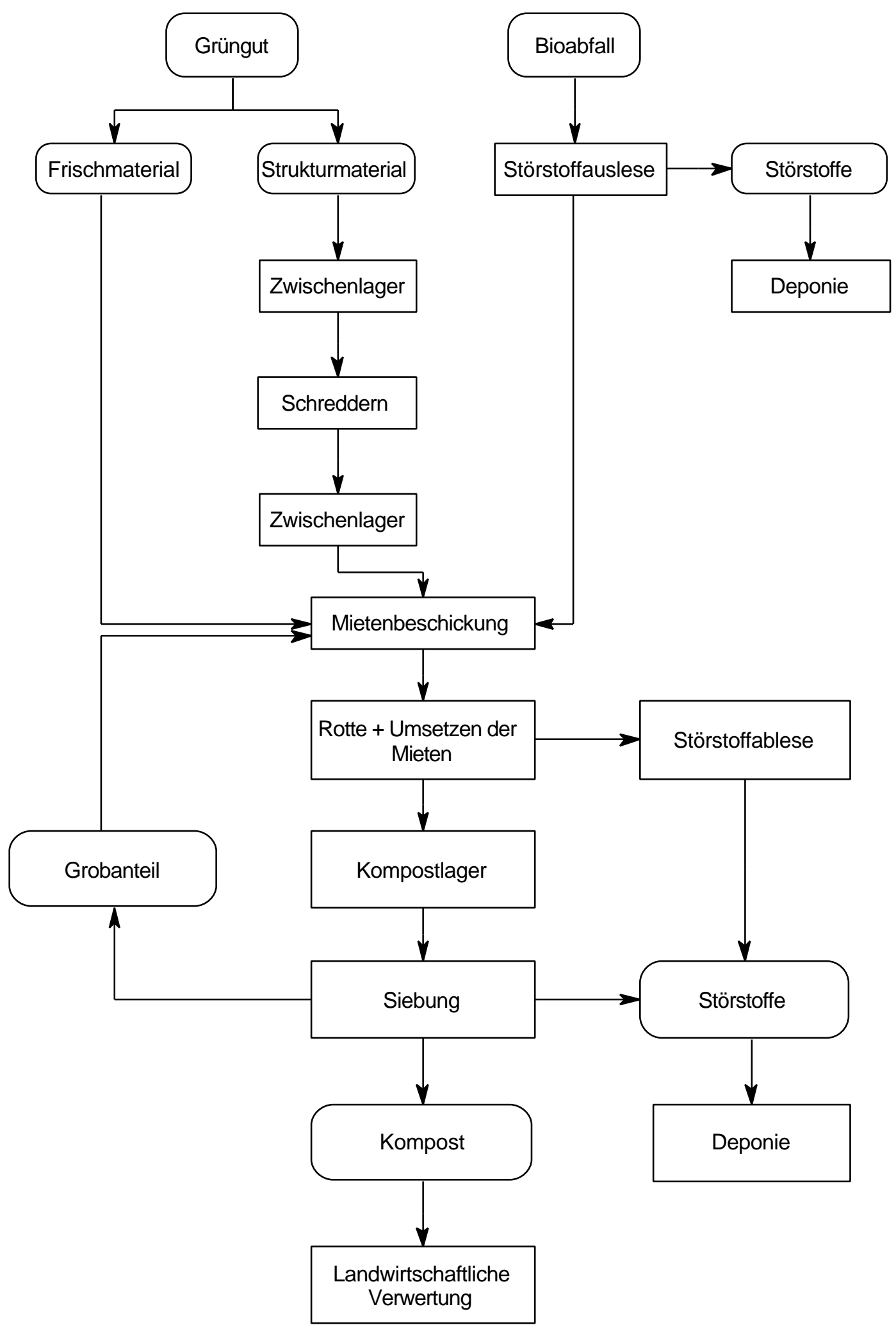

Abb.2.1: Ablaufschema der offenen Mietenkompostierung in Landwirtschaftsbetrieben (Spangenberg et.al.1998: 72; verändert). 


\subsection{Abwasser}

Das in einer offenen Kompostierungsanlage anfallende Abwasser setzt sich zusammen aus

- dem Preßwasser aus der Eigenfeuchte des Inputmaterials,

- endogenem Wasser aus Rotteprozessen, das als Sickerwasser an der Basis des Rottekörpers abgesondert wird,

- der niederschlagsabhängigen Menge an exogenem Sickerwasser und

- Regenwasser (vgl. Wintzer et.al.1996: 122 und Gronauer/Helm/Schön 1997: 67).

Abwassermenge und Schadstoffbelastung des Abwassers sind von der Beschaffenheit der Abfälle, dem Behandlungsverfahren und der Anlagentechnik abhängig (Wintzer et.al. 1996: 307):

- Durch Überdachung der Rotteflächen, die Kreislaufführung des anfallenden Sickerwassers, die Zuführung trockenen Zuschlagmaterials sowie häufiges Umsetzen der Kompostmieten kann die außerhalb der Anlage zu verwertende Abwassermenge reduziert werden.

- In den offenen Kompostierungsanlagen ist die Sickerwassermenge größer als in überdachten Anlagen, da diese durch Niederschäge erhöht wird. Das Sickerwasser weist durch den Verdünnungseffekt jedoch eine geringere organische und anorganische Belastung auf als unverdünntes Sickerwasser (Wintzer et. al. 1996: 307).

Nach TA Siedlungsabfall (Nr. 5.4.1.3.2) sind Rückstände aus dem Kompostierungsprozeß (Auslesereste, Siebreste, Absetzrückstände aus Auffangbecken für das Sickerwasser) und Abwasser vorrangig zu verwerten. Demnach ist das Abwasser sicher aufzufangen und möglichst zur Befeuchtung des Kompostierungsmaterials einzusetzen. 


\section{Rechtliche Grundlagen}

\subsection{Rechtliche Gundlagen der Genehmigung für Emichtung und Betrieb von Kompostienungsanlagen}

Das Genehmigungsverfahren für die Errichtung und den Betrieb einer Kompostierungsanlage wird in Abhängigkeit von der Durchsatzleistung durch das Bundes-Immissionsschutzgesetz (BImSchG) festgelegt (Tab.3.1).

Tab. 3.1: Genehmigungsverfahren für Kompostierungsanlagen

\begin{tabular}{|l|l|l|}
\hline $\begin{array}{l}\text { Durchsatzleistung der } \\
\text { Anlage }\end{array}$ & $\begin{array}{l}\text { Rechtsgrundlagen zur } \\
\text { Einordnung des } \\
\text { Genehmigungsverfahrens }\end{array}$ & $\begin{array}{l}\text { Art des } \\
\text { Genehmigungsverfahrens }\end{array}$ \\
\hline $\begin{array}{l}\text { \& } 10 \mathrm{Mg} / \mathrm{h} \\
\text { bzw. } \\
>87.000 \mathrm{Mg} / \mathrm{a}\end{array}$ & mit der 4. BImSchV & $\begin{array}{l}\text { förmliches } \\
\text { immissionsschutzrechtliches } \\
\text { Genehmigungsverfahren mit } \\
\text { Öffentlichkeitsbeteiligung } \\
\text { (Kompostwerk), UVP-Pflicht }\end{array}$ \\
\hline $\begin{array}{l}0,75 \mathrm{Mg} / \mathrm{h} \text { bis }<10 \mathrm{Mg} / \mathrm{h} \\
\text { bzw. } \\
6.750 \mathrm{Mg} / \mathrm{a} \text { bis }<87.000 \mathrm{Mg} / \mathrm{a}\end{array}$ & $\S 19 \mathrm{BImSchG}$ & $\begin{array}{l}\text { vereinfachtes } \\
\text { immissionsschutzrechtliches } \\
\text { Genehmigungsverfahren ohne }\end{array}$ \\
\hline $\begin{array}{l}\text { Öffentlichkeitsbeteiligung } \\
\text { bzw. } \\
<6.750 \mathrm{Mg} / \mathrm{h}\end{array}$ & $\begin{array}{l}\text { Baurecht der einzelnen } \\
\text { Bundesländer }\end{array}$ & \\
\hline
\end{tabular}

Demzufolge ist für die untersuchten Anlagengrößen mit einer Durchsatzleistung $<0,75 \mathrm{Mg} / \mathrm{h}$ bzw. <6.750 Mg/a (Helm 1997:173 und Wintzer et.al.1996:120) lediglich eine baurechtliche Genehmigung erforderlich. Diese Anlagen werden als „kleinere Anlagen“ eingestuft (Döhler et.al.1999: 170) und sind als nach dem BimSchG nicht genehmigungsbedürftige Anlagen so zu betreiben, daß

- schädliche Umwelteinwirkungen verhindert werden, die nach dem Stand der Technik vermeidbar sind,

- nach dem Stand der Technik unvermeidbare schädliche Umwelteinwirkungen auf ein Mindestmaß beschränkt werden,

- die beim Betrieb der Anlagen entstehenden Abfälle ordnungsgemäß beseitigt werden $(\S 22$ BImSchG). 
Die TA Siedlungsabfall geht ebenfalls auf Anlagen zur biologischen Abfallbehandlung ein. Demnach kann auf eine geschlossene Betriebsweise (,Einhausung“) bei kleineren Anlagen verzichtet werden, wenn eine Beeinträchtigung der Nachbarschaft sowie der Qualität des erzeugten Produkts nicht zu erwarten ist (TA Siedlungsabfall: 5.4.1.3.3).

Für die Genehmigungspraxis in Mecklenburg-Vorpommern zählen zu den Kompostierungsanlagen, für die eine Einhausung sowie eine gezielte Ablufterfassung und Reinigung nicht erforderlich ist, diejenigen mit einer Durchsatzleistung von < 0,34 Mg/h bzw. <3000 Mg/a. Zudem können die wesentlichen Vorbereitungen der Kompostierung wie Anlieferung, Störstoffauslese und Feinaufbereitung offen stattfinden. Aufgrund der relativ geringen technischen Anforderungen an diese Kompostierungsanlagen sind die Input-Materialien auf die Bioabfälle aus Haushalten (Biotonne), Garten- und Parkabfälle, biogene Rückstände aus der Landschaftspflege sowie aus der landwirtschaftlichen Pflanzenproduktion beschränkt (Ministerium für Bau, Landesentwicklung und Umwelt Mecklenburg-Vorpommern 1998: 6).

Wegen der erheblich höheren Investitionskosten rentieren sich eingehauste Anlagen i.d.R. nicht für dezentrale Kompostierungskonzepte in ländlich strukturierten Gebieten, so daß mit der Begrenzung der Durchsatzleistung auf $3000 \mathrm{Mg} / \mathrm{a}$ für vollständig offene Anlagen in Mecklenburg-Vorpommern die maximale Durchsatzleistung von Anlagen dezentraler Konzepte praktisch vorgegeben ist (Kasten/Marggraf 1999: 276). Diese Anlagen sind Gegenstand der Untersuchung.

\subsection{Geeignete Inputmaterialien für die Kompostienung}

Den Bereich der landbaulichen Verwertung behandelter Bioabfälle, wie z.B. die im Rahmen dieser Arbeit untersuchten Bioabfallkomposte, regelt die Bioabfallverordnung (BioAbfV). Demnach zählen zu den Bioabfällen Abfälle tierischer oder pflanzlicher Herkunft zur Verwertung, die durch Mikroorganismen, bodenbürtige Lebewesen oder Enzyme abgebaut werden können (mit Ausnahme von Pflanzenresten, die wie z.B. Ernterückstände auf landwirtschaftlich genutzter Fläche anfallen und auf diesen verbleiben) (BioAbfV 1998).

Für die Kompostqualität sind grundsätzlich die Inputmaterialien für den Kompostierungsprozeß, die sog. Kompostrohstoffe, ausschlaggebend (Döhler et.al.1999: 167). Als generelle Anforderungen an die Kompostrohstoffe sind deren sortenreine Erfassung sowie Schad- und Fremdstoffarmut, ihre 
Eignung im Hinblick auf Aufbereitung, Abbaubarkeit, Kompostierbarkeit, Rottezeit und die angestrebte Qualität der Erzeugnisse zu nennen (LAGA M 10 1995).

Der Anhang 1 der BioAbfV enthält eine Liste der für die Verwertung auf Flächen grundsätzlich geeigneten Bioabfälle und somit auch der grundsätzlich geeigneten Kompostrohstoffe (Tab.3.2).

Die in Tab.3.2 kursiv gedruckten Begriffe bezeichnen Bioabfälle, die zwar gemäß BioAbfV grundsätzlich für die Kompostierung und eine anschließende landwirtschaftliche Verwertung geeignet sind, jedoch nach düngemittelrechtlichen Vorschriften nicht landwirtschaftlich verwertet werden dürfen.

Sollen aus diesen Bioabfällen erzeugte Komposte landwirtschaftlich verwertet werden, dann müssen die Bioabfälle vor der Kompostierung beim Bundeslandwirtschaftsministerium als Sekundärrohstoffdünger zugelassen werden (Döhler et.al.1999: 168).

Die im Rahmen dieser Arbeit untersuchten Komposte wurden hauptsächlich aus Bioabfällen aus Haushalten und dem als Strukturmaterial erforderlichen Grüngut hergestellt und bereiten hinsichtlich der rechtlichen Zulässigkeit keine Probleme. 
Tab. 3.2: Geeignete Inputmaterialien für die Kompostierung gemäß BioAbfV (Döhler et.al.1999: 169)

\begin{tabular}{|c|c|}
\hline Potentielle Kompostrohstoffe & $\begin{array}{l}\text { Ergänzende Hinweise nach } \\
\text { Bioabfallverordnung (1998) }\end{array}$ \\
\hline $\begin{array}{l}\text { Gemüse-Abfälle } \\
\text { Obst-Abfälle }\end{array}$ & $\begin{array}{l}\text { i.d.R. Marktabfälle, nur getrennt erfaßt } \\
\text { verwertbar }\end{array}$ \\
\hline $\begin{array}{l}\text { Rinden, Holz, Holzreste, Sägemehl, Sägespäne, } \\
\text { Holzwolle }\end{array}$ & $\begin{array}{l}\text { nur im naturbelassenen Zustand bzw. aus } \\
\text { unbehandeltem Holz ohne Einschränkung } \\
\text { verwendbar, darf auch als Zusachlagstoff zu } \\
\text { anderen Bioabfällen auf Dauergrünland } \\
\text { ausgebracht werden; bei Herkunft von } \\
\text { Straßenrändern müssen Schwermetall-grenzwerte } \\
\text { eingehalten werden }\end{array}$ \\
\hline $\begin{array}{l}\text { Hornabfälle } \\
\text { Knochenabfälle } \\
\text { Pansen-Inhalt, abgepreßt } \\
\text { Eier-Schalen } \\
\text { Federn } \\
\text { Wollabfälle } \\
\text { Fabrikationsrückstände von Tabak } \\
\text { Fabrikationsrückstände von Kaffee } \\
\text { Fabrikationsrückstände von Tee } \\
\text { Fabrikationsrückstände von Kakao }\end{array}$ & $\begin{array}{l}\text { Verwertung nur, soweit } \\
\text { Tierkörperbeseitigungsgesetz dem nicht } \\
\text { entgegensteht }\end{array}$ \\
\hline Altpapier & $\begin{array}{l}\text { nur bis max. } 10 \% \text { Zugabe zur Kompostierung, } \\
\text { keine Verwendung von Hochglanzpapier und } \\
\text { Alttapeten }\end{array}$ \\
\hline Pilzmycel & $\begin{array}{l}\text { nur nach Einzelfallprüfung verwendbar, darf keine } \\
\text { Arzneimittelreste enthalten }\end{array}$ \\
\hline Bioabfall & $\begin{array}{l}\text { getrennt erfaßte Bioabfälle privater Haushalte und } \\
\text { des Kleingewerbes }\end{array}$ \\
\hline $\begin{array}{l}\text { Gras, Klee, Luzerne (Futterpflanzen) } \\
\text { Heu } \\
\text { Spelzen, Spelzen- und Getreidestaub } \\
\text { Getreide-Stroh } \\
\text { Reithallen-Boden } \\
\text { Champignonsubstrat } \\
\text { Ölsaatenrückstände } \\
\text { Zuckerrüben-Naßschnitzel } \\
\text { Malztreber, Malzkeime, Malzstaub } \\
\text { Hopfentreber } \\
\text { Trester } \\
\text { Zellulosefaserabfälle } \\
\text { Baumwolle-Verarbeitungsrückstände } \\
\text { Hanfabfälle } \\
\text { Trester von Heilpflanzen }\end{array}$ & keine Einschränkung \\
\hline $\begin{array}{l}\text { Grüngut } \\
\text { Laub }\end{array}$ & $\begin{array}{l}\text { Grüngut von Straßenrändern und } \\
\text { Industriestandorten darf nur verwendet werden, }\end{array}$ \\
\hline
\end{tabular}




\subsection{Rechtliche Gundlagen der landbaulichen Kompostverwertung}

Die Kompostverwertung wird durch das Abfall- und Düngemittelrecht geregelt.

Abfallrechtlich relevant für den Bereich der landbaulichen Kompostverwertung sind das Kreislaufwirtschafts- und Abfallgesetz (KrW-/AbfG) und die Bioabfallverordnung (BioAbfV). Demnach sind organische Abfälle, deren Anfallen nicht vermieden werden kann, einer Wiederverwertung zuzuführen ( $\$ 15 \mathrm{KrW}-/ \mathrm{AbfG})$.

Die Verwertung beinhaltet die Gewinnung von Stoffen aus Abfällen und deren Einsatz im Wirtschaftskreislauf. Die stoffliche Verwertung im Sinne des Kreislaufwirtschaftsgesetzes erfolgt entweder dadurch, daß Abfälle unmittelbar oder nach vorheriger Aufbereitung bzw. Umwandlung zu neuen Produkten in den Wirtschaftskreislauf zurückgeführt werden. Hierbei muß nach einer wirtschaftlichen Betrachtungsweise der Hauptzweck der Maßnahme in der Nutzung des Abfalls und nicht in der Beseitigung des Schadstoffpotentials liegen (§4 KrW-/AbfG).

In der Bioabfallverordnung sind Grenzwerte für Schwermetallgehalte bezüglich Blei, Cadmium, Chrom, Kupfer, Nickel, Quecksilber und Zink im Kompost und im Boden festgeschrieben, die bei der landbaulichen Kompostverwertung nicht überschritten werden dürfen. Zudem sind Aufbringungsbeschränkungen und -verbote enthalten (§ 6 BioAbfV).

Darüberhinaus enthält die Bioabfallverordnung umfassende Vorgaben hinsichtlich der Bioabfallbehandlung zur Gewährleistung der seuchen- und phytohygienischen Unbedenklichkeit. Demnach darf es zu keiner Beeinträchtigung der Gesundheit von Mensch und Tier durch Freisetzung oder Übertragung von Krankheitserregern kommen. Ebenso sind Schäden an Pflanzen, Pflanzenerzeugnissen oder Böden durch die Verbreitung von Schadorganismen zu vermeiden ( $\$ 3$ BioAbfV).

Komposte können als sog. Sekundärrohstoffdünger nach der Düngemittelverordnung zugelassen werden, wenn diese die in der BioAbfV genannten Grenzwerte nicht überschreiten und pflanzenverfügbare Nährstoffe enthalten (Döhler et.al.1999: 202). Demnach darf ein Abfallstoff nicht allein auf Grund niedriger Schadstoffgehalte auf landwirtschaftliche Flächen gebracht werden (Schadlosigkeitsprinzip), sondern muß zusätzlich den düngemittelrechtlichen Anforderungen an Stoffe nach $\S 1$ Düngemittelgesetz genügen (Nützlichkeitsprinzip). „Mit diesen Vorschriften ist die 
Landwirtschaft nicht länger ,Senke für allein nach ihren Schadstoffgehalten für eine landwirtschaftliche Verwertung geeignete Abfälle, bei deren Verwertung zudem jedes Restrisiko dem Landwirt verbleibt“" (Kluge / Embert 1996: 200).

Nach der Düngemittelverordnung (in der geänderten Fassung vom 23. Juli 1997) werden Komposte unter der o.g. Voraussetzung als Sekundärrohstoffdünger eingestuft und in Abhängigkeit von ihrem Nährstoffgehalt bestimmten Düngemitteltypen ${ }^{2}$, wie z.B. organisch-mineralischen NPK-Düngern, zugeordnet. Wird Kompost als Sekundärrohstoffdünger im Sinne des Düngemittelgesetzes auf landwirtschaftlichen Flächen ausgebracht, so unterliegt dieser der Düngeverordnung, wenn er den Nutzpflanzen zugefuihrt wird, um ihr Wachstum zu fördern, ihren Ertag zu erhöhen oder ihre Qualität zu verbessern ( 11 Düngemittelgesetz). Als Düngemittel darf der Kompost demnach im Rahmen guter fachlicher Praxis zeitlich und mengenmäßig nur so ausgebracht werden, daß die Nährstoffe von den Pflanzen weitestgehend ausgenutzt werden können und Nährstoffverluste weitestgehend vermieden werden (\$2 Düngeverordnung).

\footnotetext{
${ }^{2}$ Bioabfälle aus Haushalten sind z.B. als Sekundärrohstoffdüngertyp ,organischer NPK-Dünger“ in Verkehr zu bringen (Nährstoff-Mindestgehalte bezogen auf den Trockenrückstand: 0,5\% N, 0,3\% $\mathrm{P}_{2} \mathrm{O}_{5}$ und 0,5\% $\left.\mathrm{K}_{2} \mathrm{O}\right)($ Kiefer 1999: 460).
} 


\section{Projektbeschreibung}

\subsection{Modellversuch zur dezentralen Kompostierung im Landkreis Demmin}

Im Landkreis Demmin (Mecklenburg-Vorpommern) wurde ein Pilotprojekt zur Bioabfallentsorgung im ländlichen Raum durchgeführt. Mit Unterstützung des Ministeriums für Bau, Landesentwicklung und Umwelt Mecklenburg-Vorpommern beinhaltete dieses einen Modellversuch zur dezentralen Kompostierung von Bioabfällen und des hierzu notwendigen Strukturmaterials durch zwei Landwirtschaftsbetriebe, der in der Zeit von Oktober 1995 bis Juni 1997 stattfand (Umweltamt Demmin 1997:3). Mit Beendigung des Modellversuchs wurden mit den beiden landwirtschaftlichen Unternehmen, die die Kompostierungsanlagen im Landkreis Demmin betreiben, Verträge über die Fortsetzung der dezentralen Bioabfallentsorgung abgeschlossen.

Im Landkreis Demmin überwiegen hinsichtlich der Bevölkerungszahlen die ländlichen Gemeinden. Der Anschlußgrad der Haushalte an die Bioabfallsammlung von 22,3 \% (Umweltamt Demmin 1999) bei bereits erfolgter flächendeckender Einführung der Biotonne ist gering, was auf einen hohen Anteil an Eigenkompostierung, der in ländlich strukturierten Gebieten eine große Bedeutung zukommt, zurïckzuführen ist. Hieraus resultieren relativ geringe Mengen zu behandelnden Bioabfalls, die bei einem zentralen Entsorgungskonzept zu hohen Transportaufwendungen führen würden, insbesondere unter Berücksichtigung des Trends, bei der Neuerrichtung von zentralen Großanlagen mehrere entsorgungspflichtige Körperschaften zu einem gemeinsamen Entsorgungsgebiet zusammenzufassen. Insofern bietet sich das eingerichtete dezentrale Konzept unter dem Aspekt der Vermeidung weiter Transportwege an.

Die Kompostierung erfolgt in für die Bioabfallbehandlung umgenutzten Flachsiloanlagen mit relativ geringem Jahresinput, die Kompostverwertung auf den betriebszugehörigen Flächen (Kasten/Marggraf 1998: 278).

Der jährliche Durchsatz beträgt derzeit in den beiden Anlagen jeweils etwa $1200 \mathrm{Mg} / \mathrm{a}$. Beispielhafte Darstellungen zur Bioabfallentsorgung im Landkreis Demmin beziehen sich im folgenden auf den o.g. Modellversuch. 


\subsection{Inputmaterial für die Kompostienung}

$\mathrm{Zu}$ den für die Kompostierung in den beiden Anlagen im Landkreis Demmin zugelassenen Bioabfällen zählen die Bioabfälle aus Haushalten, Garten- und Parkabfälle, mengenmäßig deutlich geringer auch land- und forstwirtschaftliche Abfälle, Spelzen, Spelzen- und Getreidestaub, Rinden sowie Marktabfälle.

Die Bioabfälle aus Haushalten umfassen die in privaten Haushalten anfallenden kompostierbaren Abfälle, die in einem speziellen Gefäß (Biotonne) erfaßt werden. Es handelt sich um Pflanzenabfälle, Obst- und Gemüseabfälle und Speisereste.

Zum Grüngut zählen z.B. die bei der Pflege von Grünanlagen, Parkanlagen und Straßengrünstreifen anfallenden pflanzlichen Abfälle, die sortenrein auf den Kompostierungsanlagen angeliefert werden. Im wesentlichen handelt es sich um Laub, Baumschnitt, Strauch- und Rasenschnitt. Der Wassergehalt ist mit 20 bis $60 \%$ geringer als bei Bioabfällen aus Haushalten (50 bis $70 \%$ ). Das Volumengewicht der organischen Haushalts- und Küchenabfälle beträgt etwa 400 bis $800 \mathrm{~g} / \mathrm{l}$, das von zerkleinertem Baum- und Strauchschnitt liegt bei 100 bis $300 \mathrm{~g} / \mathrm{l}$ (Helm 1995: 31).

\subsection{Ablauf der Kompostienung imLandkreis Demmin}

Die mit Sammlung und Transport der Bioabfälle beauftragten Unternehmen wiegen die bei der getrennten Sammlung erfaßten Bioabfälle aus den Haushalten und befördern diese zu einer der beiden Kompostierungsanlagen. Bei der Anlieferung werden diese durch das Anlagenpersonal auf den Störstoffgehalt überprüft. Die Störstoffe werden nach jeder Anlieferung manuell ausgelesen sowie nach den in den darauffolgenden Wochen stattfindenden Umsetzvorgängen des zu Mieten aufgesetzten Materials von den Mietenoberflächen abgesammelt.

Die Anlieferung von Grüngut erfolgt sowohl im Bringsystem zu vorgegebenen Zeiten als auch durch Unternehmen, die im Auftrage der entsorgungspflichtigen Körperschaft v.a. strukturreiches Material von kommunalen Grüngut-Sammelstellen anliefern. Dieses wird, bevor es zusammen mit den Bioabfällen aus Haushalten zu Mieten aufgesetzt wird, zerkleinert, um eine Verbesserung der mikrobiellen Umsetzung zu erreichen. Hierzu wird ein mobiler Schredder durch einen Teleskoplader mit angebauter Silozange beschickt. Der Teleskoplader wird auch zur Reinigung der Annahmefläche eingesetzt.

Bei dem praktizierten Dreiecksmietenverfahren wird das Rotteausgangsmaterial zu Mieten mit spitz zulaufender Oberfläche aufgesetzt. Das Aufsetzen der Mieten erfolgt mit dem Teleskoplader und 
angebauter Schaufel auf einer Matte aus Strukturmaterial, die Preßwasser aus der Eigenfeuchte des Inputmaterials und im ersten Rotteabschnitt austretendes Sickerwasser aufnehmen soll.

Durch mehrmaliges Umsetzen der Mieten werden während des Rottevorgangs entstandene anaerobe Zonen wieder mit Sauerstoff angereichert (Wintzer et.al.1996:107). Diese Umsetzvorgänge wurden im Rahmen des Modellversuchs wöchentlich durchgeführt. Die einfache Anlagentechnik der Dreiecksmietenverfahren, die im wesentlichen aus einer Bodenplatte und einem Umsetzgerät besteht (Gronauer/Helm/Schön 1995:19), findet sich auch in den untersuchten Kompostierungsanlagen im Landkreis Demmin. Das Mietenumsetzgerät kommt hier aufgrund des geringeren Investitionsbedarfs als schlepperangebaute Variante zum Einsatz. Die Dreiecksmieten sind in diesen durch Landwirte betriebenen Anlagen 1,5 m hoch und weisen eine Breite an der Mietenbasis von etwa 2,5 m auf.

Gemäß der TA Siedlungsabfall ist das Abwasser aus Kompostierungsanlagen sicher aufzufangen und möglichst zur Befeuchtung des Kompostierungsmaterials einzusetzen (TA Siedlungsabfall Nr. 5.4.1.3.2). Bei den für die Kompostierung umgenutzten Horizontalsiloanlagen im Landkreis Demmin wird das Abwasser über Sammelschächte in der befestigten Anlagenfläche in die Sammelbehälter befördert. Es hat sich gezeigt, daß bei dem praktizierten Verfahren der offenen Mietenkompostierung aufgrund der niederschlagsabhängigen Menge an exogenem Sickerwasser eine Befeuchtung des Mietenmaterials normalerweise nicht erforderlich ist. Daher wird das Abwasser, das mengenmäßig überwiegend aus dem auf die drainierten befestigten Flächen treffenden Regenwasser besteht, mit Pumpentankwagen auf Ackerflächen der beteiligten Landwirtschaftsbetriebe ausgebracht.

Für die Kompostvermarktung ist die Siebung des Rohkomposts Voraussetzung, um Störstoffe und schwer bzw. nicht abbaubare Stoffe vom Fertigkompost abzutrennen und ein homogenes Produkt gewünschter Korngröße zu erhalten (Reloe/Schuchardt 1993:180-181). Für die landwirtschaftliche Verwertung genügt eine Absiebung grober, nicht verrotteter Bestandteile, die als Strukturmaterial wieder auf der Kompostierungsanlage verwendet werden können.

Der in den beiden dezentralen Anlagen erzeugte Fertigkompost (Rottegrad V) wird auf betriebszugehörigen Ackerflächen der beteiligten Landwirtschaftsbetriebe verwertet. 


\subsection{Verwerterbetriebe}

Die mit Komposten ausgebrachten Nährstofffrachten sind in der Düngeplanung zu berücksichtigen.

Daher ist der Viehbesatz (Großvieheinheiten/Hektar [GV/ha]) der Verwerterbetriebe als relevante Größe zu beachten, denn bei viehhaltenden Betrieben ist von einer vorzugsweisen Verwertung von Wirtschaftsdüngern tierischer Herkunft auszugehen. $\mathrm{Zu}$ unterscheiden sind folgende Fälle (vgl. Klages-Haberkern 1995: 172 und Ebertseder 1995: 90-91):

- Ackerbaubetriebe ohne bzw. mit geringer Tierhaltung (max. 0,5 GV/ha LN):

Insbesondere Marktfruchtbetriebe sind unter arbeitswirtschaftlichen Gesichtspunkten am ehesten in der Lage, die erforderlichen Arbeitsabschnitte zur Kompostierung und Kompostverwertung zeitlich in die übrigen Betriebsabläufe einzubinden (vgl. Kuhlmann et.al.1996: 60). Zudem haben sie einen gesicherten Bedarf an externen Nährstoffquellen.

- Betriebe mit Tierhaltung bis 1,5 GV / ha:

In diesen Betrieben muß primär die Verwertung der tierischen Reststoffe gesichert sein. Die Kompostausbringungsmenge ist demnach abhängig von der Viehdichte. So ist die Kompostverwertung ab etwa 1,0 GV/ha $\mathrm{LN}$ aufgrund der nur noch möglichen geringen Ausbringungsmenge praktisch uninteressant.

- Viehhaltende Betriebe von mehr als 1,5 GV / ha:

In diesen Betrieben ist die Verwertung von Bioabfallkomposten in Ergänzung zu den Wirtschaftsdüngern nicht mehr möglich.

Der Einsatz von Bioabfallkompost wird also einerseits durch den Nährstoffbedarf der angebauten Kulturen und andererseits durch die im Betrieb vorhandenen Wirtschaftsdünger bestimmt.

Einer der beiden Verwerterbetriebe bewirtschaftete während des Modellversuchs im Landkreis Demmin als Gemischtbetrieb 1134 ha landwirtschaftliche Nutzfläche. Der Anbau in 1995/96 umfaßte Winter- und Sommergetreide, Raps, Zuckerrüben und Silomais. Es wurden Rinder gehalten (entsprechend $289 \mathrm{GV}$ ), woraus sich ein Viehbesatz von 0,25 GV/ha ergab. In der Zwischenzeit wurde die Viehhaltung aufgegeben und es werden ausschließlich Marktfrüichte, insbesondere Wintergetreide, Winterraps und Zuckerrüben, angebaut. Der zweite Betrieb bewirtschaftet als Marktfruchtbetrieb 630 ha Ackerfläche. Es werden ebenfalls Wintergetreide, Raps und Zuckerrüben angebaut. 
Beide Betriebe gehören seit Beginn des Modellversuchs zu der für die Kompostverwertung favorisierten Gruppe mit einem Viehbesatz bis $0,5 \mathrm{GV} / \mathrm{ha}$.

\section{$4.5 \quad$ Kompostausbringungsflächen}

Nach der Bioabfallverordnung dürfen Komposte, die als Kompostrohstoffe auch Bioabfälle aus Haushalten enthalten, nicht auf Dauergrünland ausgebracht werden ( $\$ 7$ BioAbfV), so daß für die untersuchten Komposte ausschließlich Ackerflächen der beteiligten Verwerterbetriebe im Landkreis Demmin in Frage kommen (Tab.4.1).

Tab.4.1: Daten zu den Kompostausbringungsflächen der Verwerterbetriebe im Landkreis Demmin

\begin{tabular}{|l|c|c|}
\cline { 2 - 3 } \multicolumn{1}{c|}{} & $\begin{array}{c}\text { Einzelunternehmen Jabs } \\
\text { (Kompostierungsanlage } \\
\text { Tarnow) }\end{array}$ & $\begin{array}{c}\text { Feldfrucht Meesiger GmbH } \\
\text { (Kompostierungsanlage } \\
\text { Borrentin) }\end{array}$ \\
\hline Schlaggröße & 64 ha & 47 ha \\
\hline durchschnittliche Ackerzahl & 44 & 43 \\
\hline Bodenart & sandiger Lehm (sL) & sandiger Lehm (sL) \\
\hline Relief & eben & hügelig \\
\hline
\end{tabular}




\section{Kostenermittlung}

\section{$\underline{5.1 \quad \text { Vorgehensweise }}$}

Als kostenseitige Zielgröße zur Beurteilung der Konkurrenzfähigkeit des untersuchten Verwertungswegs dienen die spezifischen Gesamtkosten ${ }^{3}$ der offenen Dreiecksmietenkompostierung in landwirtschaftlichen „Low-Tech“-Anlagen sowie der landbaulichen Kompostverwertung.

Zu deren Ermittlung wurde zunächst der Verfahrensablauf der im Landkreis Demmin praktizierten offenen Mietenkompostierung mit anschließender Kompostausbringung in einzelne Arbeitsabschnitte zerlegt und die zugehörigen Arbeitszeitdaten ermittelt. Von der Anlieferung des Input-Materials bis zur Ausbringung des erzeugten Komposts wurden die Zeitdaten der einzelnen Arbeitsabschnitte auf einheitliche Bezugsgrößen umgerechnet, wie z.B. Arbeitszeitbedarf je Einheit angelieferten Rohmaterials. Sofern sich im Rahmen des Modellversuchs zur dezentralen Kompostierung im Landkreis Demmin Besonderheiten hinsichtlich der eingesetzten Maschinen und Geräte ergaben, wie z.B. der Einsatz eines Großschleppers bei eigentlich nur geringem Leistungsbedarf des betreffenden Arbeitsabschnitts, wurde von diesen abstrahiert, um eine realistische und damit auf andere Durchsätze und Zusammensetzungen des Rohmaterials umrechenbare Darstellung der MaschinenEinzelkosten zu erhalten. Hierzu wurden entsprechende Literaturdaten herangezogen.

Aus den Kosten pro Zeiteinheit und dem Arbeitszeitbedarf pro Leistungseinheit wurden die Kosten pro Leistungseinheit sowie in Verbindung mit den zurechenbaren Fixkosten die Einzelkosten ermittelt, die die Maschinenkosten, die Kosten für die baulichen Anlagen, die Personalkosten und die Fremdleistungskosten umfassen. Durch prozentualen Aufschlag der betrieblichen Gemeinkosten wurden die Gesamtkosten und daraus die spezifischen Gesamtkosten der Bioabfallbehandlung (spezifische Behandlungskosten) und der Kompostverwertung (spezifische Verwertungskosten) für die nach Anlagendurchsatz und Zusammensetzung des Input-Materials interessanten Varianten berechnet.

Für die Berechnung wurde davon ausgegangen, daß durch die Kompostierung des Input-Materials eine Massereduzierung von $50 \%$ eintritt (vgl. Boxberger/Helm 1991:25) und der produzierte Kompost ein Volumengewicht von 0,5 Mg/m³ aufweist (Kasten/Marggraf 1999: 278; vgl. Döhler

\footnotetext{
3 Die spezifischen Gesamtkosten beinhalten die jährlich anfallenden Gesamtkosten der Bioabfallbehandlung sowie der Kompostverwertung bezogen auf den Anlagendurchsatz.
} 
et.al.1999: 211). Zudem wurden durchschnittlich 7-tägige Umsetzintervalle angenommen und für die Herstellung von Fertigkompost eine durchschnittliche Rottedauer von 12 Wochen zugrunde gelegt (vgl. Abschnitt 2.2).

\subsection{Zeitbedarfswette der einzelnen Arbeitsgänge bei der Bioabfallbehandlung}

Zur Ermittlung des Zeitbedarfs der einzelnen Arbeitsgänge wurde weitgehend die maschinelle Ausstattung für die einzelnen Verfahrensschritte zugrunde gelegt, die auf den untersuchten Anlagen im Rahmen des beschriebenen Modellversuchs eingesetzt wurde (Tab.5.1). Je Arbeitsgang wird eine Arbeitskraft benötigt.

Tab. 5.1: Zeitbedarfswerte für die Arbeitsgänge der offenen Mietenkompostierung

\begin{tabular}{|c|c|c|}
\hline Arbeitsgang & $\begin{array}{l}\text { eingesetzte Maschinen- und } \\
\text { Gerätetechnik }\end{array}$ & Zeitbedarf \\
\hline Materialannahme & - & 4h/Woche ${ }^{1)}$ \\
\hline Manuelle Störstoffauslese & $\ldots$ & $1 \mathrm{~h} / 100 \mathrm{~m}^{3}(\text { Input })^{2)}$ \\
\hline $\begin{array}{l}\text { Zerkleinerung von } \\
\text { Strukturmaterial }\end{array}$ & $\begin{array}{l}\text { Teleskoplader } \\
\text { Silozange } \\
\text { Mobiler Schredder }\end{array}$ & $1 \mathrm{~h} / 50 \mathrm{~m}^{3}$ (Input) ${ }^{3)}$ \\
\hline $\begin{array}{l}\text { Aufsetzen einer Matte aus } \\
\text { Strukturmaterial }\end{array}$ & $\begin{array}{l}\text { Teleskoplader } \\
\text { Anbauschaufel }\end{array}$ & $0,3 \mathrm{~h} / 100 \mathrm{~m}^{3}$ (Input) $)^{2)}$ \\
\hline $\begin{array}{l}\text { Aufsetzen der } \\
\text { Dreiecksmieten }\end{array}$ & $\begin{array}{l}\text { Teleskoplader } \\
\text { Anbauschaufel }\end{array}$ & $\begin{array}{l}1 \mathrm{~h} / 20 \mathrm{~m}^{3} \text { (konditioniertes } \\
\text { Material) }\end{array}$ \\
\hline $\begin{array}{l}\text { Umsetzen der } \\
\text { Dreiecksmieten }\end{array}$ & $\begin{array}{l}\text { Schlepper } \\
\text { Mietenumsetzgerät }\end{array}$ & $0,005 \mathrm{~h} / \mathrm{m}$ (Mietenlänge) ${ }^{1)}$ \\
\hline Sieben des Fertigkomposts & $\begin{array}{l}\text { Teleskoplader } \\
\text { Anbauschaufel } \\
\text { Mobile Trommelsiebanlage }\end{array}$ & $1 \mathrm{~h} / 20 \mathrm{~m}^{3}(\text { Kompost })^{1)}{ }^{4)}$ \\
\hline $\begin{array}{l}\text { Reinigung der } \\
\text { Annahmefläche }\end{array}$ & $\begin{array}{l}\text { Teleskoplader } \\
\text { Anbauschaufel }\end{array}$ & $0,5 \mathrm{~h} / 150 \mathrm{~m}^{3}$ (Input) ${ }^{3)}$ \\
\hline $\begin{array}{l}\text { Ausbringung von } \\
\text { Abwasser }\end{array}$ & $\begin{array}{l}\text { Schlepper } \\
\text { Pumpentankwagen }\end{array}$ & $1 \mathrm{~h} / 10 \mathrm{~m}^{3}(\text { Abwasser })^{1)}$ \\
\hline
\end{tabular}




\section{$\underline{5.3 \quad \text { Kostenansätze für die Bioabfallbehandlung }}$}

\subsubsection{Maschinenkosten}

Die festen Maschinenkosten enthalten die Abschreibung sowie eine Verzinsung des eingesetzten Kapitals in Höhe von $8 \%$ des halben Anschaffungspreises. Die veränderlichen Kosten beinhalten Betriebsstoff- und Reparaturkosten.

Ausgehend von der maschinentechnischen Ausstattung in Marktfruchtbetrieben, die als Verwerterbetriebe hinsichtlich des Bedarfs an externen Nährstoffquellen zu bevorzugen sind (vgl. Abschnitt 4.4), werden die nicht in der landwirtschaftlichen Produktion eingesetzten Maschinen und Geräte kostenmäßig vollständig dem Bereich der Kompostierung zugerechnet (Tab.5.2), wobei der jeweilige Einsatzumfang unterhalb der Abschreibungsschwelle angenommen wird.

Tab. 5.2: $\quad$ Kostenansätze des einzelbetrieblichen Maschineneinsatzes

\begin{tabular}{|c|c|c|c|c|c|}
\hline Maschine / Gerät & $\begin{array}{l}\text { Anschaffungs- } \\
\text { kosten } \\
{[\mathrm{DM}]}\end{array}$ & $\begin{array}{l}\text { Nutzungsdauer } \\
\text { nach Zeit } \\
{[\mathrm{a}]}\end{array}$ & $\begin{array}{l}\text { Abschreibung } \\
{[\mathrm{DM} / \mathrm{a}]}\end{array}$ & $\begin{array}{l}\text { Festkosten } \\
\text { (gesamt) } \\
{[\mathrm{DM} / \mathrm{a}]}\end{array}$ & $\begin{array}{l}\text { veränderliche } \\
\text { Kosten }\end{array}$ \\
\hline Silozange $^{1)}$ & 8000 & 10 & 800 & 1120 & $0,30 \mathrm{DM} / \mathrm{m}^{3}$ \\
\hline Anbauschaufel $^{1)}$ & 4100 & 12 & 342 & 506 & $0,30 \mathrm{DM} / \mathrm{m}^{3}$ \\
\hline Mietenumsetzer $^{2)}$ & 15000 & 5 & 3000 & 3600 & $28 \mathrm{DM} / \mathrm{h}$ \\
\hline
\end{tabular}

1) Literaturdaten: vgl.(KTBL 1998 [2]:13)

2) Literaturdaten (KTBL 1998 [1]:125)

Wegen der hohen Anschaffungskosten werden Geräte für die Zerkleinerung von Strukturmaterial und das Sieben des Komposts bei den geringen Durchsätzen der untersuchten Anlagen überbetrieblich genutzt, ebenso der Pumpentankwagen, der in einem Marktfruchtbetrieb für die Abwasserverwertung nur wenige Stunden im Jahr benötigt wird. Für den in die Kalkulation einzubeziehenden Schlepper und den Teleskoplader werden ebenfalls Preise des überbetrieblichen Maschineneinsatzes (Einsatz von Leihmaschinen) verwendet, da der jeweils anteilige Einsatzumfang im landwirtschaftlichen Betrieb und auf der Kompostierungsanlage nur im konkreten Einzelfall ermittelt werden kann (Tab.5.3). 
Tab. 5.3: Kostenansätze des überbetrieblichen Maschineneinsatzes

\begin{tabular}{|c|c|c|}
\hline Maschine / Gerät & $\begin{array}{l}\text { Verrechnungssatz } \\
\text { (pro Einheit) }\end{array}$ & \begin{tabular}{|l} 
Verrechnungssatz \\
(gesamt) \\
inkl. \\
Betriebsstoffkosten
\end{tabular} \\
\hline Traktor $(70 \mathrm{~kW})^{1)}$ & $0,40 \mathrm{DM} / \mathrm{kW} * \mathrm{~h}$ & $33,55 \mathrm{DM} / \mathrm{h}$ \\
\hline $\begin{array}{l}\text { Teleskoplader (inkl. } \\
\text { Betriebsstoffkosten) }^{2)}\end{array}$ & - & $66,50 \mathrm{DM} / \mathrm{h}$ \\
\hline Schredder ${ }^{3)}$ & $7,50 \mathrm{DM} / \mathrm{m}^{3}$ (Output) & - \\
\hline Trommelsieb $^{3)}$ & $\begin{array}{r}5 \mathrm{DM} / \mathrm{m}^{3} \\
\text { (ungesiebterKompost) }\end{array}$ & - \\
\hline $\begin{array}{l}\text { Pumpentankwagen } \\
\left(10 \mathrm{~m}^{3}\right)^{1)}\end{array}$ & $3 \mathrm{DM} / \mathrm{m}^{3 *} \mathrm{~h}$ & $30 \mathrm{DM} / \mathrm{h}$ \\
\hline
\end{tabular}

\subsubsection{Kosten fürbauliche Einnichtungen}

Es wird ein Abschreibungszeitraum für die Anlagen entsprechend den Laufzeiten der Entsorgungsverträge mit den entsorgungspflichtigen Körperschaften, die i.d.R. 10 Jahre betragen (Kasten/Marggraf 1999: 279 und Döhler et.al.1999: 199), sowie ein Zinsansatz zur Ermittlung der Annuität von $8 \%$ gewählt. Die jährlichen Instandhaltungs- und Reparaturkosten werden zu 0,5\% der Anschaffungskosten kalkuliert (vgl. Kern/Wiemer 1990: 73).

\subsubsection{Neubau offener Kompostierungsanlagen}

Für die Konzeption der Anlagenneubauten zur Dreiecksmietenkompostierung mit Durchsatzleistungen von $<0,34 \mathrm{Mg} / \mathrm{h}$ bzw. $<3000 \mathrm{Mg} / \mathrm{a}$, die bei der Ermittlung der Behandlungskosten zu berücksichtigen sind, ist eine Einhausung nicht erforderlich (s. Abschnitt 3.1). Zudem finden hier Anlieferung, Störstoffauslese und Materialkonfektionierung offen statt. Bei diesen Anlagen zur offenen Mietenkompostierung ist der Anlieferungs- und Rottebereich, die Zwischenlagerfläche für Strukturmaterial sowie das Kompostlager $\mathrm{zu}$ befestigen. Zur Untergrundbefestigung und -abdichtung dient eine Betonplatte. Über Sammelschächte werden Regenwasser, Preß- und Sickerwasser in hierfür vorgesehene Zwischenspeicher aus Beton geleitet. 
Eine anlageneigene Waage zur Erfassung der angelieferten und abgefahrenen Bioabfall-, Grüngutund Kompostmengen ist bei den vorhandenen Durchsatzleistungen unter Kostengesichtspunkten nicht vertretbar, ebenso wie die Errichtung von Betriebsgebäuden (vgl.Gronauer et.al.1993:158). Sozialräume für das Anlagenpersonal befinden sich bezüglich des beschriebenen Projekts im Landkreis Demmin in den Landwirtschaftsbetrieben, die den Betrieb der Kompostierungsanlagen organisieren. Auf den Anlagen stehen lediglich einfache Unterstände zur Verfügung. Darüberhinaus wird im Rahmen der Kostenermittlung aus veterinärhygienischen Gründen die Einzäunung der Anlagen berïcksichtigt.

Bei der Dimensionierung des Rottebereichs ist zu beachten, daß aufgrund der eingesetzten Umsetztechnik nach jeder zweiten Miete eine Fahrgasse für den Schlepper und an den Kopfenden der Mieten Rangierflächen zum Wenden des Fahrzeugs einzuplanen sind (vgl. Gronauer et.al.1993:165). Die Dreiecksmieten haben bei einer Höhe von 1,5 m sowie einer Breite an der Mietenbasis von 2,5 m einen Flächenbedarf von 1,33 $\mathrm{m}^{2} / \mathrm{m}^{3}$ Rottematerial. Zur Dimensionierung der Rottefläche wird die maximal anfallende monatliche Inputmenge von 14\% der jährlichen Inputmenge herangezogen (Pfadler/Klages-Haberkern 1993:41), um den jahreszeitlich bedingten Schwankungen der Inputmengen Rechnung zu tragen. Für die Rangierflächen werden $40 \%$ der Rottefläche eingeplant.

Die Zwischenlagerfläche für Grüngut ist so zu dimensionieren, daß auch während anlieferungsarmer Zeiten immer ausreichend Strukturmaterial zur Verfügung steht. Die Kapazität des Kompostlagers sollte so bemessen werden, daß Kompost in Witterungsperioden, die eine Anwendung auf landwirtschaftlichen Flächen nicht zulassen, nicht ausgebracht werden muß (Gronauer et.al.1993:163) (Tab.5.4).

Tab. 5.4: Anlagendimensionierung bei der offenen Mietenkompostierung

\begin{tabular}{|l|l|}
\hline Anlagenteil & Flächenbedarf \\
\hline Anlieferungsfläche & $\begin{array}{l}5 \% \text { der Jahresinputmenge in } \mathrm{Mg} / \mathrm{a}, \\
\text { ausgedrückt in } \mathrm{m}^{2}{ }^{1)}\end{array}$ \\
\hline Rottefläche & $1,33 \mathrm{~m}^{2} / \mathrm{m}^{3}$ Rottematerial \\
\hline Rangierfläche & $40 \%$ der Rottefläche \\
\hline $\begin{array}{l}\text { Zwischenlager für } \\
\text { Strukturmaterial }\end{array}$ & $10 \%$ der Rottefläche ${ }^{1)}$ \\
\hline Kompostlager & $10 \%$ der Rottefläche ${ }^{1)}$ \\
\hline
\end{tabular}

1) Literaturdaten: vgl.(Gronauer et.al.1993:158 und 163) 
Für die Herstellung einer Betonplatte zur Untergrundbefestigung werden $110 \mathrm{DM} / \mathrm{m}^{2}$, für die Errichtung eines Abwassersammelbehälters aus Beton 110 DM/m³ angesetzt (vgl. KTBL 1997:270).

\subsubsection{Umnutzung von Flachsiloanlagen für die Kompostierung}

Die standardisierten Großsiloanlagen in den neuen Bundesländern, die überwiegend im Rahmen eines großangelegten Silobauprogramms in den 70er und 80er Jahren errichtet wurden, bieten aufgrund ihrer Größe, der Möglichkeit zum Befahren mit schweren Fahrzeugen, der aus Emissionsschutzgründen relativ großen Entfernungen zur nächsten Wohnbebauung sowie ihrer Nähe zu potentiellen landwirtschaftlichen Kompost-Ausbringungsflächen günstige Voraussetzungen für den Betrieb im Rahmen eines dezentralen Konzepts zur Bioabfallentsorgung (Bernhardt 1993:578). Diese Flachsiloanlagen weisen Größen von etwa 3.000 bis $16.000 \mathrm{~m}^{2}$ befestigter Grundfläche mit Silosickersaftbehältern (Bernhardt 1993:578), die bei für die Bioabfallkompostierung umgenutzten Anlagen für die Abwasserfassung benötigt werden, auf.

Bei den Kompostierungsanlagen im Landkreis Demmin handelt es sich um solche ehemaligen Durchfahrtsilos. Eine der beiden Anlagen weist als Einkammersilo eine befestigte Fläche von ca. $3.100 \mathrm{~m}^{2}$ auf, wobei als Rottefläche für die Kompostierung die Grundfläche der ehemaligen Silokammer mit etwa $1.525 \mathrm{~m}^{2}$ genutzt wird. Das Volumen des Sickersaftsammelbehälters, der für die Kompostierung als Abwasserspeicher dient, beträgt 150 m³. Die Anlage wurde 1980 errichtet. Bei der zweiten Anlage handelt es sich um einen Mehrkammersilo mit zwei Silokammern von jeweils etwa $1.580 \mathrm{~m}^{2}$ Grundfläche, von der bisher nur eine für die Kompostierung hergerichtet und genutzt wurde. Die befestigte Fläche umfaßt insgesamt ca. $5.200 \mathrm{~m}^{2}$, die Speicherkapazität für Anlagenabwasser beträgt $300 \mathrm{~m}^{3}$. Diese Anlage wurde 1985 gebaut.

Um die beiden Anlagen für die Bioabfallkompostierung nutzen zu können, wurden verschiedene Instandsetzungsarbeiten durchgeführt, insbesondere die Reinigung und Sanierung der Betonoberfläche, das Auftragen eines Bitumenschutzanstrichs im späteren Rottebereich sowie die Instandsetzung der Sickerwassersammelbehälter. Darüberhinaus wurden beide Anlagen eingezäunt. Die Kosten für diese Arbeiten betrugen jeweils etwa $35 \mathrm{DM} / \mathrm{m}^{2}$ Rottefläche. Dieser Ansatz wird für die Kostenermittlung in den Fällen der Umnutzung von Altanlagen verwendet.

Für beide Anlagen wurde eine baurechtliche Genehmigung für die Kompostierung von jeweils 1.600 $\mathrm{Mg} / \mathrm{a}$ (Input) erteilt. Bei der in den berechneten Kostenvarianten zugrundegelegten Umsetztechnik, die einen hohen Bedarf an Rangierflächen aufweist und die im Rahmen des Modellversuchs 
verwendet wurde, ist jedoch nur eine Durchsatzleistung von etwa $1.400 \mathrm{Mg} / \mathrm{a}$ (Input) erreichbar. Durch Herrichtung auch der zweiten Silokammer in der beschriebenen Mehrkammer-Siloanlage ist die Durchsatzleistung theoretisch auf $2.800 \mathrm{Mg}$ /a (Input) zu steigern. Für die Kostenvarianten der Anlagenumnutzung, die eine Inputmenge von mehr als $1.400 \mathrm{Mg} / \mathrm{a}$ aufweisen, wird dieser Anlagentyp verwendet.

Obwohl die standardisierten Horizontalsilos für eine Nutzungsdauer von 40 Jahren vorgesehen waren (Bernhardt 1993:578) und demnach die Abschreibungsdauer der beiden Anlagen bis 2020 bzw. 2025 reichen würde, wird für die Kostenermittlung entsprechend dem Vorgehen beim Anlagenneubau eine Abschreibungsdauer von 10 Jahren angesetzt.

\subsubsection{Personalkosten}

Die Personalkosten werden nach den tariflichen Vereinbarungen für Lohn- und Lohnnebenkosten eines Schlepperfahrers nach dessen Arbeitszeit ermittelt. Ein Abschlag in Höhe von $15 \%$ für die neuen Bundesländer wird nicht berücksichtigt.

\subsubsection{Fremdleistungskosten}

Die Fremdleistungskosten der Bioabfallkompostierung beinhalten die Kosten für die Kompostuntersuchungen nach den Anforderungen der Bioabfallverordnung sowie die Deponiekosten für Siebüberlauf, der nicht wieder als Strukturmaterial in den Kompostierungsprozeß gegeben werden kann (Störstoffe).

Der Bioabfallbehandler hat je angefangener 2.000 Mg (Frischmasse) Kompostuntersuchungen hinsichtlich der Schwermetallgehalte an Blei, Cadmium, Chrom, Kupfer, Nickel, Quecksilber und Zink sowie auf den pH-Wert, den Salzgehalt, den Gehalt der organischen Substanz, den Trockenrückstand und den Anteil an Fremdstoffen im Abstand von längstens drei Monaten durchführen zu lassen. (§ 4 BioAbfV). Hierfür werden 480 DM je Probe angesetzt (Coester/Kasten 1999:27).

Die Deponierung von $1 \mathrm{Mg}$ angelieferten Restmülls beträgt im Landkreis Demmin $130 \mathrm{DM}$. Hinsichtlich der zu erwartenden Restmüllmenge werden bei Bioabfallkompostierungsverfahren pauschal 2 Gew.-\% der Anlieferungsmenge angenommen (Döhler et.al.1999: 200). 


\subsubsection{Gemeinkosten}

Die betrieblichen Gemeinkosten, die z.B. die Kosten für die Betriebsleitung, Betriebsversicherungen, Strom, Heizung und Telefonate umfassen, entstehen unabhängig von der Leistungserstellung durch die Existenz eines Betriebes. Daher ist ihre Zuordnung zu einzelnen Leistungen aufwendig. Sie werden deshalb als prozentuale Aufschläge zu den Einzelkosten berücksichtigt.

Der Gemeinkostenanteil in Marktfruchtbetrieben beträgt etwa $10 \%$ (vgl. Langbehn / Pleßmann 1999: 62). Im Rahmen dieser Arbeit werden die Gemeinkosten als Zuschlag in Höhe von $10 \%$ auf die Einzelkosten berücksichtigt (vgl. Coester/Kasten 1999: 27).

\subsection{Kostenvarianten der Bioabfallbehandlung in landwirtschaftichen Low-Tech-Anlagen}

Es werden mehrere Varianten bezüglich des erzielten Anlagendurchsatzes (Aufkommen an Bioabfällen aus Haushalten und Strukturmaterial) und des Strukturmaterialanteils untersucht, für die jeweils die spezifischen Behandlungskosten sowohl für die Fälle des Anlagenneubaus als auch für diejenigen der Umnutzung von Altanlagen ermittelt werden (Tab. 5.5).

Die Anlagendurchsätze werden für den Bereich zwischen $400 \mathrm{Mg} / \mathrm{a}$ und $2800 \mathrm{Mg} / \mathrm{a}^{4}$ untersucht.

Der Strukturmaterialanteil wird im Bereich zwischen 20 Vol.- $\%$ und 40 Vol.-\% variiert, da es sich hierbei hinsichtlich des Kompostierungsprozesses um den Optimalbereich handelt (s. Abschnitt 2.2).

Der in diesem Bereich enthaltene Strukturmaterialanteil von 35 Vol.-\% stellt hinsichtlich der Zusammensetzung des angelieferten Rohmaterials in Tarnow und Borrentin (Landkreis Demmin) die Abrechnungsgrundlage mit der entsorgungspflichtigen Körperschaft dar und wird daher ebenfalls bearbeitet.

\footnotetext{
${ }^{4}$ Höhere Anlagendurchsätze sind für offene Kompostierungsanlagen nicht genehmigungsfähig (vgl. Ministerium für Bau, Landesentwicklung und Umwelt M-V 1998: 5).
} 
Tab. 5.5: Untersuchte Kostenvarianten der Bioabfallbehandlung

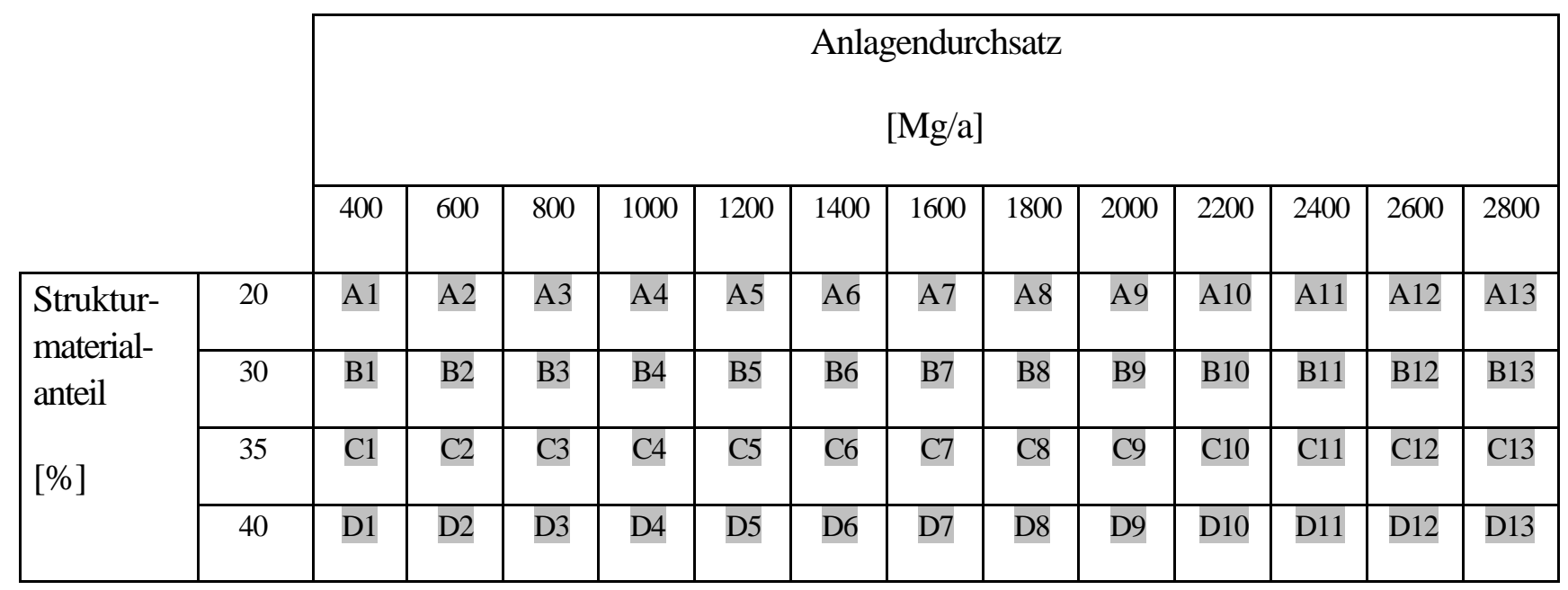

5.5 Spezifische Gesamtkosten der Bioabfallbehandlung in landwirtschaftlichen Low-Tech-Anlagen (Spezifische $\underline{\text { Behandlungskosten) }}$

Unter Berücksichtigung der genannten Einzel- und Gemeinkosten bei verschiedenen Durchsätzen für die offene Dreiecksmietenkompostierung von Bioabfällen aus Haushalten und dem erforderlichen Strukturmaterial in landwirtschaftlichen Low-tech-Anlagen wurden die spezifischen Behandlungskosten (Gesamtkosten je Mg (Input)) ermittelt (Tab.5.6, Werte gerundet). 
Tab.5.6: Spezifische Behandlungskosten der Bioabfallkompostierung in landwirtschaftlichen LowTech-Anlagen

\begin{tabular}{|c|c|c|c|c|c|c|c|c|}
\hline \multirow{3}{*}{$\begin{array}{l}\text { Anlagen- } \\
\text { durchsatz } \\
{[\mathrm{Mg} / \mathrm{a}]}\end{array}$} & \multicolumn{8}{|c|}{$\begin{array}{c}\text { Strukturmaterialanteil } \\
{[\%]}\end{array}$} \\
\hline & \multicolumn{2}{|c|}{20} & \multicolumn{2}{|c|}{30} & \multicolumn{2}{|c|}{35} & \multicolumn{2}{|c|}{40} \\
\hline & Neubau & $\begin{array}{l}\text { Alt- } \\
\text { anlage }\end{array}$ & Neubau & $\begin{array}{l}\text { Alt- } \\
\text { anlage }\end{array}$ & Neubau & $\begin{array}{l}\text { Alt- } \\
\text { anlage }\end{array}$ & Neubau & $\begin{array}{l}\text { Alt- } \\
\text { anlage }\end{array}$ \\
\hline 400 & 99,92 & 105,48 & 105,52 & 109,99 & 108,58 & 112,46 & 111,83 & 115,07 \\
\hline 600 & 89,05 & 82,62 & 94,65 & 87,13 & 97,71 & 89,60 & 100,95 & 92,21 \\
\hline 800 & 82,44 & 71,19 & 88,04 & 75,70 & 91,09 & 78,17 & 94,34 & 80,78 \\
\hline 1000 & 79,40 & 64,33 & 84,99 & 68,85 & 88,05 & 71,31 & 91,29 & 73,92 \\
\hline 1200 & 76,59 & 59,76 & 82,18 & 64,27 & 85,24 & 66,74 & 88,48 & 69,35 \\
\hline 1400 & 75,24 & 56,49 & 80,84 & 61,01 & 83,89 & 63,47 & 87,14 & 66,09 \\
\hline 1600 & 73,65 & 63,22 & 79,25 & 67,74 & 82,30 & 70,20 & 85,54 & 72,82 \\
\hline 1800 & 72,93 & 60,30 & 78,53 & 64,81 & 81,58 & 67,28 & 84,82 & 69,89 \\
\hline 2000 & 71,89 & 57,96 & 77,48 & 62,47 & 80,53 & 64,94 & 83,77 & 67,55 \\
\hline 2200 & 71,46 & 56,04 & 77,05 & 60,56 & 80,10 & 63,02 & 83,34 & 65,64 \\
\hline 2400 & 70,71 & 54,45 & 76,30 & 58,96 & 79,35 & 61,43 & 82,59 & 64,04 \\
\hline 2600 & 70,43 & 53,10 & 76,02 & 57,61 & 79,08 & 60,08 & 82,32 & 62,69 \\
\hline 2800 & 69,86 & 51,94 & 75,46 & 56,46 & 78,51 & 58,92 & 81,75 & 61,54 \\
\hline
\end{tabular}

Zur übersichtlicheren Darstellung wird die folgende Graphik der spezifischen Behandlungskosten in Abhängigkeit vom Anlagendurchsatz auf den Fall eines Strukturmaterialanteils von 35 Vol.-\% 
beschränkt (Abb. 5.1). Die graphische Darstellung der Fälle abweichender Strukturmaterialanteile befindet sich in Anhang II.

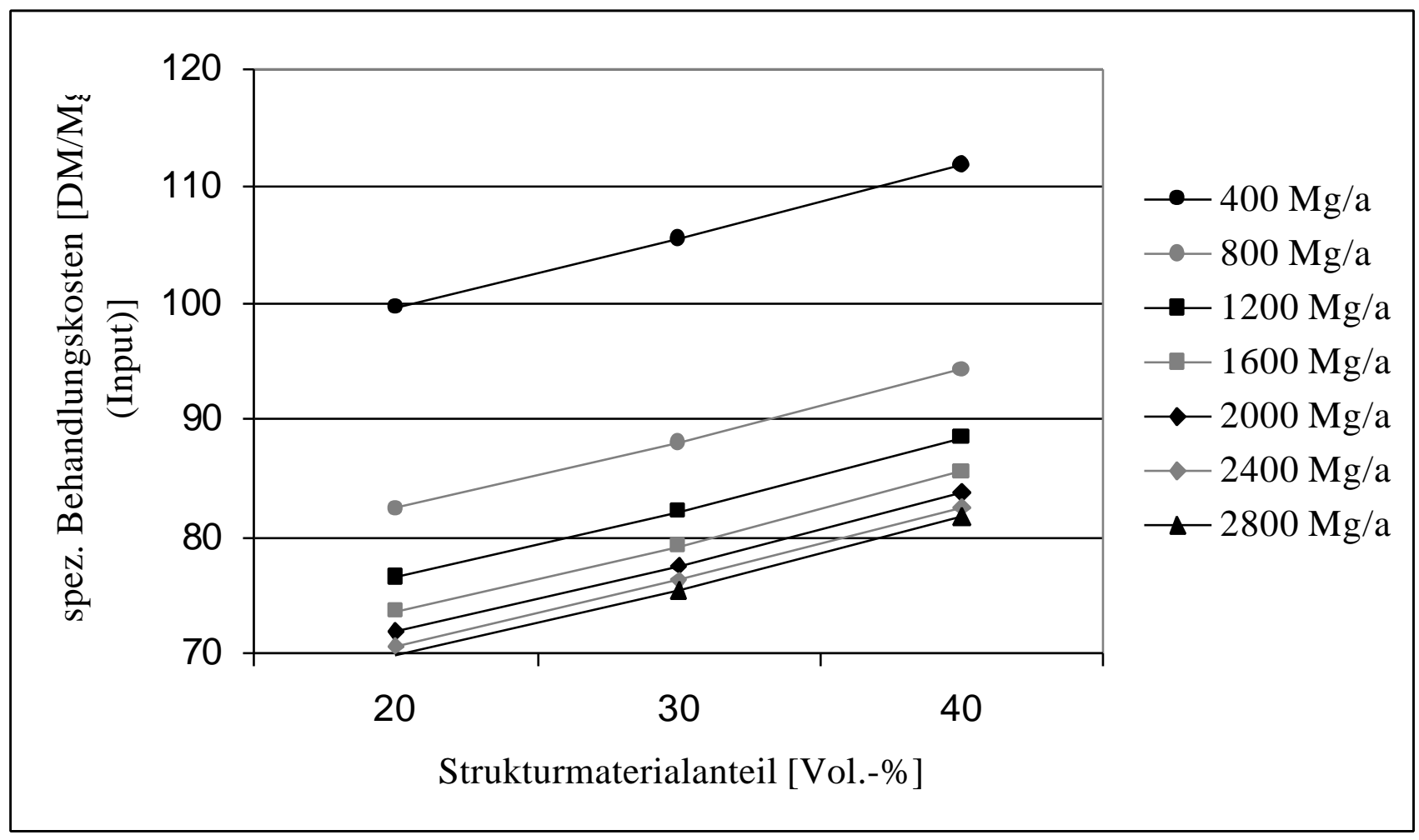

Abb. 5.1 : Spezifische Behandlungskosten in Abhängigkeit vom Anlagendurchsatz (Strukturmaterialanteil: 35 Vol.-\%) 


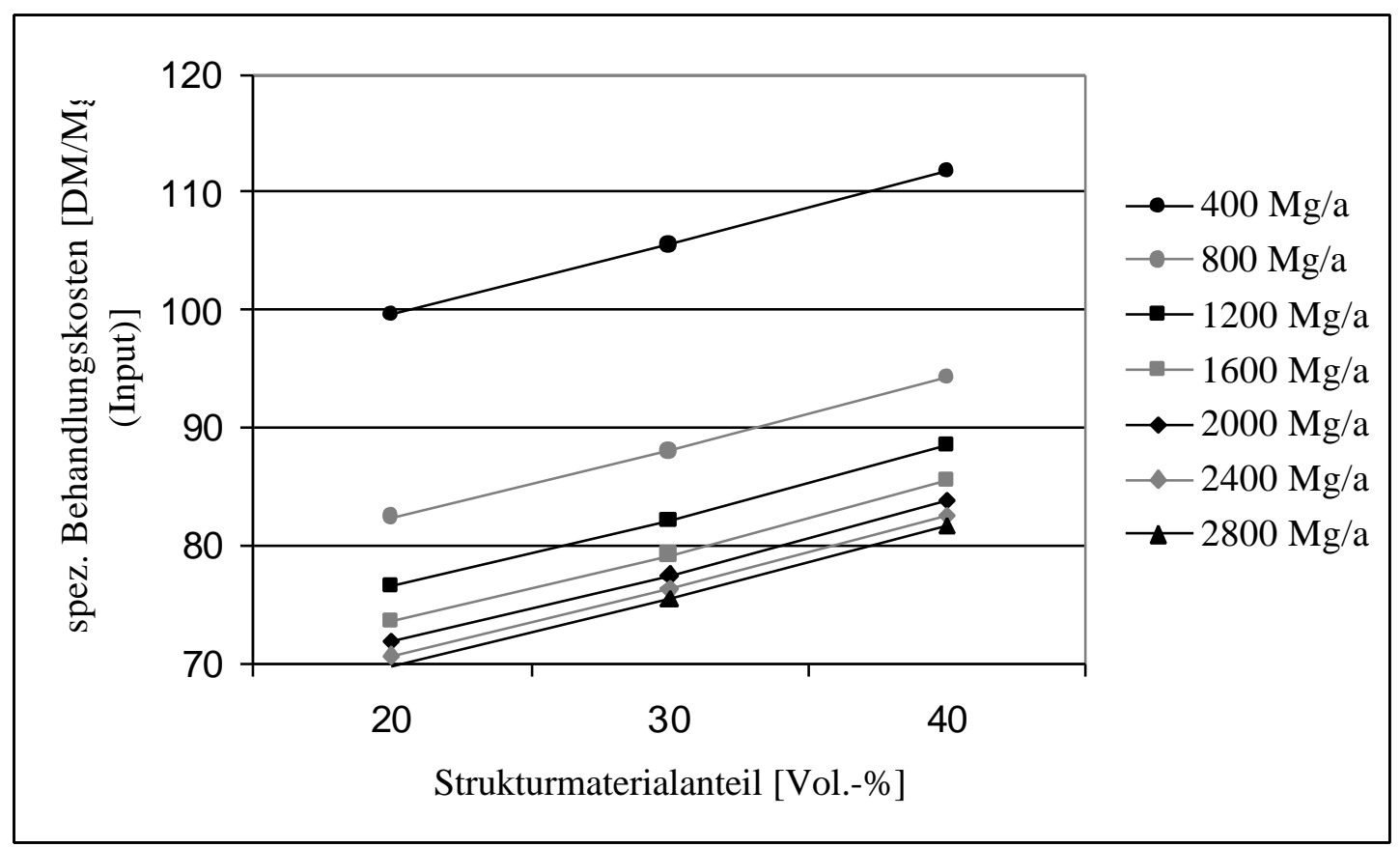

Abb. 5.2: Spezifische Behandlungskosten in Abhängigkeit vom Strukturmaterialanteil für ausgewählte Anlagendurchsätze zwischen $400 \mathrm{Mg} / \mathrm{a}$ und $2800 \mathrm{Mg} / \mathrm{a}$

Die spezifischen Behandlungskosten steigen mit zunehmenden Strukturmaterialanteil im Bereich zwischen 20 und 40 Vol.-\% linear an. Der Unterschied zwischen den genannten Fällen beträgt für die untersuchten Durchsätze bei den Anlagenneubauten etwa 12 DM/Mg (Input). Grund hierfür ist das Schreddern als notwendige Aufbereitung des strukturreichen Grünguts, das mit 7,50 DM/m³ (Output) einen relativ teuren Arbeitsgang darstellt. Mit abnehmendem Strukturmaterialanteil auf bis zu 20 Vol.-\% wird das Grüngut in den Kostenvarianten entsprechend durch Bioabfälle aus Haushalten ersetzt. Für diese organische Fraktion ist die Aufbereitung in Form der manuellen Störstoffauslese erforderlich, die geringere Kosten je Einheit verursacht.

Es ergeben sich spezifische Behandlungskosten für die untersuchten Fälle der offenen Kompostierung in Dreiecksmieten, die etwa zwischen $52 \mathrm{DM} / \mathrm{Mg}$ (Input) und $115 \mathrm{DM} / \mathrm{Mg}$ (Input) liegen. In diesen Werten hat die Ausnutzung von Synergieeffekten mit den landwirtschaftlichen Betrieben, die in den einzelnen Fällen den Betrieb der Kompostierungsanlage organisieren, durch niedrige Fixkosten der eingesetzten Maschinen und Geräte Berücksichtigung gefunden, denn die Verrechnungssätze für den überbetrieblichen Maschineneinsatz enthalten durch Unterstellung einer hohen Maschinenauslastung einen relativ geringen Fixkostenanteil.

Das betrachtete Kompostierungsverfahren, das von Landwirten bevorzugt wird (Helm 1997:175), zeichnet sich gegenüber anderen Verfahren durch einen relativ geringen Investitionsbedarf und eine 
entsprechend einer „Low-Tech“-Anlage einfachen Anlagentechnik aus. Hinsichtlich ihrer Dimensionierung mengenunabhängige und ortsfeste Anlagenausstattung ist nicht erforderlich. Hierdurch zeigt sich im Ergebnis mit zunehmendem Anlagendurchsatz ein deutlicher, gegenüber anderen Verfahren der Bioabfallbehandlung jedoch geringer Effekt der Kostendegression.

Im Vergleich der Kostenvarianten zwischen den Fällen eines Anlagenneubaus und denjenigen der Umnutzung von Altsiloanlagen zeigen sich bei niedrigen Durchsätzen zwischen 400 Mg/a und 600 $\mathrm{Mg} / \mathrm{a}$ nur geringe Unterschiede bezüglich der spezifischen Behandlungskosten. Die Werte für einen Durchsatz von $400 \mathrm{Mg} / \mathrm{a}$ weisen sogar den Anlagenneubau gegenüber der Umnutzung als vorteilhaft aus. Dahinter verbirgt sich die Tatsache, daß die Altsiloanlagen als standardisierte Bauten im Gegensatz zu den Neubauten, die in den Modellrechnungen dem jeweiligen Durchsatz angepaßt wurden, nicht in beliebigen, auf den Durchsatz abstimmbaren Größen zur Verfügung stehen. Die kleinsten Siloanlagen haben etwa $3.000 \mathrm{~m}^{2}$ befestigte Fläche (Bernhardt 1993:578). Die umgenutzte Einkammer-Siloanlage, die den Modellrechnungen für die Anlagendurchsätze bis $1.400 \mathrm{Mg} / \mathrm{a}$ zugrundeliegt, entspricht diesem kleinsten Anlagentyp und weist bei niedrigen Anlagendurchsätzen eine schlechte Ausnutzung der Fläche auf. Bei Steigerung des Durchsatzes bis zur Kapazitätsauslastung der Anlage bei $1.400 \mathrm{Mg} / \mathrm{a}$ zeigt sich dementsprechend ein wesentlich größerer Kostendegressionseffekt als in den entsprechenden Fällen des Anlagenneubaus. Aus dem beschriebenen Grund steigen die spezifischen Behandlungskosten für die Anlagenumnutzung in der Variante eines Durchsatzes von $1.600 \mathrm{Mg} / \mathrm{a}$ deutlich an: der erforderliche Wechsel zum größeren Mehrkammersilo führt zunächst wieder zu einer schlechteren Flächenausnutzung, jedoch zeigt sich auch für diesen Anlagentyp mit zunehmendem Durchsatz ein wesentlich stärkerer Kostendegressionseffekt als in den Fällen eines Anlagenneubaus. Dennoch sind die spezifischen Behandlungskosten bei einem Durchsatz von $1.600 \mathrm{Mg} / \mathrm{a}$ im Falle der Anlagenumnutzung erheblich geringer als beim Neubau, was bei dem jeweils aufgrund der verwendeten Umsetztechnik relativ hohen Rotteflächenbedarf auf die geringen Umnutzungskosten je $\mathrm{m}^{2}$ Rottefläche zurückzuführen ist. Bei etwa $2.800 \mathrm{Mg} / \mathrm{a}$ (Input) ist die Kapazitätsauslastung des umgenutzten Mehrkammersilos erreicht. Die Untersuchung der Kostenvarianten für einen Anlagendurchsatz von $3.000 \mathrm{Mg} / \mathrm{a}$ entfällt, da diese - wie bereits erwähnt - für offene Kompostierungsanlagen nicht genehmigungsfähig sind (Ministerium für Bau, Landesentwicklung und Umwelt Mecklenburg-Vorpommern 1998:5). 


\section{$\underline{5.6 \quad \text { Zeitbedarfswerte der landbaulichen Kompostverwertung }}$}

Die Wirtschaftlichkeit landwirtschaftlicher Kompostverwertung hängt von der Organisation der Transport- und Ausbringungskette ab. Neben Kosten- und Zeitfragen wird die Entscheidung des Landwirts für eine bestimmte Organisationsform auch dadurch bestimmt, inwieweit er Einfluß auf den Ausbringungszeitpunkt nehmen kann (Kuhlmann et.al.1996: 5-6). In den am Modellversuch im Landkreis Demmin beteiligten Unternehmen erfolgten Transport und Ausbringung des Komposts einzelbetrieblich, d.h. es wurde auf die jeweils eigene in den Betrieben vorhandene Mechanisierung für Transport und Ausbringung zurückgegriffen. Denkbar wäre hier auch die überbetriebliche Kompostausbringung durch Beauftragung eines Lohnunternehmens oder Maschinenrings gewesen.

Die produzierten Komposte werden landbaulich verwertet, indem diese als Dünger oder Bodenverbesserungsmittel auf landwirtschaftlicher Nutzfläche ausgebracht werden. Hierzu wird üblicherweise ein Schlepper mit Frontlader und Anbauschaufel in Kombination mit einem herkömmlichen Stalldungstreuer oder einem Tellerbreitstreuer eingesetzt.

Stand der Technik bei der Kompostausbringung sind Tellerstreuwerke, bei denen durch eine Veränderung der Tellerdrehzahl und der Stellung der Wurfleisten die Streubreite variiert werden kann, wobei den Streuaggregaten i.d.R. liegende Dosier- und Zerkleinerungswalzen sowie eine Stauklappe vorgelagert sind (Klages-Haberkern et.al.1994: 21). Bei relativ kleinen Betrieben oder einer relativ geringen auszubringenden Kompostmenge ist jedoch davon auszugehen, daß bei einzelbetrieblichen Lösungen einfache Stalldungstreuer eingesetzt werden (vgl. Kuhlmann et.al.1996: 10).

Der Zeitbedarf für diese Arbeitsgänge ist abhängig von der Schlaggröße, der mittleren Kompostanlage/Feld-Entfernung, der Ausbringungsmenge pro Hektar, der Streuerkapazität sowie der Fahrtgeschwindigkeit auf Wegen (vgl. Kuhlmann et.al.1996: 12-22).

Da im Rahmen dieser Arbeit die Fälle untersucht werden, in denen Landwirte als Bioabfallbehandler den produzierten Kompost auf betriebszugehöriger Fläche verwerten, wird bei der Ermittlung der Zeitbedarfswerte für die Kompostausbringung davon ausgegangen, daß entsprechende Flächen in einer Entfernung von $1 \mathrm{Km}$ von der Kompostierungsanlage zur Verfügung stehen. Dabei wird der Streuer mittels Traktor mit Frontlader und Anbauschaufel auf der Kompostierungsanlage beladen und anschließend der Kompost im Streuer zum Feld transportiert und dort ausgebracht. 
Darüberhinaus wird für die Kalkulation unterstellt, daß alle drei Jahre eine einmalige Ausbringung von $30 \mathrm{Mg}(\mathrm{TM})$ Bioabfallkompost pro Hektar erfolgt ${ }^{5}$, entsprechend 42,5 Mg Frischsubstanz bei etwa 70,6 \% Trockensubstanzgehalt (Kuhlmann et.al.1996: 13). Weiterhin liegt den Zeitdaten eine Arbeitsgeschwindigkeit beim Ausbringen des Komposts von $4 \mathrm{Km} / \mathrm{h}$ sowie eine Fahrtgeschwindigkeit auf Wegen von $10 \mathrm{Km} / \mathrm{h}$ bei Transport mit einem Stalldungstreuer (Ladekapazität: $5 \mathrm{Mg}$ Kompost) sowie $20 \mathrm{Km} / \mathrm{h}$ bei Transport mit dem Großstreuer zugrunde.

Unter den o.g. Prämissen beträgt die Zeit für das Ausstreuen einer Kompostladung dann etwa 1,15 h/ha beim Stalldungstreuer ${ }^{6}$ und - bedingt durch die größere Arbeitsbreite - 0,10 h/ha beim Tellerbreitstreuer. Bei Einsatz eines Großstreuers verringert sich neben der Zeit für die eigentliche Ausbringung auch diejenige für den Transport, da weniger Transportfahrten zurückgelegt werden müssen. Einen größeren Zeitraum beanspruchen Nebenzeiten, wie z.B. 28,8 Minuten für einen Ladevorgang beim Stalldungstreuer mit 6 Mg Ladekapazität (5 Mg Kompost) bzw. 33,6 Minuten für einen Ladevorgang beim Großstreuer (Tellerbreitstreuer mit $8 \mathrm{Mg}$ Nutzlast und $6 \mathrm{Mg}$ Ladekapazität für Bioabfallkompost) (Kuhlmann et.al.1996: 14 und 19).

Tab. 5.7: Zeitbedarf für die Beladung des Streuers mit Frontlader, Transport zur Kompostausbringungsfläche (mittlere Anlage-Feld-Entfernung: $1 \mathrm{Km}$ ) und Kompostausbringung mit dem Streuer (Kuhlmann et.al.1996: 14 und 19).

\begin{tabular}{|c|l|c|}
\hline \multirow{2}{*}{$\begin{array}{c}\text { Schlaggröße } \\
\text { [ha] }\end{array}$} & \multicolumn{2}{|c|}{$\begin{array}{c}|c| \\
\text { Zeitbedarf }\end{array}$} \\
\cline { 2 - 3 } & $\begin{array}{l}\text { Stalldungstreuer } \\
\text { Arbeitsbreite: } 2,2 \mathrm{~m}\end{array}$ & $\begin{array}{l}\text { Tellerbreitstreuer } \\
\text { Arbeitsbreite: } 10 \mathrm{~m}\end{array}$ \\
\hline 0,5 & 11,42 & 5,86 \\
\hline 1 & 11,41 & 5,82 \\
\hline 2 & 10,96 & 5,8 \\
\hline 5 & 10,79 & 5,78 \\
\hline
\end{tabular}

\footnotetext{
${ }^{5}$ Gemäß der Bioabfallverordnung dürfen innerhalb von drei Jahren $30 \mathrm{Mg}$ (Trockenmasse) je ha ausgebracht werden, wenn die im Kompost enthaltenen Schwermetallgehalte bestimmte Grenzwerte unterschreiten (s. Kapitel 6). Im Rahmen des Modellversuchs zur dezentralen Kompostierung im Landkreis Demmin wurden die erwähnten Grenzwerte durchgängig unterschritten.

${ }^{6}$ Ein Stalldungstreuer mit einer Nutzlast von $6 \mathrm{Mg}$ faßt aufgrund des geringen Volumengewichts von Kompost nur etwa 5 Mg Kompost (vgl. Kuhlmann et.al.1996: 14).
} 
Aufgrund der relativ langen Rüst- und Nebenzeiten bei der Kompostausbringung wird die Flächenleistung nur bei Schlaggrößen zwischen 0,5 und 2 Hektar wesentlich erhöht. Bei der vorliegenden Mechanisierung sind mit zunehmenden Schlaggrößen nur noch geringfügig höhere Flächenleistungen $\mathrm{zu}$ erwarten. Im Rahmen der Kostenermittlung werden die jeweiligen Zeitbedarfswerte für Schlaggrößen von 5 ha zugrunde gelegt.

\subsection{Kostenansätze für die landbauliche Kompostverwertung}

\subsubsection{Maschinenkosten}

Da Stalldung- bzw. Tellerbreitstreuer in den vorzugsweise die Kompostierungsanlage betreibenden Marktfruchtbetrieben üblicherweise nicht vorhanden sind, sind deren feste Kosten vollständig dem Bereich der landbaulichen Kompostverwertung zuzurechnen. Frontlader und Anbauschaufel werden ebenfalls im Rahmen einer Vollkostenrechnung berücksichtigt. Für den Schlepper wird der Preis des überbetrieblichen Maschineneinsatzes (Einsatz von Leihmaschinen) verwendet (vgl. Abschnitt 5.3.1).

Tab. 5.8: Kostenansätze der Kompostausbringung

\begin{tabular}{|c|c|c|}
\hline Maschine / Gerät & $\begin{array}{c}\text { Festkosten } \\
\text { (gesamt) } \\
{[\mathrm{DM} / \mathrm{a}]}\end{array}$ & veränderliche Kosten \\
\hline Traktor $(70 \mathrm{~kW})^{1)}$ & - & $33,55 \mathrm{DM} / \mathrm{h}$ \\
\hline Frontlader ${ }^{2)}$ & 987 & $1,25 \mathrm{DM} / \mathrm{h}$ \\
\hline Anbauschaufel $^{3)}$ & 617 & $0,10 \mathrm{DM} / \mathrm{m}^{3}$ \\
\hline $\begin{array}{l}\text { Stalldungstreuer } \\
\left(\text { einachsig, } 6 \text { t) }{ }^{4)}\right.\end{array}$ & 2660 & $0,80 \mathrm{DM} / \mathrm{Mg}$ \\
\hline $\begin{array}{l}\text { Tellerbreitstreuer } \\
(\text { Tandemachse, } 8 \mathrm{t})^{5)}\end{array}$ & 3780 & $0,80 \mathrm{DM} / \mathrm{Mg}$ \\
\hline
\end{tabular}

\footnotetext{
1) vgl. Tab. 5.3

2) Literaturdaten: vgl. (KTBL 1998 [2]: 12)

3) Literaturdaten: vgl. (KTBL 1996: 12)

4) Literaturdaten: vgl. (KTBL 1998 [2]: 21)

5) Literaturdaten: vgl. (KTBL 1998 [2]: 22)
}

\subsubsection{Personalkosten}

Die Personalkosten werden anhand des Tariflohns eines Schlepperfahrers ermittelt (vgl. 5.3.3). 


\subsubsection{Fremdleistungskosten}

Bei der erstmaligen Aufbringung von Komposten auf landwirtschaftliche Nutzfläche ist eine Bodenuntersuchung auf Schwermetalle und den pH-Wert durchzuführen ( 99 BioAbfV). Hierfür werden 208 DM je Probe angesetzt (Coester/Kasten 1999:27). Zur Ermittlung der Gesamtkosten der Kompostverwertung wird davon ausgegangen, daß im Abstand von drei Jahren eine Beprobung der Ausbringungsfläche im 5 ha-Raster vorgenommen wird.

\section{7 .4 Gemeinkosten}

Die Gemeinkosten werden als Zuschlag in Höhe von $10 \%$ auf die Einzelkosten berücksichtigt (vgl. Abschnitt 5.3.5).

\section{$\underline{5.8 \quad \text { Spezifische Gesamtkosten der landbaulichen Kompostverwertung (spezifische Verwertungskosten) }}$}

Bei der Ermittlung der Gesamtkosten landbaulicher Kompostverwertung werden ackerbauliche Maßnahmen zur Einarbeitung des Komposts nicht berücksichtigt. Da die Kompostausbringung terminlich flexibel handhabbar ist, wird von einer Einarbeitung im Zuge der Grundbodenbearbeitung ausgegangen, wobei entsprechend hohe Anforderungen an die betriebliche Schlagkraft der Ausbringung gestellt werden (Kuhlmann et. al. 1996: 21).

Unter Berïcksichtigung der ermittelten Einzel- und Gemeinkosten ergeben sich hinsichtlich der untersuchten Streuervarianten durch Bezug der Gesamtkosten auf die auszubringende Kompostmenge die spezifischen Gesamtkosten der landbaulichen Kompostverwertung (spezifische Verwertungskosten) (Tab. 5.9, Tab. 5.10, Abb. 5.3).

Tab. 5.9: Spezifische Verwertungskosten der Transport- und Ausbringungskette mit einem Stalldungstreuer (Ladekapazität: $5 \mathrm{Mg}$ Kompost) in Abhängigkeit von der auszubringenden Kompostmenge

\begin{tabular}{|c|c|c|c|c|c|c|}
\hline $\begin{array}{l}\text { Kompost- } \\
\text { menge } \\
{[\mathrm{Mg}]}\end{array}$ & $\begin{array}{l}\text { Gesamtarbeits- } \\
\text { zeitbedarf } \\
{[\mathrm{h}]}\end{array}$ & $\begin{array}{l}\text { Maschinen- } \\
\text { kosten } \\
{[\mathrm{DM}]}\end{array}$ & $\begin{array}{c}\text { Personalkosten } \\
{[\mathrm{DM}]}\end{array}$ & $\begin{array}{l}\text { Fremdleistungs- } \\
\text { kosten } \\
{[\mathrm{DM}]}\end{array}$ & $\begin{array}{l}\text { Gemeinkosten } \\
{[\mathrm{DM}]}\end{array}$ & $\begin{array}{l}\text { spez. } \\
\text { Gesamtkosten } \\
{[\mathrm{DM} / \mathrm{Mg}]}\end{array}$ \\
\hline 200 & 50,78 & 6189,01 & 1320,19 & 326,27 & 783,55 & 43,10 \\
\hline 300 & 76,16 & 7151,52 & 1980,28 & 489,41 & 962,12 & 35,28 \\
\hline 400 & 101,55 & 8114,02 & 2640,38 & 652,55 & 1140,69 & 31,37 \\
\hline
\end{tabular}




\begin{tabular}{|c|c|r|r|r|r|c|}
\hline 500 & 126,94 & 9076,53 & 3300,47 & 815,69 & 1319,27 & 29,02 \\
\hline 600 & 152,33 & 10039,04 & 3960,56 & 978,82 & 1497,84 & 27,46 \\
\hline 700 & 177,72 & 11001,54 & 4620,66 & 1141,96 & 1676,42 & 26,34 \\
\hline 800 & 203,11 & 11964,05 & 5280,75 & 1305,10 & 1854,99 & 25,51 \\
\hline 900 & 228,49 & 12926,55 & 5940,85 & 1468,24 & 2033,56 & 24,85 \\
\hline 1000 & 253,88 & 13889,06 & 6600,94 & 1631,37 & 2212,14 & 24,33 \\
\hline 1100 & 279,27 & 14851,56 & 7261,04 & 1794,51 & 2390,71 & 23,91 \\
\hline 1200 & 304,66 & 15814,07 & 7921,13 & 1957,65 & 2569,28 & 23,55 \\
\hline 1300 & 330,05 & 16776,58 & 8581,22 & 2120,78 & 2747,86 & 23,25 \\
\hline 1400 & 355,44 & 17739,08 & 9241,32 & 2283,92 & 2926,43 & 22,99 \\
\hline
\end{tabular}

Tab. 5.10: Spezifische Verwertungskosten der Transport- und Ausbringungskette mit einem Tellerbreitstreuer (Ladekapazität: 6 Mg Kompost) in Abhängigkeit von der auszubringenden Kompostmenge

\begin{tabular}{|c|c|c|c|c|c|c|}
\hline $\begin{array}{c}\text { Kompost- } \\
\text { menge } \\
{[\mathrm{Mg}]}\end{array}$ & $\begin{array}{l}\text { Gesamtarbeits- } \\
\text { zeitbedarf } \\
{[\mathrm{h}]}\end{array}$ & $\begin{array}{l}\text { Maschinen- } \\
\text { kosten } \\
{[\mathrm{DM}]}\end{array}$ & $\begin{array}{r}\text { Personalkosten } \\
{[\mathrm{DM}]}\end{array}$ & $\begin{array}{l}\text { Fremdleistungs- } \\
\text { kosten } \\
{[\mathrm{DM}]}\end{array}$ & $\begin{array}{c}\text { Gemeinkosten } \\
{[\mathrm{DM}]}\end{array}$ & $\begin{array}{l}\text { spez. } \\
\text { Gesamtkosten } \\
{[\mathrm{DM} / \mathrm{Mg}]}\end{array}$ \\
\hline 200 & 27,20 & 6507,55 & 707,20 & 326,27 & 754,10 & 41,48 \\
\hline 300 & 40,80 & 7069,33 & 1060,80 & 489,41 & 861,95 & 31,60 \\
\hline 400 & 54,40 & 7631,10 & 1414,40 & 652,55 & 969,81 & 26,67 \\
\hline 500 & 68,00 & 8192,88 & 1768,00 & 815,69 & 1077,66 & 23,71 \\
\hline 600 & 81,60 & 8754,66 & 2121,60 & 978,82 & 1185,51 & 21,73 \\
\hline 700 & 95,20 & 9316,43 & 2475,20 & 1141,96 & 1293,36 & 20,32 \\
\hline 800 & 108,80 & 9878,21 & 2828,80 & 1305,10 & 1401,21 & 19,27 \\
\hline 900 & 122,40 & 10439,98 & 3182,40 & 1468,24 & 1509,06 & 18,44 \\
\hline 1000 & 136,00 & 11001,76 & 3536,00 & 1631,37 & 1616,91 & 17,79 \\
\hline 1100 & 149,60 & 11563,54 & 3889,60 & 1794,51 & 1724,76 & 17,25 \\
\hline 1200 & 163,20 & 12125,31 & 4243,20 & 1957,65 & 1832,62 & 16,80 \\
\hline 1300 & 176,80 & 12687,09 & 4596,80 & 2120,78 & 1940,47 & 16,42 \\
\hline 1400 & 190,40 & 13252,39 & 4950,40 & 2283,92 & 2048,67 & 16,10 \\
\hline
\end{tabular}




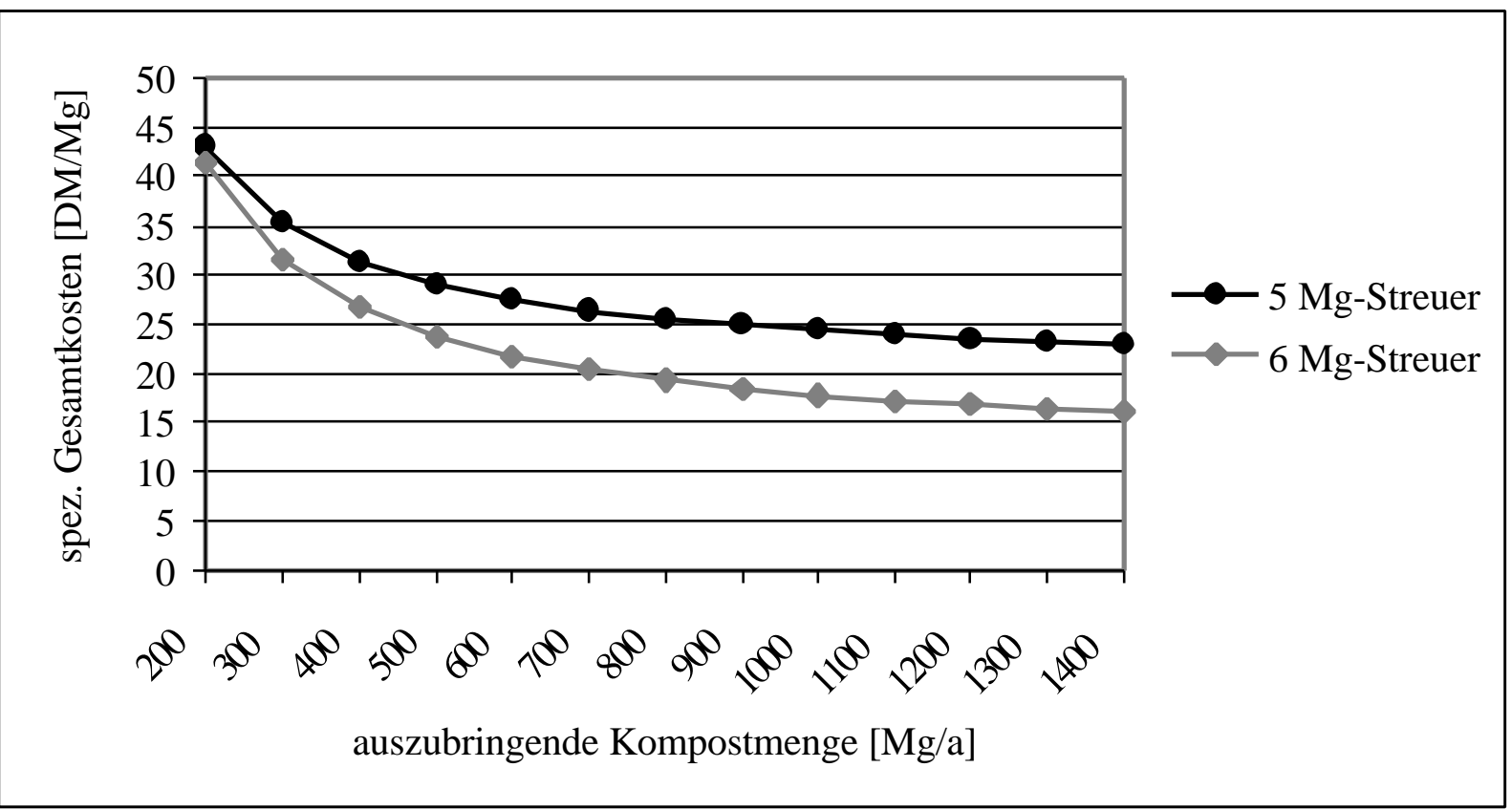

Abb. 5.3: Spezifische Verwertungskosten der Transport- und Ausbringungskette mit einem Stalldungstreuer (Ladekapazität: 5 Mg Kompost) bzw. einem Tellerbreitstreuer (Ladekapazität: 6 Mg Kompost) in Abhängigkeit von der auszubringenden Kompostmenge Bei einem weiteren Anstieg der Kompostausbringungsmengen, die der Höhe nach im Rahmen des untersuchten Konzepts zur Bioabfallbehandlung von einer einzelnen Kompostierungs-anlage nicht erreicht werden, wurden weiterhin deutlich sinkende spezifische Kosten ${ }^{7}$ für die Ausbringung von beispielhaft zugrundegelegten Kompostmengen ermittelt (Döhler et. al. 1999: 212-213) (Abb. 5.4).

Da die einzelne Kompostierungsanlage des untersuchten Anlagenkonzepts höchstens etwa 1400 $\mathrm{Mg} / \mathrm{a}$ Kompost produziert, werden entsprechend niedrige spezifische Kosten für die Transport- und Ausbringungskette bei einzelbetrieblicher Arbeitserledigung nicht erreicht. Da in dem zugrundeliegenden dezentralen Anlagenkonzept jedoch relativ weite Anfahrtswege zu den Kompostierungsanlagen zurïckzulegen sind und daher ein verhältnismäßig hoher Transportaufwand besteht, erscheint es fraglich, ob diese von Döhler et.al. (1999) ermittelten niedrigen spezifischen Gesamtkosten für die Kompostausbringung auch über niedrige Preise für den überbetrieblichen Maschineneinsatz an den kompostverwertenden Landwirt weitergegeben werden können.

\footnotetext{
${ }^{7}$ Diese spezifischen Kosten entsprechen nicht vollständig den in Tab. 5.9 und 5.10 dargestellten Werten, da diese weder die Einzelkosten für die nach der BioAbfV erforderlichen Bodenuntersuchungen noch den Gemeinkostenanteil enthalten. Zudem liegen den Berechnungen mit $24 \mathrm{Mg} / \mathrm{h}$ bei einer Streuernutzlast von $6 \mathrm{Mg}$ bzw. $72 \mathrm{Mg} / \mathrm{h}$ bei einer Streuernutzlast von $10 \mathrm{Mg}$ relativ hohe Ausbringleistungen zugrunde, die höhere Ladeleistungen und damit eine andere Maschinen- und Geräteausstattung als die den eigenen Berechnungen zugrundeliegenden erfordert.
} 


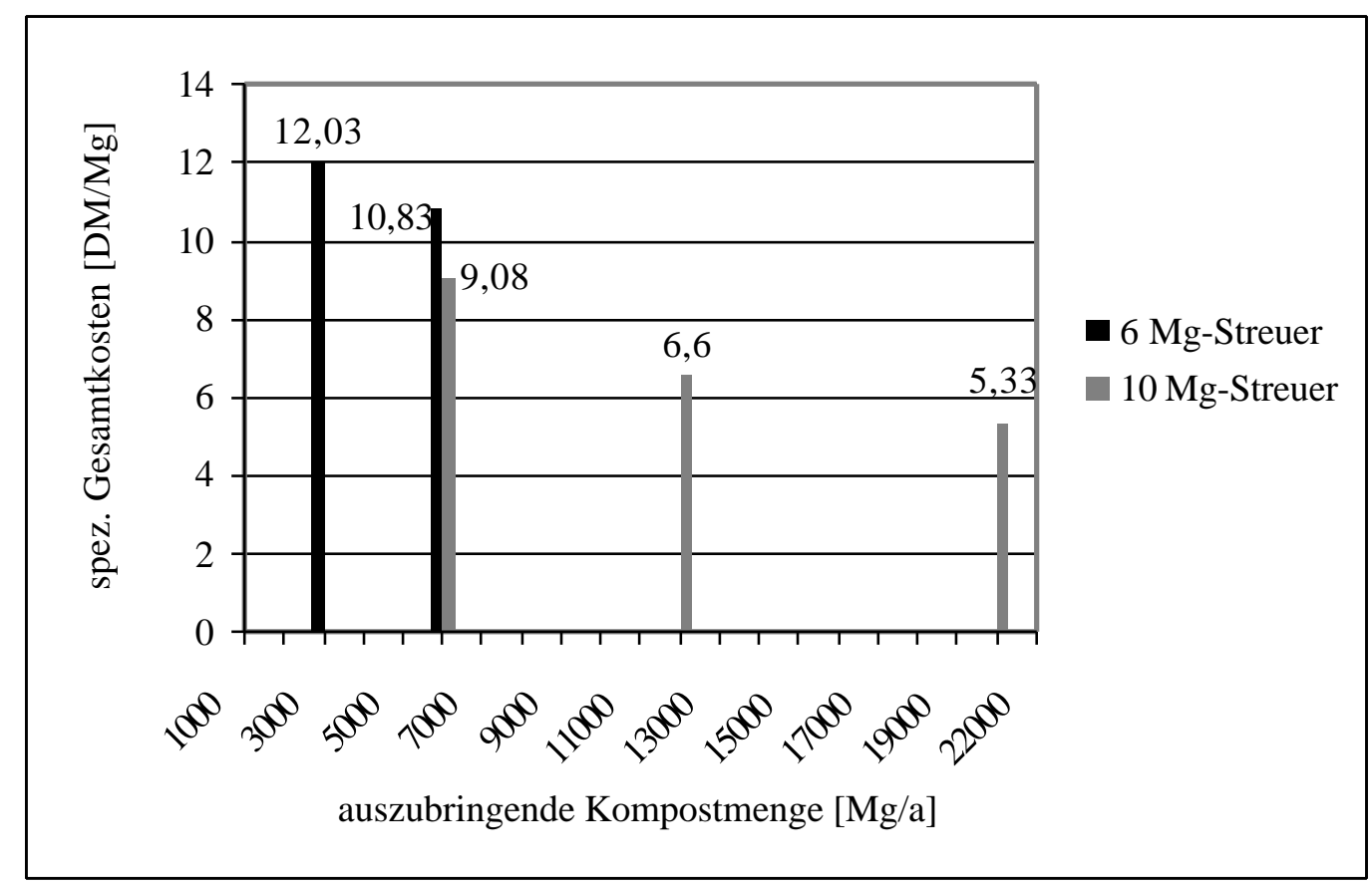

Abb. 5.4: Spezifische Gesamtkosten der Transport- und Ausbringungskette für die Fälle einer Streuer-Ladekapazität von 6 Mg Kompost bei einzelbetrieblicher bzw. 10 Mg Kompost bei überbetrieblicher Ausbringung in Abhängigkeit von der auszubringenden Kompostmenge

Um die spezifischen Gesamtkosten der Kompostverwertung (spezifische Verwertungskosten) zu denen der Bioabfallbehandlung (spezifische Behandlungskosten) in Beziehung setzen zu können, werden diese im folgenden bezogen auf den Anlagendurchsatz dargestellt (Tab. 5.11, Abb. 5.5). 
Tab. 5.11: Spezifische Verwertungskosten der Transport- und Ausbringungskette mit einem Stalldungstreuer (Ladekapazität: 5 Mg Kompost) bzw. einem Tellerbreitstreuer (Ladekapazität: 6 Mg Kompost) in Abhängigkeit vom Anlagendurchsatz

\begin{tabular}{|c|c|c|}
\hline $\begin{array}{c}\text { Anlagen- } \\
\text { durchsatz } \\
{[\mathrm{Mg} / \mathrm{a}]}\end{array}$ & \multicolumn{2}{|c|}{$\begin{array}{c}\text { Spez. Verwertungskosten } \\
{[\mathrm{DM} / \mathrm{Mg}]}\end{array}$} \\
\cline { 2 - 3 } & $5 \mathrm{Mg}$-Streuer & $6 \mathrm{Mg}$-Streuer \\
\hline 400 & 21,55 & 20,74 \\
\hline 600 & 17,64 & 15,80 \\
\hline 800 & 15,68 & 13,33 \\
\hline 1000 & 14,51 & 11,85 \\
\hline 1200 & 13,73 & 10,87 \\
\hline 1400 & 13,17 & 10,16 \\
\hline 1600 & 12,75 & 9,63 \\
\hline 1800 & 12,43 & 9,22 \\
\hline 2000 & 12,17 & 8,90 \\
\hline 2200 & 11,95 & 8,62 \\
\hline 2400 & 11,78 & 8,40 \\
\hline 2600 & 11,63 & 8,21 \\
\hline 2800 & 11,50 & 8,05 \\
\hline
\end{tabular}




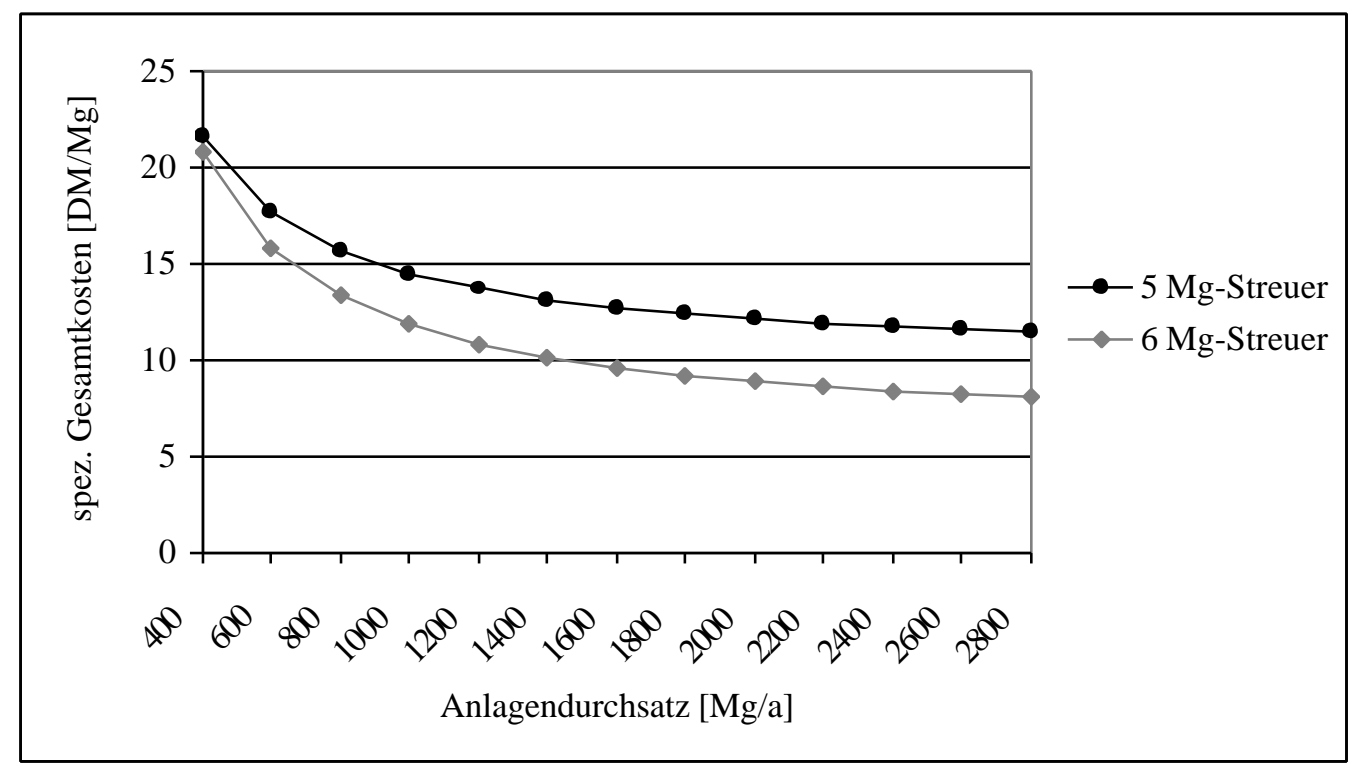

Abb. 5.5: Spezifische Verwertungskosten der Transport- und Ausbringungskette mit einem Stalldungstreuer (Ladekapazität: 5 Mg Kompost) bzw. einem Tellerbreitstreuer (Ladekapazität: 6 Mg Kompost) in Abhängigkeit vom Anlagendurchsatz

6 Risiken der Bioabfallkompostierung und der landwirtschaftlichen Kompostverwertung

\subsection{Vorgehensweise}

Durch den Betrieb einer Kompostierungsanlage und durch die landwirtschaftliche Verwertung von Bioabfallkomposten kann es zu Beeinträchtigungen der Umwelt kommen. Aus diesen Umweltbeeinträchtigungen kann dem Landwirt ein unternehmerisches Risiko erwachsen, sofern er für deren Auswirkungen haftet oder Einkommenseinbußen bzw. Vermögensschäden zu befürchten hat.

Da hinsichtlich der Bioabfallbehandlung und der Kompostverwertung unterschiedliche Auswirkungen auf die Umwelt zu untersuchen sind, werden diese Bereiche im folgenden getrennt bearbeitet. Im einzelnen werden die Umweltbeeinträchtigungen und die daraus resultierenden unternehmerischen Risiken ermittelt. Da der Landwirt diese Risiken in der Kalkulation des von ihm für die angebotenen Dienstleistungen im Rahmen der Bioabfallbehandlung und -verwertung verlangten Preises zu berücksichtigen hat, wird untersucht, welche der benannten Risikoaspekte einer monetären Bewertung zugänglich sind. 


\subsection{Risiken des Betriebs einer Kompostienungsanlage}

\subsubsection{Umweltbeinträchtigungen durch den Betrieb einer Kompostienungsanlage}

Die Umweltbeeinträchtigungen im Zusammenhang mit dem Betrieb einer Kompostierungsanlage können Belästigungen (z.B. Lärm, Geruch, Landschaftsbild) oder Belastungen (z.B. Schadgase, Sporen, Krankheitserreger, Anlagenabwasser) darstellen. Auf Grundlage der einschlägigen Gesetze und Verordnungen können bei der Genehmigung des Anlagenbetriebs Einschränkungen vorgesehen und bestimmte, technische und organisatorische Maßnahmen gefordert werden (Reloe / Schuchardt 1993: 197), um diese weitgehend zu vermeiden. Insbesondere ist eine Anlage zur biologischen Abfallbehandlung so zu errichten und zu betreiben, daß ,eine Beeinträchtigung des Betriebspersonals und / oder der Nachbarschaft durch Pilzsporen, Geruch oder schädliche Gase unterbunden wird“ (TA Siedlungsabfall 1993: 9.2.1).

Im folgenden wird auf die Umweltbeeinträchtigungen durch den Kompostierungsprozeß eingegangen, aus denen für den Landwirt, der eine Kompostierungsanlage betreibt, ein unternehmerisches Risiko erwachsen könnte. Im einzelnen wird auf Geruchsbelästigungen, Freisetzung klimarelevanter Gase und Keimbelastungen während der Kompostierung eingegangen. Lärmbelästigungen sowie Beeinträchtigung des Landschaftsbildes durch eine Kompostierungsanlage sind im Rahmen des Genehmigungsverfahrens zu bearbeiten und stellen demzufolge kein Betriebsrisiko für den Landwirt als Bioabfallbehandler dar.

Obwohl die Verwertung des Anlagenabwassers kostenmäßig der Bioabfallbehandlung zugerechnet wurde, werden die damit verbundenen Risiken von Schwermetallbelastungen im Rahmen der landbaulichen Verwertung bearbeitet, da von der Ausbringung des Anlagenabwassers auf landwirtschaftlicher Nutzfläche ausgegangen wird

\subsubsection{Geruchsstoffe}

Zwischen den verschiedenen Verfahren zur Behandlung von Bioabfällen gibt es Unterschiede hinsichtlich der Gefahr einer Geruchsfreisetzung, z.B. emittieren die Kompostierungsverfahren eine größere Menge an Geruchseinheiten als die Vergärungsverfahren. Insbesondere bei der Bioabfallkompostierung kann es zu erheblichen Geruchsemissionen kommen. Dieses ist auf geruchsbehaftetes Ausgangsmaterial, wie z.B. feuchte Küchenabfälle, und auf Emissionen im Bereich der Sammlung von Anlagenabwasser zurückzuführen. 
Beim aeroben Abbau von organischem Material im thermophilen Milieu werden erhebliche Mengen an Geruchsstoffen gebildet. Deren Freisetzung aus der ruhenden Miete findet hauptsächlich bei Materialbewegungen statt, wie z.B. dem Umsetzen der Kompostmieten. Der Hauptaustrag der Geruchsstoffe erfolgt i.d.R. zu Beginn der Heißrottephase, d.h. in den ersten ein bis zwei Wochen der Rotte. Bei den offenen unbelüfteten Rottesystemen erfolgt der Austrag der Geruchsstoffe über die thermisch induzierte Luftströmung sowie durch Diffusionsvorgänge und Luftdruckschwankungen (Ketelsen/Cuhls 1999: 466). Eine vollständige Vermeidung von Geruchsemissionen ist daher auch bei optimaler Rotteführung nicht möglich (Wintzer et.al.1996: 298).

Die Geruchsemissionen, die von geruchsintensiven Faul- und Gärstoffwechselprodukten bei Ankunft der Bioabfälle auf der Kompostierungsanlage in bereits teilweise anaeroben Milieu oder als Folge temporärer Sauerstoffunterversorgungen in der Miete verursacht werden, gehen in Abhängigkeit vom Alter des Rottematerials zurïck (Wintzer et.al.1996: 124).

Den größten Emissionsbeitrag leisten niedermolekulare Fettsäuren, wie z.B. Buttersäure, Propionsäure und Essigsäure, basische Gase wie Ammoniak und Amine sowie schwefelhaltige Substanzen, wie z.B. $\mathrm{H}_{2}$ S, Merkaptane oder Methylsulfide (Tabasaran 1994: 437).

Die Kompostierung von Bioabfällen aus Haushalten auf landwirtschaftlichen Betrieben kann aufgrund der einfachen Anlagenausstattung mit größeren Umweltbeeinträchtigungen behaftet sein als die Bioabfallkompostierung in gekapselten Anlagen (Wintzer et. al. 1996: 121). Dies ist v.a. darauf zurückzuführen, daß die TASi für solche Anlagen mit geringen Verarbeitungskapazitäten keine eingehauste Vorrotte fordert.

Darüberhinaus können von dem gesammelten Sickerwasser, z.B. wenn es unkontrolliert austritt oder verregnet wird, hohe Geruchsfrachten ausgehen. „Auch offene Sickerwasserbecken [...] stellen potentielle Emissionsquellen dar“ (Tabasaran 1994: 440).

So emittieren offene Kompostierungsanlagen häufig insbesondere in den Sommermonaten unangenehme Gerüche und führen dadurch trotz Einhaltung der vorgeschriebenen Mindestabstände ${ }^{8}$ zu Belästigungen der Anwohner.

8 In Mecklenburg-Vorpommern ist ein Standortkriterium für die Genehmigung einer Kompostierungsanlage ein Mindestabstand zur nächsten Wohnbebauung bzw. der nach Bauleitplanung zu erwartenden Wohnbebauung von $300 \mathrm{~m}$. Hierdurch kann Beenträchtigungen der Anwohner durch Immissionen (Geruch, Keime, Staub) vorgebeugt werden. 
Die Höhe eines Geruchsschwellenwertes (1 oder $\left.3 \mathrm{GE} / \mathrm{m}^{3}\right)$ und dessen zulässige Überschreitungshäufigkeit (3-5\%) ist in den einzelnen Bundesländern uneinheitlich geregelt. „Eine Technische Anleitung Geruch, die einen Grenzwert von $1 \mathrm{GE} / \mathrm{m}^{3}{ }^{9}$ vorsieht, ist in Vorbereitung“" (Wintzer et.al.1996: 124). Für die nach Baurecht genehmigten offenen Kompostierungsanlagen im Landkreis Demmin besteht die Auflage, daß die Geruchsemissionen durch bauliche, technische und betriebliche Maßnahmen so zu begrenzen sind, daß außerhalb der Grundstücksgrenze in $95 \%$ der Jahresstunden $1 \mathrm{GE} / \mathrm{m}^{3}$ nicht überschritten wird (Bauordnungsamt Demmin 1995). Zur Verminderung der Geruchsemissionen sind die Kompostmieten auf ein $20 \mathrm{~cm}$ hohes Holzhäckselbett aufzusetzen und frisch angeliefertes Input-Material aus der Biotonne nicht länger als ein Tag unbearbeitet liegen zu lassen (Bauordnungsamt Demmin 1995).

Olfaktometrische Messungen, die die Einhaltung der festgeschriebenen Grenzwerte überprüfen, wurden bisher nicht durchgeführt. Die Behörde hat sich bei Genehmigung der Anlagen jedoch vorbehalten, „die Einhaltung der zulässigen Geruchskonzentration [...] durch Geruchsintensitätsbestimmung nach VDI 3882 [...] nachweisen $\mathrm{zu}$ lassen, sofern hierzu Handlungsbedarf besteht“ (Bauordnungsamt Demmin 1995). Nach Feststellung der zuständigen Behörde war die Geruchsbelästigung über den gesamten Zeitraum des Modellversuchs als gering einzustufen (Umweltamt Demmin 1996).

Dennoch können Geruchsimmisionen insbesondere bei ungünstigen Witterungsverhältnissen auch über den Mindestabstand hinaus auftreten (Döhler et.al.1999: 172).

9 Da sich einzelne Geruchsstoffe nur sehr aufwendig quantifizieren lassen und sich die Geruchsintensität zusammenwirkender Geruchsstoffe nicht berechnen läßt, werden zur Messung von Geruchsemissionen in Anlehnung an die VDI-Richtlinie 3881 olfaktometrische Messungen durchgeführt. Dabei werden mit anteilig immer weniger geruchsneutraler Luft verdünnte, geruchsbehaftete Luftproben mehreren Testpersonen, die hinsichtlich des Geruchsempfindens einen repräsentativen Durchschnitt der Bevölkerung darstellen müssen, angeboten, bis ein Geruch wahrgenommen werden kann. Aus dem Verhältnis von geruchsneutraler zu geruchsbehafteter Luft zum Zeitpunkt der Geruchswahrnehmung lassen sich die Geruchseinheiten $\left[\mathrm{GE} / \mathrm{m}^{3}\right]$ berechnen (Tabasaran 1994: 438).

Die Geruchseinheiten (GE) geben den Faktor an, der benötigt wird, um die Menge an Geruchsmolekülen bzw. Geruchsgemischen soweit mit nicht riechender Luft zu verdünnen, „daß diese verteilt auf einen $\mathrm{m}^{3}$ Luft bei $50 \%$ der Probanden gerade noch eine Geruchsempfindung auslöst“ (Wintzer et.al.1996: 298). 


\subsubsection{Klimarelevante Gase}

Während des mikrobiellen Ab- und Umbaus organischer Substanzen werden Kohlendioxid, Methan und andere klimarelevante Gase, wie z.B. Distickstoffoxid, gebildet.

Die Kohlendioxid-Emission kann beim Abbau von biogenem Material nicht verhindert werden und findet auch in der Natur statt (Edelmann/Schleiss 1999: 338). Dabei ist die Freisetzung des Kohlendioxids, das zuvor durch den Aufbau der Biomasse der Atmosphäre entzogen wurde, klimaneutral (Wintzer et.al.1996: 124-125).

Die Bildung von Methan läßt auf anaerobe Umsetzungsprozesse in der Kompostmiete schließen. Bei der Kompostierung wurden deutliche Methanemissionen gemessen, „welche im Vergleich zum Kohlendioxid viel stärker gewichtet werden müssen“ (Edelmann/Schleiss 1999: 338). Es zeigte sich, daß sogar in Komposten, welche sehr häufig umgesetzt werden, „schon sehr rasch nach dem Umsetzen spürbare Methananteile entweichen“ (Edelmann/Schleiss 1999: 331). Grund hierfür ist, daß räumlich oder zeitlich begrenzte anaerobe Prozesse in der Kompostmiete unvermeidlich sind (Helm 1995: 32).

Bei der Kompostierung strukturreicher Pflanzenabfälle mit weitem C/N-Verhältnis ist die Methanfreisetzung geringer als bei leicht abbaubaren Pflanzen- oder Bioabfällen, weil der Abbau der organischen Substanz langsamer abläuft und die Sauerstoffversorgung günstiger ist. Wird davon ausgegangen, daß mehr als $10 \%$ des Kohlenstoffs der Rotteausgangsmaterialien methanisiert und an die Atmosphäre abgegeben wird, dann ist dieser Effekt von klimarelevanter Bedeutung (Wintzer et.al.1996: 125).

Je nach Sauerstoffangebot in der Kompostmiete kann zudem das ebenfalls klimawirksame Distickstoffoxid (Lachgas) durch Nitrifizierungs- und Denitrifizierungsprozesse gebildet werden, jedoch spielt die Bildung von Distickstoffoxid im Gegensatz zur abgeschätzten Methanfreisetzung auch dann keine Rolle, wenn man unterstellt, daß $1 \%$ des Stickstoffgehalts im Rotteausgangsmaterial als Distickstoffoxid emittiert wird (Wintzer et.al.1996: 125).

Insgesamt betrachtet haben die Methanemissionen aus anaeroben Nestern in den Kompostmieten die größte Klimarelevanz, jedoch sind Quantifizierungen mit großen Unsicherheiten behaftet (vgl. Wintzer et.al.1996: 305).

Es ist ein politisches Problem, darüber $\mathrm{zu}$ entscheiden, ob alternative Verfahren der Bioabfallbehandlung aufgrund prinzipiell geringerer klimarelevanter Emissionen der Kompostierung 
vorzuziehen sind. Der bioabfallbehandelnde Landwirt trägt durch die Emissionen des von ihm gewählten Verfahrens derzeitig kein unternehmerisches Risiko.

\subsubsection{Keime}

Organische Abfälle enthalten pathogene und nicht pathogene Bakterien, Viren, Actinomyceten und Pilze. Insbesondere bei Bioabfällen aus Haushalten ist die Keimbelastung i.d.R. deutlich höher als bei Grünabfällen (Wintzer et.al.1996: 299).

Die qualitative und quantitative Analyse der Keime während der Kompostierung zeigt die mit dem Rotteprozeß gekoppelte Verschiebung des Keimspektrums: im Zustand der Anlieferung auf der Kompostierungsanlage herrscht in den Bioabfällen aus Haushalten eine mesophile Schimmelpilz- und Bakterienflora vor, die einer thermophilen Flora während der Hauptrotte weicht. Nach der Abkühlungsphase wird der fertige Kompost wieder durch mesophile Schimmelpilze und Actinomyceten besiedelt (Schappler-Scheele/Missel 1999: 226).

Das größte Gefährdungspotential für Menschen liegt in der Mikroorganismenflora der thermophilen Rottephase, da hier potentielle Krankheitserreger, wie z.B. Aspergillusarten und thermophile Actinomyceten, in hoher Konzentration im Rottematerial und deshalb auch in den bei technischen Prozessen emittierten Bioaerosolen ${ }^{10}$ enthalten sind (Schappler-Scheele/Missel 1999: 226).

In Kompostierungsanlagen ist die Keimkonzentration wegen der Abfallzusammensetzung und der erforderlichen Aufbereitungs- und Umsetzvorgänge vergleichsweise hoch. Insbesondere die Zerkleinerung von Grünabfällen und die manuelle Fremdstoffauslese können bei den Beschäftigten Gesundheitsprobleme auslösen (Wintzer et. al. 1996: 299 und 323).

Gegenwärtig besteht Unsicherheit über geeignete Meßmethoden zur quantitativen Erfassung von Keimen und Toxinen. Weder auf internationaler noch auf nationaler Ebene existieren Grenzwerte für die zulässige Keimbelastung der Beschäftigten in Kompostierungsanlagen (Wintzer et.al.1996: 300).

\footnotetext{
${ }^{10}$ Bioaerosole stellen eine in der Luft befindliche Mischung fester und flüssiger Partikel dar, die Bakterien, Pilze, Algen, Viren, Zellbestandteile und mikrobielle Produkte, wie z.B. Endotoxine und Mykotoxine, enthalten. Die Luft fungiert dabei als Medium zur Überdauerung und Verbreitung (Schappler-Scheele/Missel 1999: 235).
} 
Luftkeimkonzentrationen in Kompostierungsanlagen variieren um $10^{2}$ bis $10^{5} \mathrm{KBE} / \mathrm{m}^{3} \mathrm{Luft}^{11}$. „Im Vergleich zu anderen Arbeits- und Lebensbereichen sowie in Anbetracht von gesundheitlich relevant erachteten Luftkeimkonzentration von $>10^{8} \mathrm{KBE} / \mathrm{m}^{3} \mathrm{Luft}$, sind die in [...] Kompostierungsanlagen gegebenen Luftkeimgehalte nicht auffällig. [...] Eine Gesamtkeimkonzentration von $10^{4} \mathrm{KBE} / \mathrm{m}^{3} \mathrm{Luft}$ wird in ganz alltäglichen Situationen (z.B. Innenräumen mit vielen Personen, belebten Straßen und anderes) erreicht. In vielen Arbeitsbereichen, z.B. in der Landwirtschaft, ist eine solche Konzentration als eher niedrig anzusehen“"(Daschner 1995: 10).

Die Bewertung von Keimgehalten in der Luft hängt neben der Konzentration auch von der Expositionszeit ab, die der Arbeitnehmer diesen Konzentrationen ausgesetzt ist (Daschner 1995: 10). Daher erscheint das anhand der Gesamtkeimgehalte bewertete Gesundheitsrisiko für Beschäftigte in offenen Kompostierungsanlagen, insbesondere im Vergleich zu gekapselten Anlagen, relativ gering: einerseits erfolgt hier keine Aufkonzentration der Keime in einem begrenzten Raum, zum anderen sind die Expositionszeiten der Beschäftigten aufgrund der geringen Mengen an zu verarbeitenden Inputmaterialien verhältnismäßig kurz.

In der Gesamtkeimzahl sind jedoch unterschiedliche Keime unabhängig von ihrer gesundheitlichen Relevanz zusammengefaßt, so daß deren Aussagekraft begrenzt ist. Bewertungen anhand gesundheitlich relevanter Größenordnungen spezifischer Keime ist v.a. aufgrund der großen Anzahl in Frage kommender Keime schwierig und bisher ergebnislos. „Die fundierte Bewertung von Keimkonzentrationen stößt im Hinblick auf gesundheitliche Relevanz auf Schwierigkeiten und ist bei der Anwendung in Abfallbehandlungsanlagen vor Ort praktisch nicht umsetzbar“" (Daschner 1995: 11).

Eine Kausalität zwischen Erkrankungen von Arbeitnehmern auf Kompostierungsanlagen und Keimzahlen sowie zwischen Erkrankungen und Anlagentyp (offen, überdacht, eingehaust) ist nach derzeitigem Kenntnisstand nicht herzustellen. Die geringe Erkrankungsrate der Kompostwerker ,läßt den Schluß zu, daß durch ein hinreichendes Arbeitsschutzniveau in Verbindung mit dem Anlagentyp

${ }^{11} \mathrm{KBE}$ : koloniebildende Einheiten 
die Kompostwerker nicht so stark exponiert sind, wie angenommen“ (Schappler-Scheele/Missel 1999: 243).

\subsubsection{Arbeitsschutzund Unfallversichenung}

\subsubsection{Arbeitsschutz}

Gemäß dem Arbeitsschutzgesetz hat der Arbeitgeber die Arbeit so zu gestalten, daß eine Gefährdung für Leben und Gesundheit der Beschäftigten möglichst gering gehalten wird. Zu diesem Zweck sind Maßnahmen nach dem Stand der Technik, Arbeitsmedizin und Hygiene zu treffen und gesicherte arbeitswirtschaftliche Erkenntnisse zu berücksichtigen (LASI 1997: 5).

Die Biostoffverordnung vom 27. Januar 1999 dient in Verbindung mit dem Arbeitsschutzgesetz der Umsetzung der EG-Richtlinie 90/679/EWG des Rates vom 26. November 1990 über den Schutz der Arbeitnehmer gegen Gefährdung durch biologische Arbeitsstoffe bei der Arbeit.

Biologische Arbeitsstoffe werden demnach definiert als Mikroorganismen, Zellkulturen und humanpathogene Endoparasiten, die beim Menschen Infektionen, sensibilisierende oder toxische Wirkungen hervorrufen können ( 2 BioStoffV).

Der Arbeitgeber hat im Rahmen einer Gefährdungsbeurteilung für alle Tätigkeiten mit biologischen Arbeitsstoffen Schutzmaßnahmen zu ermitteln, wobei die Biostoffverordnung die biologischen Arbeitsstoffe entsprechend dem von ihnen ausgehenden Infektionsrisiko in vier Risikostufen sowie die erforderlichen Sicherheitsmaßnahmen in vier Schutzstufen kategorisiert (Au/Grüneklee 1999: 278).

Erfahrungen mit der Umsetzung der Biostoffverordnung stehen derzeit noch aus. „Für den Bereich der Entsorgungswirtschaft sind mit der Biostoffverordnung eine Reihe von offenen Fragen verbunden, die nicht ohne Hilfe der Verbände oder entsprechend sachkundigen Fachgremien zu lösen sind“ (Böhm 1999: 79).

Erste Empfehlungen für den Umgang mit biologischen Arbeitsstoffen wurden bereits vom Länderausschuß für Arbeitsschutz und Sicherheit (LASI) in den Leitlinien für den Arbeitsschutz in biologischen Abfallbehandlungsanlagen genannt.

Demnach führt der Umgang mit den organischen Materialien in den Kompostierungsanlagen für die betroffenen Arbeitnehmer ,,neben der Beeinträchtigung durch ergonomische Mängel, Lärm, Geruch, 
Staub und Dieselmotoren vor allem zu einer Belastung durch biologische Arbeitsstoffe“ (LASI 1997:

1). Der Anwendungsbereich der LASI-Leitlinien erfaßt „biologische Abfallbehandlungsanlagen, in denen organische Abfallstoffe aus Haushaltungen, Gewerbe, Landwirtschaft, Garten- und Landschaftspflege (Bioabfall) in aeroben oder anaeroben mikrobiologischen Verfahren behandelt werden“ (LASI 1997: 5).

In den Leitlinien wird zwischen technischen und organisatorischen Maßnahmen zur sicheren Gestaltung der Arbeitsplätze und der persönlichen Schutzausrüstung unterschieden (Döhler et.al.1999: 180). Diese stellen jedoch inhaltlich überwiegend auf die Verhältnisse in gekapselten Anlagen zur Behandlung organischer Abfälle ab und sind deshalb für die in dieser Arbeit betrachteten Anlagen zur offenen Mietenkompostierung nur begrenzt anwendbar.

Im folgenden sind Empfehlungen der LASI-Leitlinie wiedergegeben, die auch im Rahmen des betrachteten dezentralen Anlagenkonzepts relevant sind (LASI 1997):

- Radlader und personenbesetzte Mietenwendefahrzeuge sollten in Bereichen, in denen mit verstärkter Keimbelastung zu rechnen ist, über eine geschlossene klimatisierte Kabine mit geeigneter Filteranlage verfügen.

- Während des Betriebs der Maschinen und Geräte sind Türen und Fenster geschlossen zu halten.

- Die Sauberkeit der Kabine ist sicherzustellen, z.B. durch tägliche Reinigung der Kabine und des Filters, durch Ein- und Ausstieg außerhalb belasteter Bereiche und/oder Reinigung der Arbeitskleidung.

- Ständige Arbeitsplätze im Anlieferungs- und Sichtungsbereich sind möglichst nicht einzurichten.

- Bei nicht ständigen Arbeitsplätzen zur manuellen Sortierung ist Atemschutz zu tragen.

- Beschäftigte, die an den Vorgängen zum Zerkleinern, Mischen, Beschicken und Sieben beteiligt sind, sind mit Atemschutz und, sofern erforderlich, mit Gehörschutz auszustatten. Zudem sind Schutzvorrichtungen gegen aus den Aggregaten herausschleudernde Gegenstände zu installieren.

- Persönliche Schutzausrüstungen, wie z.B. Schutzkleidung und Schutzhandschuhe, müssen vom Arbeitgeber gestellt und von den Beschäftigten getragen werden.

Hinsichtlich der Arbeitsplatzbedingungen enthält die Betriebsgenehmigung der Kompostierungsanlagen im Landkreis Demmin keine Aussagen. Nach der TASi (1993) hat die Betriebsführung jedoch so zu erfolgen, daß das Betriebspersonal nicht durch Gerüche, Schadgase und Pilzsporen belästigt wird (Nr. 5.4.1.3.3). 
Die Störstoffauslese erfolgt in beiden Kompostierungsanlagen manuell vor der Rotte. Diese Fremdstoffabtrennung vor der Rotte ist vorteilhaft, weil der erzeugte Kompost aufgrund des geringeren Anteils an zerkleinerten Plastik- und Glasstücken eine bessere Qualität aufweist.

Nachteilig ist dagegen die dabei auftretende höhere Keim- und Geruchsbelastung der Beschäftigten (Wintzer et. al. 1996: 111).

\subsubsection{Unfallversicherung}

Arbeitsunfälle des landwirtschaftlichen Unternehmers und der im Unternehmen Beschäftigten sind über die gesetzliche Unfallversicherung der landwirtschaftlichen Berufsgenossenschaft versichert. $\mathrm{Zu}$ den Arbeitsunfällen zählen ferner auch Berufskrankheiten, wobei das Risiko der Ausbildung von Berufskrankheiten für Beschäftigte in Kompostierungsanlagen derzeit als gering eingeschätzt wird (Schappler-Scheele/Missel 1999: 247).

Unter die versicherten Tätigkeiten fallen auch solche in landwirtschaftlichen Nebenbetrieben. „Damit sind Unternehmen gemeint, die ein Landwirt neben seiner Landwirtschaft, aber in wirtschaftlicher Abhängigkeit von ihr unterhält" (Möller et.al.1997: 32). Risiken in Zusammenhang mit Arbeiten auf der Kompostierungsanlage sind demnach im Rahmen des untersuchten dezentralen Konzepts durch die gesetzliche Unfallversicherung abgedeckt.

\subsubsection{Haftung für Umweltschäden}

Kommt das Haftungsrecht zur Anwendung, ist bereits ein Schaden entstanden, der finanziell auszugleichen ist. Umwelthaftungsregeln sind sowohl im BGB $\mathrm{zu}$ finden als auch in Umweltfachgesetzen.

Das BGB regelt die Haftung für den aus der Verletzung eines Schutzgutes ${ }^{12}$ oder eines Schutzgesetzes ${ }^{13}$ einem Dritten entstehenden Schaden. „Voraussetzung für die Anwendung dieser Normen ist die schuldhafte (vorsätzliche oder fahrlässige) und rechtswidrige (Verstoß gegen eine Rechtsnorm) Verletzung eines der benannten Rechtsgüter und die Entstehung eines nachweisbaren

\footnotetext{
${ }^{12}$ Schutzgut: s. §823(1) BGB - Leben, Körper, Gesundheit, Freiheit, Eigentum sowie sonstige Rechte

${ }^{13}$ Schutzgesetz: s. $§ 823(2)$ BGB
} 
Schadens, wobei zwischen Verletzung und Schaden ein kausaler Zusammenhang bestehen muß“ (Brunner/Müller 1994: 20).

Neben diesen generellen Normen existieren Umwelthaftungsspezialnormen, von denen für den Bereich der Kompostierung das Umwelthaftungsgesetz und das Wasserhaushaltsgesetz relevant sind. Diese Normen regeln die verschuldensunabhängige Gefährdungshaftung, d.h., der Verursacher haftet auch dann, wenn ihn kein Verschulden trifft. „Im Mittelpunkt steht die Gefährlichkeit bestimmter [...] Anlagen, Produkte oder Verkehrsmittel oder die typische hohe Gefährdung des betroffenen Objekts (z.B. Wasser) und der damit verbundene notwendige Schutz Dritter“ (Brunner/Müller 1994: 20).

Es werden hierbei Schäden aus Störfällen und Schäden aus rechtmäßigem Normalbetrieb erfaßt (Bilitewski et. al. 1994: 17). „Für den Betreiber einer solchen Anlage entsteht hieraus natürlich ein großes finanzielles Risiko“ (Brunner/Müller 1994: 20).

Unter Umwelthaftung wird in Anlehnung an $\S 3$ (1) Umwelthaftungsgesetz diejenige Form des Einstehenmüssens für finanzielle Einbußen verstanden, die auf dem Umweltpfad verursacht wurden, d.h. es ist ein Schaden durch Einwirkungen entstanden, die sich in Boden, Luft oder Wasser ausgebreitet haben (Salje 1997: 202).

Die schädlichen Umwelteinwirkungen können z.B. in der Zufuhr von Gasen, Dämpfen, Gerüchen, Rauch, Ruß, Wärme, Geräuschen oder Erschütterungen bestehen (Brunner/Müller 1994: 20). Soweit es sich um Schäden aus einer solchen Umwelteinwirkung handelt, ist im UmweltHG eine Haftungshöchstgrenze von 160 Mio. DM für Sachbeschädigung und für Personenschäden vorgesehen (Bilitewski et. al. 1994: 17).

Nach §1 UmweltHG haftet der Landwirt als Inhaber einer umweltgefährlichen Anlage ohne Verschulden, wenn durch Einwirkungen der Kompostierungsanlage, die sich über Boden, Luft oder Wasser ausgebreitet haben, eine Person verletzt oder getötet oder eine Sache beschädigt worden ist. „In der Anlage zu §1 UmweltHG finden sich Kompostwerke unter Ziff. 73; diese müssen nicht bestimmte Größenmerkmale erfüllen“ (Salje 1997: 203).

Der Begriff „Kompostwerk“ ist jedoch auch anders interpretierbar: zwar ist dieser Begriff nicht näher definiert, es liegt jedoch entsprechend der Begriffsregelung in der 4. BImSchV nahe, Kompostwerke als Anlagen mit einer Durchsatzmenge von mindestens $10 \mathrm{Mg} / \mathrm{h} \mathrm{zu}$ betrachten. Anlagen mit Durchsatzleistungen von $0,75 \mathrm{Mg} / \mathrm{h}$ bis weniger als $10 \mathrm{Mg} / \mathrm{h}$ werden hier lediglich als ,Anlagen zur 
Kompostierung“ bezeichnet. Die im Rahmen dieser Untersuchung betrachteten Anlagen mit einem Durchsatz von weniger als $0,75 \mathrm{Mg} / \mathrm{h}$ werden im Rahmen des vereinfachten Genehmigungsverfahrens lediglich nach Baurecht genehmigt und finden deshalb in der BImSchV keine Erwähnung.

Darüberhinaus ist haftungsrechtlich $\mathrm{zu}$ beachten, daß es sich bei Kompostierungsanlagen (ähnlich Silageflächen) um Anlagen zum Lagern wassergefährdender Stoffe handelt, die gemäß $§ 22$ (2) WHG einer strengen Gefährdungshaftung unterliegen.

Soll der erzeugte Kompost in den Verkehr gebracht werden, so greift das Produkthaftungsgesetz (Nies/Klages-Haberkern 1993: 30).

Dabei wird von Produkthaftung gesprochen, wenn der Haftungstatbestand an das Inverkehrbringen einer neu hergestellten Sache durch den Hersteller anknüpft. Wird in einem solchen Fall durch einen Produktfehler ein Personen- oder Sachschaden herbeigeführt, so ist der Produkthersteller (ohne Verschulden) zum Schadensersatz verpflichtet (Salje 1997: 204).

Diese Form der Haftung findet für den hier untersuchten Fall, in dem die Landwirte als Hersteller der Bioabfallkomposte diese auf ihren eigenen Flächen verwerten, keine Anwendung.

\subsubsection{Versichenung des Risikos von Umweltschäden}

Eine Umwelthaftpflichtversicherung zur Abdeckung des Risikos von Umweltschäden ist in Form einer Umwelthaftpflicht-Basisversicherung bei landwirtschaftlichen Unternehmen i.d.R. Bestandteil der Betriebshaftpflichtversicherung.

Bei der Versicherung herkömmlicher landwirtschaftlicher Tätigkeit werden unterschieden (Reimann/Strehler/Fry 1996: 56):

- die normale Betriebshaftpflichtversicherung mit Umweltbasisdeckung, die bereits einen Teil der Umweltrisiken abdeckt (z.B. Umweltrisiken bei der Lagerung von Gülle, Jauche oder SilageSickersäften bis $600 \mathrm{~m}^{3}$ ),

- eine zusätzliche Umwelthaftpflichtversicherung bei größeren Lagermengen von Gülle, Mineralölen, Pflanzenschutzmitteln usw.,

- eine spezielle, zusätzliche Umwelthaftpflichtversicherung, wenn spezielle Anlagen des Betriebs zulassungspflichtig nach dem Bundes-Immissionsschutzgesetz (BImSchG) sind, 
- Eine erhöhte Risikoabdeckung für Betriebe, die einer verschärften Haftung nach dem Umwelthaftungsgesetz unterliegen. Betroffen hiervon sind insbesondere Geflügel- und Schweinehalter mit mehr als 1.700 Mastschweineplätzen, 500 Sauenplätzen, 50.000 Hennenplätzen oder 100.000 Junghennenplätzen.

Die letzten beiden der genannten Voraussetzungen treffen auf Kompostierungsanlagen mit einer Durchsatzleistung $^{14}$ von weniger als $0,75 \mathrm{Mg} / \mathrm{h}$ und daher auch auf die beispielhaft untersuchten Anlagen in Borrentin und Tarnow (Landkreis Demmin) nicht zu, weil diese als sog. unbedeutende Anlagen zur Kompostierung ein vereinfachtes Genehmigungsverfahren zu durchlaufen hatten.

Jeder Landwirt benötigt die genannte Betriebshaftpflichtversicherung mit Umweltbasisdeckung, die bereits einen Teil der Umweltrisiken abdeckt. „Der Jahresbeitrag für diese Grundpolice richtet sich nach der bewirtschafteten Fläche und nach der gewählten Deckungssumme“ (Reimann/Strehler/Fry 1996: 56).

Schließt die Umweltbasisdeckung die Sickerwasserfassung bei der Bioabfallkompostierung entsprechend der Sickersaftfassung bei der Silagebereitung in Flachsiloanlagen mit ein, so gilt dies bei den meisten Versicherungen für Behälter bis $600 \mathrm{~m}^{3}$. Umfassen die Behälter mehr als diesen Rauminhalt, so sind die damit verbundenen Umweltrisiken extra zu versichern.

Die Volumina der Sickerwasserfassung auf den Kompostierungsanlagen in Tarnow und Borrentin betragen $150 \mathrm{~m}^{3}$ bzw. $300 \mathrm{~m}^{3}$, so daß keine weitere Deckung durch eine zusätzliche Umwelthaftpflichtversicherung erforderlich wäre.

Hierfür spricht auch die Tatsache, daß die bauliche Anlage zur Sickerwassersammlung gemäß den wasserwirtschaftlichen Anforderungen an Anlagen zum Lagern und Abfüllen von Jauche, Gülle, Festmist und Silagesickersäften (§ 4 Abs. 2 der Anlagenverordnung - VAwS) zu errichten und zu betreiben ist (Bauordnungsamt Demmin 1995).

${ }_{14}$ Der Begriff der Durchsatzleistung stellt auf die Eingangsseite (Input) ab und beinhaltet die rechtlich mögliche maximale Anlagenkapazität pro Stunde. Diese wird determiniert durch kapazitätsbestimmende Aggregate oder durch die Rottefläche. Letzteres ist bei der offenen Mietenkompostierung i.d.R. der Fall. Daher ist hier eine Umrechnung der Materialzuführung auf eine Betriebszeit von 24 Stunden pro Tag zulässig. $0,75 \mathrm{Mg} / \mathrm{h}$ entsprechen einer maximalen Jahresaufnahme von $6.750 \mathrm{Mg}$. 
Bei Düngemitteln, zu denen auch Bioabfallkomposte als Sekundärrohstoffdünger i.S.d. Düngemittelrechts zählen, umfaßt der Versicherungsschutz für das Lagerrisiko sowohl Gewässerschäden als auch Schäden an Boden und Luft. Risiken der Lagerung sind i.d.R. ohne Mengenbegrenzung über die Umweltbasisdeckung mitversichert (vgl. Reimann/Strehler/Fry 1996: $63)$.

Eine im Rahmen dieser Arbeit durchgeführte Umfrage unter diversen Versicherungsgesellschaften ${ }^{15}$, die sich in den Bereichen der landwirtschaftlichen Betriebshaftpflichtversicherungen engagieren, ergab, daß für Landwirte als Bioabfallbehandler die Möglichkeit besteht, die Risiken des Betriebs ihrer Kompostierungsanlage im Rahmen der Betriebshaftpflichtversicherung mit Umweltbasisdeckung abzusichern.

Nur für den Fall, daß es sich bei der jeweiligen Kompostierungsanlage um eine Anlage handele, die nach dem Umweltschutz dienenden Bestimmungen einer Genehmigungspflicht (z.B. nach der BimSchG in Verbindung mit der BimSchV) unterliege, müsse eine separate Umwelthaftpflichtversicherung abgeschlossen werden. Dabei bestehe sowohl im Rahmen der Umwelthaftpflicht-Basis- als auch in der Umwelthaftpflichtversicherung Versicherungsschutz für Normalbetriebsschäden (Kockemüller-Kublun 1998).

Da die beiden durch Landwirte betriebenen Kompostierungsanlagen im Landkreis Demmin aufgrund ihrer geringen Durchsatzleistung als sog. unbedeutende Anlagen zur Kompostierung ein vereinfachtes Genehmigungsverfahren zu durchlaufen hatten und daher keine Genehmigungen nach dem Umweltschutz dienenden Bestimmungen eingeholt werden mußten, können die Risiken des Anlagenbetriebs im Rahmen der genannten Umweltbasisdeckung abgesichert werden. Es entstehen dem Landwirt, der üblicherweise über eine Absicherung seines landwirtschaftlichen Betriebs durch eine Betriebhaftpflichtversicherung verfügt, demnach keine zusätzlichen Kosten durch die Versicherung des Risikos von Umweltbeeinträchtigungen durch den Betrieb der Kompostierungsanlage.

\footnotetext{
${ }^{15}$ Eine Auflistung dieser Versicherungsgesellschaften und Versicherungsmakler befindet sich in
} Anhang III. 


\subsection{Risiken imZusammenhang mit der landwitschaftichen Kompostverwettung}

\subsubsection{Derzetige Situation}

Kompost aus Bioabfällen wird nicht hergestellt, weil ein bestimmter Markt dieses Produkt nachfragt, sondern aus dem abfallwirtschaftlichen Interesse an einer umweltverträglichen Verringerung der Restabfallmenge (Wintzer et. al. 1996: 125). Die Landwirtschaft als potentieller Kompostverwerter steht somit im Spannungsfeld von Belastungsfaktoren und gesellschaftlichen Ansprïchen.

Im Zusammenhang mit der landwirtschaftlichen Verwertung von Komposten sind Schadensfälle nicht ausgeschlossen. Zum einen ist an gefährliche Stoffe zu denken, die als solche nicht bekannt sind oder die mit den gängigen Meßmethoden nicht erfaßbar sind. „Zum anderen ist an ,Ausreißer ${ }^{6}$ bei Messungen zu denken, also Fehler, die sich im Bereich der Behandlungsanlagen eingeschlichen haben und regelmäßig daraus resultieren, daß (unerkannt) Stoffe im Verwertungskreislauf verblieben sind, die eigentlich hätten ausgeschieden werden müssen“(Salje 1997: 201).

Die Landwirte gehen bei der Verwertung schadstoffbelasteter Stoffe auf landwirtschaftlicher Nutzfläche das Risiko einer Wertminderung bzw. eines Verlustes ihres Bodens als Produktionsgrundlage aufgrund zu hoher Schadstoffgehalte ein. Die Ungewißheit über zukünftige Grenzwertverschärfungen und die Auffindung bislang noch unbekannter oder nicht analysierbarer Schadstoffe und daraus hervorgehende Nutzungseinschränkungen haben zu einer Verunsicherung gegenüber schadstoffbelasteten Siedlungsabfällen geführt (Wintzer et. al. 1996: 293).

Der Absicherung solcher Risiken wurde bei der ähnlichen Problematik der landwirtschaftlichen Klärschlammverwertung durch Einrichtung eines sog. Entschädigungsfonds Rechnung getragen.

Der Rat von Sachverständigen für Umweltfragen stellte bereits 1985 in einem Sondergutachten „Umweltprobleme der Landwirtschaft“ fest, daß die landwirtschaftliche Klärschlammverwertung zur Schließung unterbrochener Stoffkreisläufe grundsätzlich erwünscht sei. „Dieser allgemeine Konsens zur Verwertung von Klärschlämmen in der Landwirtschaft steht allerdings unter dem Vorbehalt, daß durch die Klärschlammverwertung weder der Boden langfristig eine unverhältnismäßige Beaufschlagung mit Schadstoffen erfahren darf, noch daß kurz- und mittelfristig eine Belastung über die Nahrungskette für Menschen und Tiere erfolgt“"(Versteyl 1992: 79-80).

Um Landwirten bei Schäden, die trotz Einhaltung der Bestimmungen der Klärschlammverordnung entstanden sind, einen finanziellen Ausgleich zahlen zu können, wurden Ende 1989 vertragliche 
Regelungen zur landbaulichen Verwertung von Klärschlamm zwischen den kommunalen Spitzenverbänden auf Bundesebene, der Abwassertechnischen Vereinigung (ATV) und dem Deutschen Bauernverband vereinbart.

Diese Regelungen umfassen eine Treuhandvereinbarung über die Einrichtung eines Klärschlammfonds, die durch einen Klärschlammaufbringungsvertrag ergänzt wird. Der Klärschlammfonds stellt ein unselbständiges Treuhandvermögen dar, das von der Bundesarbeitsgemeinschaft Deutscher Kommunalversicherer verwaltet wird.

Der Klärschlammaufbringungsvertrag legte Mindestanforderungen fest, die nicht unterschritten werden durften. Zusätzliche Vereinbarungen, die schärfere Anforderungen oder eine größere Häufigkeit von Untersuchungen der Schlämme und/oder der Böden vorsahen, waren zulässig (Versteyl 85-86).

Finanziert wurde dieser freiwillige Klärschlammfonds durch die Kläranlagenbetreiber als Klärschlammabgeber. Das Fondsvolumen betrug 1996 etwa 62 Mio. DM. Sieht man von großzügig geregelten Kulanzfällen (Schadenssumme insgesamt ca. 26.000 DM seit 1990) ab, wurde der Fonds bis zu diesem Zeitpunkt nicht in Anspruch genommen (N.N. 1996: 28).

Im Zusammenhang mit der Beschlußfassung zum Kreislaufwirtschaftsgesetz wurde eine Ermächtigung zum Erlaß einer Verordnung über die Einrichtung eines gesetzlichen Klärschlammentschädigungsfonds in das Düngemittelgesetz eingefügt (N.N. 1996: 28). Dieser Verordnung hat der Bundestag bereits 1997 zugestimmt. Dieser Entschädigungsfonds dient dazu, die durch die landbauliche Klärschlammverwertung entstehenden Schäden an Personen und Sachen sowie sich daraus ergebende Folgeschäden zu ersetzen (\$9 (1) Düngemittelgesetz). Der Fonds wird von den Herstellern von Klärschlamm durch Beiträge von 20 DM je Tonne (TM) finanziert und bis zu einer Höhe von 125 Mio. DM ausgestattet (BML 1999 und N.N. 1997 b: 5). Das Fondsvolumen beträgt insgesamt 250 Mio. DM, ab 125 Mio. DM entfällt jedoch die Beitragspflicht. Vielmehr ist bei Inanspruchnahme des Fonds über die eingelegte Summe hinaus eine Nachschußpflicht der Einzahler vorgesehen. Die bei Eintritt eines Schadens durch den Fonds höchstens zu regulierende Schadenshöhe beträgt 5 Mio. DM (ATV 1998).

Für die Verwaltung des Fonds ist die Bundesanstalt für Landwirtschaft und Ernährung (BLE) zuständig (BML 1999). Der gesetzliche Klärschlammentschädigungsfonds hat am 1.01.1999 seine Arbeit aufgenommen. Die Mittel des freiwilligen Fonds bleiben jedoch auch über dieses Datum 
hinaus bestehen. Diese dienen zukünftig der Regulierung von Schäden, die durch vor dem 1.01.1999 landwirtschaftlich verwertete Klärschlämme verursacht wurden (ATV 1998).

Im Kompostierungserlaß Baden-Württemberg wird den entsorgungspflichtigen Körperschaften empfohlen, ,sich an einem Kompostfonds zu beteiligen, der einen Rechtsanspruch des Anwenders auf Erstattung von Vermögensschäden unter der Voraussetzung gewährt, daß sich die Beteiligten einem bestimmten Reglement unterwerfen“(Umweltministerium Baden-Württemberg 1994).

Im Gegensatz zur landwirtschaftlichen Klärschlammverwertung existiert bisher jedoch weder ein freiwilliger noch ein gesetzlicher Entschädigungsfonds zur Abwälzung der Risiken der Kompostverwertung. Die Einrichtung eines gesetzlichen Fonds ist derzeit auch nicht geplant (BML 1999).

Daher hat der Landwirt, der die Verwertung von Komposten auf landwirtschaftlicher Nutzfläche beabsichtigt, das Risiko z.B. einer Verschlechterung seiner Produktionsgrundlage „Boden“ selbst abzuschätzen und in seiner Preiskalkulation für die angebotenen Entsorgungsleistungen zu berücksichtigen.

Die wertmindernden Eigenschaften von Komposten, wie z.B. die Belastung mit Schadstoffen, sind ein wichtiges Kriterium für deren Verwertbarkeit, da diese zu Umweltbeeinträchtigungen und Ertragseinbußen und damit zu Vermögensschäden und Einkommensverlusten für die Verwerterbetriebe führen können. Im einzelnen wird im Rahmen der Risikodarstellung auf die Schwermetalle, organische Schadstoffe und den Salzgehalt als wertmindernde Kompostinhaltsstoffe eingegangen.

\subsubsection{Schwermetalle}

\subsubsection{Schwermetallgehalte im Bioabfallkompost}

Die Schwermetallbelastung von Komposten ist weniger vom Kompostierungsverfahren als von der Zusammensetzung des Input-Materials für die Kompostierung abhängig. Sie ist daher ein „Abbild der Schadstoffbelastung der organischen Abfälle“ (Wintzer et. al. 1996: 134).

Schwermetalle sind ubiquitär in der Umwelt verbreitet und finden sich deshalb auch in Komposten. Bioabfall- und Pflanzenabfallkomposte weisen i.d.R. ähnlich hohe Gehalte an Kupfer, Chrom, Nickel 
und Quecksilber auf (Wintzer et. a. 1996: 134). Höhere Schwermetallgehalte von Bioabfallkomposten im Vergleich zu Grüngutkomposten sind im wesentlichen auf die Stör- oder Fremdstoffe in den gesammelten Abfällen zurückzuführen.

Zwar gelangen anorganische und organische Schadstoffe primär über den Luftpfad in die Umwelt und somit auch in Komposte und andere Düngemittel. Der Schadstoffeintrag in Komposte erfolgt jedoch hauptsächlich über die Inputmaterialien für die Kompostierung, die bereits mit diesen Schadstoffen kontaminiert sind (Hackenberg et.al. 1998: 587). Aus diesen werden z.T. Metallionen, bedingt durch niedrige $\mathrm{pH}-$ Werte $\mathrm{zu}$ Beginn der Rotte, herausgelöst und im Kompost verteilt, wodurch ein Entfernen durch späteres Absieben nicht möglich ist (Högl 1995: 43). Mit abnehmendem Fremdstoffgehalt nimmt deshalb die Schwermetallbelastung der Bioabfallkomposte ab (Rieß et al. 1993: 98).

Sorgfältige Trennung von Bioabfällen und sorgfältiges Nachsortieren auf der Kompostierungsanlage führt daher $\mathrm{zu}$,niedrigen Schwermetallgehalten, die auf einem ähnlichen Niveau wie Grüngutkomposte“ (Popp/Fischer 1995: 37) und deutlich unter den in der Bioabfallverordnung geforderten Grenzwerten für Schwermetallgehalte in Komposten liegen. Diese aktuellen Grenzwerte stellen Bewertungshilfen für das Umweltgefährdungspotential von Komposten dar.

Nach der Bioabfallverordnung beträgt die höchstens zulässige Kompostausbringungsmenge innerhalb von drei Jahren unter Beachtung der düngemittelrechtlichen Regelungen $20 \mathrm{Mg}$ (Trockenmasse) je Hektar ( 6 (1) BioAbfV). Dabei dürfen die Schwermetallkonzentrationen im Kompost die in der Verordnung genannten Grenzwerte nicht überschreiten (Tab. 6.1). Werden die in $\S 4$ Absatz 3 Satz 2 der Bioabfallverordnung genannten, deutlich niedrigeren Grenzwerte hinsichtlich der Schwermetallkonzentrationen im Kompost eingehalten (Tab. 6.1), dann kann die zulässige Aufbringungsmenge bis zu $30 \mathrm{Mg}$ (Trockenmasse) je Hektar innerhalb von drei Jahren betragen.

Tab. 6.1: Höchstens zulässige Schwermetallkonzentrationen für landbaulich zu verwertende Komposte nach der Bioabfallverordnung (1998)

\begin{tabular}{|c|c|c|}
\hline \multirow[t]{2}{*}{ Schwermetall } & \multicolumn{2}{|c|}{ Kompostausbringungsmenge } \\
\hline & $\begin{array}{l}20 \mathrm{Mg}(\mathrm{TM}) / \mathrm{ha} \\
\text { innerhalb von } 3 \\
\text { Jahren } \\
{[\mathrm{mg} / \mathrm{kg} \mathrm{TS}]}\end{array}$ & $\begin{array}{l}30 \mathrm{Mg}(\mathrm{TM}) / \mathrm{ha} \\
\text { innerhalb von } 3 \\
\text { Jahren } \\
{[\mathrm{mg} / \mathrm{kg} \mathrm{TS}]}\end{array}$ \\
\hline
\end{tabular}




\begin{tabular}{|c|c|c|}
\hline $\mathrm{Pb}$ & 150 & 100 \\
\hline $\mathrm{Cd}$ & 1,5 & 1 \\
\hline $\mathrm{Cr}$ & 100 & 70 \\
\hline $\mathrm{Cu}$ & 100 & 70 \\
\hline $\mathrm{Ni}$ & 50 & 35 \\
\hline $\mathrm{Hg}$ & 1 & 0,7 \\
\hline $\mathrm{Zn}$ & 400 & 300 \\
\hline
\end{tabular}

Die Grenzwerte für die Schwermetallkonzentrationen im Kompost sind in der Bioabfallverordnung in Abhängigkeit von der maximalen Ausbringungsmenge angegeben, um die innerhalb von drei Jahren mit den Komposten auf landwirtschaftliche Flächen gelangenden Schwermetallfrachten zu beschränken (vgl. Döhler et.al.1999: 206).

Die angegebenen Werte sind auf $30 \%$ OTS $^{16}$ normiert. Ziel dieser Normierung der Schwermetallgehalte auf einen Gehalt der organischen Substanz (OS) von $30 \%$ in der Trockenmasse (TM) ist es, die Schwermetallgehalte von Komposten unterschiedlicher OS-Gehalte vergleichbar zu machen und zu verhindern, daß die Grenzwerte durch bevorzugte Produktion von Frischkomposten mit niedrigeren realen Schwermetallgehalten unterlaufen werden (Kluge/Timmermann 1995: 9 und 13), denn durch den beim Kompostierungsvorgang auftretenden Abbau der organischen Substanz kommt es zu einer Aufkonzentrierung der Schwermetalle (sog. „Residualanreicherung“) mit zunehmendem Rottegrad.

Im folgenden werden die mittleren Schwermetallgehalte der in Tarnow und Borrentin im Rahmen des Modellversuchs zur dezentralen Kompostierung im Landkreis Demmin erzeugten Bioabfallkomposte dargestellt. Zum Vergleich sind die entsprechenden (über $\mathrm{n}$ gewichteten) Mittelwerte aus insgesamt 511 Einzeluntersuchungen von Bioabfallkomposten ( Wintzer et. al. 1996: 136), die im Zeitraum von 1987 bis 1994 durchgeführt wurden, angegeben (Tab. 6.2, Abb. 6.1 und 6.2).

Tab. 6.2: Mittlere Schwermetallgehalte in Bioabfallkomposten

$\left.\begin{array}{|l|c|c|c|}\hline \text { Schwermetall } & \text { Kompost Tarnow } & \text { Kompost Borrentin } & \begin{array}{c}\text { Mittelwert } \\ 1987-1994 \\ {[\mathrm{mg} / \mathrm{kg} \mathrm{TS}]}\end{array} \\ \hline \mathrm{Pb} & 50,40 & 4 \mathrm{mg} / \mathrm{kg} \text { TS }] & {[\mathrm{mg} / \mathrm{kg} \mathrm{TS}]}\end{array}\right)$

${ }^{16}$ organische Trockensubstanz 


\begin{tabular}{|l|c|c|c|}
\hline $\mathrm{Cd}$ & 0,33 & 0,38 & 0,73 \\
\hline $\mathrm{Cr}$ & 36,48 & 47,78 & 45 \\
\hline $\mathrm{Cu}$ & 33,88 & 21,16 & 38 \\
\hline $\mathrm{Ni}$ & 9,03 & 5,9 & 23 \\
\hline $\mathrm{Hg}$ & 0,15 & 0,19 & 0,27 \\
\hline $\mathrm{Zn}$ & 217,20 & 150 & 222 \\
\hline
\end{tabular}

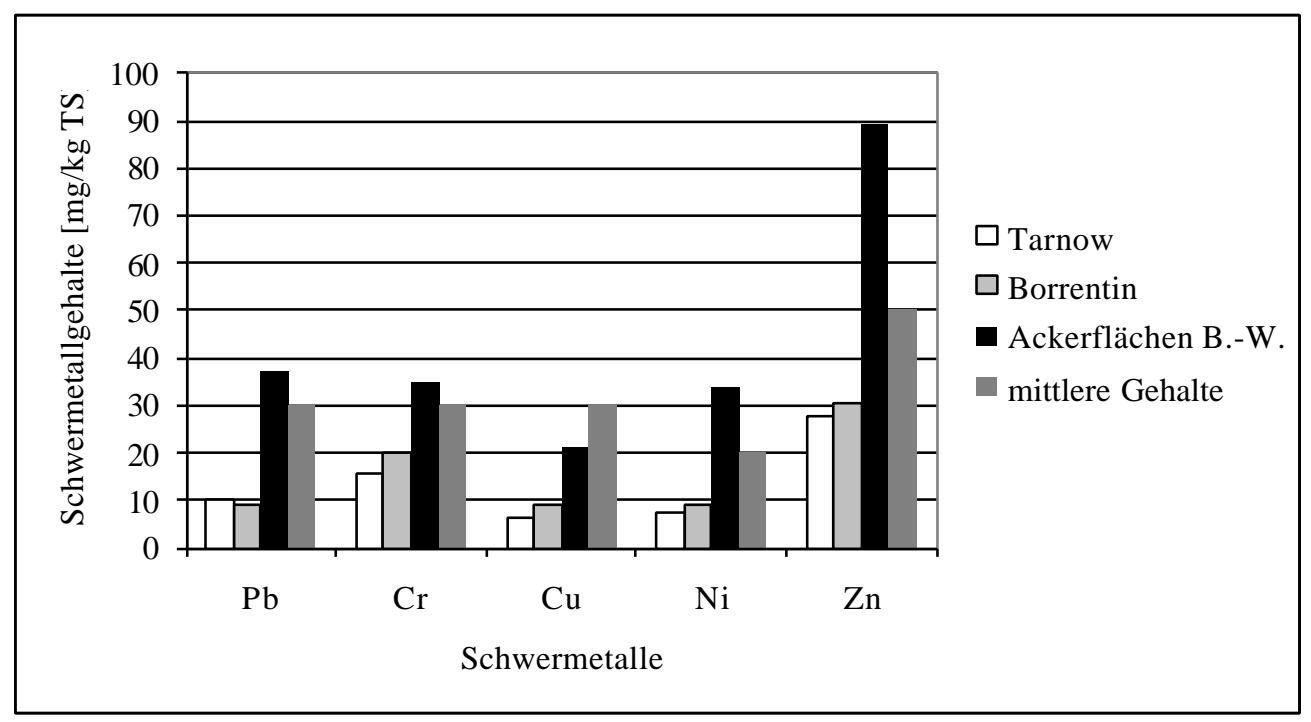

Abb. 6.1: Mittlere Gehalte an Blei, Chrom, Kupfer, Nickel und Zink in Bioabfallkomposten

Im folgenden wird dargestellt, in welchem Maße die Grenzwerte der Bioabfallverordnung (1998) durch die angegebenen mittleren Schwermetallgehalte in den Bioabfallkomposten (s. Tab. 6.1) ausgeschöpft werden für eine zulässige Kompostausbringungsmenge von höchstens $20 \mathrm{Mg} \mathrm{TM}$ innerhalb von 3 Jahren (Tab. 6.3, Abb. 6.3) bzw. $30 \mathrm{Mg}$ TM innerhalb von 3 Jahren (Tab. 6.4, Abb. 6.4). 


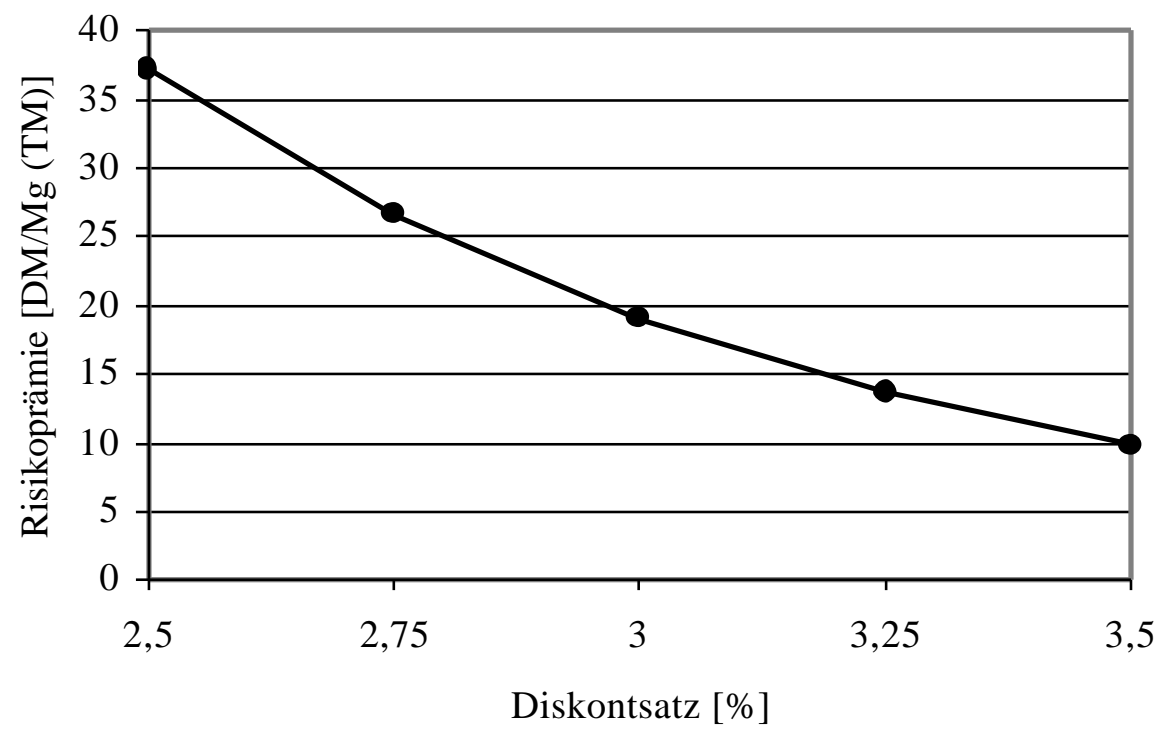

Abb. 6.2: Mittlere Gehalte an Cadmium und Quecksilber in Bioabfallkomposten

Tab. 6.3: Mittlere Schwermetallgehalte von Bioabfallkomposten in Prozent der Grenzwerte der Bioabfallverordnung für eine zulässige Kompostausbringungsmenge von höchstens $20 \mathrm{Mg} \mathrm{TM}$ innerhalb von 3 Jahren

\begin{tabular}{|l|r|r|r|}
\cline { 2 - 4 } \multicolumn{1}{c|}{} & \multicolumn{1}{l|}{ Tarnow } & Borrentin & $\begin{array}{l}\text { Mittelwerte } \\
(1987-1994) \\
{[\%]}\end{array}$ \\
\hline $\mathrm{Pb}$ & 33,60 & 28,80 & 49,33 \\
\hline $\mathrm{Cd}$ & 22,00 & 25,33 & 48,67 \\
\hline $\mathrm{Cr}$ & 36,48 & 47,78 & 45,00 \\
\hline $\mathrm{Cu}$ & 33,88 & 21,16 & 38,00 \\
\hline $\mathrm{Ni}$ & 18,06 & 11,80 & 46,00 \\
\hline $\mathrm{Hg}$ & 15,00 & 19,00 & 27,00 \\
\hline $\mathrm{Zn}$ & 54,30 & 37,50 & 55,50 \\
\hline
\end{tabular}




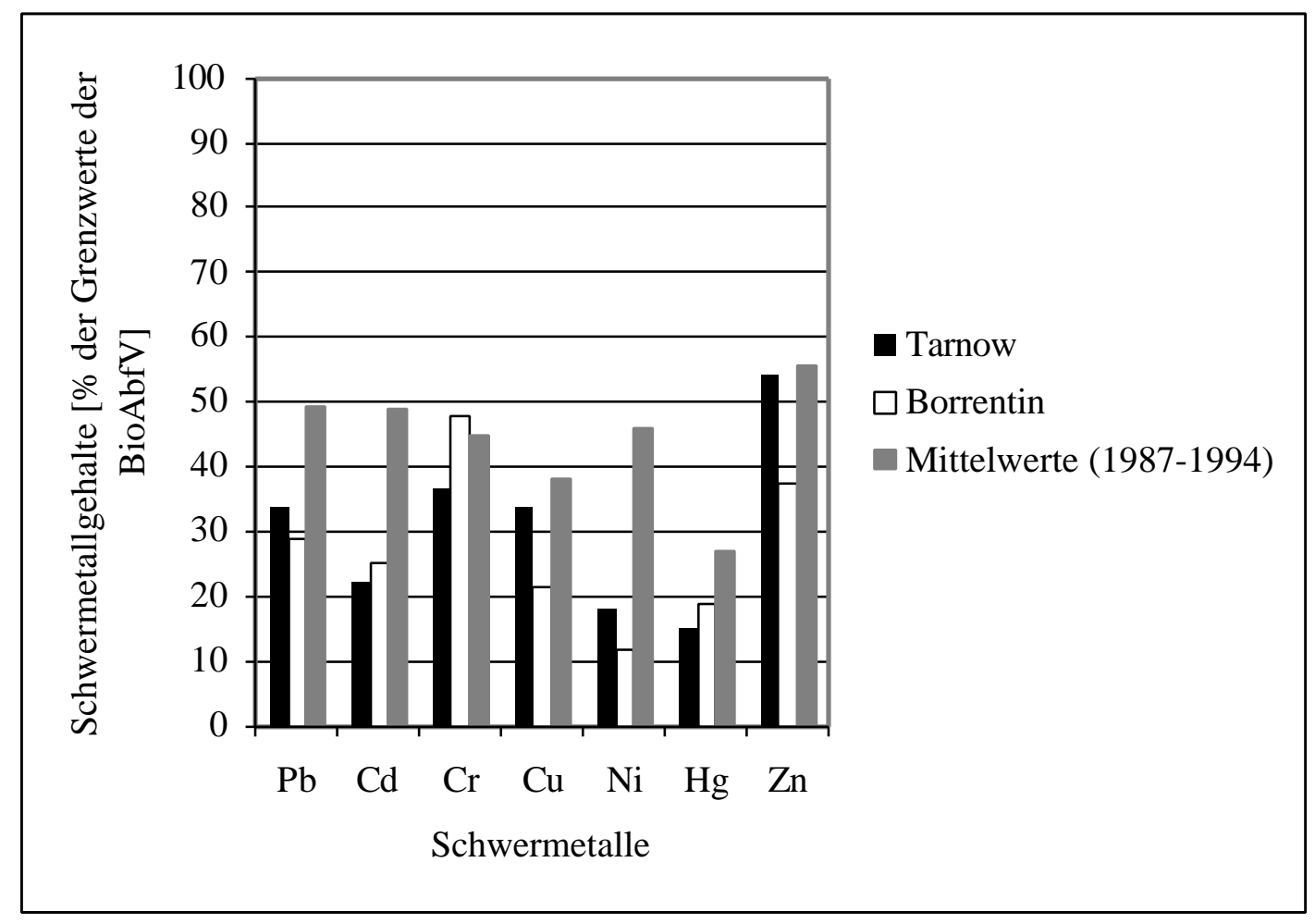

Abb. 6.3: Mittlere Schwermetallgehalte von Bioabfallkomposten in Prozent der Grenzwerte der Bioabfallverordnung für eine zulässige Kompostausbringungsmenge von höchstens $20 \mathrm{Mg} \mathrm{TM}$ innerhalb von 3 Jahren

Tab. 6.4: Mittlere Schwermetallgehalte von Bioabfallkomposten in Prozent der Grenzwerte der Bioabfallverordnung für eine zulässige Kompostausbringungsmenge von höchstens $30 \mathrm{Mg} \mathrm{TM}$ innerhalb von 3 Jahren

\begin{tabular}{|l|r|r|r|}
\cline { 2 - 4 } \multicolumn{1}{c|}{} & \multicolumn{1}{c|}{ Tarnow } & Borrentin & $\begin{array}{c}\text { Mittelwerte } \\
(1987-1994) \\
{[\%]}\end{array}$ \\
\hline $\mathrm{Pb}$ & 50,40 & 43,2 & 74 \\
\hline $\mathrm{Cd}$ & 33,00 & 38,00 & 73,00 \\
\hline $\mathrm{Cr}$ & 52,11 & 68,26 & 64,29 \\
\hline $\mathrm{Cu}$ & 48,40 & 30,23 & 54,29 \\
\hline $\mathrm{Ni}$ & 25,80 & 16,86 & 65,71 \\
\hline $\mathrm{Hg}$ & 21,43 & 27,14 & 38,57 \\
\hline $\mathrm{Zn}$ & 72,40 & 50,00 & 74,00 \\
\hline
\end{tabular}




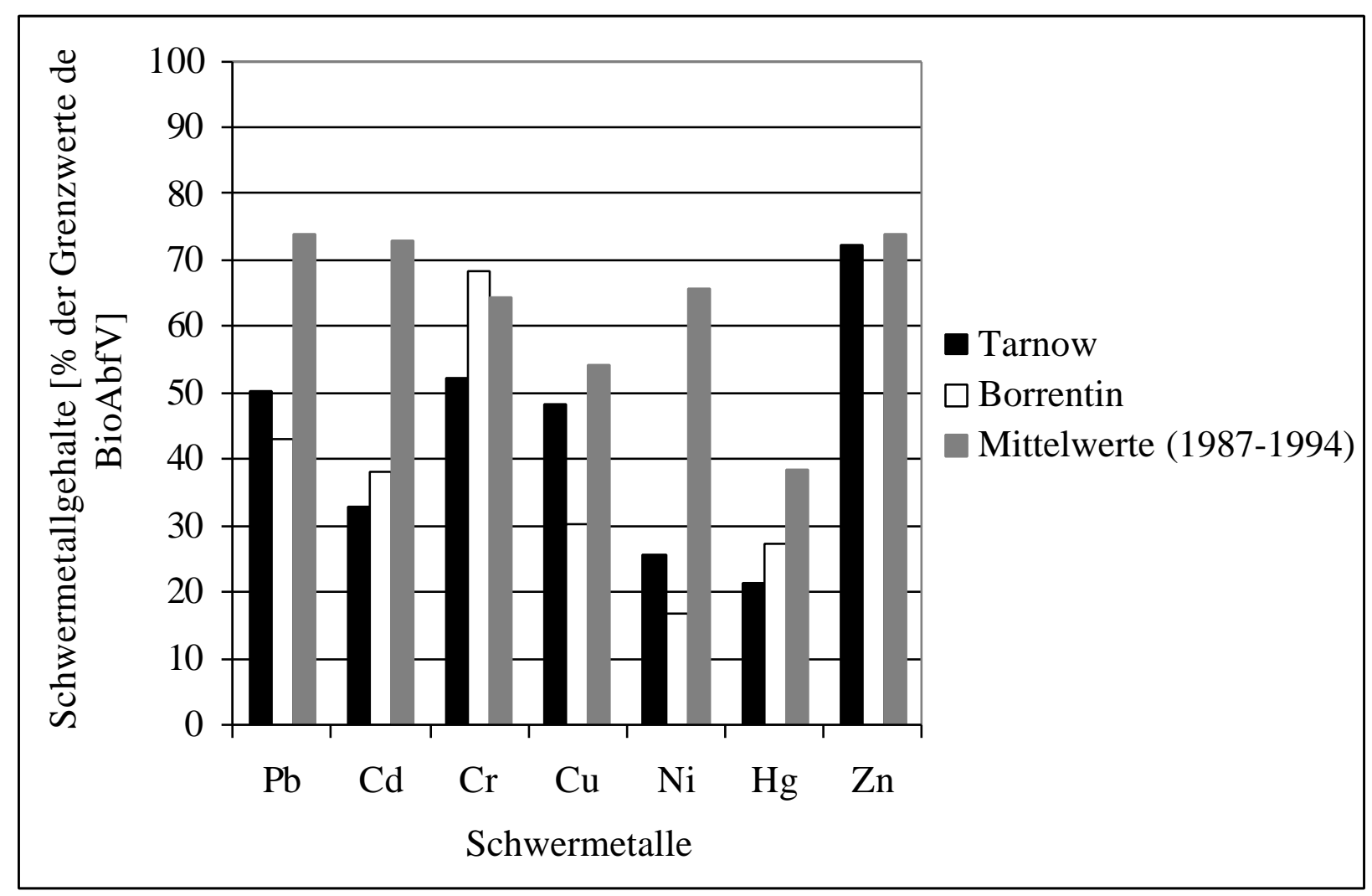

Abb. 6.4: Mittlere Schwermetallgehalte von Bioabfallkomposten in Prozent der Grenzwerte der Bioabfallverordnung für eine zulässige Kompostausbringungsmenge von höchstens $30 \mathrm{Mg}$ TM innerhalb von 3 Jahren

Die Komposte, die in den durch Landwirte betriebenen offenen Kompostierungsanlagen hergestellt wurden, unterschreiten deutlich die Grenzwerte der Bioabfallverordnung sowohl für Kompostausbringungsmengen von $20 \mathrm{Mg}$ als auch für $30 \mathrm{Mg}$ (Trockenmasse) innerhalb von drei Jahren.

So wird der Quecksilber-Grenzwert für die Ausbringung von höchstens $20 \mathrm{Mg}$ TM innerhalb von drei Jahren bei aus der Kompostierungsanlage in Tarnow stammenden Bioabfallkomposten (Mittelwert der Kompostuntersuchungen von 1996 und 1997) lediglich zu 15 \% bzw. zu etwa $21 \%$ für die höhere Kompostausbringungsmenge von $30 \mathrm{Mg}$ TM ausgefüllt. Für die Bioabfallkomposte aus Borrentin wurden mit $19 \%$ (für $20 \mathrm{Mg}$ TM Ausbringungsmenge) bzw. etwa $27 \%$ (für $30 \mathrm{Mg}$ TM Ausbringungsmenge) höhere Ausschöpfungsquoten ermittelt, die jedoch ebenfalls die als Vergleichswerte herangezogenen Ausschöpfungsquoten (über n gewichteter Mittelwert zahlreicher Einzeluntersuchungen von 1987 bis 1994) deutlich unterschreiten. 
Bei Nickel werden die Grenzwerte der Bioabfallverordnung je nach Anlage und der zugrunde liegenden maximalen Kompostausbringungsmenge zu etwa $12 \%$ bis $26 \%$ ausgeschöpft und weisen damit um mehr als die Hälfte niedrigere Ausschöpfungsquoten als die ermittelten Vergleichswerte auf. Für das Schwermetall Cadmium ergibt sich ein ähnliches Bild: die aus den beiden durch Landwirte betriebenen Anlagen stammenden Komposte enthalten Cadmium in einer Konzentration, die die gesetzlichen Grenzwerte je nach betrachtetem Fall zwischen $22 \%$ und $38 \%$ ausschöpfen, während die Vergleichswerte etwa doppelt so hoch sind.

Auch für Blei und Kupfer werden die entsprechenden Vergleichswerte deutlich sowie die gesetzlichen Grenzwerte mit bis zu einem Drittel (bei bis zu 20 Mg TM ausgebrachtem Kompost) bzw. der Hälfte (bei entsprechend $30 \mathrm{Mg} \mathrm{TM}$ ) unterschritten.

Chrom ist in den untersuchten Bioabfallkomposten in ähnlichen Größenordnungen enthalten wie in dem „Vergleichskompost“, der bezüglich des restriktiveren Grenzwerts für die höhere Kompostausbringungsmenge mit entsprechend höheren Schwermetallfrachten eine Ausschöpfungsquote von fast $65 \%$ erreicht, hingegen bei der niedrigeren Ausbringungsmenge den entsprechenden Grenzwert ebenfalls nicht zur Hälfte ausschöpft.

Bei Zink liegen die Ausschöpfungsquoten der Komposte aus den landwirtschaftlichen Low-TechAnlagen bezüglich der Grenzwerte im Vergleich $\mathrm{zu}$ den anderen ermittelten Quoten für Schwermetalle mit etwa $38 \%$ bis $54 \%$ (20 Mg TM Ausbringungsmenge) bzw. $50 \%$ bis $72 \%$ (30 Mg TM Ausbringungsmenge) relativ hoch. Diese unterschreiten jedoch wiederum die Werte des Vergleichskomposts.

Die im Rahmen des Modellversuchs zur dezentralen Kompostierung im Landkreis Demmin erzeugten Bioabfallkomposte weisen insgesamt betrachtet vergleichsweise niedrige Schwermetallgehalte auf. Dies ist hauptsächlich darauf zurückzuführen, daß die Inputmaterialien für die Rotte in relativ geringem Maße mit Schwermetallen belastet sind.

Im Landkreis Demmin überwiegen hinsichtlich der Bevölkerungszahlen die ländlichen Gemeinden. Die Bevölkerungsdichte ist mit durchschnittlich etwa 52 Einwohnern $/ \mathrm{km}^{2}$ sehr gering (Umweltamt Demmin 1999). Der Landkreis ist durch unterentwickeltes Gewerbe und fehlende Industrie gekennzeichnet. Die größten Arbeitgeberbereiche bilden Handel, Dienstleistungen, Baugewerbe und Landwirtschaft, so daß von einer relativ geringen Eintragung von anorganischen Schadstoffen über den Luftpfad ausgegangen werden kann. Zumindest der Anteil an Grüngut, der den Bioabfällen aus Haushalten zugesetzt wird und der aus Landschaftspflegemaßnahmen im Einzugsgebiet der 
Kompostierungsanlagen stammt, ist demzufolge potentiell geringer belastet als in Regionen, in denen Verbrennungsvorgänge aus Industrie, Verkehr, Kraft- und Heizwerken einen großen Anteil an Emissionen verursachen.

In Hinblick auf die Schwermetallbelastung der im Landkreis Demmin erzeugten Komposte wäre eine deutliche Verschärfung der Grenzwerte der Bioabfallverordnung ohne eine Gefährdung der landbaulichen Verwertung dieser Komposte möglich.

Auch andere Düngemittel enthalten Schwermetalle, die zu einer Bodenbelastung führen können. Das Düngemittelgesetz und die Düngemittelverordnung enthalten bisher jedoch keine Regelungen zur Begrenzung von Schadstoffeinträgen durch Ausbringung von Düngemitteln (Wintzer et.al.1996: 279). Es liegen derzeit auch keine anderen Vorgaben über maximal tolerierbare Schwermetalleinträge z.B. durch Wirtschaftsdünger vor (Hackenberg/Wegener 1999: 142).

Zur Einordnung der Bioabfallkomposte werden deren Schwermetallgehalte denen beispielhaft herangezogener Wirtschaftsdünger gegenübergestellt (Tab. 6.5, Abb. 6.5, Abb. 6.6).

Tab. 6.5: Schwermetallgehalte in verschiedenen Wirtschaftsdüngern (Wintzer et. al. 1996: 281) sowie mittlere Schwermetallgehalte der Bioabfallkomposte aus den Anlagen in Tarnow und Borrentin

\begin{tabular}{|c|c|c|c|c|c|c|}
\hline $\begin{array}{l}\text { Schwer- } \\
\text { metall }\end{array}$ & \begin{tabular}{|l} 
Kompost \\
Tarnow \\
{$[\mathrm{mg} / \mathrm{kg} \mathrm{TS}]$} \\
\end{tabular} & $\begin{array}{l}\text { Kompost } \\
\text { Borrentin } \\
{[\mathrm{mg} / \mathrm{kg} \text { TS }]}\end{array}$ & $\begin{array}{l}\text { Rindergülle } \\
{[\mathrm{mg} / \mathrm{kg} \text { TS] }}\end{array}$ & $\begin{array}{l}\text { Schweine- } \\
\text { gülle } \\
{[\mathrm{mg} / \mathrm{kg} \mathrm{TS}]}\end{array}$ & $\begin{array}{l}\text { Rindermist } \\
{[\mathrm{mg} / \mathrm{kg} \mathrm{TS}]}\end{array}$ & $\begin{array}{l}\text { Schweine- } \\
\text { mist } \\
{[\mathrm{mg} / \mathrm{kg} \mathrm{TS}]}\end{array}$ \\
\hline $\mathrm{Pb}$ & 50,40 & 43,2 & 8,95 & 10,68 & 7 & 7 \\
\hline $\mathrm{Cd}$ & 0,33 & 0,38 & 0,43 & 0,9 & 0,44 & 0,43 \\
\hline $\mathrm{Cr}$ & 36,48 & 47,78 & 5,53 & 9,54 & 20 & 11 \\
\hline $\mathrm{Cu}$ & 33,88 & 21,16 & 45 & 506 & 39 & 740 \\
\hline $\mathrm{Ni}$ & 9,03 & 5,9 & 4,75 & 18,66 & 10 & 13 \\
\hline $\mathrm{Hg}$ & 0,15 & 0,19 & $0,05^{1)}$ & $0,04^{1)}$ & k.A. & k.A. \\
\hline $\mathrm{Zn}$ & 217,20 & 150 & 235 & 965 & 213 & 1220 \\
\hline
\end{tabular}

${ }^{1)}$ (Hackenberg/Wegener 1999: 118) 


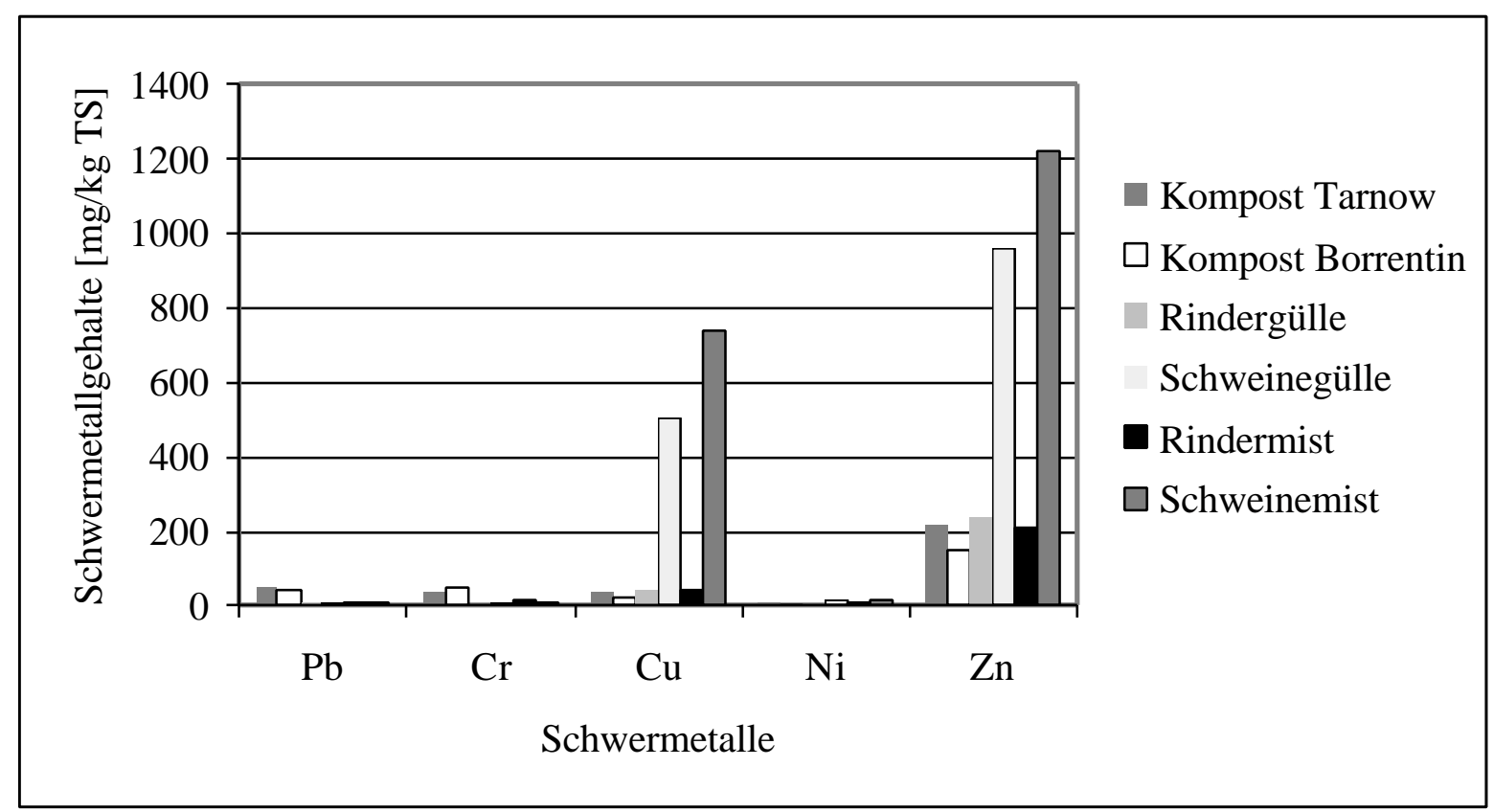

Abb. 6.5: Gehalte an Blei, Chrom, Kupfer, Nickel und Zink in verschiedenen Wirtschaftsdüngern sowie deren mittlere Gehalte in den Bioabfallkomposten aus den Anlagen in Tarnow und Borrentin

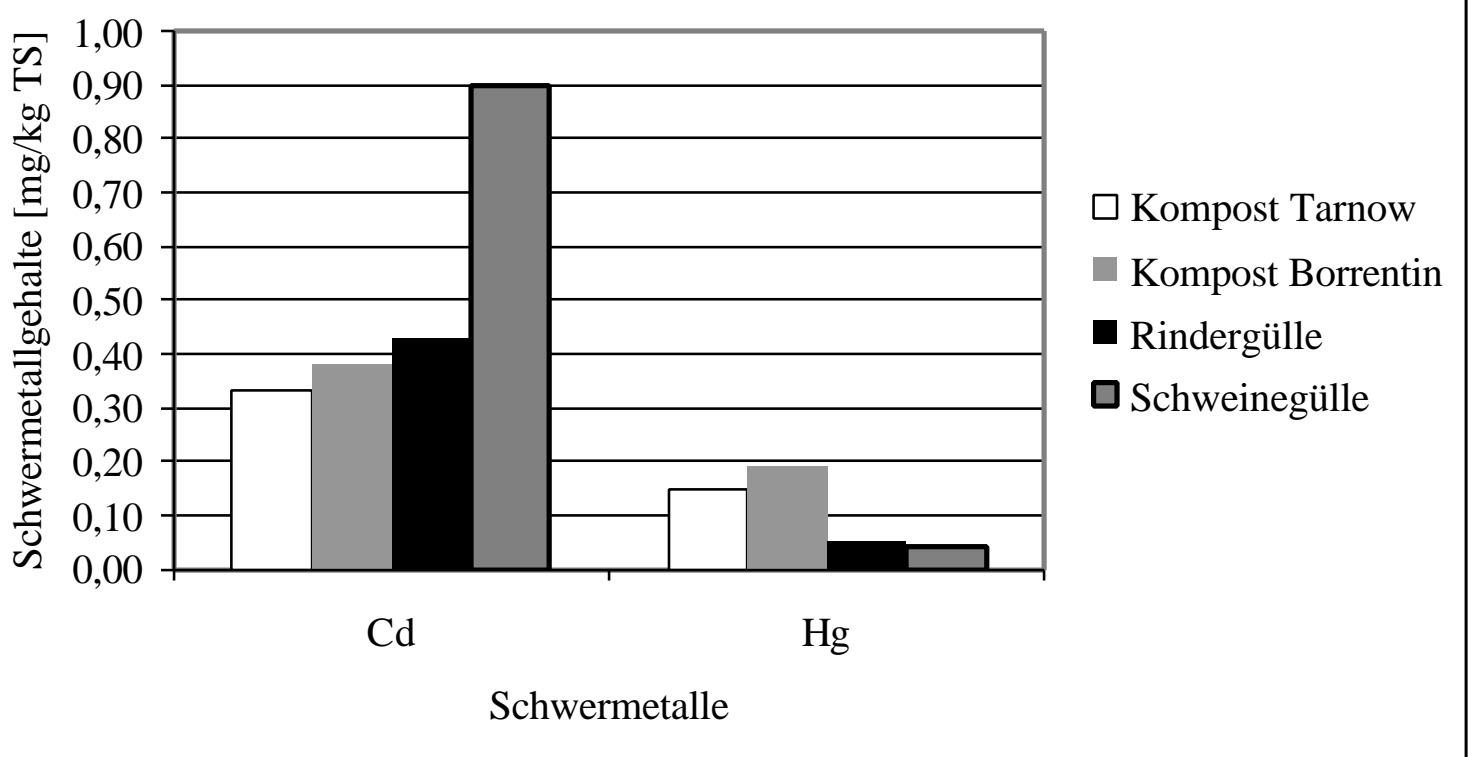

Abb. 6.6: Gehalte an Cadmium und Quecksilber in verschiedenen Wirtschaftsdüngern sowie deren mittlere Gehalte in den Bioabfallkomposten aus den Anlagen in Tarnow und Borrentin 
Im Vergleich zwischen Rinder- und Schweinegülle zeigt sich, daß diese ähnliche Konzentrationen an Blei, Quecksilber, Chrom und Nickel haben (vgl. Wintzer et.al.1996: 281), eine etwas größere Abweichung ist für das Element Cadmium festzustellen. Die Schweinegülle weist demgegenüber jedoch bis zu dreifach höhere Kupfer- und Zinkgehalte auf.

Die großen Unterschiede der Kupfer- und Zinkgehalte zwischen den Wirtschaftsdüngern verschiedener Nutztierarten, in diesem Fall Rindergülle und -mist gegenüber Schweinegülle- und mist, sind auf Unterschiede in Haltung und Fütterung zurückzuführen (vgl. Hackenberg/Wegener 1999: 119).

Die Kupfer- und Zinkgehalte der Wirtschaftsdünger aus der Schweinehaltung sind um ein Vielfaches höher als die der untersuchten Bioabfallkomposte, da Kupfer und Zink dem Futter als leistungssteigernde Elemente zugesetzt werden.

Während die Cadmiumgehalte in den Bioabfallkomposten diejenigen aus den betrachteten Wirtschaftsdüngen geringfügig bzw. im Vergleich zu Schweinegülle deutlich unterschreiten und die Nickelgehalte in vergleichbarer Größenordnung liegen, überschreiten die Chrom- und Bleigehalte diejenigen in Gülle und Mist um ein mehrfaches.

Bei einer Bewertung der Schwermetallbelastung des Bodens durch Wirtschaftsdünger ist zu berücksichtigen, daß ein Teil der Schwermetalle dem Boden zuvor über den Futterbau entzogen und über die Wirtschaftsdünger zurückgeführt wird, so daß nicht die gesamte Menge als Neueintrag angesehen werden kann (Wintzer et.al.1996: 281-282).

\subsubsection{Schwermetallgehalte im Anlagenabwasser}

Bei Anlieferung der Bioabfälle aus Haushalten kommt es im Anlieferungsbereich der Kompostierungsanlage zur Sickerwasserbildung (Preßwasser) aufgrund der Eigenfeuchte des Materials. Die Mengen sind jedoch i.d.R. so gring, daß das austretende Wasser auf dem Weg zu den Drainageschächten wieder eintrocknet (vgl. Gronauer/Helm/Schön 1997: 67).

Endogenes Wasser aus Rotteprozessen, das als Sickerwasser an der Basis des Rottekörpers abgesondert wird, entsteht nur bei einem Strukturmaterialanteil von 20 Vol.-\% und weniger (Gronauer/Helm/Schön 1997: 67). In den Anlagen im Landkreis Demmin wird mit Strukturmaterialanteilen von etwa 35 Vol.-\% gearbeitet. Bei diesen höheren Strukturmaterialanteilen tritt während der Rotte kein Sickerwasser aus. 
Nach der TA Siedlungsabfall (Nr. 5.4.1.3.2) ist das Anlagenabwasser vorrangig zu verwerten, indem es sicher aufgefangen und möglichst zur Befeuchtung des Kompostierungsmaterials eingesetzt wird.

Die Rückführung des (reinen) Sickerwassers, das in dem betrachteten Modellversuch im Landkreis Demmin aufgrund der Strukturmaterialanteile von deutlich über 20 Vol.-\% nicht anfiel, erhöht die Gefahr, daß dabei ,geruchsintensive Stoffe freigesetzt und unerwünschte Salze, nicht hygienisierte Schaderreger sowie anorganische und organische Schadstoffe in den Kompost zurückgeführt werden“ (Wintzer et.al.1996:123). Es ist demnach sicherzustellen, daß nach der Zugabe des Sickerwassers zum Rottmaterial noch eine ausreichende Hygienisierungstemperatur und -dauer in der Kompostmiete gewährleistet ist (Döhler et.al.1999: 179).

Das auf den befestigten Flächen der Anlagen anfallende Regenwasser stellt bei den untersuchten offenen Anlagentypen mengenmäßig die größte Abwasserfraktion dar. „Es ist mäßig belastet, kann zur Mietenrïckbefeuchtung verwendet oder auf landwirtschaftliche Flächen aufgebracht werden“ (Döhler et.al.1999: 179). Da in den untersuchten Anlagen die einzelnen Abwasserfraktionen nicht getrennt erfaßt werden, vermischt sich das Regenwasser mit der zweitgrößten anfallenden Abwasserfraktion, dem exogenen Sickerwasser, das v.a. aus durch die Kompostmieten hindurchsickerndem Regenwasser besteht.

Zur Ermittlung der mit dem Anlagenabwasser auf landwirtschaftlich genutzte Flächen ausgebrachten Schwermetallfrachten wurden aus dem Abwassersammelbehälter der Kompostierungsanlage in Tarnow Proben gezogen und auf deren $\mathrm{pH}-$ Wert sowie auf deren Gehalte an in der Bioabfallverordnung genannten Schwermetalle untersucht. Um feststellen zu können, ob ein deutlicher „Verdünnungdeffekt“ für die Schwermetalle aufgrund des Regenwassers eintritt, wurde die erste Mischprobe im April und die zweite in der niederschlagsärmeren Zeit im Juli entnommen.

Die ermittelten Analysedaten sind im folgenden Literaturdaten gegenübergestellt, die ebenfalls in einer dezentralen Anlage, in der die Kompostierung in offenen Dreiecksmieten betrieben wird, gefunden wurden (Gronauer/Helm/Schön 1997: 67) (Tab. 6.6, Abb. 6.7, Abb. 6.8). Zur graphischen Darstellung der Analysedaten werden bei Unterschreitung der Methodengenauigkeit die angegebenen Grenzen eingesetzt. 
Tab. 6.6: $\mathrm{pH}-$ Wert und Schwermetallgehalte im Abwasser aus offenen Anlagen zur Dreiecksmietenkompostierung

\begin{tabular}{|c|c|c|c|}
\hline Parameter & $\begin{array}{c}\text { Anlage Tarnow } \\
\text { Probe vom 15.04.99 }\end{array}$ & $\begin{array}{c}\text { Anlage Tarnow } \\
\text { Probe vom 15.07.99 }\end{array}$ & Sonstige Anlage \\
\hline pH-Wert & 6,6 & 6,8 & 6,9 \\
\hline Trockenmasse & $2,54 \mathrm{~g} / \mathrm{l}$ & $4,5 \mathrm{~g} / \mathrm{l}$ & k.A. \\
\hline $\mathrm{Cu}$ & $<0,01 \mathrm{mg} / \mathrm{l}$ & $0,088 \mathrm{mg} / \mathrm{l}$ & $0,025 \mathrm{mg} / \mathrm{l}$ \\
\hline $\mathrm{Pb}$ & $0,014 \mathrm{mg} / \mathrm{l}$ & $0,023 \mathrm{mg} / \mathrm{l}$ & $0,013 \mathrm{mg} / \mathrm{l}$ \\
\hline $\mathrm{Cd}$ & $<0,0005 \mathrm{mg} / \mathrm{l}$ & $0,002 \mathrm{mg} / \mathrm{l}$ & $0,003 \mathrm{mg} / \mathrm{l}$ \\
\hline $\mathrm{Cr}$ & $0,01 \mathrm{mg} / \mathrm{l}$ & $0,036 \mathrm{mg} / \mathrm{l}$ & $0,0037 \mathrm{mg} / \mathrm{l}$ \\
\hline $\mathrm{Ni}$ & $<0,02 \mathrm{mg} / \mathrm{l}$ & $0,049 \mathrm{mg} / \mathrm{l}$ & $0,013 \mathrm{mg} / \mathrm{l}$ \\
\hline $\mathrm{Hg}$ & $<0,00005 \mathrm{mg} / \mathrm{l}$ & $<0,00005 \mathrm{mg} / \mathrm{l}$ & $<0,0003 \mathrm{mg} / \mathrm{l}$ \\
\hline $\mathrm{Zn}$ & $0,17 \mathrm{mg} / \mathrm{l}$ & $0,402 \mathrm{mg} / \mathrm{l}$ & $0,0179 \mathrm{mg} / \mathrm{l}$ \\
\hline
\end{tabular}

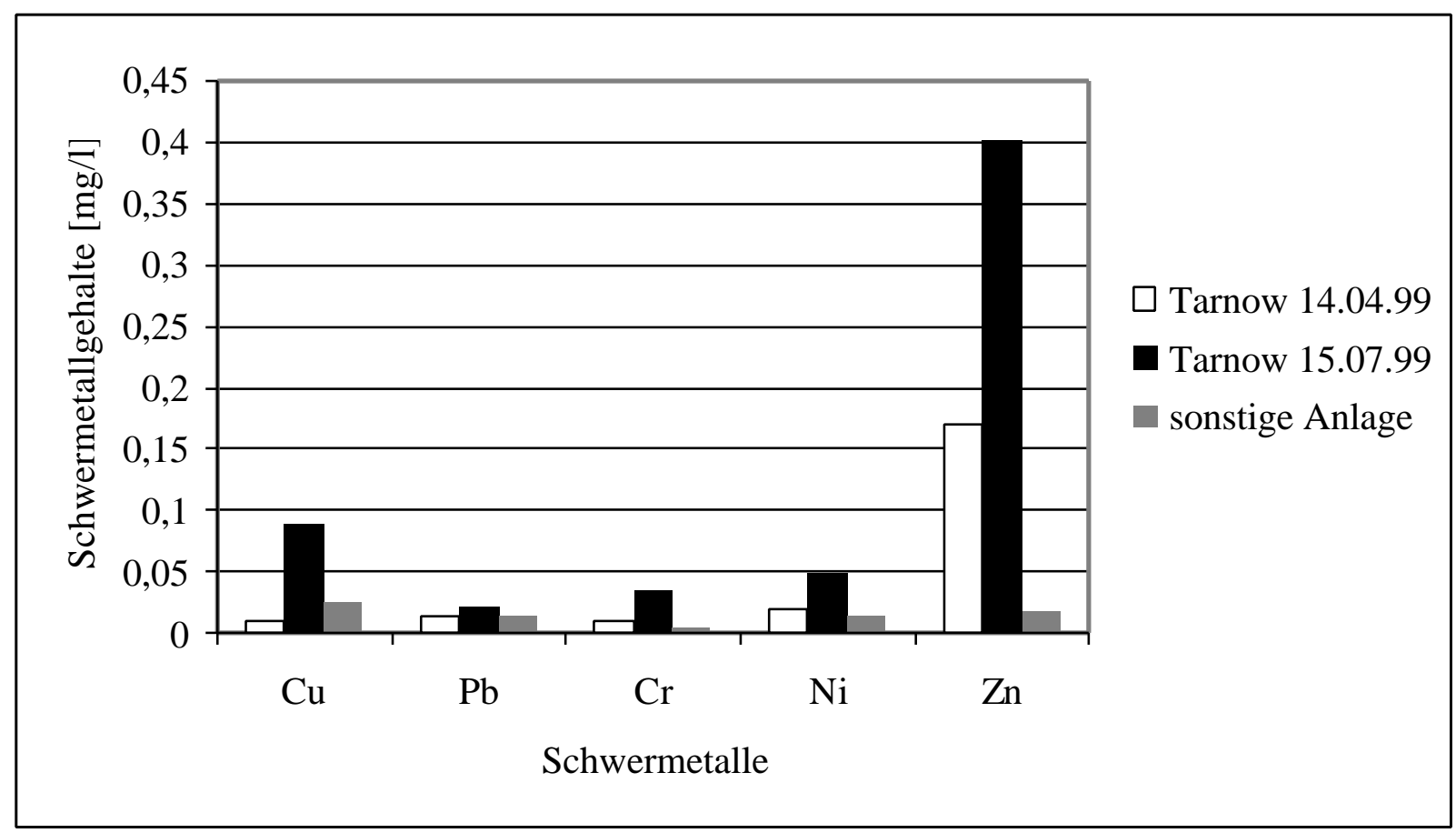

Abb. 6.7: Gehalte an Kupfer, Blei, Chrom, Nickel und Zink im Abwasser aus offenen Anlagen zur Dreiecksmietenkompostierung 


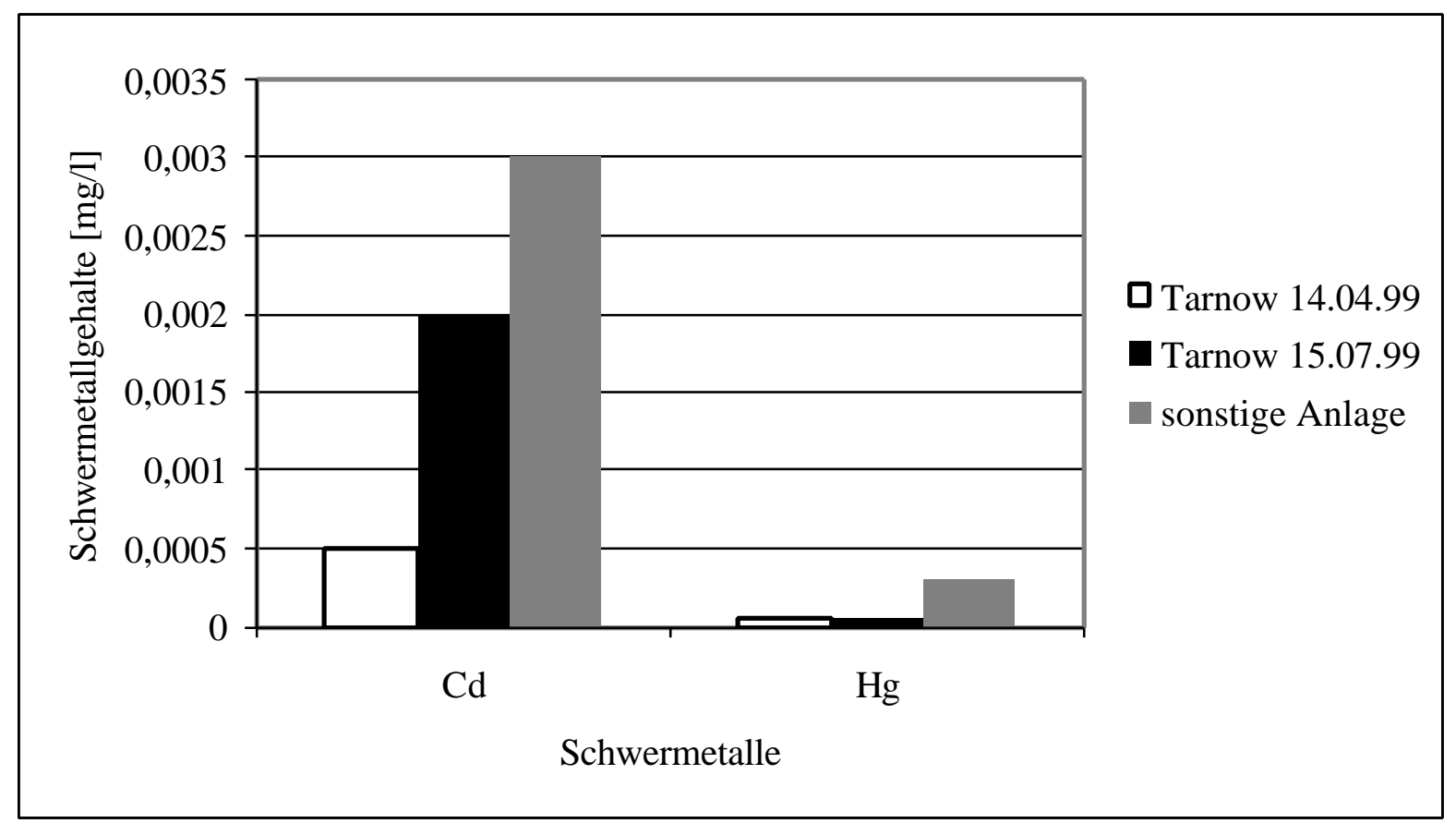

Abb. 6.8: Gehalte an Cadmium und Quecksilber im Abwasser aus offenen Anlagen zur Dreiecksmietenkompostierung

Der höhere Trockenmasseanteil in der im Juli gezogenen Probe ist ein Hinweis auf die geringeren Niederschläge in der Zeit vor der Probenahme im Vergleich zur April-Probe. Der o.g. Verdünnungseffekt durch Niederschläge für die Schwermetalle im Anlagenabwasser wird im Vergleich der Ergebnisse bestätigt. So weist die Probe vom 15.07.99 durchgängig höhere Schwermetallgehalte auf (das Unterschreiten der Methodengenauigkeit für beide Proben läßt diesen Schluß für das Element Quecksilber nicht zu).

Eine Einordnung der Vergleichsdaten ist in diesem Zusammenhang nicht möglich, da das Datum der Probenahme nicht bekannt ist. Es ist jedoch erkennbar, daß die Werte aus der Anlage in Tarnow demgegenüber bezüglich der Gehalte an Kupfer, Blei, Chrom, Nickel und Quecksilber nicht auffällig sind. Für Cadmium ist eine deutliche Unterschreitung des Vergleichswerts für beide Jahreszeiten erkennbar. Woher die gegenüber der zum Vergleich herangezogenen Anlage stammenden hohen Zinkgehalte in Tarnow stammen, konnte nicht geklärt werden. Gronauer et.al. vermuten, daß hohe Zinkkonzentrationen aus verzinkten Bauteilen bzw. Leitungen stammen (Gronauer/Helm/Schön 1997: 67). Dennoch ist hinsichtlich der Schwermetallbelastung des Anlagenabwassers nicht „,mit realen Problemen zu rechnen“ (Loll 1998: 487). 
Da im Rahmen des Modellversuchs im Landkreis Demmin eine Befeuchtung des Mietenmaterials nicht erforderlich war, wurde das Anlagenabwasser mit Pumpentankwagen auf Ackerflächen der beteiligten Landwirtschaftsbetriebe ausgebracht. In diesem Zusammenhang ist es wichtig zu wissen, welche Schwermetallfrachten dabei auf den Hektar Ackerfläche gelangen.

Im Landkreis Ebersberg in Bayern, wo ebenfalls ein dezentrales Konzept für die Bioabfallkompostierung unter Einbeziehung von Landwirten betrieben wird, wird das Anlagenabwasser aus offenen Anlagen ,,aus Wasserschutzgründen in maximalen Gaben von 10 1/ $/ \mathrm{m}^{2}$ Ackerfläche ausgebracht“ (Wintzer et.al.1996: 121), entsprechend einer Menge von 100 m³/ha. In Tarnow werden lediglich $40 \mathrm{~m}^{3} / \mathrm{ha}$ Ackerfläche verwertet.

Im folgenden werden die Schwermetallfrachten für beide genannten Aufbringungsmengen dargestellt (Tab. 6.7, Abb. 6.9 und 6.10). Zum Vergleich werden die mittleren Schwermetallfrachten bei der Verwertung von $20 \mathrm{Mg}$ (TM) Bioabfallkompost innerhalb von 3 Jahren, entsprechend einer jährlichen Ausbringungsmenge von 6,67 Mg (TM) herangezogen. Hierbei werden die mittleren Schwermetallgehalte der Komposte in Tarnow zugrunde gelegt.

Tab. 6.7: Schwermetallfrachten, die bei einmaliger Ausbringung von Anlagenabwasser und Kompost in den angegebenen Mengen auf einen Hektar Ackerfläche gelangen

\begin{tabular}{|c|c|c|c|c|c|}
\hline \multirow{3}{*}{ Schwermetall } & \multicolumn{5}{|c|}{ Schwermetallfracht $[\mathrm{g} / \mathrm{ha}]$} \\
\hline & \multicolumn{4}{|c|}{$\begin{array}{c}\text { Anlagenabwasser } \\
\text { Tarnow }\end{array}$} & \multirow{2}{*}{$\begin{array}{r}\begin{array}{r}\text { Kompost } \\
\text { Tarnow }\end{array} \\
6,67 \mathrm{Mg} / \mathrm{ha} \\
(\mathrm{TM})\end{array}$} \\
\hline & $\begin{array}{l}40 \mathrm{~m}^{3} / \mathrm{ha} \\
\text { (Probe vom } \\
14.04 .99 \text { ) }\end{array}$ & $\begin{array}{l}40 \mathrm{~m}^{3} / \mathrm{ha} \\
\text { (Probe vom } \\
15.07 .99 \text { ) }\end{array}$ & $\begin{array}{l}100 \mathrm{~m}^{3} / \mathrm{ha} \\
\text { (Probe vom } \\
14.04 .99 \text { ) }\end{array}$ & $\begin{array}{l}100 \mathrm{~m}^{3} / \mathrm{ha} \\
\text { (Probe vom } \\
15.07 .99 \text { ) }\end{array}$ & \\
\hline $\mathrm{Cu}$ & 0,4 & 3,52 & 1 & 8,8 & 225,98 \\
\hline $\mathrm{Pb}$ & 0,56 & 0,92 & 1,4 & 2,3 & 336,17 \\
\hline $\mathrm{Cd}$ & 0,02 & 0,08 & 0,05 & 0,2 & 2,2 \\
\hline $\mathrm{Cr}$ & 0,4 & 1,44 & 1 & 3,6 & 243,32 \\
\hline $\mathrm{Ni}$ & 0,8 & 1,96 & 2 & 4,9 & 60,23 \\
\hline $\mathrm{Hg}$ & 0,002 & 0,002 & 0,005 & 0,005 & 1 \\
\hline $\mathrm{Zn}$ & 6,8 & 16,08 & 17 & 40,2 & 1448,72 \\
\hline
\end{tabular}




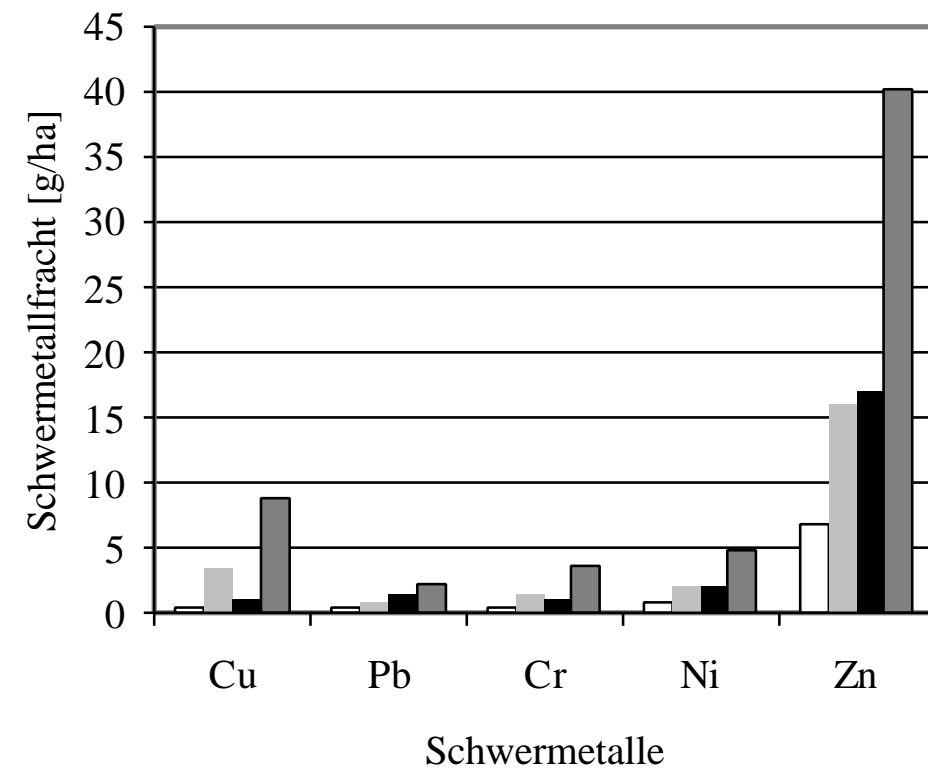

$\square 40 \mathrm{~m}^{3} / \mathrm{ha}$ (Probe: 14.04 .99$)$

$40 \mathrm{~m}^{3} / \mathrm{ha}$ (Probe: 15.07 .99$)$

$100 \mathrm{~m}^{3} / \mathrm{ha}$ (Probe: 14.04 .99$)$

$\square 100 \mathrm{~m}^{3} / \mathrm{ha}$ (Probe: 15.07 .99$)$

Abb. 6.9: Schwermetallfrachten an Kupfer, Blei, Chrom, Nickel und Zink, die bei einmaliger Ausbringung von Anlagenabwasser in den angegebenen Mengen auf einen Hektar Ackerfläche gelangen

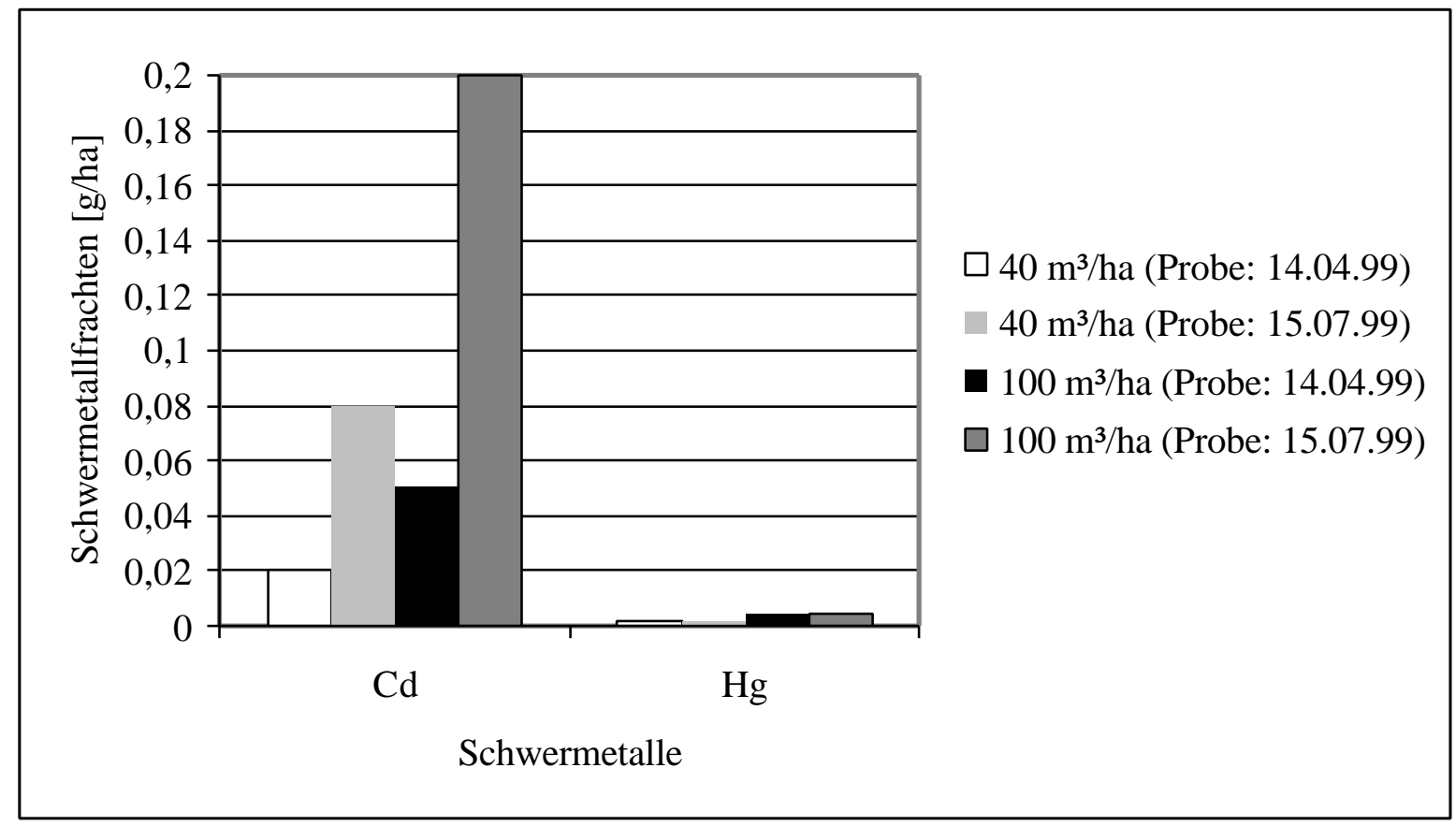

Abb. 6.10: Schwermetallfrachten an Cadmium und Quecksilber, die bei einmaliger Ausbringung von Anlagenabwasser in den angegebenen Mengen auf einen Hektar Ackerfläche gelangen 
Aufgrund des genannten Verdünnungseffekts ist hinsichtlich der Schwermetalle eine jahreszeitlich bedingte niederschlagsabhängig unterschiedliche Befrachtung des Bodens erkennbar.

Im Vergleich zu der Schwermetallfracht, die jährlich zulässigerweise mit 6,67 Mg (TM) Kompost auf Ackerflächen des Tarnower Landwirtschaftsbetriebs ausgebracht wird, sind die mit $40 \mathrm{~m}^{3} / \mathrm{ha}$ und $100 \mathrm{~m}$ 3/ha Anlagenabwasser ausgebrachten Schwermetallfrachten vernachlässigbar gering.

\subsubsection{Schwermetallgehalte im Boden}

Bei der erstmaligen Aufbringung von Bioabfallkompost auf eine bestimmte, landwirtschaftlich genutzte Fläche ist für diese eine Bodenuntersuchung auf Schwermetalle und auf den pH-Wert durchzuführen. Die Bodenuntersuchungsergebnisse sind spätestens drei Monate nach der Aufbringung der zuständigen Behörde vorzulegen. Falls für die Aufbringungsfläche eine gültige Bodenuntersuchung nach der Klärschlammverordnung vorliegt, kann diese entsprechend herangezogen werden. Werden bei der Aufbringungsfläche die in der Verordnung genannten Bodengrenzwerte überschritten, dann darf hier keine weitere Kompostverwertung erfolgen ( $\$ 9$ BioAbfV, Tab. 6.8, Abb. 6.11und 6.12).

Es gelten bei Böden der Bodenart Ton mit einem pH-Wert von weniger als 6 für Cadmium und Zink die Werte der Bodenart Lehm und bei Böden der Bodenart Lehm mit einem pH-Wert von weniger als 6 für diese Elemente die Werte der Bodenart Sand (§ 9 BioAbfV). 
Tab. 6.8: Bodengrenzwerte für Schwermetallgehalte nach der Bioabfallverordnung (1998) in Abhängigkeit von der mineralischen Bodenart

\begin{tabular}{|c|c|c|c|}
\hline \multirow[t]{2}{*}{ Schwermetall } & \multicolumn{3}{|c|}{ Bodenart } \\
\hline & $\begin{array}{l}\text { Sand } \\
{[\mathrm{mg} / \mathrm{kg} \mathrm{TS}]}\end{array}$ & $\begin{array}{l}\text { Lehm } \\
{[\mathrm{mg} / \mathrm{kg} \mathrm{TS}]}\end{array}$ & $\begin{array}{l}\text { Ton } \\
{[\mathrm{mg} / \mathrm{kg} \mathrm{TS}]}\end{array}$ \\
\hline $\mathrm{Pb}$ & 40 & 70 & 100 \\
\hline $\mathrm{Cd}$ & 0,4 & 1 & 1,5 \\
\hline $\mathrm{Cr}$ & 30 & 60 & 100 \\
\hline $\mathrm{Cu}$ & 20 & 40 & 60 \\
\hline $\mathrm{Ni}$ & 15 & 50 & 70 \\
\hline $\mathrm{Hg}$ & $\overline{0,1}$ & $\overline{0,5}$ & 1 \\
\hline $\mathrm{Zn}$ & 60 & 150 & 200 \\
\hline
\end{tabular}

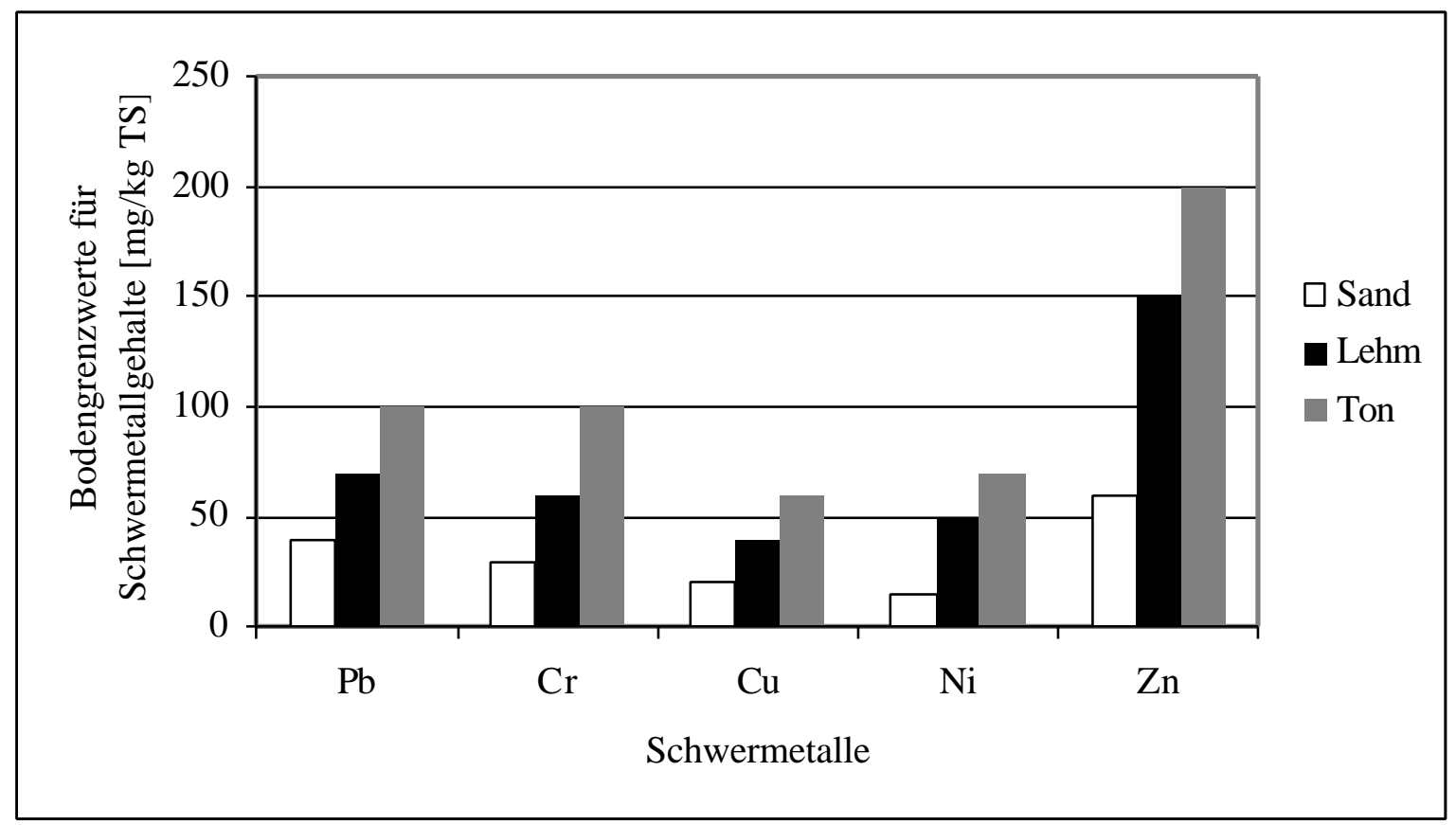

Abb. 6.11: Bodengrenzwerte für die Gehalte an Blei, Chrom, Kupfer, Nickel und Zink nach der Bioabfallverordnung (1998) in Abhängigkeit von der mineralischen Bodenart 


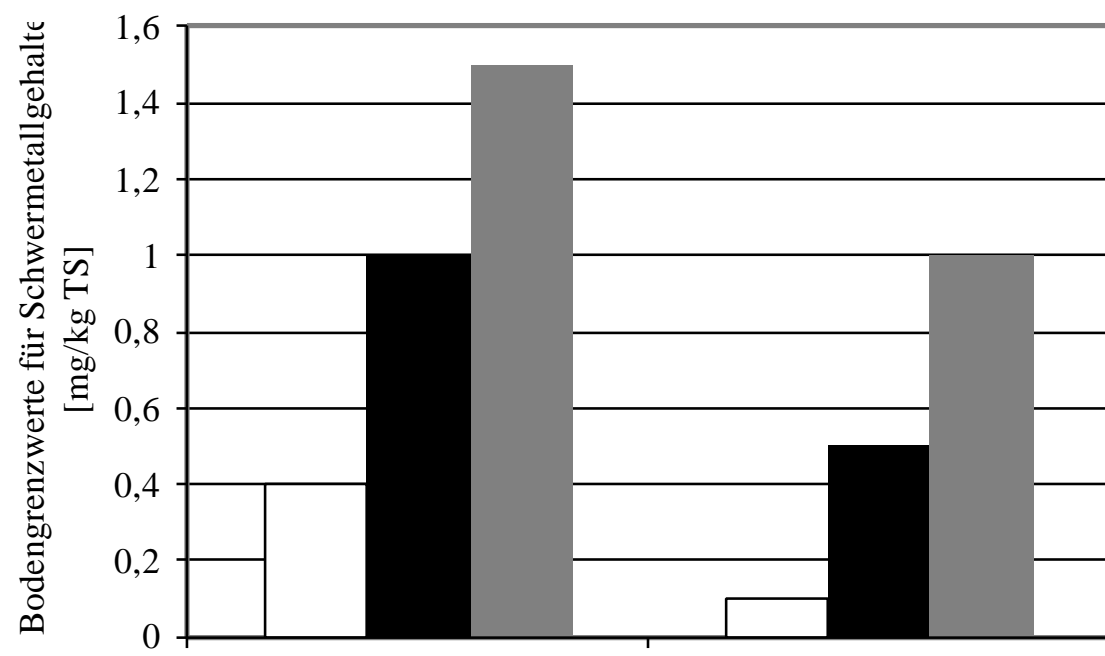

$\mathrm{Cd}$ $\mathrm{Hg}$

Schwermetalle

Abb. 6.12: Bodengrenzwerte für die Gehalte an Cadmium und Quecksilber nach der Bioabfallverordnung (1998) in Abhängigkeit von der mineralischen Bodenart

Die Bodengrenzwerte für Schwermetallgehalte werden in der Bioabfallverordnung (1998) in Abhängigkeit von der mineralischen Bodenart angegeben (Tab. 6.8). Damit wird der Tatsache Rechnung getragen, daß der Schwermetallaustrag aus dem Oberboden in tiefergelegene Bodenschichten bzw. ins Grundwasser in hohem Maße von der Sorptionsfähigkeit des Bodens abhängt. So erreichen z.B. Böden mit höheren Tongehalten eine bessere Pufferwirkung bezüglich der Schwermetalle als sandreiche Böden (vgl. Hackenberg/Wegener 1999: 33). Zudem ist die Mobilität und Pflanzenverfügbarkeit anthropogen eingetragener Schwermetalle stark vom pH-Wert abhängig: mit sinkendem pH-Wert werden die Schwermetalle mobiler (Hackenberg/Wegener 1999: 42-43). Entsprechend den Ansprüchen standortgerecht angebauter Kulturen finden sich auf ackerbaulich genutzten Sandböden innerhalb der Einteilung der mineralischen Bodenarten die niedrigsten $\mathrm{pH}-$ Werte.

Die Belastbarkeit der verschiedenen Böden mit Schwermetallen ist so unterschiedlich, daß die in der Bioabfallverordnung vorgenommene Festlegung verschiedener Bodengrenzwerte für Schwermetalle in Abhängigkeit von der mineralischen Bodenart sinnvoll ist, denn „Böden mit hoher Sorptionskraft und guter Kalkversorgung können ohne weiteres höhere Gehalte verkraften. Leichte und saure 
Böden hingegen, die oft für den Freilandgemüsebau genutzt werden, sind in der Regel sehr gering belastbar“ (Hackenberg/Wegener 1999: 43).

Die natürlichen Schwermetallgehalte in Böden können bereits so hoch sein, daß sie die genannten Bodengrenzwerte überschreiten. So liegen z.B. die natürlichen Nickelgehalte auf ca. $5 \%$ der Flächen Baden-Württembergs und Bayerns über dem Grenzwert von $50 \mathrm{mg} / \mathrm{kg}$ (TS) (vgl. Wintzer et.al.1996: 274). Eine landbauliche Kompostverwertung ist demzufolge auf diesen Flächen nicht zulässig.

Die im Ausgangsgestein des Bodens natürlich vorkommenden Schwermetalle, die durch Verwitterungs- und Mineralisierungsvorgänge freigesetzt werden können, sind dazu geeignet, von Pflanzen aufgenommen bzw. in tiefere Bodenschichten verlagert zu werden. Die geogenen Schwermetalle sind jedoch überwiegend schlecht pflanzenverfügbar und damit anders zu bewerten als die anthropogen eingetragenen Schwermetalle (Wintzer et.al.1996: 274). So weisen anthropogen eingetragene Schwermetalle in Böden (mit Ausnahme von Blei und Chrom) eine zwei- bis vierfach höhere Pflanzenverfügbarkeit auf als geogene Schwermetalle (Hackenberg/Wegener 1999: 42).

Vor diesem Hintergrund ist es sehr schwierig, „Normalgehalte“ an Schwermetallen in Böden zu definieren (vgl. Tab. 6.9).

Für Blei liegen die Gesamtgehalte in landwirtschaftlich genutzten Böden zwischen 2 und $200 \mathrm{mg} / \mathrm{kg}$, wobei höhere Konzentrationen v.a. in Böden aus bleierzhaltigem Gestein auftreten. Cadmium liegt in Konzentrationen zwischen etwa 0,01 bis $1 \mathrm{mg} / \mathrm{kg}$ und Chrom zwischen 10 und $100 \mathrm{mg} / \mathrm{kg}$ vor. Die Kupfergehalte unbelasteter Böden betragen i.d.R. 2 bis 40 mg/kg, die Nickelgehalte im Mittel etwa $45 \mathrm{mg} / \mathrm{kg}$ und die Zinkgehalte in normalen Böden zwischen 10 und $300 \mathrm{mg} / \mathrm{kg}$ (Hackenberg et.al.1998: 587-588). 
Tab. 6.9: Schwermetallgehalte in Böden

\begin{tabular}{|c|c|c|c|c|}
\hline $\begin{array}{l}\text { Schwer- } \\
\text { metall }\end{array}$ & $\begin{array}{l}\text { Ackerflächen } \\
\text { Baden- } \\
\text { Württembergs }{ }^{1)} \\
{[\mathrm{mg} / \mathrm{kg} \mathrm{TS}]}\end{array}$ & $\begin{array}{l}\text { Mittlere Boden- } \\
\text { gehalte }^{2)} \\
{[\mathrm{mg} / \mathrm{kg} \mathrm{TS}]}\end{array}$ & $\begin{array}{l}\text { Normalgehalte in } \\
\text { Böden }^{3)} \\
{[\mathrm{mg} / \mathrm{kg} \text { TS }]}\end{array}$ & $\begin{array}{l}\text { Normalgehalte } \\
\text { in Böden }{ }^{2)} \\
{[\mathrm{mg} / \mathrm{kg} \mathrm{TS}]}\end{array}$ \\
\hline $\mathrm{Pb}$ & 37 & 30 & $2-200$ & $2-60$ \\
\hline $\mathrm{Cd}$ & 0,3 & 0,2 & $0,01-1$ & $<0,5$ \\
\hline $\mathrm{Cr}$ & 35 & 30 & $10-100$ & $5-100$ \\
\hline $\mathrm{Cu}$ & 21 & 30 & $2-40$ & 4-40 \\
\hline $\mathrm{Ni}$ & 34 & 20 & 45 & $5-50$ \\
\hline $\mathrm{Hg}$ & 0,1 & 0,05 & k.A. & $<0,5$ \\
\hline $\mathrm{Zn}$ & 89 & 50 & $10-300$ & $10-80$ \\
\hline
\end{tabular}

1) (Ebertseder 1995: 87)

2) (Wintzer et.al.1996: 275)

${ }^{3)}$ (Hackenberg et.al. 1998: 587-588)

Im Rahmen dieser Arbeit wurden die Kompostausbringungsflächen in Tarnow und Borrentin (s. Tab 4.1) beprobt und auf deren $\mathrm{pH}-$ Wert sowie die geforderten Schwermetallgehalte untersucht (Tab. 6.10, Abb. 6.13 und 6.14).

Tab. 6.10: Durchschnittliche Schwermetallgehalte der Aufbringungsflächen in Tarnow und Borrentin mit den Grenzwerten der BioAbfV (für die Bodenart Lehm)

\begin{tabular}{|l|r|r|r|}
\hline $\begin{array}{c}\text { Schwer- } \\
\text { metall }\end{array}$ & Tarnow & Borrentin & \multicolumn{1}{|c|}{$\begin{array}{c}\text { BioAbfV } \\
(1998) \\
{[\mathrm{mg} / \mathrm{kg} \mathrm{TS}]}\end{array}$} \\
\hline $\mathrm{Pb}$ & 10,3 & 9,2 & 70 \\
\hline $\mathrm{Cd}$ & 0,1 & 0,12 & 1 \\
\hline $\mathrm{Cr}$ & 15,7 & 20,2 & 60 \\
\hline $\mathrm{Cu}$ & 6,5 & 9 & 40 \\
\hline $\mathrm{Ni}$ & 7,3 & 9 & 50 \\
\hline $\mathrm{Hg}$ & 0,07 & 0,05 & 0,5 \\
\hline $\mathrm{Zn}$ & 27,8 & 30,4 & 150 \\
\hline
\end{tabular}




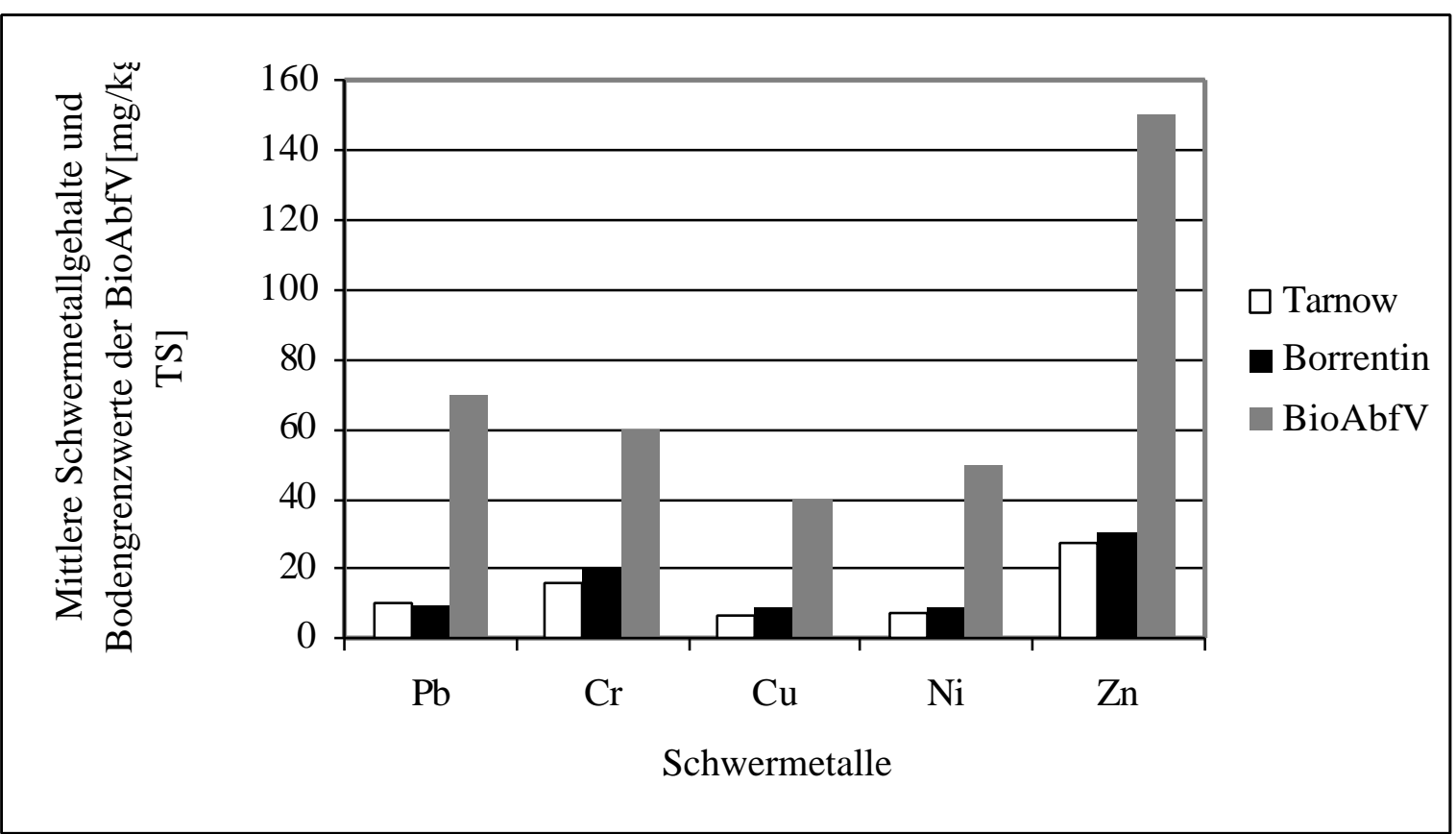

Abb. 6.13: Durchschnittliche Gehalte an Blei, Chrom, Kupfer, Nickel und Zink der Aufbringungsflächen in Tarnow und Borrentin mit den Grenzwerten der BioAbfV (für die Bodenart Lehm)

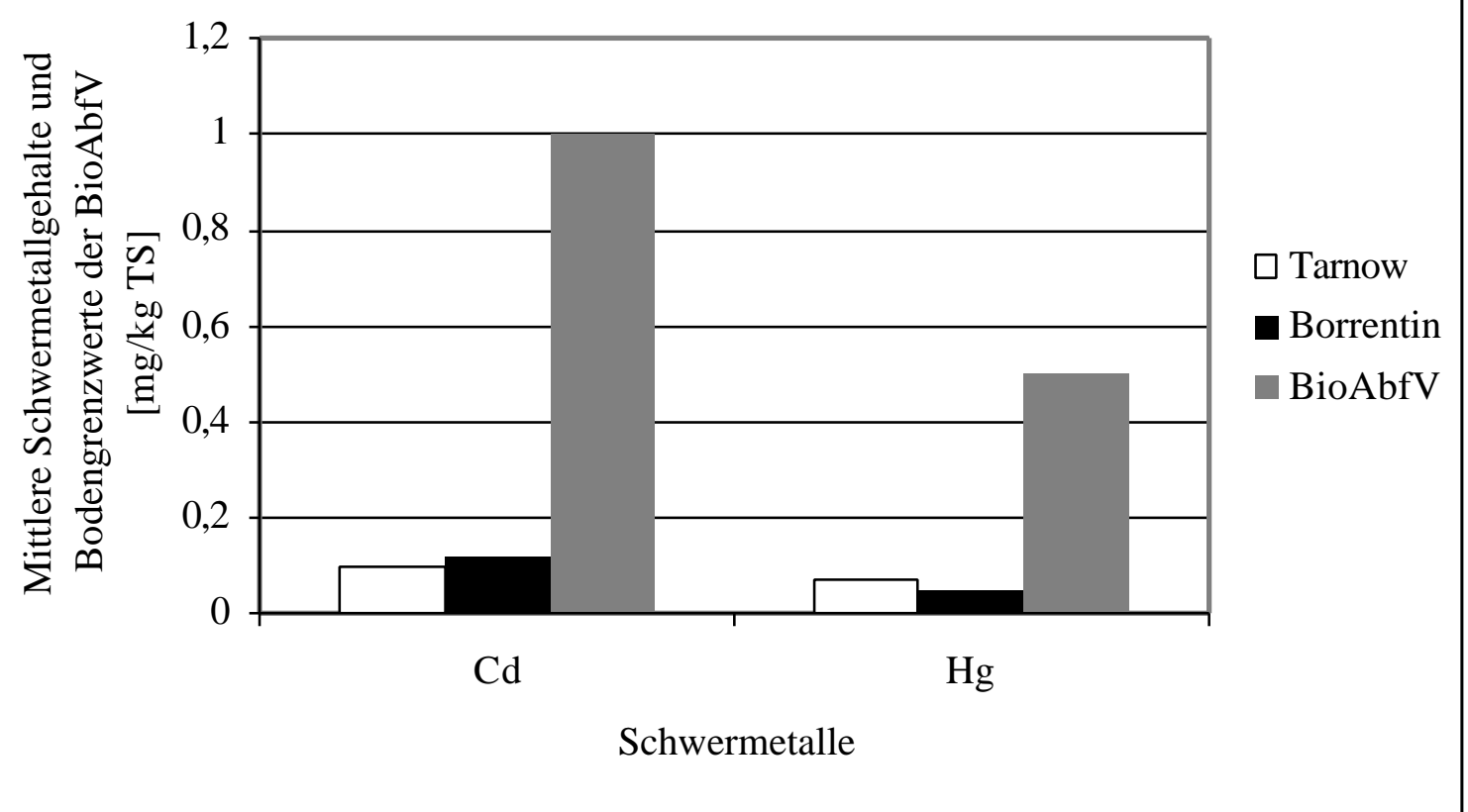

Abb. 6.14: Durchschnittliche Gehalte an Cadmium und Quecksilber der Aufbringungsflächen in Tarnow und Borrentin mit den Grenzwerten der BioAbfV (für die Bodenart Lehm) 
Im folgenden wird dargestellt, in welchem Maße die Bodengrenzwerte der Bioabfallverordnung (1998) durch die angegebenen mittleren Schwermetallgehalte in den Kompostausbringungsflächen ausgeschöpft werden (Abb. 6.15).

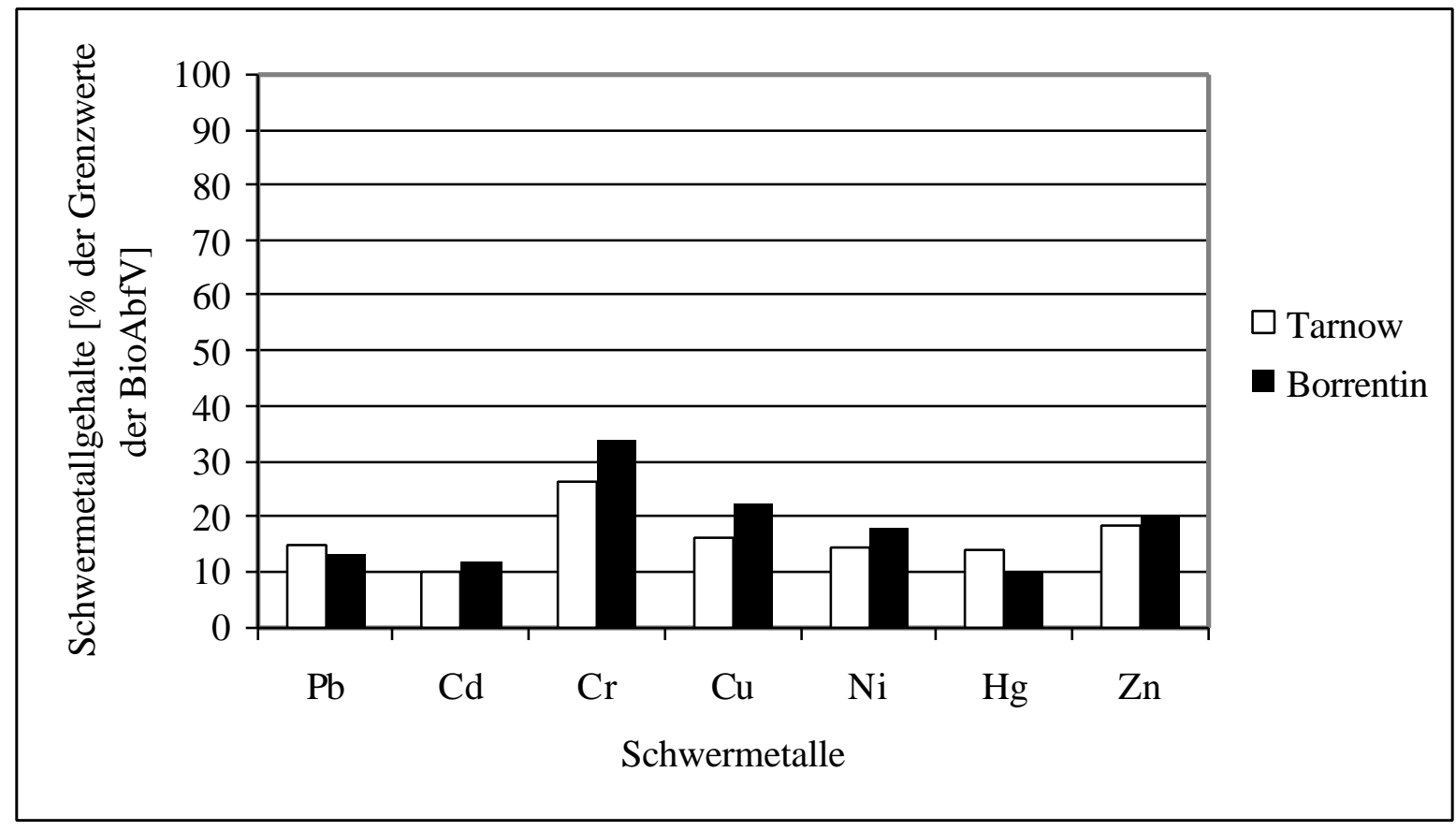

Abb. 6.15: Mittlere Schwermetallgehalte in den Kompostausbringungsflächen im Landkreis Demmin in Prozent der Bodengrenzwerte der Bioabfallverordnung für die Bodenart Lehm

Abb. 6.16 zeigt die analysierten mittleren Schwermetallgehalte der Aufbringungsflächen in Tarnow und Borrentin, in Ackerböden Baden-Württembergs (Ebertseder 1995: 87) sowie mittlere Schwermetallgehalte in Böden (Wintzer 1996: 275). 


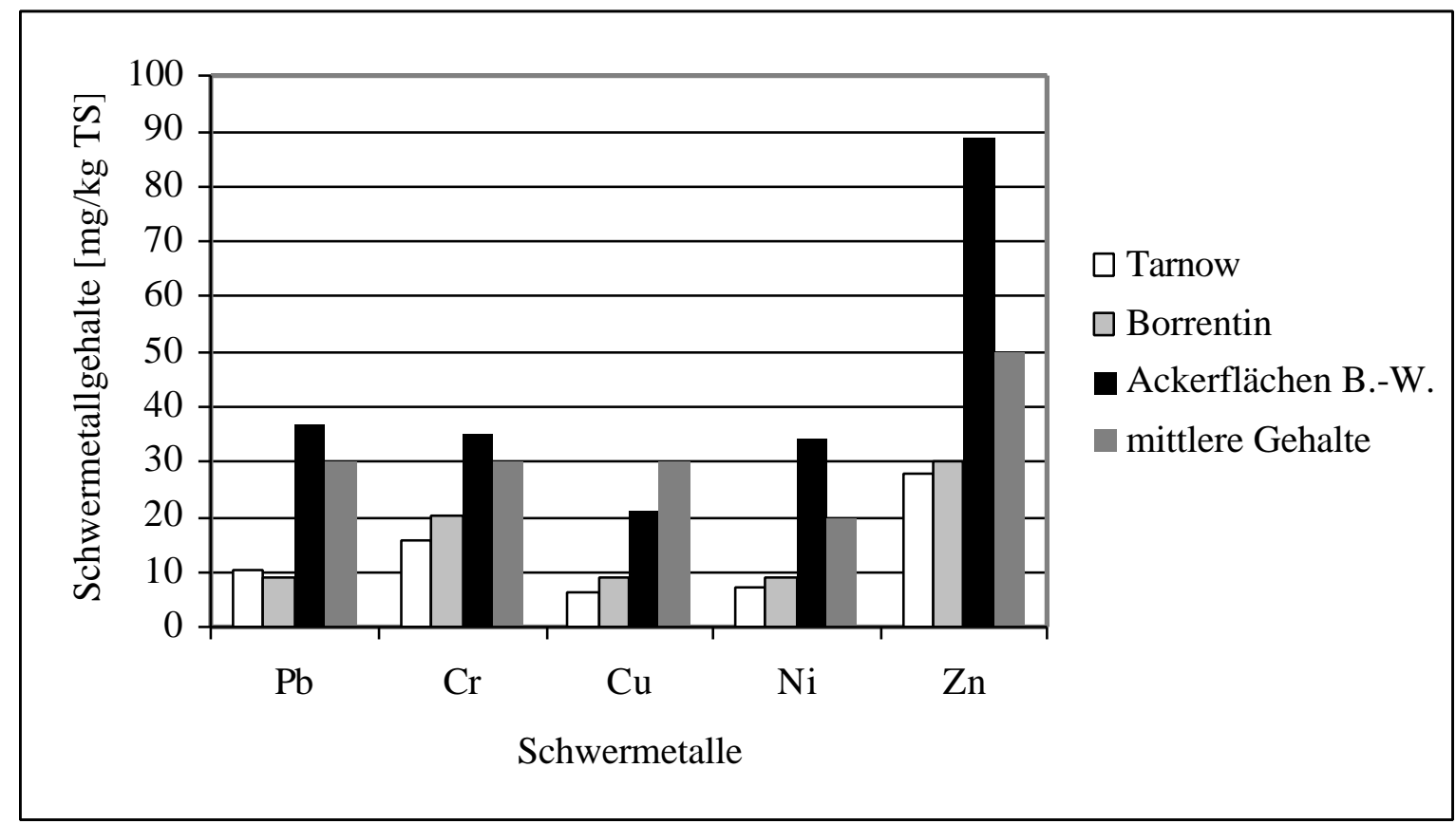

Abb. 6.16: Mittlere Schwermetallgehalte der Aufbringungsflächen in Tarnow und Borrentin, in Ackerböden Baden-Württembergs (Ebertseder 1995: 87) sowie mittlere Schwermetallgehalte in Böden (Wintzer 1996: 275)

Die Hintergrundbelastung der Kompostausbringungsflächen in Tarnow und Borrentin mit Schwermetallen ist relativ gering. Einschränkungen hinsichtlich der landbaulichen Kompostverwertung aufgrund der Vorgaben der Bioabfallverordnung gibt es nicht.

\subsubsection{Schwermetallbelastung des Bodens durch Kompostbeaufschlagung}

In Abhängigkeit von Menge und Verfügbarkeit der im Kompost enthaltenen Schwermetalle sowie der pflanzenspezifischen Aufnahmeraten besteht durch landwirtschaftliche Kompostverwertung die Gefahr der Erhöhung der Schwermetallgehalte in den beaufschlagten Böden sowie der Schwermetallkonzentrationen in den Nahrungs- und Futterpflanzen und möglicherweise des Grundwassers (Wintzer et. al. 1996: 271).

Die Risiken der anthropogenen Schwermetallbefrachtung von Böden umfassen daher u.a. die Veränderung des Bodenmilieus, die Beeinflussung der Boden(mikro-)biologie, phytotoxische Wirkungen und Minderung der Bodenfruchtbarkeit sowie Eintritt von Schwermetallen in die Nahrungskette des Menschen. „Aus humantoxikologischer Sicht ist der Metalltransfer in Futter- und Nahrungspflanzen und damit in die Nahrungskette des Menschen von besonderem Interesse“ 
(Kettrup/Bieniek 1991: 9). Dabei ist das phyto- und humantoxikologische Gefährdungspotential der Schwermetalle von deren Bodenkonzentration, der element-, pflanzenart- und pflanzenteilspezifischen Transferrate aus dem Boden sowie der konzentrationsbedingten Nutz- bzw. Schadwirkung der Schwermetalle abhängig (Wintzer et. al 1996: 287).

Mit steigendem Schwermetallgesamtgehalt im Boden nimmt auch die Löslichkeit der Schwermetalle und damit ihre Pflanzenverfügbarkeit zu (Hackenberg/Wegener 1999: 41).

Die mengenmäßige Einlagerung von Schwermetallen in einzelne Pflanzenteile ist unterschiedlich. I.d.R. überwiegt die Einlagerung in die Pflanzenwurzel, wodurch in den Ernteprodukten z.B. von Wurzelgemüse eine höhere Einlagerung zu beobachten ist als vergleichsweise von Getreide.

Die flächenbezogenen Schwermetallabreicherungen über die Ernteprodukte liegen etwa zwischen 180 g Blei, 0,3-3 g Cadmium, 1-10 g Chrom, 30-50 g Kupfer, 10-30 g Nickel und 100-500 g Zink pro Hektar und Jahr (Wintzer et.al. 1996: 288).

Es ist zu erwarten, daß in Zukunft die Qualitätsanforderungen an Kompost weiter erhöht werden: die Richtwerte werden sich den Bodenwerten annähern, da nur für die Anwendung dieser Komposte gewährleistet ist, daß eine Anreicherung von Schwermetallen im Boden ausgeschlossen werden kann (Kettrup/Bieniek 1991: 11). Enthalten Komposte nämlich ähnliche Gehalte an Schwermetallen wie die landwirtschaftlich genutzten Böden, so bedeutet dies, daß ihre Anwendung, wenn überhaupt, nur zu einer geringen Beeinflussung der Schwermetallkonzentrationen im Boden führt (Ebertseder 1995: $88)$.

Das Risiko einer Wertminderung bzw. eines Wertverlusts seiner Produktionsgrundlage „Boden“ besteht für den Landwirt v.a. darin, daß eine einmal erfolgte Bodenbelastung kaum mehr rückgängig zu machen ist, da die Kosten einer technischen Bodenreinigung den Verkehrswert der Ackerfläche für die landwirtschaftliche Produktion um ein vielfaches übersteigen würden. Deshalb ist für den Landwirt bei Überschreitung der Hintergrundbelastung des Bodens wichtig zu wissen, nach wieviel Jahren kontinuierlicher landbaulicher Kompostverwertung die zur Zeit geltenden Bodengrenzwerte erreicht sind und ein zusätzlicher Schwermetalleintrag nicht mehr tolerierbar ist. Diese Bodengrenzwerte für die Kompostverwertung, oberhalb derer zur Begrenzung von Umweltrisiken durch Schwermetallakkumulation eine weitere Beaufschlagung des Bodens nicht zulässig ist, finden sich in der Bioabfallverordnung (1998) (s. Tab. 6.8). 
Als Bewertungshilfe dient hierbei ein Vergleich des Schwermetalleintrags im Verhältnis zu den Austrägen über die Ernteentzüge und das Bodensickerwasser (Auswaschung). Die Ein- und Austräge werden im folgenden auf die obere, ackerbaulich genutzte Bodenschicht mit einer Tiefe von $30 \mathrm{~cm}$ (Ackerkrume, sog. Ap-Horizont) bezogen.

Zur Ermittlung des Schwermetalleintrags durch landbauliche Kompostverwertung wurden die mittleren Schwermetallgehalte [mg/kg TS] in den Bioabfallkomposten aus den Anlagen in Tarnow und Borrentin sowie die Mittelwerte der in zahlreichen Einzeluntersuchungen ermittelten Schwermetallgehalte von Bioabfallkomposten, die im Zeitraum von 1987 bis 1994 durchgeführt wurden (Wintzer et.al. 1996: 136), auf die Schwermetallfrachten [g/ha] umgerechnet, die bei einer jährlichen Ausbringungsmenge von 6,67 Mg (TM) (entsprechend der nach der Bioabfallverordnung höchstens zulässigen Kompostausbringungsmenge von $20 \mathrm{Mg}$ (TM) je Hektar innerhalb von 3 Jahren) in den Boden gelangen (Tab. 6.11).

Tab. 6.11: Mittlere Schwermetallfrachten, die mit 6,67 Mg (TM) Bioabfallkompost ausgebracht werden

\begin{tabular}{|c|r|r|r|}
\hline & $\begin{array}{r}\text { Kompost Tarnow } \\
{[\mathrm{g} / \mathrm{ha} \text { a }]}\end{array}$ & $\begin{array}{r}\text { Kompost Borrentin } \\
{[\mathrm{g} / \mathrm{ha} \mathrm{a}]}\end{array}$ & $\begin{array}{c}\text { Kompost (Mittelwerte } \\
1987-1994) \\
{[\mathrm{g} / \mathrm{ha} \text { a }]}\end{array}$ \\
\hline $\mathrm{Pb}$ & 336,17 & 288,14 & 493,58 \\
\hline $\mathrm{Cd}$ & 2,20 & 2,53 & 4,87 \\
\hline $\mathrm{Cr}$ & 243,32 & 318,69 & 300,15 \\
\hline $\mathrm{Cu}$ & 225,98 & 141,14 & 253,46 \\
\hline $\mathrm{Ni}$ & 60,23 & 39,35 & 153,41 \\
\hline $\mathrm{Hg}$ & 1,00 & 1,27 & 1480,74 \\
\hline $\mathrm{Zn}$ & 1448,72 & 1000,50 & \\
\hline
\end{tabular}

Weiterhin wurden die Einträge durch atmosphärische Deposition sowie durch die die Kompostdüngung ergänzende Mineraldüngung berücksichtigt. Diese ist erforderlich, da eine ausschließliche Düngung mit Kompost zur Deckung des Nährstoffbedarfs der Kulturpflanzen nicht sinnvoll ist (s. Abschnitt 7.3.1.2).

Unter Schwermetallaustrag wird bei der Berechnung der gesuchten Zeitspannen der Austrag bzw. die Auswaschung der Schwermetalle aus dem Oberboden in tiefer gelegene Bodenschichten bzw. ins 
Grundwasser sowie eine Verringerung der in der betrachteten Bodenschicht enthaltenen Schwermetalle durch Pflanzenentzug und anschließender Abfuhr mit den Ernteprodukten verstanden. Eine Schwermetallakkumulation ergibt sich dann aus der Summe der jährlichen Überschüsse (Differenz von Schwermetalleinträgen und -austrägen), die eine Konzentrationserhöhung der Schwermetalle in der Ackerkrume bewirken.

Für die Umrechnung von Bodenkonzentrationen $[\mathrm{mg} / \mathrm{kg} \mathrm{TS}]$ auf Bodengehalte $[\mathrm{g} / \mathrm{ha}]$ an Schwermetallen wird angenommen, daß der Boden eine Dichte von 1,5 Mg (TS)/ha aufweist (vgl. KTBL 1997: 330).

Ausgehend von mittleren Schwermetallgehalten in Ackerflächen (Tab. 6.9) bzw. in der Kompostausbringungsfläche in Tarnow (Tab. 6.10) sowie in Borrentin (Tab. 6.10) und unter Berïcksichtigung des atmosphärischen Eintrags, der Düngung mit Bioabfallkompost in Verbindung mit Mineraldünger, Auswaschung und Entzug über das Erntegut verbleiben bei Akkumulierung der überschüssigen Schwermetalleinträge die im folgenden ermittelten Zeitspannen bis zum Erreichen der Bodengrenzwerte der Bioabfallverordnung (Tab. 6.12 bis 6.14). 
Tab. 6.12: Zeitspannen bis zum Erreichen der Bodengrenzwerte der Bioabfallverordnung durch landbauliche Kompostverwertung unter Berücksichtigung der Kompost- und Bodenanalysen für den Landwirtschaftsbetrieb in Tarnow

\begin{tabular}{|c|c|c|c|c|c|c|c|c|}
\hline & $\mathrm{Pb}$ & $\mathrm{Cd}$ & $\mathrm{Cr}$ & $\mathrm{Cu}$ & $\mathrm{Hg}$ & $\mathrm{Ni}$ & $\mathrm{Zn}$ \\
\hline & & \multicolumn{7}{|c|}{ Normale bzw. tolerierbare Schwermetallbelastungen (mg/kg TS) } \\
\hline \multicolumn{2}{|c|}{ Kompostausbringungsfläche Tarnow } & 10,3 & 0,1 & 15,7 & 6,5 & 0,07 & 7,3 & 27,8 \\
\hline \multirow{3}{*}{$\begin{array}{l}\text { Bodengrenzwerte } \\
\text { der BioAbfV }\end{array}$} & Sand & 40 & 0,4 & 30 & 20 & 0,1 & 15 & 60 \\
\hline & Lehm & 70 & 1 & 60 & 40 & 0,5 & 50 & 150 \\
\hline & Ton & 100 & 1,5 & 100 & 60 & 1 & 70 & 200 \\
\hline & & \multicolumn{7}{|c|}{ Schwermetalleinträge (g/ha*a) } \\
\hline \multicolumn{2}{|l|}{ Atmosphärischer Eintrag ${ }^{1)}$} & 54 & 2,67 & 10 & 49 & k.A. & 10,5 & 314 \\
\hline \multicolumn{2}{|l|}{ Mineraldünger $^{2}$} & 8 & 3 & 95 & 10 & k.A. & 7 & 70 \\
\hline \multicolumn{2}{|l|}{ Bioabfallkompost Tarnow } & 336,17 & 2,2 & 243,32 & 225,98 & & 60,23 & 1448,72 \\
\hline & & \multicolumn{7}{|c|}{ Schwermetallausträge (g/ha*a) } \\
\hline \multicolumn{2}{|l|}{ Auswaschung $^{3)}$} & 1 & 0,6 & 0,7 & 20 & k.A. & 8 & 60 \\
\hline \multirow{2}{*}{\multicolumn{2}{|c|}{ Ernteentzug auf der $\mathrm{LF}^{4)}$}} & 2,37 & 2,35 & 2,23 & 41 & $0,11^{5}$ & 43 & 714 \\
\hline & & \multicolumn{7}{|c|}{ Jahre bis zum Erreichen der Bodengrenzwerte der BioAbfV } \\
\hline \multirow{2}{*}{\multicolumn{2}{|c|}{\begin{tabular}{|l|} 
Sand \\
Lehm
\end{tabular}}} & 339 & 274 & 186 & 271 & 152 & 1296 & 137 \\
\hline & & 680 & 823 & 577 & 673 & 2174 & 7189 & 519 \\
\hline \multicolumn{2}{|r|}{ Ton } & 1022 & 1280 & 1098 & 1075 & 4702 & 10556 & 732 \\
\hline
\end{tabular}

1) (Wintzer et.al.1996: 277)

2) (Wintzer et.al.1996: 280)

3) (Hackenberg / Wegener 1999: 220)

4) (Wintzer et.al.1996: 289)

5) (Hackenberg / Wegener 1999: 220) 
Tab. 6.13: Zeitspannen bis zum Erreichen der Bodengrenzwerte der Bioabfallverordnung durch landbauliche Kompostverwertung unter Berücksichtigung der Kompost- und Bodenanalysen für den Landwirtschaftsbetrieb in Borrentin

\begin{tabular}{|c|c|c|c|c|c|c|c|c|}
\hline & $\mathrm{Pb}$ & $\mathrm{Cd}$ & $\mathrm{Cr}$ & $\mathrm{Cu}$ & $\mathrm{Hg}$ & $\mathrm{Ni}$ & $\mathrm{Zn}$ \\
\hline & & \multicolumn{7}{|c|}{ Normale bzw. tolerierbare Schwermetallbelastungen (mg/kg TS) } \\
\hline \multicolumn{2}{|c|}{ Kompostausbringungsfläche Borrentin } & 9,2 & 0,12 & 20,2 & 9 & 0,05 & 9 & 30,4 \\
\hline \multirow{3}{*}{$\begin{array}{l}\text { Bodengrenzwerte } \\
\text { der BioAbfV }\end{array}$} & Sand & 40 & 0,4 & 30 & 20 & 0,1 & 15 & 60 \\
\hline & Lehm & 70 & 1 & 60 & 40 & 0,5 & 50 & 150 \\
\hline & Ton & 100 & 1,5 & 100 & 60 & 1 & 70 & 200 \\
\hline & & \multicolumn{7}{|c|}{ Schwermetalleinträge $\left(\mathrm{g} / \mathrm{ha} \mathbf{*}^{*} \mathbf{a}\right)$} \\
\hline \multicolumn{2}{|c|}{ Atmosphärischer Eintrag ${ }^{1)}$} & 54 & 2,67 & 10 & 49 & k.A. & 10,5 & 314 \\
\hline \multicolumn{2}{|l|}{ Mineraldünger $^{2}$} & 8 & 3 & 95 & 10 & k.A. & 7 & 70 \\
\hline \multicolumn{2}{|c|}{ Bioabfallkompost Borrentin } & 288,14 & 2,53 & 318,69 & 141,14 & 1,27 & 39,35 & 1000,5 \\
\hline & & \multicolumn{7}{|c|}{ Schwermetallausträge (g/ha*a) } \\
\hline \multicolumn{2}{|l|}{ Auswaschung $^{3}$} & 1 & 0,6 & 0,7 & 20 & k.A. & 8 & 60 \\
\hline \multirow{2}{*}{\multicolumn{2}{|c|}{ Ernteentzug auf der $\mathrm{LF}^{4)}$}} & 2,37 & 2,35 & 2,23 & 41 & $0,11^{5}$ & 43 & 714 \\
\hline & & \multicolumn{7}{|c|}{ Jahre bis zum Erreichen der Bodengrenzwerte der BioAbfV } \\
\hline \multicolumn{2}{|r|}{ Sand } & 400 & 240 & 105 & 356 & 194 & 4615 & 218 \\
\hline \multicolumn{2}{|r|}{ Lehm } & 789 & 754 & 426 & 1003 & 1746 & 31538 & 882 \\
\hline & Ton & 1178 & 1183 & 853 & 1649 & 3685 & 46923 & 1250 \\
\hline
\end{tabular}

1) (Wintzer et.al.1996: 277)

2) (Wintzer et.al.1996: 280)

3) (Hackenberg / Wegener 1999: 220)

4) (Wintzer et.al.1996: 289)

5) (Hackenberg / Wegener 1999: 220) 
Tab. 6.14: Zeitspannen bis zum Erreichen der Bodengrenzwerte der Bioabfallverordnung durch landbauliche Kompostverwertung unter Berücksichtigung ,normaler“ Schwermetall-gehalte im Kompost und im Boden

\begin{tabular}{|c|c|c|c|c|c|c|c|c|}
\hline & \multirow[b]{2}{*}{$\mathrm{Pb}$} & & & & & & \\
\hline & & & $\mathrm{Cd}$ & $\mathrm{Cr}$ & $\mathrm{Cu}$ & $\mathrm{Hg}$ & $\mathrm{Ni}$ & \multirow[t]{2}{*}{$\mathrm{Zn}$} \\
\hline & & \multicolumn{6}{|c|}{ Normale bzw. tolerierbare Schwermetallbelastungen (mg/kg TS) } & \\
\hline \multicolumn{2}{|c|}{ Normalgehalte in Ackerflächen ${ }^{6}$} & 30 & 0,27 & 31 & 18 & k.A. & 26 & $\overline{74}$ \\
\hline \multirow{3}{*}{$\begin{array}{l}\text { Bodengrenzwerte } \\
\text { der BioAbfV }\end{array}$} & Sand & 40 & 0,4 & 30 & 20 & 0,1 & 15 & 60 \\
\hline & Lehm & 70 & 1 & 60 & 40 & 0,5 & 50 & 150 \\
\hline & Ton & 100 & 1,5 & 100 & 60 & 1 & 70 & 200 \\
\hline & & \multicolumn{7}{|c|}{ Schwermetalleinträge (g/ha*a) } \\
\hline \multicolumn{2}{|c|}{ Atmosphärischer Eintrag ${ }^{1)}$} & 54 & 2,67 & 10 & 49 & k.A. & 10,5 & 314 \\
\hline \multicolumn{2}{|l|}{ Mineraldünger $^{2}$} & 8 & 3 & 95 & 10 & k.A. & 7 & 70 \\
\hline \multirow{2}{*}{\multicolumn{2}{|c|}{$\begin{array}{l}\text { Bioabfallkompost } \\
(\text { Mittelwert 1987-1994) }\end{array}$}} & 493,58 & 4,87 & 300,15 & 253,46 & 1,8 & 153,41 & 1480,74 \\
\hline & & & & & & & & \\
\hline & & \multicolumn{7}{|c|}{ Schwermetallausträge (g/ha*a) } \\
\hline \multicolumn{2}{|l|}{ Auswaschung $^{3)}$} & 1 & 0,6 & 0,7 & 20 & k.A. & 8 & 60 \\
\hline \multirow{2}{*}{\multicolumn{2}{|c|}{ Ernteentzug auf der LF ${ }^{4)}$}} & 2,37 & 2,35 & 2,23 & 41 & $0,11^{5}$ & 43 & 714 \\
\hline & & \multicolumn{7}{|c|}{ Jahre bis zum Erreichen der Bodengrenzwerte der BioAbfV } \\
\hline & Sand & 81 & 77 & 0 & 36 & - & 0 & 0 \\
\hline & Lehm & 326 & 433 & 324 & 394 & - & 901 & 314 \\
\hline & Ton & 570 & 729 & 772 & 752 & - & 1651 & 520 \\
\hline
\end{tabular}

1) (Wintzer et.al.1996: 277)

2) (Wintzer et.al.1996: 280)

3) (Hackenberg / Wegener 1999: 220)

4) (Wintzer et.al.1996: 289)

5) (Hackenberg / Wegener 1999: 220)

6) (Wintzer et.al.1996: 290)

7) s. Tab. 6.11

Für die im Rahmen des Modellversuchs zur dezentralen Kompostierung im Landkreis Demmin beaufschlagten Ausbringungsflächen, die der Bodenart nach dem Lehm zuzurechnen sind, wurden folgende Zeitspannen bis zum Erreichen der Bodengrenzwerte der Bioabfallverordnung ermittelt (Tab. 6.15): 
Tab. 6.15: Zeitspannen bis zum Erreichen der Bodengrenzwerte der Bioabfallverordnung auf den Kompostausbringungsflächen in Tarnow und Borrentin

\begin{tabular}{|c|c|c|}
\hline Schwermetall & $\begin{array}{l}\text { Zeitspanne für die } \\
\text { Kompostausbringungsfläche in } \\
\text { Tarnow } \\
{[\text { Jahre] }}\end{array}$ & $\begin{array}{l}\text { Zeitspanne für die } \\
\text { Kompostausbringungsfläche in } \\
\text { Borrentin } \\
\text { [Jahre] }\end{array}$ \\
\hline $\mathrm{Pb}$ & 680 & 789 \\
\hline $\mathrm{Cd}$ & 823 & 754 \\
\hline $\mathrm{Cr}$ & 577 & 426 \\
\hline $\mathrm{Cu}$ & 673 & 31538 \\
\hline $\mathrm{Ni}$ & 7189 & 1746 \\
\hline $\mathrm{Hg}$ & 2174 & 882 \\
\hline $\mathrm{Zn}$ & 519 & \\
\hline
\end{tabular}

Das Element, das zuerst den zugehörigen Bodengrenzwert erreicht, bestimmt, ab welchem Zeitpunkt kein Kompost mehr auf der entsprechenden Fläche verwertet werden darf. Dabei handelt es sich in Tarnow um Zink, das nach 519 Jahren jährlicher Kompostausbringung den derzeit gültigen Bodengrenzwert erreicht, sowie um Chrom in Borrentin, aufgrund dessen nach 426 Jahren keine weitere Kompostbeaufschlagung des Bodens erfolgen darf.

Im Ergebnisteil der Tab. 6.14 ist erkennbar, das bereits vorfindbare normale Schwermetallgehalte in Böden (geogene Grundbelastung oder sonstige Hintergrundbelastung) die relativ niedrigen Bodengrenzwerte für die Bodenart Sand überschreiten können. Eine landbauliche Kompostverwertung ist dann von vornherein ausgeschlossen, die ermittelte Zeitspanne beträgt entsprechend 0 Jahre.

In den Modellrechnungen zur Abschätzung der Zeitspannen bis zum Erreichen der Bodengrenzwerte der Bioabfallverordnung erfolgen die größten Schwermetalleinträge über die Verwertung der Bioabfallkomposte. Diese sollten in Form unschädlicher Austräge über das Erntegut ausgeglichen 
werden (Hackenberg/Wegener 1999: 217). Die mit dem Erntegut entzogenen Mengen an Schwermetallen sind jedoch relativ gering und gleichen nicht einmal den atmosphärischen Eintrag aus, so daß es bei der Verwertung von Bioabfallkomposten, deren Schwermetallgehalte regelmäßig über denen der Hintergrundwerte ,normal belasteter“ Ackerflächen liegen, zu einer Schwermetallakkumulation im Boden kommt.

Anzumerken ist hinsichtlich solcher Auffüllrechnungen, daß zur Vereinfachung Schwermetallmobilitäten unterstellt werden, die ausschließlich von der Schwermetallkonzentration im Boden und nicht von der Herkunft der Schwermetalle (geogen bzw. anthropogen) abhängen.

„Dennoch kann man aus solchen Abschätzungen schließen, daß der Eintragsüberschuß, bedingt durch die Ausbringung von [...] Kompost [...], in den nächsten Jahrzehnten noch nicht zu bedenklichen Bodenkonzentrationen führen wird“(Wintzer et. al. 1996: 291).

Nach Poletschny ist bei den in Komposten auffindbaren mittleren Schwermetallgehalten bei pflanzenbedarfsgerechter, nährstoffbezogener Kompostanwendung zwar mit einer Zunahme der Schwermetallgehalte im Boden zu rechnen, ,jedoch in einem Maße, daß selbst längerfristig in einem Zeitraum von 15 bis 20 Jahren regelmäßiger Kompostausbringung analytisch nicht meßbar ist“ (Poletschny 1995: 81).

Der Schwermetalleintrag durch landwirtschaftliche Kompostverwertung ist aufgrund der Sorptionsund Pufferkapazität des Bodens für die Bodenarten Lehm und Ton und der relativ niedrigen Transferraten in die generativen Pflanzenteile unter normalen Bodenverhältnissen nur mit einem geringfügigen Anstieg der Schwermetallbelastung in der Nahrungskette und im Grundwasser verbunden.

Das langfristige Verlagerungsrisiko für Kompostschwermetalle ist aufgrund mangelhafter Kenntnisse über die Mobilität anthropogen eingetragener Schwermetalle nicht abschätzbar (Wintzer et. al. 1996: 296).

\subsubsection{Organische Schadstoffe}


Für organische Schadstoffe enthält die Bioabfallverordnung (1998) keine Grenzwerte. Zudem werden die organischen Schadstoffe in der Verordnung nicht explizit erwähnt. Es ist lediglich festgelegt, daß neben den obligatorischen Untersuchungen auf Schwermetalle auch solche auf weitere Schadstoffe durchzuführen sind, wenn aufgrund der Art, Beschaffenheit oder Herkunft der Abfälle „Anhaltspunkte für erhöhte Gehalte an diesen Schadstoffen bestehen“ (§ 4 (8) BioAbfV).

Zudem existieren bundesweit keine standardisierten Analysevorschriften zur quantitativen Bestimmung der verschiedenen organischen Schadstoffe, „was eine einheitliche Festlegung von Richt- und Grenzwerten erschwert“ (Hackenberg et.al. 1998: 590).

Im baden-württembergischen Kompostierungserlaß wurden in Anlehnung an die novellierte Klärschlammverordnung erstmals Orientierungswerte für persistente ${ }^{17}$ organische Schadstoffe und Kompostaufbringungsmengen festgelegt (Wintzer et. al. 1996: 265).

$\mathrm{Zu}$ den aufgrund ihrer humantoxikologischen Wirksamkeit relevanten organischen Schadstoffen bei der Kompostierung gehören die polychlorierten Dibenzodioxine (PCDD), Dibenzofurane (PCDF), die polychlorierten Biphenyle (PCB) und die polyzyklischen aromatischen Kohlenwasserstoffe (PAK). Durch den Kompostierungsvorgang kommt es zu einer Anreicherung der überwiegend aus schadstoffbehafteten Staubdepositionen stammenden Schadstoffe in den Komposten (Wintzer et. al. 1996: 266).

Während erhöhte Schwermetallgehalte im Bioabfall primär auf den Eintrag metallhaltiger Partikel zurückzuführen sind, die isoliert werden können, haben sich organische Schadstoffe aufgrund adsorptiver Prozesse häufig gleichmäßig über alle Bestandteile verteilt (Scheffold 1995: 9). Hierbei ist davon auszugehen, daß die Kontamination der Komposte mit organischen Schadstoffen einer ubiquitären Grundbelastung entspricht (Hackenberg et.al. 1998: 590).

Hund et.al. (1999) stellten im Rahmen des Forschungsprojekts „Entwicklung einer Untersuchungsund Bewertungsstrategie zur Ableitung von Qualitätskriterien für Komposte“ fest, daß

\footnotetext{
${ }^{17}$ Das Merkmal „Persistenz“ deutet ein hohes Schadenspotential an, weil der Stoff in der Ökosphäre nicht umgehend abgebaut wird und damit seine Wirkungen dauerhaft entfalten kann. „Die Beschreibungen stofflicher Einwirkungen auf den Boden anhand von Schadstoffmerkmalen dokumentieren die Unwissenheit über die ökologischen Wirkungszusammenhänge“ (Fromm 1997: 132).
} 
- für den Bereich der Kompostverwertung keine Freisetzung organischer Schadstoffe in nennenswertem Ausmaß stattfand,

- keine signifikante Schadstoffaufnahme in untersuchte Pflanzen und

- keine negative Beeinträchtigung der untersuchten Bodenorganismen zu beobachten war.

Aus diesen Teilergebnissen wird der Schluß gezogen, daß, sofern keine Hinweise auf spezifische Kontaminationen der Ausgangsmaterialien bestehen, organische Schadstoffe in Komposten kein Umweltproblem darstellen (Hund et.al. 1999).

\subsubsection{Polychlorierte Dibenzodioxine (PCDD) und Dibenzofurane (PCDF)}

Die unter dem Sammelbegriff „Dioxine“ zusammengefaßten polychlorierten Dibenzodioxine und Dibenzofurane haben unter den organischen Schadstoffen wegen ihrer hohen Toxizität und langen Lebensdauer das größte Umweltgefährdungspotential für den Menschen (Wintzer et. al. 1996: 266).

PCDD/PCDF entstehen unerwünscht bei der Herstellung chlorierter Chemikalien und bei Verbrennungsprozessen organischer und anorganischer Chlorverbindungen im Temperaturbereich zwischen $300^{\circ} \mathrm{C}$ und $600^{\circ} \mathrm{C}$ (Hackenberg et.al. 1998: 588).

Dioxine gelangen überwiegend über die Atmosphäre in die Nahrungskette. Ein direkter Dioxineintrag in die Nahrungskette über die Aufnahme schadstoffbelasteter Partikel durch Weidetiere wird vermieden, indem Kompost nicht auf Dauergrünland ausgebracht wird ${ }^{18}$. Weniger Bedeutung hat aufgrund der sehr niedrigen Transferrate der Übergang vom Boden in die Pflanze. Zudem ist eine eindeutige Korrelation zwischen dem Dioxingehalt des Bodens und der Pflanze nicht abzuleiten (Wintzer et. al. 1996: 266).

Allerdings kann aufgrund der hohen Persistenz dieser Verbindungen eine Anreicherung im Boden stattfinden, da die weniger komplexen organischen Verbindungen rascher abgebaut werden. Hingegen ist die Abbaubarkeit von Dioxinen im Boden umstritten, da sie bislang weder eindeutig nachgewiesen noch widerlegt werden konnte (Wintzer et. al. 1996: 267).

\footnotetext{
${ }^{18}$ Komposte aus Bioabfällen aus Haushalten dürfen nicht auf Dauergrünland aufgebracht werden ( 77 BioAbfV).
} 
Es ergeben sich z.B. für polychlorierte Dibenzodioxine (Summe PCDD) und Dibenzofurane (PCDF), umgerechnet auf Toxizitätsäquivalente ${ }^{19}$, Belastungen von Pflanzenabfall-Komposten von durchschnittlich $11 \mathrm{ng}$ I-TEq/kg TM und für Bioabfall-Komposte von 16 ng I-TEq/kg TM. Die Hintergrundbelastung landwirtschaftlich genutzter Böden liegt im Bereich von 1 ng I-TEq/kg Boden. Im Waldboden werden in der $2 \mathrm{~cm}$ dicken Oberschicht $35 \mathrm{ng}$ I-TEq/kg und am Straßenrand $21 \mathrm{ng}$ I-TEq/kg gefunden (Scheffold 1995: 9).

Die Grundbelastung mitteleuropäischer Böden beträgt etwa 3 bis 8 ng/kg (Hackenberg et.al. 1998: $588)$.

Die bei der Kompostierung stattfindende Neubildung von etwa 1 ng I-TEq/kg Kompost spielt hinsichtlich der o.g. Dioxinbelastung von Komposten keine entscheidende Rolle (Wintzer et. al. 1996: 270).

Im baden-württembergischen Kompostierungserlaß wird als Orientierungswert für den Dioxingehalt im Kompost (bezogen auf $30 \%$ OS in der Trockenmasse) 17 ng I-TEq/kg TM (PCDD und PCDF) angegeben. Dieser Wert wird derzeit von Bioabfallkomposten bis $\mathrm{zu} 88 \%$ und von Pflanzenabfallkomposten bis zu 59\% ausgeschöpft. Werden pro Jahr und Hektar $10 \mathrm{Mg}$ (TM) Kompost ausgebracht, so wird der Boden mit einer Dioxinfracht von maximal 170 I-TEq je Hektar belastet. Bei einer Bearbeitungstiefe des Bodens von $30 \mathrm{~cm}$ entspricht dieser Wert einer jährlichen Erhöhung der Dioxinkonzentration um 0,04 ng I-TEq/kg Boden. Die Bund-Länder-Arbeitsgruppe Dioxine empfiehlt „Einschränkungen für bestimmte landwirtschaftliche Nutzung“ erst bei Bodenbelastungen von über $40 \mathrm{ng}$ I-TEq/kg Boden. Ein Vergleich mit der o.g. Hintergrundbelastung landwirtschaftlich genutzter Böden zeigt, „daß die Gefahr einer Nutzungseinschränkung über die Ausbringung dioxinhaltiger Komposte gering ist, solange die Zufuhr nicht über eine Zeitspanne von rund 100 Jahren hinaus erfolgt“(Wintzer et. al. 1996: 267).

Dennoch kommt es auch bei zukünftig stark abnehmenden Dioxingehalten in Komposten aufgrund der Langlebigkeit der Substanzen zu einer weiter voranschreitenden, schwer rückgängig zu machenden Erhöhung der Schadstoffkonzentration im Boden (Wintzer et. al. 1996: 268).

${ }^{19}$ Toxizitätsäquivalente wurden ,,als grobe Hilfsmittel für administrative Zwecke zur Abschätzung des Gesamtrisikos von Gemischen von PCDD/PCDF eingeführt“ (Wallnöfer/Engelhardt 1995: 120). 
„Über die exakte Wirkung dieser Verbindungsgruppe auf den Ertrag und den pflanzlichen Stoffwechsel ist [...] nichts bekannt“"(Wallnöfer/Engelhardt 1995: 139).

Eine Grundwassergefährdung durch Dioxine im Boden ist kaum zu befürchten, „da eine Dioxinverlagerung mit dem Sickerwasser in tiefere Bodenschichten wegen der hohen Affinität der Dioxine zu Bodenkolloiden und organischer Substanz und der sehr geringen Wasserlöslichkeit nur in geringem Maße stattfindet“" (Wintzer et. al. 1996: 268).

\subsubsection{Polychlorierte Biphenyle (PCB)}

Polychlorierte Biphenyle umfassen chlorierte aromatische Kohlenwasserstoffe, die thermisch und chemisch sehr stabil sind. Diese synthetischen Stoffe kommen in der Natur nicht vor. Sie werden jedoch industriell in größeren Mengen hergestellt und sind heute weltweit in Spuren vorhanden, ,so daß eine Kontamination des Bodens vor allem in Ballungsgebieten fast immer gegeben ist“ (Wallnöfer/Engelhardt 1995: 138). Mittel- bis langfristig ist aufgrund der Einstellung der PCBProduktion in der Bundesrepublik Deutschland mit einer abnehmenden Belastung der Komposte zu rechnen (Wintzer et. al. 1996: 270).

Die PCB-Gehalte von Bio- und Pflanzenabfallkomposten liegen zwischen 0,01 bis etwa 0,5 mg/kg (TS), während die Hintergrundbelastung landwirtschaftlich genutzter Böden durch PCB im Mittel weniger als 0,1 mg/kg Boden beträgt (Wintzer et. al. 1996: 270-271). Die Böden wenig belasteter Gebiete weisen Gehalte zwischen 0,02 und 0,1 mg/kg (TS) auf (Hackenberg et.al. 1998: 588).

Die Gefahr einer nachhaltigen PCB-Anreicherung im Boden ist gering, weil die meisten PCBVerbindungen durch UV-Strahlen oder mikrobielle Prozesse abgebaut werden. Auch ist eine Akkumulation von PCB in den Pflanzen durch landwirtschaftliche Kompostverwertung unwahrscheinlich, da die Gehalte in den Pflanzen wegen der starken Sorption im Boden nur sehr schwach mit den Bodengehalten korrelieren (Wintzer et. al. 1996: 270-271). 
Die genannten PCB-Gehalte in Pflanzenabfall- und Bioabfall-Komposten werden im Gegensatz zu denjenigen der Hausmüllkomposte, für die ein Gehalt von $1,7 \mathrm{mg} / \mathrm{kg}$ ermittelt wurde, als tolerabel gewertet (Scheffold 1995: 10).

Die Angaben zur PCB-Belastung organischer Abfälle bezieht sich nicht auf alle PCB-Verbindungen, sondern nur auf sechs Verbindungen, die mit einem vertretbaren Aufwand analysierbar sind. Für diese sog. Einzelkongeneren weist der baden-württembergische Kompostierungserlaß (1994) als Orientierungswert jeweils einen Gehalt im Kompost (bezogen auf 30 \% OS in der Trockenmasse) von $0,033 \mathrm{mg} / \mathrm{kg}(\mathrm{TM})$ aus, der aufgrund der unvermeidbaren Streuung der Analyseergebnisse in Ausnahmefällen um bis zu $30 \%$ überschritten werden darf (Umweltministerium BadenWürttemberg).

Über den Einfluß von PCBs auf den Stoffwechsel von Pflanzen ist wenig bekannt. Einzelne Experimente mit bestimmten PCB-Formulierungen belegen einen Wachstumsrückgang und eine verminderte Wasseraufnahme bei den Kontrollpflanzen. Aufnahme der PCBs und Akkumulierungsverhalten dieser Stoffe in der Pflanze variieren in Abhängigkeit von der angebauten Kultur. „Besonders bei Wurzelgemüsen wie Möhren und Radieschen sowie in Zuckerrüben und Sojabohnen ist eine aktive Aufnahme von PCB belegt. Wegen der Gefahr der Anhäufung in Endgliedern von Nahrungsketten sollten heute PCBs in Ernteprodukten einen Grenzwert von 0,05 mg/kg nicht überschreiten“ (Wallnöfer/Engelhardt 1995: 138).

Für den Bereich der landwirtschaftlichen Klärschlammverwertung wurde festgestellt, daß PCBbelastete Klärschlämme ,auf den Böden zu keiner meßbaren Anreicherung von PCB im Boden führten; auch die Feldversuche ließen keinen Zusammenhang zwischen [...] Klärschlammenge und Pflanzengehalt an PCB erkennen“"(Versteyl 1992: 84).

\subsubsection{Polyzyklische aromatische Kohlenwasserstoffe (PAK)}

Die polyzyklischen aromatischen Kohlenwasserstoffe entstehen bei unvollständigen Verbrennungsprozessen, bei denen organisches Material beteiligt ist. Die Bodengehalte liegen etwa bei $0,8 \mathrm{mg} / \mathrm{kg}$ im Humus und bis zu 3,0 mg/kg Boden in den Randstreifen an Autobahnen. Die 
Bindung der PAK in Böden erfolgt überwiegend durch Huminstoffe, wobei aufgrund der geringen Löslichkeit keine Verlagerung in tiefere Bodenschichten stattfindet (Hackenberg et.al. 1998: 588).

Aufgrund der mikrobiellen Abbaubarkeit wird ein Teil der PAK bereits in der Kompostierungsanlage abgebaut. „Die PAK-Belastung von Komposten [...] spielt sowohl im Hinblick auf eine Anreicherung im Boden als auch in der Nahrungskette eine untergeordnete Rolle, da sie schneller abgebaut werden als Dioxine und PCB“(Wintzer et. al. 1996: 271).

\subsubsection{Adsorbierbare, organisch gebundene Halogene (AOX)}

Bei den adsorbierbaren, organisch gebundenen Halogenen handelt es sich nicht um einen definierten Einzelstoff, sondern um einen Summenparameter, was methodische Schwierigkeiten mit sich bringt (Popp/Fischer 1995: 38).

Der Summenparameter AOX hat Aufnahme in die Klärschlammverordnung gefunden und könnte analog auch auf Komposte angewendet werden.

Die Höchstkonzentration für halogenorganische Verbindungen bei einer Kompost-Aufwandmenge von $10 \mathrm{Mg}$ (TM)/ha ergibt sich bei Einhaltung der maximalen Schadstofffrachten der Klärschlammverordnung zu 80 mg/kg (TS) Kompost. „Die Eignung des Summenparameters AOX für die Bewertung von Komposten ist stark umstritten, da teilweise unplausible Meßergebnisse erzielt werden“(Klages-Haberkern 1993: 74).

Im baden-württembergischen Kompostierungserlaß heißt es dazu: „Abweichend von der Klärschlammverordnung wird für den Summenwert der organischen Chlorverbindung (AOX) wegen analytischer Probleme und mangels Erkenntnisgewinn ein Orientierungswert nicht festgesetzt“ (Umweltministerium Baden-Württemberg).

\subsubsection{Salzgehalt}

Der Salzgehalt wird mittels Leitfähigkeitsmessung bestimmt und in g/l (FM) KCl angegeben (KlagesHaberkern 1993: 75). 
Der Salzgehalt von Komposten hängt von Zusammensetzung und Alter des Inputmaterials, dem Abbaugrad der organischen Substanz und dem Behandlungsverfahren ab. Sehr hohe Gehalte an wasserlöslichen Salzen werden über die Fraktion der Küchenabfälle und über junge Grasschnitte sowie andere proteinreiche und leicht abbaubare Grünabfälle in den Kompost eingetragen. Mit zunehmender Rottedauer und steigendem Proteinabbau erhöht sich die vom Salzgehalt bestimmte Leitfähigkeit (vgl. Wintzer et.al.1996: 129).

Salzreiche Komposte, d.h. die meisten Bioabfallkomposte, sind als Substratbestandteil (z.B. als Torfersatz in Blumenerden) nur in geringen Mengen einsetzbar, da sonst Salzschäden an Pflanzen auftreten können (Popp/Fischer 1995: 40). Diese sind auf spezifische Wirkungen der Salze, wie z.B. deren Toxizität, zurückzuführen (Oehmichen 1983: 339). Hohe Salzgehalte können bei salzempfindlichen Pflanzen die Nährstoffaufnahme behindern und Wachstums- und Ertragsdepressionen hervorrufen. „Die Salzgehalte von Bioabfallkomposten liegen mit einem Häufigkeitsschwerpunkt von 1,90 bis 5,60 g KCL/kg Frischsubstanz für eine Beimischung zu Pflanzensubstraten zu hoch, da größere Kompostanteile mit Salzgehalten von $2 \mathrm{~g} \mathrm{KCl} / \mathrm{kg}$ bei sensiblen Pflanzen zu Schäden führen“(Wintzer et.al.1996: 129).

Tab. 6.16: Salzgehalte in den Bioabfallkomposten aus den Anlagen in Tarnow und Borrentin

\begin{tabular}{|c|c|c|}
\hline $\begin{array}{l}\text { Datum der } \\
\text { Probenahme }\end{array}$ & Anlage & $\begin{array}{c}\text { Salzgehalt } \\
{[\mathrm{g} \text { KCL/l FM] }}\end{array}$ \\
\hline 4.09 .1996 & Tarnow & 8,74 \\
\hline 1.10 .1996 & Borrentin & 9,65 \\
\hline 13.02 .1997 & Tarnow & 7,83 \\
\hline 13.02 .1997 & Tarnow & 3,68 \\
\hline 17.03 .1997 & Borrentin & 2,85 \\
\hline 22.05 .1997 & Tarnow & 7,7 \\
\hline 22.05 .1997 & Borrentin & 2,71 \\
\hline 1.10 .1997 & Tarnow & 7,62 \\
\hline 28.10 .1997 & Tarnow & 7,95 \\
\hline 28.10 .1997 & Tarnow & 4,15 \\
\hline 26.02 .1998 & Borrentin & 7,89 \\
\hline 15.06 .1998 & Borrentin & 4,80 \\
\hline
\end{tabular}

Die Salzgehalte in den im Rahmen des Modellversuchs (Landkreis Demmin) erzeugten Bioabfallkomposten überschreiten den Wert von $2 \mathrm{~g} \mathrm{KCl} / \mathrm{kg}$ deutlich (Tab. 6.16). Zudem zeigt ein 
Vergleich der analysierten Einzelwerte für den Salzgehalt der Bioabfallkomposte eine jahreszeitlich unabhängige starke Streuung der Einzelwerte.

Das LAGA-Merkblatt M10 (1995) sieht keine Beurteilung der Salzgehalte vor. Es wird lediglich empfohlen, Komposte mit einem Salzgehalt von >5 g/l FM nicht als Mischkomponente von Blumenerden zu verwenden, da hier i.d.R. Kompostanteile im Substrat von >50 \% erreicht werden.

Für den Bereich der landwirtschaftlichen Kompostverwertung wurden sowohl die in Tarnow als auch die in Borrentin erzeugten Komposte als pflanzenverträglich eingestuft (LUFA Rostock 1996 b: 23). Eine hohe Pflanzenverträglichkeit ist insbesondere dann zu fordern, wenn Kompost in sehr großen Mengen (z.b. zu Rekultivierungszwecken) oder unmittelbar vor der Aussaat empfindlicher Kulturen ${ }^{20}$ ausgebracht wird.

Bei der landwirtschaftlichen Kompostverwertung werden wesentlich geringere Kompostanteile erreicht als im Bereich der Rekultivierung. Dennoch wurde empfohlen, zwischen Kompostausbringung und Aussaat einer salzempfindlichen Kultur einen zeitlichen Abstand zu lassen, da für die untersuchten Komposte mit steigenden Kompostanteilen in den Pflanzenverträglichkeitstests ein Rückgang der Pflanzenverträglichkeit zu verzeichnen war (LUFA 1996 b: 23).

Bei den derzeitigen Frachtenbegrenzungen für Nähr- und Schadstoffe stellt der Salzgehalt für die landwirtschaftliche Kompostverwertung hinsichtlich des Risikos von Ertragsdepressionen keinen limitierenden Faktor dar (vgl. Klages-Haberkern 1993:75 und Wintzer et.al.1996: 130).

\subsubsection{Aspekte der Phytohygiene bei landbaulicher Verwertung von Bioabfallkomposten}

${ }^{20} \mathrm{Zu}$ den salzempfindlichen Kulturen zählen Erbsen, Bohnen und Rotklee. Relativ salztolerant sind dagegen Zuckerrüben und Gerste (Oehmichen 1983: 339). 
Die phytohygienische Unbedenklichkeit bei der landbaulichen Kompostverwertung ist gegeben, wenn keine Schäden an Pflanzen, Pflanzenerzeugnissen oder Böden durch die Verbreitung von Schadorganismen zu befürchten sind (§ 3 (2) BioAbfV $)^{21}$.

Bioabfälle aus Haushalten und Grüngut können Viren enthalten, die u.U. für einige Zeit in Kompostteilchen im Boden überdauern und wieder in lebende Pflanzenteile hineingelangen können, phytopathogene Bakterien, die keine Überdauerungsorgane in Form von Sporen bilden und deshalb nur eine begrenzte Zeit auf oder in pflanzlichem Gewebe überdauern können, darüberhinaus Pilze und Schädlinge an infizierten Pflanzenresten, wie z.B. Nematoden, sowie Unkrautsamen, die keine Pathogene im eigentlichen Sinn darstellen. Pilze gehören zu den Erregern wirtschaftlich bedeutender Pflanzenkrankheiten, die durch Bildung von widerstandfähigen Dauerformen über mehrere Jahre im Boden überleben können (Strauch et.al. 1993: 114).

Es ist durchaus möglich, die evtl. im Kompostausgangsmaterial enthaltenen Schaderreger und Unkrautsamen abzutöten, wenn während des Kompostierungsvorgangs im Mieteninneren Temperaturen von $55^{\circ} \mathrm{C}$ bis $60^{\circ} \mathrm{C}$ über einen Zeitraum von vier bis sechs Wochen bestehen. Darüberhinaus müssen die Kompostmieten umgesetzt werden, damit zur Gewährleistung der notwendigen Hygienisierung auch das Material aus den Randbereichen der Mieten ins Mieteninnere mit einem deutlich höheren Temperaturniveau gelangt (Strauch et.al. 1993: 115).

In den im Rahmen dieser Arbeit untersuchten Kompostierungsanlagen kann es nach der Hygienisierung zu einer Verschleppung von Keimen und zu einer Neuinfektion des Komposts kommen, da die Behandlungsbereiche nicht vollständig voneinander getrennt sind, und einzelne Maschinen und Geräte, wie z.B. der Mietenumsetzer, sowohl im Bereich der frisch aufgesetzten Mieten als auch zur Bearbeitung des hygienisierten Kompostmaterials eingesetzt werden. Auch die Befeuchtung der Kompostmieten mit Anlagenabwasser nach Beendigung der Heißrottephase könnte eine Neuinfektion auslösen (vg. Wintzer et.al.1996: 301). Deshalb sollte das Anlagenabwasser nur dann zur Mietenbefeuchtung eingesetzt werden, wenn nach der Zugabe „noch eine ausreichende

\footnotetext{
${ }^{21}$ Die Bioabfallverordnung fordert darüberhinaus die seuchenhygienische Unbedenklichkeit der landbaulich zu verwertenden Komposte. Diese beinhaltet, daß hierdurch nicht die Gesundheit von Mensch und Tier aufgrund der Freisetzung oder Übertragung von Krankheitserregern beeinträchtigt werden darf ( 33 BioAbfV).
} 
Hygienisierungstemperatur und -dauer zur Elimination pathogener Keime gewährleistet wird“" (Döhler et.al. 1999: 179).

Der Landwirt als Betreiber einer Kompostierungsanlage hat die Bioabfallbehandlung so durchzuführen, daß die phytohygienische Unbedenklichkeit der Bioabfälle nach der Behandlung und bei der Aufbringung auf betriebseigene Böden sichergestellt ist ( 3 (3) BioAbfV). Deshalb werden Anforderungen an den Behandlungsprozeß gestellt, die im Rahmen obligatorischer Untersuchungsmaßnahmen auf den Kompostierungsanlagen überprüft werden. Diese umfassen u.a. die Überprüfung der Einhaltung der erforderlichen Behandlungstemperatur sowie die regelmäßige Endprüfung des Komposts auf hygienische Unbedenklichkeit ( $\$ 3$ BioAbfV i.V.m. Anhang 2 Nr. 2.3).

\subsection{6 Überprüfung der Versicherbarkeit des Risikos von Umweltschäden aus landbaulicher Kompostverwertung}

\subsubsection{Vorgehensweise}

Nach $\S 823$ (1) BGB haftet der Verursacher für schuldhaft rechtswidrige Eigentumsverletzungen. Ein Eigentumsschaden liegt z.B. dann vor, wenn landwirtschaftliche Grundstïcke durch Komposte so verändert werden, daß Feldfrüchte nicht mehr geerntet werden können oder sogar der Boden ausgekoffert werden muß. Für diese Substanzbeeinträchtigung haftet der Hersteller der Bioabfallkomposte als Verursacher, wenn ihm zumindest ein Fahrlässigkeitsverstoß, z.B. Nichtbeachtung von Betriebs- und Untersuchungspflichten, nachzuweisen ist (Salje 1997: 203).

Es existiert weder ein freiwilliger noch ein gesetzlicher Entschädigungsfonds zur Abwälzung der Risiken landwirtschaftlicher Kompostverwertung (s. Abschnitt 6.3.1), so daß ein Landwirt, der Komposte auf seiner landwirtschaftlichen Nutzfläche verwertet, die hiermit in Zusammenhang stehenden Risiken selbst zu tragen bzw. den Versuch zu unternehmen hat, diese auf eigene Kosten zu 
versichern. Daher wurde im Rahmen dieser Arbeit zunächst die Versicherbarkeit der genannten Risiken überprüft, weil die Versicherungsprämien zur Abdeckung definierter Einzelrisiken der Kompostverwertung herangezogen werden könnten, um diese monetär zu bewerten.

Um herauszufinden, ob die ökonomischen Risiken des Landwirts, der Bioabfallkomposte auf seiner landwirtschaftlichen Nutzfläche verwertet, versicherbar sind, wurden im April und Mai 1998 mehrere Versicherungen und Versicherungsmakler angeschrieben. Gemeinsames Kennzeichen der ausgewählten Unternehmen der Versicherungsbranche war, daß sich diese selbst bzw. entsprechende Tochterunternehmen in den Bereichen der landwirtschaftlichen Betriebshaftpflichtversicherungen sowie der Umwelthaftpflichtversicherungen engagieren.

Im einzelnen wurden folgende Versicherungsgesellschaften und - makler ${ }^{22}$ angeschrieben:

- Barmenia Allgemeine Versicherungs-AG

- LVM-Versicherungen

- $\mathrm{R}+\mathrm{V}$ Allgemeine Versicherung-AG

- Vereinte Versicherung-AG

- Gothaer Versicherungen

- Concordia

- Transatlantische Allgemeine Versicherung-AG

- Albingia Versicherungs-AG

- Gerling-Konzern / Allgemeine Versicherungs-AG

- Itzehoer Versicherung

- GHG Agrarservice GmbH

- AV-Agrarversicherungsdienst

- Gayen \& Berns Homann.

In den Anschreiben wurden folgende Risiken möglicher Umweltbeeinträchtigungen durch die landwirtschaftliche Kompostverwertung benannt:

\footnotetext{
${ }^{22}$ Die Adressen der Unternehmen sind in Anhang III aufgelistet.
} 
- Risiken durch eine erhöhte Schadstoffbelastung des Bodens und der daraus resultierenden Wertminderung bzw. dem resultierenden Wertverlust landwirtschaftlicher Nutzfläche,

- Risiken durch erhöhte Schadstoffbelastung landwirtschaftlicher Nutzpflanzen,

- Risiken durch Vermarktungsprobleme für Nutzpflanzen, die auf diesen Flächen produziert wurden.

Es wurde der Wunsch geäußert, Aussagen über deren Versicherbarkeit sowie gegebenenfalls die Höhe der Versicherungsprämien zu erhalten.

\subsubsection{Ergebnisse der Überprüfung}

Umweltschäden durch die Anwendung von Gülle und anderen gewässerschädlichen Stoffen, zu denen auch Bioabfallkomposte zählen, sind generell nicht versicherbar. „Bei Düngemitteln wird nach den neuen Bedingungen [...] nur noch das Lager- und nicht mehr das Verwendungsrisiko mitversichert. Beides war früher - in der Regel ohne Mengenbegrenzung - über die normale Betriebshaftpflicht-Police abgedeckt““ (Reimann/Strehler/Fry 1996: 59-63).

Dieses Ergebnis ergibt sich auch aus der Umfrage unter den Betriebshaftpflichtversicherern. Im folgenden werden - stellvertretend für alle Antwortschreiben - einige Antworten zitiert:

- „Das Ausbringungsrisiko / die Verwendung ist nur mitversichert, soweit Stoffe durch plötzliche und unfallartige Ereignisse bestimmungswidrig aus der Anlage entweichen. Für das bewußte Einbringen auf / in Boden, Luft oder Wasser besteht kein Versicherungsschutz; also auch nicht für daraus resultierende Folgeschäden (Vermarktungsprobleme durch erhöhte Schadstoffbelastung des Bodens)“ (Kockemüller-Kublun 1998).

- „Für das Ausbringen auf eigener landwirtschaftlicher Fläche bzw. damit u.U. verbundener Kontamination vom Boden, einschließlich daraus resultierender Umweltschäden, wird im Rahmen marktüblicher Umwelt-Haftpflicht-Versicherungen keine Deckung bereitgestellt. Neben diversen einschlägigen Ausschlußtatbeständen (z.B. Eigenschäden, Normalbetrieb [...]) ist Versicherungsschutz auch für sog. 'bestimmungsgemäße Verwendung' nicht erhältlich. 
Vergleichbar dürfte diese Problematik u.E. im Ergebnis mit dem Ausbringen von Gülle sein“ (Schenkendorf 1998 a).

- „Risiken im Zusammenhang mit der Kompostanwendung auf landwirtschaftlicher Nutzfläche sind nicht versicherbar, da es sich um bewußte und gezielte Kontaminationen des Bodens handelt" (Schenkendorf 1998 b).

- „Eine Versicherungsmöglichkeit im Rahmen einer Haftpflichtversicherung besteht nicht, da es keinen geschädigten Dritten gibt. Vielmehr handelt es sich um einen Eigenschaden des aufbringenden Landwirtes ${ }^{23}$, der weder im Rahmen einer Haftpflichtversicherung noch im Rahmen einer Sachversicherung versichert werden kann“ (Termer 1998).

Die Umfrage unter den Versicherungen und Versicherungsmaklern hat gezeigt, daß Versicherungsprämien zur Abdeckung definierter Einzelrisiken landbaulicher Kompostverwertung als Grundlage einer ökonomischen Bewertung nicht in Betracht kommen. Daher hat der Landwirt, der die Verwertung von Komposten auf landwirtschaftlicher Nutzfläche beabsichtigt, das Risiko selbst abzuschätzen und in seiner Preiskalkulation Wagniszuschläge gewissermaßen als Risikoprämie zu berïcksichtigen.

\subsubsection{Unfallversichenng}

Arbeitsunfälle des landwirtschaftlichen Unternehmers und der im Unternehmen Beschäftigten sind über die gesetzliche Unfallversicherung der landwirtschaftlichen Berufsgenossenschaft versichert (s. Abschnitt 6.2.2.2). Insofern entstehen dem Unternehmer keine zusätzlichen Kosten zur Abdeckung von Gesundheitsrisiken, die im Zusammenhang mit der Kompostverwertung stehen.

\footnotetext{
${ }^{23}$ Um einen Eigenschaden des aufbringenden Landwirts handelt es sich tatsächlich nur dann, wenn dieser Eigentümer der Kompostausbringungsfläche ist. Ist er lediglich Besitzer der Fläche aufgrund eines Pachtvertrages, so wäre der Verpächter als Eigentümer der Fläche geschädigter Dritter.
} 


\subsection{8 Ökonomische Bewertung des Bodens zur Quantifizienung der nicht versicherbaren Vemögensschäden durch Kompostverwertung}

\subsubsection{1 Ökonomische Berwertungsansätze für den Boden}

Die Bedeutung des Bodens kann anhand seiner unterschiedlichen Funktionen dargestellt werden. In der Literatur findet sich die Einteilung in vier Hauptfunktionen des Bodens (Fromm 1997: 64-68):

- Die Regelungsfunktion bezeichnet die Fähigkeit des Bodens zur Regulierung der ökosystemaren Stoff- und Energieflüsse. So ist der Boden z.B. in der Lage, durch Ab- und Umbau organischer Schadstoffe oder durch Herabsetzung der Bioverfügbarkeit von Schwermetallen anthropogen verursachte Schadstoffbelastungen $\mathrm{zu}$ bewältigen. Der Boden erfüllt damit auch eine Pufferfunktion zum Schutz des Grundwassers vor Schadstoffeinträgen (Reinhold 1995: 1).

- Die Lebensraumfunktion des Bodens umfaßt dessen Fähigkeit, Lebensraum für Biozönosen bereitzustellen.

- Die Möglichkeit, den Boden als Bebauungsfläche oder für den Abbau von Bodenschätzen zu nutzen, wird als Trägerfunktion bezeichnet.

- In der ökonomischen Bewertung des Bodens beinhaltet die Produktionsfunktion dessen Fähigkeit, als Standort für Nutzpflanzen zu dienen. „In Abgrenzung zur Lebensraumfunktion ist die Produktionsfunktion dadurch gekennzeichnet, daß zum einen Pflanzen gezielt aus einem privatwirtschaftlichen, individuellen Nutzenkalkül heraus produziert und zum anderen zur Förderung der Produktionsfunktion gezielte anthropogene Eingriffe in die Bodenstruktur vorgenommen werden. Der Mensch nimmt in diesem Fall also aktiv Einfluß auf die Biomasseproduktion“(Fromm 1997: 67).

Aus den Bodenfunktionen ergeben sich die potentiell einer anthropogenen Nutzung zur Verfügung stehenden Leistungen des Bodens. Bei einer betriebswirtschaftlichen Betrachtungsweise, bei der wie in dieser Arbeit - z.B. einzelbetriebliche Vermögensschäden und Einkommenseinbußen durch die landwirtschaftliche Kompostverwertung untersucht werden, ist bei einer ökonomischen Bewertung von Bodenleistungen jedoch nur auf diejenigen abzustellen, die als für den Landwirt ökonomisch wertvolle Leistungen erkennbar sind; denn das „Ökosystem Boden ist nur insoweit von 
ökonomischer Relevanz [...] wie den Bodenfunktionen von den Individuen ein Wert beigemessen wird“" (Fromm 1997: 72).

Die durch Regelungs- und Lebensraumfunktion bereitgestellten Leistungen ergeben sich weitgehend unabhängig von menschlichen Aktivitäten aus der Bodenstruktur. „Sie sind nicht Reflex der Nachfrage der Wirtschaftssubjekte nach diesen Leistungen, und ihre Wertschätzung manifestiert sich nicht auf Märkten“(Fromm 1997: 73).

Die ökonomische Bewertung der Träger- und der Produktionsfunktion stützt sich in Form von marktlichen Bewertungen auf die private und gewerbliche Nachfrage nach entsprechenden Flächen. Die Individuen, die über ein Nutzungsrecht für die Produktions- und Trägerfunktion verfügen, berücksichtigen die nicht marktlich bewerteten ökologischen Bodenfunktionen nur insoweit in ihren Wirtschaftlichkeitsberechnungen, wie Belastungen auf ihre eigenen Nutzungsmöglichkeiten rückwirken. Da durch Parzellierung eindeutige Handlungsrechte geschaffen wurden, wurde bisher davon ausgegangen, daß die Erhaltung des Bodens im eigenen Interesse der privaten Nutzer liege. „Übersehen wurde dabei aber, daß insbesondere Überlastungen der Regelungsfunktion oftmals erst langfristig schädigend wirken und damit im individuellen Nutzungskalkül möglicherweise nicht ausreichend Berücksichtigung finden, selbst wenn, wie im Falle der land- und forstwirtschaftlichen Nutzung, die Überlastungen auf die Leistungsfähigkeit der Produktionsfunktion rückwirken können“ (Fromm 1997: 91).

Der Landwirt betrachtet den Boden als landwirtschaftlichen Produktionsfaktor und bewertet Bodenqualität im Zusammenhang mit der landwirtschaftlichen Produktivität des Bodens. Der ökonomische Wert des Bodens wird dadurch auf die Nutzenstiftungen der Produktionswerte verkürzt.

Beeinträchtigungen der Regelungsfunktionen des Bodens finden in der ökonomischen Risikobewertung auf einzelbetrieblicher Ebene nur dann Berücksichtigung, wenn diese bereits Eingang in gesetzliche Regelwerke gefunden haben und z.B. in Form von überschrittenen Grenzoder Richtwerten für Bodengehalte zu Nutzungsbeschränkungen des Bodens für den Landwirt führen. 
Diese Nutzungsbeschränkungen können bis zum Verlust des Bodens als Produktionsgrundlage reichen. Die Höhe dieses Vermögensschadens ist zu bewerten in Höhe der Kosten, die entstehen, wenn der Landwirt so gestellt würde, als sei der Schaden nicht eingetreten.

Hierfür sind zwei Bewertungsansätze denkbar:

1. Die beeinträchtigte landwirtschaftliche Nutzfläche könnte in einen solchen Zustand versetzt werden, in dem diese wieder für die uneingeschränkte landwirtschaftliche Produktion zu nutzen ist. Die Kosten hierfür werden im folgenden als Wiederherstellungskosten bezeichnet.

2. Der Landwirt könnte durch den Erwerb einer gleichwertigen Fläche für die landwirtschaftliche Produktion so gestellt werden, als sei kein Vermögensschaden eingetreten (Ersatzbeschaffungskosten).

\subsubsection{Wiederherstellungskosten}

$\mathrm{Zu}$ untersuchen sind die Kosten, die dadurch entstehen, daß eine Fläche durch Kompostbeaufschlagung aufgrund daraus resultierender Umweltbeeinträchtigungen hinsichtlich der landwirtschaftlichen Produktion nur noch eingeschränkt nutzbar ist und anschließend durch geeignete Maßnahmen der ursprüngliche Nutzwert, den diese Fläche für den Landwirt aufwies, wiederhergestellt werden soll.

Im folgenden werden Maßnahmen dann als geeignet angesehen, wenn sich die Verbesserung des Zustands dieser Fläche hinsichtlich der Umweltbelastung innerhalb kurzer Zeit realisieren läßt. Dabei wird auf den Bereich der Schwermetallbelastung eingegangen, da nur für diese bei der landbaulichen Kompostverwertung Grenzwerte für Gehalte in landwirtschaftlich genutzten Böden vorliegen.

Zudem ist die Schwermetallbelastung der Komposte gegenwärtig eines der wichtigsten Kriterien, das sowohl die Anwendungsmöglichkeiten als auch die Einsatzmengen von Komposten determiniert (vgl. Wintzer et. al. 1996: 135).

Insbesondere die persistenten Schadstoffe, zu denen die Schwermetalle zählen, führen zu Irreversibilitäten chemischer Bodenbelastungen. Diese ergeben sich daraus, daß diese Stoffe weder 
biotisch noch abiotisch abgebaut werden. „Der Eintrag dieser Stoffe führt bei sorptionsfähigen Stoffen, d.h. bei Stoffen, die in der Bodenstruktur festgehalten werden, zu einer extrem lang andauernden Festlegung im Boden. Die Veränderung der Bodenstruktur ist aus ökologischer Sicht also in höchstem Maße irreversibel“" (Fromm 1997: 228).

Im Hinblick auf ökonomische Bewertungen sind persistente Bodenbelastungen nicht als irreversibel anzusehen, sofern diese durch technische Maßnahmen rückgängig gemacht werden können.

Das Risiko eines Vermögensschadens für den Landwirt besteht v.a. darin, daß eine einmal erfolgte Bodenbelastung zwar technisch aber ökonomisch sinnvoll kaum mehr rückgängig zu machen ist, da die Kosten einer technischen Bodenreinigung den Verkehrswert der Ackerfläche für die landwirtschaftliche Produktion um ein vielfaches übersteigen würden.

$\mathrm{Zu}$ den technischen Maßnahmen zur Herabsetzung erhöhter Schwermetallgehalte in der Ackerkrume zählt die Schwermetallabreicherung über pflanzliche Biomasse.

Diese natürliche Schwermetallabreicherung („Heavy-Metal-Harvesting“) tritt angesichts der geringen jährlichen Schwermetallentzüge jedoch erst nach einer sehr langen Bewirtschaftungsdauer von mehreren hundert bis tausend Jahren ein (Wintzer et. al. 1996: 293).

Unter diesem Aspekt ist das Heavy-Metal-Harvesting keine geeignete Maßnahme zur Wiederherstellung der belasteten Fläche für die landwirtschaftliche Produktion.

Eine andere technische Maßnahme, die die landwirtschaftliche Nutzung einer derartig belasteten Fläche nach relativ kurzer Zeit wieder zuläßt, ist die Auskofferung der gesamten Ackerkrume mit anschließendem Bodenaustausch. Die Kosten hierfür betragen etwa eine Million DM je Hektar (N.N. 1997 a). Diese Maßnahme ist unter dem o.g. Kriterium einer zügigen Wiedereingliederung dieser Fläche in die landwirtschaftliche Produktion als geeignet anzusehen.

\subsubsection{Ersatzbeschaffungskosten}

In diesem Fall soll der Schaden durch Erwerb einer gleichwertigen Fläche ausgeglichen werden. 
Diese Fläche müßte entweder die gleichen, für die landwirtschaftliche Produktion nutzenstiftenden Eigenschaften oder in der Summe ihrer Eigenschaften den gleichen Nutzwert für den Landwirt aufweisen.

Charakteristische Eigenschaften zur Beschreibung landwirtschaftlicher Nutzfläche sind z.B. Bonität, Nutzungsart, Relief und Form des Grundstücks, durchschnittliche Niederschlagszahl, Jahrestemperatur, Hauptwindrichtung und Lage hinsichtlich der inneren und äußeren Verkehrslage des Betriebes.

Kann ein gleichwertiges Grundstïck zum Ausgleich des entstandenen Schadens erworben werden, so sind die Kosten für diesen Ersatz in Höhe des Verkaufspreises anzusetzen.

Die ökonomische Bewertung des Bodens als Grundlage für die landwirtschaftliche Produktion stützt sich also in Form marktlicher Bewertungen auf die Nachfrage nach entsprechenden Flächen, so daß die Ersatzbeschaffungskosten in Höhe des Verkehrswertes derartiger Grundstuicke anzusetzen sind. Vorauszusetzen ist, daß für die durch Umweltbelastung beeinträchtigte Fläche kein akuter Handlungsbedarf aufgrund von Umweltgefährdungen besteht, da hierdurch zusätzlich Kosten für die Sicherung und Sanierung dieser Fläche zu berücksichtigen wären. Für den Fall, daß diese zu sanieren ist, ist hinsichtlich der Kosten die Wiederherstellung dieser beeinträchtigten Fläche für die landwirtschaftliche Produktion anzusetzen.

Die Verkehrswerte landwirtschaftlicher Nutzfläche differieren bundesweit sehr stark. Für die Ermittlung einer Risikoprämie für die beiden Landwirte im Landkreis Demmin sind die Verkehrswerte für entsprechende Flächen des Bundeslandes Mecklenburg-Vorpommern zugrunde zu legen.

Nach Angaben des Statistischen Landesamtes Mecklenburg-Vorpommern lag der durchschnittliche Kaufwert je Hektar in 1997 bei 5.511 DM. „Der durchschnittliche Kaufwert für Agrarflächen in Mecklenburg-Vorpommern lag 1997 erheblich unter dem Mittel von 31.852 DM je ha im alten Bundesgebiet und 6.474 DM je ha in allen neuen Bundesländern (1996)“ (N.N.1998). 


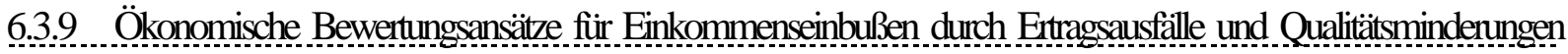 des Emteguts}

Zur Monetarisierung von landwirtschaftlichen Produktionseinbußen könnte auf Marktpreise für die landwirtschaftlichen Erzeugnisse zurückgegriffen werden.

„Aufbauend auf Dosis-Wirkungs-Funktionen kann die ökonomische Bewertung dabei im einfachsten Fall dadurch erfolgen, daß die ermittelten physischen Effekte mit dem herrschenden Marktpreis multipliziert werden“ (Fromm 1997: 181).

Der durch die Umweltbelastung induzierte Schaden errechnete sich dann als Produkt der Ertragseinbuße pro Hektar und dem entsprechenden Marktpreis. Hochgerechnet auf die betroffenen Flächen ergäbe sich der Gesamtschaden.

Dieser Kalkulationsansatz führt allerdings nur bei marginalen, d.h. nicht preiswirksamen Änderungen der Produktionsmenge und unter der Annahme, daß die Produzenten als Reaktion auf die Umweltqualitätsbeeinträchtigung keine Anpassung in ihrem Produktionsprozeß vornehmen, zu aussagekräftigen Ergebnissen. „Sobald die Effekte von großräumigen Umweltbelastungen untersucht werden, ist die Annahme konstanter Preise unrealistisch" (Fromm 1997: 182).

Als Anpassung des Produktionsprozesses auf die durch Umweltbeeinträchtigungen veränderten Umweltbedingungen für die landwirtschaftliche Produktion ist z.B. der Einsatz resistenter Pflanzensorten oder entgegenwirkender Chemikalien sowie die Umstellung der Produktionsabläufe bzw. auf andere Produkte zu nennen.

„Eine vollständige Bewertung der von Umweltbelastungen ausgehenden Produktivitätseffekte bedarf also eines erheblichen analytischen Aufwandes“ (Fromm 1997: 183).

Die durch Bodenbelastungen bedingten Schäden in der Landwirtschaft sind einer ökonomischen Bewertung grundsätzlich zugänglich.

Hinsichtlich der Kompostanwendung sind diese jedoch nicht in Form von Dosis-WirkungsBeziehungen in Höhe der auf eine definierte Schadensursache zurïckzuführenden Ertragseinbuße zu quantifizieren.

Zur Erhebung der hierzu erforderlichen Daten wären umfangreiche Feldversuche zur Differenzierung von Standorten, ackerbaulichen Maßnahmen und Fruchtarten erforderlich. Zudem wäre hier auf das zusätzliche Problem einer Überlagerung mit positiven ertragswirksamen Effekten der Kompostgabe 
zu verweisen, denn in der Tendenz solcher Versuche zeigt sich, daß durch Kompostanwendung geringfügig höhere Erträge erzielt werden (Kuhlmann et.al.1996: 49).

Einfache Modellansätze zur Abschätzungen negativer Kompostwirkungen sind nicht bekannt.

Es könnten zudem Vermarktungsprobleme entstehen für Nutzpflanzen bzw. deren Ernteprodukte, die auf kompostbeaufschlagten Flächen produziert wurden, sofern die Kompostanwendung vom Verbraucher als Qualitätsminderung angesehen wird. „Diese Risiken, die bei ordnungsgemäßer Kompostanwendung nach bisherigen Erkenntnissen sachlich nicht begründbar sind, müssen im Einzelfall abgeschätzt und mit den Erlösen aus der Kompostierung und Kompostverwertung verglichen werden“(Pfadler/Klages-Haberkern 1993: 45).

Mit der starken Zunahme der Kompostmengen durch die Einführung der flächendeckenden Bioabfallkompostierung und den Schwierigkeiten, neue Absatzpotentiale für Komposte zu schaffen und die Kompostqualität zu erhöhen, ist mit einem weiteren Preisverfall für Kompost zu rechnen (Wintzer et.al.1996: 156). Hiermit verbunden ist ein stetiger Imageverlust v.a. von Komposten und Kompostprodukten, die aus Bioabfällen produziert wurden. Ein zukünftig denkbares Negativ-Image von Kompost könnte $\mathrm{zu}$ den genannten Vermarktungsproblemen für unter Komposteinsatz produzierte Nutzpflanzen führen. Im Vertragsanbau ist deshalb die Anwendung von Bioabfallkompost bereits vielfach ausgeschlossen.

Aufgrund der Dynamik in diesem Bereich ist es nicht möglich, die empfohlene Risikoabschätzung im Einzelfall vorzunehmen.

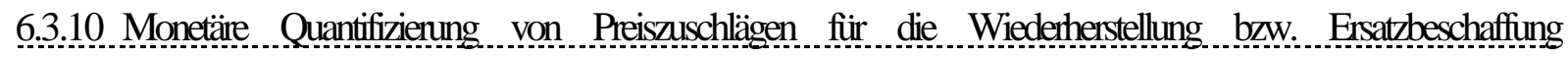
landwirtschaftlicher Nutvfläche(Risikoprämien)

\subsubsection{Ermittlung von Risikoprämien durch Diskontierung des Vermögensschadens}

Die Schwermetallakkumulation im Boden durch landwirtschaftliche Kompostverwertung bis zum Erreichen der Bodengrenzwerte der Bioabfallverordnung (1998) vollzieht sich je nach Bodenart, der Hintergrundbelastung des Bodens mit Schwermetallen sowie der Kompostqualität über unterschiedliche Zeiträume. Um diese verschiedenen Fälle vergleichbar zu machen, werden die 
zukünftigen Kosten zur Beseitigung des resultierenden Vermögensschadens für den Landwirt durch Diskontierung auf den gegenwärtigen Zeitpunkt bezogen. Aus dem so erhaltenen Gegenwartswert der Wiederherstellungs- bzw. Ersatzbeschaffungskosten sollen die jeweiligen Risikoprämien je Mg (TM) ausgebrachten Bioabfallkomposts ermittelt werden. Eine Risikoprämie könnte dem Landwirt oder folgenden Generationen als Kompensation für zukünftig eintretende Vermögensschäden zur Verfügung stehen.

Die Bewertung zukünftiger Umweltschäden basiert ,durch sich ändernde individuelle Präferenzen und Zahlungsbereitschaften, technischen Fortschritt und strukturellen Wandel und nicht zuletzt aufgrund lückenhafter naturwissenschaftlicher Kenntnisse der Wirkungen chemischer Bodenbelastungen auf einer unvollständigen Informationsbasis“ (Fromm 1997: 214).

Ein weiteres Problem der Diskontierung von langfristigen Umweltschäden ergibt sich daraus, daß Zukunftsschäden durch die Diskontierung im Gegenwartskalkül erheblich an Gewicht verlieren (Fromm 1997: 242).

Insbesondere bei Festsetzung der Schadenshöhe von langfristigen Umweltschäden ist anzumerken, daß diese u.U. zukünftig als weniger problematisch eingeschätzt werden könnten, sofern hierfür zwischenzeitlich spezifische Sanierungsmaßnahmen entwickelt werden. „Es hängt somit wiederum weitgehend von der Einschätzung des technischen Fortschritts ab, wie die Wirkungen chemischer Bodenbelastungen auf zukünftige Individuen beurteilt werden“ (Fromm 1997: 216). Aufgrund der Unkenntnis zukünftiger Schadensbeseitigungskosten und zukünftiger Verkehrswerte landwirtschaftlicher Nutzfläche werden hinsichtlich der Schadenshöhen die gegenwärtigen Bewertungen herangezogen.

In einer ersten Berechnung der Risikoprämie für die zu betrachtenden Fälle hinsichtlich der Bodenart werden die Wiederherstellungskosten zur Kennzeichnung der Schadenshöhe zugrundegelegt. Diese beinhalten die Kosten für die Auskofferung der Ackerkrume mit anschließendem Bodenaustausch als gewählte technische Maßnahme zur Schadensbeseitigung (s. Abschnitt 6.3.8.2).

Zur Ermittlung des Diskontierungszeitraums wird das einfache Modell zur Schwermetallakkumulation in landwirtschaftlich genutzten Böden herangezogen (s. Abschnitt 6.3.2.4).

Obwohl diese Auffüllrechnung vereinfachend Schwermetallmobilitäten unterstellt, die ausschließlich von der Schwermetallkonzentration im Boden und nicht von der Herkunft der Schwermetalle 
abhängen, erscheint es nicht sinnvoll, ein anspruchsvolleres Modell zur Darstellung der Schwermetallmobilität in Böden auszuwählen, da das Verhalten von anthropogen eingetragenen und geogenen Schwermetallen im Boden noch unzureichend erforscht ist.

In der zweiten Berechnung der Risikoprämie wird die Höhe der Ersatzbeschaffungskosten als Schadenshöhe angenommen. Für die beiden Landwirte im Landkreis Demmin entspricht die Schadenshöhe somit dem Verkehrswert landwirtschaftlicher Nutzfläche in MecklenburgVorpommern (s. Abschnitt 6.3.8.3).

Für beide der genannten Rechengänge werden zunächst die Risikoprämien für die konkreten Fälle im Landkreis Demmin ermittelt. Dabei werden die ermittelten Zeitspannen (s. Tab. 6.12 und 6.13) für die in Bezug auf die Kompostausbringungsflächen in Tarnow und Borrentin vorliegende Bodenart Lehm verwendet.

Anschließend werden für die Berechnungen der Risikoprämien die Zeitspannen bis zum Erreichen der Bodengrenzwerte der Bioabfallverordnung durch landbauliche Kompostverwertung unter Berücksichtigung „,normaler“ Schwermetallgehalte im Kompost und im Boden (s. Tab. 6.14) zugrunde gelegt. Bei der Berechnung der Ersatzbeschaffungskosten wird der eingetretene Schaden jeweils in Höhe des durchschnittlichen Kaufwerts für Agrarflächen im alten Bundesgebiet (1997) monetär quantifiziert (s. Abschnitt 6.3.8.3) (Tab. 6.18 und 6.19).

Tab. 6.17: Zeitspannen bis zum Überschreiten eines Bodengrenzwerts der Bioabfallverordnung in den untersuchten Fällen

\begin{tabular}{|c|c|c|c|}
\hline $\begin{array}{l}\text { Lage der } \\
\text { Ausbringungsfläche }\end{array}$ & Bodenart & $\begin{array}{l}\text { Schwermetall, dessen } \\
\text { Bodengrenzwert zuerst } \\
\text { überschritten wird }\end{array}$ & $\begin{array}{c}\text { Zeitspanne } \\
\text { [Jahre] }\end{array}$ \\
\hline Tarnow & Lehm & Zink & 519 \\
\hline Borrentin & Lehm & Chrom & 426 \\
\hline unbestimmt & Sand & - & 137 \\
\hline Tarnow & Sand & Zink & 314 \\
\hline unbestimmt & Lehm & Zink & 520 \\
\hline unbestimmt & Ton & Zink & \\
\hline
\end{tabular}


Aufgrund der Überschreitung der Bodengrenzwerte für Schwermetalle nach der BioAbfV für die Bodenart Sand durch die Grundbelastung ,normaler“ Ackerböden (s. Tab. 6.14) bezüglich der Schwermetalle Zink, Chrom und Nickel darf in diesem Fall keine landbauliche Verwertung von Bioabfallkomposten erfolgen. Für den genannten Fall ist demzufolge keine Risikoprämie ermittelbar. Um für die Bodenart Sand dennoch eine Berechnung der Risikoprämie durchführen zu können, wird ein Fall konstruiert, in dem die in Tarnow ermittelten Schwermetallgehalte im Boden und im Bioabfallkompost auf eine Ausbringungsfläche der Bodenart Sand bezogen werden (s. Tab. 6.17). Für diesen Fall kann die Berechnung deswegen durchgeführt werden, weil die Schwermetallgehalte in der Ausbringungsfläche in Tarnow die Bodengrenzwerte der Bioabfallverordnung für die Bodenart Sand unterschreiten.

Zink ist das Schwermetall, das in vier von fünf verbleibenden Fällen durch jährliche Düngung mit Bioabfallkompost in Verbindung mit Mineraldünger zuerst den zugehörigen Bodengrenzwert der Bioabfallverordnung überschreitet. Die weitere Kompostverwertung auf der betreffenden Fläche ist damit nicht zulässig. Die zugehörigen Zeitspannen, die als Diskontierungszeitraum für die folgenden Berechnungen verwendet werden, betragen bei den zugrundeliegenden Schwermetallgehalten im Boden und im Kompost in Abhängigkeit von der Bodenart zwischen 137 und 520 Jahren (Tab. $6.17)$.

Je stärker die zukünftigen Kosten diskontiert werden, desto weniger fallen sie bei den heutigen Entscheidungen zur Akzeptanz von Umweltschäden ins Gewicht bzw. desto geringer sind die durch Diskontierung des zukünftigen Vermögensschadens aufgrund der Schwermetallbelastung des Bodens zu ermittelnden Risikoprämien. „Mit steigendem Diskontsatz steigt folglich auch das Ausmaß der langfristigen Umweltbelastung“ (Mühlenkamp 1994: 185).

In Hinblick auf zukünftige Generationen sollten langfristige Umweltbelastungen möglichst vermieden werden. „Die gegenwärtige Generation hat von der vorangegangenen Generation eine weitgehend intakte Umwelt erhalten, und deshalb sollte sich auch die gegenwärtige Generation die Aufgabe stellen, soweit dies irgend möglich ist, irreversible Schäden, das heißt Schäden, die nicht wieder oder nur zu exorbitant hohen Kosten beseitigt werden können, zu verhindern“(Wicke 1991: 35-36). 
Hinsichtlich der Wahl des gesellschaftlichen Diskontsatzes ist zu folgern, daß bei der Bewertung öffentlicher Projekte niedrigere Diskontsätze als im Privatsektor zu verwenden sind, weil aus generationensübergreifender Sicht eine weitgehende Verlagerung des Umweltkonsums in die Gegenwart nicht zu rechtfertigen ist. Für den gesellschaftlichen Diskontsatz $s$ ergibt sich daraus ein Spielraum zwischen 0 (wenn man die Diskontierung grundsätzlich verwirft) und einem Wert unterhalb beobachtbarer Marktzinsen $i$ (Mühlenkamp 1994: 186-187):

$$
0 \leq \mathrm{s}<\mathrm{i} .
$$

Im Privatsektor können höhere Diskontsätze angesetzt werden, wie z.B. in Höhe beobachtbarer Marktzinsen $i$. Die vorsichtige Haltung gegenüber irreversiblen Umweltschäden soll jedoch in das Kalkül über die Wahl der Höhe des Diskontsatzes unterhalb des derzeitigen Zinsniveaus für langfristige Anlagen eingehen. Für die Diskontsätze im Privatsektor $s_{p}$ hinsichtlich der gesuchten Risikoprämien gilt demzufolge:

$$
\mathrm{s} \leq \mathrm{s}_{\mathrm{p}}<\mathrm{i} .
$$

Zur Ermittlung der Risikoprämien für die landbauliche Verwertung von Bioabfallkomposten werden im folgenden unterschiedliche Diskontsätze $\mathrm{s}_{\mathrm{p}}$ zwischen 2,5\% und 3,5\% verwendet.

Zur Berechnung des Vermögensschadens sollen die in Zukunft zum Zeitpunkt $t_{n}$ anfallenden Kosten $K\left(t_{n}\right)$ für die Schadensbeseitigung auf den gegenwärtigen Zeitpunkt $t_{0}$ abgezinst werden, wobei $s_{p}$ für den Zinssatz (Diskontsatz) und $n$ für die Zeitspanne bis zum Schadenseintritt steht. Der Gegenwartswert dieser Kosten $K\left(t_{0}\right)$ berechnet sich nach der Formel

$$
\mathrm{K}\left(\mathrm{t}_{0}\right)=\mathrm{K}\left(\mathrm{t}_{\mathrm{n}}\right) /\left(1+\mathrm{s}_{\mathrm{p}}\right)^{\mathrm{n}}
$$

Der Faktor $1 /\left(1+\mathrm{s}_{\mathrm{p}}\right)$ wird dabei häufig als Diskontrate bezeichnet (Mühlenkamp 1994: 170). 
Tab. 6.18: Gegenwartswerte ${ }^{24}$ der Schadensbeseitigungskosten $K\left(t_{0}\right)$ je Hektar Ausbringungsfläche bei unterschiedlichen Bodenarten und Kompostqualitäten für eine zukünftige Schadenshöhe von 1 Mio. DM

\begin{tabular}{|c|c|c|c|c|c|}
\hline \multirow{3}{*}{$\begin{array}{c}\text { Zinssatz } \mathrm{s}_{\mathrm{p}} \\
{[\%]}\end{array}$} & \multicolumn{5}{|c|}{ Zeitspannen [Jahre] } \\
\hline & $\begin{array}{c}519 \\
\text { (Tarnow-Lehm) }\end{array}$ & $\begin{array}{c}426 \\
\text { (Borrentin-Lehm) }\end{array}$ & $\begin{array}{c}137 \\
\text { (Tarnow-Sand) }\end{array}$ & $\begin{array}{c}314 \\
\text { (unbestimmt-Lehm) }\end{array}$ & $\begin{array}{c}520 \\
\text { (unbestimmt-Ton) }\end{array}$ \\
\hline & \multicolumn{5}{|c|}{ Schadenshöhe: 1 Mio. DM } \\
\hline 2,5 & 2,72 & 27,02 & $33.949,00$ & 429,25 & 2,65 \\
\hline 2,75 & 0,77 & 9,57 & $24.315,84$ & 199,76 & 0,75 \\
\hline 3 & 0,22 & 3,40 & $17.430,11$ & 93,13 & 0,21 \\
\hline 3,25 & 0,06 & 1,21 & $12.504,37$ & 43,50 & 0,06 \\
\hline 3,5 & 0,02 & 0,43 & $8.977,84$ & 20,36 & 0,02 \\
\hline
\end{tabular}

Tab. 6.19: Gegenwartswerte ${ }^{25}$ der Schadensbeseitigungskosten $K\left(t_{0}\right)$ je Hektar Ausbringungsfläche bei unterschiedlichen Bodenarten und Kompostqualitäten für zukünftige Schadenshöhen entsprechend den Verkehrswerten für Agrarflächen in Mecklenburg-Vorpommern bzw. den alten Bundesländern

\begin{tabular}{|c|c|c|c|c|c|}
\hline \multirow{3}{*}{$\begin{array}{c}\text { Zinssatz } \mathrm{s}_{\mathrm{p}} \\
{[\%]}\end{array}$} & \multicolumn{5}{|c|}{ Zeitspannen [Jahre] } \\
\hline & $\begin{array}{c}519 \\
\text { (Tarnow-Lehm) }\end{array}$ & $\begin{array}{c}426 \\
\text { (Borrentin-Lehm) }\end{array}$ & $\begin{array}{c}137 \\
\text { (Tarnow-Sand) }\end{array}$ & $\begin{array}{c}314 \\
\text { (unbestimmt-Lehm) }\end{array}$ & $\begin{array}{c}520 \\
\text { (unbestimmt-Ton) }\end{array}$ \\
\hline & \multicolumn{2}{|c|}{ Schadenshöhe: 5.511 DM } & \multicolumn{3}{|c|}{ Schadenshöhe: 31.852 DM } \\
\hline 2,5 & 0,02 & 0,15 & 1081,35 & 13,67 & 0,08 \\
\hline 2,75 & \multirow[t]{4}{*}{$<0,01$} & 0,05 & 774,51 & 6,36 & 0,02 \\
\hline 3 & & 0,02 & 555,18 & 2,97 & 0,01 \\
\hline 3,25 & & 0,01 & 398,29 & 1,39 & \multirow[t]{2}{*}{$<0,01$} \\
\hline 3,5 & & $<0,01$ & 285,96 & 0,65 & \\
\hline
\end{tabular}

*Die Gegenwartswerte der Schadensbeseitigungskosten sind in der Tabelle in [DM/ha] angegeben (Werte gerundet).

${ }^{24}$ Die Gegenwartswerte der Schadensbeseitigungskosten sind in der Tabelle in [DM/ha] angegeben.

${ }^{25}$ Die Gegenwartswerte der Schadensbeseitigungskosten sind in der Tabelle in [DM/ha] angegeben (Werte gerundet). 
Die Ergebnisse der Diskontierungen für die verschiedenen Ansätze der zukünftigen Schadenshöhe sowie der unterschiedlichen Zeitspannen bis zum Schadenseintritt, die in Abhängigkeit verschiedener mittlerer Kompost- und Bodenqualitäten ermittelt wurden, entsprechen den Risikoprämien für jeweils 6,67 Mg (TM) pro Jahr und Hektar landbaulich verwerteten Bioabfallkomposts, denn bei der Ermittlung der Schwermetallfrachten je Hektar Ackerfläche wurde entsprechend den Vorgaben der Bioabfallverordnung die zulässige Kompostausbringungsmenge von $20 \mathrm{Mg}$ (TM)/ha innerhalb eines Zeitraums von drei Jahren zugrundegelegt (vgl. Tab. 6.11). Um die auf diese Weise berechneten Risikobeträge mit anderen Teilergebnissen dieser Arbeit, wie z.B. den spezifischen Verwertungskosten (spezifische Gesamtkosten je $\mathrm{Mg}$ verwerteten Komposts) vergleichen zu können, sollen diese bezogen auf $1 \mathrm{Mg}(\mathrm{TM})$ Kompost angegeben werden (Risikoprämien $R P$ ). Dazu sind die Gegenwartswerte der Schadensbeseitigungskosten $K\left(t_{0}\right)$ durch die in den zugrundeliegenden Zeitspannen Zsp insgesamt ausgebrachten Kompostmengen zu dividieren:

$$
\mathrm{RP}=\mathrm{K}\left(\mathrm{t}_{0}\right) /(6,67 \mathrm{Mg}(\mathrm{TM}) * \mathrm{Zsp}) .
$$

Im folgenden werden die Risikoprämien entsprechend dargestellt (Tab. 6.20 und 6.21).

Tab. 6.20: Risikoprämien je Mg (TM) Bioabfallkompost bei zukünftigen Schadensbeseitigungskosten von $1 \mathrm{Mio}$. DM/ha und einer jährlichen Kompostausbringungsmenge von 6,67 $\mathrm{Mg}(\mathrm{TM}) / \mathrm{ha}$

\begin{tabular}{|c|c|c|c|c|c|}
\hline $\begin{array}{c}\text { Zinssatz } \mathrm{s}_{\mathrm{p}} \\
{[\%]}\end{array}$ & (Tarnow-Lehm) & (Borrentin-Lehm) & (Tarnow-Sand) & (unbestimmt-Lehm) & (unbestimmt-Ton) \\
\hline & \multicolumn{5}{|c|}{ Risikoprämien [DM/Mg (TM) Kompost] } \\
\hline 2,5 & \multirow[t]{5}{*}{$<0,01$} & 0,01 & 37,15 & 0,205 & \multirow[t]{5}{*}{$<0,01$} \\
\hline 2,75 & & \multirow[t]{4}{*}{$<0,01$} & 26,61 & 0,095 & \\
\hline 3 & & & 19,07 & 0,044 & \\
\hline 3,25 & & & 13,68 & 0,021 & \\
\hline 3,5 & & & 9,82 & 0,01 & \\
\hline
\end{tabular}

Tab. 6.21: Risikoprämien je $\mathrm{Mg}(\mathrm{TM})$ Bioabfallkompost bei zukünftigen Schadensbeseitigungskosten entsprechend den Verkehrswerten für Agrarflächen in Mecklenburg- 
Vorpommern bzw. den alten Bundesländern und einer jährlichen Kompostausbringungsmenge von $6,67 \mathrm{Mg}(\mathrm{TM}) / \mathrm{ha}$

\begin{tabular}{|c|c|c|c|c|c|}
\hline \multirow{3}{*}{$\begin{array}{c}\text { Zinssatz } \mathrm{s}_{\mathrm{p}} \\
{[\%]}\end{array}$} & \multicolumn{2}{|c|}{ Schadenshöhe: $5.511 \mathrm{DM}$} & \multicolumn{3}{|c|}{ Schadenshöhe: 31.852 DM } \\
\hline & (Tarnow-Lehm) & (Borrentin-Lehm) & (Tarnow-Sand) & (unbestimmt-Lehm) & (unbestimmt-Ton) \\
\hline & \multicolumn{5}{|c|}{ Risikoprämien [DM/Mg (TM) Kompost] } \\
\hline 2,5 & \multirow[t]{5}{*}{$<0,01$} & \multirow[t]{5}{*}{$<0,01$} & 1,18 & \multirow[t]{5}{*}{$<0,01$} & \multirow[t]{5}{*}{$<0,01$} \\
\hline 2,75 & & & 0,85 & & \\
\hline 3 & & & 0,61 & & \\
\hline 3,25 & & & 0,44 & & \\
\hline 3,5 & & & 0,31 & & \\
\hline
\end{tabular}

Für die im Rahmen des Modellversuchs zur dezentralen Kompostierung im Landkreis Demmin betriebene landbauliche Kompostverwertung ergeben sich unabhängig vom Ansatz der zukünftigen Schadenshöhe (Wiederherstellungs- oder Ersatzbeschaffungskosten) sowie vom Zinsansatz durchgängig vernachlässigbar geringe Risikobeträge.

Ebenso verhält es sich in den Fällen eines Vergleichskomposts, der auf verschiedenen Böden mit „,normalen“ Schwermetallgehalten verwertet wird, für die lediglich bei zukünftiger Schadensbeseitigung durch Bodenaustausch in Abhängigkeit vom Diskontsatz Risikoprämien von 0,01 bis 0,205 DM je Mg (TM) ausgebrachten Bioabfallkomposts angegeben werden können. Auch diese Beträge sind im Vergleich zu den spezifischen Kosten der Bioabfallbehandlung und der Kompostverwertung als vernachlässigbar einzustufen.

Nur in den Fällen, daß Bioabfallkomposte auf Sandböden aufgebracht werden, sind höhere Risikobeiträge ermittelbar, weil der Diskontierungszeitraum aufgrund der niedrigen Bodengrenzwerte an Schwermetallen für Sand relativ kurz ist. Wie einer der beispielhaft herangezogenen Fälle gezeigt hat, können bereits häufig beobachtbare Hintergrundbelastungen von Böden diese Grenzwerte überschreiten, so daß dann die Verwertung von Komposten auf diesen Flächen ausgeschlossen ist. In dem daraufhin konstruierten Fall, in dem Sandboden mit geringer Hintergrundbelastung an Schwermetallen mit im Vergleich gering belasteten Bioabfallkomposten jährlich beaufschlagt wird, wird der Bodengrenzwert für das Element Zink in der mit großem Abstand zu den anderen Fällen kürzesten Zeitspanne überschritten. Der daraus resultierende kurze Diskontierungszeitraum für die 
Schadensbeseitigungskosten führt zu vergleichsweise hohen Risikobeträgen, die in Abhängigkeit vom zugrunde liegenden Diskontsatz zwischen 0,31 DM und 1,18 DM bei Ansatz des Schadens in Höhe der Verkehrswerte der Ackerfläche sowie zwischen 9,82 DM und 37,15 DM bei Ansatz der Wiederherstellungskosten ermittelt wurden (Abb. 6.17).

Es ergibt sich, daß nur die Fälle, in denen Bioabfallkomposte auf Sandböden verwertet werden und die zukünftige Beseitigung des Schadens durch Bodenaustausch erfolgt, zu Risikobeträgen bzw. zu einkalkulierbaren Risikoprämien führt, die hinsichtlich der ökonomischen Gesamtbetrachtung des Verwertungswegs ins Gewicht fallen. Hingegen sind die Beträge bei Ansatz des Schadens in Höhe der Verkehrswerte der Ackerfläche hinsichtlich dieser Gesamtbetrachtung ebenfalls vernachlässigbar gering, wobei in Frage steht, ob die Annahme konstanter Preise für nicht nutzungsbeschränkte Ackerfläche bei deren Verknappung durch die landbauliche Verwertung schadstoffbelasteter Sekundärrohstoffe realistisch ist.

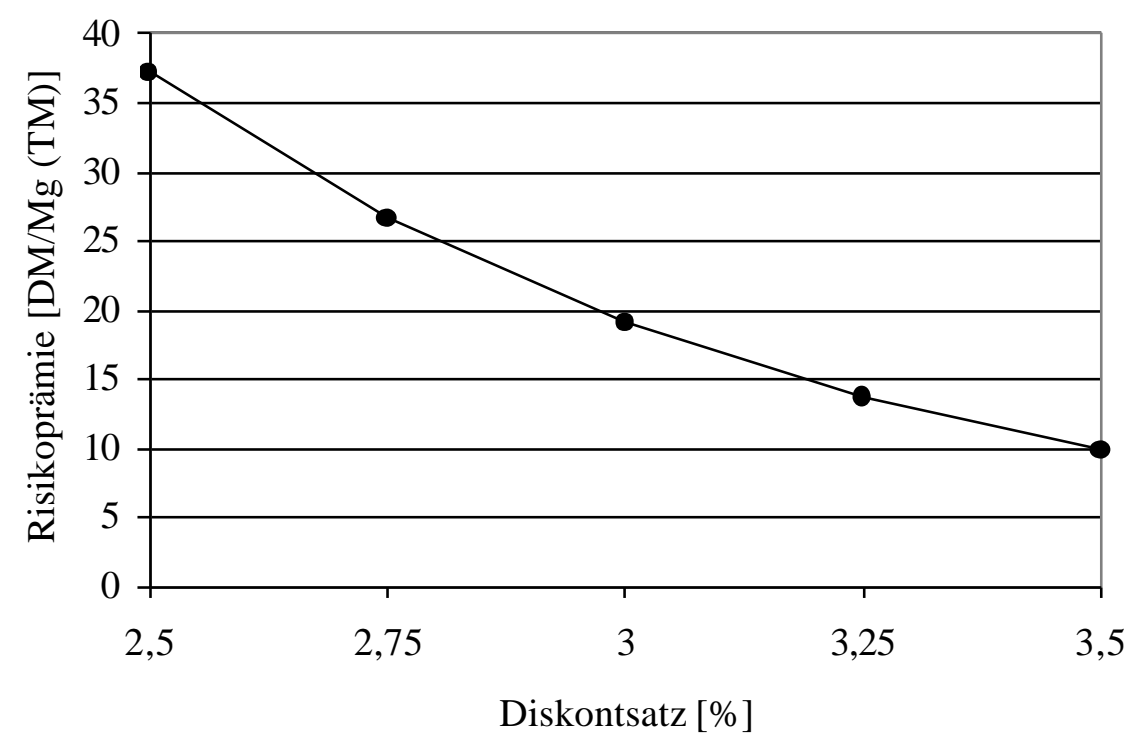

Abb. 6.17: Ermittelte Risikoprämien für die landbauliche Verwertung von relativ gering mit Schwermetallen belasteten Bioabfallkomposten auf Sandböden für unterschiedliche Diskontsätze 


\subsubsection{Ermittlung von Risikoprämien durch Umrechnung der Risikobeiträge zum Klärschlammfonds}

Ein Entschädigungsfonds zur Absicherung der Risiken landwirtschaftlicher Kompostverwertung entsprechend der landwirtschaftlichen Klärschlammverwertung - existiert nicht (s. Abschnitt 6.3.1).

Die Höhe des Risikobeitrags, den die Klärwerksbetreiber als Hersteller von Klärschlamm in den Klärschlammfonds einzahlen müssen, wird im folgenden als monetäre Bewertung des in Zusammenhang mit der auf den Boden gebrachten Schadstofffracht stehenden Risikos interpretiert.

Nach der Klärschlammverordnung (1992) ist zur Begrenzung der Schwermetallfrachten bei der landbaulichen Klärschlammverwertung die maximal zulässige Aufbringungsmenge auf $5 \mathrm{Mg}(\mathrm{TM}) / \mathrm{ha}$ innerhalb von 3 Jahren begrenzt.

Nach der Bioabfallverordnung beträgt die höchstens zulässige Kompostausbringungsmenge innerhalb von drei Jahren unter Beachtung der düngemittelrechtlichen Regelungen $20 \mathrm{Mg}(\mathrm{TM}) / \mathrm{ha}$, wobei die Schwermetallgehalte im Kompost die in der Verordnung genannten Grenzwerte nicht überschreiten dürfen. Werden die in $\S 4$ BioabfV genannten, deutlich niedrigeren Grenzwerte hinsichtlich der Schwermetallkonzentrationen im Kompost eingehalten, dann kann die zulässige Aufbringungsmenge bis zu $30 \mathrm{Mg}$ (TM)/ha innerhalb von drei Jahren betragen (s. Abschnitt 6.3.2.1). Bei diesen Aufwandmengen für Komposte werden die nach der AbfKlärV zulässigen Schwermetallfrachten i.A. nicht erreicht (Klages-Haberkern 1993: 71).

Nach der o.g. Interpretation hinsichtlich der Risikobeiträge zum Klärschlammfonds sind die ökonomischen Risiken hinsichtlich der Schadstofffrachten von $5 \mathrm{Mg}$ (TM) Klärschlamm mit denen von $20 \mathrm{Mg}$ (TM) bzw. $30 \mathrm{Mg}$ (TM) Kompost innerhalb von 3 Jahren gleichzusetzen. Der Risikobeitrag für $1 \mathrm{Mg}$ (TM) Klärschlamm entspricht demnach einer Risikoprämie für $4 \mathrm{Mg}$ (TM) bzw. $6 \mathrm{Mg}(\mathrm{TM})$ Kompost.

Die Hersteller von Klärschlamm finanzieren den Entschädigungsfonds mit Beiträgen in Höhe von 20 DM je Mg (TM) (BML 1999 und N.N. 1997 b: 5). Die aus den Risikobeiträgen zum Klärschlammfonds abgeleiteten monetären Bewertungen der Risiken der landbaulichen Kompostverwertung belaufen sich entsprechend auf 5 DM/Mg (TM) bzw. 3,33 DM/Mg (TM), sofern die Komposte die in $\S 4$ Absatz 3 Satz 2 der Bioabfallverordnung genannten Schwermetallkonzentrationen nicht überschreiten. 


\section{$7 \quad$ Nutzen der landwirtschaftlichen Kompostverwertung}

Die Wirkung des Komposts auf Boden und Pflanze ist ein Summeneffekt, der sich aus der unmittelbaren Wirkung des sich in Lösung befindlichen Teils der Pflanzennährstoffe und der physiologisch wirksamen organischen Verbindungen, die im Kompost enthalten sind oder durch mikrobielle Umsetzungen entstehen, sowie den mittelbaren chemischen und physikalischen Wirkungen auf den Boden zusammensetzt (Jungk 1995: 311).

Die physikalischen Kompostwirkungen auf den Boden umfassen

- die Verbesserung der Bodenstruktur,

- die Verbesserung der Krümelstabilität (Aggregatstabilität),

- die Verminderung der Erosionsanfälligkeit des Bodens,

- die Erhöhung der Wasserkapazität,

- eine Verstärkung der Durchlüftung,

- die Beschleunigung der Erwärmung und

- die Verbesserung der Bearbeitbarkeit und Belastbarkeit des Bodens. 
Die chemischen Kompostwirkungen auf den Boden beinhalten

- die Abgabe von Nährstoffen durch Mineralisierung,

- die Speicherung von Nährstoffen durch Adsorption,

- die Mobilisierung von Nährstoffen aus anorganischen Reserven,

- die Festlegung von Nährstoffen im Humus,

- die Bildung von Wuchs- und Hemmstoffen sowie

- die Bildung von Antibiotika (Jungk 1995: 211 und Poletschny 1995: 75).

Die Gesamtwirkung der Kompostgabe variiert nicht nur nach der Zusammensetzung des Komposts, sondern auch nach den Standortbedingungen, unter denen dieser Anwendung findet. Daher hängt der (monetäre) Wert des Komposts von vielen Einflußfaktoren ab, die in Modellrechnungen nicht vollständig erfaßt werden können, zumal bisher nicht alle Kompostwirkungen im System BodenPflanze hinreichend genau bekannt sind.

Im folgenden wird auf die für den kompostverwertenden Landwirt nutzenstiftenden Kompostwirkungen eingegangen. Monetär bewertbare Nutzwirkungen der landbaulichen Kompostverwertung können - ebenso wie Erlöse aus dem Kompostverkauf, die bei dem in dieser Arbeit betrachteten Verwertungskonzept nicht anfallen - Einfluß auf die langfristige Preisuntergrenze für die untersuchten Dienstleistungen des Landwirts haben. Daher wird untersucht, welche der benannten Nutzenaspekte einer monetären Bewertung zugänglich sind.

\subsection{Bodenverbessemde Eigenschaften von Kompost}

Bei höheren Kompostapplikationen können erhöhte Gesamt- und Grobporenvolumen im Boden gemessen sowie eine starke Zunahme von Regenwurmröhren festgestellt werden, wodurch eine Verbesserung der Durchlüftung und Wasserführung des Bodens erreicht wird (Poletschny 1995: 77). In dreijährigen Feldversuchen stellten Steffens, Asche und Pape ebenfalls eine Verbesserung der Bodenstruktur durch Kompostdüngung fest. In den Kompostvarianten wiesen die Aggregate des Oberbodens eine höhere Stabilität auf als in einer Kontrollvariante ohne Kompostapplikation. Ferner nahm in den Kompostvarianten der Anteil der Mittelporen am Gesamtporenvolumen des 
Oberbodens zu, während der Feinporenanteil signifikant abnahm. Die Kompostdüngung bewirkte zudem in der Tendenz eine Abnahme der Bodendichte (Steffens et.al. 1996: 64).

Im Ergebnis zeigte sich, daß durch die Kompostdüngung mit der Erhöhung der Aggregatstabilität, die ein Maß für die Verschlämmungsneigung von Böden darstellt, die Verschlämmung der Böden reduziert und die Wasserspeicherfähigkeit der Böden verbessert wird (Steffens et.al.1996: 64).

Zudem reichern sich regelmäßig mit Kompost gedüngte Böden mit Humus an und weisen dann eine dunklere Färbung auf. „Dies und das veränderte Porenvolumen dürften der Grund dafür sein, daß diese Böden sich in der obersten Schicht schneller erwärmen“ (Poletschny 1995: 77). Geeignete Ansätze zur monetären Bewertung der Strukturverbesserung von Böden liegen nicht vor. Eine Berücksichtigung der genannten nutzenstiftenden Wirkungen des Komposteinsatzes könnte lediglich über die Bewertung des Organikgehalts im Kompost erfolgen, der maßgeblich die Strukturverbesserung des Bodens bewirkt (s. Abschnitt 7.4.2).

\subsection{Entragssteigenungen}

Die Ertragsleistung eines Bodens wird durch Aufbringung von Komposten in dem Maße verbessert, in dem ein ertragsbegrenzender Mangel dadurch behoben wird. „Auf unfruchtbarem Boden, z.B. humusarmem Sand, konnte mit zunehmender Humusanreicherung des Bodens durch Kompost der Ertrag an Weißkohl deutlich gesteigert werden“ (Poletschny 1995: 76).

Gröblinghoff und Oehmichen fanden in Feldversuchen mit Bioabfallkompost-Applikationen unterschiedlicher Höhe in Verbindung mit mineralischen Ergänzungsdüngungen zu Raps, Getreide und Zuckerrïben Unterschiede in den Ertragsveränderungen der untersuchten Kulturen. So wurde im Getreideanbau unter Berücksichtigung einer N-Wirkung von 15\% des Gesamtstickstoffs bei der Düngung das betriebsübliche Ertragsniveau erreicht. Der Raps zeigte bei entsprechender Anrechnung des Stickstoffs leichte Ertragsdepressionen und konnte das Niveau der betriebsüblichen Düngung nicht erreichen, weil die Nährstofffreisetzung aus dem Kompost für diese Kultur mit ihrem hohen Nährstoffbedarf im Frühjahr zu spät kam. Im Zuckerrübenanbau konnten keine signifikanten Ertragssteigerungen oder Qualitätsverbesserungen nachgewiesen werden (Gröblinghoff/Oehmichen 1995: 55-58). 
Gegenüber einer Kontrollvariante ohne Düngung stiegen die Erträge in den Fällen der Düngung mit Bioabfallkompost ohne mineralische Ergänzungsdüngung um 0,5 bis $1 \%$ je $\mathrm{Mg}(\mathrm{TM}) / \mathrm{ha}$ ausgebrachten Komposts an (Gröblinghoff/Oehmichen 1995: 58).

In vergleichenden Feldversuchen in Hessen fanden Asche und Steffens auf verschiedenen hessischen Standorten der Versorgungsstufe C im ersten Anwendungsjahr ebenfalls keinen Einfluß auf Qualität und Ertrag der Zuckerrübe aufgrund der Kompostdüngung. In der zweiten Vegetationsperiode nach der Kompostapplikation ergab sich jedoch im Mittel von sieben Standorten eine signifikante Ertragssteigerung bei Winterweizen in der Frischkompostvariante um $16 \%$ im Vergleich zur ungedüngten Variante. Dagegen lag auf einem Standort ,der Kornertrag von Sommergerste in der Fertigkompostvariante aufgrund von N-Immobilisation um $20 \%$ unter dem Ertrag der Kontrollvariante“ (Asche / Steffens 1995: 59).

Im Normalfall sind Ertragswirkungen auf fruchtbaren Böden bei Kompostdüngung in Verbindung mit mineralischer Ausgleichsdüngung ,zwar meßbar, jedoch relativ bescheiden“ (Poletschny 1995: 77). Es zeigt sich also, daß in der Tendenz geringfügig höhere Erträge durch Komposteinsatz erzielbar sind, jedoch in Abhängigkeit von den Standortbedingungen und der angebauten Kultur.

Es stellt sich die Frage, ob signifikante Ertragssteigerungen als Parameter herangezogen werden könnten, ,der alle Wirkungen einer Kompostanwendung quantifiziert und monetär bewertbar macht, die sich ansonsten einer ökonomischen Bewertung entziehen“(Kuhlmann et.al. 1996: 48).

Signifikante Ertragssteigerungen, die ausschließlich auf die Kompostanwendung zurückzuführen sind, konnten bisher nicht nachgewiesen werden. Zudem ist die Zurechnung von Mehrerträgen in Feldversuchen schwierig, weil in Vergleichsvarianten mit und ohne mineralische Ergänzungsdüngung die ,Zuführung ,wirkungsgleicher‘ Nährstoffmengen kaum möglich ist“ (Kuhlmann et.al. 1996: 48).

Eine ökonomische Bewertung der Kompostapplikation durch Monetarisierung der Mehrerträge scheitert auch deshalb, weil in den durchgeführten Feldversuchen signifikante Ertragssteigerungen lediglich gegenüber den Varianten „ohne Düngung“ erzielt wurden, also gegenüber Fällen, die in der landwirtschaftlichen Praxis kaum vorkommen.

\section{$\underline{7.3 \quad \text { Wertgebende Kompostinhaltsstoffe }}$}




\subsubsection{Nährstoffgehalte in Bioabfallkomposten}

Bioabfallkomposte enthalten alle für die Pflanzenernährung notwendigen Makronährstoffe (Stickstoff,

Phosphor, Kalium, Magnesium, Kalzium) und Mikronährstoffe (Eisen, Mangan, Bor, Molybdän, Zink, Kupfer).

Hinsichtlich der im Kompost enthaltenen Pflanzennährstoffe ist zwischen

- Gesamtgehalten,

- löslichen Gehalten und

- pflanzenverfügbaren Gehalten

zu unterscheiden. „In der Regel entspricht der lösliche Anteil auch dem pflanzenverfügbaren Anteil, hingegen sagt der analytische Gesamtgehalt wenig über die in der Düngeplanung zu berücksichtigenden Mengen aus“ (Döhler et.al. 1999: 205).

Im folgenden wird anhand der im Rahmen des Modellversuchs im Landkreis Demmin ermittelten Daten aufgezeigt, welche Gesamtgehalte an Makronährstoffen in Bioabfallkomposten vorliegen. Danach wird auf die darin enthaltenen löslichen bzw. pflanzenverfügbaren Anteile eingegangen, um diese abschließend einer monetären Bewertung zu unterziehen.

\subsubsection{Gesamtgehalte an Makronährstoffen in Bioabfallkomposten}

In Tab. 7.1 sind die Gesamtgehalte an Makronährstoffen in den im Rahmen des o.g. Modellversuchs beprobten Bioabfallkomposten angegeben.

Tab. 7.1: Gesamtgehalte an Pflanzennährstoffen in den Bioabfallkomposten in Tarnow und Borrentin, angegeben in Prozent der Trockenmasse

\begin{tabular}{|l|c|c|c|c|c|c|}
\cline { 2 - 7 } \multicolumn{1}{c|}{} & \multicolumn{3}{c|}{ Bioabfallkompost Tarnow } & \multicolumn{3}{c|}{ Bioabfallkompost Borrentin } \\
\cline { 2 - 7 } \multicolumn{1}{c|}{} & Minimum & Mittelwert & Maximum & Minimum & Mittelwert & Maximum \\
\hline $\mathrm{N}$ & 0,76 & 1,27 & 1,63 & 0,81 & 1,02 & 1,37 \\
\hline $\mathrm{P}_{2} \mathrm{O}_{5}$ & 0,54 & 0,95 & 1,54 & 0,52 & 0,63 & 0,82 \\
\hline $\mathrm{K}_{2} \mathrm{O}$ & 0,72 & 1,10 & 1,51 & 0,74 & 1,01 & 1,51 \\
\hline $\mathrm{MgO}$ & 0,39 & 0,48 & 0,64 & 0,30 & 0,35 & 0,42 \\
\hline $\mathrm{CaO}$ & 2,20 & 3,61 & 5,78 & 2,53 & 3,94 & 8,44 \\
\hline
\end{tabular}

Die Einzelprobenergebnisse sind in Anhang IV dargestellt. 
Die mittleren Nährstoffgehalte der untersuchten Bioabfallkomposte liegen mit etwa 1 bis 1,3\% Stickstoff, 0,6 bis 0,9\% Phosphat $\left(\mathrm{P}_{2} \mathrm{O}_{5}\right)$ und $1 \%$ Kalium $\left(\mathrm{K}_{2} \mathrm{O}\right)$ in der Trockensubstanz in einem, bezogen auf den Nährstoffentzug landwirtschaftlicher Kulturpflanzen, relativ ausgewogenen Verhältnis N:P:K zueinander, d.h. eine Kompostgabe von ca. $10 \mathrm{Mg}(\mathrm{TM}) /$ ha entspricht in etwa den Entzügen an N, P und K durch die Pflanzen (vgl. Ebertseder 1995: 88 und Schaaf 1995: 70).

Ein Vergleich der analysierten Nährstoffgehalte mit den im Rahmen anderer Untersuchungen erhaltenen Werte zeigt, daß die im folgenden auf die aus den Anlagen in Tarnow und Borrentin stammenden Bioabfallkomposte bezogenen Aussagen exemplarisch sind, auch wenn Einzelwerte mehr oder weniger stark abweichen können (Tab. 7.2).

Tab. 7.2: Mittlere Gesamtgehalte an Pflanzennährstoffen in den Komposten in Tarnow und Borrentin sowie in zum Vergleich herangezogenen Bioabfallkomposten, angegeben in Prozent der Trockenmasse

\begin{tabular}{|l|c|c|c|c|}
\cline { 2 - 5 } \multicolumn{1}{c|}{} & $\begin{array}{c}\text { Kompost } \\
\text { Tarnow }\end{array}$ & $\begin{array}{c}\text { Kompost } \\
\text { Borrentin }\end{array}$ & $\begin{array}{c}\text { Vergleichs- } \\
\text { kompost 1 }\end{array}$ & $\begin{array}{c}\text { Vergleichs- } \\
\text { kompost 2 }\end{array}$ \\
\hline $\mathrm{N}$ & 1,27 & 1,02 & 1,21 & 1,41 \\
\hline $\mathrm{P}_{2} \mathrm{O}_{5}$ & 0,95 & 0,63 & 0,82 & 0,89 \\
\hline $\mathrm{K}_{2} \mathrm{O}$ & 1,10 & 1,01 & 1,90 & 1,68 \\
\hline $\mathrm{MgO}$ & 0,48 & 0,35 & 0,86 & 1,07 \\
\hline $\mathrm{CaO}$ & 3,61 & 3,94 & 4,72 & 4,08 \\
\hline
\end{tabular}

${ }^{1)}$ (Wintzer et.al.1996: 128) : Mittelwert zahlreicher Einzeluntersuchungen

2) (Schaaf 1995: 69) 
Nach der Bioabfallverordnung beträgt die höchstens zulässige Kompostausbringungsmenge innerhalb von drei Jahren unter Beachtung der düngemittelrechtlichen Regelungen $20 \mathrm{Mg}$ (Trockenmasse) je Hektar bzw. $30 \mathrm{Mg}(\mathrm{TM}) / \mathrm{ha}$, sofern die deutlich niedrigeren Grenzwerte hinsichtlich der Schwermetallkonzentrationen im Kompost nach § 4(3) Satz 2 BioAbfV eingehalten werden.

Im folgenden sind die Nährstoffmengen angegeben, die mit $20 \mathrm{Mg}$ (TM) bzw. $30 \mathrm{Mg}$ (TM) Bioabfallkompost aus den Anlagen in Tarnow bzw. Borrentin praxisüblich mit einem Arbeitsgang alle drei Jahre auf einen Hektar Ackerfläche ausgebracht werden können (Tab. 7.3).

Tab. 7.3: Nährstofffrachten durch landbauliche Kompostverwertung je Hektar innerhalb von 3 Jahren

\begin{tabular}{|l|c|c|c|c|}
\cline { 2 - 5 } \multicolumn{1}{c|}{} & \multicolumn{2}{c|}{$\begin{array}{c}\text { Bioabfallkompost Tarnow } \\
{[\mathrm{kg} / \text { ha in 3 Jahren] }}\end{array}$} & \multicolumn{2}{c|}{$\begin{array}{c}\text { Bioabfallkompost Borrentin } \\
{[\mathrm{kg} / \text { ha in 3 Jahren] }}\end{array}$} \\
\cline { 2 - 5 } \multicolumn{1}{c|}{} & $20 \mathrm{Mg}$ & $30 \mathrm{Mg}$ & $20 \mathrm{Mg}$ & $30 \mathrm{Mg}$ \\
\hline $\mathrm{N}$ & 254 & 381 & 204 & 306 \\
\hline $\mathrm{P}_{2} \mathrm{O}_{5}$ & 190 & 285 & 126 & 189 \\
\hline $\mathrm{K}_{2} \mathrm{O}$ & 220 & 330 & 202 & 303 \\
\hline $\mathrm{MgO}$ & 96 & 144 & 70 & 105 \\
\hline $\mathrm{CaO}$ & 722 & 1083 & 788 & 1182 \\
\hline
\end{tabular}




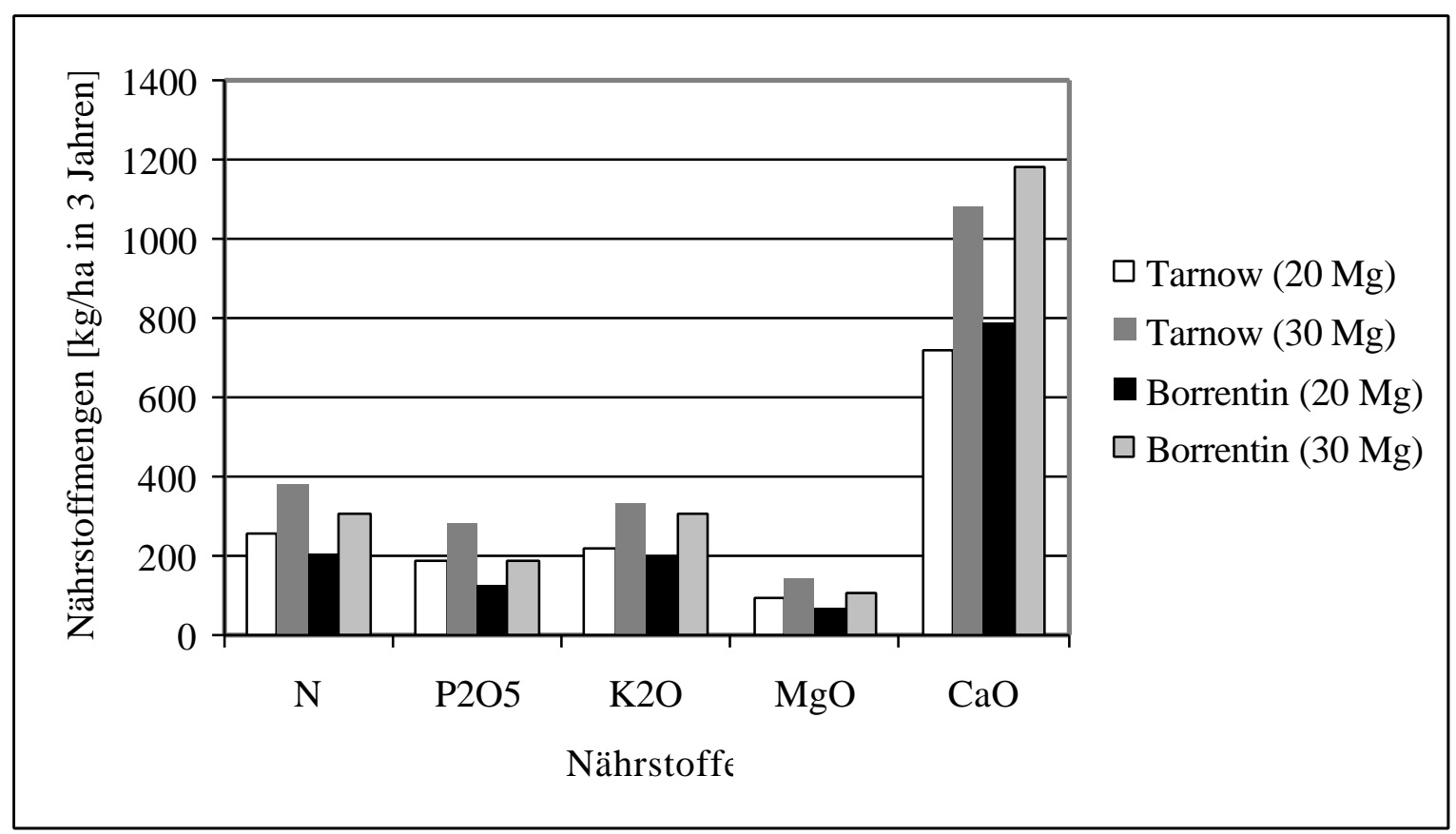

Abb. 7.1: Nährstoffmengen, die mit $20 \mathrm{Mg}$ bzw. $30 \mathrm{Mg}$ Bioabfallkompost innerhalb von 3 Jahren ausgebracht werden können

\subsubsection{Pflanzenverfügbare Gehalte an Makronährstoffen in Bioabfallkomposten}

Im Rahmen des Modellversuchs wurden die Bioabfallkomposte aus den beiden durch Landwirte betriebenen Anlagen auf ihre pflanzenverfügbaren Nährstoffgehalte untersucht. In den Analyseberichten der LUFA Rostock wurden die löslichen Nährstoffe nach der Bestimmung des Volumengewichts (sog. „Rohdichte“) des Bioabfallkomposts pro Volumeneinheit in $\mathrm{mg} / \mathrm{l}$ (Frischmasse) angegeben. Da im Rahmen dieser Arbeit der monetäre Wert der im Bioabfallkompost enthaltenen Makronährstoffe in bezug auf die Gewichtseinheit dargestellt werden soll, wurden diese Daten über die Rohdichte und den Trockenmasse-Gehalt der jeweiligen Probe auf die für pflanzenverfügbare Nährstoffgehalte übliche Einheit [mg/100 g (TM)] umgerechnet (Tab. 7.4). 
Tab. 7.4: Pflanzenverfügbare Nährstoffgehalte in den Bioabfallkomposten aus den Anlagen in Tarnow und Borrentin sowie in zum Vergleich herangezogenen Bioabfallkomposten

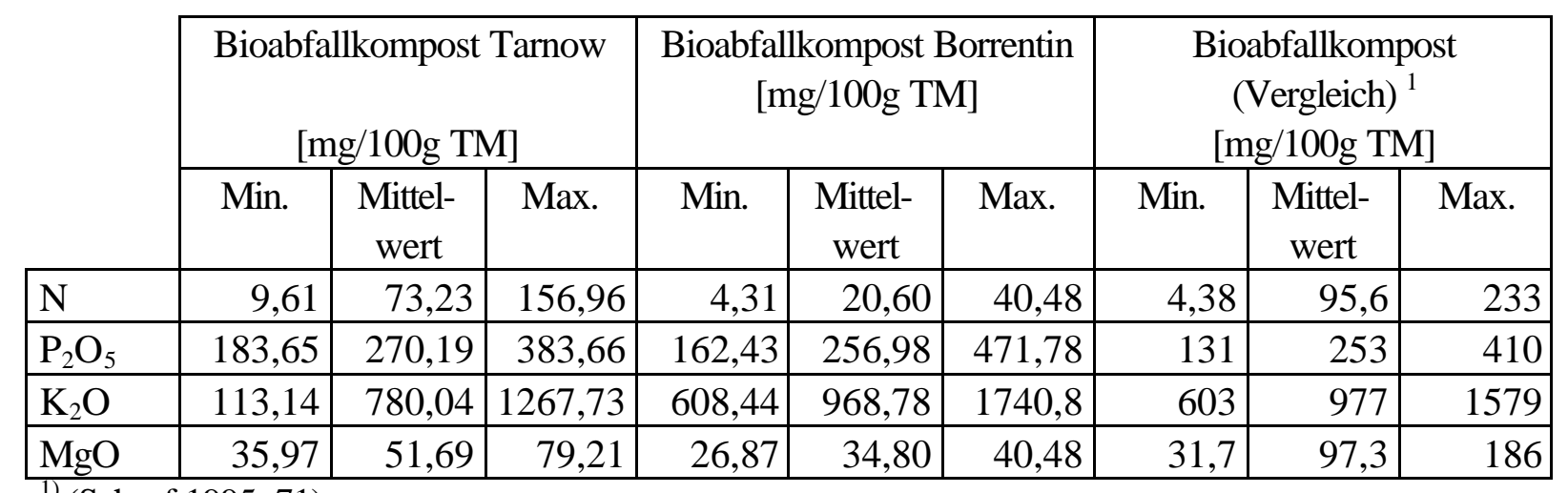

${ }^{1)}$ (Schaaf 1995: 71)

Aus den Tabellenwerten ist erkennbar, daß der im Bioabfallkompost enthaltene Stickstoff (Summenwert von $\mathrm{NO}_{3}-\mathrm{N}$ und $\mathrm{NH}_{4}-\mathrm{N}$ ) schlecht verfügbar, Phosphat deutlich besser verfügbar und Kalium in hohem Maße pflanzenverfügbar ist.

Zur Verdeutlichung dieser Aussage werden im folgenden die pflanzenverfügbaren Nährstoffstoffgehalte in Prozent der im Bioabfallkompost enthaltenen Gesamtgehalte angegeben (Tab. 7.5, Abb. 7.2).

Tab. 7.5: Prozentualer Anteil pflanzenverfügbarer Makronährstoffe in den Bioabfall-komposten aus den Anlagen in Tarnow und Borrentin in bezug auf deren Gesamtgehalte

\begin{tabular}{|l|c|c|}
\cline { 2 - 3 } \multicolumn{1}{c|}{} & $\begin{array}{c}\text { Bioabfallkompost Tarnow } \\
{[\%]}\end{array}$ & $\begin{array}{c}\text { Bioabfallkompost Borrentin } \\
{[\%]}\end{array}$ \\
\hline $\mathrm{N}$ & 5,77 & 2,02 \\
\hline $\mathrm{P}_{2} \mathrm{O}_{5}$ & 28,44 & 40,79 \\
\hline $\mathrm{K}_{2} \mathrm{O}$ & 70,91 & 95,92 \\
\hline $\mathrm{MgO}$ & 10,77 & 9,94 \\
\hline
\end{tabular}




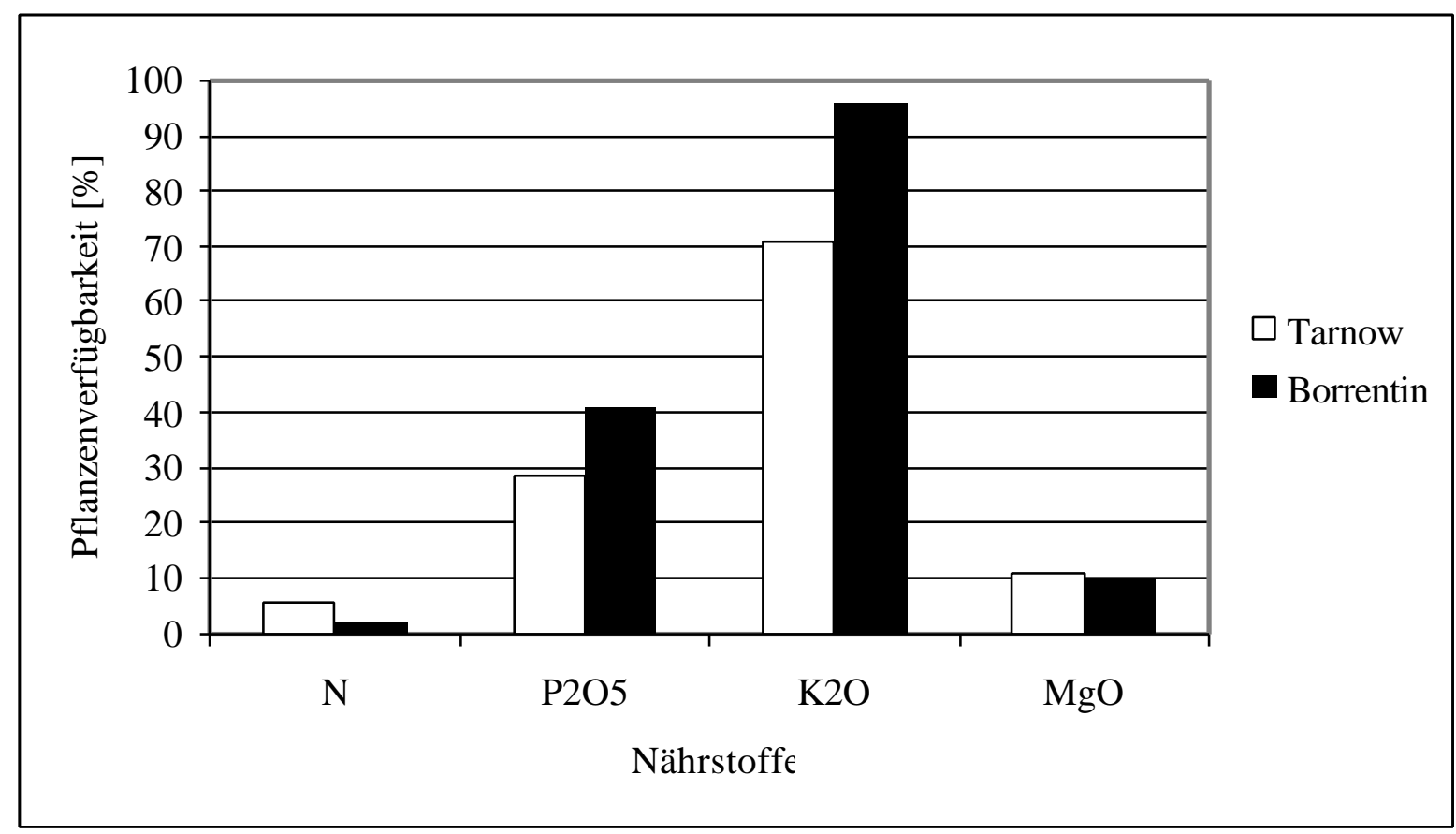

Abb. 7.2: Prozentualer Anteil pflanzenverfügbarer Makronährstoffe in den Bioabfall-komposten aus den Anlagen in Tarnow und Borrentin in bezug auf deren Gesamtgehalte

Die Verfügbarkeit von Phosphor und Kalium aus Kompost ist ähnlich hoch wie aus Mineraldüngern.

Gleiches gilt für Kalzium und Magnesium aus Kompost, deren basische Wirksamkeit ebenfalls der von mineralischen Düngekalken entspricht (Ebertseder 1995: 89).

Probleme hinsichtlich der Verfügbarkeit bereitet der Stickstoff: nach bisherigen Erkenntnissen werden bei der Kompostanwendung je nach Herkunft und bei durchschnittlichen Standortbedingungen im Anwendungsjahr maximal 10 bis $15 \%$ des Gesamtstickstoffs pflanzenverfügbar, in den folgenden Jahren jeweils etwa 2 bis $5 \%$ und langfristig insgesamt etwa 40 bis $50 \%$. Die Ausnutzungsraten von Kompost-N betragen nach 5-jähriger Anwendung nur etwa 20 $\%$, so daß in den ersten Jahren der Kompostanwendung nur geringe Einsparungen an mineralischer Ergänzungsdüngung erzielbar sind (vgl. Döhler 1995: 100). Daneben ist mit einer dauerhaften Festlegung von etwa $30 \%$ in die organische Substanz des Bodens zu rechnen, weitere 20 bis $30 \%$ des mit dem Kompost aufgebrachten Stickstoffs gehen gasförmig oder als Nitrat verloren (Fischer et al. 1993: 126 und Döhler 1995: 95). Die geringe N-Wirkung im Anwendungsjahr führt dazu, daß der Boden durch Kompostdüngung mit organisch gebundenem Stickstoff angereichert wird, wodurch sich bei späterer N-Mineralisierung die Gefahr einer Nitratauswaschung, insbesondere in Zeiten ohne Pflanzenwachstum, erhöht (Ebertseder 1995: 90 und Döhler 1995: 100). „Erst nach 
etwa 80- bis 100-jähriger Anwendung stellt sich ein Gleichgewicht zwischen N-Zufuhr und biologischem Abbau ein“ (Döhler 1995: 100). Insgesamt betrachtet wird die Pflanzenverfügbarkeit des Kompost-N maßgeblich durch die Mineralisierung des organisch gebundenen Stickstoffs und damit durch das $\mathrm{C} / \mathrm{N}-$ Verhältnis ${ }^{26}$ und weniger von den gelösten $\mathrm{N}$-Verbindungen beeinflußt (Döhler 1995: 99 und Klages-Haberkern 1993: 65).

Ein großer Teil des mit dem Kompost zugeführten Stickstoffs wird also nicht durch die angebauten Kulturpflanzen entzogen sondern in Form des organisch gebundenen Stickstoffs in der Bodenkrume gespeichert, der sich in der Düngerbilanz als Überschuß darstellt. Dieser wirkt ,jedoch nur in dem Maße umweltschädigend, in dem er durch Ausgasung und Auswaschung zu N-Verlusten in Form von $\mathrm{NO}_{3}, \mathrm{~N}_{2} \mathrm{O}$ und $\mathrm{NH}_{3}$ führt. [...] Entscheidend für die Umweltverträglichkeit von Komposten ist also, welcher Anteil des allmählich mineralisierten Kompost-N durch Pflanzen genutzt und welcher Anteil in schädlicher Form ausgetragen wird“"(Vandre 1995: 90).

In den Angaben über prozentuale Anteile pflanzenaufnehmbarer Nährstoffe in Komposten kommt zum Ausdruck, daß eine Düngung mit Kompost zur Deckung des N-Bedarfs unsinnig ist. Komposte aus der Getrenntsammlung sind in der Landwirtschaft also vor allem als Ersatz für mineralische Phosphat- und Kaliumdüngemittel einsetzbar (Schaaf 1995: 72).

Im Gegensatz zu Mineraldüngern, die hinsichtlich der Nährstoffmengen pflanzenbedarfsorientiert appliziert werden können, liegen die pflanzenverfügbaren Nährstoffe in Komposten in bestimmten Verhältnissen vor. So bestimmt der Nährstoff, dessen pflanzenverfügbare Anteil die Entzugsmenge

\footnotetext{
${ }^{26}$ Bei C/N-Verhältnissen > 20 wirkt sich das Stickstoffangebot aus der abzubauenden Masse so begrenzend auf das Wachstum der Mikroorganismen im Boden aus, daß zum vollständigen Abbau der C-reichen organischen Masse zusätzlicher Stickstoff benötigt wird. Diesen nehmen die Mikroorganismen aus der Bodenlösung auf, sie immobilisieren also zeitweilig den pflanzenverfügbaren Stickstoff im Boden. Mineralisierung und Immobilisierung bedingen sich daher gegenseitig (Bauemer 1990: 92).

$\mathrm{Ab}$ C/N-Verhältnissen >30 sind kaum noch Stickstoffwirkungen im Boden aufgrund der Kompostgabe zu beobachten. Bei Komposten mit C/N-Verhältnissen >40 ist grundsätzlich mit N-Fixierungen zu rechnen, die ohne eine ergänzende mineralische Stickstoffdüngung mit entsprechenden Wuchsstörungen der Pflanzen verbunden sein können (Reinhold 1995: 16).
} 
der angebauten Kultur bei der zugrunde liegenden Ertragserwartung erreicht, die Applikationsmenge des Komposts.

In Bioabfallkomposten sind dabei Phosphor oder Kalium als Leitnährstoffe anzusehen. Das bedeutet, daß die Höchstmenge der Kompostgabe am Phosphor- oder Kaliumbedarf der Kulturen auszurichten ist, um eine Überversorgung mit diesen Nährstoffen zu vermeiden. „Der fehlende Stickstoff ist bedarfsgerecht durch Mineraldünger zu ergänzen“ (Kuhlmann et.al. 1996: 35).

\subsubsection{Monetäre Bewertung der pflanzenverfügbaren Makronährstoffe}

Bei der monetären Bewertung der im Kompost enthaltenen Nährstoffe wird davon ausgegangen, daß durch die landbauliche Kompostverwertung Mineraldünger ersetzt und dadurch Düngerkosten eingespart werden können (vgl. Wintzer et.al. 1996: 262).

Die im Kompost enthaltenen Nährstoffe weisen jedoch keinen echten Marktwert auf (Kuhlmann et.al. 1996: 35). Deshalb dient zur Abschätzung des Nährstoffwerts der Marktwert der wirkungsgleichen Menge eines zuzukaufenden Substituts, d.h. der monetäre Wert pflanzenverfügbarer Nährstoffe im Bioabfallkompost wird über durchschnittliche Handelsdüngerpreise für entsprechende Nährstoffmengen aus Mineraldüngern auf der Basis von Einzelnährstoffen ermittelt. Dazu sind zunächst für verschiedene Düngersorten und -preise die Preise je kg Nährstoff (Phosphor, Kalium, Magnesium und Kalzium in Oxidform) zu ermitteln (Tab. 7.6). 
Tab. 7.6: Nährstoffgehalte und Preise verschiedener Mineraldüngersorten

\begin{tabular}{|c|c|c|c|c|}
\hline Nährstoff & Düngersorte $^{1}$ & $\begin{array}{c}\text { Nährstoffgehalt } \\
{[\%]} \\
\end{array}$ & $\begin{array}{c}\text { Nettopreis } \\
{[\mathrm{DM} / 100 \mathrm{~kg}]}\end{array}$ & $\begin{array}{c}\text { Preis für } 1 \mathrm{~kg} \\
\text { Nährstoff } \\
{[\mathrm{DM} / \mathrm{kg}]}\end{array}$ \\
\hline \multirow[t]{3}{*}{$\begin{array}{l}\text { Stickstoff } \\
\text { (N) }\end{array}$} & $\begin{array}{l}\text { Kalkammon- } \\
\text { salpeter }\end{array}$ & 27 & 22 & 0,81 \\
\hline & Harnstoff & 46 & 33 & 0,72 \\
\hline & $\mathrm{AHL}^{27}$ & 28 & $20^{2}$ & 0,71 \\
\hline \multirow{4}{*}{$\begin{array}{l}\text { Phosphor } \\
\left(\mathrm{P}_{2} \mathrm{O}_{5}\right)\end{array}$} & Superphosphat & 18 & 23 & 1,28 \\
\hline & Novaphos & 23 & 23 & 1,00 \\
\hline & Hyperphos & 26 & 29 & 1,12 \\
\hline & Thomasphosphat & 15 & 18 & 1,20 \\
\hline $\begin{array}{l}\text { Kalium } \\
\left(\mathrm{K}_{2} \mathrm{O}\right)\end{array}$ & 60er Kali & 60 & 26 & 0,43 \\
\hline $\begin{array}{l}\text { Magnesium } \\
(\mathrm{MgO})\end{array}$ & Kieserit & 27 & 22 & 0,81 \\
\hline \multirow{3}{*}{$\begin{array}{l}\text { Kalzium } \\
(\mathrm{CaO})\end{array}$} & Branntkalk & 90 & 14 & 0,16 \\
\hline & $\begin{array}{l}\text { Kohlensaurer } \\
\text { Kalk }\end{array}$ & 45 & 2,40 & 0,05 \\
\hline & Hüttenkalk & 45 & 9,50 & 0,21 \\
\hline
\end{tabular}

1) (KTBL-Taschenbuch Landwirtschaft 1998/99: 80)

${ }^{2)}$ AHL-Preis der „Ländliche Dienstleistungs- und Handels-GmbH Anklam“, Frühjahr 1999

In Hinblick auf den Überblick in Tab. 7.6 wurden die Preise zur Bewertung der Einzelnährstoffe gewählt (Tab. 7.7). 
Tab. 7.7: Preisansätze für die einzelnen Nährstoffe

\begin{tabular}{|l|c|}
\hline Nährstoff & $\begin{array}{c}\text { Monetäre Bewertung } \\
{[\mathrm{DM} / \mathrm{kg} \text { Nährstoff }]}\end{array}$ \\
\hline $\mathrm{N}$ & 0,75 \\
\hline $\mathrm{P}_{2} \mathrm{O}_{5}$ & 1,15 \\
\hline $\mathrm{K}_{2} \mathrm{O}$ & 0,43 \\
\hline $\mathrm{MgO}$ & 0,81 \\
\hline $\mathrm{CaO}$ & 0,14 \\
\hline
\end{tabular}

Für die betriebswirtschaftliche Beurteilung kann davon ausgegangen werden, daß die im Kompost vorliegenden Mengen an Kalium und Phosphor voll angerechnet werden und daher zugekaufte Mineraldünger im Verhältnis 1:1 ersetzen können. Erleichtert wird dieser Ansatz dadurch, daß allgemein eine fruchtfolgebezogene Grunddüngung erfolgt und somit etwa alle drei Jahre durchgeführt wird, so daß eine volle Anrechnung gerechtfertigt ist (Kuhlmann et.al. 1996: 35).

Ebenso wird hinsichtlich der im Kompost enthaltenen Mengen an Magnesium und Kalzium vorgegangen (vgl. Reinhold 1995: 12), die im Rahmen dieser Arbeit als Nährstoffe und nicht anhand ihrer Kalkwirkung als Bodendünger monetär bewertet werden. „Der betriebswirtschaftliche Erfolg einer Kalkung hängt wesentlich von den Anbauverhältnissen ab (Fruchtfolge, Bodenart, Ziel-pH...), so daß eine sachgerechte Kalkulation des Kalkungserfolges kaum möglich erscheint" (Kuhlmann et.al. 1996: 36).

Tab. 7.8: Monetäre Bewertung der anrechenbaren Nährstoffgehalte an Phosphor, Kalium, Magnesium und Kalzium für $1 \mathrm{Mg}$ (TM) Bioabfallkompost aus den Anlagen in Tarnow und Borrentin

\begin{tabular}{|c|c|c|c|c|}
\hline \multirow{3}{*}{ Nährstoff } & \multicolumn{2}{|c|}{ Kompost Tarnow } & \multicolumn{2}{c|}{ Kompost Borrentin } \\
\cline { 2 - 5 } & $\begin{array}{c}\text { enthaltene Nähr- } \\
\text { Stoffmenge } \\
{[\mathrm{kg}]}\end{array}$ & $\begin{array}{c}\text { monetäre } \\
\text { Bewertung } \\
{[\mathrm{DM}]}\end{array}$ & $\begin{array}{c}\text { Enthaltene Nähr- } \\
\text { Stoffmenge } \\
{[\mathrm{kg}]}\end{array}$ & $\begin{array}{c}\text { monetäre } \\
\text { Bewertung } \\
{[\mathrm{DM}]}\end{array}$ \\
\hline $\mathrm{P}_{2} \mathrm{O}_{5}$ & 9,50 & 10,93 & 6,30 & 7,25 \\
\hline
\end{tabular}

${ }^{27}$ AHL: Ammoniumnitrat-Harnstoff-Lösung 


\begin{tabular}{|l|r|r|r|r|}
\hline $\mathrm{K}_{2} \mathrm{O}$ & 11,00 & 4,73 & 10,1 & 4,34 \\
\hline $\mathrm{MgO}$ & 4,80 & 3,89 & 3,50 & 2,84 \\
\hline $\mathrm{CaO}$ & 36,10 & 5,05 & 39,40 & 5,52 \\
\hline
\end{tabular}

Der Stickstoffgehalt von Bioabfallkompost kann hingegen nicht in seiner Gesamtheit angerechnet werden, da dieser zum überwiegenden Teil in organisch gebundener Form vorliegt und erst anteilig während der Mineralisation der organischen Substanz freigesetzt wird (s. Abschnitt 7.4.1.2).

Um den monetären Wert des im Kompost enthaltenen Stickstoffs angeben zu können, ist die Reihe der zu Marktpreisen bewerteten Mineraldüngeräquivalente der Stickstoff-Nachlieferungen aus dem Kompost auf das Anwendungsjahr abzuzinsen (Tab. 7.8).

Hinsichtlich des Mineralisierungsvorgangs wird von folgenden Annahmen ausgegangen:

- In dem Jahr, in dem der Kompost ausgebracht wird (Anwendungsjahr), werden $10 \%$ des enthaltenen Stickstoffs (Gesamtgehalt) mineralisiert, im zweiten Jahr noch $5 \%$ und in jedem weiteren Jahr werden gleichbleibend $3 \%$ nachgeliefert (vgl. Kuhlmann et.al. 1996: 40).

- Insgesamt werden langfristig etwa $50 \%$ des im Kompost enthaltenen Stickstoffs mineralisiert (s. Abschnitt 7.3.1.2). Aufgrund der getroffenen Annahmen bezüglich der N-Nachlieferung ist dieser Anteil des im Anwendungsjahr vorhandenen Stickstoffs etwa im 13. Jahr nach der Kompostausbringung mineralisiert und damit pflanzenverfügbar geworden.

Zur Bewertung der einzelnen Nachlieferungen wird ein zukünftig gleichbleibender Preis für den Einzelnährstoff Stickstoff von 0,75 DM/kg (s. Tab. 7.7) unterstellt.

Der Gegenwartswert $N l\left(t_{0}\right)$ der monetär bewerteten Nachlieferung im $n$-ten Jahr $N l\left(t_{n}\right)$ berechnet sich nach folgender Formel, wobei $i$ für den Zinssatz (Diskontsatz) steht:

$$
\mathrm{Nl}\left(\mathrm{t}_{0}\right)=\mathrm{Nl}\left(\mathrm{t}_{\mathrm{n}}\right) /(1+\mathrm{i}) \mathrm{n}
$$

Der Diskontsatz für die Abzinsung der zukünftigen Nachlieferungen auf das Anwendungsjahr wird entsprechend den beobachtbaren Marktzinsen für längerfristige Anlagen in Höhe von 5 \% gewählt. 
In $1 \mathrm{Mg}$ (TM) Bioabfallkompost aus Tarnow sind im Mittel der Untersuchungen 12,7 kg Stickstoff (Gesamtgehalt) enthalten, in Komposten aus Borrentin entsprechend 10,2 kg N (vgl. Tab. 7.2). Die monetäre Bewertung des Stickstoffanteils in den Bioabfallkomposten, der unter den o.g. Annahmen im Anwendungsjahr sowie den Folgejahren insgesamt pflanzenverfügbar wird, ist in Tab. 7.9 für die Kompostierungsanlage in Tarnow und in Tab. 7.10 für die Anlage in Borrentin dargestellt. Danach wird eine zusammenfassende monetäre Bewertung der anrechenbaren Nährstoffgehalte an Stickstoff, Phosphor, Kalium, Magnesium und Kalzium, die in $1 \mathrm{Mg}$ (TM) Bioabfallkompost aus den Anlagen in Tarnow bzw. Borrentin enthalten sind, durchgeführt (Tab. 7.11).

Tab. 7.9: Monetäre Bewertung der N-Nachlieferungen für den mittleren Gesamtgehalt an Stickstoff für $1 \mathrm{Mg}$ (TM) Bioabfallkompost aus der Anlage in Tarnow

\begin{tabular}{|c|c|c|c|c|}
\cline { 2 - 5 } \multicolumn{1}{c|}{} & $\begin{array}{c}\text { Mineralisation } \\
{[\%]}\end{array}$ & $\begin{array}{c}\text { Mineralisierte } \\
\text { N-Menge } \\
{[\mathrm{kg}]}\end{array}$ & $\begin{array}{c}\mathrm{Nl}\left(\mathrm{t}_{\mathrm{n}}\right) \\
{[\mathrm{DM}]}\end{array}$ & $\begin{array}{c}\mathrm{Nl}\left(\mathrm{t}_{0}\right) \\
{[\mathrm{DM}]}\end{array}$ \\
\hline Anwendungsjahr & 10 & 1,270 & 0,95 & 0,95 \\
\hline 1. Jahr & 5 & 0,635 & 0,48 & 0,46 \\
\hline 2. Jahr & 3 & 0,381 & 0,29 & 0,26 \\
\hline 3. Jahr & 3 & 0,381 & 0,29 & 0,25 \\
\hline 4. Jahr & 3 & 0,381 & 0,29 & 0,24 \\
\hline 5. Jahr & 3 & 0,381 & 0,29 & 0,23 \\
\hline 6. Jahr & 3 & 0,381 & 0,29 & 0,22 \\
\hline 7. Jahr & 3 & 0,381 & 0,29 & 0,21 \\
\hline 8. Jahr & 3 & 0,381 & 0,29 & 0,20 \\
\hline 9. Jahr & 3 & 0,381 & 0,29 & 0,19 \\
\hline 10. Jahr & 3 & 0,381 & 0,29 & 0,18 \\
\hline 11. Jahr & 3 & 0,381 & 0,29 & 0,17 \\
\hline 12. Jahr & 3 & 0,381 & 0,29 & 0,16 \\
\hline 13. Jahr & 3 & 0,381 & 0,29 & 0,15 \\
\hline Summe & 51 & 6,477 & 4,91 & $\mathbf{3 , 8 7}$ \\
\hline
\end{tabular}


Tab. 7.10: Monetäre Bewertung der N-Nachlieferungen für den mittleren Gesamtgehalt an Stickstoff für $1 \mathrm{Mg}$ (TM) Bioabfallkompost aus der Anlage in Borrentin

\begin{tabular}{|c|c|c|c|c|}
\cline { 2 - 5 } \multicolumn{1}{c|}{} & $\begin{array}{c}\text { Mineralisation } \\
{[\%]}\end{array}$ & $\begin{array}{c}\text { Mineralisierte } \\
\text { N-Menge } \\
{[\mathrm{kg}]}\end{array}$ & $\begin{array}{c}\mathrm{Nl}\left(\mathrm{t}_{\mathrm{n}}\right) \\
{[\mathrm{DM}]}\end{array}$ & $\begin{array}{c}\mathrm{Nl}\left(\mathrm{t}_{0}\right) \\
{[\mathrm{DM}]}\end{array}$ \\
\hline Anwendungsjahr & 10 & 1,020 & 0,77 & 0,77 \\
\hline 1. Jahr & 5 & 0,510 & 0,38 & 0,36 \\
\hline 2. Jahr & 3 & 0,306 & 0,23 & 0,21 \\
\hline 3. Jahr & 3 & 0,306 & 0,23 & 0,20 \\
\hline 4. Jahr & 3 & 0,306 & 0,23 & 0,19 \\
\hline 5. Jahr & 3 & 0,306 & 0,23 & 0,18 \\
\hline 6. Jahr & 3 & 0,306 & 0,23 & 0,17 \\
\hline 7. Jahr & 3 & 0,306 & 0,23 & 0,16 \\
\hline 8. Jahr & 3 & 0,306 & 0,23 & 0,16 \\
\hline 9. Jahr & 3 & 0,306 & 0,23 & 0,15 \\
\hline 10. Jahr & 3 & 0,306 & 0,23 & 0,14 \\
\hline 11. Jahr & 3 & 0,306 & 0,23 & 0,13 \\
\hline 12. Jahr & 3 & 0,306 & 0,23 & 0,13 \\
\hline 13. Jahr & 3 & 0,306 & 0,23 & 0,12 \\
\hline Summe & 51 & 5,202 & 3,91 & $\mathbf{3 , 0 7}$ \\
\hline
\end{tabular}

Tab. 7.11: Monetäre Bewertung der anrechenbaren Nährstoffgehalte an Stickstoff, Phosphor, Kalium, Magnesium und Kalzium, die in $1 \mathrm{Mg}$ (TM) Bioabfallkompost aus den Anlagen in Tarnow bzw. Borrentin enthalten sind

\begin{tabular}{|l|c|c|}
\hline \multirow{2}{*}{ Nährstoff } & \multicolumn{2}{|c|}{ Wert der Nährstoffe [DM] } \\
\cline { 2 - 3 } & $\begin{array}{c}\text { Bioabfallkompost } \\
\text { Tarnow }\end{array}$ & $\begin{array}{c}\text { Bioabfallkompost } \\
\text { Borrentin }\end{array}$ \\
\hline $\mathrm{N}$ & 3,87 & 3,07 \\
\hline $\mathrm{P}_{2} \mathrm{O}_{5}$ & 10,93 & 7,25 \\
\hline $\mathrm{K}_{2} \mathrm{O}$ & 4,73 & 4,34 \\
\hline $\mathrm{MgO}$ & 3,89 & 2,84 \\
\hline $\mathrm{CaO}$ & 5,05 & 5,52 \\
\hline Summe & 28,47 & 23,02 \\
\hline
\end{tabular}

Der anrechenbare Düngerwert von $1 \mathrm{Mg}$ (TM) Bioabfallkompost, der anhand der mittleren pflanzenverfügbaren Nährstoffgehalte an Stickstoff, Phosphor, Kalium, Magnesium und Kalzium der 
in den Anlagen in Tarnow und Borrentin erzeugten Komposte ermittelt wurde, beträgt 28,47 DM für den Tarnower sowie 23,02 DM für den Borrentiner Bioabfallkompost.

\subsubsection{Spurennährstoffe (Mikronährstoffe)}

$\mathrm{Zu}$ den unentbehrlichen Mikronährstoffen zählen die Schwermetalle Eisen, Kupfer, Mangan, Molybdän und Zink sowie die Nichtmetalle Bor und Chlor, denen die Wirksamkeit in geringer Konzentration gemeinsam ist. Mikronährstoffmangel führt - ebenso wie ein Mangel an Hauptnährstoffen - zu Wachstumsstörungen und spezifischen Mangelsymptomen bei den Pflanzen, die durch Düngung mit dem betreffenden Nährstoff behoben werden können (Oehmichen 1983: 369).

Mancherorts bedingen durch hohe Ernten verursachte jährliche Entzugsmengen für bestimmte Mikronährstoffe latente Mangelerscheinungen, die die erzielbare Ertragsleistung einschränken. Organische Dünger weisen teilweise erhebliche Gehalte an Spurenelementen auf, ,so daß sich oftmals diese Zufuhr als ausreichend erweist" (Hege 1992: 129).

Die Gehalte an Mikronährstoffen in Bioabfallkomposten können demzufolge bei geringen Bodengehalten als positiver Beitrag zur Mikronährstoffversorgung der Pflanzen gewertet werden. Bei hohen Bodengehalten an diesen Elementen und geringem Pflanzenbedarf ist ein entsprechender Eintrag jedoch als negativ zu bewerten (vgl. Wintzer et.al. 1996: 277).

Die Bedeutung einiger Schwermetalle als Spurenelemente für Pflanzen ist unumstritten, wenn auch nicht immer feststeht, welche Elemente als essentiell zu bezeichnen sind. „Außerdem ist nicht abschließend geklärt, in welchen Konzentrationen sie zu Mangel- oder Toxizitätserscheinungen führen“ (Huber 1995: 144). Aufgrund dieser fehlenden naturwissenschaftlichen Grundlagen ist eine ökonomische Bewertung der Mikronährstoffversorgung mit Bioabfallkomposten nicht möglich.

\subsubsection{Organikgehalt in Bioabfallkomposten}


Die Düngung mit organischen Stoffen dient vor allem dazu, durch Mineralisierung abgebaute organische Substanz im Boden zu ersetzen, um die Bodenfruchtbarkeit langfristig zu erhalten.

Kompost ist in erster Linie ein Humuslieferant, der zum Erhalt oder zur Neubildung des Humusgehalts auf den ackerbaulich genutzten Flächen beitragen kann. Ein hoher Humusgehalt im Kompost hat einen günstigen Einfluß auf die Luft- und Wasserführung, die biologische Aktivität und die Sorptionskapazitäten des Bodens. Kompost stellt also einen Wert durch Lieferung organischer Masse dar (Wintzer et.al. 1996: 126).

Im Gegensatz zur Nährstoffwirkung organischer Dünger ist deren Humuswirkung (Einfluß auf die Humusanreicherung im Boden) durch keine andere Düngungsmaßnahme zu ersetzen. „Hier haben die organischen Dünger und damit auch die Komposte ihr spezifisches positives Wirkungsfeld““ (Reinhold 1995: 2).

Unter Humus wird die abgestorbene organische Masse verstanden, die sich in einem Abbau-, Umbau- und Aufbauprozeß befindet und keine einheitliche und stabile Substanz darstellt. Entsprechend der Funktion des Humus im Boden wird zwischen Nähr- und Dauerhumus unterschieden (Oehmichen 1983: 33-34). Die Einflußbereiche dieser beiden Funktionsgruppen sind in folgender Tabelle dargestellt (nach Reinhold 1995: 2, verändert):

Tab. 7.12: Wesentliche Einflußbereiche von Humus im Boden

\begin{tabular}{|ll|ll|}
\hline & Nährhumus & \multicolumn{1}{c|}{ Dauerhumus } \\
\hline$\bullet$ & Ernährung der Bodenmikroben & $\bullet$ & Nährstoffspeicherung \\
$\bullet$ & Freisetzung von Kohlendioxid & $\bullet$ & Wasserspeicherung \\
$\bullet$ & Freisetzung von Stickstoff & $\bullet$ & Durchlüftung \\
$\bullet$ & Freisetzung von Phosphor & $\bullet$ & Erwärmung \\
\hline
\end{tabular}

Der Nährhumus ist der leicht zersetzbare und leicht umwandelbare Anteil des Humus im Boden, der den Bodenlebewesen, insbesondere den Mikroorganismen, als Nahrung dient. Bei der Mineralisierung dieser organischen Masse werden Wasser, Wärme und Pflanzennährstoffe, wie z.B. P- und S-Verbindungen, K-, Mg-, und Ca-Salze, Spurennährstoffe sowie $\mathrm{CO}_{2}$ und $\mathrm{NH}_{3}$, frei. Dauerhumus ist der schwer zersetzbare Anteil des Humus. Dauerhumusstoffe verbessern die Struktur 
des Bodens, sind aber nur begrenzt anreicherungsfähig (Oehmichen 1983: 35). Sie stellen im Wesentlichen das Endprodukt der Stoffwechselrückstände der Bodenorganismen dar (Reinhold 1995: 3).

Sand- und Lehmböden weisen unterschiedliche Gehalte an Nähr- und Dauerhumus sowie an Bodenorganismen auf. Aufgrund der geringeren Mengen an Nährhumus müssen die Bodenorganismen in Sandböden mit etwa der halben Ausgangsmenge an Nahrung existieren, wie diejenigen in Lehmböden, woraus sich deren höheres Aneignungsvermögen für Nahrungsstoffe ergibt. „Bei entsprechendem Nahrungsangebot, das auch durch Kompostgaben deutlich erhöht werden kann, reagieren die Bodenorganismen im Sandboden wesentlich aggressiver als die im Lehmboden“, was sich in einer stark erhöhten Umsetzrate organischer Dünger in sandigen Böden zeigt (Reinhold 1995: 4).

Auf Sandböden könnte die regelmäßige Aufbringung von Bioabfallkomposten aufgrund möglicher Ertragssteigerungen betriebswirtschaftlich sinnvoll sein (vgl. Wintzer et.al. 1996: 150). In diesem Zusammenhang ist jedoch auf das im Vergleich zu Lehmböden niedrige Adsorbtionspotential für Stoffwechselprodukte in Sandböden hinzuweisen: die nach einer organischen Düngung verstärkt auftretenden phytotoxischen organischen Zwischenprodukte geringer Löslichkeit können ihre schädigende Wirkung über eine gewisse Zeit voll entfalten mit der möglichen Folge von Wurzelnekrosen, die häufig mit sekundärem Befall durch bodenbürtige pilzliche und bakterielle Pflanzenkrankheiten verbunden sind. „Den erheblichen Unterschieden zwischen Sand- und Lehmböden in der Ernährung und ,Entsorgung' ihrer Bodenorganismen muß besonders bei der organischen Düngung und damit bei der Kompostanwendung Rechnung getragen werden, will man nicht starke Störungen im Ökosystem der hochgradig sensiblen Sandböden hinnehmen“ (Reinhold 1995: 4).

Andererseits verdanken insbesondere die humusarmen, grundwasserfernen Sandböden der intensiven Zufuhr von organischer Substanz ihre heutige Kulturwürdigkeit. So hängt z.B. das Wasserspeicherungsvermögen des Sandbodens wesentlich von dessen Humusgehalt ab (Renius et.al. 1992: 27-28).

Die Humuswirkung von Komposten im Boden wird durch die Menge organischer Substanz bestimmt, die mit einer Kompostgabe auf eine Fläche ausgebracht wird. Zur Kennzeichnung der 
Menge organischer Substanz wird diese in \% der Kompost-Trockenmasse angegeben (Reinhold 1995: 15).

Der organische Substanzgehalt von Komposten wird durch die Zusammensetzung der Ausgangsmaterialien, der Rottezeit und den Abbaubedingungen bestimmt. Dieser schwankt zwischen etwa $14 \%$ und $63 \%$ und sollte entsprechend den Qualitätsanforderungen der Bundesgütegemeinschaft Kompost mindestens $20 \%$ (bezogen auf die Trockenmasse von Fertigkomposten) betragen (Wintzer et.al.1996: 126).

Die Gehalte an organischer Substanz in den im Rahmen des Modellversuchs im Landkreis Demmin erzeugten Bioabfallkomposten sind in Tab. 7.13 dargestellt.

Tab. 7.13: Gehalte an organischer Substanz in Prozent der Trockenmasse (sog. ,organische Trockensubstanz" OTS) in den Bioabfallkomposten in Tarnow und Borrentin

\begin{tabular}{|c|c|c|c|}
\hline \multicolumn{2}{|c|}{ Bioabfallkompost Tarnow } & \multicolumn{2}{c|}{ Bioabfallkompost Borrentin } \\
\hline Datum der Probenahme & $\begin{array}{c}\text { OTS } \\
{[\% \mathrm{TM}]}\end{array}$ & Datum der Probenahme & $\begin{array}{c}\text { OTS } \\
{[\% \mathrm{TM}]}\end{array}$ \\
\hline 4.09 .1996 & 14,9 & 1.10 .1996 & 28,2 \\
\hline 13.02 .1997 & 20,0 & 17.03 .1997 & 21,6 \\
\hline 13.02 .1997 & 30,7 & 22.05 .1997 & 23,2 \\
\hline 22.05 .1997 & 34,3 & 28.10 .1997 & 25,6 \\
\hline 1.10 .1997 & 39,7 & 28.10 .1997 & 14,9 \\
\hline Mittelwert & 27,9 & Mittelwert & 22,7 \\
\hline
\end{tabular}

Die o.g Qualitätsanforderung wird im Mittel der Untersuchungen erfüllt. Die niedrigen Werte von unter $20 \%$ (OTS) sind vermutlich auf lange Rottedauern des beprobten Materials zurückzuführen, da mit zunehmender Rottedauer der Organikgehalt durch die Freisetzung von Kohlendioxid verringert wird.

Die Bedeutung des Organikgehalts von Bioabfallkomposten hängt davon ab, welche anderen Organiklieferanten durch den Komposteinsatz substituiert werden. Ein nennenswerter landwirtschaftlicher Bedarf an organikhaltigen Komposten ist aufgrund der betriebsinternen Möglichkeiten, den Organikverlust des Bodens zu ersetzen, in der Regel jedoch nicht vorhanden. Lediglich auf Flächen, deren Humusbilanz z.B. aufgrund eines hohen Hackfruchtanteils nicht über Ernterückstände und aufgrund der betrieblichen Gegebenheiten auch nicht über Wirtschaftsdünger 
ausgeglichen werden kann, ist der organischen Substanz im Kompost ein ökonomischer Wert beizumessen (Wintzer et.al.1996: 260).

In den am Modellversuch beteiligten Landwirtschaftsbetrieben ist eine Fremdzufuhr von Organik aus ackerbaulicher Sicht nicht notwendig, da die Humusbilanz durch die Einarbeitung von Stroh und anderen Ernterückständen ausgeglichen werden kann. Ein monetärer Wert ist der organischen Masse der in Tarnow und Borrentin landbaulich verwerteten Bioabfallkomposte also deswegen nicht zuzumessen, da auf den betreffenden Standorten eine ausreichende Humusversorgung gegeben ist.

Ist dagegen eine Ergänzung des Humusvorrats erforderlich, so kann durch die Verwertung der Bioabfallkomposte in Hinblick auf die Humusversorgung des Standortes eine Gründüngung ersetzt und deren Kosten eingespart werden (Kuhlmann et.al. 1996: 47).

Die eingesparten Erstellungskosten einer Kleegrasgemenge-Gründüngung als Stoppelsaat werden im folgenden zur monetären Bewertung der im Bioabfallkompost enthaltenen organischen Substanz herangezogen.

Für die Kalkulation der genannten Erstellungskosten werden die Arbeitsgänge

- Pflügen mit Packer,

- Kreiseleggendrillen,

- Stickstoff-Düngung mit einem Exaktstreuer sowie

- Mulchen des Aufwuchses

berücksichtigt (vgl. Renius et.al. 1992: 220). Dabei werden Preise des überbetrieblichen Maschineneinsatzes zugrunde gelegt, da in diesen die proportionalisierten Fixkosten sowie die Personalkosten berücksichtigt sind. Die einzelnen Kostenansätze zeigt Tabelle 7.14.

Tab. 7.14: Kalkulation der Kosten einer Kleegrasgemenge-Gründüngung

\begin{tabular}{|l|c|}
\hline $\begin{array}{c}\text { Arbeitsgang bzw. } \\
\text { Betriebsmittel }\end{array}$ & $\begin{array}{c}\text { Kostenansatz } \\
{[\mathrm{DM} / \mathrm{ha}]}\end{array}$ \\
\hline${\text { Pflügen } \text { mit Packer }^{1)}}$ & 100,00 \\
\hline Kreiseleggendrillen $^{1)}$ & 90,00 \\
\hline
\end{tabular}




\begin{tabular}{|l|c|}
\hline Düngung mit Exaktstreuer ${ }^{1)}$ & 15,00 \\
\hline Mulchen $^{1)}$ & 80,00 \\
\hline Saatgut $^{2)}$ & 54,75 \\
\hline N-Dünger & 37,50 \\
\hline Summe & 377,25 \\
\hline
\end{tabular}

1) Literaturdaten: vgl.(KTBL 1998 [2]:53)

2) Saatgutkosten für Kleegrasgemenge (2/3 Deutsches Weidelgras und 1/3 Weißklee) bei einer Aussaatmenge von $15 \mathrm{~kg} / \mathrm{ha}$ (Neubrandenburger Saaten 1998).

${ }^{3)}$ Düngerkosten bei einer Aufwandmenge von $50 \mathrm{~kg}$ N/ha (vgl. Renius et.al. 1992: 220 und 221) bei einem Stickstoffpreis von $0,75 \mathrm{DM} / \mathrm{kg}$ (s. Tab. 7.7)

Es wird angenommen, daß die Gründüngung als Stoppelfrucht eine Netto-Lieferung von $3 \mathrm{Mg}$ (OTS) je Hektar erbringt (Kuhlmann et.al. 1996: 47).

In der Beispielkalkulation entsprechen also 3 Mg (OTS) einem Wert von 377,25 DM.

Die Bioabfallkomposte aus den Anlagen in Tarnow und Borrentin wiesen im Mittel der Untersuchungen je Mg (TM) 0,279 Mg (OTS) bzw. 0,227 Mg (OTS) (s. Tab. 7.13) auf. Die organische Substanz von $1 \mathrm{Mg}(\mathrm{TM})$ Bioabfallkompost aus Tarnow weist demnach einen monetären Wert von 35,08 DM, diejenige aus Borrentiner Bioabfallkompost von 28,55 DM auf.

\section{$7.4 \quad$ Ressourcenschonung durch Kompostverwertung}

Die im Kompost enthaltene organische Masse stellt einen Wert dar aufgrund der Möglichkeit, hiermit Torfprodukte zu substituieren und auf diese Weise Ressourcen zu schonen.

Die niedrigen Marktpreise für Torf, die in Abhängigkeit von Qualität und Abnahmemenge zwischen 20 und 40 DM/Mg liegen, spiegeln die inländische Torfknappheit nicht wider. „Daran dürfte sich trotz der zur Neige gehenden Torfvorräte auch zukünftig wenig ändern, da andere europäische Länder und ehemalige Ostblockstaaten über umfangreiche Torfvorkommen verfügen und sowohl die Abbau- als auch die Transportkosten gering sind“ (Wintzer et.al. 1996: 261).

Neben der Ressourcenschonung durch Torfsubstitution ist dem Kompost auch ein Wert beizumessen durch die Verringerung der Freisetzung von im Torf gebundenem Kohlenstoff, denn beim mikrobiellen Torfabbau entsteht Kohlendioxid, welches aufgrund der langsamen Torfneubildung zur Konzentrationserhöhung klimarelevanter Gase beiträgt. „Der Geldwert der Einsparung liegt, wenn 
zwischen 100 und $250 \mathrm{DM}$ pro Tonne vermiedenem $\mathrm{CO}_{2}$ für alternative Maßnahmen zur Kohlendioxidverringerung angesetzt werden, zwischen 45 und 113 DM pro Tonne Kompost (40 \% TS), der Torf substituiert“ (Wintzer et.al. 1996: 261-262).

Aus einzelbetrieblicher Sicht finden die ökologischen Vorteile der Substitution von Torf durch andere Organiklieferanten aufgrund der relativ niedrigen Torfpreise bisher nicht in ökonomischen Berechnungen Berücksichtigung. Zudem werden heutzutage im Ackerbau Torfe als Organiklieferant nicht mehr eingesetzt.

\section{Schlußfolgerungen hinsichtlich der Konkurrenzfähigkeit des untersuchten Verwertungswegs}

\subsection{Praktizierte Verfahren der Bioabfallbehandlung}

Für Kompostierungsverfahren (s. Abschnitt 2.3) sind grundsätzlich die strukturreicheren Ausgangsmaterialien mit relativ geringem Wassergehalt geeignet, wie z.B. Grünabfälle und Bioabfälle aus überwiegend ländlich strukturierten Gebieten. „Bioabfälle aus städtischen Gebieten sowie Küchen- und Speiseabfälle sind grundsätzlich ebenfalls kompostierbar, erfordern aufgrund ihres relativ hohen Wassergehalts jedoch eine hohe Beimengung strukturreicherer Materialien, so daß teilweise eine Vergärung angebrachter ist“" (Kern 1999: 295).

Vorteile der Vergärung liegen in den geringen Geruchsemissionen durch geschlossene Anlagentechnik, dem relativ geringen Flächenverbrauch für die Anlagen sowie in der Erzeugung von Biogas (UBA 1995: 351).

Maßgebliche Anforderung an zu vergärende Substrate ist, daß deren organische Masse leicht fermentierbar ist. Geeignet hierfür sind Fette und Kohlenhydrate, eiweiß- oder ligninreiche Substrate dagegen weniger (Wintzer et.al. 1996: 174). Da z.B. Zellulose und Lignine nur sehr schlecht unter anaeroben Bedingungen abgebaut werden, müßten die Grünabfälle in einer aeroben 
Behandlungsstufe, wie z.B. in Form einer Nachrotte auf Mieten, nachbehandelt werden, um einen weitergehenden Abbau der organischen Fraktion zu erreichen (UBA 1995: 351). Zudem sind für Substrate in Biogasanlagen niedrige TM-Gehalte zu fordern, die sich für die Naßfermentation zwischen 10-15\% sowie für die Trockenfermentation zwischen 30 und $40 \%$ bewegen (Scheffold 1995). Für die Naßverfahren sind Gülle und ähnlich flüssige Stoffe besser geeignet als die demgegenüber relativ trockenen Bioabfälle, bei den derzeit betriebenen Anlagen nach dem Trockenverfahren besteht das Input-Material dagegen überwiegend aus Bioabfall privater Haushalte sowie gewerblicher Organik, wie z.B. Speisereste, Lebensmittel und Produktionsrückstände (Kern 1999: 299).

Gras- und holzartige Stoffe aus der Pflege von kommunalen Flächen und Straßenbegleitflächen weisen TM-Gehalte von etwa 25 bis $35 \%$ für das grasartige und 40 bis $50 \%$ für das holzartige Material auf. Die holzartigen Bestandteile eignen sich sowohl aufgrund ihres relativ hohen TMGehalts als auch wegen ihrer ligninreichen Bestandteile nicht als Substrat für Biogasanlagen. Die grasartigen Rückstände aus der Landschaftspflege könnten hingegen z.B. als Substrat zur Cofermentation in landwirtschaftliche Gülle-Biogasanlagen eingebracht werden. (Wintzer et.al. 1996: 173174). Bei der Cofermentation erfüllt der landwirtschaftliche Betrieb neben der Bioabfallbehandlung gleichzeitig Dienstleistungen als Lieferant von Strom, Wärme und Sekundärrohstoffdüngern.

Das Biogaspotential, das durch die gemeinsame Vergärung von Gülle sowie industriellen, gewerblichen und kommunalen Abfällen erschlossen werden kann, beläuft sich auf etwa 6,7 Mrd. $\mathrm{m}^{3}$ Biogas pro Jahr, was in energetischer Hinsicht ca. $7 \%$ des derzeitigen Erdgasverbrauchs Deutschlands entspricht (Weiland 1997: 205).

Das strukturreiche Grüngut könnte alternativ zur Kompostierung auch direkt verwertet werden (sog. Flächenkompostierung). Hierbei wird das Input-Material geschreddert und in Form von Grünguthäcksel mit einem Großflächenstreuer auf landwirtschaftlicher Nutzfläche ausgebracht. Zu bedenken ist hierbei jedoch, daß es bei der Flächenkompostierung zu keiner Erwärmung des Rotteguts kommt, so daß die Gefahr besteht, daß phytopathogene Organismen zu einer Belastung der Flächen führen (Strauch et.al. 1993: 115).

Denkbar als Alternative zur Bioabfallbehandlung durch Mischung der Bioabfälle mit strukturreichen Grünabfällen und anschließender Kompostierung ist also die getrennte Behandlung der 
unterschiedlichen Fraktionen. So könnten die strukturarmen Bioabfälle aus Haushalten einer Vergärung unterzogen und die strukturreichen Grünabfälle direkt verwertet werden.

\subsection{Stand der Bioabfallbehandlung in Deutschland}

In Deutschland existieren derzeit Behandlungskapazitäten für organische (kommunale) Abfälle von etwa 8,5 Mio. Mg, wobei der überwiegende Anteil aerob in Kompostierungsanlagen behandelt wird (ca. 7,1 Mio. Mg) und lediglich 1,2 Mio. Mg anaerob behandelt werden (Kern/Funda/Mayer 1998: 694).

Kern, Funda und Mayer ermittelten im Rahmen einer bundesweiten Umfrage, daß gegenwärtig 61 $\%$ der Anlagen zur aeroben Bioabfallbehandlung, die zusammen etwa $50 \%$ der gesamten aeroben Kompostierungskapazitäten stellen, das Verfahren der offenen oder (teil-) überdachten Mietenkompostierung nutzen. Dabei wird etwa ein Drittel der bundesweit erzeugten Komposte mittels Radlader umgesetzt, mehr als zwei Drittel aller Kompostierungsanlagen verfügen über keine Zwangsbelüftung (Kern/Funda/Mayer 1998: 696).

Hinsichtlich der Anlagenanzahl liegt der Schwerpunkt bundesweit bei den kleineren Anlagen (unter 6.500 Mg/a Anlagenkapazität), während hinsichtlich der Anlagenkapazität ein Trend zu Anlagen mit etwa 20.000 bis $50.000 \mathrm{Mg} / \mathrm{a}$ zu beobachten ist. Dabei liegt die mittlere Anlagengröße in den Alten Bundesländern bei ca. $12.500 \mathrm{Mg} / \mathrm{a}$ Kapazität je Anlage, in den Neuen Bundesländern bei etwa 14.400 Mg/a (Kern 1999: 305).

In den Neuen Ländern wurde die Anlagenkapazität in nur zwei Jahren verdoppelt. Dabei wurden überwiegend Anlagenkapazitäten in einfachen Mietensystemen bereitgestellt, die ohne Zwangsbelüftung gesteuert werden und mit etwa $15.000 \mathrm{Mg} / \mathrm{a}$ Anlagenkapazität fast doppelt so groß sind wie in den Alten Ländern (Kern/Funda/Mayer 1998: 698).

Überkapazitäten bis zu über $600.000 \mathrm{Mg} / \mathrm{a}$ in den einzelnen Bundesländern der Neuen Länder und geringe spezifische Behandlungskosten durch die relativ einfache Anlagentechnik sind als Grund dafür zu sehen, daß seit einigen Jahren eine ,,verstärkte Umlenkung von nativ-organischen Abfällen von den Alten in die Neuen Länder“ festzustellen ist (Kern/Funda/Mayer 1998: 698-699). Ein Grund für den weitgehenden Verzicht auf aufwendige Anlagentechnik wird auf die geringere Siedlungsdichte in den Neuen Ländern zurückgeführt. „Außerdem werden viele Anlagen auf ehemaligen Betriebsgeländen von Landwirtschaftlichen Produktionsgenossenschaften (LPG) betrieben, so daß diese Anlagen im 
Gegensatz zu einer neu errichteten Anlage auf der ,grünen Wiese‘ in vorhandene Strukturen integriert werden können“ (Kern/Funda/Mayer 1998: 699).

\section{$\underline{8.3 \quad \text { Ergebnisse der Untersuchung und Diskussion }}$}

Die Behandlungskosten für Bioabfälle wurden Anfang der 90er Jahre mit etwa $250 \mathrm{DM} / \mathrm{Mg}$ bis 400 DM/Mg angelieferten Bioabfalls sehr hoch kalkuliert (Helm 1997: 174). Durch zunehmende Konkurrenz innerhalb dieses Dienstleistungsbereichs ist das Preisniveau für die Behandlung einer Tonne Bioabfall bei Neuabschluß von Entsorgungsverträgen auf etwa $150 \mathrm{DM} / \mathrm{Mg}$ Bioabfall gesunken, wobei dieses regional auch deutlich niedriger bei etwa $100 \mathrm{DM} / \mathrm{Mg}$ Bioabfall liegen kann. An diesem Preisrahmen ist der untersuchte Verwertungsweg, ein dezentrales Anlagenkonzept unter der Regie von Landwirten, hinsichtlich der kostenseitigen Konkurrenzfähigkeit zu messen.

Wie hoch die Anzahl an Kompostierungsanlagen in einem Entsorgungsgebiet und damit das Maß an Dezentralität des untersuchten Anlagenkonzepts sein kann, hängt von dem Mindestdurchsatz ab, den eine Anlage erzielen muß, um hinsichtlich der spezifischen Behandlungskosten konkurrenzfähig zu sein.

Im Landkreis Ebersberg wurde ein dezentrales Konzept zur Bioabfallentsorgung installiert. Die Bioabfälle aus Haushalten werden zusammen mit dem notwendigen Strukturmaterial in 13 Kompostierungsanlagen, die einzelne Landwirte errichteten und betreiben, behandelt. Die Durchsatzleistung der Anlagen beträgt $650 \mathrm{Mg} / \mathrm{a}$ (Umweltamt Demmin 1997:3). Der produzierte Kompost sowie das anfallende Abwasser werden auf landwirtschaftlicher Nutzfläche verwertet (Anduschus 1993:37). Die Kosten der Bioabfallbehandlung hierfür werden mit 270 bis 320 DM/Mg (Input) angegeben (Wintzer et.al.1996:121) und liegen damit in ihrer Größenordnung etwa doppelt so hoch wie der derzeitig bei Neuabschlüssen von Entsorgungsverträgen erzielbare Preis. Es ist davon auszugehen, daß dieses Konzept unter den heutigen Marktverhältnissen bei Neuabschluß eines Entsorgungsvertrages auch unter Berücksichtigung der gegenüber Konzepten mit höherer Zentralität verringerten Transportkosten unter Kostengesichtspunkten nicht konkurrenzfähig wäre.

Aus dem relativ geringen Aufkommen an Bioabfällen aus der getrennten Sammlung und unter Berücksichtigung wirtschaftlicher Anlagendurchsätze resultiert, daß im Landkreis Demmin lediglich zwei Kompostierungsanlagen betrieben werden. Bei den Anlagendurchsätzen von jeweils etwa 
1.200 Mg/a und spezifischen Behandlungskosten von unter 70 DM/Mg (Input) kann dieses Konzept auch ohne Einbeziehung der verringerten Transportkosten unter diesem Aspekt mit zentralen Großanlagen konkurrieren. Dies gilt nicht uneingeschränkt für die entsprechende Variante der Errichtung von Anlagenneubauten, die sich mit ermittelten spezifischen Behandlungskosten von etwa $85 \mathrm{DM} / \mathrm{Mg}$ (Input) bereits im unteren Segment des heutigen Preisrahmens befindet. Unter Berücksichtigung des Gewinnanteils als Preisbestandteil und der Tendenz weiter sinkender Preise für die Bioabfallbehandlung könnte eine neu errichtete Anlage des genannten Anlagendurchsatzes unter Kostengesichtspunkten bereits problematisch sein. Gleiches gilt prinzipiell auch für die geringeren Durchsätze $(<1.200 \mathrm{Mg} / \mathrm{a})$ bei Anlagenneubau sowie diejenigen Fälle der Umnutzung von Altsiloanlagen mit Durchsätzen unter $800 \mathrm{Mg} / \mathrm{a}$. Die Variante mit $400 \mathrm{Mg} / \mathrm{a}$ Durchsatz ist aus heutiger Sicht mit spezifischen Kosten, die teilweise über regional beobachtbaren Preisen liegen, indiskutabel.

Bei Anlagendurchsätzen ab etwa $800 \mathrm{Mg} / \mathrm{a}$ mit spezifischen Behandlungskosten zwischen 70 und 80 $\mathrm{DM} / \mathrm{Mg}$ (Input) beginnt der kostenmäßig konkurrenzfähige Anlagenbetrieb bei Nutzung von Altanlagen für die Fälle, in denen eine hohe Flächenausnutzung des Rottebereichs vorliegt. Ab Durchsätzen über $1.400 \mathrm{Mg} / \mathrm{a}$ sinken die Behandlungskosten je Mg Inputmaterial entsprechend der Kapazität der umgenutzten Siloanlage auf unter 70 DM/Mg. In den Fällen des Anlagenneubaus wird das Kostenniveau von etwa $80 \mathrm{DM} / \mathrm{Mg}$ erst bei Durchsätzen über $2.000 \mathrm{Mg} / \mathrm{a}$ erreicht (bei niedrigen Strukturmaterialanteilen bereits eher). Bei diesen Durchsätzen sind offene Kompostierungsanlagen zwar prinzipiell genehmigungsfähig (s. Abschnitt 3.1), jedoch u.U. aus Emissionsschutzgründen problematisch.

Die spezifischen Behandlungskosten bei Anlagenneubau und Durchsätzen zwischen 1.200 Mg/a und 2.000 Mg/a unterschreiten bei Strukturmaterialanteilen ab $30 \%$ kaum $80 \mathrm{DM} / \mathrm{Mg}$ (Input), jedoch ist aufgrund der in den untersuchten Kostenvarianten dem jährlichen Durchsatz angepaßten Anlagenkapazität ein nur relativ geringer Effekt der Kostendegression zu beobachten. Ist die entsorgungspflichtige Körperschaft bereit, in Hinblick auf die Vorteile der gesicherten Verwertung und der geringeren Transportkosten im oberen Bereich der aktuellen Preisspanne die Dienstleistungen der Bioabfallbehandlung zu vergüten, so könnte bei den genannten Durchsätzen auch ein Konzept zur dezentralen Bioabfallkompostierung in Anlagenneubauten umgesetzt werden.

Die Umnutzung von Altsiloanlagen für die Bioabfallkompostierung ist aufgrund der erforderlichen Anlagengrößen v.a. in den Neuen Bundesländern möglich. Eine erhebliche Senkung der spezifischen Behandlungskosten durch Umnutzung von Altanlagen gegenüber der Errichtung von 
Anlagenneubauten liegt insbesondere dann vor, wenn die Siloanlage hinsichtlich ihres Durchsatzes in den Bereich der Kapazitätsauslastung gelangt. Ansonsten sind Vorteile bezüglich der spezifischen Behandlungskosten gegenüber dem Anlagenneubau bei geringen Durchsätzen kaum bzw. nicht vorhanden. Mit steigenden Durchsätzen und hoher Kapazitätsauslastung sind geringere Kosten von bis zu $20 \mathrm{DM} / \mathrm{Mg}$ (Input) realisierbar.

Einen wesentlichen Beitrag zur Konkurrenzfähigkeit dezentraler Kompostierungskonzepte mit Anlagendurchsätzen zwischen 800 und $2.000 \mathrm{Mg} / \mathrm{a}$ liefert die Tatsache, daß für diese eine offene Betriebsweise genehmigungsfähig ist. Weil in den dargestellten Low-Tech-Anlagen durch Verwendung von schlepperangebauten Umsetzgeräten ein hoher Bedarf an Rangierflächen besteht, würde der Anlagenbetrieb im Falle einer notwendigen Einhausung überproportional verteuert (vgl. Gronauer/Helm/Schön 1995:19).

Die monetären Werte der untersuchten ökonomischen Aspekte dieses Verwertungswegs, die die Kosten der Bioabfallbehandlung und Kompostverwertung, die hiermit verbundenen Risiken sowie die nutzenstiftenden Kompostwirkungen umfassen, sind in Tab. 8.1 dargestellt. Dabei sind die monetären Bewertungen hinsichtlich der genannten Aspekte in den im Rahmen dieser Arbeit ermittelten Spannen angegeben.

Tab. 8.1: Monetäre Bewertung der Einzelgößßen

\begin{tabular}{|l|l|l|}
\cline { 2 - 3 } \multicolumn{1}{c|}{} & $\begin{array}{l}\text { Betrieb einer } \\
\text { Kompostierungsanlage }\end{array}$ & $\begin{array}{l}\text { Landwirtschaftliche } \\
\text { Kompostverwertung }\end{array}$ \\
\hline Kosten & $\begin{array}{l}\text { je nach Durchsatz, Strukturmaterial- } \\
\text { anteil und Baukosten } \\
\text { von etwa 52 bis 115 DM/Mg (Input) } \\
\text { bzw. } \\
\text { ca. 145 bis 325 DM/Mg (TM) Kompost }\end{array}$ & $\begin{array}{l}\text { ca. 16 bis 44 DM/Mg Kompost } \\
\text { bzw. } \\
\text { ca. 22 bis 62 DM/Mg (TM) Kompost }\end{array}$ \\
\hline Risiken & $\begin{array}{l}\text { im Rahmen der } \\
\text { Betriebshaftpflichtversicherung mit } \\
\text { Umweltbasisdeckung abgedeckt }\end{array}$ & $\begin{array}{l}\text { ca. 0 bis 37 DM/Mg (TM) Kompost, } \\
\text { schwerpunktmäßig zwischen } \\
\text { etwa 0 und 5 DM/Mg (TM) Kompost }\end{array}$ \\
\hline
\end{tabular}




\begin{tabular}{|l|l|l|}
\hline Nutzen & $\begin{array}{l}\text { Vergütung für die Dienstleistung der } \\
\text { Bioabfallbehandlung durch die } \\
\text { entsorgungspflichtige Körperschaft }\end{array}$ & $\begin{array}{l}\text { Düngerwert: } \\
\text { ca. 25 DM/Mg (TM) Kompost }\end{array}$ \\
& $\begin{array}{l}\text { Wert der organischen Masse: } \\
\text { ca. 0 bis 35 DM/Mg (TM) Kompost } \\
\text { in Abhängigkeit von den } \\
\text { Standortbedingungen }\end{array}$ \\
\hline
\end{tabular}

Es zeigt sich, daß insbesondere die spezifischen Behandlungskosten (Kosten des Betriebs einer Kompostierungsanlage je Mg (Input)) die langfristige Preisuntergrenze für die untersuchten Konzepte der Bioabfallentsorgung determinieren, weil sich die monetär bewerteten Einzelgrößen der landwirtschaftlichen Kompostverwertung größenordnungsmäßig aufheben.

Die Konkurrenzfähigkeit des untersuchten Verwertungswegs zeigt sich demnach in einem Vergleich der spezifischen Behandlungskosten unterschiedlicher Verfahrens- und Anlagenkonzepte zur Bioabfallbehandlung, da bei den Verwertungswegen, die schließlich eine Vermarktung der erzeugten Bioabfallkomposte vorsehen, zukünftig kaum noch Erlöse erzielbar sein werden (Wintzer et.al. 1996: 156).

Auksutat und Löffler ermittelten in einer Studie die spezifischen Behandlungskosten der Bioabfallkompostierung für - entsprechend den zugrundeliegenden Anlagendurchsätzen von 10.000, 20.000, 40.000 und 60.000 Jahrestonnen - zentrale Anlagen (Auksutat/Löffler 1998: 10-49). Diese betragen demnach - ebenfalls ohne Berücksichtigung möglicher Erlöse aus der Kompostvermarktung - 198 DM/Mg bei einer Durchsatzleistung bzw. Anlagenkapazität von $10.000 \mathrm{Mg} / \mathrm{a}, 181 \mathrm{DM} / \mathrm{Mg}$ bei $20.000 \mathrm{Mg} / \mathrm{a}, 126 \mathrm{DM} / \mathrm{Mg}$ bei $40.000 \mathrm{Mg} / \mathrm{a}$ sowie $109 \mathrm{DM} / \mathrm{Mg}$ bei $60.000 \mathrm{Mg} / \mathrm{a}$ (Auksutat/Löffler 1998: 10-49).

Die spezifischen Behandlungskosten der Vergärung ermittelte Kern unter Berücksichtigung der erforderlichen Kompostierung des Gärreststoffs sowie der Erlöse aus dem Elektrizitätsverkauf (Kern 1999: 318). Im Mittel betragen diese bei einer Durchsatzleistung von $5.000 \mathrm{Mg} / \mathrm{a}$ zwischen 180 $\mathrm{DM} / \mathrm{Mg}$ und $270 \mathrm{DM} / \mathrm{Mg}$ (bei einem mittleren Wert von ca. $220 \mathrm{DM} / \mathrm{Mg}$ ), bei $10.000 \mathrm{Mg} / \mathrm{a}$ zwischen 150 und $250 \mathrm{Mg} / \mathrm{a}$ (bei einem mittleren Wert von etwa $180 \mathrm{DM} / \mathrm{Mg}$ ) sowie bei ca. 20.000 Mg/a zwischen 100 und 200 DM/Mg (mittlerer Wert ca. 140 DM/Mg) (Kern 1999: 320).

Maßgeblich für die Wettbewerbsfähigkeit der Biogasgewinnung ist neben der Kostenseite, in welchem Umfang das Biogas energetisch genutzt und ökonomisch vergütet wird (Wintzer et.al. 1996: 
194). Insbesondere bei der Cofermentation dürfte in vielen Fällen der Anlagenbetrieb jedoch aufgrund der ökonomischen Bedeutung der eingenommenen Abfallgebühren für die Wettbewerbsfähigkeit nicht auf die effiziente Biogasproduktion sondern auf hohe Mengendurchsätze an Cofermentationsrohstoffen ausgerichtet sein (Wintzer et.al. 1996: 196). Insofern stellt sich hier die Situation ähnlich dar wie im Bereich der Bioabfallkompostierung, die unter ökonomischen Gesichtspunkten weniger auf die Erzeugung und Verwertung hochwertiger Komposte als vielmehr auf die Vergütung für die Dienstleistung der Bioabfallbehandlung durch die entsorgungspflichtigen Körperschaften abzielt.

Strittig ist derzeit die Gültigkeit des Stromeinspeisegesetzes ${ }^{28}$ für die Biogas-Verstromung, da im Gesetzestext die Verwertung von außerlandwirtschaftlichen Abfällen nicht explizit berücksichtigt wird. „Die Stromvergütung kann daher im Einzelfall unter dem gesetzlich festgelegten Mindestbetrag liegen, wodurch sich die Wirtschaftlichkeit des Anlagenbetriebes erheblich verschlechtern kann“ (Weiland 1997: 209).

Darüberhinaus wird die Cofermentation nur dann der Land- und Forstwirtschaft zugerechnet, wenn die verarbeiteten Substrate überwiegend (>50\%) aus dem landwirtschaftlichen Betrieb stammen und die erzeugte Energie auch überwiegend in diesem verwertet wird. „In allen anderen Fällen erfolgt die steuerliche Bewertung der Cofermentation unter gewerblichen Gesichtspunkten und somit zu wesentlich ungünstigeren steuerlichen Konditionen“(Weiland 1997: 209).

Kasten ermittelte hinsichtlich der Fraktion der strukturreichen Grünabfälle in einem Vergleich der spezifischen Gesamtkosten (spezifische Behandlungs- und Verwertungskosten) der Flächenkompostierung und der offenen Dreicksmietenkompostierung von Grüngut in kleinen dezentralen Anlagen deutliche Kostenvorteile für die direkte Verwertung von Grünguthäcksel (Coester/Kasten 1999: 28).

Es ergaben sich spezifische Gesamtkosten von rd. $15 \mathrm{DM} / \mathrm{m}^{3}$ (FM) für die direkte Verwertung der Grünguthäcksel in Form der Flächenkompostierung. Dies entspricht je nach Dichte des Ausgangsmaterials Kosten zwischen ca. 75 und 120 DM/Mg angeliefertem Grüngut. Andere Untersuchungen ergaben Kosten der Flächenkompostierung, die - sofern ebenfalls die Aufwendungen vom Zerkleinern über das Zwischenlagern auf zu diesem Zweck befestigten Untergrund bis zur

${ }^{28}$ Gesetz über die Einspeisung vom Strom aus erneuerbaren Energien in das öffentliche Netz (Stromeinspeisegesetz) vom 7. Dezember 1990 
Ausbringung berücksichtigt wurden - in etwa gleicher Höhe liegen (vgl. Wintzer et.al. 1996: 103104).

Für die offene Mietenkompostierung ergaben sich aufgrund der intensiveren Behandlung der Ausgangsmaterialien höhere spezifische Gesamtkosten in Höhe von rd. $22 \mathrm{DM} / \mathrm{m}^{3}$ (FM), wenn bei möglicher Übereinstimmung gleiche maschinelle Ausstattung mit dem Verfahren der direkten Verwertung zugrunde gelegt wurde, entsprechend etwa 115 bis $180 \mathrm{DM} / \mathrm{Mg}$ angeliefertes Grüngut. In der Literatur finden sich diesbezüglich spezifische Gesamtkosten für die Pflanzenabfallkompostierung zwischen rd. 100 und 190 DM/Mg Input (FM), einschließlich der Erfassungskosten von 25 bis 50 DM/Mg (FM) und abzüglich möglicher Erlöse von 0 bis 30 DM/Mg Kompost (Wintzer et.al. 1996: 109-110). Hierdurch wurden die in der Beispielrechnung gefundenen Werte ebenfalls bestätigt. Im Kostenvergleich der beiden Verwertungswege ergibt sich also ein Vorteil von etwa 40 bis 60 $\mathrm{DM} / \mathrm{Mg}(\mathrm{FM})$ zugunsten der Flächenkompostierung. 


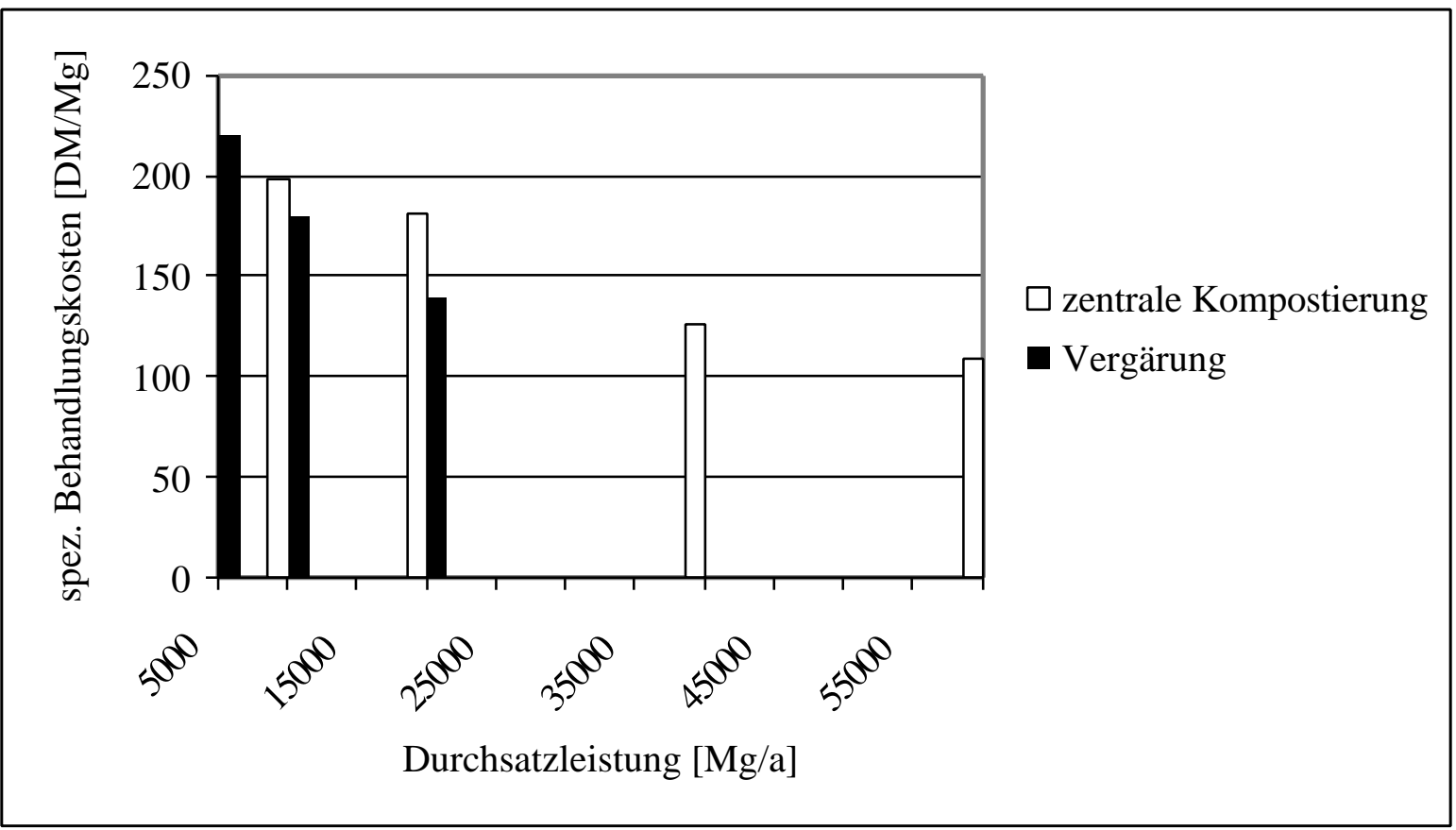

Abb. 8.1: Mittlere spezifische Behandlungskosten der Kompostierung in zentralen Großanlagen (nach Auksutat und Löffler 1998: 10-49) und der Vergärung (nach Kern 1999: 320) in Abhängigkeit von der Durchsatzleistung

Die im Rahmen dieser Arbeit untersuchten dezentralen Low-Tech-Anlagen mit relativ geringen Anlagendurchsätzen sind hinsichtlich der spezifischen Kosten im Vergleich zu zentralen Kompostierungsanlagen bzw. zu alternativen Verfahren der Bioabfallbehandlung wettbewerbsfähig (vgl. Kasten/Marggraf 1999: 283). Die Gründe hierfür sind in der einfachen Anlagentechnik, der rechtlichen Zulässigkeit des Verzichts auf eine Einhausung der Anlage sowie vorhandene Synergieeffekte des landwirtschaftlichen Betriebs mit dem Betrieb der Kompostierungsanlage zu sehen. 


\section{Zusammenfassung}

Gemäß den abfallrechtlichen Vorschriften wird vielfach die organische Fraktion des Hausmülls getrennt gesammelt und gesondert behandelt, um diese Stoffe in aufbereiteter Form einer Verwertung zuzuführen. Als häufigste Form der Aufbereitung werden die Bioabfälle aus Haushalten zusammen mit dem erforderlichen Strukturmaterial kompostiert, um diese anschließend in den Stoffkreislauf zurückführen zu können. Aufgrund der Sättigung regionaler Kompostmärkte erhält die landwirtschaftliche Verwertung der Bioabfallkomposte in diesem Zusammenhang einen zunehmenden Stellenwert. Eine Möglichkeit, die bisher eingeschränkte Bereitschaft zur landwirtschaftlichen Kompostverwertung zu erhöhen, könnte darin bestehen, Landwirte als Betreiber von Kompostierungsanlagen zu gewinnen, die in diesem Zusammenhang offene Kleinanlagen bevorzugen, weil der Investitionsbedarf relativ gering ist und sich die produzierten Komposte im eigenen Betrieb verwerten lassen. Solche Anlagen können wegen geringer Durchsatzleistungen, die insbesondere aus Emissionsschutzgründen begrenzt sind, nur im Rahmen dezentraler Entsorgungskonzepte für Bioabfälle betrieben werden.

Ziel dieser Arbeit war es, die Bedingungen darzustellen, unter denen diese dezentralen Konzepte der Bioabfallkompostierung in landwirtschaftlichen Low-Tech-Anlagen und der anschließenden landbaulichen Verwertung der produzierten Komposte konkurrenzfähig sind. Dazu wurden die ökonomischen Aspekte dieses Verwertungswegs untersucht, die die Kosten und unternehmerischen Risiken der Bioabfallbehandlung und Kompostverwertung sowie die nutzenstiftenden Kompostwirkungen beinhalten. Als verbreitetes Verfahren wurde die Kompostierung in offenen Dreiecksmieten zugrundegelegt, die auch in dem beispielhaft herangezogenen Modellversuch in Mecklenburg-Vorpommern (Landkreis Demmin) zur dezentralen Bioabfallkompostierung in Altsiloanlagen praktiziert wurde.

Umweltbeeinträchtigungen durch den Betrieb einer Kompostierungsanlage stellen für die Landwirte unternehmerische Risiken dar, sofern diese für deren Auswirkungen haften oder Einkommenseinbußen bzw. Vermögensschäden zu befürchten haben. Für die untersuchten Anlagengrößen sind diese Risiken jedoch im Rahmen der üblicherweise vorhandenen Betriebshaftpflichtversicherung mit Umweltbasisdeckung bereits abgedeckt.

Die Landwirte gehen bei der landbaulichen Verwertung der schadstoffbelasteten Bioabfallkomposte das Risiko einer Wertminderung bzw. eines Verlusts ihres Bodens als Produktionsgrundlage 
aufgrund zu hoher Schadstoffgehalte ein. Es existiert weder ein freiwilliger noch ein gesetzlicher Entschädigungsfonds zur Abwälzung dieser Risiken, so daß ein Landwirt, der Komposte auf seiner landwirtschaftlichen Nutzfläche verwertet, die hiermit in Zusammenhang stehenden Risiken selbst zu tragen hat. Eine Umfrage unter Versicherungsgesellschaften und Versicherungsmaklern, die sich in den Bereichen der landwirtschaftlichen Betriebshaftpflichtversicherungen sowie der Umwelthaftpflicht-versicherungen engagieren, zeigte, daß Versicherungsprämien zur Abdeckung definierter Einzelrisiken landbaulicher Kompostverwertung als Grundlage einer ökonomischen Bewertung nicht in Betracht kommen. Zur Risikobewertung wurden deshalb die in Bioabfallkomposten enthaltenen Schadstoffe herangezogen. Dabei wurden zur Beurteilung des Umweltgefährdungspotentials der Schwermetallgehalte im Kompost und im Boden die Grenzwerte der Bioabfallverordnung verwendet. Für die organischen Schadstoffe enthält die Bioabfallverordnung (1998) keine Grenzwerte. Nach aktuellem Kenntnisstand stellen organische Schadstoffe in Komposten jedoch kein Umweltproblem dar, sofern keine Hinweise auf spezifische Kontaminationen der Ausgangsmaterialien bestehen.

Ausgehend von mittleren Schwermetallgehalten in Ackerflächen bzw. in den beprobten Kompostausbringungsflächen in Tarnow und Borrentin sowie unter Berücksichtigung des atmosphärischen Eintrags, der Düngung mit Bioabfallkompost in Verbindung mit Mineraldünger, Auswaschung und Entzug über das Erntegut wurden durch Akkumulierung der überschüssigen Schwermetalleinträge die Zeitspannen bis zum Erreichen der Bodengrenzwerte der Bioabfallverordnung ermittelt. Um diese verschiedenen Fälle vergleichbar zu machen, wurden die zukünftigen Kosten zur Beseitigung des resultierenden Vermögensschadens für den Landwirt durch Diskontierung auf den gegenwärtigen Zeitpunkt bezogen. Aus dem so erhaltenen Gegenwartswert der Wiederherstellungs- bzw. Ersatzbeschaffungskosten der landwirtschaftlichen Nutzfläche wurden Risikobeträge je Mg (TM) ausgebrachten Bioabfallkomposts ermittelt, die z.B. dem Landwirt oder folgenden Generationen als Kompensation für die zukünftig eintretenden Vermögensschäden zur Verfügung stehen könnten. Die so ermittelten Beträge sind in der Mehrzahl der berechneten Fälle als vernachlässigbar einzustufen. Nur in den Fällen, in denen Bioabfallkomposte auf Sandböden aufgebracht werden, sind höhere Risikobeträge ermittelbar, weil der Diskontierungszeitraum aufgrund der hier niedrigen Bodengrenzwerte für Schwermetalle relativ kurz ist.

Die aus den Risikobeiträgen zum Klärschlammfonds abgeleiteten monetären Bewertungen der Risiken landbaulicher Kompostverwertung belaufen sich auf 5 DM/Mg (TM) bzw. 3,33 DM/Mg (TM) Kompost. 
Die monetäre Bewertung der nutzenstiftenden Kompostwirkungen über signifikante Ertragssteigerungen, die ausschließlich auf die Kompostanwendung zurückzuführen sind, war nicht möglich, weil diese bisher nicht nachgewiesen werden konnten. Es konnte jedoch der Düngerwert von Bioabfallkomposten ermittelt werden. Weil die im Kompost enthaltenen Nährstoffe keinen Marktwert aufweisen, wurde der monetäre Wert pflanzenverfügbarer Nährstoffe im Bioabfallkompost über durchschnittliche Handelsdüngerpreise für entsprechende Nährstoffmengen aus Mineraldüngern auf der Basis von Einzelnährstoffen ermittelt. Der anrechenbare Düngerwert von $1 \mathrm{Mg}$ (TM) Bioabfallkompost beträgt demnach etwa $25 \mathrm{DM}$.

Bioabfallkomposte weisen bodenverbessernde Eigenschaften auf, die v.a. auf deren Organikgehalt zurückzuführen sind. Insbesondere wird durch die Kompostdüngung die Aggregatstabilität und Wasserspeicherfähigkeit von Böden verbessert. Ein monetärer Wert ist der organischen Masse in Komposten nicht zuzumessen, wenn auf der Ausbringungsfläche eine ausreichende Humusversorgung gegeben ist. Ist dagegen eine Ergänzung des Humusvorrats erforderlich, so kann durch die Verwertung der Bioabfallkomposte in Hinblick auf die Humusversorgung des Standortes eine Gründüngung ersetzt und deren Kosten eingespart werden. Der daraus abgeleitete Wert beläuft sich auf bis zu 35 DM/Mg (TM) Bioabfallkompost.

Es zeigte sich, daß insbesondere die spezifischen Behandlungskosten die langfristige Preisuntergrenze für die untersuchten Konzepte der Bioabfallentsorgung determinieren, weil sich die monetär bewerteten Einzelgrößen der landwirtschaftlichen Kompostverwertung größenordnungsmäßig aufheben. Zur Überprüfung der Konkurrenzfähigkeit des untersuchten Verwertungswegs kamen als Alternativen zur Bioabfallkompostierung in dezentralen Low-Tech-Anlagen sowohl die Bioabfallbehandlung in zentralen Kompostierungsanlagen mit Durchsätzen zwischen etwa 10.000 und 60.000 Jahrestonnen sowie eine getrennte Behandlung der Abfallfraktionen in Form der Vergärung von strukturarmen Bioabfällen bei gleichzeitiger Flächenkompostierung des gehäckselten strukturreichen Grünguts in Betracht. Dabei zeigte sich die Wettbewerbsfähigkeit der untersuchten dezentralen Low-Tech-Anlagen schon bei Durchsätzen ab etwa $800 \mathrm{Mg} / \mathrm{a}$ für die Bioabfallbehandlung in umgenutzen Altsiloanlagen bzw. ab etwa $1200 \mathrm{Mg} / \mathrm{a}$ bei Bioabfallkompostierung in Anlagenneubauten. Die Gründe hierfür sind in der einfachen Anlagentechnik, der rechtlichen Zulässigkeit des Verzichts auf eine Einhausung der Anlagen sowie vorhandene Synergieeffekte des landwirtschaftlichen Betriebs mit dem Betrieb der Kompostierungsanlage zu sehen. 


\section{Literaturverzeichnis}

AbfKlärV: Klärschlammverordnung vom 15. April 1992

Anduschus, K. (1993): Möglichkeiten der Kompostierung von biogenen Siedlungsabfällen in der Landwirtschaft unter besonderer Berücksichtigung der Situation in den Neuen Bundesländern, Diplomarbeit, unveröffentlicht

Asche, E.; Steffens, D. (1995): Einfluß von Bioabfallkomposten unterschiedlicher Reifegrade auf Ertrag, N-Dynamik und Bodenstruktur im Feldversuch auf neun Standorten in Hessen, S. 59-74, in: Kolloqium über die Verwertung von Komposten im Pflanzenbau, Hrsg.: HLRL/HLVA, Kassel

ATV (Abwassertechnische Vereinigung e.V./ 1998): persönliche Mitteilung Herr Esch, 27.04.1998

Au, M.; Grüneklee, E. (1999): Leitlinien des Arbeitsschutzes in Abfallbehandlungsanlagen des Länderausschusses für Arbeitsschutz und Sicherheitstechnik; in: Bio- und Restabfallbehandlung III, Hrsg.: K. Wiemer, M. Kern, Witzenhausen

Auksutat, M.; Löffler, R. (1998): Kostenstrukturuntersuchung von Abfallbeseitigungs-verfahren, Hrsg.: Umweltbundesamt, Berlin

Bauordnungsamt Demmin (1995): Anlage zur Baugenehmigung der Kompostierungsanlage in Tarnow (Auflagen), Demmin 4.10.1995

Baeumer, K. (1990): Grundlagen der Integration einschließlich Planungs- und Entscheidungskriterien für den Praktiker, in: Integrierter Landbau - Systeme umweltbewußter Pflanzenproduktion, Hrsg.: R. Diercks, R. Heitefuss, München

Bernhardt, M. (1993): Kompostierung in Alt-Siloanlagen - Chance für eine dezentrale Bioabfallkompostierung im Bundesland Brandenburg; Abfallwirtschaftsjournal 5 Nr.7; S.576-580

Bilitewski, B.; Härdtle, G.; Marek, K. (1994): Abfallwirtschaft, Berlin-Heidelberg, 2. Auflage

BImSchG: Gesetz zum Schutz vor schädlichen Umweltwirkungen durch Luftverunreinigungen, Geräusche, Erschütterungen und ähnliche Vorgänge (Bundes-Immissionsschutzgesetz) in der Fassung der Bekanntmachung vom 14. Mai 1990, zul. geändert am 19.10.1998

BImSchV: Vierte Verordnung zur Durchführung des Bundes-Immissionsschutzgesetzes (Verordnung über genehmigungsbedürftige Anlagen - 4.BImSchV), in der Fassung der Bekanntmachung vom 14. März 1997, zul. geändert am 20.04.1998

BioAbfV: Verordnung über die Verwertung von Bioabfällen auf landwirtschaftlich, forstwirtschaftlich und gärtnerisch genutzten Böden (Bioabfallverordnung) vom 21. September 1998 
BioStoffV: Verordnung über Sicherheit und Gesundheitsschutz bei Tätigkeiten mit biologischen Arbeitsstoffen (Biostoffverordnung) vom 29. Januar 1999

BML (1999): Bundesministerium für Ernährung, Landwirtschaft und Forsten, persönliche Mitteilung Dr. von Heydebrand, 19.08.1999

Böhm, R. (1999): Ist die Anwendung der Biostoff-Verordnung in der Abfallwirtschaft sinnvoll und möglich?, in: Bio- und Restabfallbehandlung III, Hrsg.: K. Wiemer, M. Kern, Witzenhausen

Boxberger, J.; Helm, M. (1991): Aspekte der Rückführung des kompostierbaren Anteils der Haushaltsabfälle auf landwirtschaftliche Flächen, in: Biologische Verwertung und Behandlung organischer Haushaltsabfälle, Bayerisches Landesamt für Umweltschutz (Hrsg.), München; S.25-36

Brunner, G.; Müller, R.(1994): Handbuch für die Umweltpraxis im Betrieb: Rechtsfragen des Immissions- und des Gewässerschutzes, der Abfallentsorgung und des Umgangs mit Gefahrstoffen, Berlin-München

Coester, M.; Kasten, J. (1999): Grüngutkompost oder Grünguthäcksel?- Vergleichende Betrachtung zwischen den ökologisch und ökonomisch günstigen Verwertungswegen von Grüngutabfällen im ländlichen Raum; in: Müll und Abfall, 31.Jg.,Heft 1; S.22-28

Daschner, F. (1995): Bewertung der hygienischen Situation von Abfallwirtschaftsanlagen im Hinblick auf luftgetragene Keime, ENTSORGA Schriften 15, Köln

dlz (1992): Technik und Verfahren der Kompostierung, in: Landschaft pflegen, Sonderheft Nr.3, München; S. 48-54

dlz (1998): Agriview99; Landmaschinen-Marktiubersicht (CD-ROM)

Döhler, H. (1995): Kurz- und langfristige Wirkung des Kompost-N: -theoretische Ableitung und Quantifizierung des Düngebedarfes - S. 95-100, in: Kolloqium über die Verwertung von Komposten im Pflanzenbau, Hrsg.: HLRL/HLVA, Kassel

Döhler, H.; Eckel, H.; Eurich-Menden, B.; Klages-Haberkern, S.; Schieß1, K.; Schultheiß, U.; Schwab, M. (1999): Kompostierung; Sonderdruck des RKL (Rationalisierungs-Kuratorium für Landwirtschaft); Rendsburg-Osterrönfeld

Düngemittelverordnung: vom 9. Juli 1991, zuletzt geändert durch 2. Verordnung zur Änderung düngemittelrechtlicher Vorschriften vom 16. Juli 1997

Düngemittelgesetz: vom 15. November 1977, zuletzt geändert am 27. September 1994

Düngeverordnung: Verordnung über die Grundsätze der guten fachlichen Praxis beim Düngen, vom 26. Januar 1996

Ebertseder, Th. (1995): Grundlagen der landwirtschaftlichen Kompostverwertung; in: Komposte in der Landwirtschaft; KTBL-Arbeitspapier 223, Münster-Hiltrup; S.87-91 
Edelmann, W.; Schleiss, K. (1999): Gegenüberstellung der Ökobilanzen und Kosten von Kompostierung, Vergärung und thermischer Behandlung biogener Abfälle; in: Bio- und Restabfallbehandlung III, Hrsg.: K. Wiemer, M. Kern, Witzenhausen

Fischer, P.; Rasp, H.; Döhler, H.; Popp, L. (1993): Kompostanwendung - Aspekte der Pflanzenernährung, in: Kompostierung und landwirtschaftliche Kompostverwertung; KTBLArbeitspapier 191, Münster-Hiltrup; S. 125-151

Fromm, O. (1997): Möglichkeiten und Grenzen einer ökonomischen Bewertung des Ökosystems Boden, Frankfurt am Main-Berlin-Bern-New York-Paris-Wien

Gröblinghoff, F.; Oehmichen, J. (1995): Untersuchung über die Verwendung von Bio-Kompost im Landbau: Ergebnisse von Feldversuchen mit Getreide, Winterraps und Zuckerrüben, S. 55-58, in: Kolloqium über die Verwertung von Komposten im Pflanzenbau, Hrsg.: HLRL/HLVA, Kassel

Gronauer, A.; Helm, M.; Popp, L.; Rittel, L (1993): Planerische Anforderungen an Kompostierungsanlagen; in: Kompostierung und landwirtschaftliche Kompostverwertung; KTBLArbeitspapier 191; Münster-Hiltrup; 152-170

Gronauer, A.; Helm, M.; Schön, H. (1995): Bioabfallkompostierung- Chancen und Anforderungen an die Verfahrenstechnik; in: Komposte in der Landwirtschaft; KTBL-Arbeitspapier 223, MünsterHiltrup; S.15-22

Gronauer, A.; Helm, M.; Schön, H. (1997): Verfahren und Konzepte der Bioabfallkompostierung Vergleich-Bewertung-Empfehlungen; Teilbericht 1; Bayerische Landesanstalt für Landtechnik der TU München-Weihenstephan

Gronauer, A.; Helm, M. (1995): Einflußfaktoren auf den Rotteprozeß und das Potential gasförmiger Emissionen; in: Komposte in der Landwirtschaft; KTBL-Arbeitspapier 223; Münster-Hiltrup; 23-35

Hackenberg, S.; Wegener, H. (1999): Schadstoffeinträge in Böden durch Wirtschafts- und Mineraldünger, Komposte und Klärschlamm sowie durch atmosphärische Deposition - Regionale Frachtenmodelle zur Bewertung relevanter Schadstoffeinträge, Witzenhausen

Hackenberg, S.; Wegener, H.; Eurich-Menden, B. (1998): Schadstoffe im Bioabfall und Kompost; in: Müll und Abfall, 30.Jg.,Heft 9; S.587-591

Hege, H. (1992): Pflanzenernährung und Düngung im Integrierten Pflanzenbau, S. 96-165 in: Die Landwirtschaft, 10. Auflage, München

Helm, M. (1995): Prozeßführung bei der Kompostierung von organischen Reststoffen aus Haushalten, KTBL-Schrift 371, Münster-Hiltrup

Helm, M. (1997): Entwicklungsstand und Einsatz von Kompostierungsanlagen, in: Landwirtschaft als Dienstleister, KTBL-Arbeitspapier 240, Münster-Hiltrup, S.171-176 
Högl, D. (1995): Kompostqualität, 42-49, in: Komposte in der Landwirtschaft, Hrsg.: KTBL, Darmstadt

Huber, W.; Huber, A. (1995): Schadstoffbelastungen für Wasserpflanzen, in: Schadwirkungen auf Pflanzen, Hrsg.: B. Hock, E. Elstner, 3. Auflage, Heidelberg, Berlin, Oxford

Hund, K.; Kördel, W.; Kurth, H.-H. (1999): Entwicklung einer Untersuchungs- und Bewertungsstrategie zur Ableitung von Qualitätskriterien für Komposte, Fraunhofer-Institut für Umweltchemie und Ökotoxikologie, Foliensatz zum Vortrag im Rahmen des Kasseler Abfallforums 1999

Jungk, A. (1995): Pflanzennährstoffe und Düngemittel, in: Schadwirkungen auf Pflanzen, Hrsg.: B. Hock, E. Elstner, 3. Auflage, Heidelberg, Berlin, Oxford

Kasten, J.; Marggraf, R. (1998): Ökonomische Aspekte der Kompostierung von Bioabfällen aus Haushalten durch Landwirtschaftsbetriebe sowie der landwirtschaftlichen Kompostverwertung, in: Bioabfallverwertung, Initiativen zum Umweltschutz Bd.10, Osnabrück und Darmstadt, S.277-278

Kasten, J.; Marggraf, R. (1999): Dezentrale Bioabfallkompostierung in landwirtschaftlichen „LowTech“-Anlagen - Kostenuntersuchung eines Konzepts zur Bioabfallbehandlung im ländlichen Raum; in: Müll und Abfall, 31.Jg.,Heft 5; S.275-284

Kern, M.; Wiemer, K. (1990): Kostenstrukturen der Boxenkompostierung - Arbeitswirtschaft und Betriebskosten -, in: Abfallwirtschaft 4, Kassel

Kern, M.; Funda, K.; Mayer, M. (1998): Stand der biologischen Abfallbehandlung in Deutschland; in: Müll und Abfall, 30.Jg.,Heft 11; S.694-699

Kern, M. (1999): Stand und Perspektiven der biologischen Abfallbehandlung in Deutschland, in: Bio- und Restabfallbehandlung III, Hrsg.: K. Wiemer, M. Kern, Witzenhausen

Ketelsen, K., Cuhls, C. (1999): Emissionen bei der mechanisch-biologischen Behandlung von Restabfällen und deren Minimierung bei gekapselten MBA-Systemen, in: Bio- und Restabfallbehandlung III, Hrsg.: K. Wiemer, M. Kern, Witzenhausen

Kettrup, A.; Bieniek, D. (1991): Toxikologische Aspekte der Verwertung und Behandlung organischer Haushaltsabfälle, 8-14, in: Biologische Verwertung und Behandlung organischer Haushaltsabfälle, Hrsg.: Bayerisches Landesamt für Umweltschutz, München

Kiefer, J. (1999): Neue Rechtslage bei der landwirtschaftlichen Verwertung von Abfallstoffen; in: Müll und Abfall, 31.Jg.,Heft 8; S.460-464

Klages-Haberkern, S. (1993): Qualitätskriterien für Komposte, 65-85, in: Kompostierung und landwirtschaftliche Kompostverwertung, Hrsg.: KTBL, Darmstadt

Klages-Haberkern, S.; Schwab, M.; Döhler, H. (1994): Kompost: Was Sie jetzt wissen müssen; in: DLG-Mitteilungen 12/1994, S.18-21 
Kluge, R.; Embert, G. (1996): Das Düngemittelrecht. Landwirtschaftsverlag Münster-Hiltrup

Kluge, R.; Timmermann, F. (1995): Landbauliche Bewertung der Schwermetalle in organischen Reststoffen: Über normierte Gehalte oder über reale Frachten?, S. 9-19, in: Kolloqium über die Verwertung von Komposten im Pflanzenbau, Hrsg.: HLRL/HLVA, Kassel

Kockemüller-Kublun (1998): Abteilung Produktbereich der Itzehoer Versicherungen, schriftliche Mitteilung vom 5.05.1998

KrW-/AbfG: Gesetz zur Vermeidung von Rückständen, Verwertung von Sekundärrohstoffen und Entsorgung von Abfällen (Kreislaufwirtschafts- und Abfallgesetz) vom 27.September 1994

KTBL (Hrsg.) (1996): Taschenbuch Landwirtschaft - Daten für die Betriebskalkulation in der Landwirtschaft; 18. Auflage; München

KTBL (Hrsg.) (1997): Betriebsplanung 1997/98 - Daten für die Betriebsplanung in der Landwirtschaft; 15.Auflage; Münster-Hiltrup

KTBL (Hrsg.) (1998) [1]: Landschaftspflege - Daten zur Kalkulation von Arbeitszeit und Maschinenkosten; 4. Auflage; Münster-Hiltrup

KTBL (Hrsg.) (1998) [2]: Taschenbuch Landwirtschaft - Daten für die Betriebskalkulation in der Landwirtschaft; 19. Auflage; München

Kuhlmann, F.; Müller, H.; Jäger, C.; Möller, D. (1996): Einsatzmöglichkeiten und Absatzpotentiale von Biokompost in der Landwirtschaft, in: Umweltverträgliche Anwendung von Bioabfallkompost in der Landwirtschaft, Studie an der Universität Giessen

LAGA M 10 (1995): Länderarbeitsgemeinschaft Abfall, Merkblatt M 10: Qualitätskriterien und Anwendungsempfehlungen für Kompost, Berlin

Langbehn, C.; Pleßmann, F. (1999): Getreidebau nach 2000 - Orientierungslinien für den landwirtschaftlichen Unternehmer, in: GetreideMagazin, 5. Jg, Heft 2

LASI (Länderausschuß für Arbeitsschutz und Sicherheitstechnik / 1997): Leitlinien für den Arbeitsschutz in biologischen Abfallbehandlungsanlagen, LASI-Veröffentlichung LV13

Loll, U. (1998): Sickerwasser aus Kompostierungs- und Anaerobanlagen; in: Bio- und Restabfallbehandlung II; Hrsg.: K. Wiemer, M. Kern, Witzenhausen

LUFA Rostock (1996a): Hinweise zur offenen Mietenkompostierung; Rostock

LUFA Rostock (1996 b): Arbeitsbericht über Qualitätsuntersuchungen in Kompostierungs-anlagen, Rostock 
Ministerium für Bau, Landesentwicklung und Umwelt Mecklenburg-Vorpommern (1998a): Hinweise für die Genehmigung von Kompostierungsanlagen, Schwerin

Ministerium für Bau, Landesentwicklung und Umwelt Mecklenburg-Vorpommern (1998b): persönliche Mitteilung Herr Kröhan, Referat VIII, Schwerin 21.04.1998

Möller, H.; Kock, U.; Reimann, J.; Strehler, K.; Fry, B.(1997): Die beste Vorsorge für ihre Familie, top agrar - Sonderheft, Münster

Mühlenkamp, H.(1994): Kosten-Nutzen-Analyse, München

Nies, V.; Klages-Haberkern, S.(1993): Rechtliche Vorgaben für die Kompostierung und Kompostanwendung, 9-31, in: Kompostierung und landwirtschaftliche Kompostverwertung, Hrsg.: KTBL, Darmstadt

N.N. (1996): Landwirtschaftliche Klärschlammverwertung, Hrsg.: Abwassertechnische Vereinigung e.V. (ATV), Hennef

N.N.(1997 a): in: Bauernzeitung, Ausgabe Mecklenburg-Vorpommern, 38. Jg., Heft 22,

N.N.(1997 b): in: Bauernzeitung, Ausgabe Mecklenburg-Vorpommern, 38. Jg., Heft 41

N.N. (1998): "Mehr Verkäufe, aber geringere Kaufwerte", in: Bauernzeitung, Ausgabe Mecklenburg-Vorpommern, 39. Jg., Heft 31

N.N. (1999): Kompost-Journal - Info-Blatt 1999, Backhus Kompost-Technologie

Oehmichen, J. (1983): Pflanzenproduktion; Band 1: Grundlagen; Berlin, Hamburg

Pfadler, W.; Klages-Haberkern, S. (1993): Unternehmerische Aspekte bei der Behandlung und Verwertung von Grüngut und Bioabfall; in: Kompostierung und landwirtschaftliche Kompostverwertung; KTBL-Arbeitspapier 191; Münster-Hiltrup; 34-48

Poletschny, H. (1995): Bodenverbessernde Wirkung von Kompost in der Landwirtschaft, S. 75-82, in: Kolloqium über die Verwertung von Komposten im Pflanzenbau, Hrsg.: HLRL/HLVA, Kassel

Popp, L.; Fischer, P. (1995): Beurteilung der Kompostqualität, 36-41, in: Komposte in der Landwirtschaft, Hrsg.: KTBL, Darmstadt

Popp, L.; Helm, M.; Gronauer, A.; Boxberger, J. (1993): Verwertung inbegriffen - Landwirte als Betreiber von Kompostwerken - ein Überblick, in: RHINO-Fachkongreß Bioabfall-Management '93, Köln; S.357-359

Reimann, J.; Strehler, K.; Fry, B.(1996): Haus und Hof optimal versichern, top agrar - Sonderheft, Münster 
Reinhold, J. (1995): Qualität und Anwendung von Komposten, in: Schriften für die Kompostierungspraxis; Gütegemeinschaft Kompost Berlin-Brandenburg-Sachsen-Anhalt e.V.

Reloe, H.; Schuchardt, F. (1993): Kompostierungstechnik und -verfahren; KTBL-Arbeitspapier 191; Münster-Hiltrup; 171-200

Renius, W.; Lütke Entrup, E.; Lütke Entrup, N. (1992): Zwischenfruchtbau zur Futtergewinnung und Gründüngung - ein Baustein zur Bodenfruchtbarkeit und zum Umweltschutz, 3. Auflage, Frankfurt

Rieß, P.; Schramm, K.; Klages-Haberkern, S. (1993): Der Einfluß der Inputmaterialien auf die Kompostqualität, 86-108, in: Kompostierung und landwirtschaftliche Kompostverwertung, Hrsg.: KTBL, Darmstadt

Salje, P. (1997): Umwelt- und Produkthaftung der Produzenten, Lieferanten und Nutzer von Klärschlämmen und Komposten an Beispielen aus der Praxis, 201-205, in: Agrarrecht, Heft 7, 27. Jahrgang

Schaaf, H. (1995): Düngen mit Kompost im integrierten Pflanzenbau - ein Kosten-NutzenVergleich; in: Tagungsband „Kompost für die Landwirtschaft“; Rheinisches Institut für Ökologie

Schappler-Scheele, B.; Missel, Th. (1999): Gefährdungsanalyse von Keimemissionen in Kompostierungsanlagen und arbeitsmedizinische Relevanz für die Praxis - Ergebnisse einer Untersuchung von 42 Kompostierungsanlagen, in: Bio- und Restabfallbehandlung III, Hrsg.: K. Wiemer, M. Kern, Witzenhausen

Scheffold, K.(1995): Biologische Behandlung von Abfällen, in: Unterlagen zum Weiterbildenden Studium Bauingenieurwesen - Wasser und Umwelt, Kurs "Abfallwirtschaft I - Siedlungsabfälle", Hannover

Schenkendorf, P. (1998 a): Gayen \& Berns und Homann (Versicherungsmakler), schriftliche Mitteilung vom 28.04.1998

Schenkendorf, P. (1998 b): Gayen \& Berns und Homann (Versicherungsmakler), persönliche Mitteilung vom 11.05.1998

Schuchardt, F. (1995): Grundlagen der Kompostierung, in: Komposte in der Landwirtschaft, KTBL-Arbeitspapier 223, Münster-Hiltrup, S. 7-14

Spangenberg, B.; Hupfer, P.; Jehle, M.; Kreß, J. (1998): Dezentrale Kompostierung - sinnvolle Variante der Bioabfallverwertung ?; in: Müll und Abfall, 30.Jg.,Heft 2; S.70-74

Steffens, D.; Asche, E.; Pape, H. (1996): Einfluß von Biokompost verschiedener Reifegrade auf die Bodenfruchtbarkeit, in: Umweltverträgliche Anwendung von Bioabfallkompost in der Landwirtschaft, Studie an der Universität Giessen 
Strauch, D.; Philipp, W.; Menke, G.; Bruns, C. (1993): Aspekte der Hygiene (Humanhygiene, Veterinärhygiene und Phytohygiene) und des Arbeitsschutzes, 109-124, in: Kompostierung und landwirtschaftliche Kompostverwertung, Hrsg.: KTBL, Darmstadt

Tabasaran, O. (1994): Abfallwirtschaft, Abfalltechnik: Siedlungsabfälle, Berlin

TA Siedlungsabfall (1993): Dritte allgemeine Verwaltungsvorschrift zum Abfallgesetz; Technische Anleitung zur Vermeidung, Verwertung, Behandlung und sonstigen Entsorgung von Siedlungsabfällen

Termer (1998): Concordia Versicherungs-Gesellschaft auf Gegenseitigkeit, schriftliche Mitteilung vom 23.04.1998

UBA (1995): Umweltbundesamt (Hrsg.); Jahresbericht 1995, Berlin

Umweltamt Demmin (1997): Dezentrale Kompostierung im Landkreis Demmin; Bericht zum Modellversuch

Umweltamt Demmin (1999), Frau Schrader, persönliche Mitteilung

UmweltHG: Umwelthaftungsgesetz vom 10. Dezember 1990

Umweltministerium Baden-Württemberg (1994): Kompostierungserlaß Baden-Württemberg vom 1. April 1994

Vandre, R. (1995): Kurz- und langfristige Ausnutzung des Kompost-N: Eine Literaturstudie, S. 8793, in: Kolloqium über die Verwertung von Komposten im Pflanzenbau, Hrsg.: HLRL/HLVA, Kassel

Versteyl, L.(1992): Abfall und Altlasten, München

Wallnöfer, P.R.; Engelhardt, G.(1995): Schadstoffe aus dem Boden, 118-140, in: Schadwirkungen auf Pflanzen: Lehrbuch der Pflanzentoxikologie, B. Hock/E. Elstner (Hrsg.), Heidelberg-BerlinOxford, 3. Auflage

Weiland, P. (1997): Kofermentation - Perspektiven und Rahmenbedingungen, in: Landwirtschaft als Dienstleister, KTBL-Arbeitspapier 240, Münster-Hiltrup, S.202-209

WHG: Gesetz zur Ordnung des Wasserhaushalts (Wasserhaushaltsgesetz) in der Fassung vom 12. November 1996

Wicke, L. (1991): Umweltökonomie und Umweltpolitik, München

Wintzer, D.; Leible, L.; Rösch, Ch.; Bräutigam, R.; Fürniß, B.; Sardemann, G. (1996): Wege zur umweltverträglichen Verwertung organischer Abfälle; in: Abfallwirtschaft in Forschung und Praxis; Band 97; Berlin 



\section{Inhaltsverzeichnis}

\section{Abbildungsverzeichnis \\ Tabellenverzeichnis \\ Abkürzungsverzeichnis}

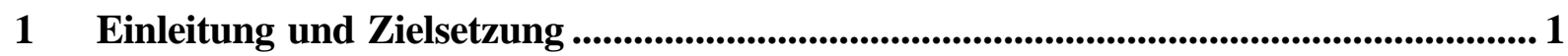

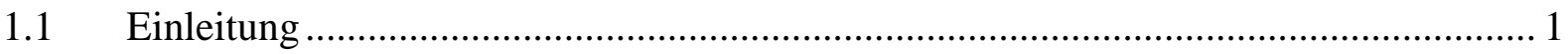

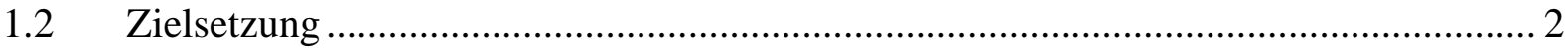

$1.3 \quad$ Vorgehensweise

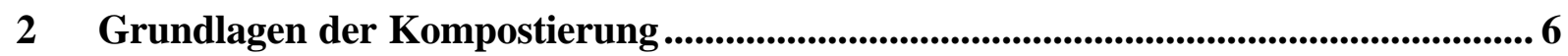

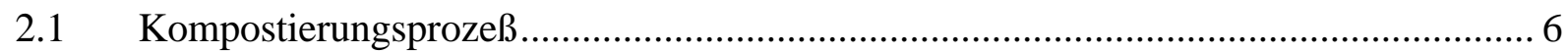

2.2 Rottegrad, Strukturmaterialanteil und Umsetzintervall.......................................... 7

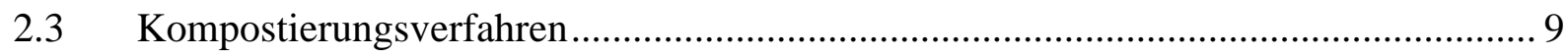

2.4 Verfahrensschritte der offenen Mietenkompostierung.............................................. 12

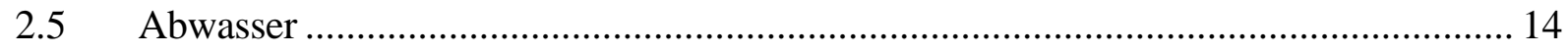

3 Rechtliche Grundlagen ........................................................................................ 15

3.1 Rechtliche Grundlagen der Genehmigung für Errichtung und Betrieb von

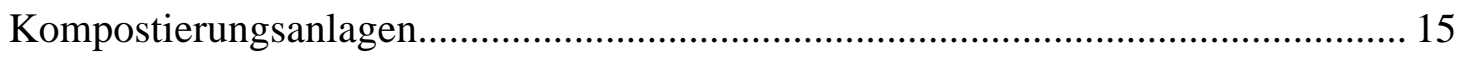

3.2 Geeignete Inputmaterialien für die Kompostierung ............................................ 16

3.3 Rechtliche Grundlagen der landbaulichen Kompostverwertung................................ 19

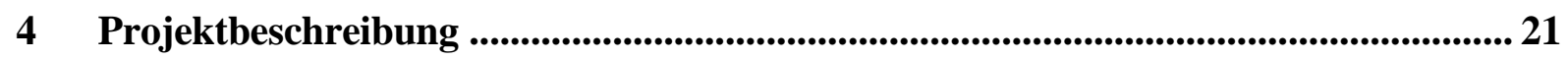

4.1 Modellversuch zur dezentralen Kompostierung im Landkreis Demmin..................... 21

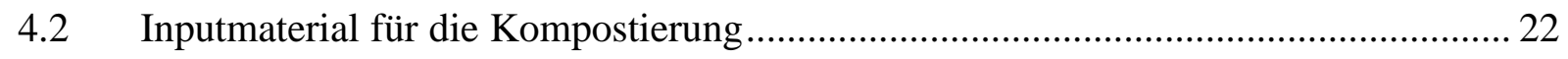




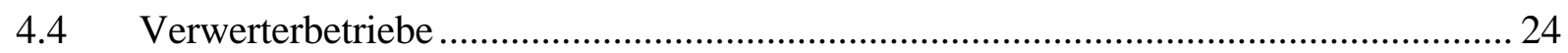

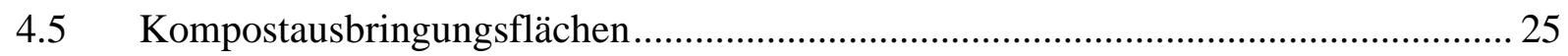

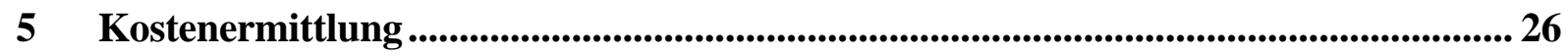

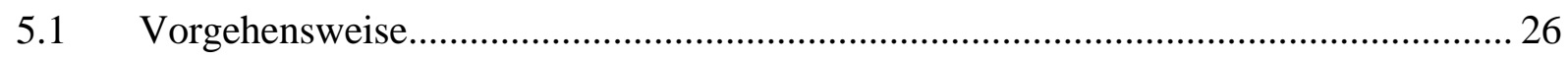

5.2 Zeitbedarfswerte der einzelnen Arbeitsgänge bei der Bioabfallbehandlung................ 27

5.3 Kostenansätze für die Bioabfallbehandlung ...................................................... 28

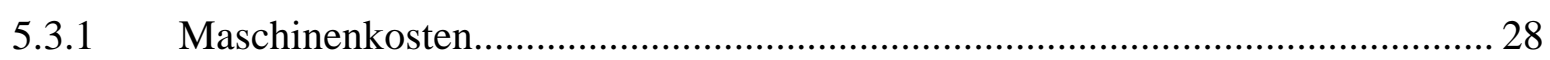

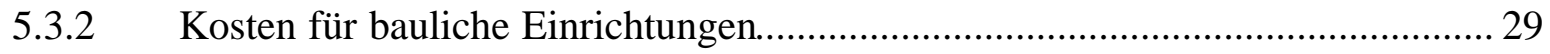

5.3.2.1 Neubau offener Kompostierungsanlagen................................................... 29

5.3.2.2 Umnutzung von Flachsiloanlagen für die Kompostierung............................. 31

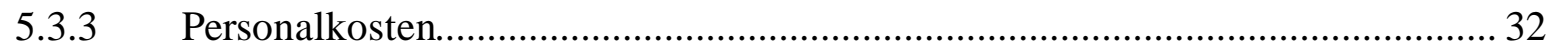

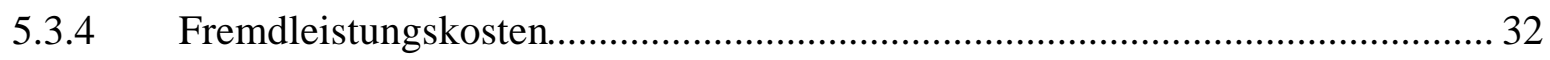

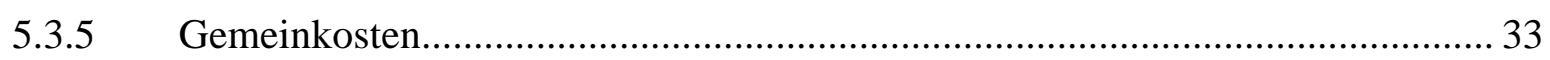

5.4 Kostenvarianten der Bioabfallbehandlung in landwirtschaftlichen

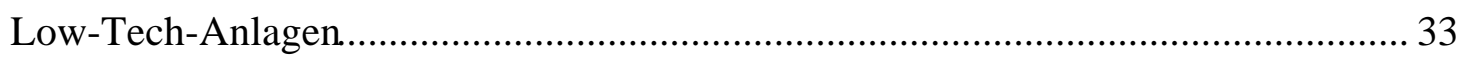

5.5 Spezifische Gesamtkosten der Bioabfallbehandlung in landwirtschaftlichen Low-

Tech-Anlagen (Spezifische Behandlungskosten) ................................................... 34

5.6 Zeitbedarfswerte der landbaulichen Kompostverwertung........................................ 38

5.7 Kostenansätze für die landbauliche Kompostverwertung ........................................ 40

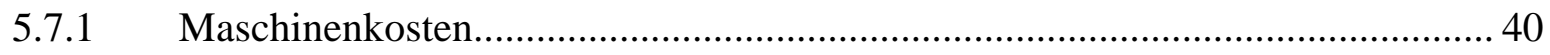

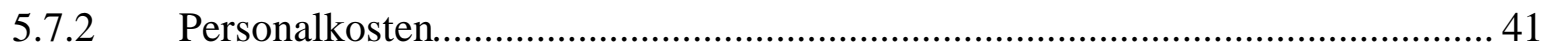

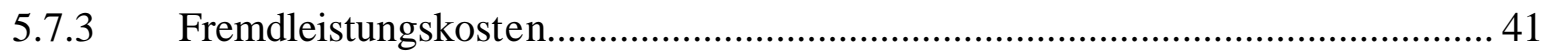

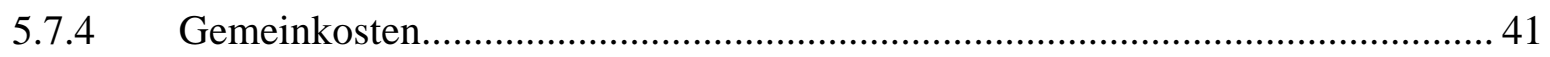

5.8 Spezifische Gesamtkosten der landbaulichen Kompostverwertung (spezifische Verwertungskosten) 


\section{Risiken der Bioabfallkompostierung und der landwirtschaftlichen}

Kompostverwertung.

6.1 Vorgehensweise

6.2 Risiken des Betriebs einer Kompostierungsanlage ............................................. 47

6.2.1 Umweltbeeinträchtigungen durch den Betrieb einer Kompostierungsanlage..... 47

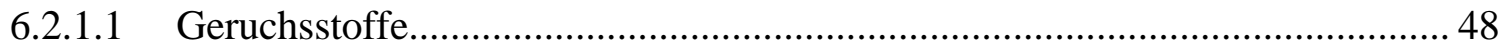

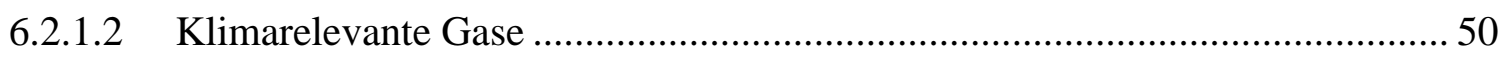

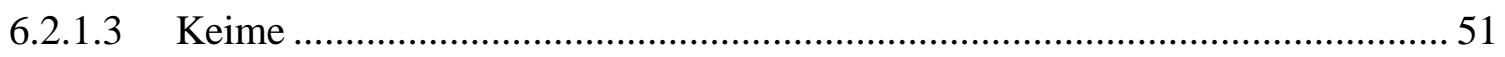

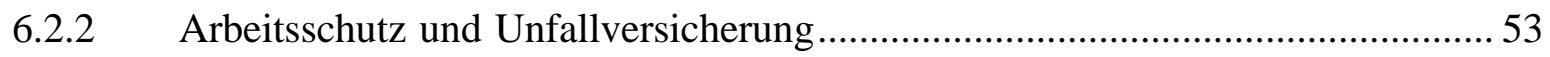

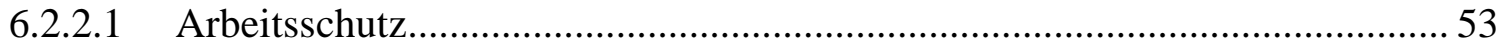

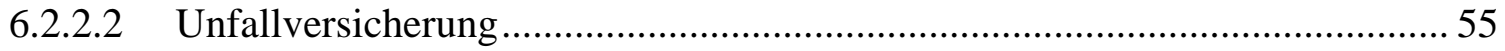

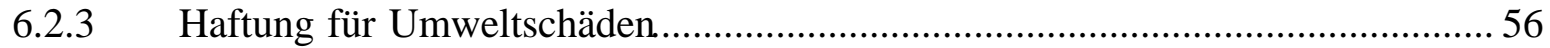

6.2.4 Versicherung des Risikos von Umweltschäden.............................................. 58

6.3 Risiken im Zusammenhang mit der landwirtschaftlichen Kompostverwertung.......... 60

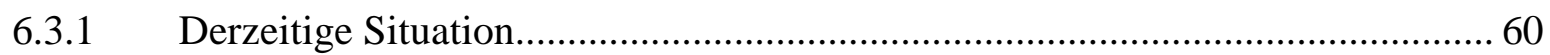

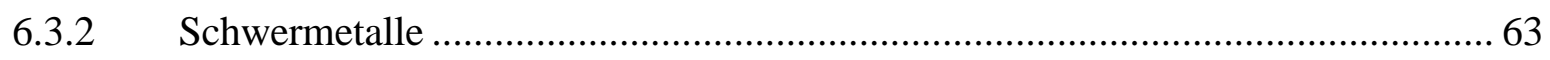

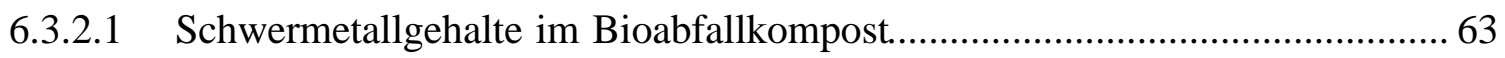

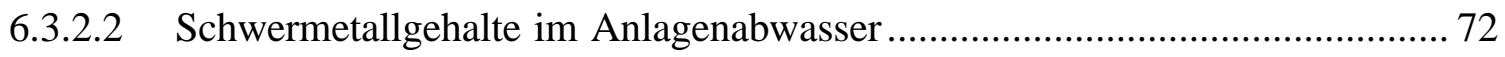

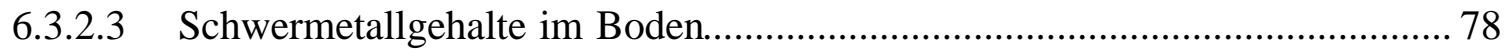

6.3.2.4 Schwermetallbelastung des Bodens durch Kompostbeaufschlagung............... 85

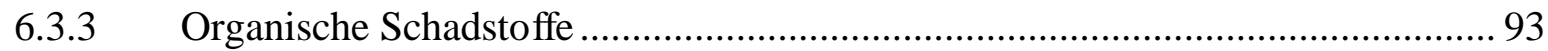

6.3.3.1 Polychlorierte Dibenzodioxine (PCDD) und Dibenzofurane (PCDF) ............. 95

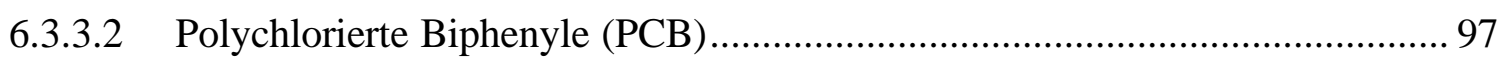

6.3.3.3 Polyzyklische aromatische Kohlenwasserstoffe (PAK)................................ 98

6.3.3.4 Adsorbierbare, organisch gebundene Halogene (AOX).................................. 99

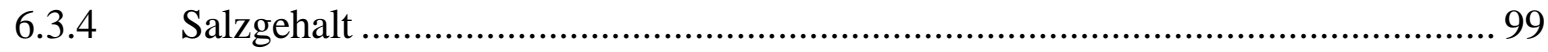

6.3.5 Aspekte der Phytohygiene bei landbaulicher Verwertung von Bioabfallkomposten.

6.3.6 Überprüfung der Versicherbarkeit des Risikos von Umweltschäden aus landbaulicher Kompostverwertung ............................................................ 103

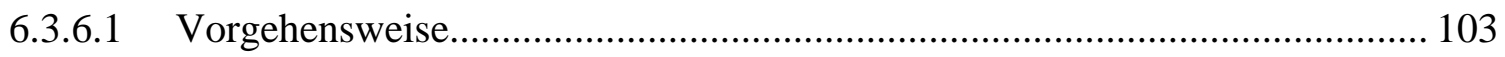

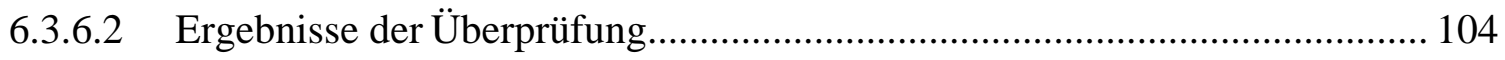

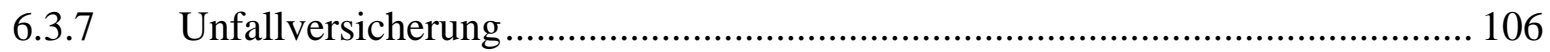


6.3.8 Ökonomische Bewertung des Bodens zur Quantifizierung der nicht versicherbaren Vermögensschäden durch Kompostverwertung ....................... 106

6.3.8.1 Ökonomische Berwertungsansätze für den Boden......................................... 106

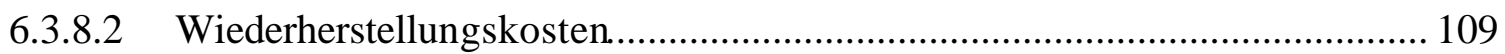

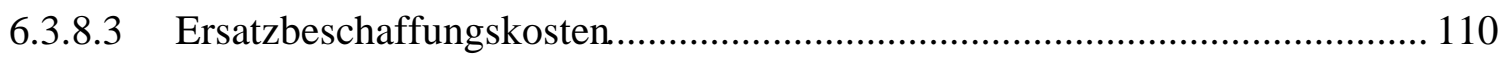

6.3.9 Ökonomische Bewertungsansätze für Einkommenseinbußen durch

Ertragsausfälle und Qualitätsminderungen des Ernteguts.

6.3.10 Monetäre Quantifizierung von Preiszuschlägen für die Wiederherstellung bzw.

Ersatzbeschaffung landwirtschaftlicher Nutzfläche (Risikoprämien)

6.3.10.1 Ermittlung von Risikoprämien durch Diskontierung des Vermögensschadens

6.3.10.2 Ermittlung von Risikoprämien durch Umrechnung der Risikobeiträge zum Klärschlammfonds

7 Nutzen der landwirtschaftlichen Kompostverwertung........................................... 123

7.1 Bodenverbessernde Eigenschaften von Kompost ............................................... 124

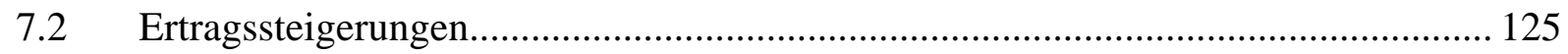

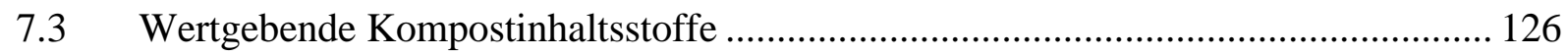

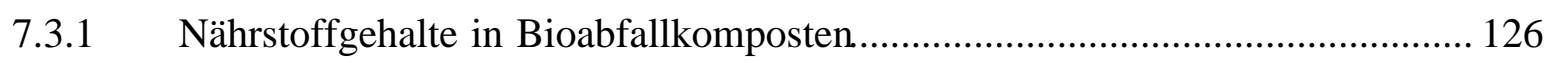

7.3.1.1 Gesamtgehalte an Makronährstoffen in Bioabfallkomposten.........................127

7.3.1.2 Pflanzenverfügbare Gehalte an Makronährstoffen in Bioabfallkomposten... 129

7.3.1.3 Monetäre Bewertung der pflanzenverfügbaren Makronährstoffe .................. 133

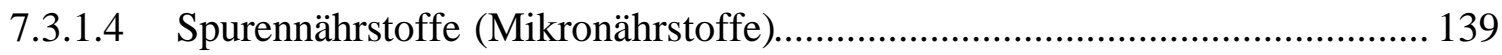

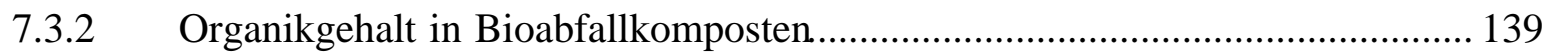

7.4 Ressourcenschonung durch Kompostverwertung ............................................... 144

8 Schlußfolgerungen hinsichtlich der Konkurrenzfähigkeit des untersuchten

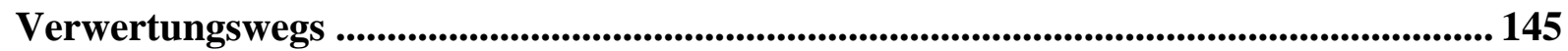

8.1 Praktizierte Verfahren der Bioabfallbehandlung...................................................... 145

8.2 Stand der Bioabfallbehandlung in Deutschland .................................................. 146

8.3 Ergebnisse der Untersuchung und Diskussion................................................... 147 
9 Zusammenfassung .

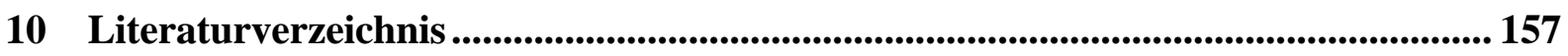

\section{Danksagung}

Anhang 


\section{Abbildungsverzeichnis}

Abb.2.1: Ablaufschema der offenen Mietenkompostierung in 13

Landwirtschaftsbetrieben

Abb. 5.1: Spezifische Behandlungskosten in Abhängigkeit vom

Anlagendurchsatz (Strukturmaterialanteil: 35 Vol.-\%)

Abb. 5.2: Spezifische Behandlungskosten in Abhängigkeit vom

Strukturmaterialanteil für ausgewählte Anlagendurchsätze zwischen $400 \mathrm{Mg} / \mathrm{a}$ und $2800 \mathrm{Mg} / \mathrm{a}$

Abb. 5.3: Spezifische Verwertungskosten der Transport- und Ausbringungskette mit einem Stalldungstreuer (Ladekapazität: 5 Mg Kompost) bzw. einem Tellerbreitstreuer (Ladekapazität: 6 Mg Kompost) in Abhängigkeit von der auszubringenden Kompostmenge

Abb. 5.4: Spezifische Gesamtkosten der Transport- und Ausbringungskette für die Fälle einer Streuer-Ladekapazität von $6 \mathrm{Mg}$ Kompost bei einzelbetrieblicher bzw. $10 \mathrm{Mg}$ Kompost bei überbetrieblicher Ausbringung in Abhängigkeit von der auszubringenden Kompostmenge

Abb. 5.5: Spezifische Verwertungskosten der Transport- und Ausbringungskette mit einem Stalldungstreuer (Ladekapazität: 5 Mg Kompost) bzw. einem Tellerbreitstreuer (Ladekapazität: $6 \mathrm{Mg}$ Kompost) in Abhängigkeit vom Anlagendurchsatz

Abb. 6.1: Mittlere Gehalte an Blei, Chrom, Kupfer, Nickel und Zink in Bioabfallkomposten

Abb. 6.2: Mittlere Gehalte an Cadmium und Quecksilber in Bioabfallkomposten

Abb. 6.3: Mittlere Schwermetallgehalte von Bioabfallkomposten in Prozent der

Grenzwerte der Bioabfallverordnung für eine zulässige

Kompostausbringungsmenge von höchstens $20 \mathrm{Mg}$ innerhalb von 3

Jahren

Abb. 6.4: Mittlere Schwermetallgehalte von Bioabfallkomposten in Prozent der Grenzwerte der Bioabfallverordnung für eine zulässige

Kompostausbringungsmenge von höchstens $30 \mathrm{Mg}$ innerhalb von 3 Jahren

Abb. 6.5: Gehalte an Blei, Chrom, Kupfer, Nickel und Zink in verschiedenen Wirtschaftsdüngern sowie deren mittlere Gehalte in den Bioabfallkomposten aus den Anlagen in Tarnow und Borrentin

Abb. 6.6: Gehalte an Cadmium und Quecksilber in verschiedenen Wirtschaftsdüngern sowie deren mittlere Gehalte in den Bioabfallkomposten aus den Anlagen in Tarnow und Borrentin

Abb. 6.7: Gehalte an Kupfer, Blei, Chrom, Nickel und Zink im Abwasser aus offenen Anlagen zur Dreiecksmietenkompostierung

Abb. 6.8: Gehalte an Cadmium und Quecksilber im Abwasser aus offenen Anlagen zur Dreiecksmietenkompostierung

Abb. 6.9: Schwermetallfrachten an Kupfer, Blei, Chrom, Nickel und Zink, die bei einmaliger Ausbringung von Anlagenabwasser und Kompost in den angegebenen Mengen auf einen Hektar Ackerfläche gelangen

Abb. 6.10: Schwermetallfrachten an Cadmium und Quecksilber, die bei einmaliger Ausbringung von Anlagenabwasser und Kompost in den angegebenen Mengen auf einen Hektar Ackerfläche gelangen 
Abb. 6.11: Bodengrenzwerte für die Gehalte an Blei, Chrom, Kupfer, Nickel und Zink nach der Bioabfallverordnung (1998) in Abhängigkeit von der mineralischen Bodenart

Abb. 6.12: Bodengrenzwerte für die Gehalte an Cadmium und Quecksilber nach der Bioabfallverordnung (1998) in Abhängigkeit von der mineralischen Bodenart

Abb.6.13: Durchschnittliche Gehalte an Blei, Chrom, Kupfer, Nickel und Zink der Aufbringungsflächen in Tarnow und Borrentin mit den Grenzwerten der BioAbfV (für die Bodenart Lehm)

Abb. 6.14: Durchschnittliche Gehalte an Cadmium und Quecksilber der Aufbringungsflächen in Tarnow und Borrentin mit den Grenzwerten der BioAbfV (für die Bodenart Lehm)

Abb. 6.15: Mittlere Schwermetallgehalte in den Kompostausbringungsflächen im Landkreis Demmin in Prozent der Bodengrenzwerte der Bioabfallverordnung für die Bodenart Lehm

Abb. 6.16: Mittlere Schwermetallgehalte der Aufbringungsflächen in Tarnow und Borrentin, in Ackerböden Baden-Württembergs sowie mittlere Schwermetallgehalte in Böden

Abb. 6.17: Ermittelte Risikoprämien für die landbauliche Verwertung von relativ gering mit Schwermetallen belasteten Bioabfallkomposten auf Sandböden für unterschiedliche Diskontsätze

Abb. 7.1: Nährstoffmengen, die mit $20 \mathrm{Mg}$ bzw. $30 \mathrm{Mg}$ Bioabfallkompost innerhalb von 3 Jahren ausgebracht werden können

Abb. 7.2: Prozentualer Anteil pflanzenverfügbarer Makronährstoffe in den Bioabfallkomposten aus den Anlagen in Tarnow und Borrentin in bezug auf deren Gesamtgehalte

Abb. 8.1: Mittlere spezifische Behandlungskosten der Kompostierung in zentralen Großanlagen und der Vergärung in Abhängigkeit von der Durchsatzleistung 


\section{Abkürzungsverzeichnis}

a

$\mathrm{Cd}$

$\mathrm{Cr}$

$\mathrm{Cu}$

evtl.

FM

$\mathrm{g}$

Gew.-\%

GV

$\mathrm{h}$

ha

$\mathrm{Hg}$

i.A.

$\mathrm{Km}$

1

LN

$\mathrm{m}$

$\max$.

$\mathrm{Mg}$

$\mathrm{mg}$

Mio.

Mrd.

ng

$\mathrm{Ni}$

o.g.

OS

OTS

$\mathrm{Pb}$

$\mathrm{pH}-\mathrm{Wert}$

Teq

TM

TS

u.E.

u.U.

v.a.

Vol.-\%

z.B.

$\mathrm{Zn}$
Jahr

Cadmium

Chrom

Kupfer

eventuell

Frischmasse

Gramm

Gewichtsprozent

Großvieh-Einheit

Stunde

Hektar

Quecksilber

im Allgemeinen

Kilometer

Liter

landwirtschaftliche Nutzfläche

Meter

maximal

Gewichtstonne (Megagramm)

Milligramm

Million

Milliarde

Nanogramm

Nickel

oben genannt

organische Substanz

organische Trockensubstanz

Blei

negativer dekadischer Logarithmus der Wasserstoffionenaktivität

Toxizitätsäquivalent

Trockenmasse

Trockensubstanz

unter Einschränkungen

unter Umständen

vor allem

Volumenprozent

zum Beispiel

Zink 


\section{Abkürzungsverzeichnis}

a

$\mathrm{Cd}$

$\mathrm{Cr}$

$\mathrm{Cu}$

evtl.

FM

$\mathrm{g}$

Gew.-\%

GV

$\mathrm{h}$

ha

$\mathrm{Hg}$

i.A.

$\mathrm{Km}$

1

LN

$\mathrm{m}$

$\max$.

$\mathrm{Mg}$

$\mathrm{mg}$

Mio.

Mrd.

ng

$\mathrm{Ni}$

o.g.

OS

OTS

$\mathrm{Pb}$

$\mathrm{pH}-\mathrm{Wert}$

Teq

TM

TS

u.E.

u.U.

v.a.

Vol.-\%

z.B.

$\mathrm{Zn}$
Jahr

Cadmium

Chrom

Kupfer

eventuell

Frischmasse

Gramm

Gewichtsprozent

Großvieh-Einheit

Stunde

Hektar

Quecksilber

im Allgemeinen

Kilometer

Liter

landwirtschaftliche Nutzfläche

Meter

maximal

Gewichtstonne (Megagramm)

Milligramm

Million

Milliarde

Nanogramm

Nickel

oben genannt

organische Substanz

organische Trockensubstanz

Blei

negativer dekadischer Logarithmus der Wasserstoffionenaktivität

Toxizitätsäquivalent

Trockenmasse

Trockensubstanz

unter Einschränkungen

unter Umständen

vor allem

Volumenprozent

zum Beispiel

Zink 
Kostenvariante A1

\section{\begin{tabular}{|l|l|}
\hline MATERIAL \\
\hline
\end{tabular}}

Jahresinputmenge

Zusammensetzung

Dichte

\begin{tabular}{|l|l|}
\hline Dichte & \\
\hline & \\
\hline & \\
\hline
\end{tabular}

Volumen

\begin{tabular}{|l|l|}
\hline & \\
\hline & \\
\hline & \\
\hline & \\
\hline
\end{tabular}

Gewichtsanteil

\begin{tabular}{|l|l|}
\hline & \\
\hline Rottedauer & \\
\hline durchschnittliches \\
\hline Monatsaufkommen \\
\hline maximaler Monatsanfall \\
\hline \multicolumn{2}{|l|}{} \\
\hline \multicolumn{2}{|l|}{ TS-Gehalt (Fertigkompost) } \\
\hline
\end{tabular}

TS-Gehalt (Fertigkompost)

Mietenhöhe

Mietenbasisbreite

\section{ANLAGENDIMENSIONIERUNG}

\section{Anlagenteil $\quad$ Berechnungsgrundlage}

Anlieferungsfläche

Rottefläche

Rangierfläche

Zwischenlager für

Strukturmaterial

Kompostlager

Anlagenfläche (gesamt)

zu verwertende

Abwassermenge

$10 \%$

\begin{tabular}{|r|r|l|}
\hline & & \\
\hline & 400,00 & $\mathrm{Mg} / \mathrm{a}$ \\
\hline & $80 \%$ & Vol.-\% \\
\hline & $20 \%$ & Vol.-\% \\
\hline & 0,6 & $\mathrm{Mg} / \mathrm{m}^{3}$ \\
\hline & 0,3 & $\mathrm{Mg} / \mathrm{m}^{3}$ \\
\hline
\end{tabular}

0,54

$0,5 \mathrm{Mg} / \mathrm{m}^{3}$

$740,74 \mathrm{~m}^{3} / \mathrm{a}$

$592,59 \mathrm{~m}^{3} / \mathrm{a}$

$444,44 \mathrm{~m}^{3 / a}$

$148,15 \mathrm{~m}^{3 / a}$

$400,00 \mathrm{~m}^{3} / \mathrm{a}$

$355,56 \mathrm{Mg} / \mathrm{a}$

44,44 $\mathrm{Mg} / \mathrm{a}$

$200,00 \mathrm{Mg} / \mathrm{a}$

12 Wochen

$30,77 \mathrm{Mg}$

$56,98 \mathrm{~m}^{3}$ (kon)

$56,00 \mathrm{Mg}$

$103,70 \mathrm{~m}^{3}$

$61,70 \%$

$1,5 \mathrm{~m}$

$2,5 \mathrm{~m}$

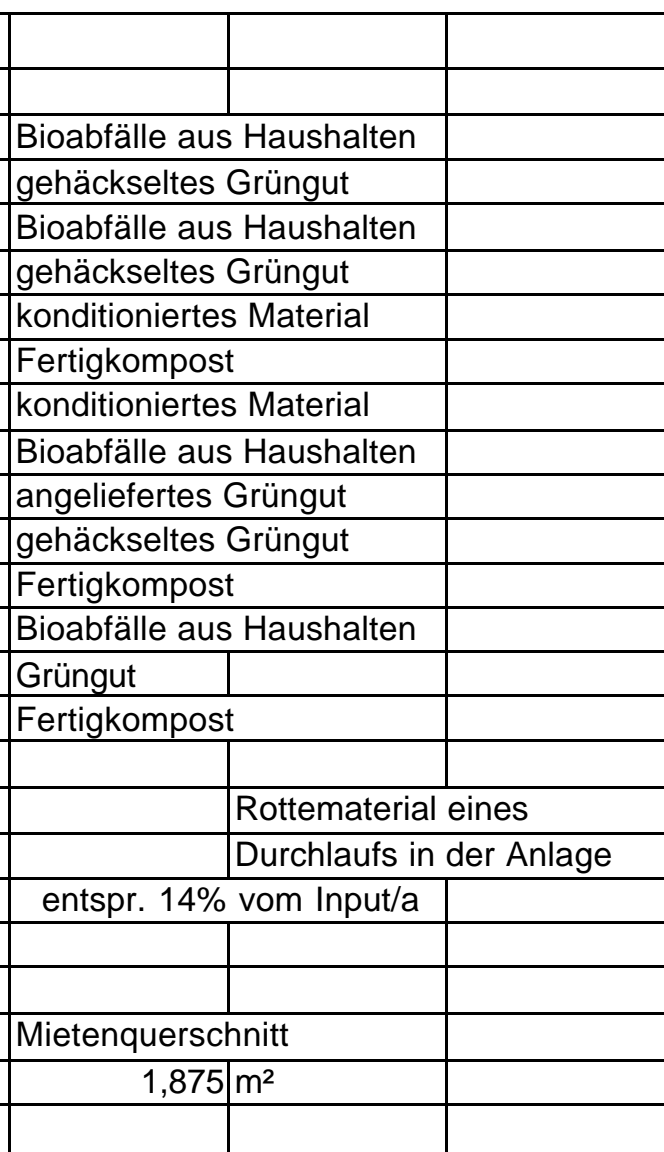

Anlagenneubau

$5 \%$ vom Input in Mg/a, ausgedrückt in $\mathrm{m}^{2}$

$1,33 \mathrm{~m}^{2} / \mathrm{m}^{3}$ Rottematerial bei max.M.-Anfall

$40 \%$ der Rottefläche

der Rottefläche

$10 \%$ der Rottefläche

\begin{tabular}{|r|l|l|}
$10 \%$ & der Rottefläche \\
\hline & & \\
\hline & & \\
\hline 0,2 & $\mathrm{~m}^{3} / \mathrm{m}^{2 *} \mathrm{a}$ & \\
\hline
\end{tabular}

\begin{tabular}{l|l}
\hline \\
\hline
\end{tabular}

$20,00 \mathrm{~m}^{2}$

$295,90 \mathrm{~m}^{2}$

$118,36 \mathrm{~m}^{2}$

29,59

$29,59 \mathrm{~m}^{2}$

$493,44 \mathrm{~m}^{2}$

$98,69 \mathrm{~m}^{3} / \mathrm{a}$

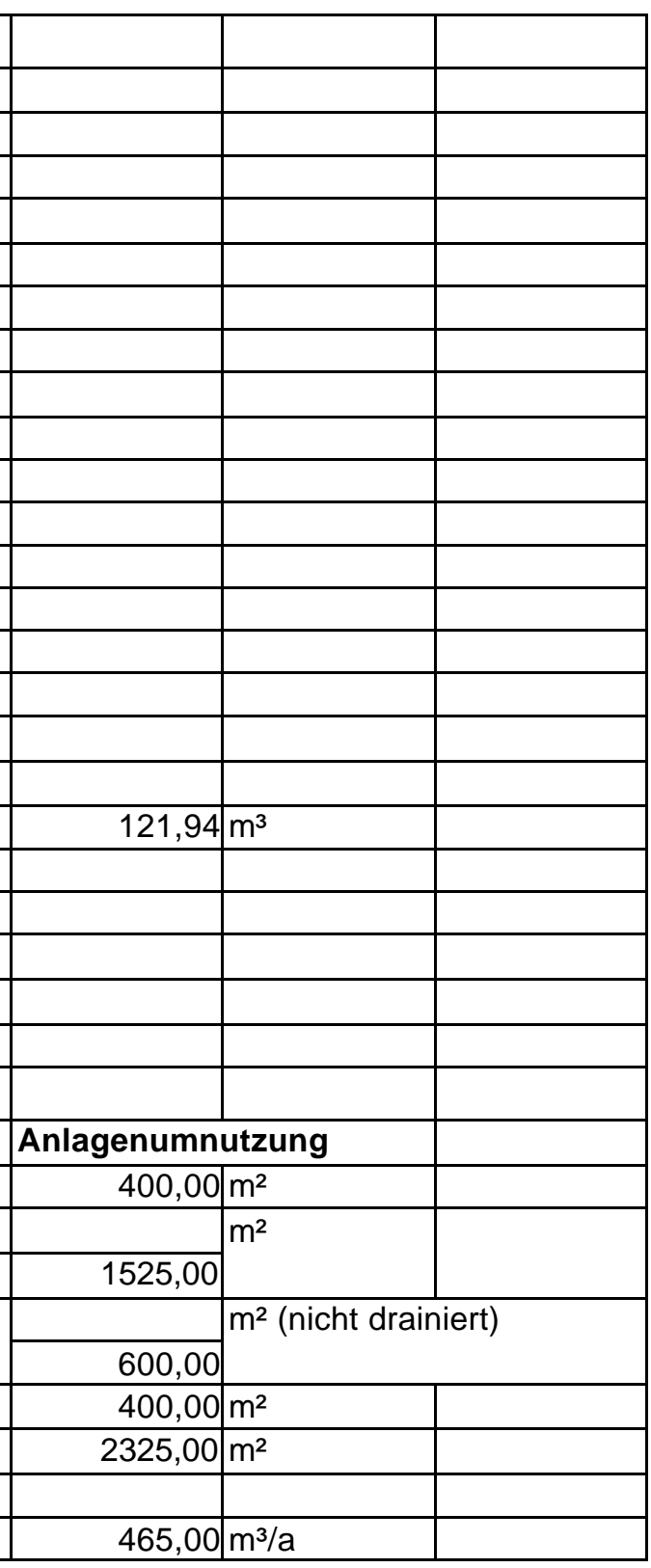




\begin{tabular}{|c|c|c|c|c|c|c|c|c|c|c|}
\hline \multicolumn{11}{|l|}{ ZEITEN } \\
\hline \multicolumn{3}{|l|}{ Arbeitsgang } & \multicolumn{2}{|c|}{ eingesetzte Maschinen } & \multicolumn{2}{|c|}{ Zeitbedarf/Einheit } & \multicolumn{2}{|c|}{ geleistete Einheiten } & \multicolumn{2}{|c|}{ Zeitbedarf/Jahr } \\
\hline \multicolumn{3}{|c|}{ Materialannahme } & & & 4,000 & h/Woche & 52,000 & Wochen/a & 208,000 & $h / a$ \\
\hline \multicolumn{3}{|c|}{ Manuelle Störstoffauslese } & & & 1,000 & $h / 100 m^{3}(\operatorname{In})$ & $1.037,037$ & $\mathrm{~m}^{3} / \mathrm{a}$ & 10,370 & $h / a$ \\
\hline \multicolumn{3}{|c|}{ Zerkleinerung von Strukturmaterial } & \multicolumn{2}{|l|}{ TL, SZ, Schr. } & 1,000 & $h / 50 m^{3}(\ln )$ & 444,444 & $\mathrm{~m}^{3} / \mathrm{a}$ & 8,889 & $h / a$ \\
\hline \multicolumn{3}{|c|}{ Aufsetzen einer Matte aus Strukturmat. } & \multicolumn{2}{|l|}{$\mathrm{TL}, \mathrm{AS}$} & 0,300 & $\mathrm{~h} / 100 \mathrm{~m}^{3}$ (kon) & 740,741 & $\mathrm{~m}^{3} / \mathrm{a}$ & 2,222 & $h / a$ \\
\hline \multicolumn{3}{|c|}{ Aufsetzen der Dreiecksmieten } & \multicolumn{2}{|l|}{ TL, AS } & 1,000 & $\mathrm{~h} / 20 \mathrm{~m}^{3}$ (kon) & 740,741 & $\mathrm{~m}^{3} / \mathrm{a}$ & 37,037 & $\mathrm{~h} / \mathrm{a}$ \\
\hline \multicolumn{3}{|c|}{ Umsetzen der Dreiecksmieten } & \multicolumn{2}{|l|}{ Schl., MU } & 0,005 & $\mathrm{~h} / \mathrm{m}$ (Mietenl.) & $3.381,728$ & $\mathrm{~m} / \mathrm{a}$ & 16,909 & $\mathrm{~h} / \mathrm{a}$ \\
\hline \multicolumn{3}{|c|}{ Reinigung der Annahmefläche } & \multicolumn{2}{|l|}{ TL, AS } & 0,500 & $h / 150 m^{3}(\ln )$ & $1.037,037$ & $\mathrm{~m}^{3} / \mathrm{a}$ & 3,457 & $\mathrm{~h} / \mathrm{a}$ \\
\hline \multicolumn{3}{|l|}{ Sieben } & \multicolumn{2}{|l|}{ TL, AS, Sieb } & 1,000 & $\mathrm{~h} / 20 \mathrm{~m}^{3}(\mathrm{kom})$ & 400,000 & $\mathrm{~m}^{3} / \mathrm{a}$ & 20,000 & $\mathrm{~h} / \mathrm{a}$ \\
\hline \multicolumn{3}{|c|}{ Abw.-Ausbringung bei Neubau } & \multicolumn{2}{|l|}{ Schl.,PT } & 1,000 & $\mathrm{~h} / 10 \mathrm{~m}^{3}(\mathrm{Abw})$ & 98,688 & $\mathrm{~m}^{3} / \mathrm{a}$ & 9,869 & $h / a$ \\
\hline \multicolumn{3}{|c|}{ Abw.-Ausbringung bei Umnutzung } & \multicolumn{2}{|l|}{ Schl., PT } & 1,000 & $\mathrm{~h} / 10 \mathrm{~m}^{3}(\mathrm{Abw})$ & 465,000 & $\mathrm{~m}^{3} / \mathrm{a}$ & 46,500 & $h / a$ \\
\hline \multicolumn{11}{|c|}{ Abkürzungen für die eingesetzten Maschinen: } \\
\hline \multicolumn{3}{|c|}{\begin{tabular}{|l|l|} 
TL - Teleskoplader & \\
\end{tabular}} & Schl. - Schlepp & per & & & & & & \\
\hline MU- Mietenum & etzer & & Schr. - Schred & dder & & & & & & \\
\hline SZ - Silozange & & & PT - Pumpenta & tankwagen & & & & & & \\
\hline AS - Anbausc & aufel & & & & & & & & & \\
\hline MASCHINE & NKOSTEN & & & & & & & & & \\
\hline Maschine / G & & Fixkosten & & Variable Kost & ten & Einheiten/a & & Maschinen-Ei & inzelkosten & \\
\hline Traktor (Neub & & 0,00 & $D M / a$ & 33,55 & $D M / h$ & 26,78 & $\mathrm{~h} / \mathrm{a}$ & 898,38 & $\mathrm{DM} / \mathrm{a}$ & \\
\hline Traktor (Umnu & zung) & 0,00 & $\mathrm{DM} / \mathrm{a}$ & 33,55 & $D M / h$ & 63,41 & $\mathrm{~h} / \mathrm{a}$ & $2.127,36$ & $\mathrm{DM} / \mathrm{a}$ & \\
\hline Teleskoplader & & 0,00 & $D M / a$ & 66,50 & $\mathrm{DM} / \mathrm{h}$ & 71,60 & $h / a$ & $4.761,73$ & $\mathrm{DM} / \mathrm{a}$ & \\
\hline Schredder & & 0,00 & DM/a & 7,50 & $\mathrm{DM} / \mathrm{m}^{3}$ (Out) & 148,15 & $\mathrm{~m}^{3} / \mathrm{a}$ & $1.111,11$ & $\mathrm{DM} / \mathrm{a}$ & \\
\hline Trommelsieb & & 0,00 & $\mathrm{DM} / \mathrm{a}$ & 5,00 & $\mathrm{DM} / \mathrm{m}^{3}(\mathrm{Kom})$ & 400,00 & $\mathrm{~m}^{3} / \mathrm{a}$ & $2.000,00$ & $D M / a$ & \\
\hline PumpenTW ( & abau) & 0,00 & $\mathrm{DM} / \mathrm{a}$ & 30,00 & $\mathrm{DM} / \mathrm{h}$ & 9,87 & $\mathrm{~h} / \mathrm{a}$ & 296,07 & $\mathrm{DM} / \mathrm{a}$ & \\
\hline PumpenTW (L & nnutzung) & 0,00 & $D M / a$ & 30,00 & $D M / h$ & 46,50 & $h / a$ & $1.395,00$ & $\mathrm{DM} / \mathrm{a}$ & \\
\hline Silozange & & $1.120,00$ & DM/a & 0,30 & $\mathrm{DM} / \mathrm{m}^{3}$ & 444,44 & $\mathrm{~m}^{3} / \mathrm{a}$ & $1.253,33$ & $\mathrm{DM} / \mathrm{a}$ & \\
\hline Anbauschaufe & & 506,00 & $\mathrm{DM} / \mathrm{a}$ & 0,30 & $\mathrm{DM} / \mathrm{m}^{3}$ & $2.918,52$ & $m^{3} / a$ & $1.381,56$ & $\mathrm{DM} / \mathrm{a}$ & \\
\hline Mietenumsetz & & $3.600,00$ & $\mathrm{DM} / \mathrm{a}$ & 28,00 & $\mathrm{DM} / \mathrm{h}$ & 16,91 & $\mathrm{~h} / \mathrm{a}$ & $4.073,44$ & $\mathrm{DM} / \mathrm{a}$ & \\
\hline & & & & & & Summe (Neuk & bau) & $15.775,62$ & $\mathrm{DM} / \mathrm{a}$ & \\
\hline & & & & & & Summe (Umn & hutzung) & $18.103,53$ & $\mathrm{DM} / \mathrm{a}$ & \\
\hline PERSONA & KOSTEN & & & & & & & & & \\
\hline & Std.-Lohn in & kl.Lohn-NK & Arbeitsstd. pro & Jahr & Personal-Einz & zelkosten & & & & \\
\hline Neubau & 26,00 & $\mathrm{DM} / \mathrm{h}$ & 316,75 & $\mathrm{~h} / \mathrm{a}$ & $8.235,57$ & $D M / a$ & & & & \\
\hline Umnutzung & 26,00 & DM/h & 353,38 & $h / a$ & $9.187,98$ & DM/a & & & & \\
\hline
\end{tabular}




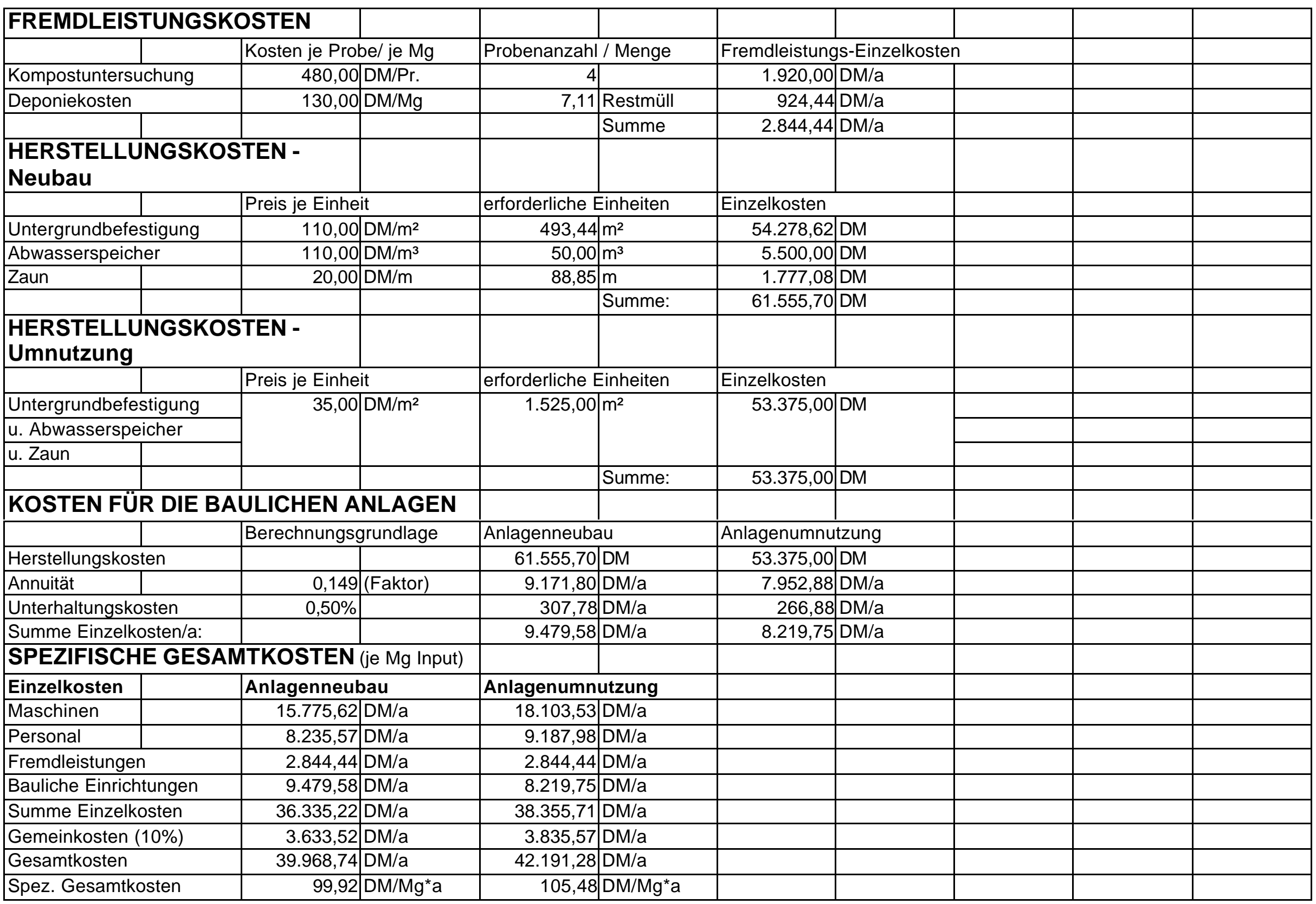


Kostenvariante A2

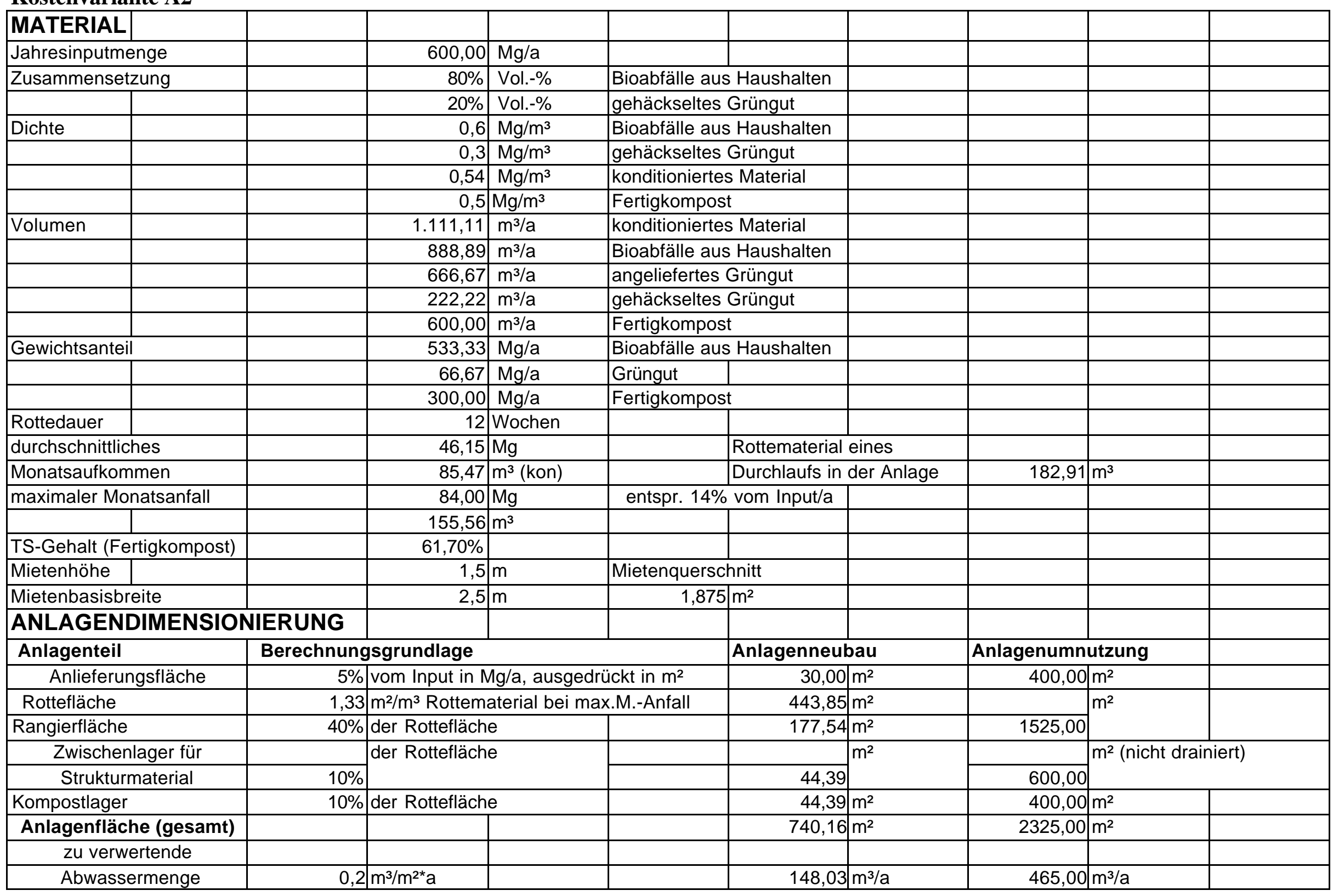




\begin{tabular}{|c|c|c|c|c|c|c|c|c|c|c|}
\hline \multicolumn{11}{|l|}{ ZEITEN } \\
\hline \multicolumn{3}{|l|}{ Arbeitsgang } & \multicolumn{2}{|c|}{ eingesetzte Maschinen } & \multicolumn{2}{|c|}{ Zeitbedarf/Einheit } & \multicolumn{2}{|c|}{ geleistete Einheiten } & \multicolumn{2}{|c|}{ Zeitbedarf/Jahr } \\
\hline \multicolumn{3}{|c|}{ Materialannahme } & & & 4,000 & h/Woche & 52,000 & Wochen/a & 208,000 & $h / a$ \\
\hline \multicolumn{3}{|c|}{ Manuelle Störstoffauslese } & & & 1,000 & $h / 100 m^{3}(\operatorname{In})$ & $1.555,556$ & $\mathrm{~m}^{3} / \mathrm{a}$ & 15,556 & $h / a$ \\
\hline \multicolumn{3}{|c|}{ Zerkleinerung von Strukturmaterial } & TL, SZ, Schr. & & 1,000 & $h / 50 m^{3}(\ln )$ & 666,667 & $\mathrm{~m}^{3} / \mathrm{a}$ & 13,333 & $h / a$ \\
\hline \multicolumn{3}{|c|}{ Aufsetzen einer Matte aus Strukturmat. } & TL, AS & & 0,300 & $\mathrm{~h} / 100 \mathrm{~m}^{3}$ (kon) & $1.111,111$ & $\mathrm{~m}^{3} / \mathrm{a}$ & 3,333 & $\mathrm{~h} / \mathrm{a}$ \\
\hline \multicolumn{3}{|c|}{ Aufsetzen der Dreiecksmieten } & TL, AS & & 1,000 & $\mathrm{~h} / 20 \mathrm{~m}^{3}$ (kon) & $1.111,111$ & $\mathrm{~m}^{3} / \mathrm{a}$ & 55,556 & $h / a$ \\
\hline \multicolumn{3}{|c|}{ Umsetzen der Dreiecksmieten } & Schl., MU & & 0,005 & $\mathrm{~h} / \mathrm{m}$ (Mietenl.) & $5.072,593$ & $\mathrm{~m} / \mathrm{a}$ & 25,363 & $\mathrm{~h} / \mathrm{a}$ \\
\hline \multicolumn{3}{|c|}{ Reinigung der Annahmefläche } & TL, AS & & 0,500 & $h / 150 m^{3}(\ln )$ & $1.555,556$ & $\mathrm{~m}^{3} / \mathrm{a}$ & 5,185 & $h / a$ \\
\hline \multicolumn{3}{|l|}{ Sieben } & TL, AS, Sieb & & 1,000 & $\mathrm{~h} / 20 \mathrm{~m}^{3}(\mathrm{kom})$ & 600,000 & $\mathrm{~m}^{3} / \mathrm{a}$ & 30,000 & $\mathrm{~h} / \mathrm{a}$ \\
\hline \multicolumn{3}{|c|}{ Abw.-Ausbringung bei Neubau } & Schl.,PT & & 1,000 & $\mathrm{~h} / 10 \mathrm{~m}^{3}(\mathrm{Abw})$ & 148,033 & $\mathrm{~m}^{3} / \mathrm{a}$ & 14,803 & $\mathrm{~h} / \mathrm{a}$ \\
\hline \multicolumn{3}{|c|}{ Abw.-Ausbringung bei Umnutzung } & Schl., PT & & 1,000 & $\mathrm{~h} / 10 \mathrm{~m}^{3}(\mathrm{Abw})$ & 465,000 & $\mathrm{~m}^{3} / \mathrm{a}$ & 46,500 & $h / a$ \\
\hline \multicolumn{11}{|c|}{ Abkürzungen für die eingesetzten Maschinen: } \\
\hline \multicolumn{2}{|c|}{ TL - Teleskoplader } & & \multicolumn{2}{|c|}{ Schl. - Schlepper } & & & & & & \\
\hline \multicolumn{2}{|c|}{\begin{tabular}{|l} 
MU- Mietenumsetzer \\
\end{tabular}} & & Schr. - Schred & dder & & & & & & \\
\hline \multicolumn{2}{|c|}{ SZ - Silozange } & & PT - Pumpenta & tankwagen & & & & & & \\
\hline \multicolumn{11}{|c|}{ AS - Anbauschaufel } \\
\hline \multicolumn{11}{|c|}{ MASCHINENKOSTEN } \\
\hline \multicolumn{2}{|c|}{ Maschine / Gerät } & Fixkosten & & \multicolumn{2}{|c|}{ Variable Kosten } & Einheiten/a & & \multicolumn{2}{|c|}{ Maschinen-Einzelkosten } & \\
\hline Traktor (Neub & au) & 0,00 & $\mathrm{DM} / \mathrm{a}$ & 33,55 & $\mathrm{DM} / \mathrm{h}$ & 40,17 & $h / a$ & $1.347,58$ & $\mathrm{DM} / \mathrm{a}$ & \\
\hline Traktor (Umnı & itzung) & 0,00 & $\mathrm{DM} / \mathrm{a}$ & 33,55 & $\mathrm{DM} / \mathrm{h}$ & 71,86 & $\mathrm{~h} / \mathrm{a}$ & $2.411,00$ & $\mathrm{DM} / \mathrm{a}$ & \\
\hline Teleskoplader & & 0,00 & $\mathrm{DM} / \mathrm{a}$ & 66,50 & $\mathrm{DM} / \mathrm{h}$ & 107,41 & $\mathrm{~h} / \mathrm{a}$ & $7.142,59$ & $\mathrm{DM} / \mathrm{a}$ & \\
\hline Schredder & & 0,00 & $\mathrm{DM} / \mathrm{a}$ & 7,50 & $\mathrm{DM} / \mathrm{m}^{3}$ (Out) & 222,22 & $\mathrm{~m}^{3} / \mathrm{a}$ & $1.666,67$ & $\mathrm{DM} / \mathrm{a}$ & \\
\hline Trommelsieb & & 0,00 & $\mathrm{DM} / \mathrm{a}$ & 5,00 & $\mathrm{DM} / \mathrm{m}^{3}(\mathrm{Kom})$ & 600,00 & $m^{3} / a$ & $3.000,00$ & $\mathrm{DM} / \mathrm{a}$ & \\
\hline PumpenTW (I & Veubau) & 0,00 & $\mathrm{DM} / \mathrm{a}$ & 30,00 & $\mathrm{DM} / \mathrm{h}$ & 14,80 & $\mathrm{~h} / \mathrm{a}$ & 444,10 & $\mathrm{DM} / \mathrm{a}$ & \\
\hline PumpenTW (L & Jmnutzung) & 0,00 & $\mathrm{DM} / \mathrm{a}$ & 30,00 & $D M / h$ & 46,50 & $\mathrm{~h} / \mathrm{a}$ & $1.395,00$ & $\mathrm{DM} / \mathrm{a}$ & \\
\hline Silozange & & $1.120,00$ & DM/a & 0,30 & $\mathrm{DM} / \mathrm{m}^{3}$ & 666,67 & $\mathrm{~m}^{3} / \mathrm{a}$ & $1.320,00$ & $\mathrm{DM} / \mathrm{a}$ & \\
\hline Anbauschaufe & & 506,00 & $\mathrm{DM} / \mathrm{a}$ & 0,30 & $\mathrm{DM} / \mathrm{m}^{3}$ & $4.377,78$ & $\mathrm{~m}^{3} / \mathrm{a}$ & $1.819,33$ & $\mathrm{DM} / \mathrm{a}$ & \\
\hline Mietenumsetz & & $3.600,00$ & $\mathrm{DM} / \mathrm{a}$ & 28,00 & $\mathrm{DM} / \mathrm{h}$ & 25,36 & $h / a$ & $4.310,16$ & $\mathrm{DM} / \mathrm{a}$ & \\
\hline & & & & & & Summe (Neuk & bau) & $21.050,43$ & $\mathrm{DM} / \mathrm{a}$ & \\
\hline & & & & & & Summe (Umn & uutzung) & $23.064,76$ & $\mathrm{DM} / \mathrm{a}$ & \\
\hline PERSONA & LOSTEN & & & & & & & & & \\
\hline & Std.-Lohn inkl & I.Lohn-NK & Arbeitsstd. pro & o Jahr & Personal-Einz & zelkosten & & & & \\
\hline Neubau & 26,00 & $D M / h$ & 371,13 & $\mathrm{~h} / \mathrm{a}$ & $9.649,36$ & $D M / a$ & & & & \\
\hline Umnutzung & 26,00 & $D M / h$ & 402,83 & $h / a$ & $10.473,47$ & DM/a & & & & \\
\hline
\end{tabular}




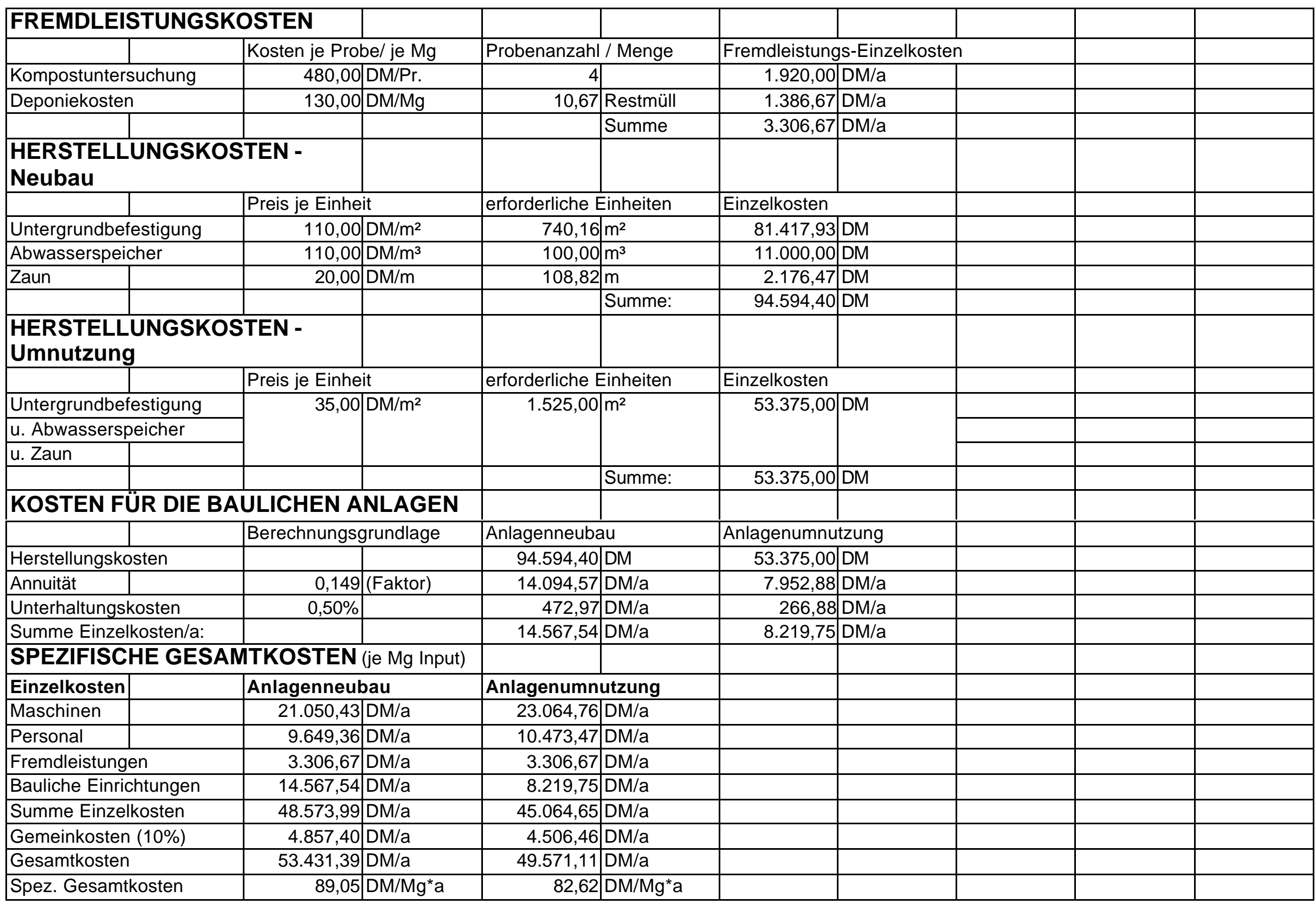


Kostenvariante A3

\section{MATERIAL}

Jahresinputmenge

Zusammensetzung

\begin{tabular}{|l|l|}
\hline & \\
\hline Dichte & \\
\hline & \\
\hline & \\
\hline & \\
\hline Volumen & \\
\hline & \\
\hline & \\
\hline & \\
\hline & \\
\hline
\end{tabular}

Gewichtsanteil

\section{Rottedauer}

durchschnittliches

Monatsaufkommen

maximaler Monatsanfall

\begin{tabular}{|l|}
\hline \\
\hline TS-Gehalt (Fertigkompost)
\end{tabular}

Mietenhöhe

Mietenbasisbreite

\section{ANLAGENDIMENSIONIERUNG}

\section{Anlagenteil}

Anlieferungsfläche

Rottefläche

Rangierfläche

Zwischenlager für

Strukturmaterial

Kompostlager

Anlagenfläche (gesamt)

zu verwertende

Abwassermenge

t)

$\mid$

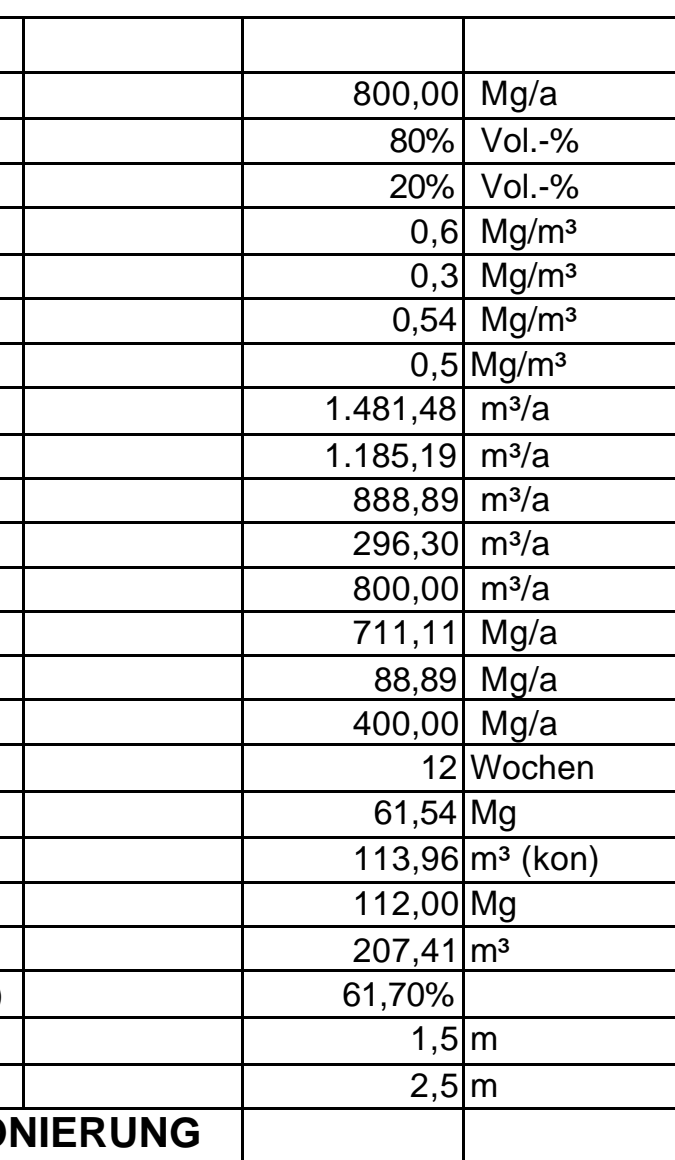

Berechnungsgrundlage

5\% vom Input in $\mathrm{Mg} / \mathrm{a}$, ausgedrückt in $\mathrm{m}^{2}$

$1,33 \mathrm{~m}^{2} / \mathrm{m}^{3}$ Rottematerial bei max.M.-Anfall

$40 \%$ der Rottefläche

der Rottefläche

$10 \%$ der Rottefläche

$0,2 \mathrm{~m}^{3} / \mathrm{m}^{2 \star} \mathrm{a}$

Grüngut

\begin{tabular}{|c|c|c|}
\hline ax.M.-Anfall & 591,80 & $\mathrm{~m}^{2}$ \\
\hline & 236,72 & $\mathrm{~m}^{2}$ \\
\hline & & $m^{2}$ \\
\hline & 59,18 & \\
\hline & 59,18 & $\mathrm{~m}^{2}$ \\
\hline & 986,88 & $\mathrm{~m}^{2}$ \\
\hline & & \\
\hline & 197,38 & $\mathrm{~m}^{3} / \mathrm{a}$ \\
\hline
\end{tabular}

Bioabfälle aus Haushalten

gehäckseltes Grüngut

Bioabfälle aus Haushalten

gehäckseltes Grüngut

konditioniertes Material

Fertigkompost

konditioniertes Material

Bioabfälle aus Haushalten

angeliefertes Grüngut

gehäckseltes Grüngut

Fertigkompost

Bioabfälle aus Haushalten

Fertigkompost

\begin{tabular}{l|l}
\hline & \\
\hline & Rottematerial eines \\
\hline & Durchlaufs in der Anlage
\end{tabular}

entspr. 14\% vom Input/a

Mietenquerschnitt

\begin{tabular}{|r|l}
\hline $1,875 \mathrm{~m}^{2}$ & \\
\hline & \\
\end{tabular}

Anlagenneubau

$40,00 \mathrm{~m}^{2}$

Anlagenumnutzung

\begin{tabular}{r|l|l|l|}
\hline 400,00 & $\mathrm{~m}^{2}$ & \\
\cline { 1 - 2 } & $\mathrm{m}^{2}$ & \\
\cline { 1 - 2 } & $\mathrm{m}^{2}$ (nicht drainiert) \\
\hline 400,00 & & \\
\hline 400,00 & $\mathrm{~m}^{2}$ & \\
\hline 2325,00 & $\mathrm{~m}^{2}$ & \\
\hline 465,00 & $\mathrm{~m}^{3} / \mathrm{a}$ & \\
\hline
\end{tabular}




\begin{tabular}{|c|c|c|c|c|c|c|c|c|c|c|}
\hline \multicolumn{11}{|l|}{ ZEITEN } \\
\hline \multicolumn{3}{|l|}{ Arbeitsgang } & \multicolumn{2}{|c|}{ eingesetzte Maschinen } & \multicolumn{2}{|c|}{ Zeitbedarf/Einheit } & \multicolumn{2}{|c|}{ geleistete Einheiten } & \multicolumn{2}{|c|}{ Zeitbedarf/Jahr } \\
\hline \multicolumn{3}{|c|}{ Materialannahme } & & & 4,000 & h/Woche & 52,000 & Wochen/a & 208,000 & $h / a$ \\
\hline \multicolumn{3}{|c|}{ Manuelle Störstoffauslese } & & & 1,000 & $h / 100 m^{3}(\operatorname{In})$ & $2.074,074$ & $\mathrm{~m}^{3} / \mathrm{a}$ & 20,741 & $h / a$ \\
\hline \multicolumn{3}{|c|}{ Zerkleinerung von Strukturmaterial } & TL, SZ, Schr. & & 1,000 & $h / 50 m^{3}(\ln )$ & 888,889 & $\mathrm{~m}^{3} / \mathrm{a}$ & 17,778 & $h / a$ \\
\hline \multicolumn{3}{|c|}{ Aufsetzen einer Matte aus Strukturmat. } & TL, AS & & 0,300 & $\mathrm{~h} / 100 \mathrm{~m}^{3}$ (kon) & $1.481,481$ & $\mathrm{~m}^{3} / \mathrm{a}$ & 4,444 & $h / a$ \\
\hline \multicolumn{3}{|c|}{ Aufsetzen der Dreiecksmieten } & TL, AS & & 1,000 & $\mathrm{~h} / 20 \mathrm{~m}^{3}$ (kon) & $1.481,481$ & $\mathrm{~m}^{3} / \mathrm{a}$ & 74,074 & $\mathrm{~h} / \mathrm{a}$ \\
\hline \multicolumn{3}{|c|}{ Umsetzen der Dreiecksmieten } & Schl., MU & & 0,005 & $\mathrm{~h} / \mathrm{m}$ (Mietenl.) & $6.763,457$ & $\mathrm{~m} / \mathrm{a}$ & 33,817 & $\mathrm{~h} / \mathrm{a}$ \\
\hline \multicolumn{3}{|c|}{ Reinigung der Annahmefläche } & TL, AS & & 0,500 & $\mathrm{~h} / 150 \mathrm{~m}^{3}(\ln )$ & $2.074,074$ & $\mathrm{~m}^{3} / \mathrm{a}$ & 6,914 & $h / a$ \\
\hline \multicolumn{3}{|l|}{ Sieben } & TL, AS, Sieb & & 1,000 & $\mathrm{~h} / 20 \mathrm{~m}^{3}(\mathrm{kom})$ & 800,000 & $\mathrm{~m}^{3} / \mathrm{a}$ & 40,000 & $\mathrm{~h} / \mathrm{a}$ \\
\hline \multicolumn{3}{|c|}{ Abw.-Ausbringung bei Neubau } & Schl.,PT & & 1,000 & $\mathrm{~h} / 10 \mathrm{~m}^{3}(\mathrm{Abw})$ & 197,377 & $\mathrm{~m}^{3} / \mathrm{a}$ & 19,738 & $\mathrm{~h} / \mathrm{a}$ \\
\hline \multicolumn{3}{|c|}{ Abw.-Ausbringung bei Umnutzung } & Schl., PT & & 1,000 & $\mathrm{~h} / 10 \mathrm{~m}^{3}(\mathrm{Abw})$ & 465,000 & $\mathrm{~m}^{3} / \mathrm{a}$ & 46,500 & $h / a$ \\
\hline \multicolumn{11}{|c|}{ Abkürzungen für die eingesetzten Maschinen: } \\
\hline \multicolumn{2}{|c|}{ TL - Teleskoplader } & & \multicolumn{2}{|c|}{ Schl. - Schlepper } & & & & & & \\
\hline \multicolumn{2}{|c|}{\begin{tabular}{|l} 
MU- Mietenumsetzer \\
\end{tabular}} & & Schr. - Schred & dder & & & & & & \\
\hline \multicolumn{2}{|c|}{ SZ - Silozange } & & PT - Pumpenta & tankwagen & & & & & & \\
\hline \multicolumn{11}{|c|}{ AS - Anbauschaufel } \\
\hline \multicolumn{11}{|c|}{ MASCHINENKOSTEN } \\
\hline \multicolumn{2}{|c|}{ Maschine / Gerät } & Fixkosten & & \multicolumn{2}{|c|}{ Variable Kosten } & Einheiten/a & & \multicolumn{2}{|c|}{ Maschinen-Einzelkosten } & \\
\hline Traktor (Neub & au) & 0,00 & $\mathrm{DM} / \mathrm{a}$ & 33,55 & $\mathrm{DM} / \mathrm{h}$ & 53,55 & $h / a$ & $1.796,77$ & $\mathrm{DM} / \mathrm{a}$ & \\
\hline Traktor (Umnı & itzung) & 0,00 & $\mathrm{DM} / \mathrm{a}$ & 33,55 & $\mathrm{DM} / \mathrm{h}$ & 80,32 & $\mathrm{~h} / \mathrm{a}$ & $2.694,64$ & $\mathrm{DM} / \mathrm{a}$ & \\
\hline Teleskoplader & & 0,00 & $\mathrm{DM} / \mathrm{a}$ & 66,50 & $\mathrm{DM} / \mathrm{h}$ & 143,21 & $\mathrm{~h} / \mathrm{a}$ & $9.523,46$ & $\mathrm{DM} / \mathrm{a}$ & \\
\hline Schredder & & 0,00 & $\mathrm{DM} / \mathrm{a}$ & 7,50 & $\mathrm{DM} / \mathrm{m}^{3}$ (Out) & 296,30 & $m^{3} / a$ & $2.222,22$ & $\mathrm{DM} / \mathrm{a}$ & \\
\hline Trommelsieb & & 0,00 & $\mathrm{DM} / \mathrm{a}$ & 5,00 & $\mathrm{DM} / \mathrm{m}^{3}(\mathrm{Kom})$ & 800,00 & $m^{3} / a$ & $4.000,00$ & $\mathrm{DM} / \mathrm{a}$ & \\
\hline PumpenTW (I & Veubau) & 0,00 & $\mathrm{DM} / \mathrm{a}$ & 30,00 & $\mathrm{DM} / \mathrm{h}$ & 19,74 & $\mathrm{~h} / \mathrm{a}$ & 592,13 & $\mathrm{DM} / \mathrm{a}$ & \\
\hline PumpenTW (L & Jmnutzung) & 0,00 & $D M / a$ & 30,00 & $D M / h$ & 46,50 & $\mathrm{~h} / \mathrm{a}$ & $1.395,00$ & $\mathrm{DM} / \mathrm{a}$ & \\
\hline Silozange & & $1.120,00$ & DM/a & 0,30 & $\mathrm{DM} / \mathrm{m}^{3}$ & 888,89 & $\mathrm{~m}^{3} / \mathrm{a}$ & $1.386,67$ & $\mathrm{DM} / \mathrm{a}$ & \\
\hline Anbauschaufe & & 506,00 & $\mathrm{DM} / \mathrm{a}$ & 0,30 & $\mathrm{DM} / \mathrm{m}^{3}$ & $5.837,04$ & $\mathrm{~m}^{3} / \mathrm{a}$ & $2.257,11$ & $\mathrm{DM} / \mathrm{a}$ & \\
\hline Mietenumsetz & & $3.600,00$ & $\mathrm{DM} / \mathrm{a}$ & 28,00 & $\mathrm{DM} / \mathrm{h}$ & 33,82 & $h / a$ & $4.546,88$ & $\mathrm{DM} / \mathrm{a}$ & \\
\hline & & & & & & Summe (Neub & bau) & $26.325,24$ & $\mathrm{DM} / \mathrm{a}$ & \\
\hline & & & & & & Summe (Umn & uutzung) & $28.025,99$ & $\mathrm{DM} / \mathrm{a}$ & \\
\hline PERSONAI & LOSTEN & & & & & & & & & \\
\hline & Std.-Lohn inkl & I.Lohn-NK & Arbeitsstd. pro & o Jahr & Personal-Einz & zelkosten & & & & \\
\hline Neubau & 26,00 & $D M / h$ & 425,51 & $\mathrm{~h} / \mathrm{a}$ & $11.063,15$ & $D M / a$ & & & & \\
\hline Umnutzung & 26,00 & $D M / h$ & 452,27 & $h / a$ & $11.758,97$ & DM/a & & & & \\
\hline
\end{tabular}




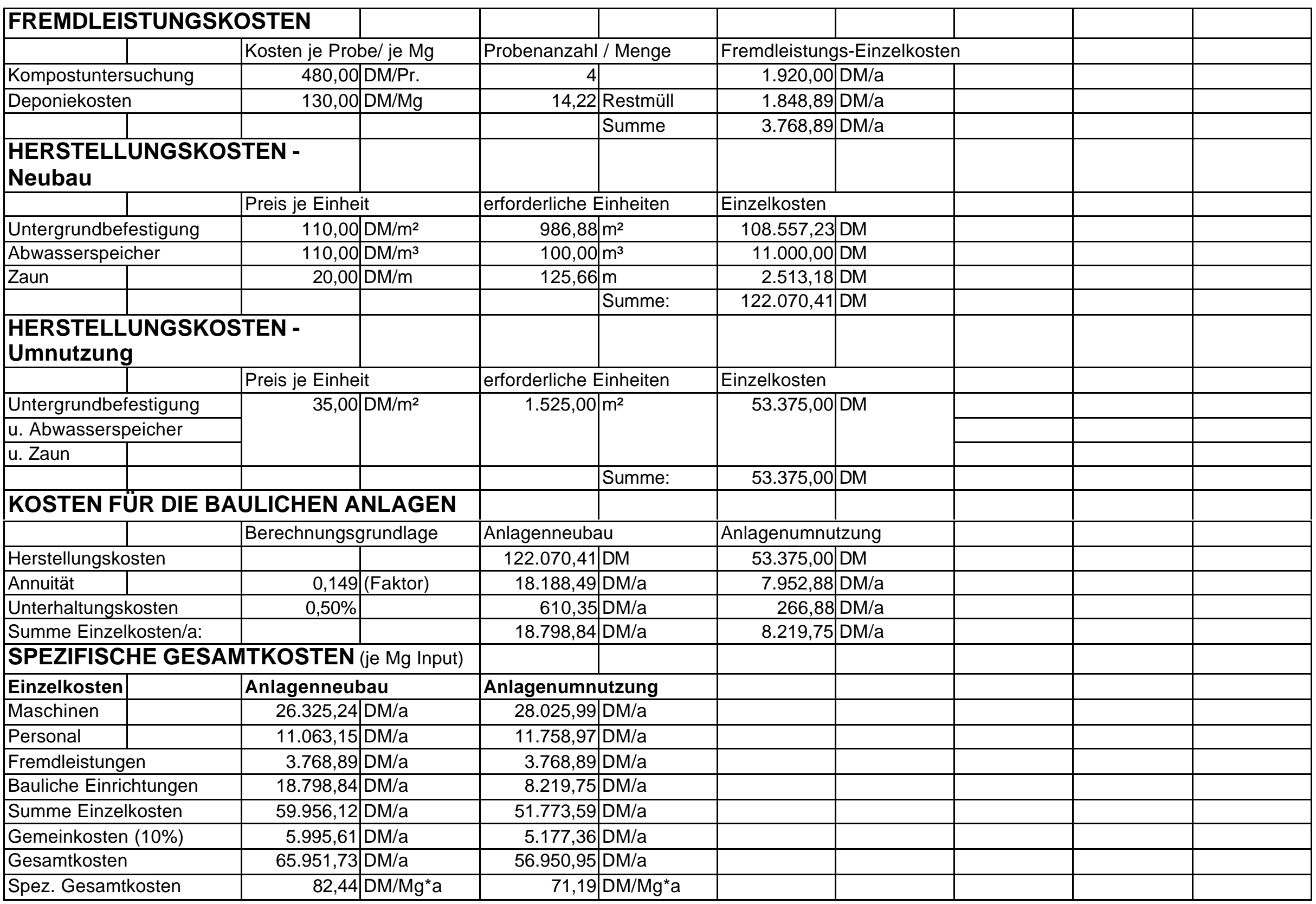


Kostenvariante A4

\section{MATERIAL}

Jahresinputmenge

Zusammensetzung

\begin{tabular}{|l|l|}
\hline & \\
\hline Dichte & \\
\hline & \\
\hline & \\
\hline & \\
\hline Volumen & \\
\hline & \\
\hline & \\
\hline & \\
\hline & \\
\hline
\end{tabular}

Gewichtsanteil

\section{Rottedauer}

durchschnittliches

Monatsaufkommen

maximaler Monatsanfall

\begin{tabular}{|l|}
\hline \\
\hline TS-Gehalt (Fertigkompost)
\end{tabular}

Mietenhöhe

Mietenbasisbreite

\section{ANLAGENDIMENSIONIERUNG}

\section{Anlagenteil}

Anlieferungsfläche

Rottefläche

Rangierfläche

Zwischenlager für

Strukturmaterial

Kompostlager

Anlagenfläche (gesamt)

zu verwertende

Abwassermenge

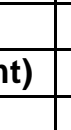

(3)

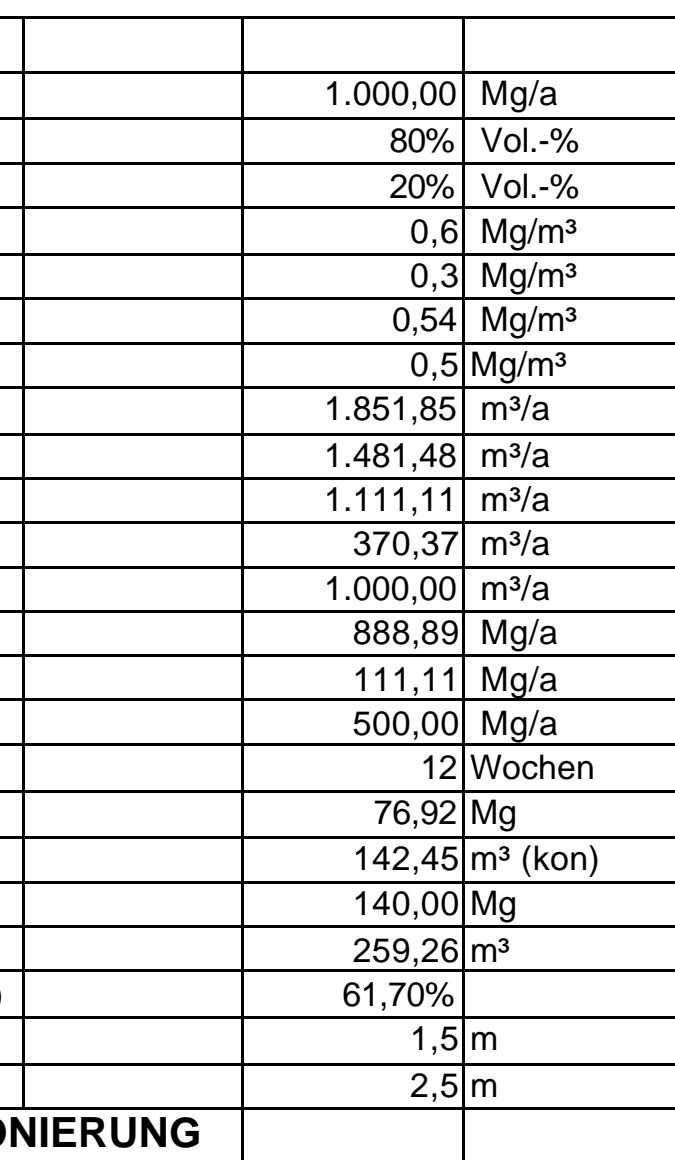

Berechnungsgrundlage

5\% vom Input in $\mathrm{Mg} / \mathrm{a}$, ausgedrückt in $\mathrm{m}^{2}$

$1,33 \mathrm{~m}^{2} / \mathrm{m}^{3}$ Rottematerial bei max.M.-Anfall

$40 \%$ der Rottefläche

der Rottefläche

$10 \%$ der Rottefläche

$0,2 \mathrm{~m}^{3} / \mathrm{m}^{2 \star} \mathrm{a}$

Grüngut

\begin{tabular}{|c|c|c|}
\hline ax.M.-Anfall & 739,75 & $\mathrm{~m}^{2}$ \\
\hline & 295,90 & $m^{2}$ \\
\hline & & $\mathrm{m}^{2}$ \\
\hline & 73,98 & \\
\hline & 73,98 & $\mathrm{~m}^{2}$ \\
\hline & 1233,60 & $\mathrm{~m}^{2}$ \\
\hline & 246,72 & $m^{3} / a$ \\
\hline
\end{tabular}

Bioabfälle aus Haushalten

gehäckseltes Grüngut

Bioabfälle aus Haushalten

gehäckseltes Grüngut

konditioniertes Material

Fertigkompost

konditioniertes Material

Bioabfälle aus Haushalten

angeliefertes Grüngut

gehäckseltes Grüngut

Fertigkompost

Bioabfälle aus Haushalten

Fertigkompost

\begin{tabular}{l|l}
\hline & \\
\hline & Rottematerial eines \\
\hline & Durchlaufs in der Anlage
\end{tabular}

entspr. 14\% vom Input/a

Mietenquerschnitt

\begin{tabular}{|r|l|l}
\hline 1,875 & $\mathrm{~m}^{2}$ & \\
& &
\end{tabular}

Anlagenneubau

Anlagenumnutzung

\begin{tabular}{|c|c|c|}
\hline 400,00 & $\mathrm{~m}^{2}$ & \\
\hline & $\mathrm{m}^{2}$ & \\
\hline 1525,00 & & \\
\hline & $m^{2}(r$ & ert) \\
\hline 600,00 & & \\
\hline 400,00 & $\mathrm{~m}^{2}$ & \\
\hline 2325,00 & $\mathrm{~m}^{2}$ & \\
\hline & & \\
\hline 465,00 & $\mathrm{~m}^{3} / \mathrm{a}$ & \\
\hline
\end{tabular}




\begin{tabular}{|c|c|c|c|c|c|c|c|c|c|c|}
\hline \multicolumn{11}{|l|}{ ZEITEN } \\
\hline \multicolumn{3}{|l|}{ Arbeitsgang } & \multicolumn{2}{|c|}{ eingesetzte Maschinen } & \multicolumn{2}{|c|}{ Zeitbedarf/Einheit } & \multicolumn{2}{|c|}{ geleistete Einheiten } & \multicolumn{2}{|c|}{ Zeitbedarf/Jahr } \\
\hline \multicolumn{3}{|c|}{ Materialannahme } & & & 4,000 & h/Woche & 52,000 & Wochen/a & 208,000 & $h / a$ \\
\hline \multicolumn{3}{|c|}{ Manuelle Störstoffauslese } & & & 1,000 & $h / 100 m^{3}(\operatorname{In})$ & $2.592,593$ & $\mathrm{~m}^{3} / \mathrm{a}$ & 25,926 & $h / a$ \\
\hline \multicolumn{3}{|c|}{ Zerkleinerung von Strukturmaterial } & TL, SZ, Schr. & & 1,000 & $h / 50 m^{3}(\ln )$ & $1.111,111$ & $\mathrm{~m}^{3} / \mathrm{a}$ & 22,222 & $h / a$ \\
\hline \multicolumn{3}{|c|}{ Aufsetzen einer Matte aus Strukturmat. } & TL, AS & & 0,300 & $\mathrm{~h} / 100 \mathrm{~m}^{3}$ (kon) & $1.851,852$ & $\mathrm{~m}^{3} / \mathrm{a}$ & 5,556 & $h / a$ \\
\hline \multicolumn{3}{|c|}{ Aufsetzen der Dreiecksmieten } & TL, AS & & 1,000 & $\mathrm{~h} / 20 \mathrm{~m}^{3}$ (kon) & $1.851,852$ & $\mathrm{~m}^{3} / \mathrm{a}$ & 92,593 & $\mathrm{~h} / \mathrm{a}$ \\
\hline \multicolumn{3}{|c|}{ Umsetzen der Dreiecksmieten } & Schl., MU & & 0,005 & $\mathrm{~h} / \mathrm{m}$ (Mietenl.) & $8.454,321$ & $\mathrm{~m} / \mathrm{a}$ & 42,272 & $h / a$ \\
\hline \multicolumn{3}{|c|}{ Reinigung der Annahmefläche } & TL, AS & & 0,500 & $h / 150 m^{3}(\ln )$ & $2.592,593$ & $\mathrm{~m}^{3} / \mathrm{a}$ & 8,642 & $h / a$ \\
\hline \multicolumn{3}{|l|}{ Sieben } & TL, AS, Sieb & & 1,000 & $\mathrm{~h} / 20 \mathrm{~m}^{3}(\mathrm{kom})$ & $1.000,000$ & $\mathrm{~m}^{3} / \mathrm{a}$ & 50,000 & $\mathrm{~h} / \mathrm{a}$ \\
\hline \multicolumn{3}{|c|}{ Abw.-Ausbringung bei Neubau } & Schl.,PT & & 1,000 & $\mathrm{~h} / 10 \mathrm{~m}^{3}(\mathrm{Abw})$ & 246,721 & $\mathrm{~m}^{3} / \mathrm{a}$ & 24,672 & $h / a$ \\
\hline \multicolumn{3}{|c|}{ Abw.-Ausbringung bei Umnutzung } & Schl., PT & & 1,000 & $\mathrm{~h} / 10 \mathrm{~m}^{3}(\mathrm{Abw})$ & 465,000 & $\mathrm{~m}^{3} / \mathrm{a}$ & 46,500 & $h / a$ \\
\hline \multicolumn{11}{|c|}{ Abkürzungen für die eingesetzten Maschinen: } \\
\hline \multicolumn{2}{|c|}{ TL - Teleskoplader } & & \multicolumn{2}{|c|}{ Schl. - Schlepper } & & & & & & \\
\hline \multicolumn{2}{|c|}{\begin{tabular}{|l} 
MU- Mietenumsetzer \\
\end{tabular}} & & Schr. - Schred & dder & & & & & & \\
\hline \multicolumn{2}{|c|}{ SZ - Silozange } & & PT - Pumpenta & tankwagen & & & & & & \\
\hline \multicolumn{11}{|c|}{ AS - Anbauschaufel } \\
\hline \multicolumn{11}{|c|}{ MASCHINENKOSTEN } \\
\hline \multicolumn{2}{|c|}{ Maschine / Gerät } & Fixkosten & & \multicolumn{2}{|c|}{ Variable Kosten } & Einheiten/a & & \multicolumn{2}{|c|}{ Maschinen-Einzelkosten } & \\
\hline Traktor (Neub & au) & 0,00 & $\mathrm{DM} / \mathrm{a}$ & 33,55 & $\mathrm{DM} / \mathrm{h}$ & 66,94 & $\mathrm{~h} / \mathrm{a}$ & $2.245,96$ & $\mathrm{DM} / \mathrm{a}$ & \\
\hline Traktor (Umnı & itzung) & 0,00 & $\mathrm{DM} / \mathrm{a}$ & 33,55 & $\mathrm{DM} / \mathrm{h}$ & 88,77 & $\mathrm{~h} / \mathrm{a}$ & $2.978,29$ & $\mathrm{DM} / \mathrm{a}$ & \\
\hline Teleskoplader & & 0,00 & $\mathrm{DM} / \mathrm{a}$ & 66,50 & $\mathrm{DM} / \mathrm{h}$ & 179,01 & $\mathrm{~h} / \mathrm{a}$ & $11.904,32$ & $\mathrm{DM} / \mathrm{a}$ & \\
\hline Schredder & & 0,00 & $\mathrm{DM} / \mathrm{a}$ & 7,50 & $\mathrm{DM} / \mathrm{m}^{3}$ (Out) & 370,37 & $\mathrm{~m}^{3} / \mathrm{a}$ & $2.777,78$ & $\mathrm{DM} / \mathrm{a}$ & \\
\hline Trommelsieb & & 0,00 & $\mathrm{DM} / \mathrm{a}$ & 5,00 & $\mathrm{DM} / \mathrm{m}^{3}(\mathrm{Kom})$ & $1.000,00$ & $m^{3} / a$ & $5.000,00$ & $\mathrm{DM} / \mathrm{a}$ & \\
\hline PumpenTW (I & Veubau) & 0,00 & $\mathrm{DM} / \mathrm{a}$ & 30,00 & $\mathrm{DM} / \mathrm{h}$ & 24,67 & $\mathrm{~h} / \mathrm{a}$ & 740,16 & $\mathrm{DM} / \mathrm{a}$ & \\
\hline PumpenTW (L & Jmnutzung) & 0,00 & $D M / a$ & 30,00 & $D M / h$ & 46,50 & $h / a$ & $1.395,00$ & $\mathrm{DM} / \mathrm{a}$ & \\
\hline Silozange & & $1.120,00$ & DM/a & 0,30 & $\mathrm{DM} / \mathrm{m}^{3}$ & $1.111,11$ & $\mathrm{~m}^{3} / \mathrm{a}$ & $1.453,33$ & $\mathrm{DM} / \mathrm{a}$ & \\
\hline Anbauschaufe & & 506,00 & $\mathrm{DM} / \mathrm{a}$ & 0,30 & $\mathrm{DM} / \mathrm{m}^{3}$ & $7.296,30$ & $m^{3} / a$ & $2.694,89$ & $\mathrm{DM} / \mathrm{a}$ & \\
\hline Mietenumsetz & & $3.600,00$ & $\mathrm{DM} / \mathrm{a}$ & 28,00 & $\mathrm{DM} / \mathrm{h}$ & 42,27 & $\mathrm{~h} / \mathrm{a}$ & $4.783,60$ & $\mathrm{DM} / \mathrm{a}$ & \\
\hline & & & & & & Summe (Neuk & bau) & $31.600,05$ & $\mathrm{DM} / \mathrm{a}$ & \\
\hline & & & & & & Summe (Umn & uutzung) & $32.987,21$ & $\mathrm{DM} / \mathrm{a}$ & \\
\hline PERSONA & LOSTEN & & & & & & & & & \\
\hline & Std.-Lohn inkl & I.Lohn-NK & Arbeitsstd. pro & o Jahr & Personal-Einz & zelkosten & & & & \\
\hline Neubau & 26,00 & $D M / h$ & 479,88 & $\mathrm{~h} / \mathrm{a}$ & $12.476,93$ & $D M / a$ & & & & \\
\hline Umnutzung & 26,00 & $D M / h$ & 501,71 & $h / a$ & $13.044,46$ & $D M / a$ & & & & \\
\hline
\end{tabular}




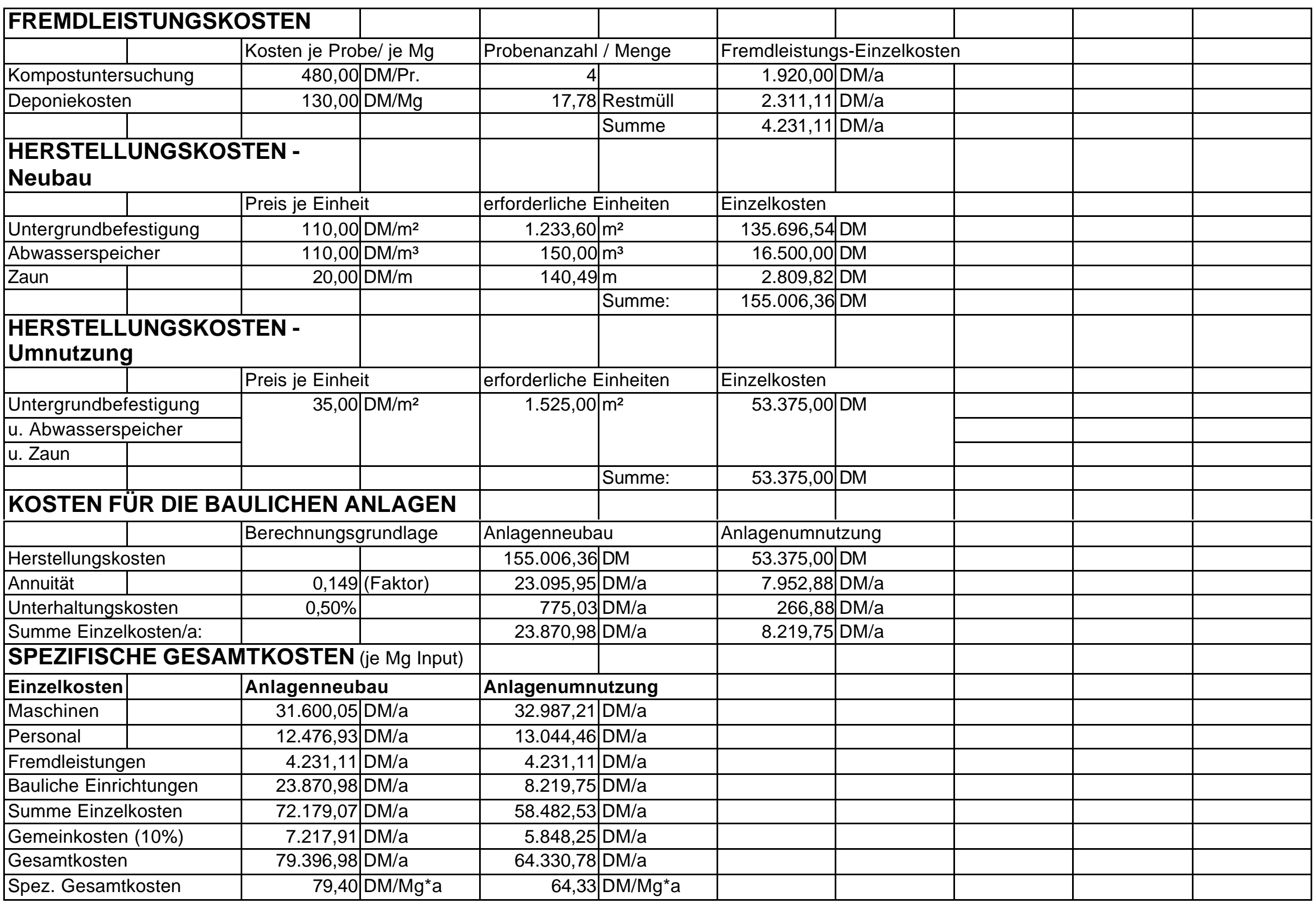


Kostenvariante A5

\section{MATERIAL}

Jahresinputmenge

Zusammensetzung

\begin{tabular}{|l|l|}
\hline & \\
\hline Dichte & \\
\hline & \\
\hline & \\
\hline & \\
\hline Volumen & \\
\hline & \\
\hline & \\
\hline & \\
\hline & \\
\hline
\end{tabular}

Gewichtsanteil

\section{Rottedauer}

durchschnittliches

Monatsaufkommen

maximaler Monatsanfall

\begin{tabular}{|l|}
\hline \\
\hline TS-Gehalt (Fertigkompost)
\end{tabular}

Mietenhöhe

Mietenbasisbreite

\section{ANLAGENDIMENSIONIERUNG}

\section{Anlagenteil}

Anlieferungsfläche

Rottefläche

Rangierfläche

Zwischenlager für

Strukturmaterial

Kompostlager

Anlagenfläche (gesamt)

zu verwertende

Abwassermenge

(3)

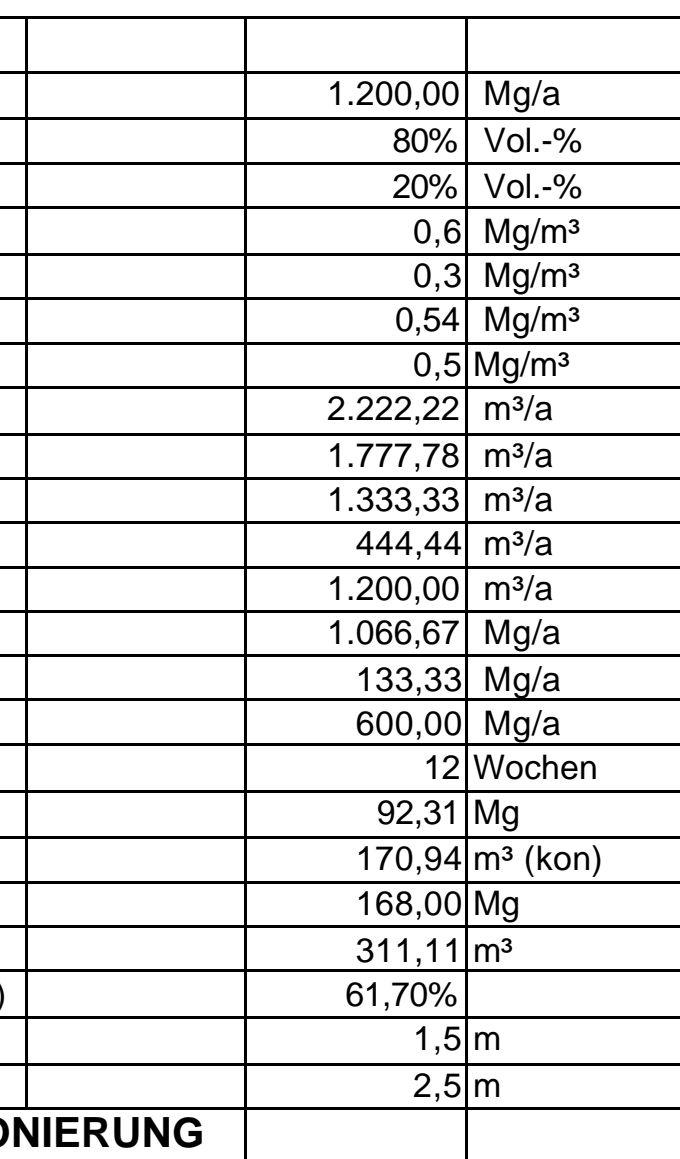

Berechnungsgrundlage

5\% vom Input in Mg/a, ausgedrückt in $\mathrm{m}^{2}$

$1,33 \mathrm{~m}^{2} / \mathrm{m}^{3}$ Rottematerial bei max.M.-Anfall

$40 \%$ der Rottefläche

der Rottefläche

$10 \%$ der Rottefläche

|

$0,2 \mathrm{~m}^{3} / \mathrm{m}^{2 \star} \mathrm{a}$

Grüngut

\begin{tabular}{|c|c|c|}
\hline ax.M.-Anfall & 887,70 & $\mathrm{~m}^{2}$ \\
\hline & 355,08 & $\mathrm{~m}^{2}$ \\
\hline & & $\mathrm{m}^{2}$ \\
\hline & 88,77 & \\
\hline & 88,77 & $\mathrm{~m}^{2}$ \\
\hline & 1480,33 & $\mathrm{~m}^{2}$ \\
\hline & 296,07 & $m^{3} / a$ \\
\hline
\end{tabular}

Bioabfälle aus Haushalten

gehäckseltes Grüngut

Bioabfälle aus Haushalten

gehäckseltes Grüngut

konditioniertes Material

Fertigkompost

konditioniertes Material

Bioabfälle aus Haushalten

angeliefertes Grüngut

gehäckseltes Grüngut

Fertigkompost

Bioabfälle aus Haushalten

Fertigkompost

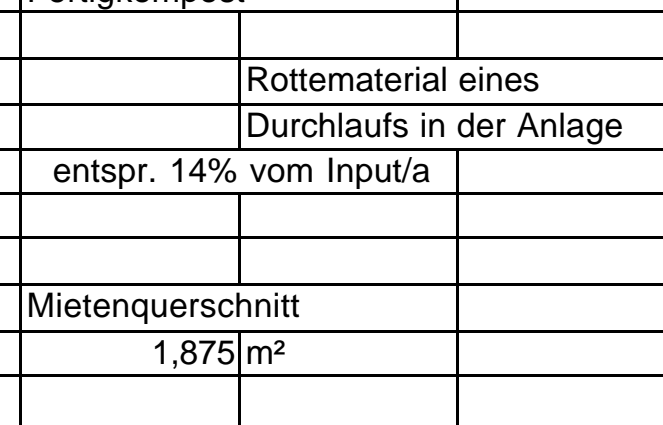

Anlagenneubau

$60,00 \mathrm{~m}^{2}$

Anlagenumnutzung

\begin{tabular}{r|l|l|l|}
\hline 400,00 & $\mathrm{~m}^{2}$ & \\
\cline { 1 - 2 } & $\mathrm{m}^{2}$ & \\
\cline { 1 - 2 } & $\mathrm{m}^{2}$ (nicht drainiert) \\
\cline { 1 - 3 } 4000,00 & & \\
\hline 2300,00 & $\mathrm{~m}^{2}$ & \\
\hline 465,00 & $\mathrm{~m}^{2}$ & \\
\hline 465,00 & $\mathrm{~m}^{3} / \mathrm{a}$ & \\
\hline
\end{tabular}




\begin{tabular}{|c|c|c|c|c|c|c|c|c|c|c|}
\hline ZEITEN & & & & & & & & & & \\
\hline Arbeitsgang & & & eingesetzte $\mathrm{M}$ & Maschinen & Zeitbedarf/Ei & inheit & geleistete Ein & nheiten & Zeitbedarf/Ja & ahr \\
\hline Materialannah & ime & & & & 4,000 & h/Woche & 52,000 & Wochen/a & 208,000 & $h / a$ \\
\hline Manuelle Stör & stoffauslese & & & & 1,000 & $h / 100 m^{3}(\ln )$ & $3.111,111$ & $\mathrm{~m}^{3} / \mathrm{a}$ & 31,111 & $h / a$ \\
\hline Zerkleinerung & von Strukturm & naterial & TL, SZ, Schr. & & 1,000 & $h / 50 m^{3}(\operatorname{In})$ & $1.333,333$ & $\mathrm{~m}^{3} / \mathrm{a}$ & 26,667 & $h / a$ \\
\hline Aufsetzen ein & er Matte aus S & Strukturmat. & TL, AS & & 0,300 & $\mathrm{~h} / 100 \mathrm{~m}^{3}$ (kon) & $2.222,222$ & $\mathrm{~m}^{3} / \mathrm{a}$ & 6,667 & $h / a$ \\
\hline Aufsetzen der & Dreiecksmiete & & TL, AS & & 1,000 & $\mathrm{~h} / 20 \mathrm{~m}^{3}$ (kon) & $2.222,222$ & $\mathrm{~m}^{3} / \mathrm{a}$ & 111,111 & $\mathrm{~h} / \mathrm{a}$ \\
\hline Umsetzen der & Dreiecksmiete & & Schl., MU & & 0,005 & $\mathrm{~h} / \mathrm{m}$ (Mietenl.) & $10.145,185$ & $\mathrm{~m} / \mathrm{a}$ & 50,726 & $h / a$ \\
\hline Reinigung der & Annahmefläch & & TL, AS & & 0,500 & $h / 150 m^{3}(\ln )$ & $3.111,111$ & $\mathrm{~m}^{3} / \mathrm{a}$ & 10,370 & $h / a$ \\
\hline Sieben & & & TL, AS, Sieb & & 1,000 & $\mathrm{~h} / 20 \mathrm{~m}^{3}(\mathrm{kom})$ & $1.200,000$ & $\mathrm{~m}^{3} / \mathrm{a}$ & 60,000 & $h / a$ \\
\hline Abw.-Ausbring & gung bei Neub & & Schl.,PT & & 1,000 & $\mathrm{~h} / 10 \mathrm{~m}^{3}(\mathrm{Abw})$ & 296,065 & $\mathrm{~m}^{3} / \mathrm{a}$ & 29,607 & $h / a$ \\
\hline Abw.-Ausbring & gung bei Umnu & utzung & Schl., PT & & 1,000 & $\mathrm{~h} / 10 \mathrm{~m}^{3}(\mathrm{Abw})$ & 465,000 & $\mathrm{~m}^{3} / \mathrm{a}$ & 46,500 & $h / a$ \\
\hline Abkürzungen & für die eingese & etzten Maschin & nen: & & & & & & & \\
\hline TL - Teleskop & lader & & Schl. - Schlepp & per & & & & & & \\
\hline MU- Mietenum & nsetzer & & Schr. - Schred & dder & & & & & & \\
\hline SZ - Silozange & & & PT - Pumpenta & tankwagen & & & & & & \\
\hline AS - Anbausc & haufel & & & & & & & & & \\
\hline MASCHINE & ENKOSTEN & & & & & & & & & \\
\hline Maschine / G & erät & Fixkosten & & Variable Kost & ten & Einheiten/a & & Maschinen-Ei & inzelkosten & \\
\hline Traktor (Neub & au) & 0,00 & $\mathrm{DM} / \mathrm{a}$ & 33,55 & $D M / h$ & 80,33 & $\mathrm{~h} / \mathrm{a}$ & $2.695,15$ & $\mathrm{DM} / \mathrm{a}$ & \\
\hline Traktor (Umnu & itzung) & 0,00 & $\mathrm{DM} / \mathrm{a}$ & 33,55 & $D M / h$ & 97,23 & $\mathrm{~h} / \mathrm{a}$ & $3.261,93$ & $\mathrm{DM} / \mathrm{a}$ & \\
\hline Teleskoplader & & 0,00 & $D M / a$ & 66,50 & $\mathrm{DM} / \mathrm{h}$ & 214,81 & $\mathrm{~h} / \mathrm{a}$ & $14.285,19$ & $\mathrm{DM} / \mathrm{a}$ & \\
\hline Schredder & & 0,00 & DM/a & 7,50 & $\mathrm{DM} / \mathrm{m}^{3}$ (Out) & 444,44 & $\mathrm{~m}^{3} / \mathrm{a}$ & 3.333,33 & $\mathrm{DM} / \mathrm{a}$ & \\
\hline Trommelsieb & & 0,00 & $D M / a$ & 5,00 & $\mathrm{DM} / \mathrm{m}^{3}(\mathrm{Kom})$ & $1.200,00$ & $m^{3} / a$ & $6.000,00$ & $\mathrm{DM} / \mathrm{a}$ & \\
\hline PumpenTW ( & Veubau) & 0,00 & $\mathrm{DM} / \mathrm{a}$ & 30,00 & $\mathrm{DM} / \mathrm{h}$ & 29,61 & $\mathrm{~h} / \mathrm{a}$ & 888,20 & $\mathrm{DM} / \mathrm{a}$ & \\
\hline PumpenTW (L & Jmnutzung) & 0,00 & $D M / a$ & 30,00 & $D M / h$ & 46,50 & $h / a$ & $1.395,00$ & $\mathrm{DM} / \mathrm{a}$ & \\
\hline Silozange & & $1.120,00$ & DM/a & 0,30 & $\mathrm{DM} / \mathrm{m}^{3}$ & $1.333,33$ & $\mathrm{~m}^{3} / \mathrm{a}$ & $1.520,00$ & $\mathrm{DM} / \mathrm{a}$ & \\
\hline Anbauschaufe & & 506,00 & $\mathrm{DM} / \mathrm{a}$ & 0,30 & $\mathrm{DM} / \mathrm{m}^{3}$ & $8.755,56$ & $\mathrm{~m}^{3} / \mathrm{a}$ & $3.132,67$ & $\mathrm{DM} / \mathrm{a}$ & \\
\hline Mietenumsetz & & $3.600,00$ & $\mathrm{DM} / \mathrm{a}$ & 28,00 & $\mathrm{DM} / \mathrm{h}$ & 50,73 & $\mathrm{~h} / \mathrm{a}$ & $5.020,33$ & $\mathrm{DM} / \mathrm{a}$ & \\
\hline & & & & & & Summe (Neuk & bau) & $36.874,86$ & $\mathrm{DM} / \mathrm{a}$ & \\
\hline & & & & & & Summe (Umn & hutzung) & $37.948,44$ & $\mathrm{DM} / \mathrm{a}$ & \\
\hline PERSONA & LOSTEN & & & & & & & & & \\
\hline & Std.-Lohn inkl & I.Lohn-NK & Arbeitsstd. pro & Jahr & Personal-Einz & zelkosten & & & & \\
\hline Neubau & 26,00 & $D M / h$ & 534,26 & $\mathrm{~h} / \mathrm{a}$ & 13.890,72 & $D M / a$ & & & & \\
\hline Umnutzung & 26,00 & $D M / h$ & 551,15 & $h / a$ & $14.329,95$ & $D M / a$ & & & & \\
\hline
\end{tabular}




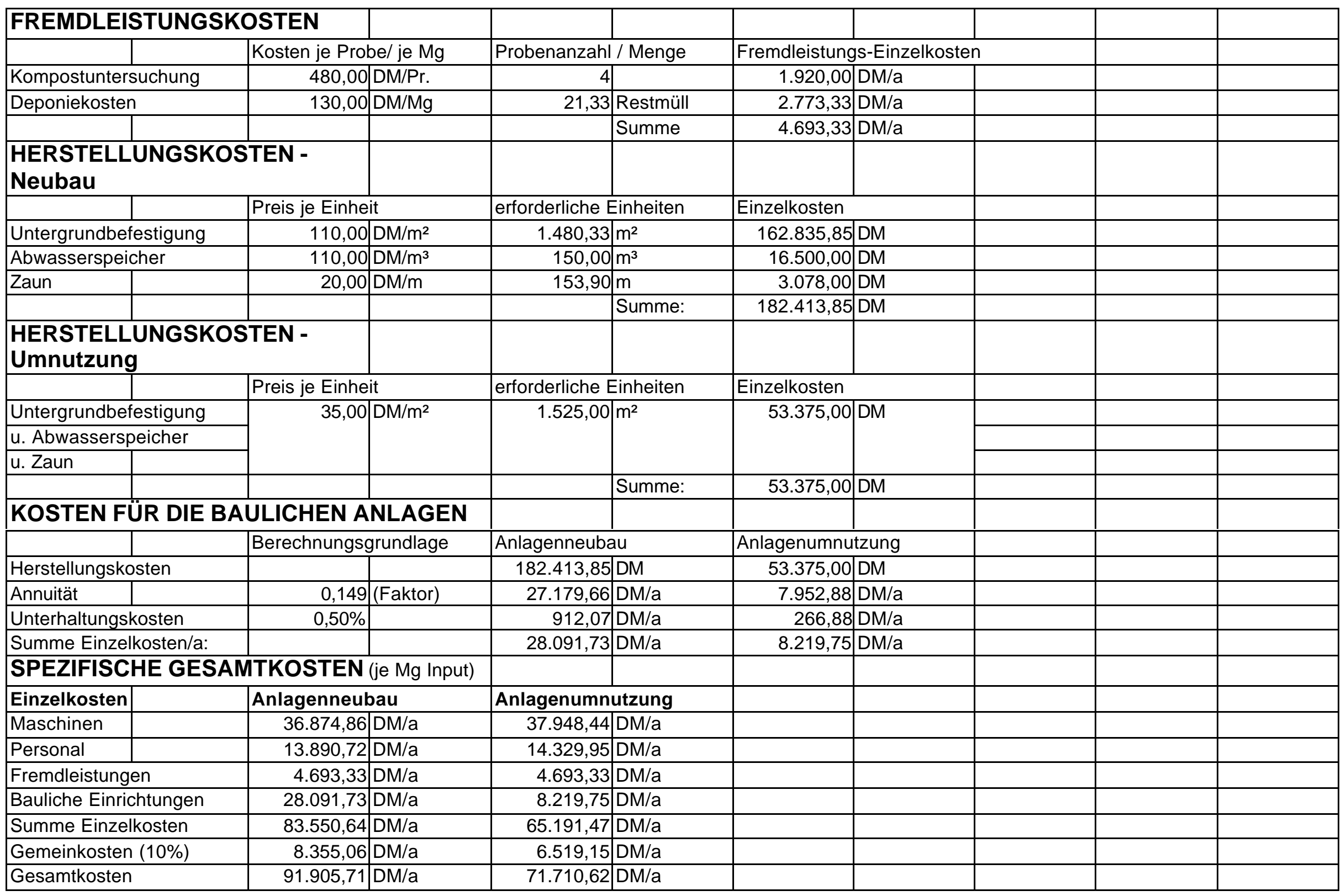


Kostenvariante A6

\section{MATERIAL}

Jahresinputmenge

Zusammensetzung

\begin{tabular}{|l|l|}
\hline & \\
\hline Dichte & \\
\hline & \\
\hline & \\
\hline & \\
\hline Volumen & \\
\hline & \\
\hline & \\
\hline & \\
\hline &
\end{tabular}

Gewichtsanteil

\section{Rottedauer}

durchschnittliches

Monatsaufkommen

maximaler Monatsanfall

\begin{tabular}{|l|}
\hline \\
\hline TS-Gehalt (Fertigkompost)
\end{tabular}

Mietenhöhe

Mietenbasisbreite

\section{ANLAGENDIMENSIONIERUNG}

\section{Anlagenteil}

Anlieferungsfläche

Rottefläche

Rangierfläche

Zwischenlager für

Strukturmaterial

Kompostlager

Anlagenfläche (gesamt)

zu verwertende

Abwassermenge

|

$\mid$

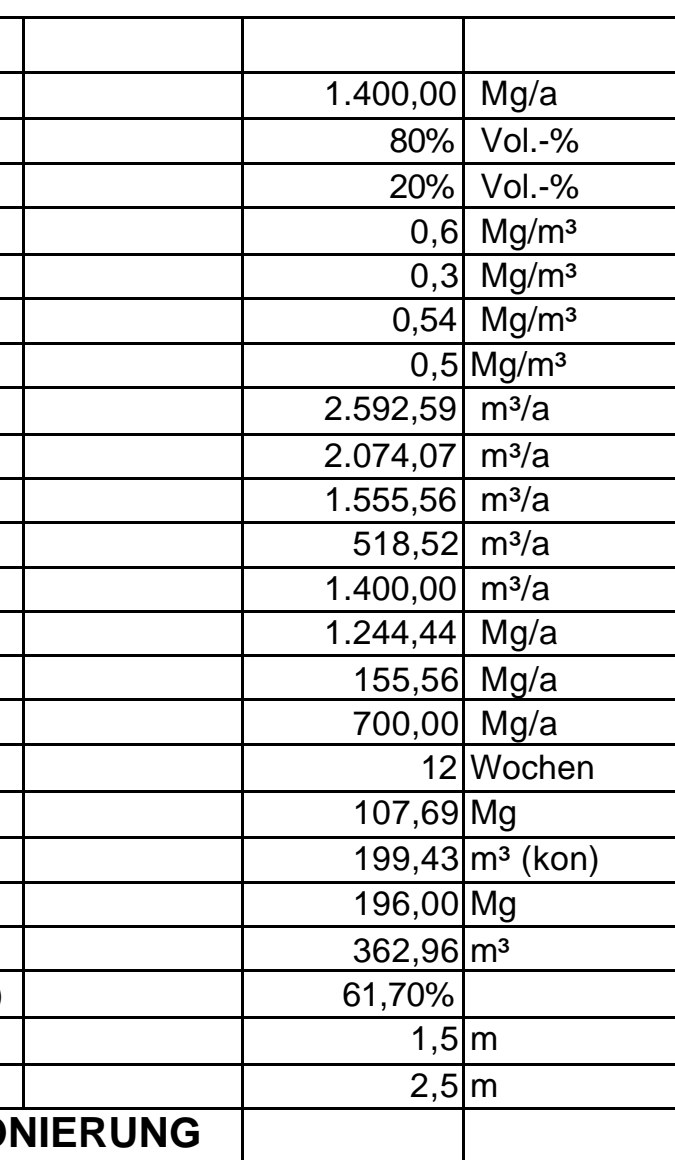

Berechnungsgrundlage

5\% 1 vom Input in Mg/a, ausgedrückt in $\mathrm{m}^{2}$

$1,33 \mathrm{~m}^{2} / \mathrm{m}^{3}$ Rottematerial bei max.M.-Anfall

$40 \%$ der Rottefläche

der Rottefläche

$10 \%$ der Rottefläche

$0,2 \mathrm{~m}^{3} / \mathrm{m}^{2 \star} \mathrm{a}$

Grüngut

\begin{tabular}{|c|c|c|}
\hline ax.M.-Anfall & 1035,65 & $\mathrm{~m}^{2}$ \\
\hline & 414,26 & $\mathrm{~m}^{2}$ \\
\hline & & $\mathrm{m}^{2}$ \\
\hline & 103,57 & \\
\hline & 103,57 & $\mathrm{~m}^{2}$ \\
\hline & 1727,05 & $\mathrm{~m}^{2}$ \\
\hline & 345,41 & $\mathrm{~m}^{3} / \mathrm{a}$ \\
\hline
\end{tabular}

Bioabfälle aus Haushalten

gehäckseltes Grüngut

Bioabfälle aus Haushalten

gehäckseltes Grüngut

konditioniertes Material

Fertigkompost

konditioniertes Material

Bioabfälle aus Haushalten

angeliefertes Grüngut

gehäckseltes Grüngut

Fertigkompost

Bioabfälle aus Haushalten

Fertigkompost

\begin{tabular}{l|l}
\hline & \\
\hline & Rottematerial eines
\end{tabular}

entspr. 14\% vom Input/a

Mietenquerschnitt

\begin{tabular}{|r|l}
\hline $1,875 \mathrm{~m}^{2}$ & \\
\hline & \\
\end{tabular}

Anlagenneubau

Anlagenumnutzung

$400,00 \mathrm{~m}^{2}$

\begin{tabular}{|r|l|l|}
\hline 1525,00 & & \\
\cline { 1 - 2 } & \multicolumn{2}{|l|}{$\mathrm{m}^{2}$ (nicht drainiert) } \\
\hline 600,00 & & \\
\hline 400,00 & $\mathrm{~m}^{2}$ & \\
\hline 2325,00 & $\mathrm{~m}^{2}$ & \\
\hline 465,00 & $\mathrm{~m}^{3} / \mathrm{a}$ & \\
\hline
\end{tabular}




\begin{tabular}{|c|c|c|c|c|c|c|c|c|c|c|}
\hline \multicolumn{11}{|l|}{ ZEITEN } \\
\hline \multicolumn{3}{|l|}{ Arbeitsgang } & \multicolumn{2}{|c|}{ eingesetzte Maschinen } & \multicolumn{2}{|c|}{ Zeitbedarf/Einheit } & \multicolumn{2}{|c|}{ geleistete Einheiten } & \multicolumn{2}{|c|}{ Zeitbedarf/Jahr } \\
\hline \multicolumn{3}{|c|}{ Materialannahme } & & & 4,000 & h/Woche & 52,000 & Wochen/a & 208,000 & $h / a$ \\
\hline \multicolumn{3}{|c|}{ Manuelle Störstoffauslese } & & & 1,000 & $h / 100 m^{3}(\operatorname{In})$ & $3.629,630$ & $\mathrm{~m}^{3} / \mathrm{a}$ & 36,296 & $h / a$ \\
\hline \multicolumn{3}{|c|}{ Zerkleinerung von Strukturmaterial } & TL, SZ, Schr. & & 1,000 & $h / 50 m^{3}(\ln )$ & $1.555,556$ & $\mathrm{~m}^{3} / \mathrm{a}$ & 31,111 & $h / a$ \\
\hline \multicolumn{3}{|c|}{ Aufsetzen einer Matte aus Strukturmat. } & TL, AS & & 0,300 & $\mathrm{~h} / 100 \mathrm{~m}^{3}$ (kon) & $2.592,593$ & $\mathrm{~m}^{3} / \mathrm{a}$ & 7,778 & $\mathrm{~h} / \mathrm{a}$ \\
\hline \multicolumn{3}{|c|}{ Aufsetzen der Dreiecksmieten } & TL, AS & & 1,000 & $\mathrm{~h} / 20 \mathrm{~m}^{3}$ (kon) & $2.592,593$ & $\mathrm{~m}^{3} / \mathrm{a}$ & 129,630 & $h / a$ \\
\hline \multicolumn{3}{|c|}{ Umsetzen der Dreiecksmieten } & Schl., MU & & 0,005 & $\mathrm{~h} / \mathrm{m}$ (Mietenl.) & $11.836,049$ & $\mathrm{~m} / \mathrm{a}$ & 59,180 & $h / a$ \\
\hline \multicolumn{3}{|c|}{ Reinigung der Annahmefläche } & TL, AS & & 0,500 & $h / 150 m^{3}(\ln )$ & $3.629,630$ & $\mathrm{~m}^{3} / \mathrm{a}$ & 12,099 & $\mathrm{~h} / \mathrm{a}$ \\
\hline \multicolumn{3}{|l|}{ Sieben } & TL, AS, Sieb & & 1,000 & $\mathrm{~h} / 20 \mathrm{~m}^{3}(\mathrm{kom})$ & $1.400,000$ & $\mathrm{~m}^{3} / \mathrm{a}$ & 70,000 & $\mathrm{~h} / \mathrm{a}$ \\
\hline \multicolumn{3}{|c|}{ Abw.-Ausbringung bei Neubau } & Schl.,PT & & 1,000 & $\mathrm{~h} / 10 \mathrm{~m}^{3}(\mathrm{Abw})$ & 345,409 & $\mathrm{~m}^{3} / \mathrm{a}$ & 34,541 & $\mathrm{~h} / \mathrm{a}$ \\
\hline \multicolumn{3}{|c|}{ Abw.-Ausbringung bei Umnutzung } & Schl., PT & & 1,000 & $\mathrm{~h} / 10 \mathrm{~m}^{3}(\mathrm{Abw})$ & 465,000 & $\mathrm{~m}^{3} / \mathrm{a}$ & 46,500 & $h / a$ \\
\hline \multicolumn{11}{|c|}{ Abkürzungen für die eingesetzten Maschinen: } \\
\hline \multicolumn{2}{|c|}{ TL - Teleskoplader } & & \multicolumn{2}{|c|}{ Schl. - Schlepper } & & & & & & \\
\hline \multicolumn{2}{|c|}{\begin{tabular}{|l} 
MU- Mietenumsetzer \\
\end{tabular}} & & Schr. - Schred & dder & & & & & & \\
\hline \multicolumn{2}{|c|}{ SZ - Silozange } & & PT - Pumpenta & tankwagen & & & & & & \\
\hline \multicolumn{11}{|c|}{ AS - Anbauschaufel } \\
\hline \multicolumn{11}{|c|}{ MASCHINENKOSTEN } \\
\hline \multicolumn{2}{|c|}{ Maschine / Gerät } & Fixkosten & & \multicolumn{2}{|c|}{ Variable Kosten } & Einheiten/a & & \multicolumn{2}{|c|}{ Maschinen-Einzelkosten } & \\
\hline Traktor (Neub & au) & 0,00 & $\mathrm{DM} / \mathrm{a}$ & 33,55 & $\mathrm{DM} / \mathrm{h}$ & 93,72 & $h / a$ & $3.144,35$ & $\mathrm{DM} / \mathrm{a}$ & \\
\hline Traktor (Umnı & itzung) & 0,00 & $\mathrm{DM} / \mathrm{a}$ & 33,55 & $\mathrm{DM} / \mathrm{h}$ & 105,68 & $\mathrm{~h} / \mathrm{a}$ & $3.545,57$ & $\mathrm{DM} / \mathrm{a}$ & \\
\hline Teleskoplader & & 0,00 & $\mathrm{DM} / \mathrm{a}$ & 66,50 & $\mathrm{DM} / \mathrm{h}$ & 250,62 & $h / a$ & $16.666,05$ & $\mathrm{DM} / \mathrm{a}$ & \\
\hline Schredder & & 0,00 & $\mathrm{DM} / \mathrm{a}$ & 7,50 & $\mathrm{DM} / \mathrm{m}^{3}$ (Out) & 518,52 & $\mathrm{~m}^{3} / \mathrm{a}$ & $3.888,89$ & $\mathrm{DM} / \mathrm{a}$ & \\
\hline Trommelsieb & & 0,00 & $\mathrm{DM} / \mathrm{a}$ & 5,00 & $\mathrm{DM} / \mathrm{m}^{3}(\mathrm{Kom})$ & $1.400,00$ & $\mathrm{~m}^{3} / \mathrm{a}$ & $7.000,00$ & $\mathrm{DM} / \mathrm{a}$ & \\
\hline PumpenTW (I & Veubau) & 0,00 & $\mathrm{DM} / \mathrm{a}$ & 30,00 & $\mathrm{DM} / \mathrm{h}$ & 34,54 & $\mathrm{~h} / \mathrm{a}$ & $1.036,23$ & $\mathrm{DM} / \mathrm{a}$ & \\
\hline PumpenTW (L & Jmnutzung) & 0,00 & $D M / a$ & 30,00 & $D M / h$ & 46,50 & $h / a$ & $1.395,00$ & $\mathrm{DM} / \mathrm{a}$ & \\
\hline Silozange & & $1.120,00$ & DM/a & 0,30 & $\mathrm{DM} / \mathrm{m}^{3}$ & $1.555,56$ & $m^{3} / a$ & $1.586,67$ & $\mathrm{DM} / \mathrm{a}$ & \\
\hline Anbauschaufe & & 506,00 & $\mathrm{DM} / \mathrm{a}$ & 0,30 & $\mathrm{DM} / \mathrm{m}^{3}$ & $10.214,81$ & $m^{3} / a$ & $3.570,44$ & $\mathrm{DM} / \mathrm{a}$ & \\
\hline Mietenumsetz & & $3.600,00$ & $\mathrm{DM} / \mathrm{a}$ & 28,00 & $\mathrm{DM} / \mathrm{h}$ & 59,18 & $\mathrm{~h} / \mathrm{a}$ & $5.257,05$ & $\mathrm{DM} / \mathrm{a}$ & \\
\hline & & & & & & Summe (Neuk & bau) & $42.149,67$ & $\mathrm{DM} / \mathrm{a}$ & \\
\hline & & & & & & Summe (Umn & hutzung) & $42.909,67$ & $\mathrm{DM} / \mathrm{a}$ & \\
\hline PERSONAI & LOSTEN & & & & & & & & & \\
\hline & Std.-Lohn inkl & I.Lohn-NK & Arbeitsstd. pro & o Jahr & Personal-Einz & zelkosten & & & & \\
\hline Neubau & 26,00 & $D M / h$ & 588,63 & $\mathrm{~h} / \mathrm{a}$ & $15.304,50$ & $\mathrm{DM} / \mathrm{a}$ & & & & \\
\hline Umnutzung & 26,00 & $D M / h$ & 600,59 & $h / a$ & $15.615,44$ & $D M / a$ & & & & \\
\hline
\end{tabular}




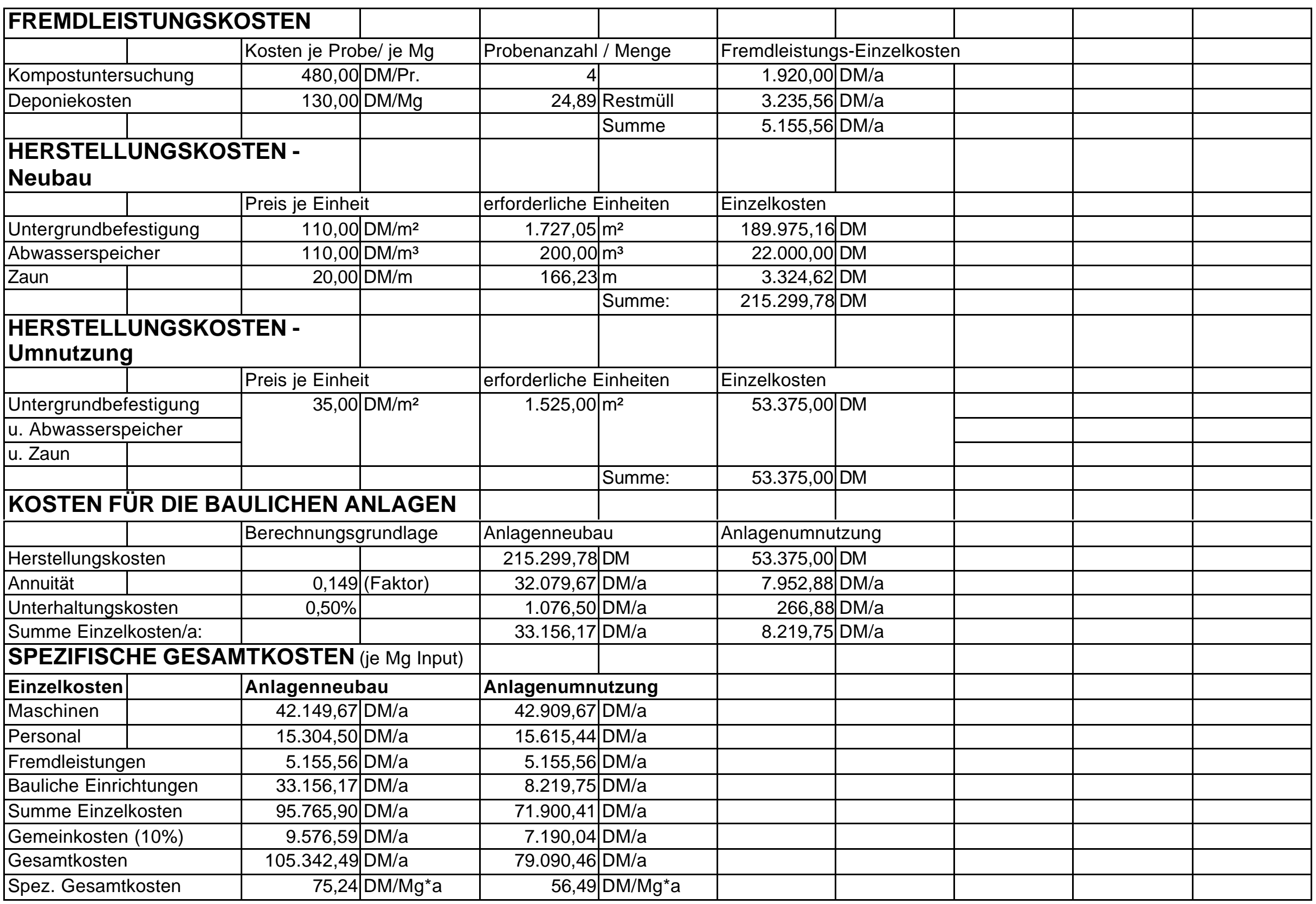


Kostenvariante A7

\section{MATERIAL}

Jahresinputmenge

Zusammensetzung

\begin{tabular}{|l|l|}
\hline & \\
\hline Dichte & \\
\hline & \\
\hline & \\
\hline & \\
\hline Volumen & \\
\hline & \\
\hline & \\
\hline & \\
\hline & \\
\hline
\end{tabular}

Gewichtsanteil

\section{Rottedauer}

durchschnittliches

Monatsaufkommen

maximaler Monatsanfall

\begin{tabular}{|l}
\hline \\
TS-Gehalt (Fertigkompost)
\end{tabular}

Mietenhöhe

Mietenbasisbreite

\section{ANLAGENDIMENSIONIERUNG}

\section{Anlagenteil}

Anlieferungsfläche

Rottefläche

Rangierfläche

Zwischenlager für

Strukturmaterial

Kompostlager

Anlagenfläche (gesamt)

zu verwertende

Abwassermenge

\section{|}

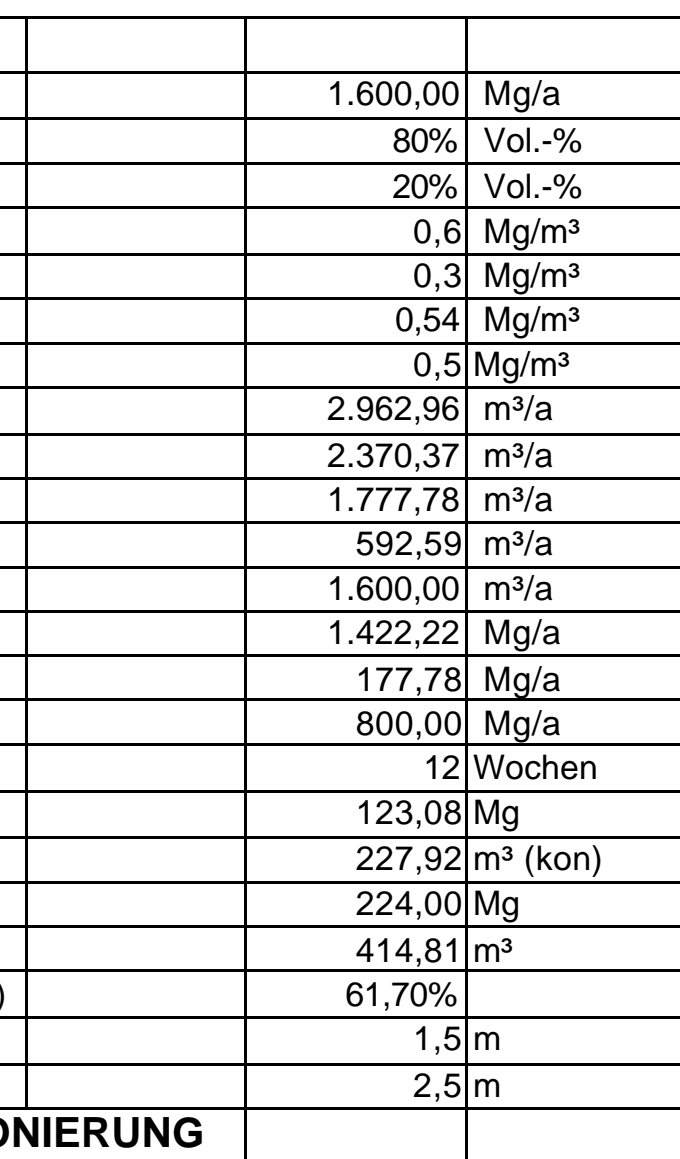

Berechnungsgrundlage

5\% 1 vom Input in Mg/a, ausgedrückt in $\mathrm{m}^{2}$

$1,33 \mathrm{~m}^{2} / \mathrm{m}^{3}$ Rottematerial bei max.M.-Anfall

$40 \%$ der Rottefläche

der Rottefläche

$10 \%$ der Rottefläche

$+$

$0,2 \mathrm{~m}^{3} / \mathrm{m}^{2 \star} \mathrm{a}$

Grüngut

\begin{tabular}{|c|c|c|}
\hline ax.M.-Anfall & 1183,60 & $\mathrm{~m}^{2}$ \\
\hline & 473,44 & $\mathrm{~m}^{2}$ \\
\hline & & $m^{2}$ \\
\hline & 118,36 & \\
\hline & 118,36 & $\mathrm{~m}^{2}$ \\
\hline & 1973,77 & $\mathrm{~m}^{2}$ \\
\hline & & \\
\hline & 394,75 & $m^{3} / a$ \\
\hline
\end{tabular}

Bioabfälle aus Haushalten

gehäckseltes Grüngut

Bioabfälle aus Haushalten

gehäckseltes Grüngut

konditioniertes Material

Fertigkompost

konditioniertes Material

Bioabfälle aus Haushalten

angeliefertes Grüngut

gehäckseltes Grüngut

Fertigkompost

Bioabfälle aus Haushalten

Fertigkompost

\begin{tabular}{l|l|l}
\hline & & \\
\hline & Rottematerial eines
\end{tabular}

entspr. 14\% vom Input/a

Mietenquerschnitt

\begin{tabular}{|r|l|l|}
\hline 1,875 & $\mathrm{~m}^{2}$ & \\
& &
\end{tabular}

Anlagenneubau

Anlagenumnutzung

\begin{tabular}{|r|l|l|}
\hline 850,00 & $\mathrm{~m}^{2}$ & \\
\hline 3160,00 & & \\
& & \\
\hline & & \\
\hline 850,00 & $\mathrm{~m}^{2}$ & \\
\hline 4860,00 & $\mathrm{~m}^{2}$ & \\
\hline 972,00 & $\mathrm{~m}^{3} / \mathrm{a}$ & \\
\hline
\end{tabular}




\begin{tabular}{|c|c|c|c|c|c|c|c|c|c|c|}
\hline \multicolumn{11}{|l|}{ ZEITEN } \\
\hline \multicolumn{3}{|l|}{ Arbeitsgang } & \multicolumn{2}{|c|}{ eingesetzte Maschinen } & \multicolumn{2}{|c|}{ Zeitbedarf/Einheit } & \multicolumn{2}{|c|}{ geleistete Einheiten } & \multicolumn{2}{|c|}{ Zeitbedarf/Jahr } \\
\hline \multicolumn{3}{|c|}{ Materialannahme } & & & 4,000 & h/Woche & 52,000 & Wochen/a & 208,000 & $h / a$ \\
\hline \multicolumn{3}{|c|}{ Manuelle Störstoffauslese } & & & 1,000 & $h / 100 m^{3}(\operatorname{In})$ & $4.148,148$ & $\mathrm{~m}^{3} / \mathrm{a}$ & 41,481 & $h / a$ \\
\hline \multicolumn{3}{|c|}{ Zerkleinerung von Strukturmaterial } & TL, SZ, Schr. & & 1,000 & $h / 50 m^{3}(\ln )$ & $1.777,778$ & $\mathrm{~m}^{3} / \mathrm{a}$ & 35,556 & $h / a$ \\
\hline \multicolumn{3}{|c|}{ Aufsetzen einer Matte aus Strukturmat. } & TL, AS & & 0,300 & $\mathrm{~h} / 100 \mathrm{~m}^{3}$ (kon) & $2.962,963$ & $\mathrm{~m}^{3} / \mathrm{a}$ & 8,889 & $h / a$ \\
\hline \multicolumn{3}{|c|}{ Aufsetzen der Dreiecksmieten } & TL, AS & & 1,000 & $\mathrm{~h} / 20 \mathrm{~m}^{3}$ (kon) & $2.962,963$ & $\mathrm{~m}^{3} / \mathrm{a}$ & 148,148 & $\mathrm{~h} / \mathrm{a}$ \\
\hline \multicolumn{3}{|c|}{ Umsetzen der Dreiecksmieten } & Schl., MU & & 0,005 & $\mathrm{~h} / \mathrm{m}$ (Mietenl.) & $13.526,914$ & $\mathrm{~m} / \mathrm{a}$ & 67,635 & $\mathrm{~h} / \mathrm{a}$ \\
\hline \multicolumn{3}{|c|}{ Reinigung der Annahmefläche } & TL, AS & & 0,500 & $\mathrm{~h} / 150 \mathrm{~m}^{3}(\ln )$ & $4.148,148$ & $\mathrm{~m}^{3} / \mathrm{a}$ & 13,827 & $\mathrm{~h} / \mathrm{a}$ \\
\hline \multicolumn{3}{|l|}{ Sieben } & TL, AS, Sieb & & 1,000 & $\mathrm{~h} / 20 \mathrm{~m}^{3}(\mathrm{kom})$ & $1.600,000$ & $\mathrm{~m}^{3} / \mathrm{a}$ & 80,000 & $\mathrm{~h} / \mathrm{a}$ \\
\hline \multicolumn{3}{|c|}{ Abw.-Ausbringung bei Neubau } & Schl.,PT & & 1,000 & $\mathrm{~h} / 10 \mathrm{~m}^{3}(\mathrm{Abw})$ & 394,754 & $\mathrm{~m}^{3} / \mathrm{a}$ & 39,475 & $h / a$ \\
\hline \multicolumn{3}{|c|}{ Abw.-Ausbringung bei Umnutzung } & Schl., PT & & 1,000 & $\mathrm{~h} / 10 \mathrm{~m}^{3}(\mathrm{Abw})$ & 972,000 & $\mathrm{~m}^{3} / \mathrm{a}$ & 97,200 & $h / a$ \\
\hline \multicolumn{11}{|c|}{ Abkürzungen für die eingesetzten Maschinen: } \\
\hline \multicolumn{2}{|c|}{ TL - Teleskoplader } & & \multicolumn{2}{|c|}{ Schl. - Schlepper } & & & & & & \\
\hline \multicolumn{2}{|c|}{ MU- Mietenumsetzer } & & Schr. - Schred & dder & & & & & & \\
\hline \multicolumn{2}{|c|}{ SZ - Silozange } & & PT - Pumpenta & tankwagen & & & & & & \\
\hline \multicolumn{11}{|c|}{ AS - Anbauschaufel } \\
\hline \multicolumn{11}{|c|}{ MASCHINENKOSTEN } \\
\hline \multicolumn{2}{|c|}{ Maschine / Gerät } & Fixkosten & & \multicolumn{2}{|c|}{ Variable Kosten } & Einheiten/a & & \multicolumn{2}{|c|}{ Maschinen-Einzelkosten } & \\
\hline Traktor (Neub & au) & 0,00 & $\mathrm{DM} / \mathrm{a}$ & 33,55 & $\mathrm{DM} / \mathrm{h}$ & 107,11 & $\mathrm{~h} / \mathrm{a}$ & $3.593,54$ & $\mathrm{DM} / \mathrm{a}$ & \\
\hline Traktor (Umnı & itzung) & 0,00 & $\mathrm{DM} / \mathrm{a}$ & 33,55 & $\mathrm{DM} / \mathrm{h}$ & 164,83 & $\mathrm{~h} / \mathrm{a}$ & $5.530,20$ & $\mathrm{DM} / \mathrm{a}$ & \\
\hline Teleskoplader & & 0,00 & $\mathrm{DM} / \mathrm{a}$ & 66,50 & $\mathrm{DM} / \mathrm{h}$ & 286,42 & $h / a$ & $19.046,91$ & $\mathrm{DM} / \mathrm{a}$ & \\
\hline Schredder & & 0,00 & $\mathrm{DM} / \mathrm{a}$ & 7,50 & $\mathrm{DM} / \mathrm{m}^{3}$ (Out) & 592,59 & $\mathrm{~m}^{3} / \mathrm{a}$ & $4.444,44$ & $\mathrm{DM} / \mathrm{a}$ & \\
\hline Trommelsieb & & 0,00 & $\mathrm{DM} / \mathrm{a}$ & 5,00 & $\mathrm{DM} / \mathrm{m}^{3}(\mathrm{Kom})$ & $1.600,00$ & $\mathrm{~m}^{3} / \mathrm{a}$ & $8.000,00$ & $\mathrm{DM} / \mathrm{a}$ & \\
\hline PumpenTW (I & Veubau) & 0,00 & $\mathrm{DM} / \mathrm{a}$ & 30,00 & $\mathrm{DM} / \mathrm{h}$ & 39,48 & $\mathrm{~h} / \mathrm{a}$ & $1.184,26$ & $\mathrm{DM} / \mathrm{a}$ & \\
\hline PumpenTW (L & Jmnutzung) & 0,00 & $D M / a$ & 30,00 & $D M / h$ & 97,20 & $\mathrm{~h} / \mathrm{a}$ & $2.916,00$ & $\mathrm{DM} / \mathrm{a}$ & \\
\hline Silozange & & $1.120,00$ & DM/a & 0,30 & $\mathrm{DM} / \mathrm{m}^{3}$ & $1.777,78$ & $\mathrm{~m}^{3} / \mathrm{a}$ & $1.653,33$ & $\mathrm{DM} / \mathrm{a}$ & \\
\hline Anbauschaufe & & 506,00 & $\mathrm{DM} / \mathrm{a}$ & 0,30 & $\mathrm{DM} / \mathrm{m}^{3}$ & $11.674,07$ & $\mathrm{~m}^{3} / \mathrm{a}$ & $4.008,22$ & $\mathrm{DM} / \mathrm{a}$ & \\
\hline Mietenumsetz & & $3.600,00$ & $\mathrm{DM} / \mathrm{a}$ & 28,00 & $\mathrm{DM} / \mathrm{h}$ & 67,63 & $\mathrm{~h} / \mathrm{a}$ & $5.493,77$ & $\mathrm{DM} / \mathrm{a}$ & \\
\hline & & & & & & Summe (Neub & bau) & $47.424,48$ & $\mathrm{DM} / \mathrm{a}$ & \\
\hline & & & & & & Summe (Umn & uutzung) & $51.092,88$ & $\mathrm{DM} / \mathrm{a}$ & \\
\hline PERSONAI & LOSTEN & & & & & & & & & \\
\hline & Std.-Lohn inkl & I.Lohn-NK & Arbeitsstd. pro & o Jahr & Personal-Einz & zelkosten & & & & \\
\hline Neubau & 26,00 & $D M / h$ & 643,01 & $\mathrm{~h} / \mathrm{a}$ & $16.718,29$ & $\mathrm{DM} / \mathrm{a}$ & & & & \\
\hline Umnutzung & 26,00 & $D M / h$ & 700,74 & $h / a$ & $18.219,13$ & DM/a & & & & \\
\hline
\end{tabular}




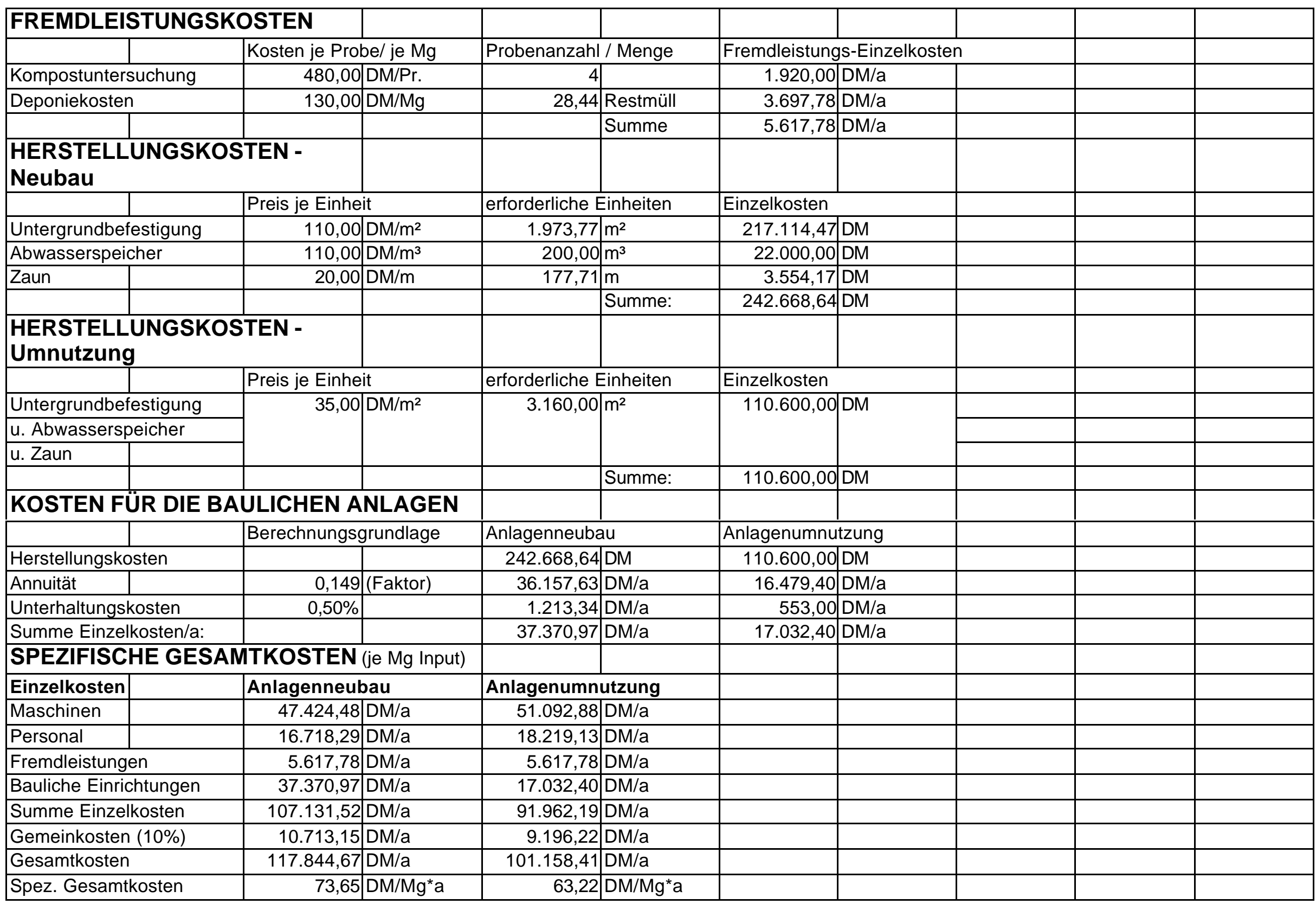


Kostenvariante A8

\section{MATERIAL}

Jahresinputmenge

Zusammensetzung

\begin{tabular}{|l|l|}
\hline & \\
\hline Dichte & \\
\hline & \\
\hline & \\
\hline & \\
\hline Volumen & \\
\hline & \\
\hline & \\
\hline & \\
\hline & \\
\hline
\end{tabular}

Gewichtsanteil

\section{Rottedauer}

durchschnittliches

Monatsaufkommen

maximaler Monatsanfall

\begin{tabular}{|l|}
\hline \\
\hline TS-Gehalt (Fertigkompost)
\end{tabular}

Mietenhöhe

Mietenbasisbreite

\section{ANLAGENDIMENSIONIERUNG}

\section{Anlagenteil}

Anlieferungsfläche

Rottefläche

Rangierfläche

Zwischenlager für

Strukturmaterial

Kompostlager

Anlagenfläche (gesamt)

zu verwertende

Abwassermenge

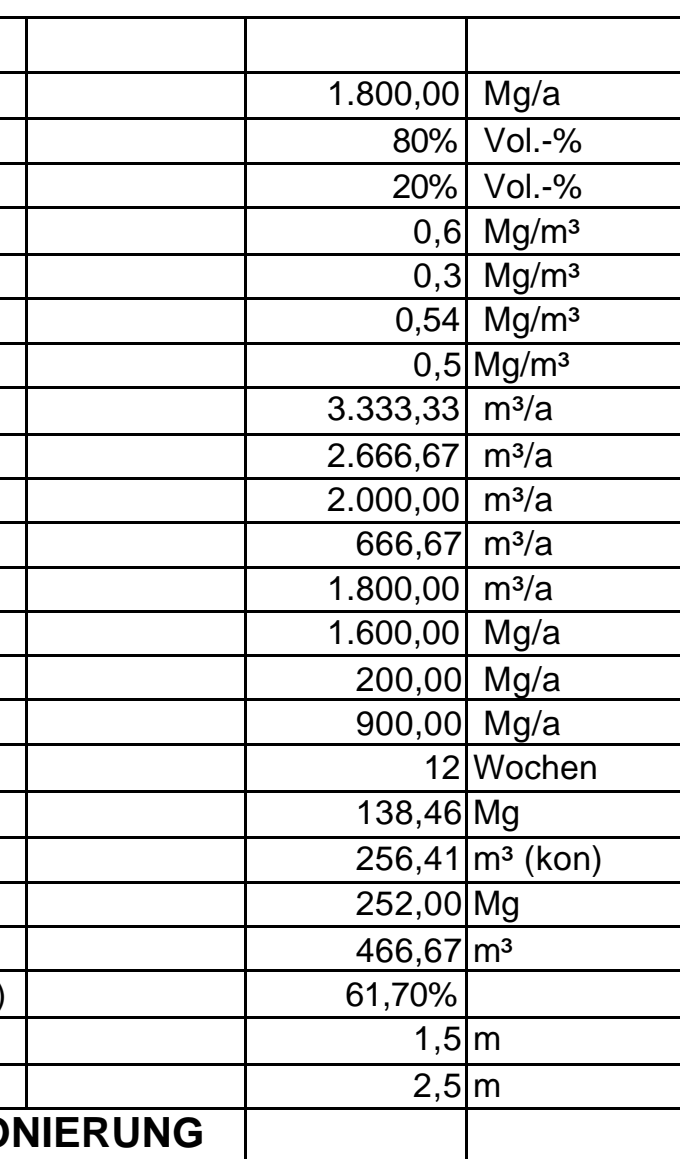

Berechnungsgrundlage

$5 \%$ vom Input in Mg/a, ausgedrückt in $\mathrm{m}^{2}$

$1,33 \mathrm{~m}^{2} / \mathrm{m}^{3}$ Rottematerial bei max.M.-Anfall

$40 \%$ der Rottefläche

der Rottefläche $10 \%$

$10 \%$ der Rottefläche

|

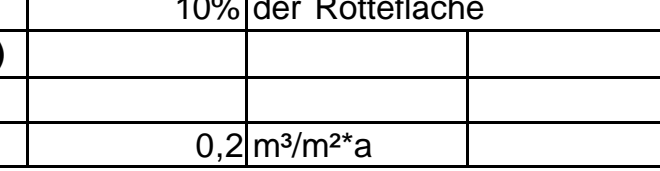

Grüngut
Bioabfälle aus Haushalten

gehäckseltes Grüngut

Bioabfälle aus Haushalten

gehäckseltes Grüngut

konditioniertes Material

Fertigkompost

konditioniertes Material

Bioabfälle aus Haushalten

angeliefertes Grüngut

gehäckseltes Grüngut

Fertigkompost

Bioabfälle aus Haushalten

Fertigkompost

\begin{tabular}{|c|c|c|}
\hline \multicolumn{3}{|l|}{ 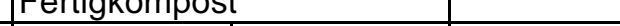 } \\
\hline & & \\
\hline & \multicolumn{2}{|c|}{ Rottematerial eines } \\
\hline & \multicolumn{2}{|c|}{ Durchlaufs in der Anlage } \\
\hline \multicolumn{3}{|c|}{ entspr. 14\% vom Input/a } \\
\hline & & \\
\hline & & \\
\hline \multicolumn{3}{|c|}{ Mietenquerschnitt } \\
\hline 1,875 & $m^{2}$ & \\
\hline & & \\
\hline
\end{tabular}

Anlagenneubau

$90,00 \mathrm{~m}^{2}$

\begin{tabular}{|c|c|c|}
\hline .M.-Anfall & 1331,56 & $\mathrm{~m}^{2}$ \\
\hline & 532,62 & $\mathrm{~m}^{2}$ \\
\hline & & $\mathrm{m}^{2}$ \\
\hline & 133,16 & \\
\hline & 133,16 & $\mathrm{~m}^{2}$ \\
\hline & 2220,49 & $\mathrm{~m}^{2}$ \\
\hline & 444,10 & $\mathrm{~m}^{3} / \mathrm{a}$ \\
\hline
\end{tabular}

Anlagenumnutzung

$850,00 \mathrm{~m}^{2}$

\begin{tabular}{|c|c|}
\hline & $\mathrm{m}^{2}$ \\
\hline 3160,00 & \\
\hline & \\
\hline 850,00 & $\mathrm{~m}^{2}$ \\
\hline 4860,00 & $m^{2}$ \\
\hline 972,00 & $\mathrm{~m}^{3} / \mathrm{a}$ \\
\hline
\end{tabular}




\begin{tabular}{|c|c|c|c|c|c|c|c|c|c|c|}
\hline \multicolumn{11}{|l|}{ ZEITEN } \\
\hline \multicolumn{3}{|l|}{ Arbeitsgang } & \multicolumn{2}{|c|}{ eingesetzte Maschinen } & \multicolumn{2}{|c|}{ Zeitbedarf/Einheit } & \multicolumn{2}{|c|}{ geleistete Einheiten } & \multicolumn{2}{|c|}{ Zeitbedarf/Jahr } \\
\hline \multicolumn{3}{|c|}{ Materialannahme } & & & 4,000 & h/Woche & 52,000 & Wochen/a & 208,000 & $h / a$ \\
\hline \multicolumn{3}{|c|}{ Manuelle Störstoffauslese } & & & 1,000 & $h / 100 m^{3}(\operatorname{In})$ & $4.666,667$ & $\mathrm{~m}^{3} / \mathrm{a}$ & 46,667 & $\mathrm{~h} / \mathrm{a}$ \\
\hline \multicolumn{3}{|c|}{ Zerkleinerung von Strukturmaterial } & TL, SZ, Schr. & & 1,000 & $h / 50 m^{3}(\ln )$ & $2.000,000$ & $\mathrm{~m}^{3} / \mathrm{a}$ & 40,000 & $h / a$ \\
\hline \multicolumn{3}{|c|}{ Aufsetzen einer Matte aus Strukturmat. } & TL, AS & & 0,300 & $\mathrm{~h} / 100 \mathrm{~m}^{3}$ (kon) & $3.333,333$ & $\mathrm{~m}^{3} / \mathrm{a}$ & 10,000 & $h / a$ \\
\hline \multicolumn{3}{|c|}{ Aufsetzen der Dreiecksmieten } & TL, AS & & 1,000 & $\mathrm{~h} / 20 \mathrm{~m}^{3}$ (kon) & $3.333,333$ & $\mathrm{~m}^{3} / \mathrm{a}$ & 166,667 & $\mathrm{~h} / \mathrm{a}$ \\
\hline \multicolumn{3}{|c|}{ Umsetzen der Dreiecksmieten } & Schl., MU & & 0,005 & $\mathrm{~h} / \mathrm{m}$ (Mietenl.) & $15.217,778$ & $\mathrm{~m} / \mathrm{a}$ & 76,089 & $\mathrm{~h} / \mathrm{a}$ \\
\hline \multicolumn{3}{|c|}{ Reinigung der Annahmefläche } & TL, AS & & 0,500 & $h / 150 m^{3}(\ln )$ & $4.666,667$ & $\mathrm{~m}^{3} / \mathrm{a}$ & 15,556 & $\mathrm{~h} / \mathrm{a}$ \\
\hline \multicolumn{3}{|l|}{ Sieben } & TL, AS, Sieb & & 1,000 & $\mathrm{~h} / 20 \mathrm{~m}^{3}(\mathrm{kom})$ & $1.800,000$ & $\mathrm{~m}^{3} / \mathrm{a}$ & 90,000 & $\mathrm{~h} / \mathrm{a}$ \\
\hline \multicolumn{3}{|c|}{ Abw.-Ausbringung bei Neubau } & Schl.,PT & & 1,000 & $\mathrm{~h} / 10 \mathrm{~m}^{3}(\mathrm{Abw})$ & 444,098 & $\mathrm{~m}^{3} / \mathrm{a}$ & 44,410 & $h / a$ \\
\hline \multicolumn{3}{|c|}{ Abw.-Ausbringung bei Umnutzung } & Schl., PT & & 1,000 & $\mathrm{~h} / 10 \mathrm{~m}^{3}(\mathrm{Abw})$ & 972,000 & $\mathrm{~m}^{3} / \mathrm{a}$ & 97,200 & $h / a$ \\
\hline \multicolumn{11}{|c|}{ Abkürzungen für die eingesetzten Maschinen: } \\
\hline \multicolumn{2}{|c|}{ TL - Teleskoplader } & & \multicolumn{2}{|c|}{ Schl. - Schlepper } & & & & & & \\
\hline \multicolumn{2}{|c|}{ MU- Mietenumsetzer } & & Schr. - Schred & dder & & & & & & \\
\hline \multicolumn{2}{|c|}{ SZ - Silozange } & & PT - Pumpenta & tankwagen & & & & & & \\
\hline \multicolumn{11}{|c|}{ AS - Anbauschaufel } \\
\hline \multicolumn{11}{|c|}{ MASCHINENKOSTEN } \\
\hline \multicolumn{2}{|c|}{ Maschine / Gerät } & Fixkosten & & \multicolumn{2}{|c|}{ Variable Kosten } & Einheiten/a & & \multicolumn{2}{|c|}{ Maschinen-Einzelkosten } & \\
\hline Traktor (Neub & au) & 0,00 & $\mathrm{DM} / \mathrm{a}$ & 33,55 & $\mathrm{DM} / \mathrm{h}$ & 120,50 & $h / a$ & $4.042,73$ & $\mathrm{DM} / \mathrm{a}$ & \\
\hline Traktor (Umnı & itzung) & 0,00 & $\mathrm{DM} / \mathrm{a}$ & 33,55 & $\mathrm{DM} / \mathrm{h}$ & 173,29 & $\mathrm{~h} / \mathrm{a}$ & $5.813,84$ & $\mathrm{DM} / \mathrm{a}$ & \\
\hline Teleskoplader & & 0,00 & $\mathrm{DM} / \mathrm{a}$ & 66,50 & $\mathrm{DM} / \mathrm{h}$ & 322,22 & $h / a$ & $21.427,78$ & $\mathrm{DM} / \mathrm{a}$ & \\
\hline Schredder & & 0,00 & $\mathrm{DM} / \mathrm{a}$ & 7,50 & $\mathrm{DM} / \mathrm{m}^{3}$ (Out) & 666,67 & $\mathrm{~m}^{3} / \mathrm{a}$ & $5.000,00$ & $\mathrm{DM} / \mathrm{a}$ & \\
\hline Trommelsieb & & 0,00 & $\mathrm{DM} / \mathrm{a}$ & 5,00 & $\mathrm{DM} / \mathrm{m}^{3}(\mathrm{Kom})$ & $1.800,00$ & $\mathrm{~m}^{3} / \mathrm{a}$ & $9.000,00$ & $\mathrm{DM} / \mathrm{a}$ & \\
\hline PumpenTW (I & Veubau) & 0,00 & $\mathrm{DM} / \mathrm{a}$ & 30,00 & $\mathrm{DM} / \mathrm{h}$ & 44,41 & $\mathrm{~h} / \mathrm{a}$ & $1.332,29$ & $\mathrm{DM} / \mathrm{a}$ & \\
\hline PumpenTW (L & Jmnutzung) & 0,00 & $D M / a$ & 30,00 & $D M / h$ & 97,20 & $h / a$ & $2.916,00$ & $\mathrm{DM} / \mathrm{a}$ & \\
\hline Silozange & & $1.120,00$ & DM/a & 0,30 & $\mathrm{DM} / \mathrm{m}^{3}$ & $2.000,00$ & $\mathrm{~m}^{3} / \mathrm{a}$ & $1.720,00$ & $\mathrm{DM} / \mathrm{a}$ & \\
\hline Anbauschaufe & & 506,00 & $\mathrm{DM} / \mathrm{a}$ & 0,30 & $\mathrm{DM} / \mathrm{m}^{3}$ & $13.133,33$ & $\mathrm{~m}^{3} / \mathrm{a}$ & $4.446,00$ & $\mathrm{DM} / \mathrm{a}$ & \\
\hline Mietenumsetz & & $3.600,00$ & $\mathrm{DM} / \mathrm{a}$ & 28,00 & $\mathrm{DM} / \mathrm{h}$ & 76,09 & $h / a$ & $5.730,49$ & $\mathrm{DM} / \mathrm{a}$ & \\
\hline & & & & & & Summe (Neuk & bau) & $52.699,29$ & $\mathrm{DM} / \mathrm{a}$ & \\
\hline & & & & & & Summe (Umn & hutzung) & $56.054,11$ & $\mathrm{DM} / \mathrm{a}$ & \\
\hline PERSONA & LOSTEN & & & & & & & & & \\
\hline & Std.-Lohn inkl & I.Lohn-NK & Arbeitsstd. pro & o Jahr & Personal-Einz & zelkosten & & & & \\
\hline Neubau & 26,00 & $D M / h$ & 697,39 & $\mathrm{~h} / \mathrm{a}$ & $18.132,08$ & $D M / a$ & & & & \\
\hline Umnutzung & 26,00 & $D M / h$ & 750,18 & $h / a$ & $19.504,62$ & $D M / a$ & & & & \\
\hline
\end{tabular}




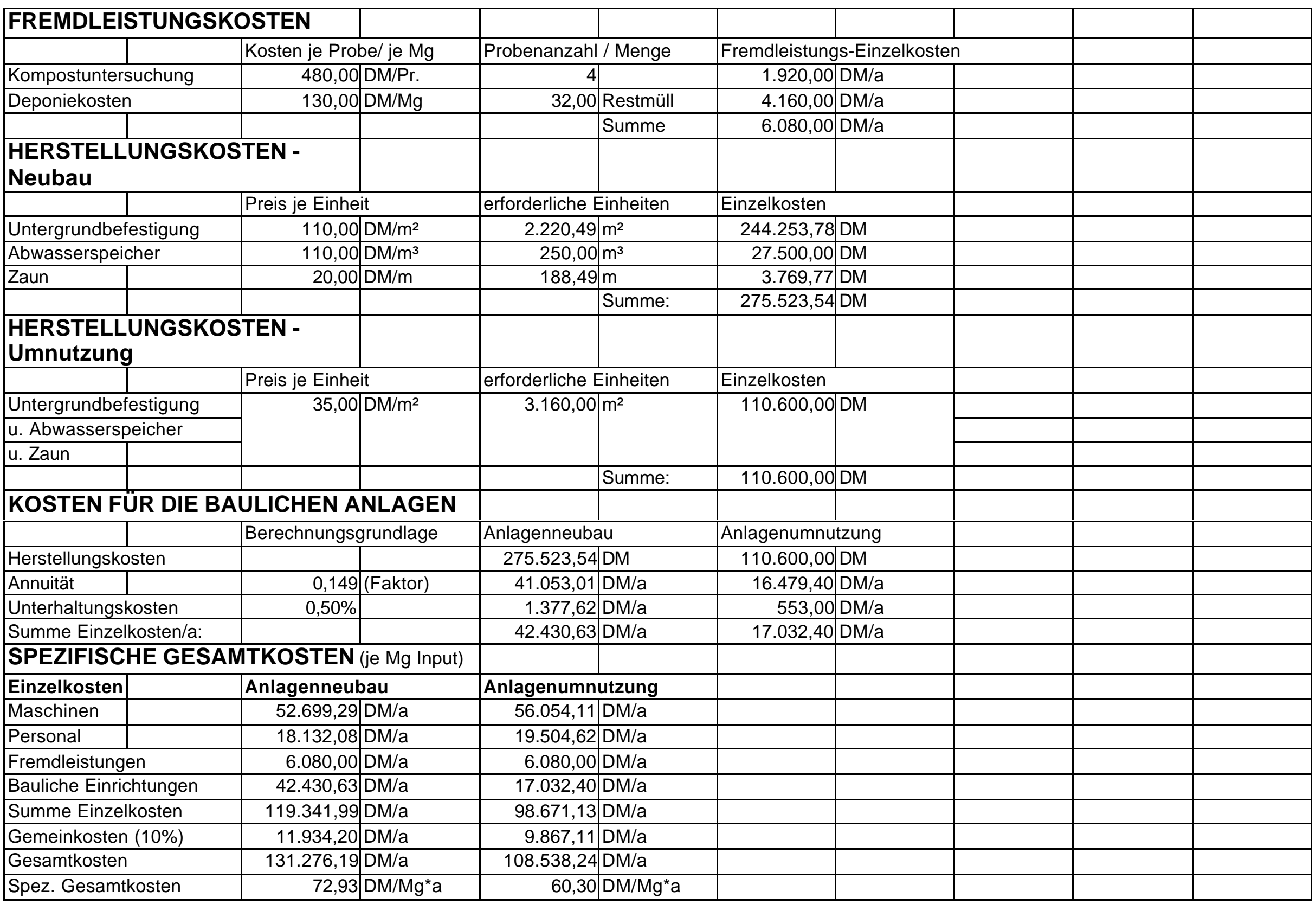


Kostenvariante A9

\section{MATERIAL}

Jahresinputmenge

Zusammensetzung

\begin{tabular}{|l|l|}
\hline & \\
\hline Dichte & \\
\hline & \\
\hline & \\
\hline & \\
\hline & \\
\hline & \\
\hline & \\
\hline & \\
\hline &
\end{tabular}

Gewichtsanteil

\section{Rottedauer}

durchschnittliches

Monatsaufkommen

maximaler Monatsanfall

\begin{tabular}{|l|}
\hline \\
\hline TS-Gehalt (Fertigkompost)
\end{tabular}

Mietenhöhe

Mietenbasisbreite

\section{ANLAGENDIMENSIONIERUNG}

\section{Anlagenteil}

Anlieferungsfläche

Rottefläche

Rangierfläche

Zwischenlager für

Strukturmaterial

Kompostlager

Anlagenfläche (gesamt)

zu verwertende

Abwassermenge

\section{|}

+

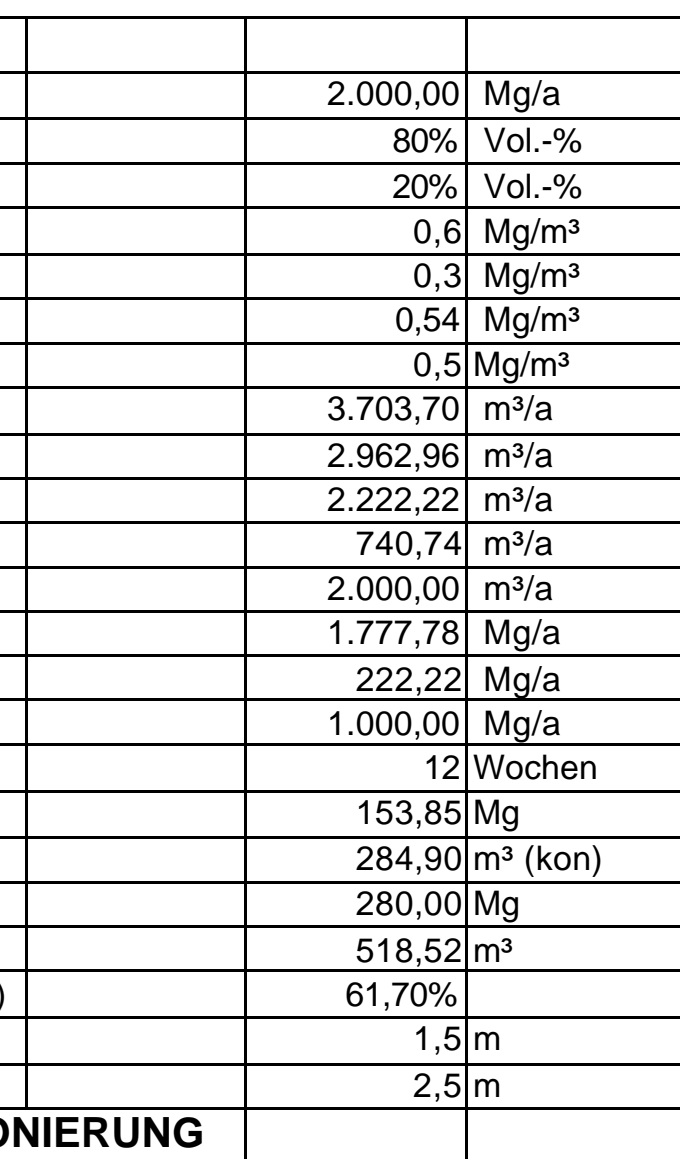

Berechnungsgrundlage

$5 \%$ vom Input in Mg/a, ausgedrückt in $\mathrm{m}^{2}$

$1,33 \mathrm{~m}^{2} / \mathrm{m}^{3}$ Rottematerial bei max.M.-Anfall

$40 \%$ der Rottefläche

der Rottefläche

$10 \%$ der Rottefläche

$0,2 \mathrm{~m}^{3} / \mathrm{m}^{2 \star} \mathrm{a}$

Grüngut

\begin{tabular}{|c|c|c|}
\hline ax.M.-Anfall & 1479,51 & $m^{2}$ \\
\hline & 591,80 & $\mathrm{~m}^{2}$ \\
\hline & & $\mathrm{m}^{2}$ \\
\hline & 147,95 & \\
\hline & 147,95 & $\mathrm{~m}^{2}$ \\
\hline & 2467,21 & $\mathrm{~m}^{2}$ \\
\hline & 493,44 & $\mathrm{~m}^{3} / \mathrm{a}$ \\
\hline
\end{tabular}

Bioabfälle aus Haushalten

gehäckseltes Grüngut

Bioabfälle aus Haushalten

gehäckseltes Grüngut

konditioniertes Material

Fertigkompost

konditioniertes Material

Bioabfälle aus Haushalten

angeliefertes Grüngut

gehäckseltes Grüngut

Fertigkompost

Bioabfälle aus Haushalten

Fertigkompost

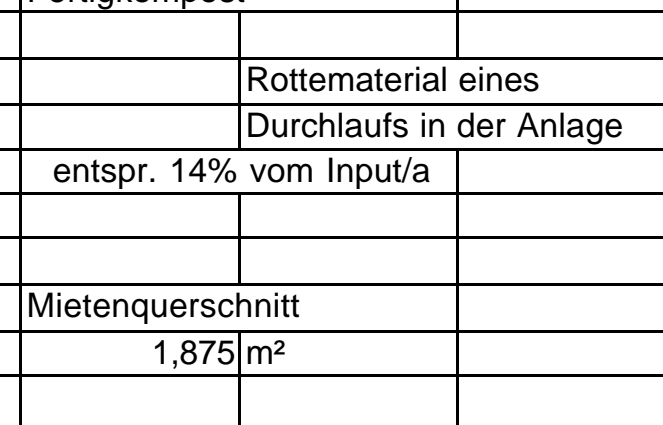

Anlagenneubau

\section{Anlagenumnutzung}

$850,00 \mathrm{~m}^{2}$

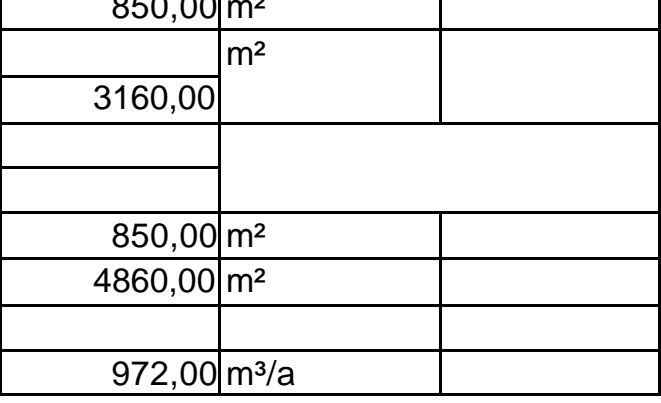




\begin{tabular}{|c|c|c|c|c|c|c|c|c|c|c|}
\hline ZEITEN & & & & & & & & & & \\
\hline Arbeitsgang & & & eingesetzte $\mathrm{M}$ & Maschinen & Zeitbedarf/Ei & inheit & geleistete Ein & nheiten & Zeitbedarf/Ja & ahr \\
\hline Materialannah & ime & & & & 4,000 & h/Woche & 52,000 & Wochen/a & 208,000 & $h / a$ \\
\hline Manuelle Stör & stoffauslese & & & & 1,000 & $h / 100 m^{3}(\ln )$ & $5.185,185$ & $\mathrm{~m}^{3} / \mathrm{a}$ & 51,852 & $h / a$ \\
\hline Zerkleinerung & von Strukturm & naterial & TL, SZ, Schr. & & 1,000 & $h / 50 m^{3}(\operatorname{In})$ & $2.222,222$ & $\mathrm{~m}^{3} / \mathrm{a}$ & 44,444 & $h / a$ \\
\hline Aufsetzen ein & er Matte aus S & Strukturmat. & TL, AS & & 0,300 & $\mathrm{~h} / 100 \mathrm{~m}^{3}$ (kon) & $3.703,704$ & $\mathrm{~m}^{3} / \mathrm{a}$ & 11,111 & $h / a$ \\
\hline Aufsetzen der & Dreiecksmiete & & TL, AS & & 1,000 & $\mathrm{~h} / 20 \mathrm{~m}^{3}$ (kon) & $3.703,704$ & $\mathrm{~m}^{3} / \mathrm{a}$ & 185,185 & $h / a$ \\
\hline Umsetzen der & Dreiecksmiete & & Schl., MU & & 0,005 & $\mathrm{~h} / \mathrm{m}$ (Mietenl.) & $16.908,642$ & $\mathrm{~m} / \mathrm{a}$ & 84,543 & $\mathrm{~h} / \mathrm{a}$ \\
\hline Reinigung der & Annahmefläch & & TL, AS & & 0,500 & $h / 150 m^{3}(\ln )$ & $5.185,185$ & $\mathrm{~m}^{3} / \mathrm{a}$ & 17,284 & $h / a$ \\
\hline Sieben & & & TL, AS, Sieb & & 1,000 & $\mathrm{~h} / 20 \mathrm{~m}^{3}(\mathrm{kom})$ & $2.000,000$ & $\mathrm{~m}^{3} / \mathrm{a}$ & 100,000 & $h / a$ \\
\hline Abw.-Ausbring & gung bei Neub & & Schl.,PT & & 1,000 & $\mathrm{~h} / 10 \mathrm{~m}^{3}(\mathrm{Abw})$ & 493,442 & $\mathrm{~m}^{3} / \mathrm{a}$ & 49,344 & $h / a$ \\
\hline Abw.-Ausbring & gung bei Umnu & utzung & Schl., PT & & 1,000 & $\mathrm{~h} / 10 \mathrm{~m}^{3}(\mathrm{Abw})$ & 972,000 & $\mathrm{~m}^{3} / \mathrm{a}$ & 97,200 & $h / a$ \\
\hline Abkürzungen & für die eingese & etzten Maschin & nen: & & & & & & & \\
\hline TL - Teleskop & lader & & Schl. - Schlepp & per & & & & & & \\
\hline MU- Mietenum & nsetzer & & Schr. - Schred & dder & & & & & & \\
\hline SZ - Silozange & & & PT - Pumpenta & tankwagen & & & & & & \\
\hline AS - Anbausc & haufel & & & & & & & & & \\
\hline MASCHINE & ENKOSTEN & & & & & & & & & \\
\hline Maschine / G & erät & Fixkosten & & Variable Kost & ten & Einheiten/a & & Maschinen-Ei & inzelkosten & \\
\hline Traktor (Neub & au) & 0,00 & $\mathrm{DM} / \mathrm{a}$ & 33,55 & $D M / h$ & 133,89 & $h / a$ & $4.491,92$ & $\mathrm{DM} / \mathrm{a}$ & \\
\hline Traktor (Umnu & itzung) & 0,00 & $\mathrm{DM} / \mathrm{a}$ & 33,55 & $D M / h$ & 181,74 & $\mathrm{~h} / \mathrm{a}$ & $6.097,48$ & $\mathrm{DM} / \mathrm{a}$ & \\
\hline Teleskoplader & & 0,00 & $D M / a$ & 66,50 & $\mathrm{DM} / \mathrm{h}$ & 358,02 & $h / a$ & $23.808,64$ & $\mathrm{DM} / \mathrm{a}$ & \\
\hline Schredder & & 0,00 & DM/a & 7,50 & $\mathrm{DM} / \mathrm{m}^{3}$ (Out) & 740,74 & $\mathrm{~m}^{3} / \mathrm{a}$ & $5.555,56$ & $\mathrm{DM} / \mathrm{a}$ & \\
\hline Trommelsieb & & 0,00 & DM/a & 5,00 & $\mathrm{DM} / \mathrm{m}^{3}(\mathrm{Kom})$ & $2.000,00$ & $m^{3} / a$ & $10.000,00$ & $\mathrm{DM} / \mathrm{a}$ & \\
\hline PumpenTW ( & Veubau) & 0,00 & $\mathrm{DM} / \mathrm{a}$ & 30,00 & $\mathrm{DM} / \mathrm{h}$ & 49,34 & $\mathrm{~h} / \mathrm{a}$ & $1.480,33$ & $\mathrm{DM} / \mathrm{a}$ & \\
\hline PumpenTW (L & Jmnutzung) & 0,00 & $D M / a$ & 30,00 & $D M / h$ & 97,20 & $h / a$ & $2.916,00$ & $\mathrm{DM} / \mathrm{a}$ & \\
\hline Silozange & & $1.120,00$ & DM/a & 0,30 & $\mathrm{DM} / \mathrm{m}^{3}$ & $2.222,22$ & $m^{3} / a$ & $1.786,67$ & $D M / a$ & \\
\hline Anbauschaufe & & 506,00 & $\mathrm{DM} / \mathrm{a}$ & 0,30 & $\mathrm{DM} / \mathrm{m}^{3}$ & $14.592,59$ & $\mathrm{~m}^{3} / \mathrm{a}$ & $4.883,78$ & $\mathrm{DM} / \mathrm{a}$ & \\
\hline Mietenumsetz & & $3.600,00$ & $\mathrm{DM} / \mathrm{a}$ & 28,00 & $\mathrm{DM} / \mathrm{h}$ & 84,54 & $\mathrm{~h} / \mathrm{a}$ & $5.967,21$ & $\mathrm{DM} / \mathrm{a}$ & \\
\hline & & & & & & Summe (Neuk & bau) & $57.974,10$ & $\mathrm{DM} / \mathrm{a}$ & \\
\hline & & & & & & Summe (Umn & hutzung) & $61.015,34$ & $\mathrm{DM} / \mathrm{a}$ & \\
\hline PERSONA & LOSTEN & & & & & & & & & \\
\hline & Std.-Lohn inkl & I.Lohn-NK & Arbeitsstd. pro & Jahr & Personal-Einz & zelkosten & & & & \\
\hline Neubau & 26,00 & $D M / h$ & 751,76 & $\mathrm{~h} / \mathrm{a}$ & $19.545,86$ & $D M / a$ & & & & \\
\hline Umnutzung & 26,00 & $D M / h$ & 799,62 & $h / a$ & $20.790,11$ & $\mathrm{DM} / \mathrm{a}$ & & & & \\
\hline
\end{tabular}




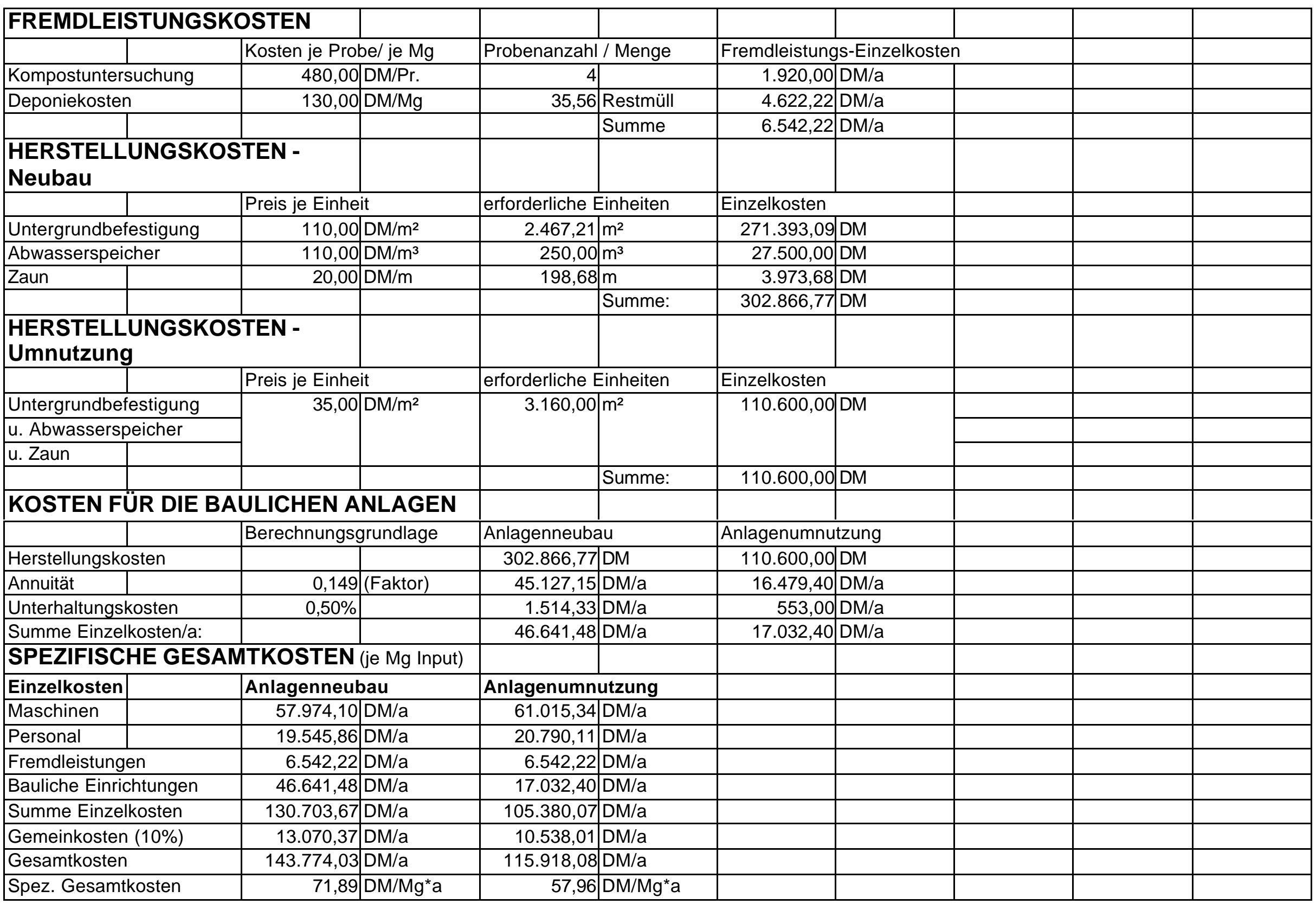


Kostenvariante A10

\section{MATERIAL}

Jahresinputmenge

Zusammensetzung

\begin{tabular}{|l|l|}
\hline & \\
\hline Dichte & \\
\hline & \\
\hline & \\
\hline & \\
\hline & \\
\hline & \\
\hline & \\
\hline & \\
\hline &
\end{tabular}

Gewichtsanteil

\section{Rottedauer}

durchschnittliches

Monatsaufkommen

maximaler Monatsanfall

\begin{tabular}{|l}
\hline \\
TS-Gehalt (Fertigkompost)
\end{tabular}

Mietenhöhe

Mietenbasisbreite

\section{ANLAGENDIMENSIONIERUNG}

\section{Anlagenteil}

Anlieferungsfläche

Rottefläche

Rangierfläche

Zwischenlager für

Strukturmaterial

Kompostlager

Anlagenfläche (gesamt)

zu verwertende

Abwassermenge

\section{|}

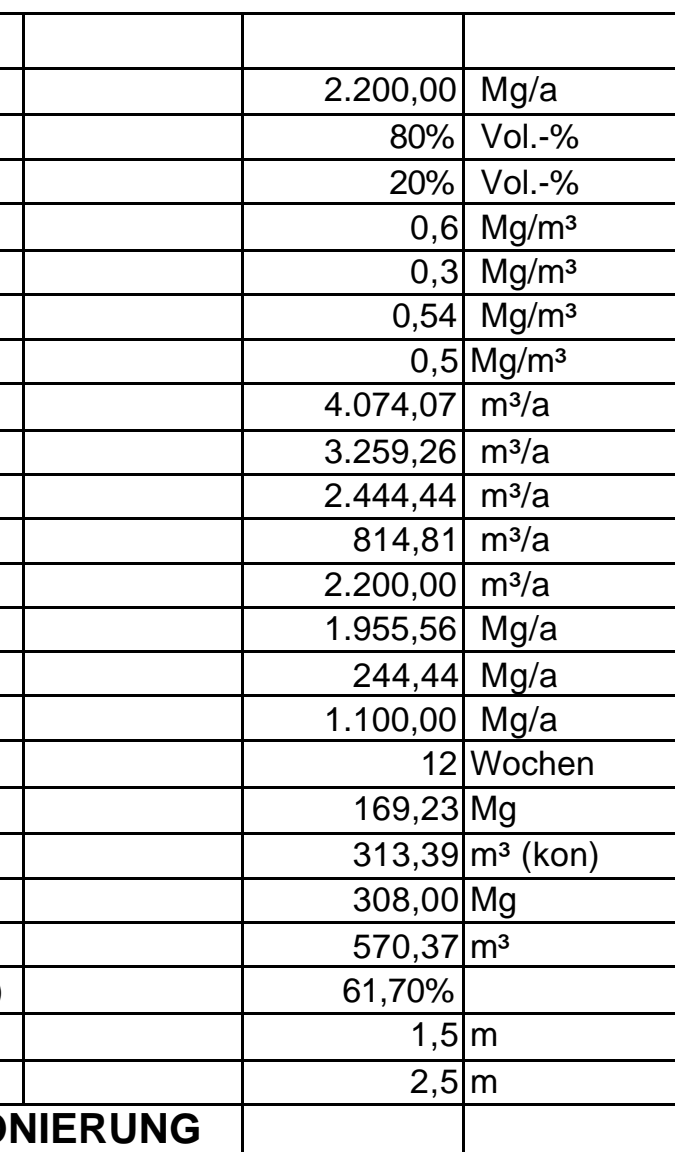

Berechnungsgrundlage

5\% vom Input in Mg/a, ausgedrückt in $\mathrm{m}^{2}$

$1,33 \mathrm{~m}^{2} / \mathrm{m}^{3}$ Rottematerial bei max.M.-Anfall

$40 \%$ der Rottefläche

der Rottefläche

$10 \%$ der Rottefläche

$+$

$0,2 \mathrm{~m}^{3} / \mathrm{m}^{2 \star} \mathrm{a}$

Grüngut

\begin{tabular}{|c|c|c|}
\hline ax.M.-Anfall & 1627,46 & $\mathrm{~m}^{2}$ \\
\hline & 650,98 & $\mathrm{~m}^{2}$ \\
\hline & & $m^{2}$ \\
\hline & 162,75 & \\
\hline & 162,75 & $\mathrm{~m}^{2}$ \\
\hline & 2713,93 & $\mathrm{~m}^{2}$ \\
\hline & & \\
\hline & 542,79 & $\mathrm{~m}^{3} / \mathrm{a}$ \\
\hline
\end{tabular}

Bioabfälle aus Haushalten

gehäckseltes Grüngut

Bioabfälle aus Haushalten

gehäckseltes Grüngut

konditioniertes Material

Fertigkompost

konditioniertes Material

Bioabfälle aus Haushalten

angeliefertes Grüngut

gehäckseltes Grüngut

Fertigkompost

Bioabfälle aus Haushalten

Fertigkompost

\begin{tabular}{l|l}
\hline & \\
\hline & Rottematerial eines \\
\hline & Durchlaufs in der Anlage
\end{tabular}

entspr. 14\% vom Input/a

Mietenquerschnitt

\begin{tabular}{|r|l}
\hline $1,875 \mathrm{~m}^{2}$ & \\
\hline & \\
\end{tabular}

Anlagenneubau

Anlagenumnutzung

\begin{tabular}{|r|l|l|}
\hline 850,00 & $\mathrm{~m}^{2}$ & \\
\hline 3160,00 & & \\
& & \\
\hline & & \\
\hline 850,00 & $\mathrm{~m}^{2}$ & \\
\hline 4860,00 & $\mathrm{~m}^{2}$ & \\
\hline 972,00 & $\mathrm{~m}^{3} / \mathrm{a}$ & \\
\hline
\end{tabular}




\begin{tabular}{|c|c|c|c|c|c|c|c|c|c|c|}
\hline ZEITEN & & & & & & & & & & \\
\hline Arbeitsgang & & & eingesetzte $\mathrm{M}$ & Maschinen & Zeitbedarf/Ei & inheit & geleistete Eir & nheiten & Zeitbedarf/Ja & ahr \\
\hline Materialannah & ime & & & & 4,000 & h/Woche & 52,000 & Wochen/a & 208,000 & $h / a$ \\
\hline Manuelle Stör & stoffauslese & & & & 1,000 & $h / 100 m^{3}(\ln )$ & $5.703,704$ & $\mathrm{~m}^{3} / \mathrm{a}$ & 57,037 & $\mathrm{~h} / \mathrm{a}$ \\
\hline Zerkleinerung & von Strukturm & naterial & TL, SZ, Schr. & & 1,000 & $h / 50 m^{3}(\operatorname{In})$ & $2.444,444$ & $\mathrm{~m}^{3} / \mathrm{a}$ & 48,889 & $h / a$ \\
\hline Aufsetzen ein & er Matte aus S & Strukturmat. & TL, AS & & 0,300 & $\mathrm{~h} / 100 \mathrm{~m}^{3}$ (kon) & $4.074,074$ & $\mathrm{~m}^{3} / \mathrm{a}$ & 12,222 & $h / a$ \\
\hline Aufsetzen der & Dreiecksmiete & & TL, AS & & 1,000 & $\mathrm{~h} / 20 \mathrm{~m}^{3}$ (kon) & $4.074,074$ & $\mathrm{~m}^{3} / \mathrm{a}$ & 203,704 & $h / a$ \\
\hline Umsetzen der & Dreiecksmiete & & Schl., MU & & 0,005 & $\mathrm{~h} / \mathrm{m}$ (Mietenl.) & $18.599,506$ & $\mathrm{~m} / \mathrm{a}$ & 92,998 & $\mathrm{~h} / \mathrm{a}$ \\
\hline Reinigung der & Annahmefläch & & TL, AS & & 0,500 & $\mathrm{~h} / 150 \mathrm{~m}^{3}(\mathrm{In})$ & $5.703,704$ & $\mathrm{~m}^{3} / \mathrm{a}$ & 19,012 & $h / a$ \\
\hline Sieben & & & TL, AS, Sieb & & 1,000 & $\mathrm{~h} / 20 \mathrm{~m}^{3}(\mathrm{kom})$ & $2.200,000$ & $\mathrm{~m}^{3} / \mathrm{a}$ & 110,000 & $h / a$ \\
\hline Abw.-Ausbring & gung bei Neub & & Schl.,PT & & 1,000 & $\mathrm{~h} / 10 \mathrm{~m}^{3}(\mathrm{Abw})$ & 542,786 & $\mathrm{~m}^{3} / \mathrm{a}$ & 54,279 & $h / a$ \\
\hline Abw.-Ausbring & gung bei Umnu & utzung & Schl., PT & & 1,000 & $\mathrm{~h} / 10 \mathrm{~m}^{3}(\mathrm{Abw})$ & 972,000 & $\mathrm{~m}^{3} / \mathrm{a}$ & 97,200 & $h / a$ \\
\hline Abkürzungen & für die eingese & etzten Maschin & nen: & & & & & & & \\
\hline TL - Teleskop & lader & & Schl. - Schlepp & per & & & & & & \\
\hline MU- Mietenum & nsetzer & & Schr. - Schred & dder & & & & & & \\
\hline SZ - Silozange & & & PT - Pumpenta & tankwagen & & & & & & \\
\hline AS - Anbausc & haufel & & & & & & & & & \\
\hline MASCHINE & ENKOSTEN & & & & & & & & & \\
\hline Maschine / G & erät & Fixkosten & & Variable Kost & ten & Einheiten/a & & Maschinen-Ei & inzelkosten & \\
\hline Traktor (Neub & au) & 0,00 & $\mathrm{DM} / \mathrm{a}$ & 33,55 & $D M / h$ & 147,28 & $\mathrm{~h} / \mathrm{a}$ & $4.941,11$ & $\mathrm{DM} / \mathrm{a}$ & \\
\hline Traktor (Umnu & itzung) & 0,00 & $\mathrm{DM} / \mathrm{a}$ & 33,55 & $D M / h$ & 190,20 & $\mathrm{~h} / \mathrm{a}$ & $6.381,13$ & $\mathrm{DM} / \mathrm{a}$ & \\
\hline Teleskoplader & & 0,00 & $D M / a$ & 66,50 & $\mathrm{DM} / \mathrm{h}$ & 393,83 & $\mathrm{~h} / \mathrm{a}$ & $26.189,51$ & $\mathrm{DM} / \mathrm{a}$ & \\
\hline Schredder & & 0,00 & DM/a & 7,50 & $\mathrm{DM} / \mathrm{m}^{3}$ (Out) & 814,81 & $\mathrm{~m}^{3} / \mathrm{a}$ & $6.111,11$ & $\mathrm{DM} / \mathrm{a}$ & \\
\hline Trommelsieb & & 0,00 & DM/a & 5,00 & $\mathrm{DM} / \mathrm{m}^{3}(\mathrm{Kom})$ & $2.200,00$ & $\mathrm{~m}^{3} / \mathrm{a}$ & $11.000,00$ & $\mathrm{DM} / \mathrm{a}$ & \\
\hline PumpenTW ( & Veubau) & 0,00 & $\mathrm{DM} / \mathrm{a}$ & 30,00 & $\mathrm{DM} / \mathrm{h}$ & 54,28 & $\mathrm{~h} / \mathrm{a}$ & $1.628,36$ & $\mathrm{DM} / \mathrm{a}$ & \\
\hline PumpenTW (L & Jmnutzung) & 0,00 & $D M / a$ & 30,00 & $D M / h$ & 97,20 & $\mathrm{~h} / \mathrm{a}$ & $2.916,00$ & $\mathrm{DM} / \mathrm{a}$ & \\
\hline Silozange & & $1.120,00$ & DM/a & 0,30 & $\mathrm{DM} / \mathrm{m}^{3}$ & $2.444,44$ & $\mathrm{~m}^{3} / \mathrm{a}$ & $1.853,33$ & $\mathrm{DM} / \mathrm{a}$ & \\
\hline Anbauschaufe & & 506,00 & $\mathrm{DM} / \mathrm{a}$ & 0,30 & $\mathrm{DM} / \mathrm{m}^{3}$ & $16.051,85$ & $m^{3} / a$ & $5.321,56$ & $\mathrm{DM} / \mathrm{a}$ & \\
\hline Mietenumsetz & & $3.600,00$ & $\mathrm{DM} / \mathrm{a}$ & 28,00 & $\mathrm{DM} / \mathrm{h}$ & 93,00 & $\mathrm{~h} / \mathrm{a}$ & $6.203,93$ & $\mathrm{DM} / \mathrm{a}$ & \\
\hline & & & & & & Summe (Neub & oau) & $63.248,91$ & $\mathrm{DM} / \mathrm{a}$ & \\
\hline & & & & & & Summe (Umns & utzung) & $65.976,56$ & $\mathrm{DM} / \mathrm{a}$ & \\
\hline PERSONA & LOSTEN & & & & & & & & & \\
\hline & Std.-Lohn inkl & I.Lohn-NK & Arbeitsstd. pro & o Jahr & Personal-Einz & zelkosten & & & & \\
\hline Neubau & 26,00 & $D M / h$ & 806,14 & $\mathrm{~h} / \mathrm{a}$ & $20.959,65$ & $D M / a$ & & & & \\
\hline Umnutzung & 26,00 & $D M / h$ & 849,06 & $\mathrm{~h} / \mathrm{a}$ & $22.075,60$ & DM/a & & & & \\
\hline
\end{tabular}




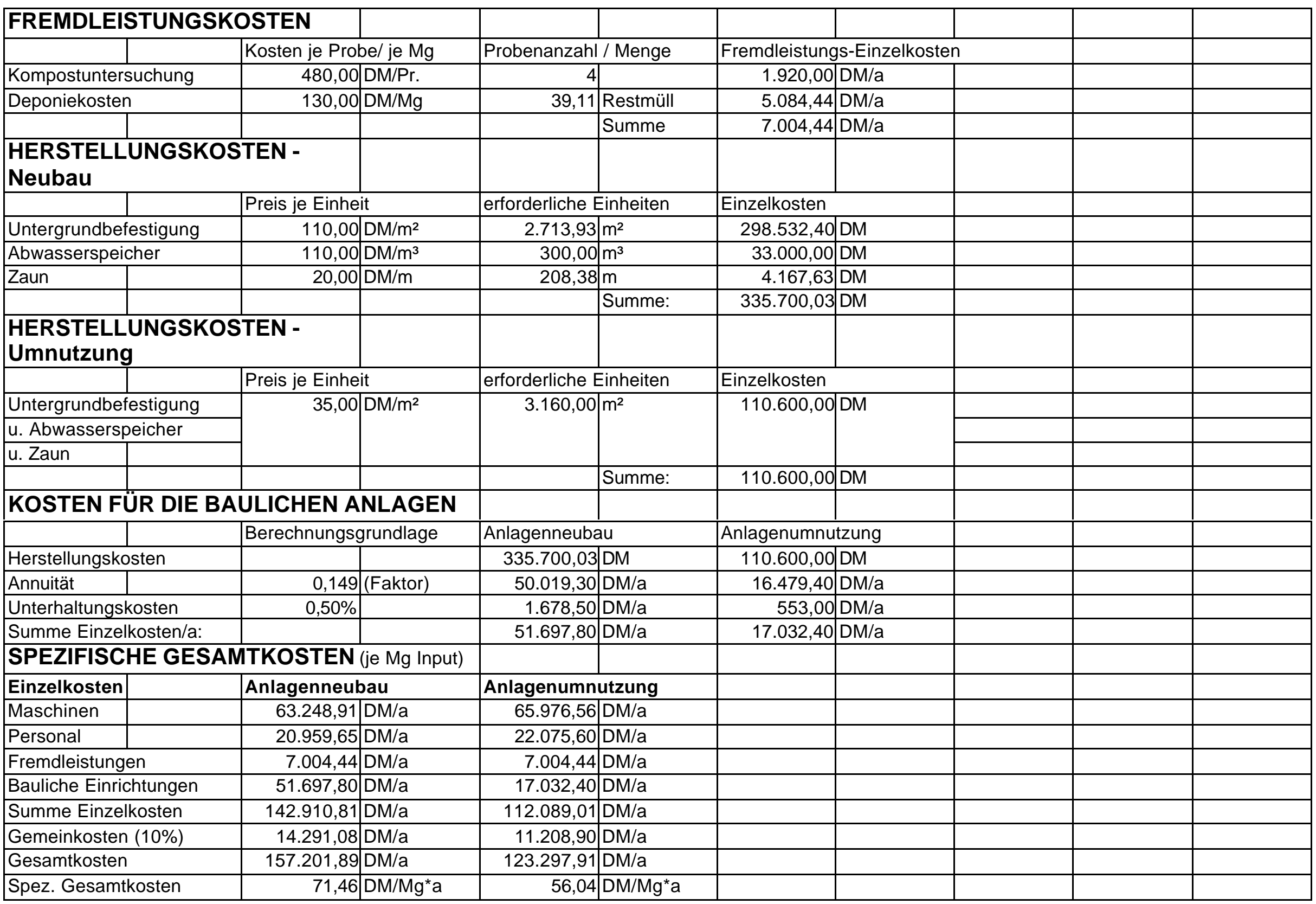


Kostenvariante A11

\section{MATERIAL}

Jahresinputmenge

Zusammensetzung

\begin{tabular}{|l|l|}
\hline & \\
\hline Dichte & \\
\hline & \\
\hline & \\
\hline & \\
\hline & \\
\hline & \\
\hline & \\
\hline & \\
\hline &
\end{tabular}

Gewichtsanteil

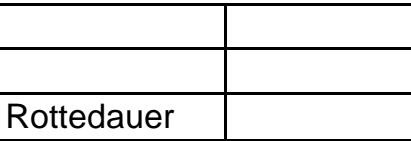

durchschnittliches

Monatsaufkommen

maximaler Monatsanfall

TS-Gehalt (Fertigkompost)

Mietenhöhe

Mietenbasisbreite

\section{ANLAGENDIMENSIONIERUNG}

\section{Anlagenteil}

Anlieferungsfläche

Rottefläche

Rangierfläche

Zwischenlager für

Strukturmaterial

Kompostlager

Anlagenfläche (gesamt)

zu verwertende

Abwassermenge

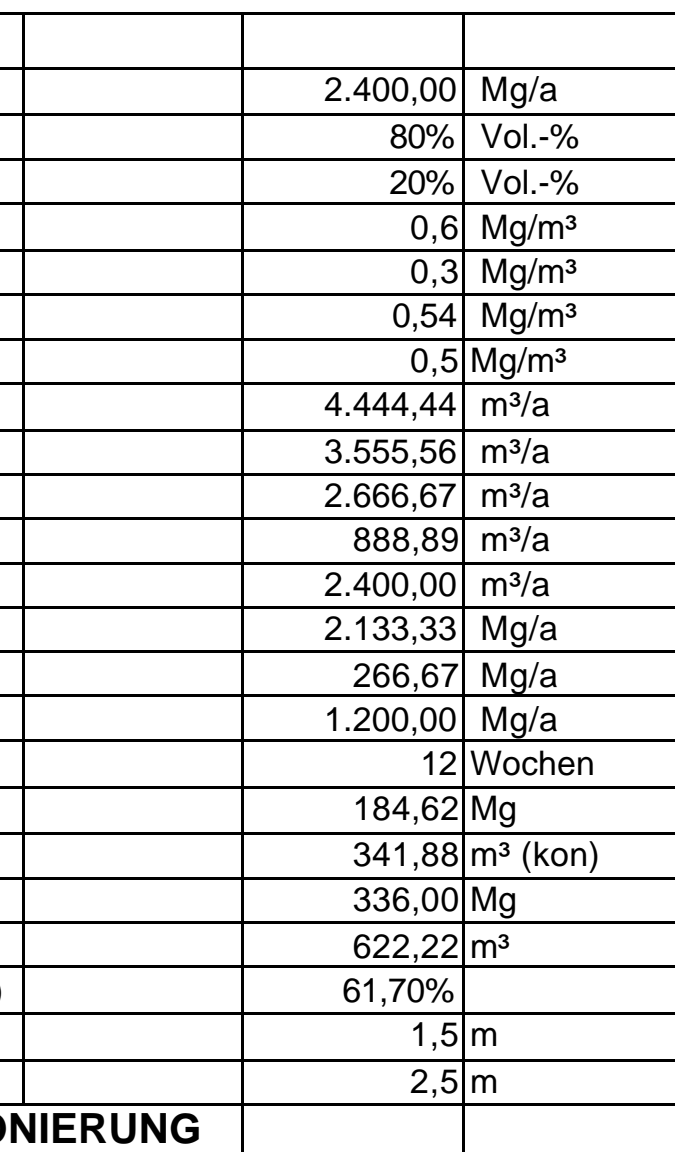

Berechnungsgrundlage

$5 \%$ vom Input in Mg/a, ausgedrückt in $\mathrm{m}^{2}$

$1,33 \mathrm{~m}^{2} / \mathrm{m}^{3}$ Rottematerial bei max.M.-Anfall

$40 \%$ der Rottefläche

der Rottefläche

$10 \%$

$10 \%$ der Rottefläche

\begin{tabular}{|r|l|l|l|} 
& $10 \%$ & der Rottefläche \\
\hline & & & \\
\hline & 0,2 & $\mathrm{~m}^{3} / \mathrm{m}^{2 *} \mathrm{a}$ & \\
\hline
\end{tabular}

Grüngut
Bioabfälle aus Haushalten

gehäckseltes Grüngut

Bioabfälle aus Haushalten

gehäckseltes Grüngut

konditioniertes Material

Fertigkompost

konditioniertes Material

Bioabfälle aus Haushalten

angeliefertes Grüngut

gehäckseltes Grüngut

Fertigkompost

Bioabfälle aus Haushalten

Fertigkompost

\begin{tabular}{|c|c|c|}
\hline \\
\hline & \multicolumn{2}{|c|}{ Rottematerial eines } \\
\hline & \multicolumn{2}{|c|}{ Durchlaufs in der Anlage } \\
\hline \multicolumn{3}{|c|}{ entspr. 14\% vom Input/a } \\
\hline & & \\
\hline \multicolumn{3}{|c|}{ Mietenquerschnitt } \\
\hline 1,875 & $\mathrm{~m}^{2}$ & \\
\hline & & \\
\hline
\end{tabular}

Anlagenneubau

\begin{tabular}{|c|c|c|}
\hline x.M.-Anfall & 1775,41 & $\mathrm{~m}^{2}$ \\
\hline & 710,16 & $\mathrm{~m}^{2}$ \\
\hline & & $\mathrm{m}^{2}$ \\
\hline & 177,54 & \\
\hline & 177,54 & $\mathrm{~m}^{2}$ \\
\hline & 2960,65 & $m^{2}$ \\
\hline & 592,13 & $m^{3} / a$ \\
\hline
\end{tabular}

Anlagenumnutzung

$850,00 \mathrm{~m}^{2}$

\begin{tabular}{|r|l|l|}
\hline & $\mathrm{m}^{2}$ & \\
& \multicolumn{3}{|l|}{850,00} & $\mathrm{~m}^{2}$ & \\
\hline & & \\
\hline 850,00 & $\mathrm{~m}^{2}$ & \\
\hline 4860,00 & $\mathrm{~m}^{2}$ & \\
\hline & & \\
\hline 972,00 & $\mathrm{~m}^{3} / \mathrm{a}$ & \\
\hline
\end{tabular}




\begin{tabular}{|c|c|c|c|c|c|c|c|c|c|c|}
\hline \multicolumn{11}{|l|}{ ZEITEN } \\
\hline \multicolumn{3}{|l|}{ Arbeitsgang } & \multicolumn{2}{|c|}{ eingesetzte Maschinen } & \multicolumn{2}{|c|}{ Zeitbedarf/Einheit } & \multicolumn{2}{|c|}{ geleistete Einheiten } & \multicolumn{2}{|c|}{ Zeitbedarf/Jahr } \\
\hline \multicolumn{3}{|c|}{ Materialannahme } & & & 4,000 & h/Woche & 52,000 & Wochen/a & 208,000 & $h / a$ \\
\hline \multicolumn{3}{|c|}{ Manuelle Störstoffauslese } & & & 1,000 & $h / 100 m^{3}(\operatorname{In})$ & $6.222,222$ & $\mathrm{~m}^{3} / \mathrm{a}$ & 62,222 & $h / a$ \\
\hline \multicolumn{3}{|c|}{ Zerkleinerung von Strukturmaterial } & TL, SZ, Schr. & & 1,000 & $h / 50 m^{3}(\ln )$ & $2.666,667$ & $\mathrm{~m}^{3} / \mathrm{a}$ & 53,333 & $h / a$ \\
\hline \multicolumn{3}{|c|}{ Aufsetzen einer Matte aus Strukturmat. } & TL, AS & & 0,300 & $\mathrm{~h} / 100 \mathrm{~m}^{3}$ (kon) & $4.444,444$ & $\mathrm{~m}^{3} / \mathrm{a}$ & 13,333 & $\mathrm{~h} / \mathrm{a}$ \\
\hline \multicolumn{3}{|c|}{ Aufsetzen der Dreiecksmieten } & TL, AS & & 1,000 & $\mathrm{~h} / 20 \mathrm{~m}^{3}$ (kon) & $4.444,444$ & $\mathrm{~m}^{3} / \mathrm{a}$ & 222,222 & $h / a$ \\
\hline \multicolumn{3}{|c|}{ Umsetzen der Dreiecksmieten } & Schl., MU & & 0,005 & $\mathrm{~h} / \mathrm{m}$ (Mietenl.) & $20.290,370$ & $\mathrm{~m} / \mathrm{a}$ & 101,452 & $h / a$ \\
\hline \multicolumn{3}{|c|}{ Reinigung der Annahmefläche } & TL, AS & & 0,500 & $\mathrm{~h} / 150 \mathrm{~m}^{3}(\ln )$ & $6.222,222$ & $\mathrm{~m}^{3} / \mathrm{a}$ & 20,741 & $\mathrm{~h} / \mathrm{a}$ \\
\hline \multicolumn{3}{|l|}{ Sieben } & TL, AS, Sieb & & 1,000 & $\mathrm{~h} / 20 \mathrm{~m}^{3}(\mathrm{kom})$ & $2.400,000$ & $\mathrm{~m}^{3} / \mathrm{a}$ & 120,000 & $\mathrm{~h} / \mathrm{a}$ \\
\hline \multicolumn{3}{|c|}{ Abw.-Ausbringung bei Neubau } & Schl.,PT & & 1,000 & $\mathrm{~h} / 10 \mathrm{~m}^{3}(\mathrm{Abw})$ & 592,130 & $\mathrm{~m}^{3} / \mathrm{a}$ & 59,213 & $\mathrm{~h} / \mathrm{a}$ \\
\hline \multicolumn{3}{|c|}{ Abw.-Ausbringung bei Umnutzung } & Schl., PT & & 1,000 & $\mathrm{~h} / 10 \mathrm{~m}^{3}(\mathrm{Abw})$ & 972,000 & $\mathrm{~m}^{3} / \mathrm{a}$ & 97,200 & $h / a$ \\
\hline \multicolumn{11}{|c|}{ Abkürzungen für die eingesetzten Maschinen: } \\
\hline \multicolumn{2}{|c|}{ TL - Teleskoplader } & & \multicolumn{2}{|c|}{ Schl. - Schlepper } & & & & & & \\
\hline \multicolumn{2}{|c|}{\begin{tabular}{|l} 
MU- Mietenumsetzer \\
\end{tabular}} & & Schr. - Schred & dder & & & & & & \\
\hline \multicolumn{2}{|c|}{ SZ - Silozange } & & PT - Pumpenta & tankwagen & & & & & & \\
\hline \multicolumn{11}{|c|}{ AS - Anbauschaufel } \\
\hline \multicolumn{11}{|c|}{ MASCHINENKOSTEN } \\
\hline \multicolumn{2}{|c|}{ Maschine / Gerät } & Fixkosten & & \multicolumn{2}{|c|}{ Variable Kosten } & Einheiten/a & & \multicolumn{2}{|c|}{ Maschinen-Einzelkosten } & \\
\hline Traktor (Neub & au) & 0,00 & $\mathrm{DM} / \mathrm{a}$ & 33,55 & $\mathrm{DM} / \mathrm{h}$ & 160,66 & $h / a$ & $5.390,31$ & $\mathrm{DM} / \mathrm{a}$ & \\
\hline Traktor (Umnı & itzung) & 0,00 & $\mathrm{DM} / \mathrm{a}$ & 33,55 & $\mathrm{DM} / \mathrm{h}$ & 198,65 & $\mathrm{~h} / \mathrm{a}$ & $6.664,77$ & $\mathrm{DM} / \mathrm{a}$ & \\
\hline Teleskoplader & & 0,00 & $\mathrm{DM} / \mathrm{a}$ & 66,50 & $\mathrm{DM} / \mathrm{h}$ & 429,63 & $\mathrm{~h} / \mathrm{a}$ & $28.570,37$ & $\mathrm{DM} / \mathrm{a}$ & \\
\hline Schredder & & 0,00 & $\mathrm{DM} / \mathrm{a}$ & 7,50 & $\mathrm{DM} / \mathrm{m}^{3}$ (Out) & 888,89 & $\mathrm{~m}^{3} / \mathrm{a}$ & $6.666,67$ & $\mathrm{DM} / \mathrm{a}$ & \\
\hline Trommelsieb & & 0,00 & $\mathrm{DM} / \mathrm{a}$ & 5,00 & $\mathrm{DM} / \mathrm{m}^{3}(\mathrm{Kom})$ & $2.400,00$ & $\mathrm{~m}^{3} / \mathrm{a}$ & $12.000,00$ & $\mathrm{DM} / \mathrm{a}$ & \\
\hline PumpenTW (I & Veubau) & 0,00 & $\mathrm{DM} / \mathrm{a}$ & 30,00 & $\mathrm{DM} / \mathrm{h}$ & 59,21 & $\mathrm{~h} / \mathrm{a}$ & $1.776,39$ & $\mathrm{DM} / \mathrm{a}$ & \\
\hline PumpenTW (L & Jmnutzung) & 0,00 & $D M / a$ & 30,00 & $D M / h$ & 97,20 & $h / a$ & $2.916,00$ & $\mathrm{DM} / \mathrm{a}$ & \\
\hline Silozange & & $1.120,00$ & DM/a & 0,30 & $\mathrm{DM} / \mathrm{m}^{3}$ & $2.666,67$ & $\mathrm{~m}^{3} / \mathrm{a}$ & $1.920,00$ & $\mathrm{DM} / \mathrm{a}$ & \\
\hline Anbauschaufe & & 506,00 & $\mathrm{DM} / \mathrm{a}$ & 0,30 & $\mathrm{DM} / \mathrm{m}^{3}$ & $17.511,11$ & $m^{3} / a$ & $5.759,33$ & $\mathrm{DM} / \mathrm{a}$ & \\
\hline Mietenumsetz & & $3.600,00$ & $\mathrm{DM} / \mathrm{a}$ & 28,00 & $\mathrm{DM} / \mathrm{h}$ & 101,45 & $\mathrm{~h} / \mathrm{a}$ & $6.440,65$ & $\mathrm{DM} / \mathrm{a}$ & \\
\hline & & & & & & Summe (Neub & bau) & $68.523,72$ & $\mathrm{DM} / \mathrm{a}$ & \\
\hline & & & & & & Summe (Umn & uutzung) & $70.937,79$ & $\mathrm{DM} / \mathrm{a}$ & \\
\hline PERSONA & LOSTEN & & & & & & & & & \\
\hline & Std.-Lohn inkl & I.Lohn-NK & Arbeitsstd. pro & o Jahr & Personal-Einz & zelkosten & & & & \\
\hline Neubau & 26,00 & $D M / h$ & 860,52 & $\mathrm{~h} / \mathrm{a}$ & $22.373,44$ & $D M / a$ & & & & \\
\hline Umnutzung & 26,00 & $D M / h$ & 898,50 & $h / a$ & $23.361,10$ & DM/a & & & & \\
\hline
\end{tabular}




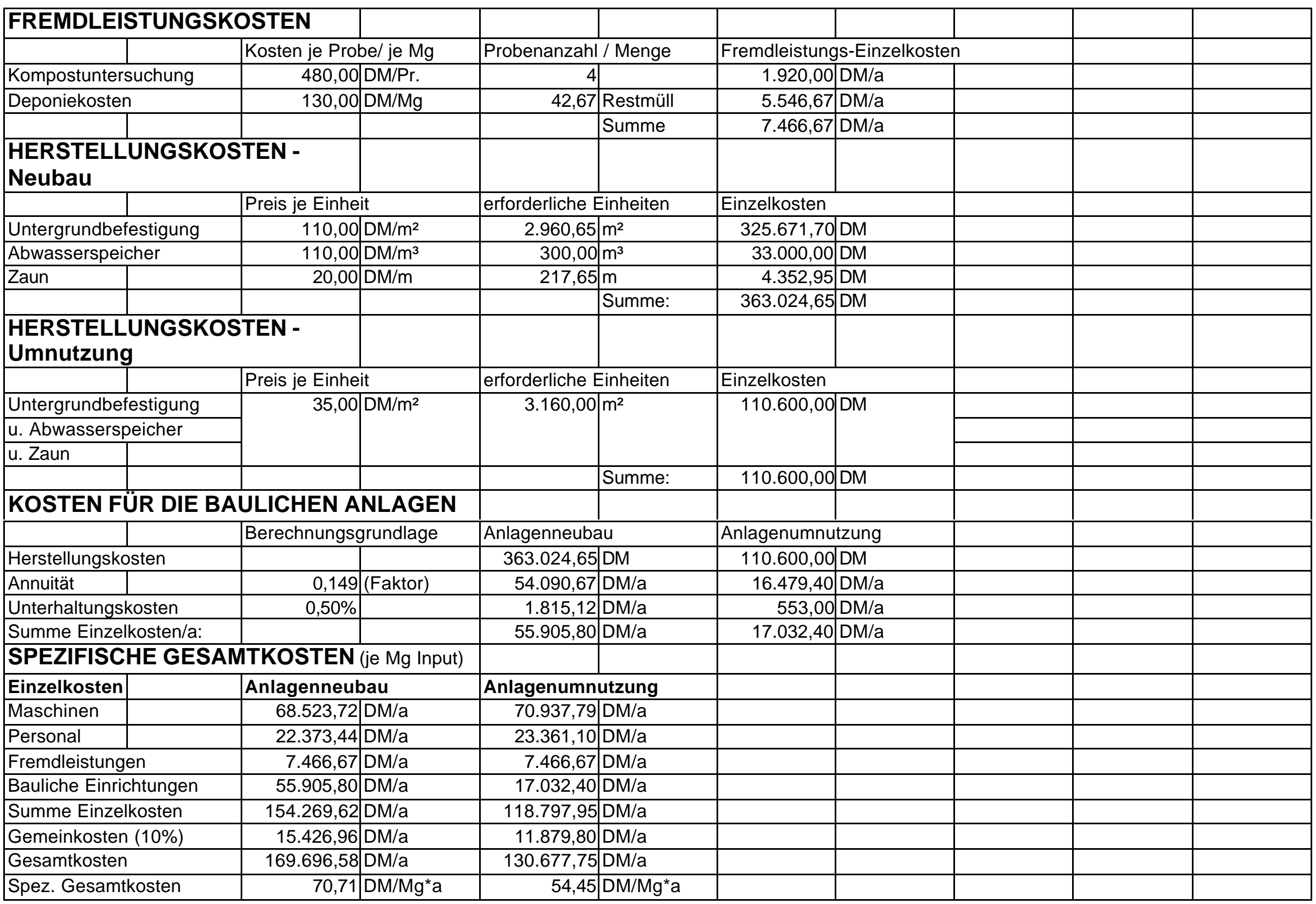


Kostenvariante A12

\section{MATERIAL}

Jahresinputmenge

Zusammensetzung

\begin{tabular}{|l|l|}
\hline & \\
\hline Dichte & \\
\hline & \\
\hline & \\
\hline & \\
\hline & \\
\hline & \\
\hline & \\
\hline & \\
\hline &
\end{tabular}

Gewichtsanteil

\section{Rottedauer}

durchschnittliches

Monatsaufkommen

maximaler Monatsanfall

\begin{tabular}{|l}
\hline \\
TS-Gehalt (Fertigkompost)
\end{tabular}

Mietenhöhe

Mietenbasisbreite

\section{ANLAGENDIMENSIONIERUNG}

\section{Anlagenteil}

Anlieferungsfläche

Rottefläche

Rangierfläche

Zwischenlager für

Strukturmaterial

Kompostlager

Anlagenfläche (gesamt)

zu verwertende

Abwassermenge

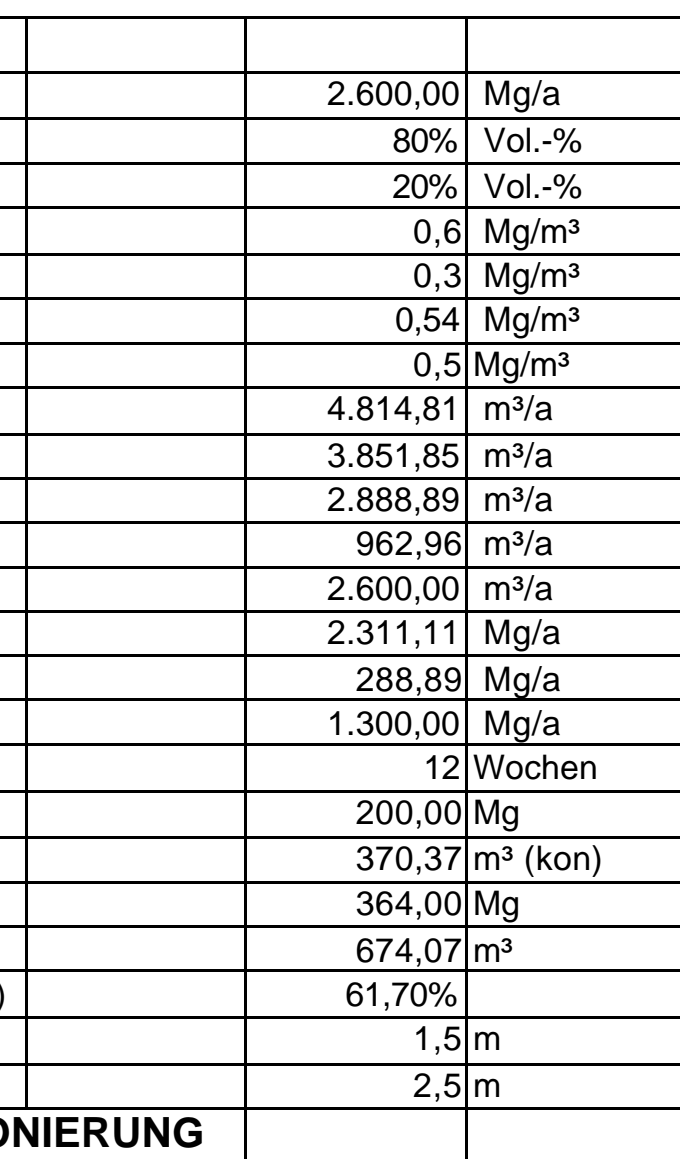

Berechnungsgrundlage

5\% vom Input in Mg/a, ausgedrückt in $\mathrm{m}^{2}$

$1,33 \mathrm{~m}^{2} / \mathrm{m}^{3}$ Rottematerial bei max.M.-Anfall

$40 \%$ der Rottefläche

der Rottefläche $10 \%$

$10 \%$ der Rottefläche

|

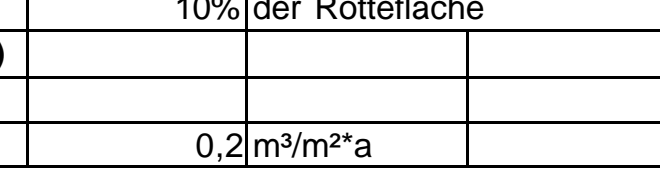

Grüngut
Bioabfälle aus Haushalten

gehäckseltes Grüngut

Bioabfälle aus Haushalten

gehäckseltes Grüngut

konditioniertes Material

Fertigkompost

konditioniertes Material

Bioabfälle aus Haushalten

angeliefertes Grüngut

gehäckseltes Grüngut

Fertigkompost

Bioabfälle aus Haushalten

Fertigkompost

\begin{tabular}{|c|c|c|}
\hline \\
\hline & \multicolumn{2}{|c|}{ Rottematerial eines } \\
\hline & \multicolumn{2}{|c|}{ Durchlaufs in der Anlage } \\
\hline \multicolumn{3}{|c|}{ entspr. 14\% vom Input/a } \\
\hline & & \\
\hline \multicolumn{3}{|c|}{ Mietenquerschnitt } \\
\hline 1,875 & $\mathrm{~m}^{2}$ & \\
\hline & & \\
\hline
\end{tabular}

Anlagenneubau

\begin{tabular}{|c|c|c|}
\hline x.M.-Anfall & 1923,36 & $\mathrm{m}^{2}$ \\
\hline & 769,34 & $m^{2}$ \\
\hline & & $m^{2}$ \\
\hline & 192,34 & \\
\hline & 192,34 & $\mathrm{~m}^{2}$ \\
\hline & 3207,37 & $m^{2}$ \\
\hline & 61147 & $m 3 / 0$ \\
\hline & 641,47 & $\mathrm{~m}^{3} / \mathrm{a}$ \\
\hline
\end{tabular}

Anlagenumnutzung

$850,00 \mathrm{~m}^{2}$

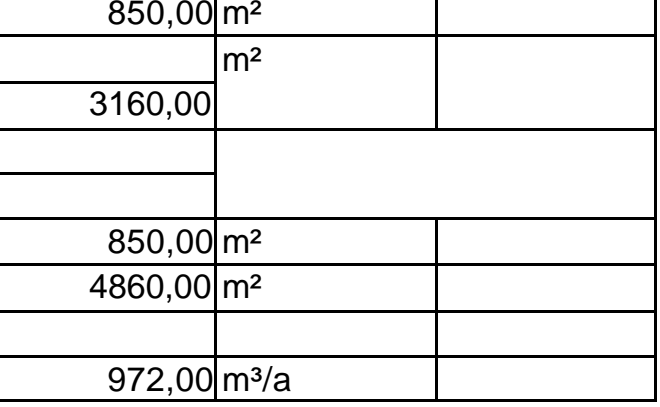




\begin{tabular}{|c|c|c|c|c|c|c|c|c|c|c|}
\hline \multicolumn{11}{|l|}{ ZEITEN } \\
\hline \multicolumn{3}{|l|}{ Arbeitsgang } & \multicolumn{2}{|c|}{ eingesetzte Maschinen } & \multicolumn{2}{|c|}{ Zeitbedarf/Einheit } & \multicolumn{2}{|c|}{ geleistete Einheiten } & \multicolumn{2}{|c|}{ Zeitbedarf/Jahr } \\
\hline \multicolumn{3}{|c|}{ Materialannahme } & & & 4,000 & h/Woche & 52,000 & Wochen/a & 208,000 & $h / a$ \\
\hline \multicolumn{3}{|c|}{ Manuelle Störstoffauslese } & & & 1,000 & $h / 100 m^{3}(\operatorname{In})$ & $6.740,741$ & $\mathrm{~m}^{3} / \mathrm{a}$ & 67,407 & $\mathrm{~h} / \mathrm{a}$ \\
\hline \multicolumn{3}{|c|}{ Zerkleinerung von Strukturmaterial } & TL, SZ, Schr. & & 1,000 & $h / 50 m^{3}(\ln )$ & $2.888,889$ & $\mathrm{~m}^{3} / \mathrm{a}$ & 57,778 & $h / a$ \\
\hline \multicolumn{3}{|c|}{ Aufsetzen einer Matte aus Strukturmat. } & TL, AS & & 0,300 & $\mathrm{~h} / 100 \mathrm{~m}^{3}$ (kon) & $4.814,815$ & $\mathrm{~m}^{3} / \mathrm{a}$ & 14,444 & $\mathrm{~h} / \mathrm{a}$ \\
\hline \multicolumn{3}{|c|}{ Aufsetzen der Dreiecksmieten } & TL, AS & & 1,000 & $\mathrm{~h} / 20 \mathrm{~m}^{3}$ (kon) & $4.814,815$ & $\mathrm{~m}^{3} / \mathrm{a}$ & 240,741 & $\mathrm{~h} / \mathrm{a}$ \\
\hline \multicolumn{3}{|c|}{ Umsetzen der Dreiecksmieten } & Schl., MU & & 0,005 & $\mathrm{~h} / \mathrm{m}$ (Mietenl.) & $21.981,235$ & $\mathrm{~m} / \mathrm{a}$ & 109,906 & $\mathrm{~h} / \mathrm{a}$ \\
\hline \multicolumn{3}{|c|}{ Reinigung der Annahmefläche } & TL, AS & & 0,500 & $\mathrm{~h} / 150 \mathrm{~m}^{3}(\ln )$ & $6.740,741$ & $\mathrm{~m}^{3} / \mathrm{a}$ & 22,469 & $\mathrm{~h} / \mathrm{a}$ \\
\hline \multicolumn{3}{|l|}{ Sieben } & TL, AS, Sieb & & 1,000 & $\mathrm{~h} / 20 \mathrm{~m}^{3}(\mathrm{kom})$ & $2.600,000$ & $\mathrm{~m}^{3} / \mathrm{a}$ & 130,000 & $\mathrm{~h} / \mathrm{a}$ \\
\hline \multicolumn{3}{|c|}{ Abw.-Ausbringung bei Neubau } & Schl.,PT & & 1,000 & $\mathrm{~h} / 10 \mathrm{~m}^{3}(\mathrm{Abw})$ & 641,475 & $\mathrm{~m}^{3} / \mathrm{a}$ & 64,147 & $h / a$ \\
\hline \multicolumn{3}{|c|}{ Abw.-Ausbringung bei Umnutzung } & Schl., PT & & 1,000 & $\mathrm{~h} / 10 \mathrm{~m}^{3}(\mathrm{Abw})$ & 972,000 & $\mathrm{~m}^{3} / \mathrm{a}$ & 97,200 & $h / a$ \\
\hline \multicolumn{11}{|c|}{ Abkürzungen für die eingesetzten Maschinen: } \\
\hline \multicolumn{2}{|c|}{ TL - Teleskoplader } & & \multicolumn{2}{|c|}{ Schl. - Schlepper } & & & & & & \\
\hline \multicolumn{2}{|c|}{\begin{tabular}{|l} 
MU- Mietenumsetzer \\
\end{tabular}} & & Schr. - Schred & dder & & & & & & \\
\hline \multicolumn{2}{|c|}{ SZ - Silozange } & & PT - Pumpenta & tankwagen & & & & & & \\
\hline \multicolumn{11}{|c|}{ AS - Anbauschaufel } \\
\hline \multicolumn{11}{|c|}{ MASCHINENKOSTEN } \\
\hline \multicolumn{2}{|c|}{ Maschine / Gerät } & Fixkosten & & \multicolumn{2}{|c|}{ Variable Kosten } & Einheiten/a & & \multicolumn{2}{|c|}{ Maschinen-Einzelkosten } & \\
\hline Traktor (Neub & au) & 0,00 & $\mathrm{DM} / \mathrm{a}$ & 33,55 & $\mathrm{DM} / \mathrm{h}$ & 174,05 & $\mathrm{~h} / \mathrm{a}$ & $5.839,50$ & $\mathrm{DM} / \mathrm{a}$ & \\
\hline Traktor (Umnı & itzung) & 0,00 & $\mathrm{DM} / \mathrm{a}$ & 33,55 & $\mathrm{DM} / \mathrm{h}$ & 207,11 & $\mathrm{~h} / \mathrm{a}$ & $6.948,41$ & $\mathrm{DM} / \mathrm{a}$ & \\
\hline Teleskoplader & & 0,00 & $\mathrm{DM} / \mathrm{a}$ & 66,50 & $\mathrm{DM} / \mathrm{h}$ & 465,43 & $\mathrm{~h} / \mathrm{a}$ & $30.951,23$ & $\mathrm{DM} / \mathrm{a}$ & \\
\hline Schredder & & 0,00 & $\mathrm{DM} / \mathrm{a}$ & 7,50 & $\mathrm{DM} / \mathrm{m}^{3}$ (Out) & 962,96 & $\mathrm{~m}^{3} / \mathrm{a}$ & $7.222,22$ & $\mathrm{DM} / \mathrm{a}$ & \\
\hline Trommelsieb & & 0,00 & $\mathrm{DM} / \mathrm{a}$ & 5,00 & $\mathrm{DM} / \mathrm{m}^{3}(\mathrm{Kom})$ & $2.600,00$ & $\mathrm{~m}^{3} / \mathrm{a}$ & $13.000,00$ & $\mathrm{DM} / \mathrm{a}$ & \\
\hline PumpenTW (I & Veubau) & 0,00 & $\mathrm{DM} / \mathrm{a}$ & 30,00 & $\mathrm{DM} / \mathrm{h}$ & 64,15 & $\mathrm{~h} / \mathrm{a}$ & $1.924,42$ & $\mathrm{DM} / \mathrm{a}$ & \\
\hline PumpenTW (L & Jmnutzung) & 0,00 & $D M / a$ & 30,00 & $D M / h$ & 97,20 & $\mathrm{~h} / \mathrm{a}$ & $2.916,00$ & $\mathrm{DM} / \mathrm{a}$ & \\
\hline Silozange & & $1.120,00$ & DM/a & 0,30 & $\mathrm{DM} / \mathrm{m}^{3}$ & $2.888,89$ & $\mathrm{~m}^{3} / \mathrm{a}$ & $1.986,67$ & $\mathrm{DM} / \mathrm{a}$ & \\
\hline Anbauschaufe & & 506,00 & $\mathrm{DM} / \mathrm{a}$ & 0,30 & $\mathrm{DM} / \mathrm{m}^{3}$ & $18.970,37$ & $\mathrm{~m}^{3} / \mathrm{a}$ & $6.197,11$ & $\mathrm{DM} / \mathrm{a}$ & \\
\hline Mietenumsetz & & $3.600,00$ & $\mathrm{DM} / \mathrm{a}$ & 28,00 & $\mathrm{DM} / \mathrm{h}$ & 109,91 & $\mathrm{~h} / \mathrm{a}$ & $6.677,37$ & $\mathrm{DM} / \mathrm{a}$ & \\
\hline & & & & & & Summe (Neub & bau) & $73.798,53$ & $\mathrm{DM} / \mathrm{a}$ & \\
\hline & & & & & & Summe (Umn & uutzung) & $75.899,02$ & $\mathrm{DM} / \mathrm{a}$ & \\
\hline PERSONA & LOSTEN & & & & & & & & & \\
\hline & Std.-Lohn inkl & I.Lohn-NK & Arbeitsstd. pro & o Jahr & Personal-Einz & zelkosten & & & & \\
\hline Neubau & 26,00 & $D M / h$ & 914,89 & $\mathrm{~h} / \mathrm{a}$ & $23.787,22$ & $D M / a$ & & & & \\
\hline Umnutzung & 26,00 & $D M / h$ & 947,95 & $h / a$ & $24.646,59$ & DM/a & & & & \\
\hline
\end{tabular}




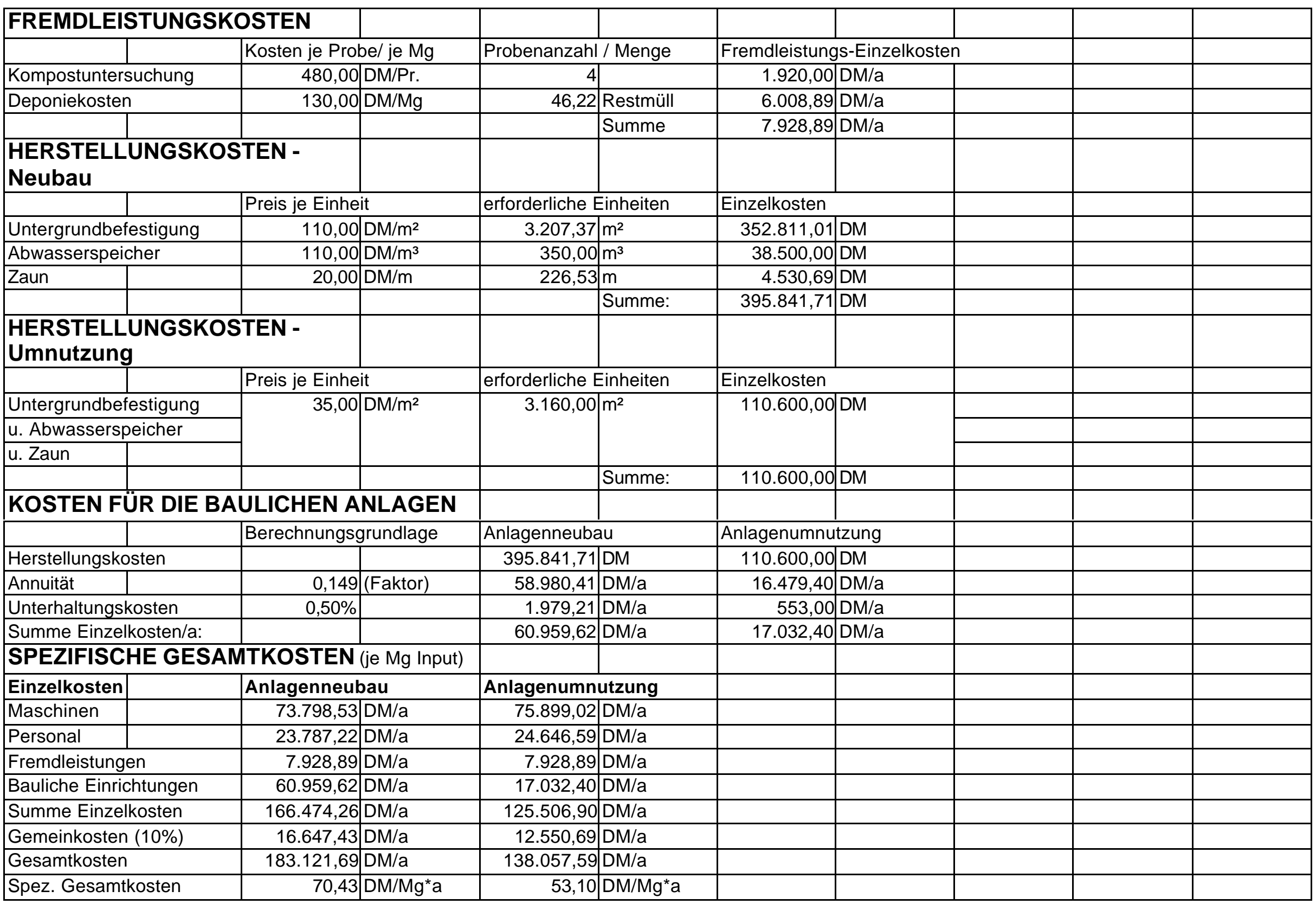


Kostenvariante A13

\section{MATERIAL}

Jahresinputmenge

Zusammensetzung

\begin{tabular}{|l|l|}
\hline & \\
\hline Dichte & \\
\hline & \\
\hline & \\
\hline & \\
\hline & \\
\hline & \\
\hline & \\
\hline & \\
\hline &
\end{tabular}

Gewichtsanteil

\section{Rottedauer}

durchschnittliches

Monatsaufkommen

maximaler Monatsanfall

\begin{tabular}{|l}
\hline \\
TS-Gehalt (Fertigkompost)
\end{tabular}

Mietenhöhe

Mietenbasisbreite

\section{ANLAGENDIMENSIONIERUNG}

\section{Anlagenteil}

Anlieferungsfläche

Rottefläche

Rangierfläche

Zwischenlager für

Strukturmaterial

Kompostlager

Anlagenfläche (gesamt)

zu verwertende

Abwassermenge

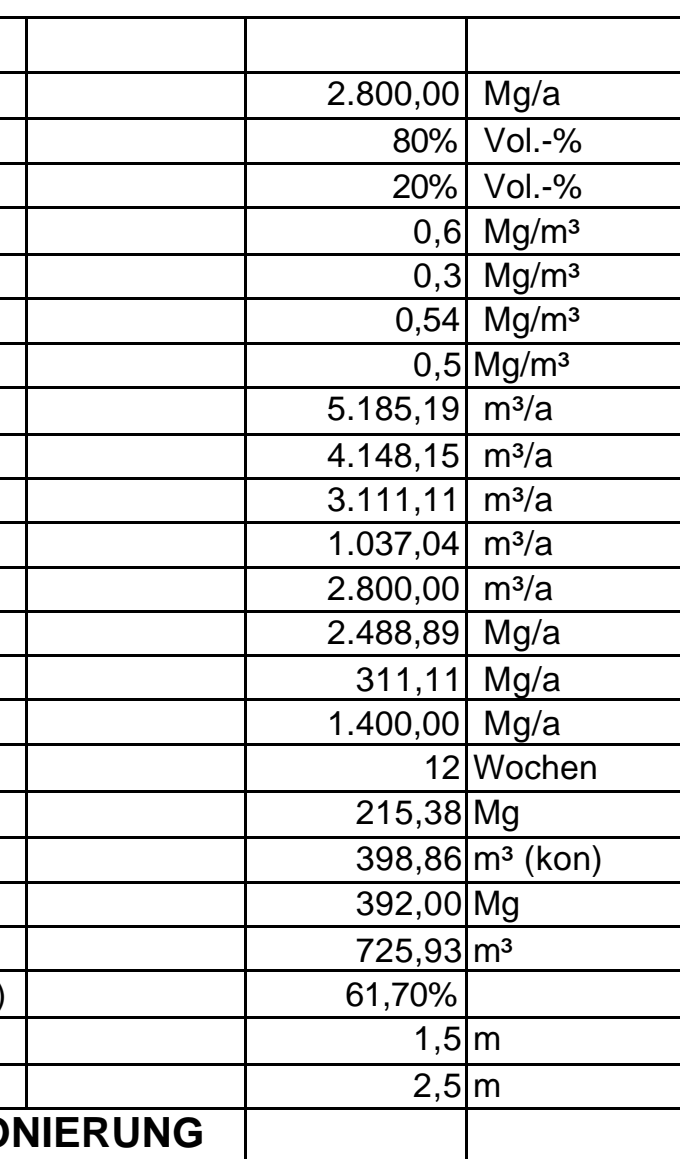

Berechnungsgrundlage

5\% vom Input in Mg/a, ausgedrückt in $\mathrm{m}^{2}$

$1,33 \mathrm{~m}^{2} / \mathrm{m}^{3}$ Rottematerial bei max.M.-Anfall

$40 \%$ der Rottefläche

der Rottefläche $10 \%$

$10 \%$ der Rottefläche

\begin{tabular}{|r|l|l|l|} 
& $10 \%$ & der Rottefläche \\
\hline & & & \\
\hline & 0,2 & $\mathrm{~m}^{3} / \mathrm{m}^{2 *} \mathrm{a}$ & \\
\hline
\end{tabular}

Grüngut
Bioabfälle aus Haushalten

gehäckseltes Grüngut

Bioabfälle aus Haushalten

gehäckseltes Grüngut

konditioniertes Material

Fertigkompost

konditioniertes Material

Bioabfälle aus Haushalten

angeliefertes Grüngut

gehäckseltes Grüngut

Fertigkompost

Bioabfälle aus Haushalten

Fertigkompost

\begin{tabular}{|c|c|c|}
\hline \\
\hline & & \\
\hline & \multicolumn{2}{|c|}{ Rottematerial eines } \\
\hline & \multicolumn{2}{|c|}{ Durchlaufs in der Anlage } \\
\hline \multicolumn{3}{|c|}{ entspr. 14\% vom Input/a } \\
\hline & & \\
\hline & & \\
\hline \multicolumn{3}{|c|}{ Mietenquerschnitt } \\
\hline 1,875 & $m^{2}$ & \\
\hline
\end{tabular}

Anlagenneubau

\begin{tabular}{|c|c|c|}
\hline x.M.-Anfall & 2071,31 & $\mathrm{~m}^{2}$ \\
\hline & 828,52 & $m^{2}$ \\
\hline & & $m^{2}$ \\
\hline & 207,13 & \\
\hline & 207,13 & $\mathrm{~m}^{2}$ \\
\hline & 3454,09 & $m^{2}$ \\
\hline & & \\
\hline & 690,82 & $\mathrm{~m}^{3} / \mathrm{a}$ \\
\hline
\end{tabular}

Anlagenumnutzung

$850,00 \mathrm{~m}^{2}$

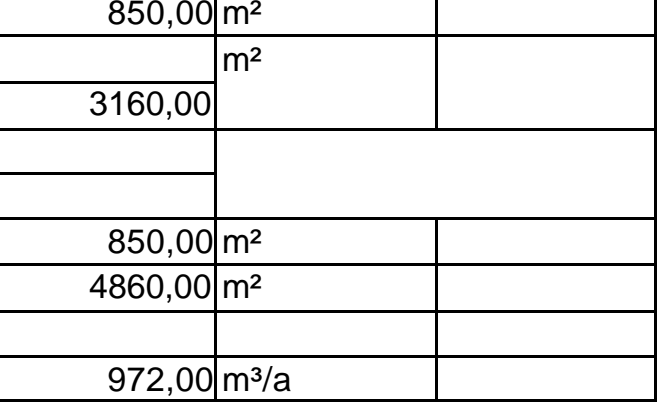




\begin{tabular}{|c|c|c|c|c|c|c|c|c|c|c|}
\hline \multicolumn{11}{|l|}{ ZEITEN } \\
\hline \multicolumn{3}{|l|}{ Arbeitsgang } & \multicolumn{2}{|c|}{ eingesetzte Maschinen } & \multicolumn{2}{|c|}{ Zeitbedarf/Einheit } & \multicolumn{2}{|c|}{ geleistete Einheiten } & \multicolumn{2}{|c|}{ Zeitbedarf/Jahr } \\
\hline \multicolumn{3}{|c|}{ Materialannahme } & & & 4,000 & h/Woche & 52,000 & Wochen/a & 208,000 & $h / a$ \\
\hline \multicolumn{3}{|c|}{ Manuelle Störstoffauslese } & & & 1,000 & $h / 100 m^{3}(\operatorname{In})$ & $7.259,259$ & $\mathrm{~m}^{3} / \mathrm{a}$ & 72,593 & $\mathrm{~h} / \mathrm{a}$ \\
\hline \multicolumn{3}{|c|}{ Zerkleinerung von Strukturmaterial } & TL, SZ, Schr. & & 1,000 & $h / 50 m^{3}(\ln )$ & $3.111,111$ & $\mathrm{~m}^{3} / \mathrm{a}$ & 62,222 & $h / a$ \\
\hline \multicolumn{3}{|c|}{ Aufsetzen einer Matte aus Strukturmat. } & TL, AS & & 0,300 & $\mathrm{~h} / 100 \mathrm{~m}^{3}$ (kon) & $5.185,185$ & $\mathrm{~m}^{3} / \mathrm{a}$ & 15,556 & $h / a$ \\
\hline \multicolumn{3}{|c|}{ Aufsetzen der Dreiecksmieten } & TL, AS & & 1,000 & $\mathrm{~h} / 20 \mathrm{~m}^{3}$ (kon) & $5.185,185$ & $\mathrm{~m}^{3} / \mathrm{a}$ & 259,259 & $h / a$ \\
\hline \multicolumn{3}{|c|}{ Umsetzen der Dreiecksmieten } & Schl., MU & & 0,005 & $\mathrm{~h} / \mathrm{m}$ (Mietenl.) & $23.672,099$ & $\mathrm{~m} / \mathrm{a}$ & 118,360 & $h / a$ \\
\hline \multicolumn{3}{|c|}{ Reinigung der Annahmefläche } & TL, AS & & 0,500 & $h / 150 m^{3}(\ln )$ & $7.259,259$ & $\mathrm{~m}^{3} / \mathrm{a}$ & 24,198 & $\mathrm{~h} / \mathrm{a}$ \\
\hline \multicolumn{3}{|l|}{ Sieben } & TL, AS, Sieb & & 1,000 & $\mathrm{~h} / 20 \mathrm{~m}^{3}(\mathrm{kom})$ & $2.800,000$ & $\mathrm{~m}^{3} / \mathrm{a}$ & 140,000 & $\mathrm{~h} / \mathrm{a}$ \\
\hline \multicolumn{3}{|c|}{ Abw.-Ausbringung bei Neubau } & Schl.,PT & & 1,000 & $\mathrm{~h} / 10 \mathrm{~m}^{3}(\mathrm{Abw})$ & 690,819 & $\mathrm{~m}^{3} / \mathrm{a}$ & 69,082 & $h / a$ \\
\hline \multicolumn{3}{|c|}{ Abw.-Ausbringung bei Umnutzung } & Schl., PT & & 1,000 & $\mathrm{~h} / 10 \mathrm{~m}^{3}(\mathrm{Abw})$ & 972,000 & $\mathrm{~m}^{3} / \mathrm{a}$ & 97,200 & $h / a$ \\
\hline \multicolumn{11}{|c|}{ Abkürzungen für die eingesetzten Maschinen: } \\
\hline \multicolumn{2}{|c|}{ TL - Teleskoplader } & & \multicolumn{2}{|c|}{ Schl. - Schlepper } & & & & & & \\
\hline \multicolumn{2}{|c|}{\begin{tabular}{|l} 
MU- Mietenumsetzer \\
\end{tabular}} & & Schr. - Schred & dder & & & & & & \\
\hline \multicolumn{2}{|c|}{ SZ - Silozange } & & PT - Pumpenta & tankwagen & & & & & & \\
\hline \multicolumn{11}{|c|}{ AS - Anbauschaufel } \\
\hline \multicolumn{11}{|c|}{ MASCHINENKOSTEN } \\
\hline \multicolumn{2}{|c|}{ Maschine / Gerät } & Fixkosten & & \multicolumn{2}{|c|}{ Variable Kosten } & Einheiten/a & & \multicolumn{2}{|c|}{ Maschinen-Einzelkosten } & \\
\hline Traktor (Neub & au) & 0,00 & $\mathrm{DM} / \mathrm{a}$ & 33,55 & $\mathrm{DM} / \mathrm{h}$ & 187,44 & $\mathrm{~h} / \mathrm{a}$ & $6.288,69$ & $\mathrm{DM} / \mathrm{a}$ & \\
\hline Traktor (Umnı & itzung) & 0,00 & $\mathrm{DM} / \mathrm{a}$ & 33,55 & $\mathrm{DM} / \mathrm{h}$ & 215,56 & $\mathrm{~h} / \mathrm{a}$ & $7.232,05$ & $\mathrm{DM} / \mathrm{a}$ & \\
\hline Teleskoplader & & 0,00 & $\mathrm{DM} / \mathrm{a}$ & 66,50 & $\mathrm{DM} / \mathrm{h}$ & 501,23 & $\mathrm{~h} / \mathrm{a}$ & $33.332,10$ & $\mathrm{DM} / \mathrm{a}$ & \\
\hline Schredder & & 0,00 & $\mathrm{DM} / \mathrm{a}$ & 7,50 & $\mathrm{DM} / \mathrm{m}^{3}$ (Out) & $1.037,04$ & $\mathrm{~m}^{3} / \mathrm{a}$ & $7.777,78$ & $\mathrm{DM} / \mathrm{a}$ & \\
\hline Trommelsieb & & 0,00 & $\mathrm{DM} / \mathrm{a}$ & 5,00 & $\mathrm{DM} / \mathrm{m}^{3}(\mathrm{Kom})$ & $2.800,00$ & $\mathrm{~m}^{3} / \mathrm{a}$ & $14.000,00$ & $\mathrm{DM} / \mathrm{a}$ & \\
\hline PumpenTW (I & Veubau) & 0,00 & $\mathrm{DM} / \mathrm{a}$ & 30,00 & $\mathrm{DM} / \mathrm{h}$ & 69,08 & $\mathrm{~h} / \mathrm{a}$ & $2.072,46$ & $\mathrm{DM} / \mathrm{a}$ & \\
\hline PumpenTW (L & Jmnutzung) & 0,00 & $D M / a$ & 30,00 & $D M / h$ & 97,20 & $h / a$ & $2.916,00$ & $\mathrm{DM} / \mathrm{a}$ & \\
\hline Silozange & & $1.120,00$ & DM/a & 0,30 & $\mathrm{DM} / \mathrm{m}^{3}$ & $3.111,11$ & $\mathrm{~m}^{3} / \mathrm{a}$ & $2.053,33$ & $\mathrm{DM} / \mathrm{a}$ & \\
\hline Anbauschaufe & & 506,00 & $\mathrm{DM} / \mathrm{a}$ & 0,30 & $\mathrm{DM} / \mathrm{m}^{3}$ & $20.429,63$ & $\mathrm{~m}^{3} / \mathrm{a}$ & $6.634,89$ & $\mathrm{DM} / \mathrm{a}$ & \\
\hline Mietenumsetz & & $3.600,00$ & $\mathrm{DM} / \mathrm{a}$ & 28,00 & $\mathrm{DM} / \mathrm{h}$ & 118,36 & $h / a$ & $6.914,09$ & $\mathrm{DM} / \mathrm{a}$ & \\
\hline & & & & & & Summe (Neuk & bau) & $79.073,34$ & $\mathrm{DM} / \mathrm{a}$ & \\
\hline & & & & & & Summe (Umn & hutzung) & $80.860,25$ & $\mathrm{DM} / \mathrm{a}$ & \\
\hline PERSONA & LOSTEN & & & & & & & & & \\
\hline & Std.-Lohn inkl & I.Lohn-NK & Arbeitsstd. pro & o Jahr & Personal-Einz & zelkosten & & & & \\
\hline Neubau & 26,00 & $D M / h$ & 969,27 & $\mathrm{~h} / \mathrm{a}$ & $25.201,01$ & $\mathrm{DM} / \mathrm{a}$ & & & & \\
\hline Umnutzung & 26,00 & $D M / h$ & 997,39 & $h / a$ & $25.932,08$ & DM/a & & & & \\
\hline
\end{tabular}




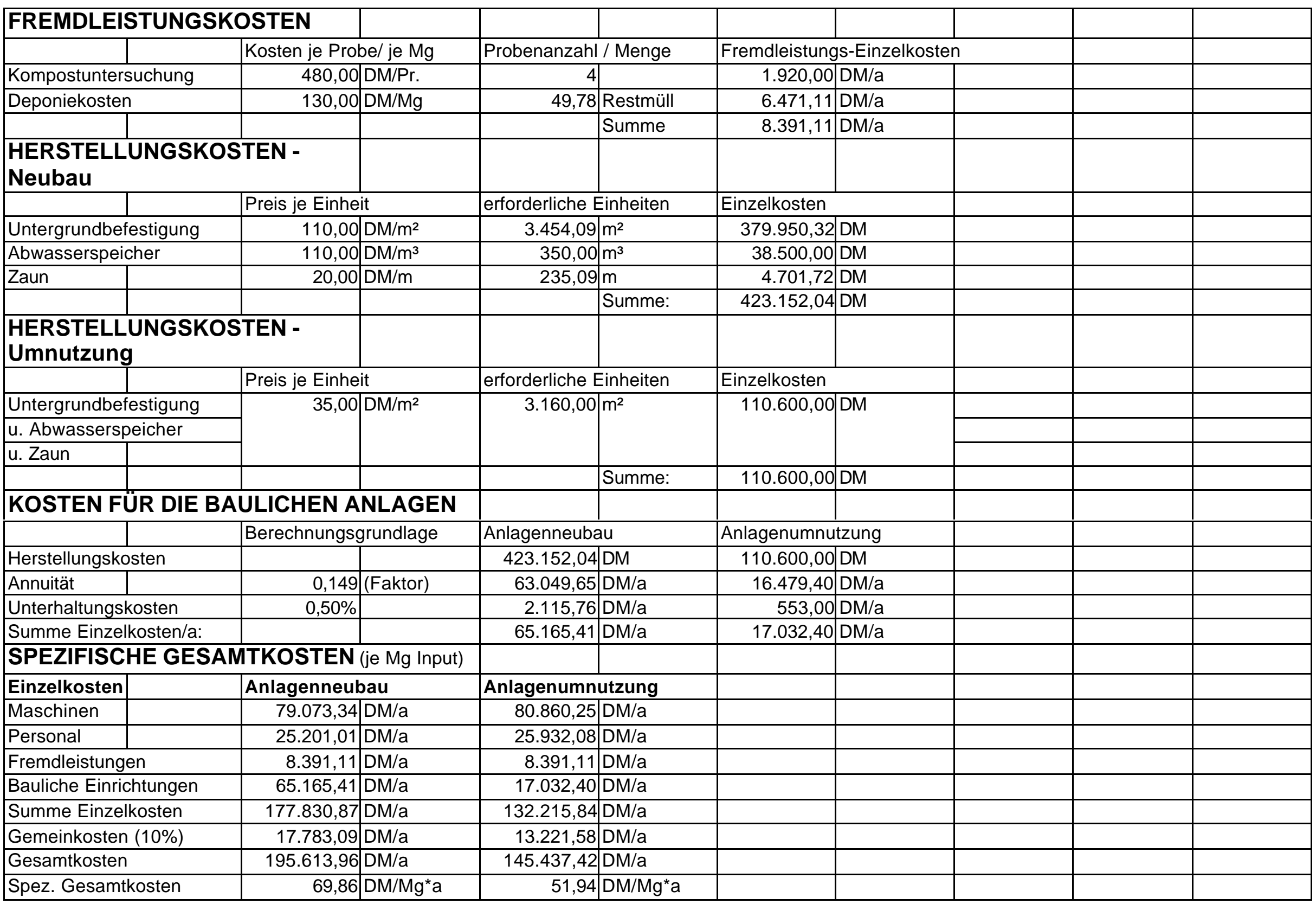


Kostenvariante B1

\section{MATERIAL}

Jahresinputmenge

Zusammensetzung

\begin{tabular}{|l|l|}
\hline & \\
\hline Dichte & \\
\hline & \\
\hline & \\
\hline & \\
\hline Volumen & \\
\hline & \\
\hline & \\
\hline & \\
\hline &
\end{tabular}

Gewichtsanteil

\section{Rottedauer}

durchschnittliches

Monatsaufkommen

maximaler Monatsanfall

\begin{tabular}{|l|}
\hline \\
\hline TS-Gehalt (Fertigkompost)
\end{tabular}

Mietenhöhe

Mietenbasisbreite

\section{ANLAGENDIMENSIONIERUNG}

\section{Anlagenteil}

Anlieferungsfläche

Rottefläche

Rangierfläche

Zwischenlager für

Strukturmaterial

Kompostlager

Anlagenfläche (gesamt)

zu verwertende

Abwassermenge

\section{|}

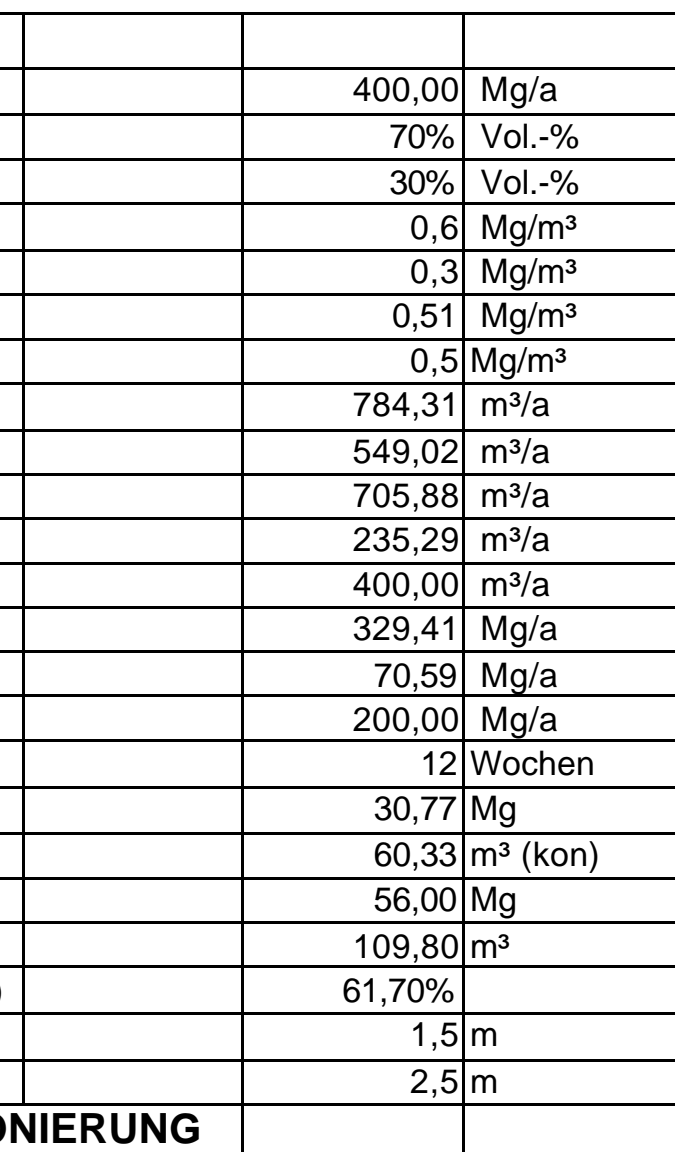

Berechnungsgrundlage

5\% vom Input in Mg/a, ausgedrückt in $\mathrm{m}^{2}$

$1,33 \mathrm{~m}^{2} / \mathrm{m}^{3}$ Rottematerial bei max.M.-Anfall

$40 \%$ der Rottefläche

der Rottefläche

$10 \%$ der Rottefläche

$+$

$0,2 \mathrm{~m}^{3} / \mathrm{m}^{2 \star} \mathrm{a}$

Grüngut

\begin{tabular}{|c|c|c|}
\hline ax.M.-Anfall & 308,92 & $\mathrm{~m}^{2}$ \\
\hline & 123,57 & $\mathrm{~m}^{2}$ \\
\hline & & $\mathrm{m}^{2}$ \\
\hline & 30,89 & \\
\hline & 30,89 & $\mathrm{~m}^{2}$ \\
\hline & 514,26 & $\mathrm{~m}^{2}$ \\
\hline & 102,85 & $\mathrm{~m}^{3} / \mathrm{a}$ \\
\hline
\end{tabular}

Bioabfälle aus Haushalten

gehäckseltes Grüngut

Bioabfälle aus Haushalten

gehäckseltes Grüngut

konditioniertes Material

Fertigkompost

konditioniertes Material

Bioabfälle aus Haushalten

angeliefertes Grüngut

gehäckseltes Grüngut

Fertigkompost

Bioabfälle aus Haushalten

Fertigkompost

\begin{tabular}{l|l} 
& \\
\hline & Rottematerial eines
\end{tabular}

entspr. 14\% vom Input/a

Mietenquerschnitt

\begin{tabular}{|r|l}
\hline $1,875 \mathrm{~m}^{2}$ & \\
\hline & \\
\end{tabular}

Anlagenneubau

Anlagenumnutzung

$400,00 \mathrm{~m}^{2}$

\begin{tabular}{|r|l|l|}
\hline 1525,00 & & \\
\cline { 1 - 2 } & \multicolumn{2}{|l|}{$\mathrm{m}^{2}$ (nicht drainiert) } \\
\hline 600,00 & & \\
\hline 400,00 & $\mathrm{~m}^{2}$ & \\
\hline 2325,00 & $\mathrm{~m}^{2}$ & \\
\hline 465,00 & $\mathrm{~m}^{3} / \mathrm{a}$ & \\
\hline
\end{tabular}




\begin{tabular}{|c|c|c|c|c|c|c|c|c|c|c|}
\hline ZEITEN & & & & & & & & & & \\
\hline Arbeitsgang & & & eingesetzte $\mathrm{M}$ & Maschinen & Zeitbedarf/Ei & inheit & geleistete Ein & nheiten & Zeitbedarf/Ja & ahr \\
\hline Materialannah & ime & & & & 4,000 & h/Woche & 52,000 & Wochen/a & 208,000 & $h / a$ \\
\hline Manuelle Stör & stoffauslese & & & & 1,000 & $h / 100 m^{3}(\ln )$ & \begin{tabular}{|c|}
$1.254,902$ \\
\end{tabular} & $\mathrm{~m}^{3} / \mathrm{a}$ & 12,549 & $h / a$ \\
\hline Zerkleinerung & von Strukturm & naterial & TL, SZ, Schr. & & 1,000 & $h / 50 m^{3}(\operatorname{In})$ & 705,882 & $\mathrm{~m}^{3} / \mathrm{a}$ & 14,118 & $h / a$ \\
\hline Aufsetzen ein & er Matte aus S & Strukturmat. & TL, AS & & 0,300 & $\mathrm{~h} / 100 \mathrm{~m}^{3}$ (kon) & 784,314 & $\mathrm{~m}^{3} / \mathrm{a}$ & 2,353 & $\mathrm{~h} / \mathrm{a}$ \\
\hline Aufsetzen der & Dreiecksmiete & & TL, AS & & 1,000 & $\mathrm{~h} / 20 \mathrm{~m}^{3}$ (kon) & 784,314 & $\mathrm{~m}^{3} / \mathrm{a}$ & 39,216 & $h / a$ \\
\hline Umsetzen der & Dreiecksmiete & & Schl., MU & & 0,005 & $\mathrm{~h} / \mathrm{m}$ (Mietenl.) & $3.530,458$ & $\mathrm{~m} / \mathrm{a}$ & 17,652 & $h / a$ \\
\hline Reinigung der & Annahmefläch & & TL, AS & & 0,500 & $h / 150 m^{3}(\ln )$ & $1.254,902$ & $\mathrm{~m}^{3} / \mathrm{a}$ & 4,183 & $\mathrm{~h} / \mathrm{a}$ \\
\hline Sieben & & & TL, AS, Sieb & & 1,000 & $\mathrm{~h} / 20 \mathrm{~m}^{3}(\mathrm{kom})$ & 400,000 & $\mathrm{~m}^{3} / \mathrm{a}$ & 20,000 & $h / a$ \\
\hline Abw.-Ausbring & gung bei Neub & & Schl.,PT & & 1,000 & $\mathrm{~h} / 10 \mathrm{~m}^{3}(\mathrm{Abw})$ & 102,853 & $\mathrm{~m}^{3} / \mathrm{a}$ & 10,285 & $h / a$ \\
\hline Abw.-Ausbring & gung bei Umnu & utzung & Schl., PT & & 1,000 & $\mathrm{~h} / 10 \mathrm{~m}^{3}(\mathrm{Abw})$ & 465,000 & $\mathrm{~m}^{3} / \mathrm{a}$ & 46,500 & $h / a$ \\
\hline Abkürzungen & für die eingese & etzten Maschin & nen: & & & & & & & \\
\hline TL - Teleskop & lader & & Schl. - Schlepp & per & & & & & & \\
\hline MU- Mietenum & nsetzer & & Schr. - Schred & dder & & & & & & \\
\hline SZ - Silozange & & & PT - Pumpenta & tankwagen & & & & & & \\
\hline AS - Anbausc & haufel & & & & & & & & & \\
\hline MASCHINE & ENKOSTEN & & & & & & & & & \\
\hline Maschine / G & erät & Fixkosten & & Variable Kost & ten & Einheiten/a & & Maschinen-Ei & inzelkosten & \\
\hline Traktor (Neub & au) & 0,00 & $\mathrm{DM} / \mathrm{a}$ & 33,55 & $D M / h$ & 27,94 & $\mathrm{~h} / \mathrm{a}$ & 937,31 & $\mathrm{DM} / \mathrm{a}$ & \\
\hline Traktor (Umnu & itzung) & 0,00 & $\mathrm{DM} / \mathrm{a}$ & 33,55 & $D M / h$ & 64,15 & $\mathrm{~h} / \mathrm{a}$ & $2.152,31$ & $\mathrm{DM} / \mathrm{a}$ & \\
\hline Teleskoplader & & 0,00 & $D M / a$ & 66,50 & $\mathrm{DM} / \mathrm{h}$ & 79,87 & $h / a$ & $5.311,31$ & $\mathrm{DM} / \mathrm{a}$ & \\
\hline Schredder & & 0,00 & DM/a & 7,50 & $\mathrm{DM} / \mathrm{m}^{3}$ (Out) & 235,29 & $\mathrm{~m}^{3} / \mathrm{a}$ & $1.764,71$ & $\mathrm{DM} / \mathrm{a}$ & \\
\hline Trommelsieb & & 0,00 & $D M / a$ & 5,00 & $\mathrm{DM} / \mathrm{m}^{3}(\mathrm{Kom})$ & 400,00 & $\mathrm{~m}^{3} / \mathrm{a}$ & $2.000,00$ & $\mathrm{DM} / \mathrm{a}$ & \\
\hline PumpenTW ( & Veubau) & 0,00 & $\mathrm{DM} / \mathrm{a}$ & 30,00 & $\mathrm{DM} / \mathrm{h}$ & 10,29 & $\mathrm{~h} / \mathrm{a}$ & 308,56 & $\mathrm{DM} / \mathrm{a}$ & \\
\hline PumpenTW (L & Jmnutzung) & 0,00 & $D M / a$ & 30,00 & $D M / h$ & 46,50 & $h / a$ & $1.395,00$ & $\mathrm{DM} / \mathrm{a}$ & \\
\hline Silozange & & $1.120,00$ & DM/a & 0,30 & $\mathrm{DM} / \mathrm{m}^{3}$ & 705,88 & $\mathrm{~m}^{3} / \mathrm{a}$ & $1.331,76$ & $\mathrm{DM} / \mathrm{a}$ & \\
\hline Anbauschaufe & & 506,00 & $\mathrm{DM} / \mathrm{a}$ & 0,30 & $\mathrm{DM} / \mathrm{m}^{3}$ & $3.223,53$ & $\mathrm{~m}^{3} / \mathrm{a}$ & $1.473,06$ & $\mathrm{DM} / \mathrm{a}$ & \\
\hline Mietenumsetz & & $3.600,00$ & $\mathrm{DM} / \mathrm{a}$ & 28,00 & $\mathrm{DM} / \mathrm{h}$ & 17,65 & $h / a$ & $4.094,26$ & $\mathrm{DM} / \mathrm{a}$ & \\
\hline & & & & & & Summe (Neuk & bau) & $17.220,96$ & $\mathrm{DM} / \mathrm{a}$ & \\
\hline & & & & & & Summe (Umn & hutzung) & $19.522,41$ & $\mathrm{DM} / \mathrm{a}$ & \\
\hline PERSONA & LOSTEN & & & & & & & & & \\
\hline & Std.-Lohn inkl & I.Lohn-NK & Arbeitsstd. pro & o Jahr & Personal-Einz & zelkosten & & & & \\
\hline Neubau & 26,00 & $D M / h$ & 328,36 & $\mathrm{~h} / \mathrm{a}$ & $8.537,25$ & $D M / a$ & & & & \\
\hline Umnutzung & 26,00 & $D M / h$ & 364,57 & $\mathrm{~h} / \mathrm{a}$ & $9.478,84$ & $D M / a$ & & & & \\
\hline
\end{tabular}




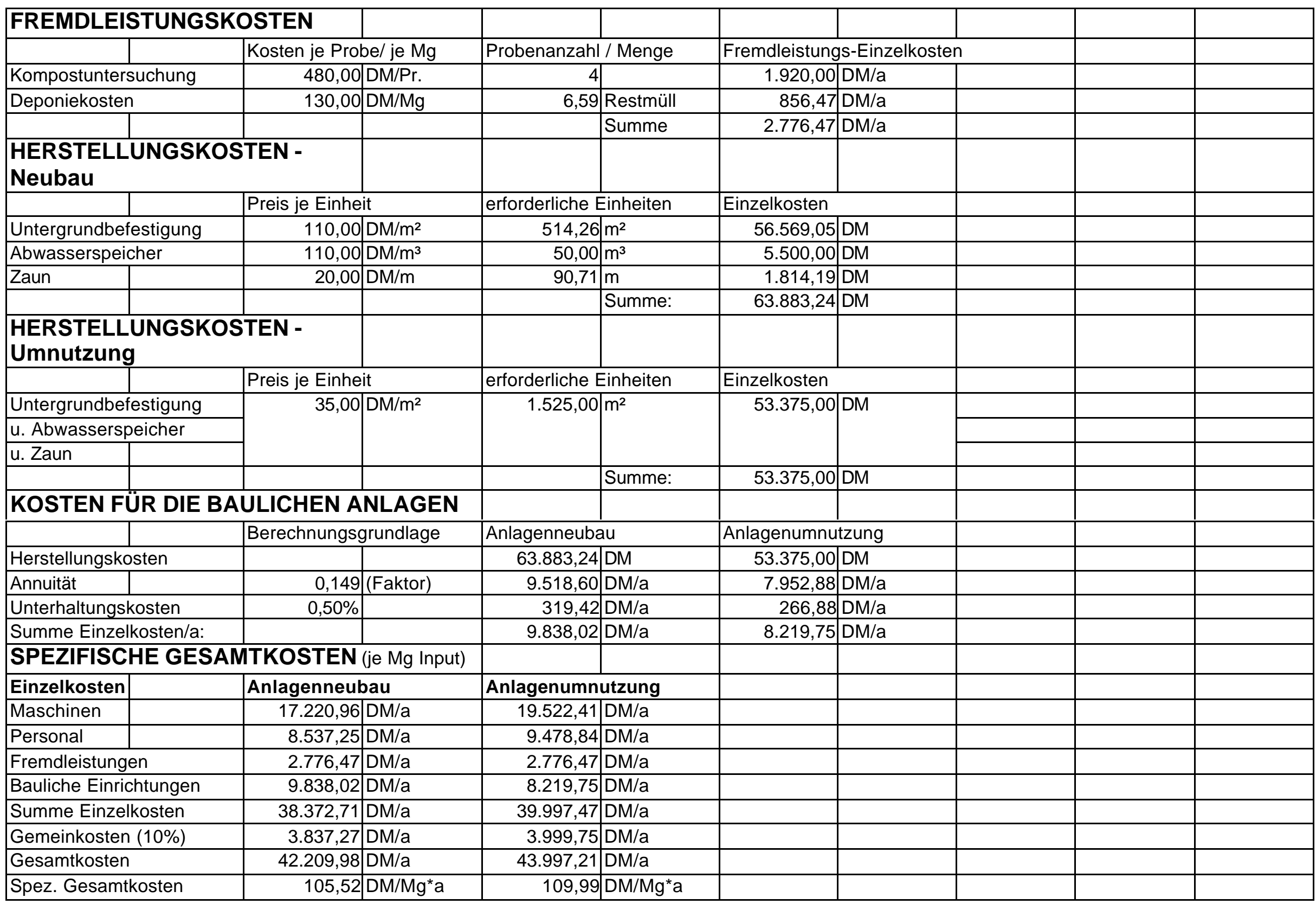


Kostenvariante B2

\section{MATERIAL}

Jahresinputmenge

Zusammensetzung

\begin{tabular}{|l|l|}
\hline & \\
\hline Dichte & \\
\hline & \\
\hline & \\
\hline & \\
\hline & \\
\hline & \\
\hline & \\
\hline & \\
\hline &
\end{tabular}

Gewichtsanteil

\section{Rottedauer}

durchschnittliches

Monatsaufkommen

maximaler Monatsanfall

\begin{tabular}{|l}
\hline \\
TS-Gehalt (Fertigkompost)
\end{tabular}

Mietenhöhe

Mietenbasisbreite

\section{ANLAGENDIMENSIONIERUNG}

\section{Anlagenteil}

Anlieferungsfläche

Rottefläche

Rangierfläche

Zwischenlager für

Strukturmaterial

Kompostlager

Anlagenfläche (gesamt)

zu verwertende

Abwassermenge

\section{|}

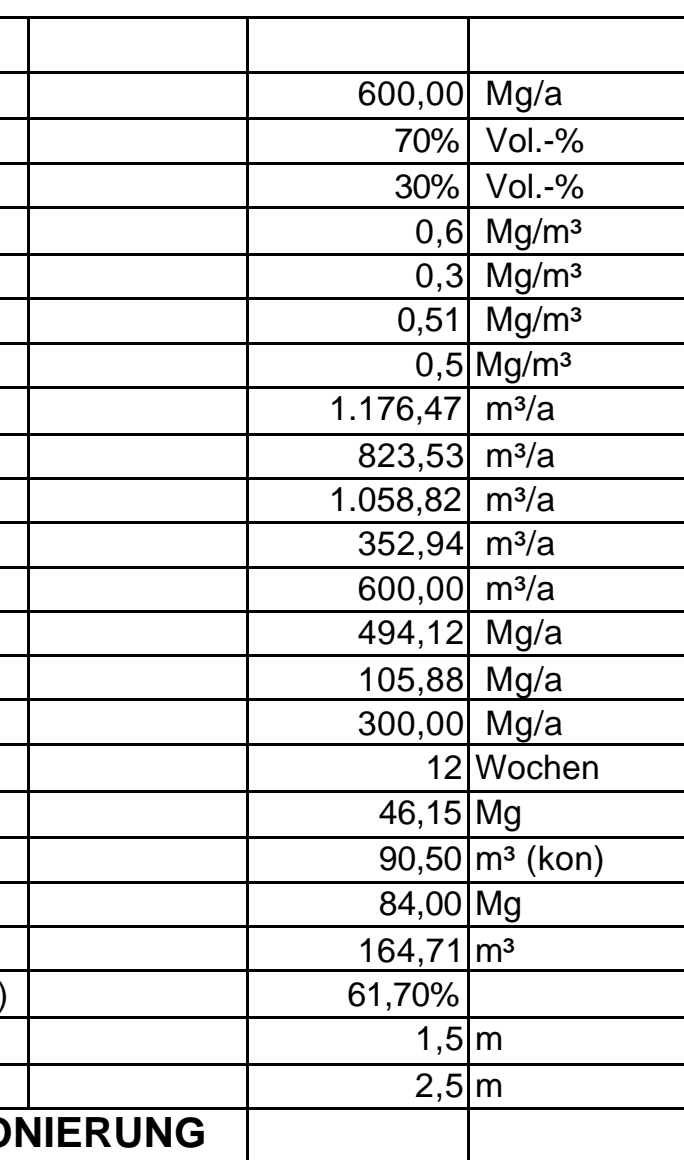

Berechnungsgrundlage

5\% vom Input in Mg/a, ausgedrückt in $\mathrm{m}^{2}$

$1,33 \mathrm{~m}^{2} / \mathrm{m}^{3}$ Rottematerial bei max.M.-Anfall

$40 \%$ der Rottefläche

der Rottefläche

$10 \%$ der Rottefläche

$+$

$0,2 \mathrm{~m}^{3} / \mathrm{m}^{2 \star} \mathrm{a}$

Grüngut

\begin{tabular}{|c|c|c|}
\hline ax.M.-Anfall & 463,37 & $\mathrm{~m}^{2}$ \\
\hline & 185,35 & $\mathrm{~m}^{2}$ \\
\hline & & $\mathrm{m}^{2}$ \\
\hline & 46,34 & \\
\hline & 46,34 & $\mathrm{~m}^{2}$ \\
\hline & 771,40 & $\mathrm{~m}^{2}$ \\
\hline & & \\
\hline & 154,28 & $\mathrm{~m}^{3} / \mathrm{a}$ \\
\hline
\end{tabular}

Bioabfälle aus Haushalten

gehäckseltes Grüngut

Bioabfälle aus Haushalten

gehäckseltes Grüngut

konditioniertes Material

Fertigkompost

konditioniertes Material

Bioabfälle aus Haushalten

angeliefertes Grüngut

gehäckseltes Grüngut

Fertigkompost

Bioabfälle aus Haushalten

Fertigkompost

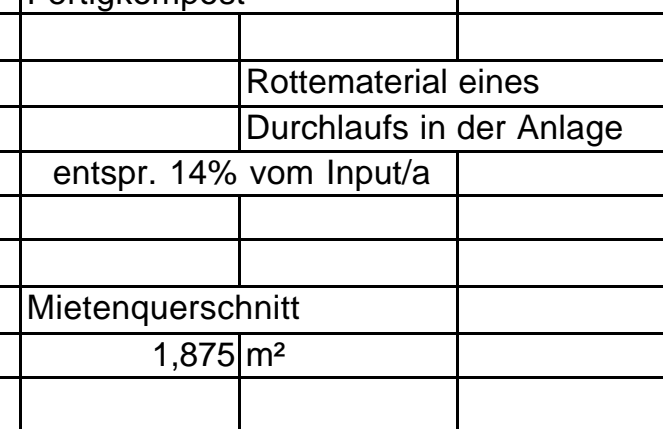

Anlagenneubau

Anlagenumnutzung

$400,00 \mathrm{~m}^{2}$

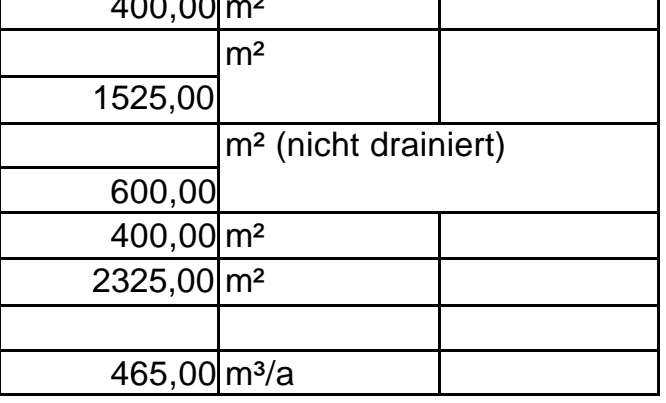




\begin{tabular}{|c|c|c|c|c|c|c|c|c|c|c|}
\hline \multicolumn{11}{|l|}{ ZEITEN } \\
\hline \multicolumn{3}{|l|}{ Arbeitsgang } & \multicolumn{2}{|c|}{ eingesetzte Maschinen } & \multicolumn{2}{|c|}{ Zeitbedarf/Einheit } & \multicolumn{2}{|c|}{ geleistete Einheiten } & \multicolumn{2}{|c|}{ Zeitbedarf/Jahr } \\
\hline \multicolumn{3}{|c|}{ Materialannahme } & & & 4,000 & h/Woche & 52,000 & Wochen/a & 208,000 & $h / a$ \\
\hline \multicolumn{3}{|c|}{ Manuelle Störstoffauslese } & & & 1,000 & $\mathrm{~h} / 100 \mathrm{~m}^{3}(\ln )$ & $1.882,353$ & $\mathrm{~m}^{3} / \mathrm{a}$ & 18,824 & $\mathrm{~h} / \mathrm{a}$ \\
\hline \multicolumn{3}{|c|}{ Zerkleinerung von Strukturmaterial } & TL, SZ, Schr. & & 1,000 & $h / 50 m^{3}(\ln )$ & $1.058,824$ & $\mathrm{~m}^{3} / \mathrm{a}$ & 21,176 & $h / a$ \\
\hline \multicolumn{3}{|c|}{ Aufsetzen einer Matte aus Strukturmat. } & TL, AS & & 0,300 & $\mathrm{~h} / 100 \mathrm{~m}^{3}$ (kon) & $1.176,471$ & $\mathrm{~m}^{3} / \mathrm{a}$ & 3,529 & $h / a$ \\
\hline \multicolumn{3}{|c|}{ Aufsetzen der Dreiecksmieten } & TL, AS & & 1,000 & $\mathrm{~h} / 20 \mathrm{~m}^{3}$ (kon) & $1.176,471$ & $\mathrm{~m}^{3} / \mathrm{a}$ & 58,824 & $\mathrm{~h} / \mathrm{a}$ \\
\hline \multicolumn{3}{|c|}{ Umsetzen der Dreiecksmieten } & Schl., MU & & 0,005 & $\mathrm{~h} / \mathrm{m}$ (Mietenl.) & $5.295,686$ & $\mathrm{~m} / \mathrm{a}$ & 26,478 & $\mathrm{~h} / \mathrm{a}$ \\
\hline \multicolumn{3}{|c|}{ Reinigung der Annahmefläche } & TL, AS & & 0,500 & $h / 150 m^{3}(\ln )$ & $1.882,353$ & $\mathrm{~m}^{3} / \mathrm{a}$ & 6,275 & $h / a$ \\
\hline \multicolumn{3}{|l|}{ Sieben } & TL, AS, Sieb & & 1,000 & $\mathrm{~h} / 20 \mathrm{~m}^{3}(\mathrm{kom})$ & 600,000 & $\mathrm{~m}^{3} / \mathrm{a}$ & 30,000 & $\mathrm{~h} / \mathrm{a}$ \\
\hline \multicolumn{3}{|c|}{ Abw.-Ausbringung bei Neubau } & Schl.,PT & & 1,000 & $\mathrm{~h} / 10 \mathrm{~m}^{3}(\mathrm{Abw})$ & 154,279 & $\mathrm{~m}^{3} / \mathrm{a}$ & 15,428 & $\mathrm{~h} / \mathrm{a}$ \\
\hline \multicolumn{3}{|c|}{ Abw.-Ausbringung bei Umnutzung } & Schl., PT & & 1,000 & $\mathrm{~h} / 10 \mathrm{~m}^{3}(\mathrm{Abw})$ & 465,000 & $\mathrm{~m}^{3} / \mathrm{a}$ & 46,500 & $h / a$ \\
\hline \multicolumn{11}{|c|}{ Abkürzungen für die eingesetzten Maschinen: } \\
\hline \multicolumn{2}{|c|}{ TL - Teleskoplader } & & \multicolumn{2}{|c|}{ Schl. - Schlepper } & & & & & & \\
\hline \multicolumn{2}{|c|}{ MU- Mietenumsetzer } & & Schr. - Schred & dder & & & & & & \\
\hline \multicolumn{2}{|c|}{ SZ - Silozange } & & PT - Pumpenta & tankwagen & & & & & & \\
\hline \multicolumn{11}{|c|}{ AS - Anbauschaufel } \\
\hline \multicolumn{11}{|c|}{ MASCHINENKOSTEN } \\
\hline \multicolumn{2}{|c|}{ Maschine / Gerät } & Fixkosten & & \multicolumn{2}{|c|}{ Variable Kosten } & Einheiten/a & & \multicolumn{2}{|c|}{ Maschinen-Einzelkosten } & \\
\hline Traktor (Neub & au) & 0,00 & $\mathrm{DM} / \mathrm{a}$ & 33,55 & $\mathrm{DM} / \mathrm{h}$ & 41,91 & $\mathrm{~h} / \mathrm{a}$ & $1.405,96$ & $\mathrm{DM} / \mathrm{a}$ & \\
\hline Traktor (Umnı & itzung) & 0,00 & $\mathrm{DM} / \mathrm{a}$ & 33,55 & $\mathrm{DM} / \mathrm{h}$ & 72,98 & $\mathrm{~h} / \mathrm{a}$ & $2.448,43$ & $\mathrm{DM} / \mathrm{a}$ & \\
\hline Teleskoplader & & 0,00 & $\mathrm{DM} / \mathrm{a}$ & 66,50 & $\mathrm{DM} / \mathrm{h}$ & 119,80 & $\mathrm{~h} / \mathrm{a}$ & $7.966,96$ & $\mathrm{DM} / \mathrm{a}$ & \\
\hline Schredder & & 0,00 & $\mathrm{DM} / \mathrm{a}$ & 7,50 & $\mathrm{DM} / \mathrm{m}^{3}$ (Out) & 352,94 & $\mathrm{~m}^{3} / \mathrm{a}$ & $2.647,06$ & $\mathrm{DM} / \mathrm{a}$ & \\
\hline Trommelsieb & & 0,00 & $\mathrm{DM} / \mathrm{a}$ & 5,00 & $\mathrm{DM} / \mathrm{m}^{3}(\mathrm{Kom})$ & 600,00 & $\mathrm{~m}^{3} / \mathrm{a}$ & $3.000,00$ & $\mathrm{DM} / \mathrm{a}$ & \\
\hline PumpenTW (I & Veubau) & 0,00 & $\mathrm{DM} / \mathrm{a}$ & 30,00 & $\mathrm{DM} / \mathrm{h}$ & 15,43 & $\mathrm{~h} / \mathrm{a}$ & 462,84 & $\mathrm{DM} / \mathrm{a}$ & \\
\hline PumpenTW (L & Jmnutzung) & 0,00 & $\mathrm{DM} / \mathrm{a}$ & 30,00 & $D M / h$ & 46,50 & $\mathrm{~h} / \mathrm{a}$ & $1.395,00$ & $\mathrm{DM} / \mathrm{a}$ & \\
\hline Silozange & & $1.120,00$ & DM/a & 0,30 & $\mathrm{DM} / \mathrm{m}^{3}$ & $1.058,82$ & $m^{3} / a$ & $1.437,65$ & $\mathrm{DM} / \mathrm{a}$ & \\
\hline Anbauschaufe & & 506,00 & $\mathrm{DM} / \mathrm{a}$ & 0,30 & $\mathrm{DM} / \mathrm{m}^{3}$ & $4.835,29$ & $\mathrm{~m}^{3} / \mathrm{a}$ & $1.956,59$ & $\mathrm{DM} / \mathrm{a}$ & \\
\hline Mietenumsetz & & $3.600,00$ & $\mathrm{DM} / \mathrm{a}$ & 28,00 & $\mathrm{DM} / \mathrm{h}$ & 26,48 & $\mathrm{~h} / \mathrm{a}$ & $4.341,40$ & $\mathrm{DM} / \mathrm{a}$ & \\
\hline & & & & & & Summe (Neuk & bau) & $23.218,45$ & $\mathrm{DM} / \mathrm{a}$ & \\
\hline & & & & & & Summe (Umn & hutzung) & $25.193,08$ & $\mathrm{DM} / \mathrm{a}$ & \\
\hline PERSONA & LOSTEN & & & & & & & & & \\
\hline & Std.-Lohn inkl & I.Lohn-NK & Arbeitsstd. pro & o Jahr & Personal-Einz & zelkosten & & & & \\
\hline Neubau & 26,00 & $D M / h$ & 388,53 & $\mathrm{~h} / \mathrm{a}$ & $10.101,88$ & $D M / a$ & & & & \\
\hline Umnutzung & 26,00 & $D M / h$ & 419,61 & $h / a$ & $10.909,75$ & $D M / a$ & & & & \\
\hline
\end{tabular}




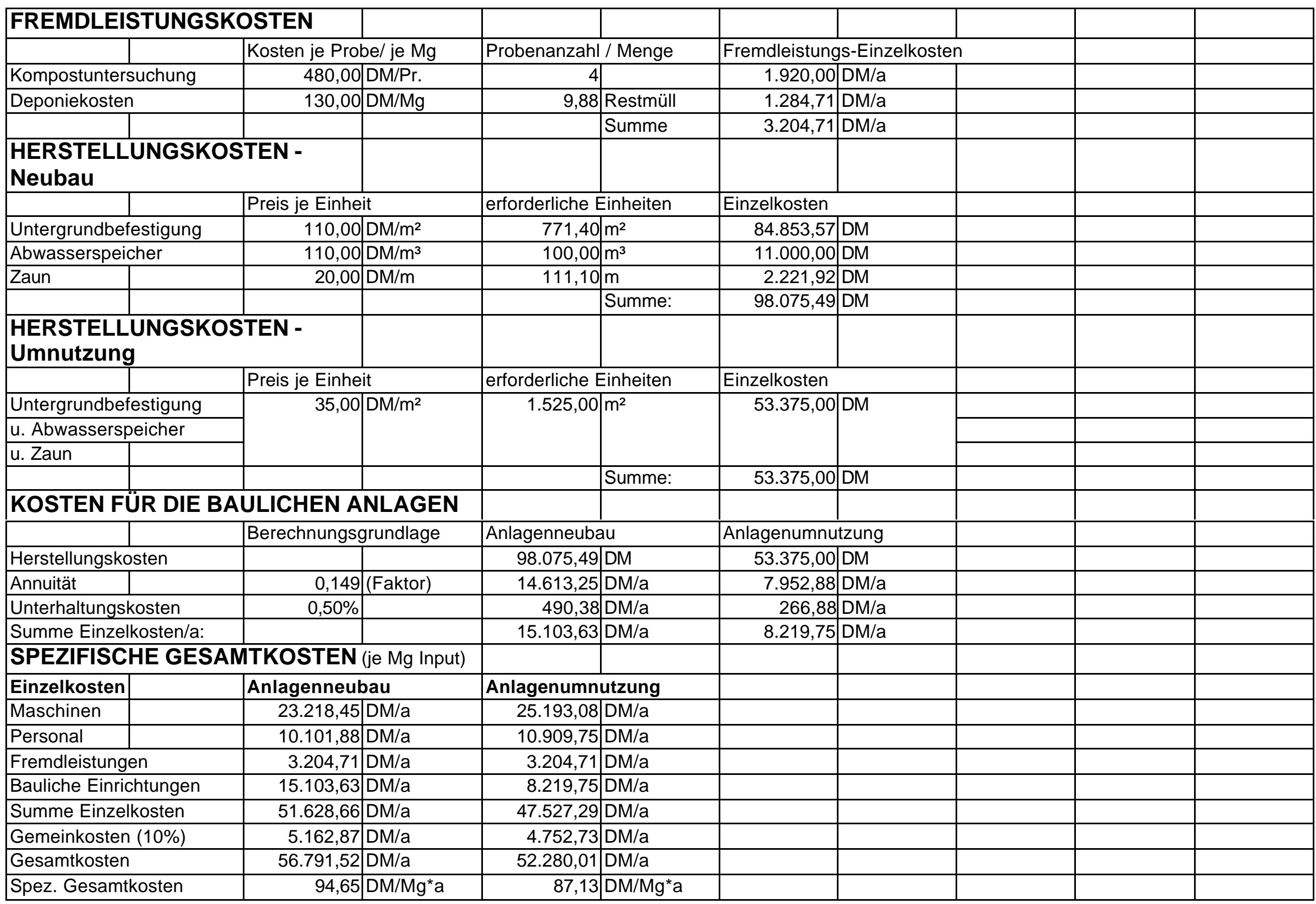


Kostenvariante B3

\section{MATERIAL}

Jahresinputmenge

Zusammensetzung

\begin{tabular}{|l|l|}
\hline & \\
\hline Dichte & \\
\hline & \\
\hline & \\
\hline & \\
\hline & \\
\hline & \\
\hline & \\
\hline & \\
\hline &
\end{tabular}

Gewichtsanteil

\section{Rottedauer}

durchschnittliches

Monatsaufkommen

maximaler Monatsanfall

\begin{tabular}{|l|}
\hline \\
\hline TS-Gehalt (Fertigkompost)
\end{tabular}

Mietenhöhe

Mietenbasisbreite

\section{ANLAGENDIMENSIONIERUNG}

\section{Anlagenteil}

Anlieferungsfläche

Rottefläche

Rangierfläche

Zwischenlager für

Strukturmaterial

Kompostlager

Anlagenfläche (gesamt)

zu verwertende

Abwassermenge

\section{|}

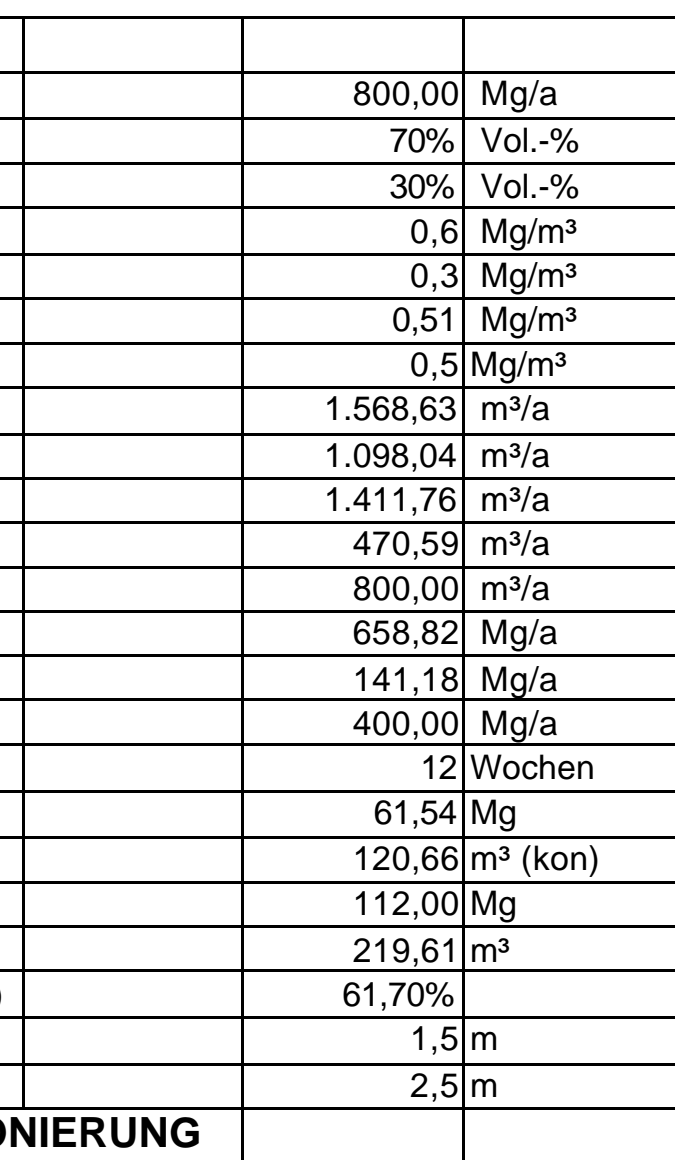

Berechnungsgrundlage

5\% vom Input in $\mathrm{Mg} / \mathrm{a}$, ausgedrückt in $\mathrm{m}^{2}$

$1,33 \mathrm{~m}^{2} / \mathrm{m}^{3}$ Rottematerial bei max.M.-Anfall

$40 \%$ der Rottefläche

der Rottefläche

$10 \%$ der Rottefläche

$+$

$0,2 \mathrm{~m}^{3} / \mathrm{m}^{2 \star} \mathrm{a}$

Grüngut

\begin{tabular}{|c|c|c|}
\hline ax.M.-Anfall & 617,83 & $\mathrm{~m}^{2}$ \\
\hline & 247,13 & $\mathrm{~m}^{2}$ \\
\hline & & $\mathrm{m}^{2}$ \\
\hline & 61,78 & \\
\hline & 61,78 & $\mathrm{~m}^{2}$ \\
\hline & 1028,53 & $\mathrm{~m}^{2}$ \\
\hline & & \\
\hline & 205,71 & $\mathrm{~m}^{3} / \mathrm{a}$ \\
\hline
\end{tabular}

Bioabfälle aus Haushalten

gehäckseltes Grüngut

Bioabfälle aus Haushalten

gehäckseltes Grüngut

konditioniertes Material

Fertigkompost

konditioniertes Material

Bioabfälle aus Haushalten

angeliefertes Grüngut

gehäckseltes Grüngut

Fertigkompost

Bioabfälle aus Haushalten

Fertigkompost

\begin{tabular}{l|l}
\hline & \\
\hline & Rottematerial eines \\
\hline & Durchlaufs in der Anlage
\end{tabular}

entspr. 14\% vom Input/a

Mietenquerschnitt

\begin{tabular}{|r|l}
\hline $1,875 \mathrm{~m}^{2}$ & \\
\hline & \\
\end{tabular}

Anlagenneubau

$40,00 \mathrm{~m}^{2}$

Anlagenumnutzung

\begin{tabular}{r|l|l|l|}
\hline 400,00 & $\mathrm{~m}^{2}$ & \\
\cline { 1 - 2 } & $\mathrm{m}^{2}$ & \\
\cline { 1 - 2 } & $\mathrm{m}^{2}$ (nicht drainiert) \\
\hline 400,00 & & \\
\hline 400,00 & $\mathrm{~m}^{2}$ & \\
\hline 2325,00 & $\mathrm{~m}^{2}$ & \\
\hline 465,00 & $\mathrm{~m}^{3} / \mathrm{a}$ & \\
\hline
\end{tabular}




\begin{tabular}{|c|c|c|c|c|c|c|c|c|c|c|}
\hline \multicolumn{11}{|l|}{ ZEITEN } \\
\hline \multicolumn{3}{|l|}{ Arbeitsgang } & \multicolumn{2}{|c|}{ eingesetzte Maschinen } & \multicolumn{2}{|c|}{ Zeitbedarf/Einheit } & \multicolumn{2}{|c|}{ geleistete Einheiten } & \multicolumn{2}{|c|}{ Zeitbedarf/Jahr } \\
\hline \multicolumn{3}{|c|}{ Materialannahme } & & & 4,000 & h/Woche & 52,000 & Wochen/a & 208,000 & $h / a$ \\
\hline \multicolumn{3}{|c|}{ Manuelle Störstoffauslese } & & & 1,000 & $\mathrm{~h} / 100 \mathrm{~m}^{3}(\ln )$ & $2.509,804$ & $\mathrm{~m}^{3} / \mathrm{a}$ & 25,098 & $\mathrm{~h} / \mathrm{a}$ \\
\hline \multicolumn{3}{|c|}{ Zerkleinerung von Strukturmaterial } & TL, SZ, Schr. & & 1,000 & $h / 50 m^{3}(\ln )$ & $1.411,765$ & $\mathrm{~m}^{3} / \mathrm{a}$ & 28,235 & $h / a$ \\
\hline \multicolumn{3}{|c|}{ Aufsetzen einer Matte aus Strukturmat. } & TL, AS & & 0,300 & $\mathrm{~h} / 100 \mathrm{~m}^{3}$ (kon) & $1.568,627$ & $\mathrm{~m}^{3} / \mathrm{a}$ & 4,706 & $h / a$ \\
\hline \multicolumn{3}{|c|}{ Aufsetzen der Dreiecksmieten } & TL, AS & & 1,000 & $\mathrm{~h} / 20 \mathrm{~m}^{3}$ (kon) & $1.568,627$ & $\mathrm{~m}^{3} / \mathrm{a}$ & 78,431 & $\mathrm{~h} / \mathrm{a}$ \\
\hline \multicolumn{3}{|c|}{ Umsetzen der Dreiecksmieten } & Schl., MU & & 0,005 & $\mathrm{~h} / \mathrm{m}$ (Mietenl.) & $7.060,915$ & $\mathrm{~m} / \mathrm{a}$ & 35,305 & $\mathrm{~h} / \mathrm{a}$ \\
\hline \multicolumn{3}{|c|}{ Reinigung der Annahmefläche } & TL, AS & & 0,500 & $h / 150 m^{3}(\ln )$ & $2.509,804$ & $\mathrm{~m}^{3} / \mathrm{a}$ & 8,366 & $h / a$ \\
\hline \multicolumn{3}{|l|}{ Sieben } & TL, AS, Sieb & & 1,000 & $\mathrm{~h} / 20 \mathrm{~m}^{3}(\mathrm{kom})$ & 800,000 & $\mathrm{~m}^{3} / \mathrm{a}$ & 40,000 & $\mathrm{~h} / \mathrm{a}$ \\
\hline \multicolumn{3}{|c|}{ Abw.-Ausbringung bei Neubau } & Schl.,PT & & 1,000 & $\mathrm{~h} / 10 \mathrm{~m}^{3}(\mathrm{Abw})$ & 205,706 & $\mathrm{~m}^{3} / \mathrm{a}$ & 20,571 & $\mathrm{~h} / \mathrm{a}$ \\
\hline \multicolumn{3}{|c|}{ Abw.-Ausbringung bei Umnutzung } & Schl., PT & & 1,000 & $\mathrm{~h} / 10 \mathrm{~m}^{3}(\mathrm{Abw})$ & 465,000 & $\mathrm{~m}^{3} / \mathrm{a}$ & 46,500 & $h / a$ \\
\hline \multicolumn{11}{|c|}{ Abkürzungen für die eingesetzten Maschinen: } \\
\hline \multicolumn{2}{|c|}{ TL - Teleskoplader } & & \multicolumn{2}{|c|}{ Schl. - Schlepper } & & & & & & \\
\hline \multicolumn{2}{|c|}{ MU- Mietenumsetzer } & & Schr. - Schred & dder & & & & & & \\
\hline \multicolumn{2}{|c|}{ SZ - Silozange } & & PT - Pumpenta & tankwagen & & & & & & \\
\hline \multicolumn{11}{|c|}{ AS - Anbauschaufel } \\
\hline \multicolumn{11}{|c|}{ MASCHINENKOSTEN } \\
\hline \multicolumn{2}{|c|}{ Maschine / Gerät } & Fixkosten & & \multicolumn{2}{|c|}{ Variable Kosten } & Einheiten/a & & \multicolumn{2}{|c|}{ Maschinen-Einzelkosten } & \\
\hline Traktor (Neub & au) & 0,00 & $\mathrm{DM} / \mathrm{a}$ & 33,55 & $\mathrm{DM} / \mathrm{h}$ & 55,88 & $\mathrm{~h} / \mathrm{a}$ & $1.874,61$ & $\mathrm{DM} / \mathrm{a}$ & \\
\hline Traktor (Umnı & itzung) & 0,00 & $\mathrm{DM} / \mathrm{a}$ & 33,55 & $\mathrm{DM} / \mathrm{h}$ & 81,80 & $\mathrm{~h} / \mathrm{a}$ & $2.744,54$ & $\mathrm{DM} / \mathrm{a}$ & \\
\hline Teleskoplader & & 0,00 & $\mathrm{DM} / \mathrm{a}$ & 66,50 & $\mathrm{DM} / \mathrm{h}$ & 159,74 & $\mathrm{~h} / \mathrm{a}$ & $10.622,61$ & $\mathrm{DM} / \mathrm{a}$ & \\
\hline Schredder & & 0,00 & $\mathrm{DM} / \mathrm{a}$ & 7,50 & $\mathrm{DM} / \mathrm{m}^{3}$ (Out) & 470,59 & $\mathrm{~m}^{3} / \mathrm{a}$ & $3.529,41$ & $\mathrm{DM} / \mathrm{a}$ & \\
\hline Trommelsieb & & 0,00 & $\mathrm{DM} / \mathrm{a}$ & 5,00 & $\mathrm{DM} / \mathrm{m}^{3}(\mathrm{Kom})$ & 800,00 & $\mathrm{~m}^{3} / \mathrm{a}$ & $4.000,00$ & $\mathrm{DM} / \mathrm{a}$ & \\
\hline PumpenTW (I & Veubau) & 0,00 & $\mathrm{DM} / \mathrm{a}$ & 30,00 & $\mathrm{DM} / \mathrm{h}$ & 20,57 & $\mathrm{~h} / \mathrm{a}$ & 617,12 & $\mathrm{DM} / \mathrm{a}$ & \\
\hline PumpenTW (L & Jmnutzung) & 0,00 & $\mathrm{DM} / \mathrm{a}$ & 30,00 & $D M / h$ & 46,50 & $h / a$ & $1.395,00$ & $\mathrm{DM} / \mathrm{a}$ & \\
\hline Silozange & & $1.120,00$ & DM/a & 0,30 & $\mathrm{DM} / \mathrm{m}^{3}$ & $1.411,76$ & $\mathrm{~m}^{3} / \mathrm{a}$ & $1.543,53$ & $\mathrm{DM} / \mathrm{a}$ & \\
\hline Anbauschaufe & & 506,00 & $\mathrm{DM} / \mathrm{a}$ & 0,30 & $\mathrm{DM} / \mathrm{m}^{3}$ & $6.447,06$ & $m^{3} / a$ & $2.440,12$ & $\mathrm{DM} / \mathrm{a}$ & \\
\hline Mietenumsetz & & $3.600,00$ & $\mathrm{DM} / \mathrm{a}$ & 28,00 & $\mathrm{DM} / \mathrm{h}$ & 35,30 & $h / a$ & $4.588,53$ & $\mathrm{DM} / \mathrm{a}$ & \\
\hline & & & & & & Summe (Neuk & bau) & $29.215,93$ & $\mathrm{DM} / \mathrm{a}$ & \\
\hline & & & & & & Summe (Umn & futzung) & $30.863,74$ & $\mathrm{DM} / \mathrm{a}$ & \\
\hline PERSONA & LOSTEN & & & & & & & & & \\
\hline & Std.-Lohn inkl & I.Lohn-NK & Arbeitsstd. pro & o Jahr & Personal-Einz & zelkosten & & & & \\
\hline Neubau & 26,00 & $D M / h$ & 448,71 & $\mathrm{~h} / \mathrm{a}$ & 11.666,51 & $\mathrm{DM} / \mathrm{a}$ & & & & \\
\hline Umnutzung & 26,00 & $D M / h$ & 474,64 & $h / a$ & $12.340,67$ & DM/a & & & & \\
\hline
\end{tabular}




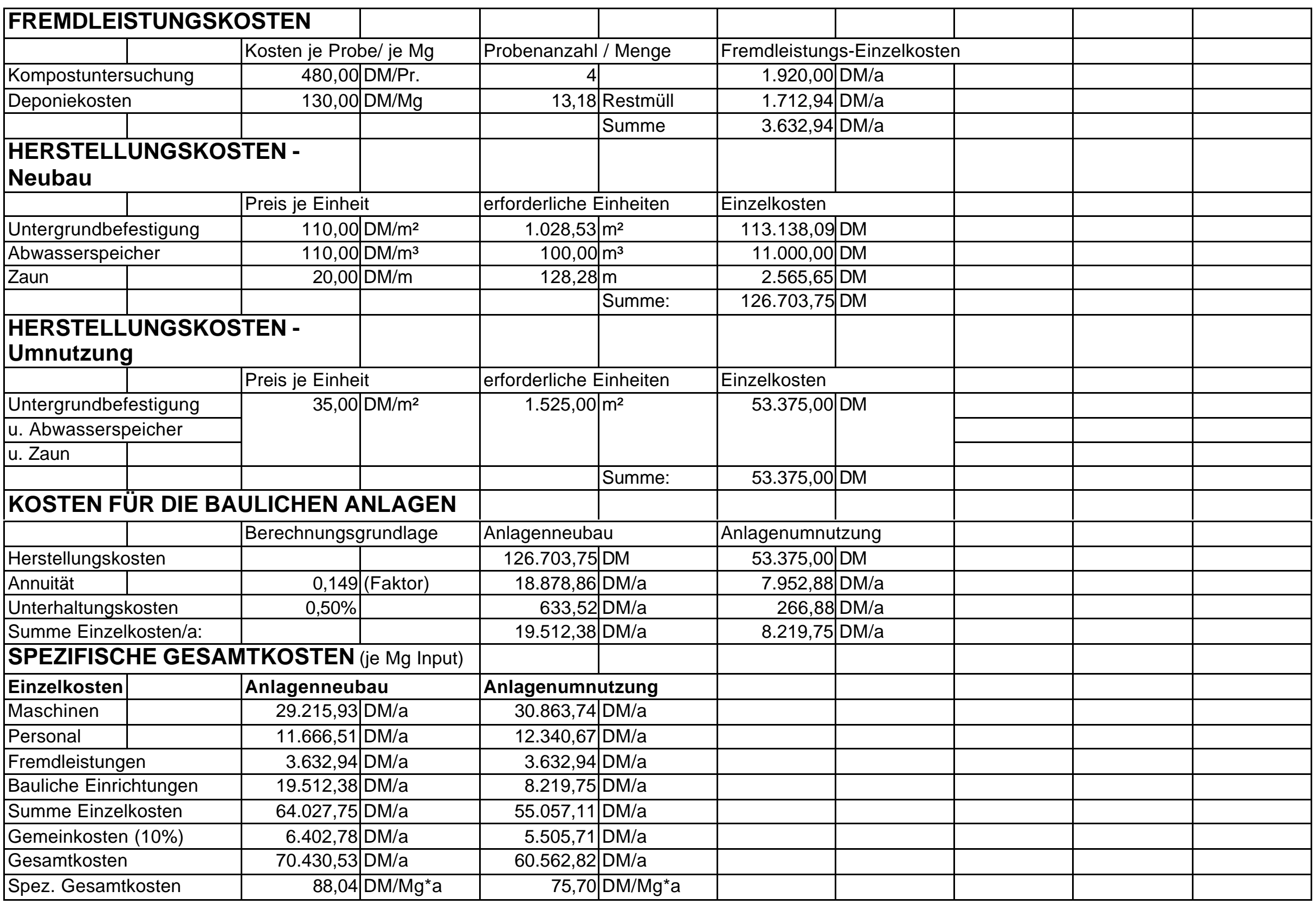


Kostenvariante B4

\section{MATERIAL}

Jahresinputmenge

Zusammensetzung

\begin{tabular}{|l|l|}
\hline & \\
\hline Dichte & \\
\hline & \\
\hline & \\
\hline & \\
\hline Volumen & \\
\hline & \\
\hline & \\
\hline & \\
\hline &
\end{tabular}

Gewichtsanteil

\section{Rottedauer}

durchschnittliches

Monatsaufkommen

maximaler Monatsanfall

\begin{tabular}{|l}
\hline \\
TS-Gehalt (Fertigkompost)
\end{tabular}

Mietenhöhe

Mietenbasisbreite

\section{ANLAGENDIMENSIONIERUNG}

\section{Anlagenteil}

Anlieferungsfläche

Rottefläche

Rangierfläche

Zwischenlager für

Strukturmaterial

Kompostlager

Anlagenfläche (gesamt)

zu verwertende

Abwassermenge

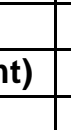

(3)

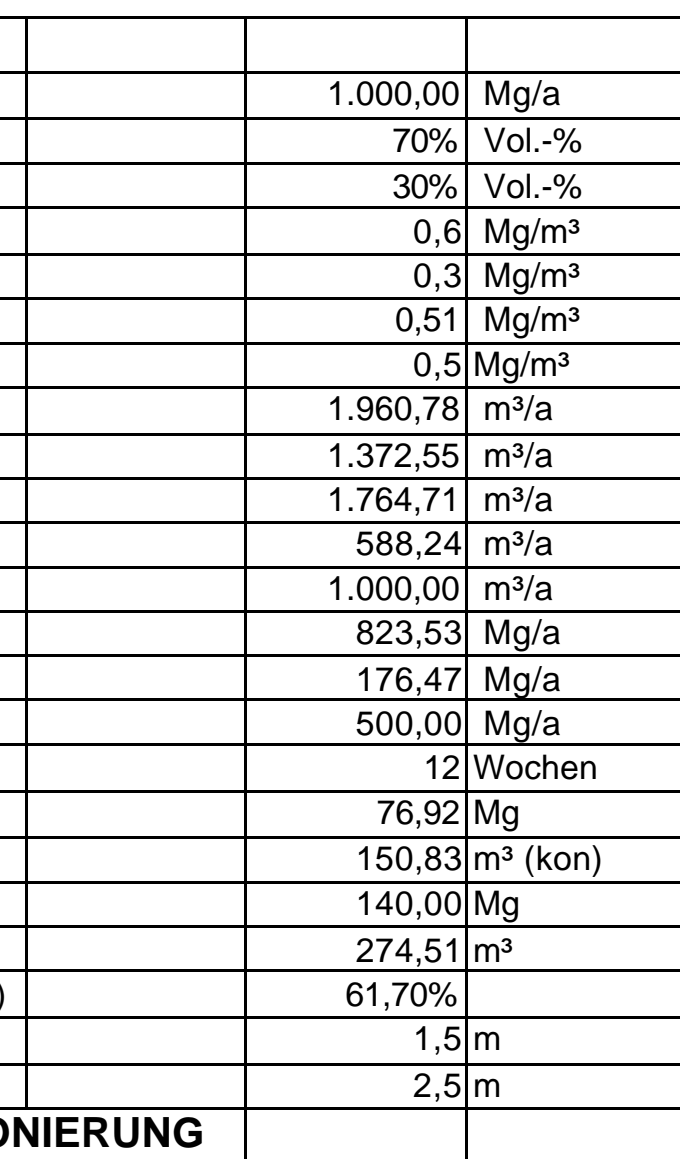

Berechnungsgrundlage

5\% vom Input in $\mathrm{Mg} / \mathrm{a}$, ausgedrückt in $\mathrm{m}^{2}$

$1,33 \mathrm{~m}^{2} / \mathrm{m}^{3}$ Rottematerial bei max.M.-Anfall

$40 \%$ der Rottefläche

der Rottefläche

$10 \%$ der Rottefläche

$0,2 \mathrm{~m}^{3} / \mathrm{m}^{2 \star} \mathrm{a}$

Grüngut

\begin{tabular}{|c|c|c|}
\hline ax.M.-Anfall & 772,29 & $\mathrm{~m}^{2}$ \\
\hline & 308,92 & $\mathrm{~m}^{2}$ \\
\hline & & $\mathrm{m}^{2}$ \\
\hline & 77,23 & \\
\hline & 77,23 & $\mathrm{~m}^{2}$ \\
\hline & 1285,66 & $\mathrm{~m}^{2}$ \\
\hline & & \\
\hline & 257,13 & $\mathrm{~m}^{3} / \mathrm{a}$ \\
\hline
\end{tabular}

Bioabfälle aus Haushalten

gehäckseltes Grüngut

Bioabfälle aus Haushalten

gehäckseltes Grüngut

konditioniertes Material

Fertigkompost

konditioniertes Material

Bioabfälle aus Haushalten

angeliefertes Grüngut

gehäckseltes Grüngut

Fertigkompost

Bioabfälle aus Haushalten

Fertigkompost

\begin{tabular}{l|l}
\hline & \\
\hline & Rottematerial eines
\end{tabular}

entspr. 14\% vom Input/a

Mietenquerschnitt

\begin{tabular}{|r|l}
\hline $1,875 \mathrm{~m}^{2}$ & \\
\hline & \\
\end{tabular}

Anlagenneubau

Anlagenumnutzung

$400,00 \mathrm{~m}^{2}$

\begin{tabular}{|r|l|l|}
\hline & $\mathrm{m}^{2}$ & \\
& 1525,00 & \multicolumn{2}{|l|}{$\mathrm{m}^{2}$ (nicht drainiert) } \\
\hline 600,00 & & \\
\hline 400,00 & $\mathrm{~m}^{2}$ & \\
\hline 2325,00 & $\mathrm{~m}^{2}$ & \\
\hline & & \\
\hline 465,00 & $\mathrm{~m}^{3} / \mathrm{a}$ & \\
\hline
\end{tabular}




\begin{tabular}{|c|c|c|c|c|c|c|c|c|c|c|}
\hline \multicolumn{11}{|l|}{ ZEITEN } \\
\hline \multicolumn{3}{|l|}{ Arbeitsgang } & \multicolumn{2}{|c|}{ eingesetzte Maschinen } & \multicolumn{2}{|c|}{ Zeitbedarf/Einheit } & \multicolumn{2}{|c|}{ geleistete Einheiten } & \multicolumn{2}{|c|}{ Zeitbedarf/Jahr } \\
\hline \multicolumn{3}{|c|}{ Materialannahme } & & & 4,000 & h/Woche & 52,000 & Wochen/a & 208,000 & $h / a$ \\
\hline \multicolumn{3}{|c|}{ Manuelle Störstoffauslese } & & & 1,000 & $h / 100 m^{3}(\operatorname{In})$ & $3.137,255$ & $\mathrm{~m}^{3} / \mathrm{a}$ & 31,373 & $\mathrm{~h} / \mathrm{a}$ \\
\hline \multicolumn{3}{|c|}{ Zerkleinerung von Strukturmaterial } & TL, SZ, Schr. & & 1,000 & $h / 50 m^{3}(\ln )$ & $1.764,706$ & $\mathrm{~m}^{3} / \mathrm{a}$ & 35,294 & $h / a$ \\
\hline \multicolumn{3}{|c|}{ Aufsetzen einer Matte aus Strukturmat. } & TL, AS & & 0,300 & $\mathrm{~h} / 100 \mathrm{~m}^{3}$ (kon) & $1.960,784$ & $\mathrm{~m}^{3} / \mathrm{a}$ & 5,882 & $h / a$ \\
\hline \multicolumn{3}{|c|}{ Aufsetzen der Dreiecksmieten } & TL, AS & & 1,000 & $\mathrm{~h} / 20 \mathrm{~m}^{3}$ (kon) & $1.960,784$ & $\mathrm{~m}^{3} / \mathrm{a}$ & 98,039 & $\mathrm{~h} / \mathrm{a}$ \\
\hline \multicolumn{3}{|c|}{ Umsetzen der Dreiecksmieten } & Schl., MU & & 0,005 & $\mathrm{~h} / \mathrm{m}$ (Mietenl.) & $8.826,144$ & $\mathrm{~m} / \mathrm{a}$ & 44,131 & $\mathrm{~h} / \mathrm{a}$ \\
\hline \multicolumn{3}{|c|}{ Reinigung der Annahmefläche } & TL, AS & & 0,500 & $h / 150 m^{3}(\ln )$ & $3.137,255$ & $\mathrm{~m}^{3} / \mathrm{a}$ & 10,458 & $\mathrm{~h} / \mathrm{a}$ \\
\hline \multicolumn{3}{|l|}{ Sieben } & TL, AS, Sieb & & 1,000 & $\mathrm{~h} / 20 \mathrm{~m}^{3}(\mathrm{kom})$ & $1.000,000$ & $\mathrm{~m}^{3} / \mathrm{a}$ & 50,000 & $\mathrm{~h} / \mathrm{a}$ \\
\hline \multicolumn{3}{|c|}{ Abw.-Ausbringung bei Neubau } & Schl.,PT & & 1,000 & $\mathrm{~h} / 10 \mathrm{~m}^{3}(\mathrm{Abw})$ & 257,132 & $\mathrm{~m}^{3} / \mathrm{a}$ & 25,713 & $\mathrm{~h} / \mathrm{a}$ \\
\hline \multicolumn{3}{|c|}{ Abw.-Ausbringung bei Umnutzung } & Schl., PT & & 1,000 & $\mathrm{~h} / 10 \mathrm{~m}^{3}(\mathrm{Abw})$ & 465,000 & $\mathrm{~m}^{3} / \mathrm{a}$ & 46,500 & $h / a$ \\
\hline \multicolumn{11}{|c|}{ Abkürzungen für die eingesetzten Maschinen: } \\
\hline \multicolumn{2}{|c|}{ TL - Teleskoplader } & & \multicolumn{2}{|c|}{ Schl. - Schlepper } & & & & & & \\
\hline \multicolumn{2}{|c|}{\begin{tabular}{|l} 
MU- Mietenumsetzer \\
\end{tabular}} & & Schr. - Schred & dder & & & & & & \\
\hline \multicolumn{2}{|c|}{ SZ - Silozange } & & PT - Pumpenta & tankwagen & & & & & & \\
\hline \multicolumn{11}{|c|}{ AS - Anbauschaufel } \\
\hline \multicolumn{11}{|c|}{ MASCHINENKOSTEN } \\
\hline \multicolumn{2}{|c|}{ Maschine / Gerät } & Fixkosten & & \multicolumn{2}{|c|}{ Variable Kosten } & Einheiten/a & & \multicolumn{2}{|c|}{ Maschinen-Einzelkosten } & \\
\hline Traktor (Neub & au) & 0,00 & $\mathrm{DM} / \mathrm{a}$ & 33,55 & $\mathrm{DM} / \mathrm{h}$ & 69,84 & $\mathrm{~h} / \mathrm{a}$ & $2.343,26$ & $\mathrm{DM} / \mathrm{a}$ & \\
\hline Traktor (Umnı & itzung) & 0,00 & $\mathrm{DM} / \mathrm{a}$ & 33,55 & $\mathrm{DM} / \mathrm{h}$ & 90,63 & $\mathrm{~h} / \mathrm{a}$ & $3.040,66$ & $\mathrm{DM} / \mathrm{a}$ & \\
\hline Teleskoplader & & 0,00 & $\mathrm{DM} / \mathrm{a}$ & 66,50 & $\mathrm{DM} / \mathrm{h}$ & 199,67 & $\mathrm{~h} / \mathrm{a}$ & $13.278,27$ & $\mathrm{DM} / \mathrm{a}$ & \\
\hline Schredder & & 0,00 & $\mathrm{DM} / \mathrm{a}$ & 7,50 & $\mathrm{DM} / \mathrm{m}^{3}$ (Out) & 588,24 & $\mathrm{~m}^{3} / \mathrm{a}$ & $4.411,76$ & $\mathrm{DM} / \mathrm{a}$ & \\
\hline Trommelsieb & & 0,00 & $\mathrm{DM} / \mathrm{a}$ & 5,00 & $\mathrm{DM} / \mathrm{m}^{3}(\mathrm{Kom})$ & $1.000,00$ & $\mathrm{~m}^{3} / \mathrm{a}$ & $5.000,00$ & $\mathrm{DM} / \mathrm{a}$ & \\
\hline PumpenTW (I & Veubau) & 0,00 & $\mathrm{DM} / \mathrm{a}$ & 30,00 & $\mathrm{DM} / \mathrm{h}$ & 25,71 & $\mathrm{~h} / \mathrm{a}$ & 771,40 & $\mathrm{DM} / \mathrm{a}$ & \\
\hline PumpenTW (L & Jmnutzung) & 0,00 & $D M / a$ & 30,00 & $D M / h$ & 46,50 & $h / a$ & $1.395,00$ & $\mathrm{DM} / \mathrm{a}$ & \\
\hline Silozange & & $1.120,00$ & DM/a & 0,30 & $\mathrm{DM} / \mathrm{m}^{3}$ & $1.764,71$ & $\mathrm{~m}^{3} / \mathrm{a}$ & $1.649,41$ & $\mathrm{DM} / \mathrm{a}$ & \\
\hline Anbauschaufe & & 506,00 & $\mathrm{DM} / \mathrm{a}$ & 0,30 & $\mathrm{DM} / \mathrm{m}^{3}$ & $8.058,82$ & $m^{3} / a$ & $2.923,65$ & $\mathrm{DM} / \mathrm{a}$ & \\
\hline Mietenumsetz & & $3.600,00$ & $\mathrm{DM} / \mathrm{a}$ & 28,00 & $\mathrm{DM} / \mathrm{h}$ & 44,13 & $\mathrm{~h} / \mathrm{a}$ & $4.835,66$ & $\mathrm{DM} / \mathrm{a}$ & \\
\hline & & & & & & Summe (Neuk & bau) & $35.213,41$ & $\mathrm{DM} / \mathrm{a}$ & \\
\hline & & & & & & Summe (Umn & hutzung) & $36.534,41$ & $\mathrm{DM} / \mathrm{a}$ & \\
\hline PERSONA & LOSTEN & & & & & & & & & \\
\hline & Std.-Lohn inkl & I.Lohn-NK & Arbeitsstd. pro & o Jahr & Personal-Einz & zelkosten & & & & \\
\hline Neubau & 26,00 & $D M / h$ & 508,89 & $\mathrm{~h} / \mathrm{a}$ & $13.231,13$ & $D M / a$ & & & & \\
\hline Umnutzung & 26,00 & $D M / h$ & 529,68 & $h / a$ & $13.771,59$ & DM/a & & & & \\
\hline
\end{tabular}




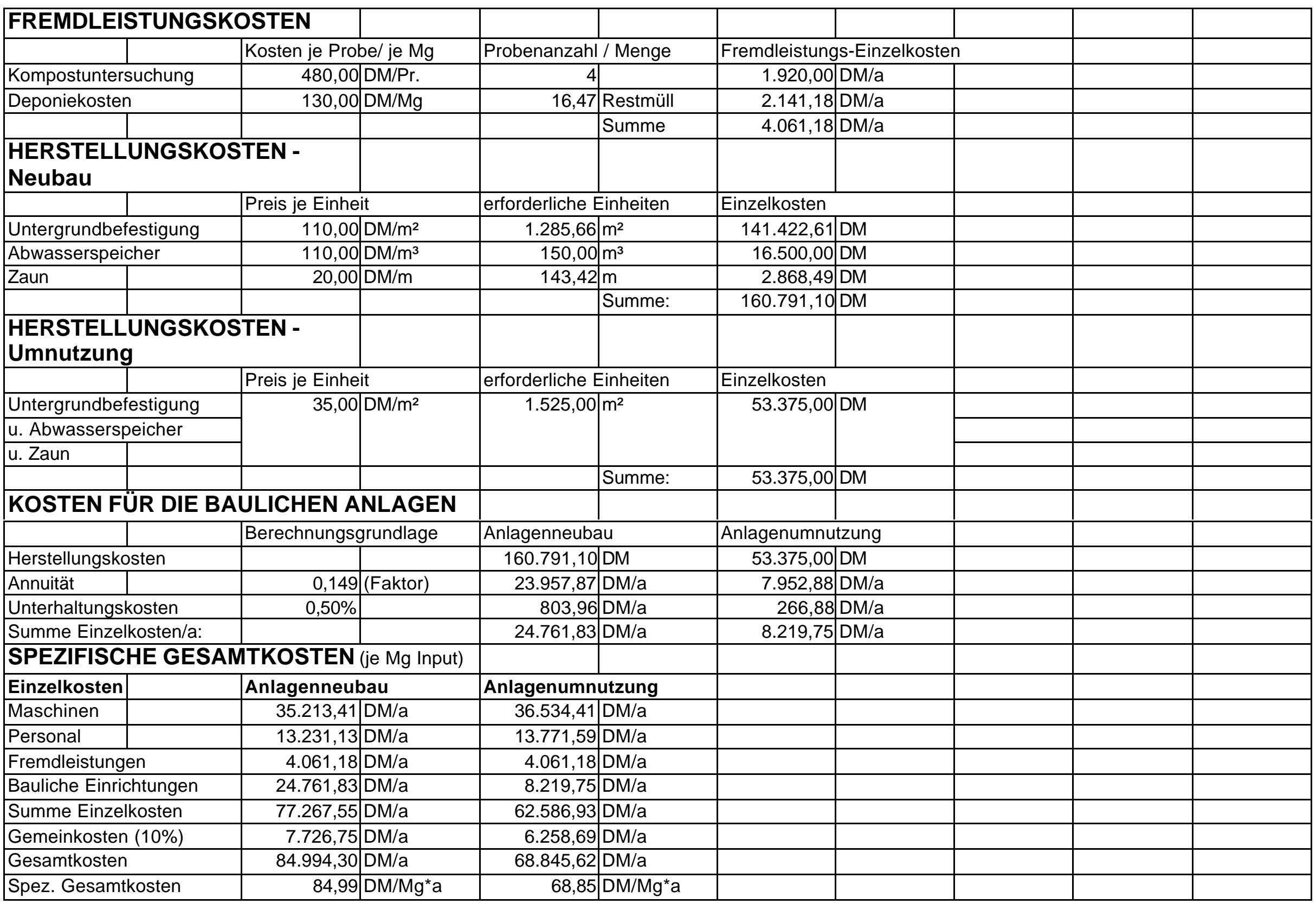


Kostenvariante B5

\section{MATERIAL}

Jahresinputmenge

Zusammensetzung

\begin{tabular}{|l|l|}
\hline & \\
\hline Dichte & \\
\hline & \\
\hline & \\
\hline & \\
\hline & \\
\hline & \\
\hline & \\
\hline & \\
\hline &
\end{tabular}

Gewichtsanteil

\section{Rottedauer}

durchschnittliches

Monatsaufkommen

maximaler Monatsanfall

\begin{tabular}{|l}
\hline \\
TS-Gehalt (Fertigkompost)
\end{tabular}

Mietenhöhe

Mietenbasisbreite

\section{ANLAGENDIMENSIONIERUNG}

\section{Anlagenteil}

Anlieferungsfläche

Rottefläche

Rangierfläche

Zwischenlager für

Strukturmaterial

Kompostlager

Anlagenfläche (gesamt)

zu verwertende

Abwassermenge

t)

$\mid$

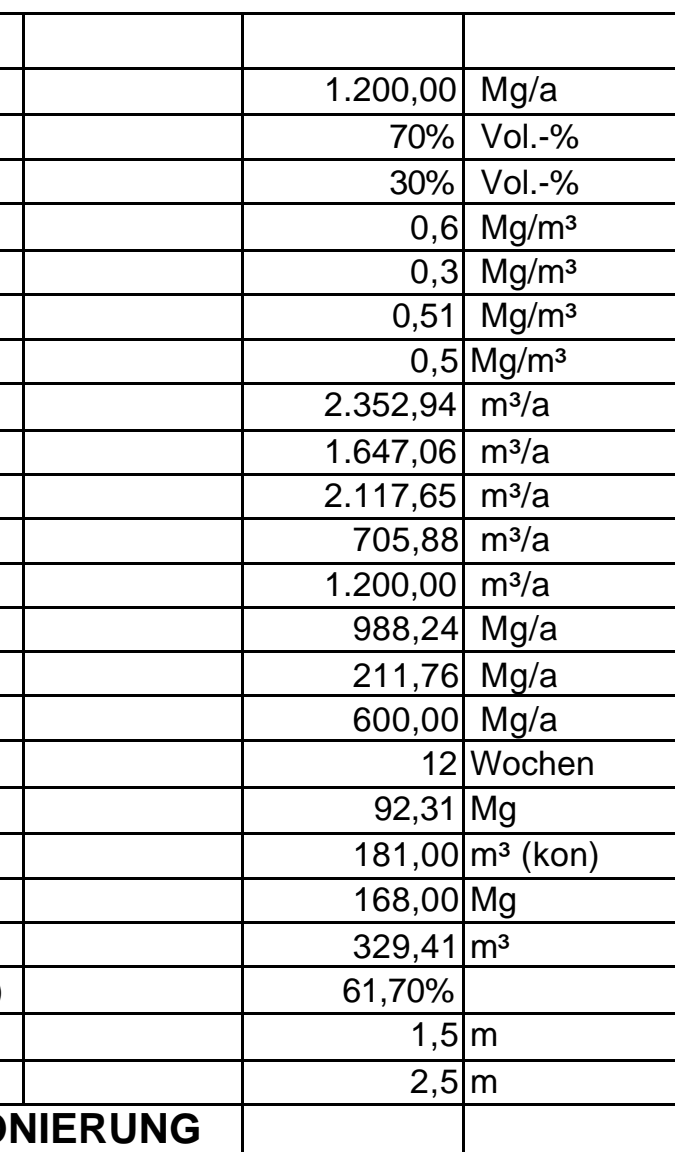

Berechnungsgrundlage

5\% vom Input in Mg/a, ausgedrückt in $\mathrm{m}^{2}$

$1,33 \mathrm{~m}^{2} / \mathrm{m}^{3}$ Rottematerial bei max.M.-Anfall

$40 \%$ der Rottefläche

der Rottefläche

$10 \%$ der Rottefläche

$0,2 \mathrm{~m}^{3} / \mathrm{m}^{2 \star} \mathrm{a}$

Grüngut

\begin{tabular}{|c|c|c|}
\hline ax.M.-Anfall & 926,75 & $\mathrm{~m}^{2}$ \\
\hline & 370,70 & $\mathrm{~m}^{2}$ \\
\hline & & $\mathrm{m}^{2}$ \\
\hline & 92,67 & \\
\hline & 92,67 & $\mathrm{~m}^{2}$ \\
\hline & 1542,79 & $\mathrm{~m}^{2}$ \\
\hline & & \\
\hline & 308,56 & $\mathrm{~m}^{3} / \mathrm{a}$ \\
\hline
\end{tabular}

Bioabfälle aus Haushalten

gehäckseltes Grüngut

Bioabfälle aus Haushalten

gehäckseltes Grüngut

konditioniertes Material

Fertigkompost

konditioniertes Material

Bioabfälle aus Haushalten

angeliefertes Grüngut

gehäckseltes Grüngut

Fertigkompost

Bioabfälle aus Haushalten

Fertigkompost

\begin{tabular}{l|l}
\hline & \\
\hline & Rottematerial eines \\
\hline & Durchlaufs in der Anlage
\end{tabular}

entspr. 14\% vom Input/a

Mietenquerschnitt

\begin{tabular}{|r|l|l}
\hline 1,875 & $\mathrm{~m}^{2}$ & \\
& &
\end{tabular}

Anlagenneubau

Anlagenumnutzung

\begin{tabular}{|c|c|c|}
\hline 400,00 & $\mathrm{~m}^{2}$ & \\
\hline & $\mathrm{m}^{2}$ & \\
\hline 1525,00 & & \\
\hline & $m^{2}(r$ & ert) \\
\hline 600,00 & & \\
\hline 400,00 & $\mathrm{~m}^{2}$ & \\
\hline 2325,00 & $\mathrm{~m}^{2}$ & \\
\hline & & \\
\hline 465,00 & $\mathrm{~m}^{3} / \mathrm{a}$ & \\
\hline
\end{tabular}




\begin{tabular}{|c|c|c|c|c|c|c|c|c|c|c|}
\hline \multicolumn{11}{|l|}{ ZEITEN } \\
\hline \multicolumn{3}{|l|}{ Arbeitsgang } & \multicolumn{2}{|c|}{ eingesetzte Maschinen } & \multicolumn{2}{|c|}{ Zeitbedarf/Einheit } & \multicolumn{2}{|c|}{ geleistete Einheiten } & \multicolumn{2}{|c|}{ Zeitbedarf/Jahr } \\
\hline \multicolumn{3}{|c|}{ Materialannahme } & & & 4,000 & h/Woche & 52,000 & Wochen/a & 208,000 & $h / a$ \\
\hline \multicolumn{3}{|c|}{ Manuelle Störstoffauslese } & & & 1,000 & $h / 100 m^{3}(\operatorname{In})$ & $3.764,706$ & $\mathrm{~m}^{3} / \mathrm{a}$ & 37,647 & $\mathrm{~h} / \mathrm{a}$ \\
\hline \multicolumn{3}{|c|}{ Zerkleinerung von Strukturmaterial } & TL, SZ, Schr. & & 1,000 & $h / 50 m^{3}(\ln )$ & $2.117,647$ & $\mathrm{~m}^{3} / \mathrm{a}$ & 42,353 & $h / a$ \\
\hline \multicolumn{3}{|c|}{ Aufsetzen einer Matte aus Strukturmat. } & TL, AS & & 0,300 & $\mathrm{~h} / 100 \mathrm{~m}^{3}$ (kon) & $2.352,941$ & $\mathrm{~m}^{3} / \mathrm{a}$ & 7,059 & $h / a$ \\
\hline \multicolumn{3}{|c|}{ Aufsetzen der Dreiecksmieten } & TL, AS & & 1,000 & $\mathrm{~h} / 20 \mathrm{~m}^{3}$ (kon) & $2.352,941$ & $\mathrm{~m}^{3} / \mathrm{a}$ & 117,647 & $\mathrm{~h} / \mathrm{a}$ \\
\hline \multicolumn{3}{|c|}{ Umsetzen der Dreiecksmieten } & Schl., MU & & 0,005 & $\mathrm{~h} / \mathrm{m}$ (Mietenl.) & $10.591,373$ & $\mathrm{~m} / \mathrm{a}$ & 52,957 & $\mathrm{~h} / \mathrm{a}$ \\
\hline \multicolumn{3}{|c|}{ Reinigung der Annahmefläche } & TL, AS & & 0,500 & $\mathrm{~h} / 150 \mathrm{~m}^{3}(\ln )$ & $3.764,706$ & $\mathrm{~m}^{3} / \mathrm{a}$ & 12,549 & $\mathrm{~h} / \mathrm{a}$ \\
\hline \multicolumn{3}{|l|}{ Sieben } & TL, AS, Sieb & & 1,000 & $\mathrm{~h} / 20 \mathrm{~m}^{3}(\mathrm{kom})$ & $1.200,000$ & $\mathrm{~m}^{3} / \mathrm{a}$ & 60,000 & $\mathrm{~h} / \mathrm{a}$ \\
\hline \multicolumn{3}{|c|}{ Abw.-Ausbringung bei Neubau } & Schl.,PT & & 1,000 & $\mathrm{~h} / 10 \mathrm{~m}^{3}(\mathrm{Abw})$ & 308,558 & $\mathrm{~m}^{3} / \mathrm{a}$ & 30,856 & $h / a$ \\
\hline \multicolumn{3}{|c|}{ Abw.-Ausbringung bei Umnutzung } & Schl., PT & & 1,000 & $\mathrm{~h} / 10 \mathrm{~m}^{3}(\mathrm{Abw})$ & 465,000 & $\mathrm{~m}^{3} / \mathrm{a}$ & 46,500 & $h / a$ \\
\hline \multicolumn{11}{|c|}{ Abkürzungen für die eingesetzten Maschinen: } \\
\hline \multicolumn{2}{|c|}{ TL - Teleskoplader } & & \multicolumn{2}{|c|}{ Schl. - Schlepper } & & & & & & \\
\hline \multicolumn{2}{|c|}{\begin{tabular}{|l} 
MU- Mietenumsetzer \\
\end{tabular}} & & Schr. - Schred & dder & & & & & & \\
\hline \multicolumn{2}{|c|}{ SZ - Silozange } & & PT - Pumpenta & tankwagen & & & & & & \\
\hline \multicolumn{11}{|c|}{ AS - Anbauschaufel } \\
\hline \multicolumn{11}{|c|}{ MASCHINENKOSTEN } \\
\hline \multicolumn{2}{|c|}{ Maschine / Gerät } & Fixkosten & & \multicolumn{2}{|c|}{ Variable Kosten } & Einheiten/a & & \multicolumn{2}{|c|}{ Maschinen-Einzelkosten } & \\
\hline Traktor (Neub & au) & 0,00 & $\mathrm{DM} / \mathrm{a}$ & 33,55 & $\mathrm{DM} / \mathrm{h}$ & 83,81 & $\mathrm{~h} / \mathrm{a}$ & $2.811,92$ & $\mathrm{DM} / \mathrm{a}$ & \\
\hline Traktor (Umnı & itzung) & 0,00 & $\mathrm{DM} / \mathrm{a}$ & 33,55 & $\mathrm{DM} / \mathrm{h}$ & 99,46 & $\mathrm{~h} / \mathrm{a}$ & $3.336,78$ & $\mathrm{DM} / \mathrm{a}$ & \\
\hline Teleskoplader & & 0,00 & $\mathrm{DM} / \mathrm{a}$ & 66,50 & $\mathrm{DM} / \mathrm{h}$ & 239,61 & $\mathrm{~h} / \mathrm{a}$ & $15.933,92$ & $\mathrm{DM} / \mathrm{a}$ & \\
\hline Schredder & & 0,00 & $\mathrm{DM} / \mathrm{a}$ & 7,50 & $\mathrm{DM} / \mathrm{m}^{3}$ (Out) & 705,88 & $\mathrm{~m}^{3} / \mathrm{a}$ & $5.294,12$ & $\mathrm{DM} / \mathrm{a}$ & \\
\hline Trommelsieb & & 0,00 & $\mathrm{DM} / \mathrm{a}$ & 5,00 & $\mathrm{DM} / \mathrm{m}^{3}(\mathrm{Kom})$ & $1.200,00$ & $\mathrm{~m}^{3} / \mathrm{a}$ & $6.000,00$ & $\mathrm{DM} / \mathrm{a}$ & \\
\hline PumpenTW (I & Veubau) & 0,00 & $\mathrm{DM} / \mathrm{a}$ & 30,00 & $\mathrm{DM} / \mathrm{h}$ & 30,86 & $\mathrm{~h} / \mathrm{a}$ & 925,68 & $\mathrm{DM} / \mathrm{a}$ & \\
\hline PumpenTW (L & Jmnutzung) & 0,00 & $D M / a$ & 30,00 & $D M / h$ & 46,50 & $\mathrm{~h} / \mathrm{a}$ & $1.395,00$ & $\mathrm{DM} / \mathrm{a}$ & \\
\hline Silozange & & $1.120,00$ & DM/a & 0,30 & $\mathrm{DM} / \mathrm{m}^{3}$ & $2.117,65$ & $\mathrm{~m}^{3} / \mathrm{a}$ & $1.755,29$ & $\mathrm{DM} / \mathrm{a}$ & \\
\hline Anbauschaufe & & 506,00 & $\mathrm{DM} / \mathrm{a}$ & 0,30 & $\mathrm{DM} / \mathrm{m}^{3}$ & $9.670,59$ & $\mathrm{~m}^{3} / \mathrm{a}$ & $3.407,18$ & $\mathrm{DM} / \mathrm{a}$ & \\
\hline Mietenumsetz & & $3.600,00$ & $\mathrm{DM} / \mathrm{a}$ & 28,00 & $\mathrm{DM} / \mathrm{h}$ & 52,96 & $h / a$ & $5.082,79$ & $\mathrm{DM} / \mathrm{a}$ & \\
\hline & & & & & & Summe (Neub & bau) & $41.210,89$ & $\mathrm{DM} / \mathrm{a}$ & \\
\hline & & & & & & Summe (Umn & uutzung) & $42.205,08$ & $\mathrm{DM} / \mathrm{a}$ & \\
\hline PERSONAI & LOSTEN & & & & & & & & & \\
\hline & Std.-Lohn inkl & I.Lohn-NK & Arbeitsstd. pro & o Jahr & Personal-Einz & zelkosten & & & & \\
\hline Neubau & 26,00 & $D M / h$ & 569,07 & $\mathrm{~h} / \mathrm{a}$ & $14.795,76$ & $D M / a$ & & & & \\
\hline Umnutzung & 26,00 & $D M / h$ & 584,71 & $\mathrm{~h} / \mathrm{a}$ & $15.202,51$ & $\mathrm{DM} / \mathrm{a}$ & & & & \\
\hline
\end{tabular}




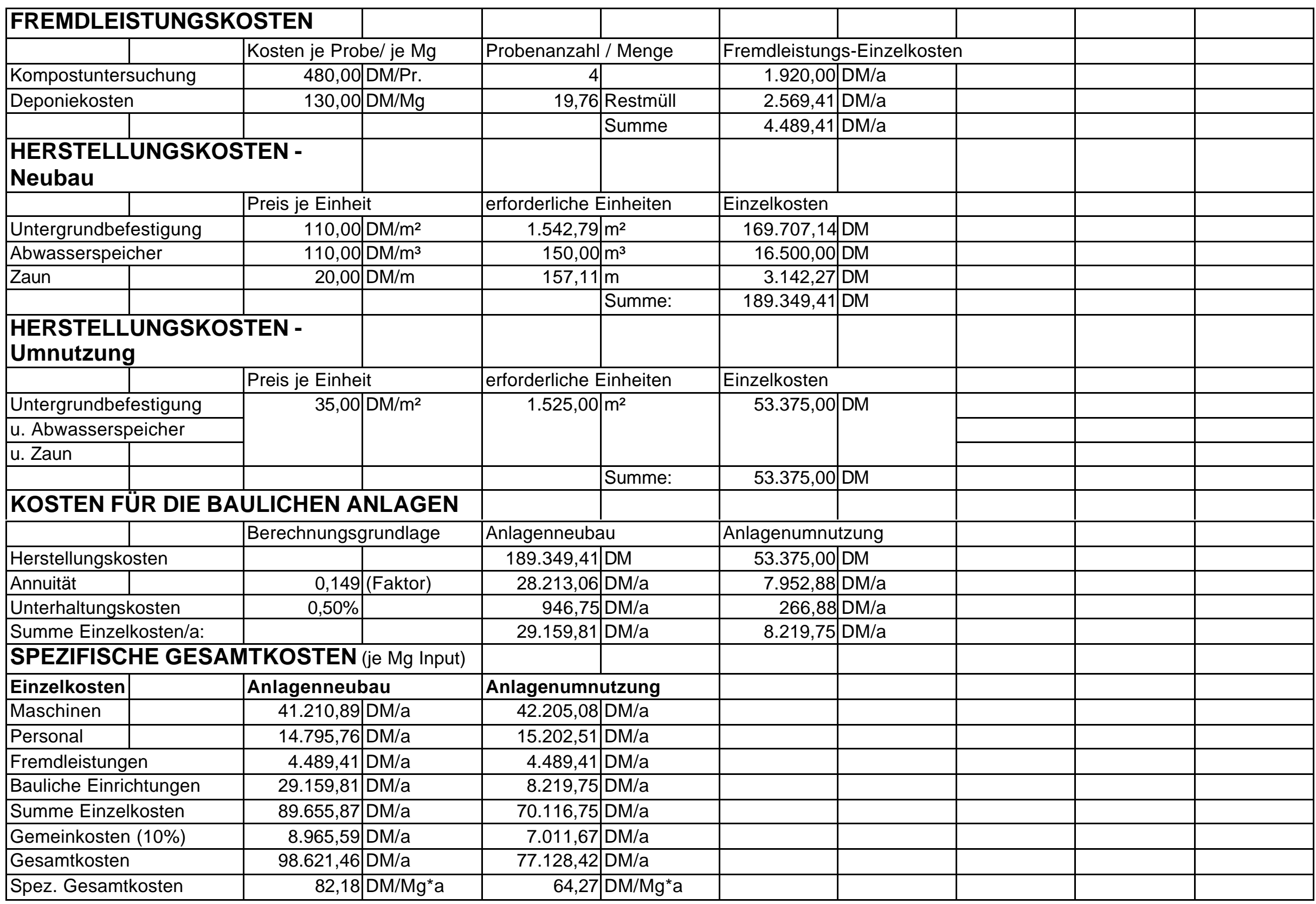


Kostenvariante B6

\section{MATERIAL}

Jahresinputmenge

Zusammensetzung

\begin{tabular}{|l|l|}
\hline & \\
\hline Dichte & \\
\hline & \\
\hline & \\
\hline & \\
\hline Volumen & \\
\hline & \\
\hline & \\
\hline & \\
\hline &
\end{tabular}

Gewichtsanteil

\section{Rottedauer}

durchschnittliches

Monatsaufkommen

maximaler Monatsanfall

\begin{tabular}{|l}
\hline \\
TS-Gehalt (Fertigkompost)
\end{tabular}

Mietenhöhe

Mietenbasisbreite

\section{ANLAGENDIMENSIONIERUNG}

\section{Anlagenteil}

Anlieferungsfläche

Rottefläche

Rangierfläche

Zwischenlager für

Strukturmaterial

Kompostlager

Anlagenfläche (gesamt)

zu verwertende

Abwassermenge

\section{|}

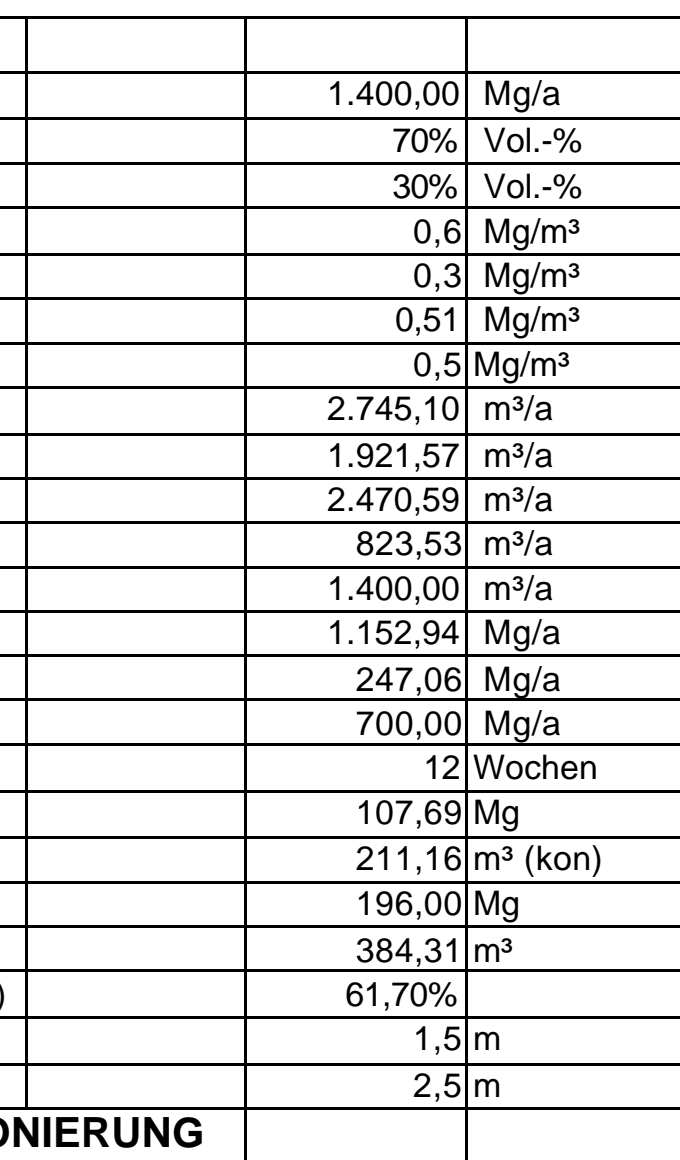

Berechnungsgrundlage

5\% vom Input in $\mathrm{Mg} / \mathrm{a}$, ausgedrückt in $\mathrm{m}^{2}$

$1,33 \mathrm{~m}^{2} / \mathrm{m}^{3}$ Rottematerial bei max.M.-Anfall

$40 \%$ der Rottefläche

der Rottefläche

$10 \%$ der Rottefläche

$+$

$0,2 \mathrm{~m}^{3} / \mathrm{m}^{2 \star} \mathrm{a}$

Grüngut

\begin{tabular}{|c|c|c|}
\hline ax.M.-Anfall & 1081,20 & $\mathrm{~m}^{2}$ \\
\hline & 432,48 & $\mathrm{~m}^{2}$ \\
\hline & & $m^{2}$ \\
\hline & 108,12 & \\
\hline & 108,12 & $\mathrm{~m}^{2}$ \\
\hline & 1799,92 & $\mathrm{~m}^{2}$ \\
\hline & & \\
\hline & 359,98 & $\mathrm{~m}^{3} / \mathrm{a}$ \\
\hline
\end{tabular}

Bioabfälle aus Haushalten

gehäckseltes Grüngut

Bioabfälle aus Haushalten

gehäckseltes Grüngut

konditioniertes Material

Fertigkompost

konditioniertes Material

Bioabfälle aus Haushalten

angeliefertes Grüngut

gehäckseltes Grüngut

Fertigkompost

Bioabfälle aus Haushalten

Fertigkompost

\begin{tabular}{l|l}
\hline & \\
\hline & Rottematerial eines \\
\hline & Durchlaufs in der Anlage
\end{tabular}

entspr. 14\% vom Input/a

Mietenquerschnitt

\begin{tabular}{|r|l}
\hline $1,875 \mathrm{~m}^{2}$ & \\
\hline & \\
\end{tabular}

Anlagenneubau

Anlagenumnutzung

$400,00 \mathrm{~m}^{2}$

\begin{tabular}{|r|l|l|}
\hline 1525,00 & & \\
\cline { 1 - 2 } & \multicolumn{2}{|l|}{$\mathrm{m}^{2}$ (nicht drainiert) } \\
\hline 600,00 & & \\
\hline 400,00 & $\mathrm{~m}^{2}$ & \\
\hline 2325,00 & $\mathrm{~m}^{2}$ & \\
\hline 465,00 & $\mathrm{~m}^{3} / \mathrm{a}$ & \\
\hline
\end{tabular}




\begin{tabular}{|c|c|c|c|c|c|c|c|c|c|c|}
\hline ZEITEN & & & & & & & & & & \\
\hline Arbeitsgang & & & eingesetzte $\mathrm{M}$ & Maschinen & Zeitbedarf/Ei & inheit & geleistete Eir & nheiten & Zeitbedarf/Jal & ahr \\
\hline Materialannah & ime & & & & 4,000 & h/Woche & 52,000 & Wochen/a & 208,000 & $h / a$ \\
\hline Manuelle Stör & stoffauslese & & & & 1,000 & $h / 100 m^{3}(\ln )$ & $4.392,157$ & $\mathrm{~m}^{3} / \mathrm{a}$ & 43,922 & $h / a$ \\
\hline Zerkleinerung & von Strukturm & naterial & TL, SZ, Schr. & & 1,000 & $h / 50 m^{3}(\operatorname{In})$ & $2.470,588$ & $\mathrm{~m}^{3} / \mathrm{a}$ & 49,412 & $h / a$ \\
\hline Aufsetzen ein & er Matte aus S & Strukturmat. & TL, AS & & 0,300 & $\mathrm{~h} / 100 \mathrm{~m}^{3}$ (kon) & $2.745,098$ & $\mathrm{~m}^{3} / \mathrm{a}$ & 8,235 & $h / a$ \\
\hline Aufsetzen der & Dreiecksmiete & & TL, AS & & 1,000 & $\mathrm{~h} / 20 \mathrm{~m}^{3}$ (kon) & $2.745,098$ & $\mathrm{~m}^{3} / \mathrm{a}$ & 137,255 & $h / a$ \\
\hline Umsetzen der & Dreiecksmiete & & Schl., MU & & 0,005 & $\mathrm{~h} / \mathrm{m}$ (Mietenl.) & $12.356,601$ & $\mathrm{~m} / \mathrm{a}$ & 61,783 & $\mathrm{~h} / \mathrm{a}$ \\
\hline Reinigung der & Annahmefläch & & TL, AS & & 0,500 & $\mathrm{~h} / 150 \mathrm{~m}^{3}(\mathrm{In})$ & $4.392,157$ & $\mathrm{~m}^{3} / \mathrm{a}$ & 14,641 & $h / a$ \\
\hline Sieben & & & TL, AS, Sieb & & 1,000 & $\mathrm{~h} / 20 \mathrm{~m}^{3}(\mathrm{kom})$ & $1.400,000$ & $\mathrm{~m}^{3} / \mathrm{a}$ & 70,000 & $h / a$ \\
\hline Abw.-Ausbring & gung bei Neub & & Schl.,PT & & 1,000 & $\mathrm{~h} / 10 \mathrm{~m}^{3}(\mathrm{Abw})$ & 359,985 & $\mathrm{~m}^{3} / \mathrm{a}$ & 35,998 & $h / a$ \\
\hline Abw.-Ausbring & gung bei Umnu & utzung & Schl., PT & & 1,000 & $\mathrm{~h} / 10 \mathrm{~m}^{3}(\mathrm{Abw})$ & 465,000 & $\mathrm{~m}^{3} / \mathrm{a}$ & 46,500 & $h / a$ \\
\hline Abkürzungen & für die eingese & etzten Maschin & nen: & & & & & & & \\
\hline TL - Teleskop & lader & & Schl. - Schlepp & per & & & & & & \\
\hline MU- Mietenum & nsetzer & & Schr. - Schred & dder & & & & & & \\
\hline SZ - Silozange & & & PT - Pumpenta & tankwagen & & & & & & \\
\hline AS - Anbausc & haufel & & & & & & & & & \\
\hline MASCHINE & ENKOSTEN & & & & & & & & & \\
\hline Maschine / G & erät & Fixkosten & & Variable Kost & ten & Einheiten/a & & Maschinen-Ei & inzelkosten & \\
\hline Traktor (Neub & au) & 0,00 & $\mathrm{DM} / \mathrm{a}$ & 33,55 & $\mathrm{DM} / \mathrm{h}$ & 97,78 & $\mathrm{~h} / \mathrm{a}$ & $3.280,57$ & $\mathrm{DM} / \mathrm{a}$ & \\
\hline Traktor (Umnu & itzung) & 0,00 & $\mathrm{DM} / \mathrm{a}$ & 33,55 & $\mathrm{DM} / \mathrm{h}$ & 108,28 & $\mathrm{~h} / \mathrm{a}$ & $3.632,89$ & $\mathrm{DM} / \mathrm{a}$ & \\
\hline Teleskoplader & & 0,00 & $D M / a$ & 66,50 & $\mathrm{DM} / \mathrm{h}$ & 279,54 & $\mathrm{~h} / \mathrm{a}$ & $18.589,58$ & $\mathrm{DM} / \mathrm{a}$ & \\
\hline Schredder & & 0,00 & DM/a & 7,50 & $\mathrm{DM} / \mathrm{m}^{3}$ (Out) & 823,53 & $\mathrm{~m}^{3} / \mathrm{a}$ & $6.176,47$ & $\mathrm{DM} / \mathrm{a}$ & \\
\hline Trommelsieb & & 0,00 & DM/a & 5,00 & $\mathrm{DM} / \mathrm{m}^{3}(\mathrm{Kom})$ & $1.400,00$ & $\mathrm{~m}^{3} / \mathrm{a}$ & $7.000,00$ & $\mathrm{DM} / \mathrm{a}$ & \\
\hline PumpenTW ( & Veubau) & 0,00 & $\mathrm{DM} / \mathrm{a}$ & 30,00 & $\mathrm{DM} / \mathrm{h}$ & 36,00 & $\mathrm{~h} / \mathrm{a}$ & $1.079,95$ & $\mathrm{DM} / \mathrm{a}$ & \\
\hline PumpenTW (L & Jmnutzung) & 0,00 & $D M / a$ & 30,00 & $\mathrm{DM} / \mathrm{h}$ & 46,50 & $\mathrm{~h} / \mathrm{a}$ & $1.395,00$ & $\mathrm{DM} / \mathrm{a}$ & \\
\hline Silozange & & $1.120,00$ & DM/a & 0,30 & $\mathrm{DM} / \mathrm{m}^{3}$ & $2.470,59$ & $\mathrm{~m}^{3} / \mathrm{a}$ & $1.861,18$ & $D M / a$ & \\
\hline Anbauschaufe & & 506,00 & $\mathrm{DM} / \mathrm{a}$ & 0,30 & $\mathrm{DM} / \mathrm{m}^{3}$ & $11.282,35$ & $m^{3} / a$ & $3.890,71$ & $\mathrm{DM} / \mathrm{a}$ & \\
\hline Mietenumsetz & & $3.600,00$ & $\mathrm{DM} / \mathrm{a}$ & 28,00 & $\mathrm{DM} / \mathrm{h}$ & 61,78 & $\mathrm{~h} / \mathrm{a}$ & $5.329,92$ & $\mathrm{DM} / \mathrm{a}$ & \\
\hline & & & & & & Summe (Neub & oau) & $47.208,38$ & $\mathrm{DM} / \mathrm{a}$ & \\
\hline & & & & & & Summe (Umns & utzung) & $47.875,75$ & $\mathrm{DM} / \mathrm{a}$ & \\
\hline PERSONA & LOSTEN & & & & & & & & & \\
\hline & Std.-Lohn inkl & I.Lohn-NK & Arbeitsstd. pro & o Jahr & Personal-Einze & zelkosten & & & & \\
\hline Neubau & 26,00 & $D M / h$ & 629,25 & $\mathrm{~h} / \mathrm{a}$ & $16.360,38$ & $D M / a$ & & & & \\
\hline Umnutzung & 26,00 & $D M / h$ & 639,75 & $\mathrm{~h} / \mathrm{a}$ & $16.633,42$ & $D M / a$ & & & & \\
\hline
\end{tabular}




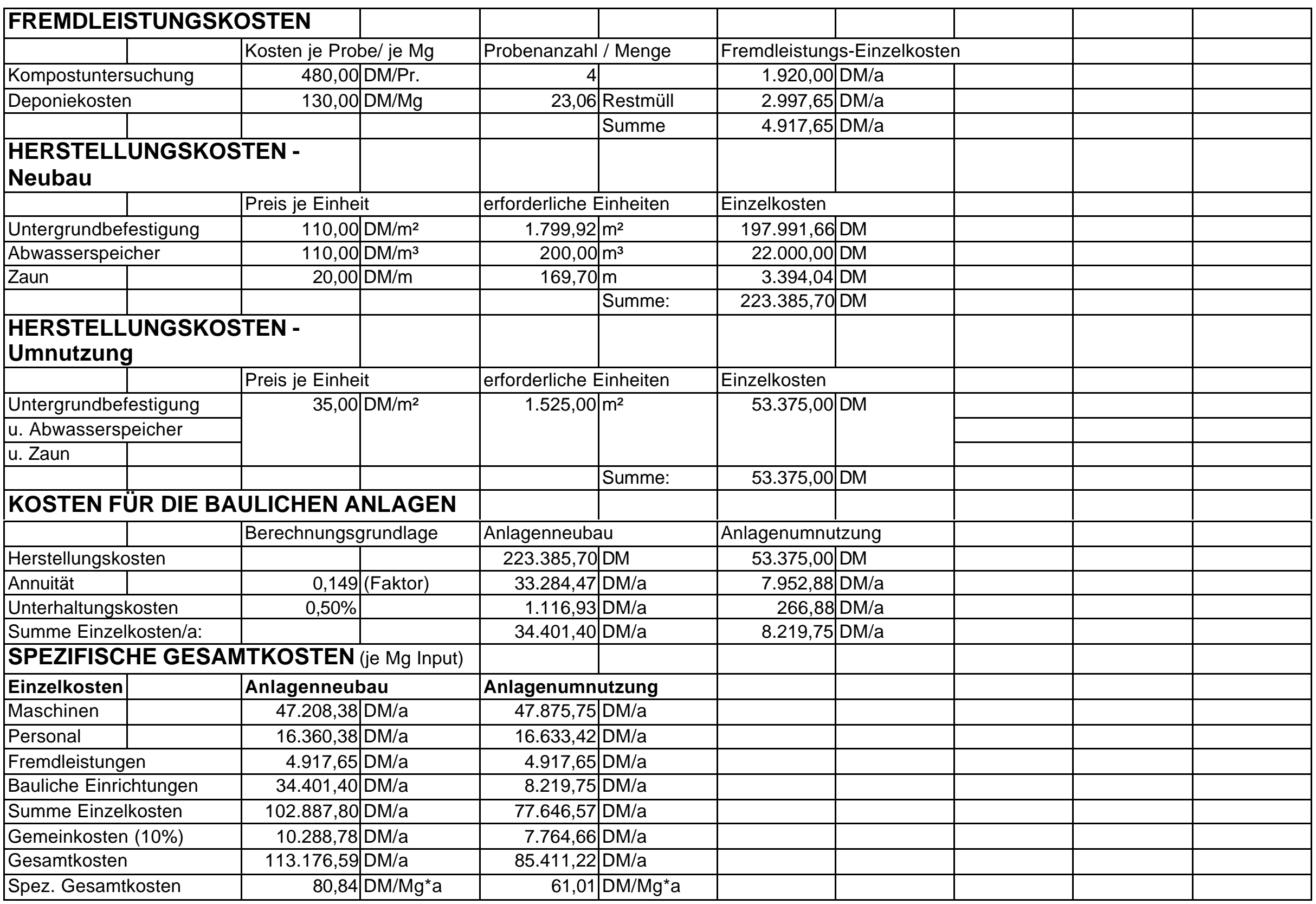


Kostenvariante B7

\section{MATERIAL}

Jahresinputmenge

Zusammensetzung

\begin{tabular}{|l|l|}
\hline & \\
\hline Dichte & \\
\hline & \\
\hline & \\
\hline & \\
\hline & \\
\hline & \\
\hline & \\
\hline & \\
\hline &
\end{tabular}

Gewichtsanteil

\section{Rottedauer}

durchschnittliches

Monatsaufkommen

maximaler Monatsanfall

\begin{tabular}{|l}
\hline \\
TS-Gehalt (Fertigkompost)
\end{tabular}

Mietenhöhe

Mietenbasisbreite

\section{ANLAGENDIMENSIONIERUNG}

\section{Anlagenteil}

Anlieferungsfläche

Rottefläche

Rangierfläche

Zwischenlager für

Strukturmaterial

Kompostlager

Anlagenfläche (gesamt)

zu verwertende

Abwassermenge

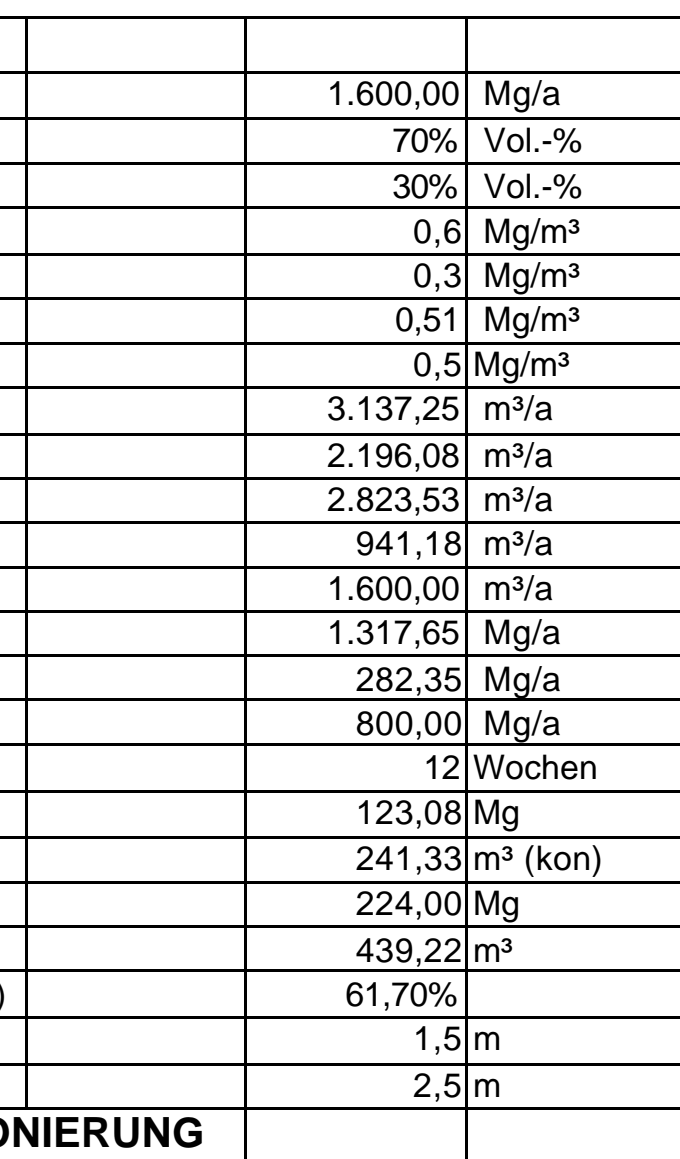

Berechnungsgrundlage

5\% 1 vom Input in Mg/a, ausgedrückt in $\mathrm{m}^{2}$

$1,33 \mathrm{~m}^{2} / \mathrm{m}^{3}$ Rottematerial bei max.M.-Anfall

$40 \%$ der Rottefläche

der Rottefläche $10 \%$

$10 \%$ der Rottefläche

\begin{tabular}{|r|l|l|l|} 
& $10 \%$ & der Rottefläche \\
\hline & & & \\
\hline & 0,2 & $\mathrm{~m}^{3} / \mathrm{m}^{2 *} \mathrm{a}$ & \\
\hline
\end{tabular}

Grüngut
Bioabfälle aus Haushalten

gehäckseltes Grüngut

Bioabfälle aus Haushalten

gehäckseltes Grüngut

konditioniertes Material

Fertigkompost

konditioniertes Material

Bioabfälle aus Haushalten

angeliefertes Grüngut

gehäckseltes Grüngut

Fertigkompost

Bioabfälle aus Haushalten

Fertigkompost

\begin{tabular}{|c|c|c|}
\hline \\
\hline & & \\
\hline & \multicolumn{2}{|c|}{ Rottematerial eines } \\
\hline & \multicolumn{2}{|c|}{ Durchlaufs in der Anlage } \\
\hline \multicolumn{3}{|c|}{ entspr. 14\% vom Input/a } \\
\hline & & \\
\hline & & \\
\hline \multicolumn{3}{|c|}{ Mietenquerschnitt } \\
\hline 1,875 & $m^{2}$ & \\
\hline
\end{tabular}

Anlagenneubau

$80,00 \mathrm{~m}^{2}$

\begin{tabular}{r|r|l|l|} 
& & 1235,66 & $\mathrm{~m}^{2}$ \\
\cline { 2 - 3 } & & 494,26 & $\mathrm{~m}^{2}$ \\
\hline & & 123,57 & $\mathrm{~m}^{2}$ \\
& & 123,57 & $\mathrm{~m}^{2}$ \\
\hline & & 2057,06 & $\mathrm{~m}^{2}$ \\
\hline & & 411,41 & $\mathrm{~m}^{3} / \mathrm{a}$ \\
\hline
\end{tabular}

Anlagenumnutzung

$850,00 \mathrm{~m}^{2}$

\begin{tabular}{|r|l|l|}
\hline & $\mathrm{m}^{2}$ & \\
& \multicolumn{3}{|l|}{850,00} & $\mathrm{~m}^{2}$ & \\
\hline & & \\
\hline 850,00 & $\mathrm{~m}^{2}$ & \\
\hline 4860,00 & $\mathrm{~m}^{2}$ & \\
\hline & & \\
\hline 972,00 & $\mathrm{~m}^{3} / \mathrm{a}$ & \\
\hline
\end{tabular}




\begin{tabular}{|c|c|c|c|c|c|c|c|c|c|c|}
\hline ZEITEN & & & & & & & & & & \\
\hline Arbeitsgang & & & eingesetzte $\mathrm{M}$ & Maschinen & Zeitbedarf/Ei & inheit & geleistete Ein & nheiten & Zeitbedarf/Ja & ahr \\
\hline Materialannah & ime & & & & 4,000 & h/Woche & 52,000 & Wochen/a & 208,000 & $h / a$ \\
\hline Manuelle Stör & stoffauslese & & & & 1,000 & $h / 100 m^{3}(\ln )$ & $5.019,608$ & $\mathrm{~m}^{3} / \mathrm{a}$ & 50,196 & $h / a$ \\
\hline Zerkleinerung & von Strukturm & naterial & TL, SZ, Schr. & & 1,000 & $h / 50 m^{3}(\operatorname{In})$ & $2.823,529$ & $\mathrm{~m}^{3} / \mathrm{a}$ & 56,471 & $h / a$ \\
\hline Aufsetzen ein & er Matte aus S & Strukturmat. & TL, AS & & 0,300 & $\mathrm{~h} / 100 \mathrm{~m}^{3}$ (kon) & $3.137,255$ & $\mathrm{~m}^{3} / \mathrm{a}$ & 9,412 & $h / a$ \\
\hline Aufsetzen der & Dreiecksmiete & & TL, AS & & 1,000 & $\mathrm{~h} / 20 \mathrm{~m}^{3}$ (kon) & $3.137,255$ & $\mathrm{~m}^{3} / \mathrm{a}$ & 156,863 & $\mathrm{~h} / \mathrm{a}$ \\
\hline Umsetzen der & Dreiecksmiete & & Schl., MU & & 0,005 & $\mathrm{~h} / \mathrm{m}$ (Mietenl.) & $14.121,830$ & $\mathrm{~m} / \mathrm{a}$ & 70,609 & $\mathrm{~h} / \mathrm{a}$ \\
\hline Reinigung der & Annahmefläch & & TL, AS & & 0,500 & $h / 150 m^{3}(\ln )$ & $5.019,608$ & $\mathrm{~m}^{3} / \mathrm{a}$ & 16,732 & $h / a$ \\
\hline Sieben & & & TL, AS, Sieb & & 1,000 & $\mathrm{~h} / 20 \mathrm{~m}^{3}(\mathrm{kom})$ & $1.600,000$ & $\mathrm{~m}^{3} / \mathrm{a}$ & 80,000 & $h / a$ \\
\hline Abw.-Ausbring & gung bei Neub & & Schl.,PT & & 1,000 & $\mathrm{~h} / 10 \mathrm{~m}^{3}(\mathrm{Abw})$ & 411,411 & $\mathrm{~m}^{3} / \mathrm{a}$ & 41,141 & $h / a$ \\
\hline Abw.-Ausbring & gung bei Umnu & utzung & Schl., PT & & 1,000 & $\mathrm{~h} / 10 \mathrm{~m}^{3}(\mathrm{Abw})$ & 972,000 & $\mathrm{~m}^{3} / \mathrm{a}$ & 97,200 & $h / a$ \\
\hline Abkürzungen & für die eingese & etzten Maschin & nen: & & & & & & & \\
\hline TL - Teleskop & lader & & Schl. - Schlepp & per & & & & & & \\
\hline MU- Mietenum & nsetzer & & Schr. - Schred & dder & & & & & & \\
\hline SZ - Silozange & & & PT - Pumpenta & tankwagen & & & & & & \\
\hline AS - Anbausc & haufel & & & & & & & & & \\
\hline MASCHINE & ENKOSTEN & & & & & & & & & \\
\hline Maschine / G & erät & Fixkosten & & Variable Kost & ten & Einheiten/a & & Maschinen-Ei & inzelkosten & \\
\hline Traktor (Neub & au) & 0,00 & $\mathrm{DM} / \mathrm{a}$ & 33,55 & $D M / h$ & 111,75 & $\mathrm{~h} / \mathrm{a}$ & $3.749,22$ & $\mathrm{DM} / \mathrm{a}$ & \\
\hline Traktor (Umnu & itzung) & 0,00 & $\mathrm{DM} / \mathrm{a}$ & 33,55 & $D M / h$ & 167,81 & $\mathrm{~h} / \mathrm{a}$ & $5.630,00$ & $\mathrm{DM} / \mathrm{a}$ & \\
\hline Teleskoplader & & 0,00 & $D M / a$ & 66,50 & $\mathrm{DM} / \mathrm{h}$ & 319,48 & $\mathrm{~h} / \mathrm{a}$ & $21.245,23$ & $\mathrm{DM} / \mathrm{a}$ & \\
\hline Schredder & & 0,00 & DM/a & 7,50 & $\mathrm{DM} / \mathrm{m}^{3}$ (Out) & 941,18 & $\mathrm{~m}^{3} / \mathrm{a}$ & $7.058,82$ & $\mathrm{DM} / \mathrm{a}$ & \\
\hline Trommelsieb & & 0,00 & $D M / a$ & 5,00 & $\mathrm{DM} / \mathrm{m}^{3}(\mathrm{Kom})$ & $1.600,00$ & $\mathrm{~m}^{3} / \mathrm{a}$ & $8.000,00$ & $\mathrm{DM} / \mathrm{a}$ & \\
\hline PumpenTW ( & Veubau) & 0,00 & $\mathrm{DM} / \mathrm{a}$ & 30,00 & $\mathrm{DM} / \mathrm{h}$ & 41,14 & $h / a$ & $1.234,23$ & $\mathrm{DM} / \mathrm{a}$ & \\
\hline PumpenTW (L & Jmnutzung) & 0,00 & $D M / a$ & 30,00 & $D M / h$ & 97,20 & $h / a$ & $2.916,00$ & $\mathrm{DM} / \mathrm{a}$ & \\
\hline Silozange & & $1.120,00$ & DM/a & 0,30 & $\mathrm{DM} / \mathrm{m}^{3}$ & $2.823,53$ & $\mathrm{~m}^{3} / \mathrm{a}$ & $1.967,06$ & $\mathrm{DM} / \mathrm{a}$ & \\
\hline Anbauschaufe & & 506,00 & $\mathrm{DM} / \mathrm{a}$ & 0,30 & $\mathrm{DM} / \mathrm{m}^{3}$ & $12.894,12$ & $m^{3} / a$ & $4.374,24$ & $\mathrm{DM} / \mathrm{a}$ & \\
\hline Mietenumsetz & & $3.600,00$ & $\mathrm{DM} / \mathrm{a}$ & 28,00 & $\mathrm{DM} / \mathrm{h}$ & 70,61 & $\mathrm{~h} / \mathrm{a}$ & $5.577,06$ & $\mathrm{DM} / \mathrm{a}$ & \\
\hline & & & & & & Summe (Neuk & bau) & $53.205,86$ & $\mathrm{DM} / \mathrm{a}$ & \\
\hline & & & & & & Summe (Umn & lutzung) & $56.768,40$ & $\mathrm{DM} / \mathrm{a}$ & \\
\hline PERSONA & LOSTEN & & & & & & & & & \\
\hline & Std.-Lohn inkl & I.Lohn-NK & Arbeitsstd. pro & o Jahr & Personal-Einz & zelkosten & & & & \\
\hline Neubau & 26,00 & $D M / h$ & 689,42 & $\mathrm{~h} / \mathrm{a}$ & $17.925,01$ & $\mathrm{DM} / \mathrm{a}$ & & & & \\
\hline Umnutzung & 26,00 & $D M / h$ & 745,48 & $\mathrm{~h} / \mathrm{a}$ & $19.382,54$ & $D M / a$ & & & & \\
\hline
\end{tabular}




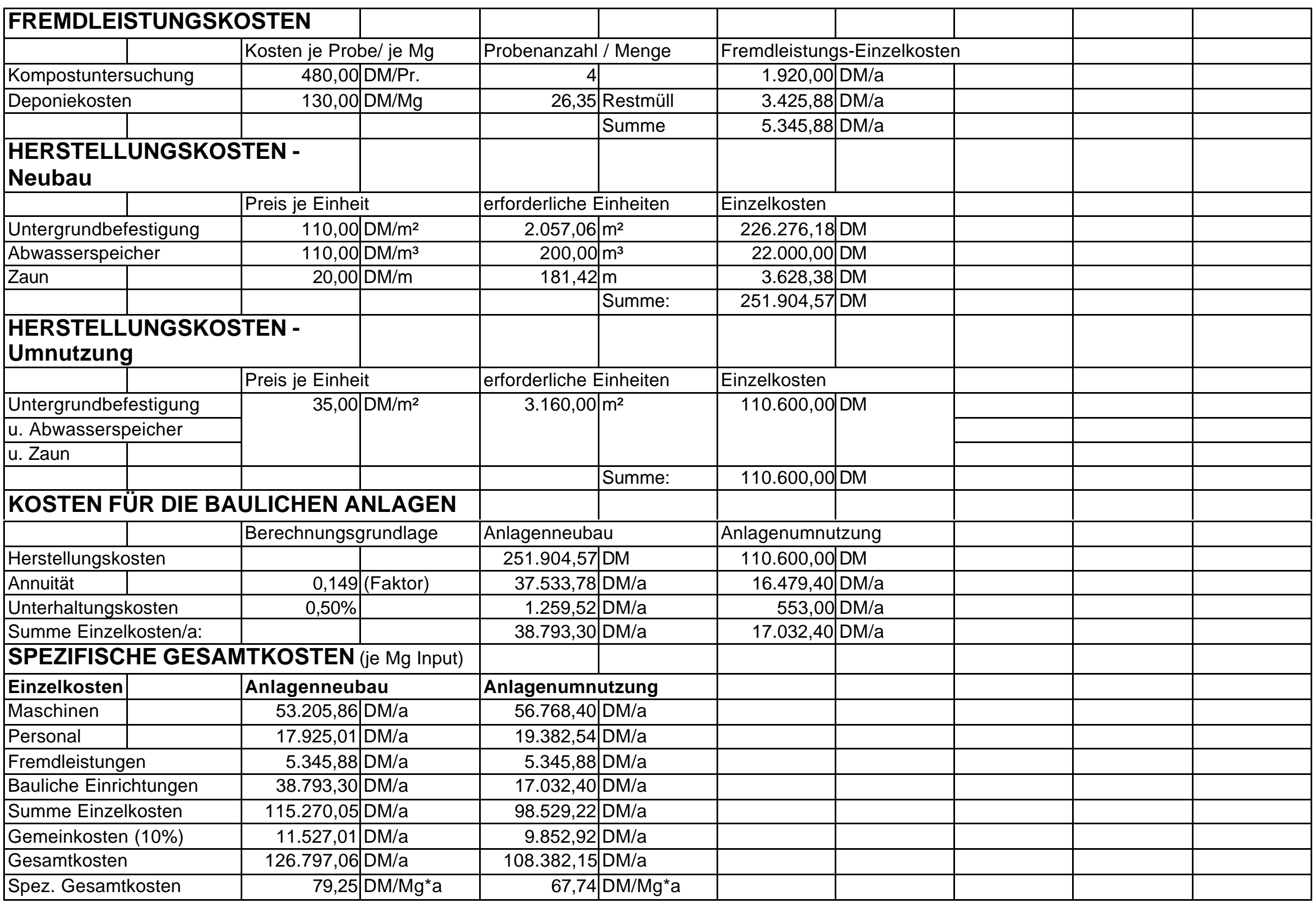


Kostenvariante B8

\section{MATERIAL}

Jahresinputmenge

Zusammensetzung

\begin{tabular}{|l|l|}
\hline & \\
\hline Dichte & \\
\hline & \\
\hline & \\
\hline & \\
\hline Volumen & \\
\hline & \\
\hline & \\
\hline & \\
\hline & \\
\hline
\end{tabular}

Gewichtsanteil

\section{Rottedauer}

durchschnittliches

Monatsaufkommen

maximaler Monatsanfall

\begin{tabular}{|l}
\hline \\
TS-Gehalt (Fertigkompost)
\end{tabular}

Mietenhöhe

Mietenbasisbreite

\section{ANLAGENDIMENSIONIERUNG}

\section{Anlagenteil}

Anlieferungsfläche

Rottefläche

Rangierfläche

Zwischenlager für

Strukturmaterial

Kompostlager

Anlagenfläche (gesamt)

zu verwertende

Abwassermenge

\section{|}

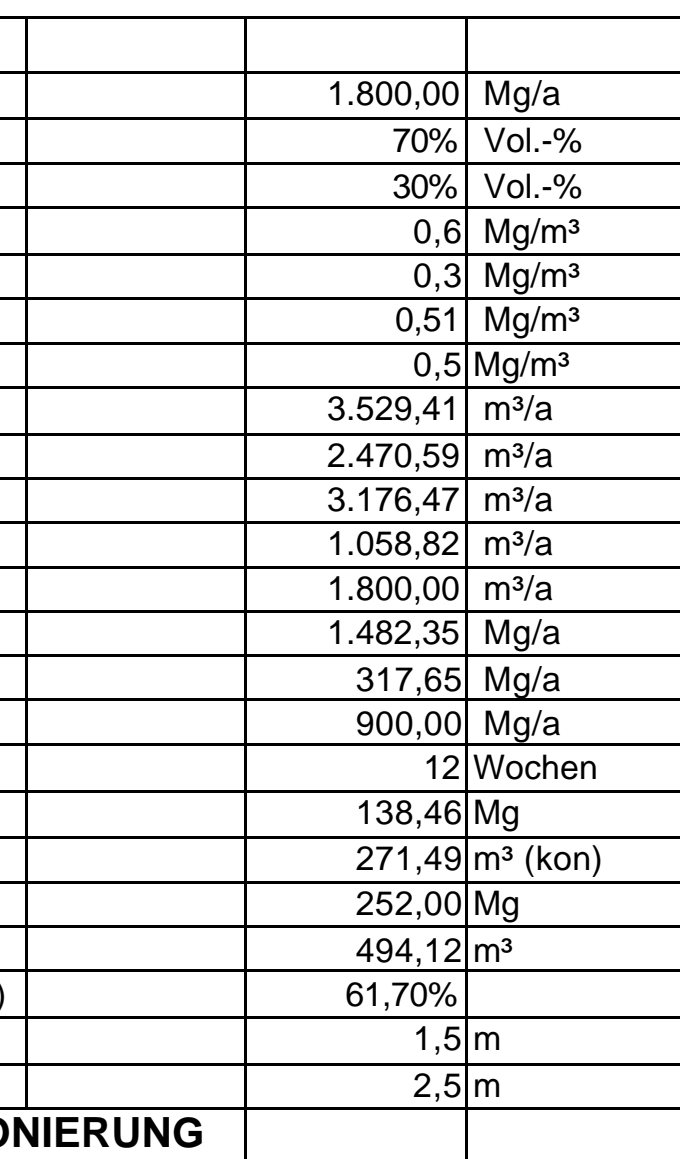

Berechnungsgrundlage

5\% 1 vom Input in Mg/a, ausgedrückt in $\mathrm{m}^{2}$

$1,33 \mathrm{~m}^{2} / \mathrm{m}^{3}$ Rottematerial bei max.M.-Anfall

$40 \%$ der Rottefläche

der Rottefläche

$10 \%$ der Rottefläche

$+$

$0,2 \mathrm{~m}^{3} / \mathrm{m}^{2 \star} \mathrm{a}$

Grüngut

\begin{tabular}{|c|c|c|}
\hline ax.M.-Anfall & 1390,12 & $m^{2}$ \\
\hline & 556,05 & $m^{2}$ \\
\hline & & $m^{2}$ \\
\hline & 139,01 & \\
\hline & 139,01 & $m^{2}$ \\
\hline & 2314,19 & $\mathrm{~m}^{2}$ \\
\hline & 462,84 & $m^{3} / a$ \\
\hline
\end{tabular}

Bioabfälle aus Haushalten

gehäckseltes Grüngut

Bioabfälle aus Haushalten

gehäckseltes Grüngut

konditioniertes Material

Fertigkompost

konditioniertes Material

Bioabfälle aus Haushalten

angeliefertes Grüngut

gehäckseltes Grüngut

Fertigkompost

Bioabfälle aus Haushalten

Fertigkompost

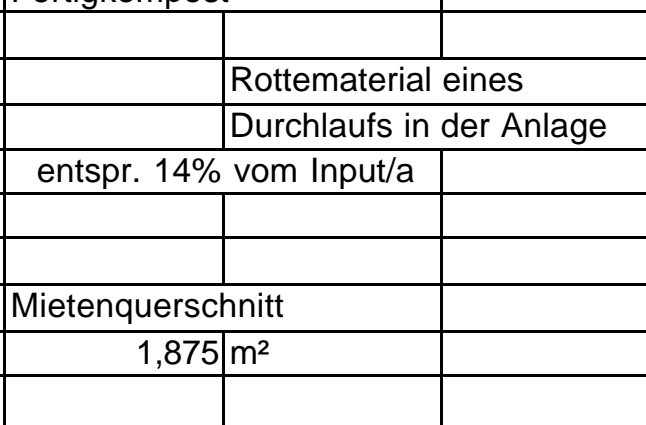

Anlagenneubau

$90,00 \mathrm{~m}^{2}$

Anlagenumnutzung

\begin{tabular}{r|l|l|l|}
\hline 850,00 & $\mathrm{~m}^{2}$ & \\
\cline { 1 - 2 } & \multicolumn{2}{|l|}{$\mathrm{m}^{2}$} & \\
\cline { 1 - 1 } & & \\
\cline { 1 - 2 } 850,00 & $\mathrm{~m}^{2}$ & \\
\hline 4860,00 & $\mathrm{~m}^{2}$ & \\
\hline 972,00 & $\mathrm{~m}^{3} / \mathrm{a}$ & \\
\hline
\end{tabular}




\begin{tabular}{|c|c|c|c|c|c|c|c|c|c|c|}
\hline \multicolumn{11}{|l|}{ ZEITEN } \\
\hline \multicolumn{3}{|l|}{ Arbeitsgang } & \multicolumn{2}{|c|}{ eingesetzte Maschinen } & \multicolumn{2}{|c|}{ Zeitbedarf/Einheit } & \multicolumn{2}{|c|}{ geleistete Einheiten } & \multicolumn{2}{|c|}{ Zeitbedarf/Jahr } \\
\hline \multicolumn{3}{|c|}{ Materialannahme } & & & 4,000 & h/Woche & 52,000 & Wochen/a & 208,000 & $h / a$ \\
\hline \multicolumn{3}{|c|}{ Manuelle Störstoffauslese } & & & 1,000 & $h / 100 m^{3}(\operatorname{In})$ & $5.647,059$ & $\mathrm{~m}^{3} / \mathrm{a}$ & 56,471 & $h / a$ \\
\hline \multicolumn{3}{|c|}{ Zerkleinerung von Strukturmaterial } & TL, SZ, Schr. & & 1,000 & $h / 50 m^{3}(\ln )$ & $3.176,471$ & $\mathrm{~m}^{3} / \mathrm{a}$ & 63,529 & $h / a$ \\
\hline \multicolumn{3}{|c|}{ Aufsetzen einer Matte aus Strukturmat. } & TL, AS & & 0,300 & $\mathrm{~h} / 100 \mathrm{~m}^{3}$ (kon) & $3.529,412$ & $\mathrm{~m}^{3} / \mathrm{a}$ & 10,588 & $\mathrm{~h} / \mathrm{a}$ \\
\hline \multicolumn{3}{|c|}{ Aufsetzen der Dreiecksmieten } & TL, AS & & 1,000 & $\mathrm{~h} / 20 \mathrm{~m}^{3}$ (kon) & $3.529,412$ & $\mathrm{~m}^{3} / \mathrm{a}$ & 176,471 & $\mathrm{~h} / \mathrm{a}$ \\
\hline \multicolumn{3}{|c|}{ Umsetzen der Dreiecksmieten } & Schl., MU & & 0,005 & $\mathrm{~h} / \mathrm{m}$ (Mietenl.) & $15.887,059$ & $\mathrm{~m} / \mathrm{a}$ & 79,435 & $\mathrm{~h} / \mathrm{a}$ \\
\hline \multicolumn{3}{|c|}{ Reinigung der Annahmefläche } & TL, AS & & 0,500 & $\mathrm{~h} / 150 \mathrm{~m}^{3}(\ln )$ & $5.647,059$ & $\mathrm{~m}^{3} / \mathrm{a}$ & 18,824 & $\mathrm{~h} / \mathrm{a}$ \\
\hline \multicolumn{3}{|l|}{ Sieben } & TL, AS, Sieb & & 1,000 & $\mathrm{~h} / 20 \mathrm{~m}^{3}(\mathrm{kom})$ & $1.800,000$ & $\mathrm{~m}^{3} / \mathrm{a}$ & 90,000 & $\mathrm{~h} / \mathrm{a}$ \\
\hline \multicolumn{3}{|c|}{ Abw.-Ausbringung bei Neubau } & Schl.,PT & & 1,000 & $\mathrm{~h} / 10 \mathrm{~m}^{3}(\mathrm{Abw})$ & 462,838 & $\mathrm{~m}^{3} / \mathrm{a}$ & 46,284 & $h / a$ \\
\hline \multicolumn{3}{|c|}{ Abw.-Ausbringung bei Umnutzung } & Schl., PT & & 1,000 & $\mathrm{~h} / 10 \mathrm{~m}^{3}(\mathrm{Abw})$ & 972,000 & $\mathrm{~m}^{3} / \mathrm{a}$ & 97,200 & $h / a$ \\
\hline \multicolumn{11}{|c|}{ Abkürzungen für die eingesetzten Maschinen: } \\
\hline \multicolumn{2}{|c|}{ TL - Teleskoplader } & & \multicolumn{2}{|c|}{ Schl. - Schlepper } & & & & & & \\
\hline \multicolumn{2}{|c|}{\begin{tabular}{|l} 
MU- Mietenumsetzer \\
\end{tabular}} & & Schr. - Schred & dder & & & & & & \\
\hline \multicolumn{2}{|c|}{ SZ - Silozange } & & PT - Pumpenta & tankwagen & & & & & & \\
\hline \multicolumn{11}{|c|}{ AS - Anbauschaufel } \\
\hline \multicolumn{11}{|c|}{ MASCHINENKOSTEN } \\
\hline \multicolumn{2}{|c|}{ Maschine / Gerät } & Fixkosten & & \multicolumn{2}{|c|}{ Variable Kosten } & Einheiten/a & & \multicolumn{2}{|c|}{ Maschinen-Einzelkosten } & \\
\hline Traktor (Neub & au) & 0,00 & $\mathrm{DM} / \mathrm{a}$ & 33,55 & $\mathrm{DM} / \mathrm{h}$ & 125,72 & $h / a$ & $4.217,87$ & $\mathrm{DM} / \mathrm{a}$ & \\
\hline Traktor (Umnı & itzung) & 0,00 & $\mathrm{DM} / \mathrm{a}$ & 33,55 & $\mathrm{DM} / \mathrm{h}$ & 176,64 & $\mathrm{~h} / \mathrm{a}$ & $5.926,11$ & $\mathrm{DM} / \mathrm{a}$ & \\
\hline Teleskoplader & & 0,00 & $\mathrm{DM} / \mathrm{a}$ & 66,50 & $\mathrm{DM} / \mathrm{h}$ & 359,41 & $\mathrm{~h} / \mathrm{a}$ & $23.900,88$ & $\mathrm{DM} / \mathrm{a}$ & \\
\hline Schredder & & 0,00 & $\mathrm{DM} / \mathrm{a}$ & 7,50 & $\mathrm{DM} / \mathrm{m}^{3}$ (Out) & $1.058,82$ & $\mathrm{~m}^{3} / \mathrm{a}$ & $7.941,18$ & $\mathrm{DM} / \mathrm{a}$ & \\
\hline Trommelsieb & & 0,00 & $\mathrm{DM} / \mathrm{a}$ & 5,00 & $\mathrm{DM} / \mathrm{m}^{3}(\mathrm{Kom})$ & $1.800,00$ & $\mathrm{~m}^{3} / \mathrm{a}$ & $9.000,00$ & $\mathrm{DM} / \mathrm{a}$ & \\
\hline PumpenTW (I & Veubau) & 0,00 & $\mathrm{DM} / \mathrm{a}$ & 30,00 & $\mathrm{DM} / \mathrm{h}$ & 46,28 & $\mathrm{~h} / \mathrm{a}$ & $1.388,51$ & $\mathrm{DM} / \mathrm{a}$ & \\
\hline PumpenTW (L & Jmnutzung) & 0,00 & $D M / a$ & 30,00 & $D M / h$ & 97,20 & $h / a$ & $2.916,00$ & $\mathrm{DM} / \mathrm{a}$ & \\
\hline Silozange & & $1.120,00$ & DM/a & 0,30 & $\mathrm{DM} / \mathrm{m}^{3}$ & $3.176,47$ & $\mathrm{~m}^{3} / \mathrm{a}$ & $2.072,94$ & $\mathrm{DM} / \mathrm{a}$ & \\
\hline Anbauschaufe & & 506,00 & $\mathrm{DM} / \mathrm{a}$ & 0,30 & $\mathrm{DM} / \mathrm{m}^{3}$ & $14.505,88$ & $\mathrm{~m}^{3} / \mathrm{a}$ & $4.857,76$ & $\mathrm{DM} / \mathrm{a}$ & \\
\hline Mietenumsetz & & $3.600,00$ & $\mathrm{DM} / \mathrm{a}$ & 28,00 & $\mathrm{DM} / \mathrm{h}$ & 79,44 & $h / a$ & $5.824,19$ & $\mathrm{DM} / \mathrm{a}$ & \\
\hline & & & & & & Summe (Neub & bau) & $59.203,34$ & $\mathrm{DM} / \mathrm{a}$ & \\
\hline & & & & & & Summe (Umn & uutzung) & $62.439,07$ & $\mathrm{DM} / \mathrm{a}$ & \\
\hline PERSONAI & LOSTEN & & & & & & & & & \\
\hline & Std.-Lohn inkl & I.Lohn-NK & Arbeitsstd. pro & o Jahr & Personal-Einz & zelkosten & & & & \\
\hline Neubau & 26,00 & $D M / h$ & 749,60 & $\mathrm{~h} / \mathrm{a}$ & $19.489,64$ & $D M / a$ & & & & \\
\hline Umnutzung & 26,00 & $D M / h$ & 800,52 & $h / a$ & $20.813,46$ & $D M / a$ & & & & \\
\hline
\end{tabular}




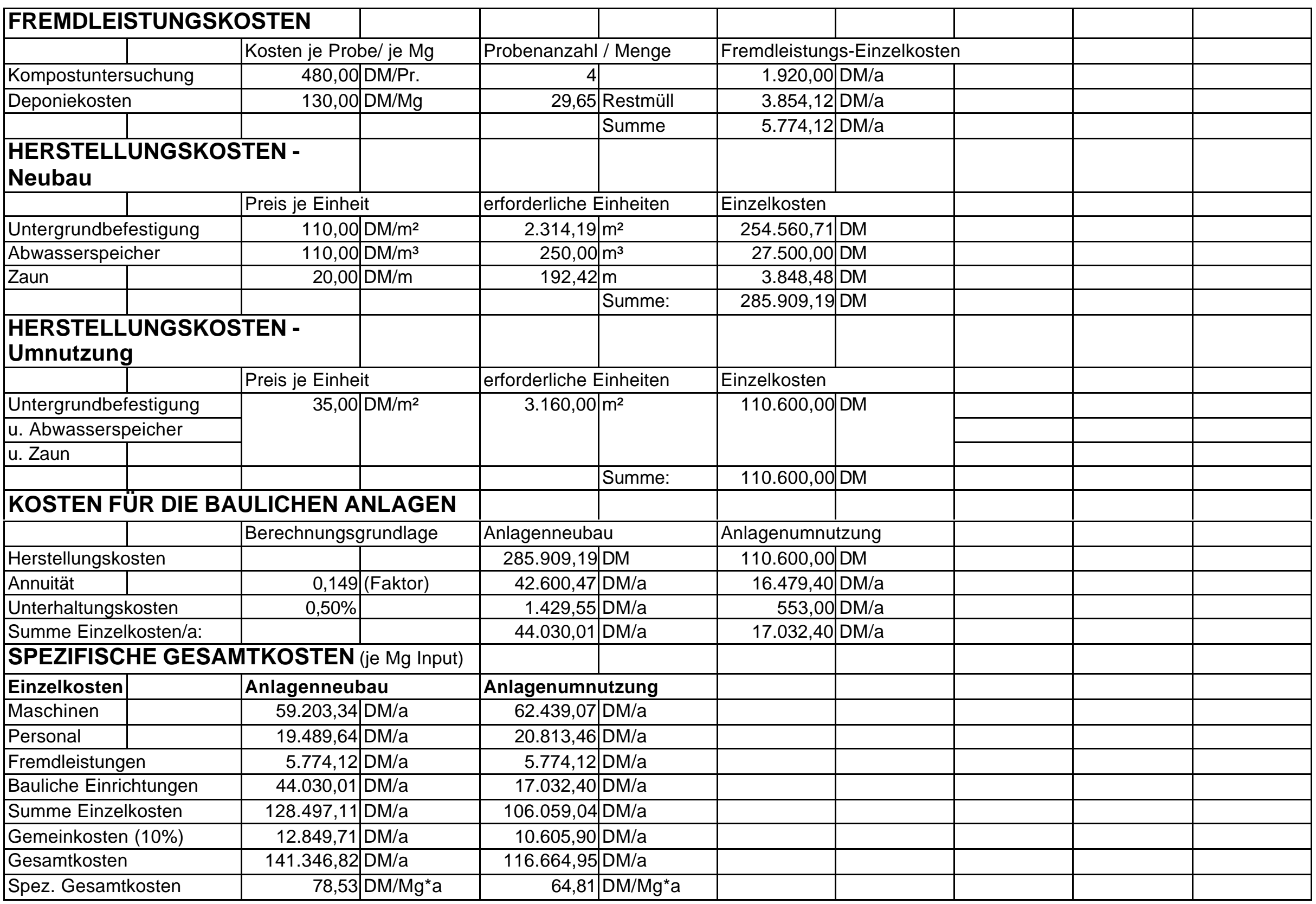


Kostenvariante B9

\section{MATERIAL}

Jahresinputmenge

Zusammensetzung

\begin{tabular}{|l|l|}
\hline & \\
\hline Dichte & \\
\hline & \\
\hline & \\
\hline & \\
\hline & \\
\hline & \\
\hline & \\
\hline & \\
\hline &
\end{tabular}

Gewichtsanteil

\section{Rottedauer}

durchschnittliches

Monatsaufkommen

maximaler Monatsanfall

\begin{tabular}{|l}
\hline \\
TS-Gehalt (Fertigkompost)
\end{tabular}

Mietenhöhe

Mietenbasisbreite

\section{ANLAGENDIMENSIONIERUNG}

\section{Anlagenteil}

Anlieferungsfläche

Rottefläche

Rangierfläche

Zwischenlager für

Strukturmaterial

Kompostlager

Anlagenfläche (gesamt)

zu verwertende

Abwassermenge

\section{|}

+

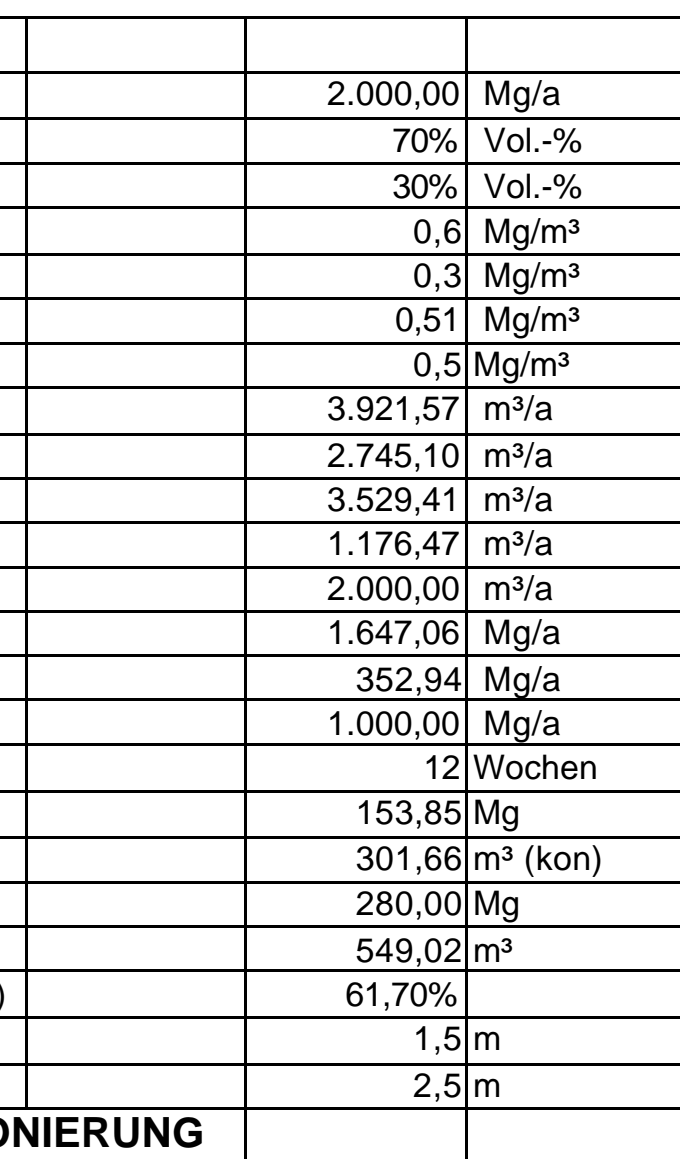

Berechnungsgrundlage

5\% vom Input in Mg/a, ausgedrückt in $\mathrm{m}^{2}$

$1,33 \mathrm{~m}^{2} / \mathrm{m}^{3}$ Rottematerial bei max.M.-Anfall

$40 \%$ der Rottefläche

der Rottefläche

$10 \%$ der Rottefläche

$0,2 \mathrm{~m}^{3} / \mathrm{m}^{2 \star} \mathrm{a}$

Grüngut

\begin{tabular}{|c|c|c|}
\hline ax.M.-Anfall & 1544,58 & $\mathrm{~m}^{2}$ \\
\hline & 617,83 & $\mathrm{~m}^{2}$ \\
\hline & & $\mathrm{m}^{2}$ \\
\hline & 154,46 & \\
\hline & 154,46 & $\mathrm{~m}^{2}$ \\
\hline & 2571,32 & $\mathrm{~m}^{2}$ \\
\hline & & \\
\hline & 514,26 & $\mathrm{~m}^{3} / \mathrm{a}$ \\
\hline
\end{tabular}

Bioabfälle aus Haushalten

gehäckseltes Grüngut

Bioabfälle aus Haushalten

gehäckseltes Grüngut

konditioniertes Material

Fertigkompost

konditioniertes Material

Bioabfälle aus Haushalten

angeliefertes Grüngut

gehäckseltes Grüngut

Fertigkompost

Bioabfälle aus Haushalten

Fertigkompost

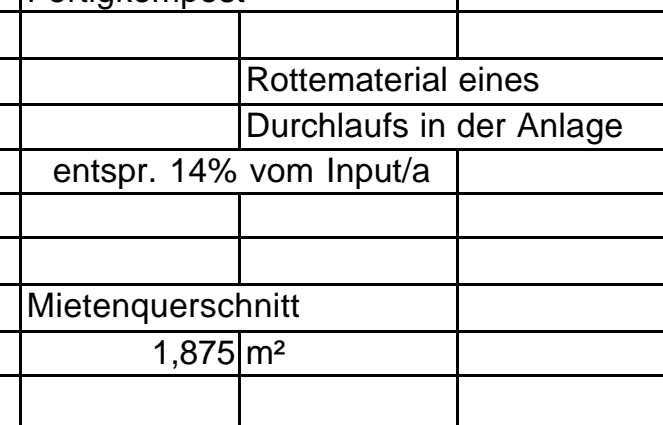

Anlagenneubau

\section{Anlagenumnutzung}

$850,00 \mathrm{~m}^{2}$

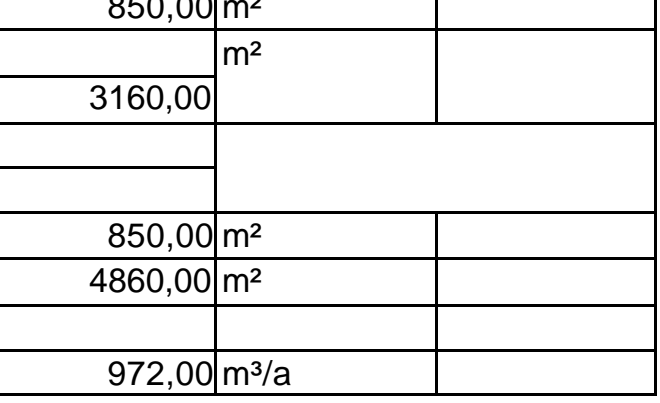




\begin{tabular}{|c|c|c|c|c|c|c|c|c|c|c|}
\hline ZEITEN & & & & & & & & & & \\
\hline Arbeitsgang & & & eingesetzte $\mathrm{M}$ & Maschinen & Zeitbedarf/Ei & inheit & geleistete Ein & nheiten & Zeitbedarf/Ja & ahr \\
\hline Materialannah & ime & & & & 4,000 & h/Woche & 52,000 & Wochen/a & 208,000 & $h / a$ \\
\hline Manuelle Stör & stoffauslese & & & & 1,000 & $h / 100 m^{3}(\ln )$ & $6.274,510$ & $\mathrm{~m}^{3} / \mathrm{a}$ & 62,745 & $h / a$ \\
\hline Zerkleinerung & von Strukturm & naterial & TL, SZ, Schr. & & 1,000 & $h / 50 m^{3}(\operatorname{In})$ & $3.529,412$ & $\mathrm{~m}^{3} / \mathrm{a}$ & 70,588 & $h / a$ \\
\hline Aufsetzen ein & er Matte aus S & Strukturmat. & TL, AS & & 0,300 & $\mathrm{~h} / 100 \mathrm{~m}^{3}$ (kon) & $3.921,569$ & $\mathrm{~m}^{3} / \mathrm{a}$ & 11,765 & $h / a$ \\
\hline Aufsetzen der & Dreiecksmiete & & TL, AS & & 1,000 & $\mathrm{~h} / 20 \mathrm{~m}^{3}$ (kon) & $3.921,569$ & $\mathrm{~m}^{3} / \mathrm{a}$ & 196,078 & $\mathrm{~h} / \mathrm{a}$ \\
\hline Umsetzen der & Dreiecksmiete & & Schl., MU & & 0,005 & $\mathrm{~h} / \mathrm{m}$ (Mietenl.) & $17.652,288$ & $\mathrm{~m} / \mathrm{a}$ & 88,261 & $\mathrm{~h} / \mathrm{a}$ \\
\hline Reinigung der & Annahmefläch & & TL, AS & & 0,500 & $h / 150 m^{3}(\ln )$ & $6.274,510$ & $\mathrm{~m}^{3} / \mathrm{a}$ & 20,915 & $h / a$ \\
\hline Sieben & & & TL, AS, Sieb & & 1,000 & $\mathrm{~h} / 20 \mathrm{~m}^{3}(\mathrm{kom})$ & $2.000,000$ & $\mathrm{~m}^{3} / \mathrm{a}$ & 100,000 & $h / a$ \\
\hline Abw.-Ausbring & gung bei Neub & & Schl.,PT & & 1,000 & $\mathrm{~h} / 10 \mathrm{~m}^{3}(\mathrm{Abw})$ & 514,264 & $\mathrm{~m}^{3} / \mathrm{a}$ & 51,426 & $h / a$ \\
\hline Abw.-Ausbring & gung bei Umnu & utzung & Schl., PT & & 1,000 & $\mathrm{~h} / 10 \mathrm{~m}^{3}(\mathrm{Abw})$ & 972,000 & $\mathrm{~m}^{3} / \mathrm{a}$ & 97,200 & $h / a$ \\
\hline Abkürzungen & für die eingese & etzten Maschin & nen: & & & & & & & \\
\hline TL - Teleskop & lader & & Schl. - Schlepp & per & & & & & & \\
\hline MU- Mietenum & nsetzer & & Schr. - Schred & dder & & & & & & \\
\hline SZ - Silozange & & & PT - Pumpenta & tankwagen & & & & & & \\
\hline AS - Anbausc & haufel & & & & & & & & & \\
\hline MASCHINE & ENKOSTEN & & & & & & & & & \\
\hline Maschine / G & erät & Fixkosten & & Variable Kost & ten & Einheiten/a & & Maschinen-Ei & inzelkosten & \\
\hline Traktor (Neub & au) & 0,00 & $\mathrm{DM} / \mathrm{a}$ & 33,55 & $D M / h$ & 139,69 & $h / a$ & $4.686,53$ & $\mathrm{DM} / \mathrm{a}$ & \\
\hline Traktor (Umnu & itzung) & 0,00 & $\mathrm{DM} / \mathrm{a}$ & 33,55 & $D M / h$ & 185,46 & $\mathrm{~h} / \mathrm{a}$ & $6.222,23$ & $\mathrm{DM} / \mathrm{a}$ & \\
\hline Teleskoplader & & 0,00 & $D M / a$ & 66,50 & $\mathrm{DM} / \mathrm{h}$ & 399,35 & $\mathrm{~h} / \mathrm{a}$ & $26.556,54$ & $\mathrm{DM} / \mathrm{a}$ & \\
\hline Schredder & & 0,00 & DM/a & 7,50 & $\mathrm{DM} / \mathrm{m}^{3}$ (Out) & $1.176,47$ & $\mathrm{~m}^{3} / \mathrm{a}$ & $8.823,53$ & $\mathrm{DM} / \mathrm{a}$ & \\
\hline Trommelsieb & & 0,00 & DM/a & 5,00 & $\mathrm{DM} / \mathrm{m}^{3}(\mathrm{Kom})$ & $2.000,00$ & $\mathrm{~m}^{3} / \mathrm{a}$ & $10.000,00$ & $\mathrm{DM} / \mathrm{a}$ & \\
\hline PumpenTW ( & Veubau) & 0,00 & $\mathrm{DM} / \mathrm{a}$ & 30,00 & $\mathrm{DM} / \mathrm{h}$ & 51,43 & $\mathrm{~h} / \mathrm{a}$ & $1.542,79$ & $\mathrm{DM} / \mathrm{a}$ & \\
\hline PumpenTW (L & Jmnutzung) & 0,00 & $D M / a$ & 30,00 & $D M / h$ & 97,20 & $h / a$ & $2.916,00$ & $\mathrm{DM} / \mathrm{a}$ & \\
\hline Silozange & & $1.120,00$ & DM/a & 0,30 & $\mathrm{DM} / \mathrm{m}^{3}$ & $3.529,41$ & $\mathrm{~m}^{3} / \mathrm{a}$ & $2.178,82$ & $D M / a$ & \\
\hline Anbauschaufe & & 506,00 & $\mathrm{DM} / \mathrm{a}$ & 0,30 & $\mathrm{DM} / \mathrm{m}^{3}$ & $16.117,65$ & $\mathrm{~m}^{3} / \mathrm{a}$ & $5.341,29$ & $\mathrm{DM} / \mathrm{a}$ & \\
\hline Mietenumsetz & & $3.600,00$ & $\mathrm{DM} / \mathrm{a}$ & 28,00 & $\mathrm{DM} / \mathrm{h}$ & 88,26 & $h / a$ & $6.071,32$ & $\mathrm{DM} / \mathrm{a}$ & \\
\hline & & & & & & Summe (Neuk & bau) & $65.200,82$ & $\mathrm{DM} / \mathrm{a}$ & \\
\hline & & & & & & Summe (Umn & hutzung) & $68.109,73$ & $\mathrm{DM} / \mathrm{a}$ & \\
\hline PERSONA & LOSTEN & & & & & & & & & \\
\hline & Std.-Lohn inkl & I.Lohn-NK & Arbeitsstd. pro & o Jahr & Personal-Einz & zelkosten & & & & \\
\hline Neubau & 26,00 & $D M / h$ & 809,78 & $\mathrm{~h} / \mathrm{a}$ & $21.054,26$ & $D M / a$ & & & & \\
\hline Umnutzung & 26,00 & $D M / h$ & 855,55 & $\mathrm{~h} / \mathrm{a}$ & $22.244,38$ & DM/a & & & & \\
\hline
\end{tabular}




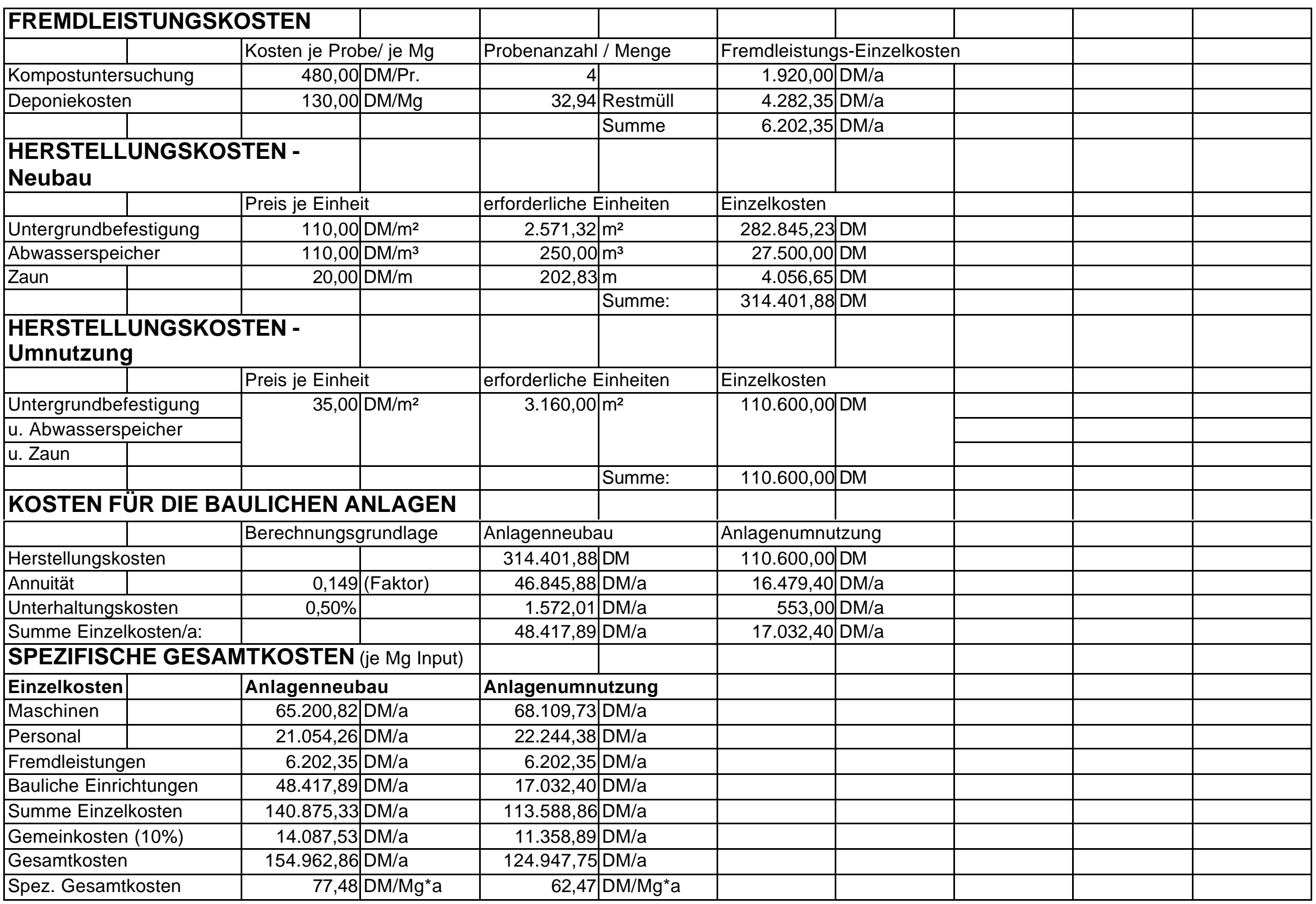


Kostenvariante B10

\section{MATERIAL}

Jahresinputmenge

Zusammensetzung

\begin{tabular}{|l|l|}
\hline & \\
\hline Dichte & \\
\hline & \\
\hline & \\
\hline & \\
\hline Volumen & \\
\hline & \\
\hline & \\
\hline & \\
\hline &
\end{tabular}

Gewichtsanteil

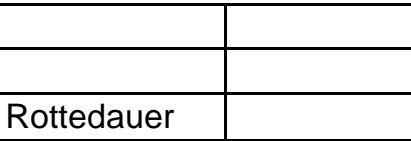

durchschnittliches

Monatsaufkommen

maximaler Monatsanfall

TS-Gehalt (Fertigkompost)

Mietenhöhe

Mietenbasisbreite

\section{ANLAGENDIMENSIONIERUNG}

\section{Anlagenteil}

Anlieferungsfläche

Rottefläche

Rangierfläche

Zwischenlager für

Strukturmaterial

Kompostlager

Anlagenfläche (gesamt)

zu verwertende

Abwassermenge

\section{|}

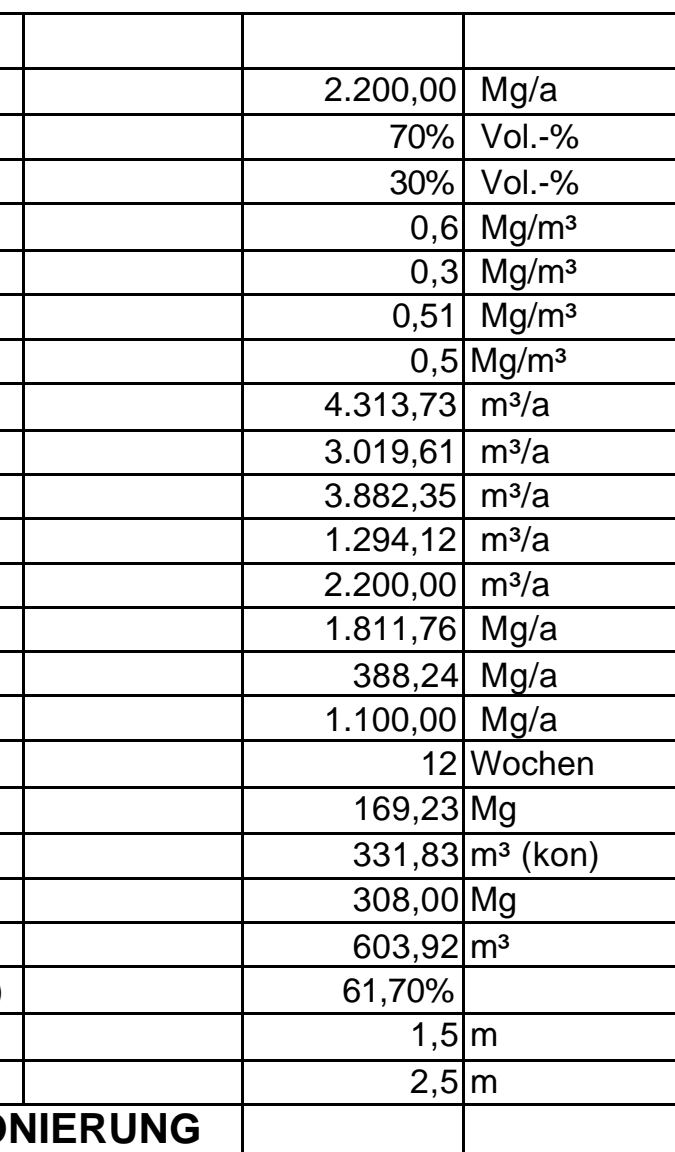

Berechnungsgrundlage

5\% vom Input in Mg/a, ausgedrückt in $\mathrm{m}^{2}$

$1,33 \mathrm{~m}^{2} / \mathrm{m}^{3}$ Rottematerial bei max.M.-Anfall

$40 \%$ der Rottefläche

der Rottefläche

$10 \%$ der Rottefläche

$+$

$0,2 \mathrm{~m}^{3} / \mathrm{m}^{2 *} \mathrm{a}$

Grüngut

\begin{tabular}{|c|c|c|}
\hline ax.M.-Anfall & 1699,03 & $\mathrm{~m}^{2}$ \\
\hline & 679,61 & $\mathrm{~m}^{2}$ \\
\hline & & $\mathrm{m}^{2}$ \\
\hline & 169,90 & \\
\hline & 169,90 & $\mathrm{~m}^{2}$ \\
\hline & 2828,45 & $m^{2}$ \\
\hline & 565.69 & $m^{3} / a$ \\
\hline
\end{tabular}

Bioabfälle aus Haushalten

gehäckseltes Grüngut

Bioabfälle aus Haushalten

gehäckseltes Grüngut

konditioniertes Material

Fertigkompost

konditioniertes Material

Bioabfälle aus Haushalten

angeliefertes Grüngut

gehäckseltes Grüngut

Fertigkompost

Bioabfälle aus Haushalten

Fertigkompost

\begin{tabular}{|c|c|c|}
\hline & \multicolumn{2}{|c|}{ Rottematerial eines } \\
\hline & \multicolumn{2}{|c|}{ Durchlaufs in der Anlage } \\
\hline \multicolumn{3}{|c|}{ entspr. $14 \%$ vom Input/a } \\
\hline & & \\
\hline \multirow{2}{*}{\multicolumn{3}{|c|}{ Mietenquerschnitt }} \\
\hline & & \\
\hline 1,875 & $\mathrm{~m}^{2}$ & \\
\hline
\end{tabular}

Anlagenneubau

\section{Anlagenumnutzung}

$850,00 \mathrm{~m}^{2}$

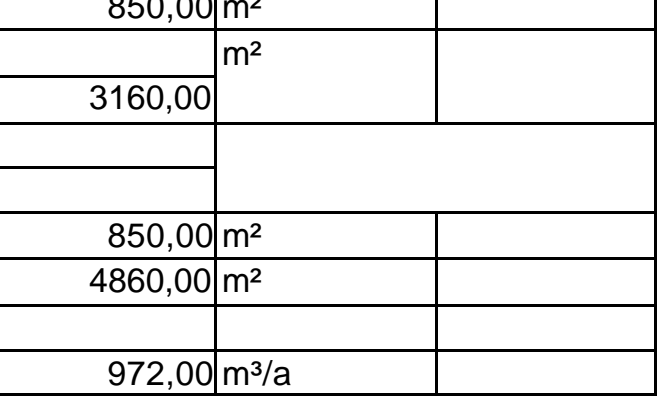




\begin{tabular}{|c|c|c|c|c|c|c|c|c|c|c|}
\hline ZEITEN & & & & & & & & & & \\
\hline Arbeitsgang & & & eingesetzte $\mathrm{M}$ & Maschinen & Zeitbedarf/Ei & inheit & geleistete Ein & nheiten & Zeitbedarf/Ja & ahr \\
\hline Materialannah & ime & & & & 4,000 & h/Woche & 52,000 & Wochen/a & 208,000 & $h / a$ \\
\hline Manuelle Stör & stoffauslese & & & & 1,000 & $\mathrm{~h} / 100 \mathrm{~m}^{3}(\ln )$ & $6.901,961$ & $\mathrm{~m}^{3} / \mathrm{a}$ & 69,020 & $h / a$ \\
\hline Zerkleinerung & von Strukturm & naterial & TL, SZ, Schr. & & 1,000 & $h / 50 m^{3}(\operatorname{In})$ & $3.882,353$ & $\mathrm{~m}^{3} / \mathrm{a}$ & 77,647 & $h / a$ \\
\hline Aufsetzen ein & er Matte aus S & Strukturmat. & TL, AS & & 0,300 & $\mathrm{~h} / 100 \mathrm{~m}^{3}$ (kon) & $4.313,725$ & $\mathrm{~m}^{3} / \mathrm{a}$ & 12,941 & $h / a$ \\
\hline Aufsetzen der & Dreiecksmiete & & TL, AS & & 1,000 & $\mathrm{~h} / 20 \mathrm{~m}^{3}$ (kon) & $4.313,725$ & $\mathrm{~m}^{3} / \mathrm{a}$ & 215,686 & $h / a$ \\
\hline Umsetzen der & Dreiecksmiete & & Schl., MU & & 0,005 & $\mathrm{~h} / \mathrm{m}$ (Mietenl.) & $19.417,516$ & $\mathrm{~m} / \mathrm{a}$ & 97,088 & $\mathrm{~h} / \mathrm{a}$ \\
\hline Reinigung der & Annahmefläch & & TL, AS & & 0,500 & $h / 150 m^{3}(\ln )$ & $6.901,961$ & $\mathrm{~m}^{3} / \mathrm{a}$ & 23,007 & $\mathrm{~h} / \mathrm{a}$ \\
\hline Sieben & & & TL, AS, Sieb & & 1,000 & $\mathrm{~h} / 20 \mathrm{~m}^{3}(\mathrm{kom})$ & $2.200,000$ & $\mathrm{~m}^{3} / \mathrm{a}$ & 110,000 & $h / a$ \\
\hline Abw.-Ausbring & gung bei Neub & & Schl.,PT & & 1,000 & $\mathrm{~h} / 10 \mathrm{~m}^{3}(\mathrm{Abw})$ & 565,690 & $\mathrm{~m}^{3} / \mathrm{a}$ & 56,569 & $h / a$ \\
\hline Abw.-Ausbring & gung bei Umnu & utzung & Schl., PT & & 1,000 & $\mathrm{~h} / 10 \mathrm{~m}^{3}(\mathrm{Abw})$ & 972,000 & $\mathrm{~m}^{3} / \mathrm{a}$ & 97,200 & $h / a$ \\
\hline Abkürzungen & für die eingese & etzten Maschin & nen: & & & & & & & \\
\hline TL - Teleskop & lader & & Schl. - Schlepp & per & & & & & & \\
\hline MU- Mietenum & nsetzer & & Schr. - Schred & dder & & & & & & \\
\hline SZ - Silozange & & & PT - Pumpenta & tankwagen & & & & & & \\
\hline AS - Anbausc & haufel & & & & & & & & & \\
\hline MASCHINE & ENKOSTEN & & & & & & & & & \\
\hline Maschine / G & erät & Fixkosten & & Variable Kost & ten & Einheiten/a & & Maschinen-Ei & inzelkosten & \\
\hline Traktor (Neub & au) & 0,00 & $\mathrm{DM} / \mathrm{a}$ & 33,55 & $D M / h$ & 153,66 & $h / a$ & $5.155,18$ & $\mathrm{DM} / \mathrm{a}$ & \\
\hline Traktor (Umnu & itzung) & 0,00 & $\mathrm{DM} / \mathrm{a}$ & 33,55 & $D M / h$ & 194,29 & $\mathrm{~h} / \mathrm{a}$ & $6.518,35$ & $\mathrm{DM} / \mathrm{a}$ & \\
\hline Teleskoplader & & 0,00 & DM/a & 66,50 & $D M / h$ & 439,28 & $\mathrm{~h} / \mathrm{a}$ & $29.212,19$ & $\mathrm{DM} / \mathrm{a}$ & \\
\hline Schredder & & 0,00 & DM/a & 7,50 & $\mathrm{DM} / \mathrm{m}^{3}$ (Out) & $1.294,12$ & $\mathrm{~m}^{3} / \mathrm{a}$ & $9.705,88$ & $\mathrm{DM} / \mathrm{a}$ & \\
\hline Trommelsieb & & 0,00 & $D M / a$ & 5,00 & $\mathrm{DM} / \mathrm{m}^{3}(\mathrm{Kom})$ & $2.200,00$ & $\mathrm{~m}^{3} / \mathrm{a}$ & $11.000,00$ & $\mathrm{DM} / \mathrm{a}$ & \\
\hline PumpenTW ( & Veubau) & 0,00 & $\mathrm{DM} / \mathrm{a}$ & 30,00 & $\mathrm{DM} / \mathrm{h}$ & 56,57 & $h / a$ & $1.697,07$ & $\mathrm{DM} / \mathrm{a}$ & \\
\hline PumpenTW (L & Jmnutzung) & 0,00 & $\mathrm{DM} / \mathrm{a}$ & 30,00 & $D M / h$ & 97,20 & $\mathrm{~h} / \mathrm{a}$ & $2.916,00$ & $\mathrm{DM} / \mathrm{a}$ & \\
\hline Silozange & & $1.120,00$ & DM/a & 0,30 & $\mathrm{DM} / \mathrm{m}^{3}$ & $3.882,35$ & $\mathrm{~m}^{3} / \mathrm{a}$ & $2.284,71$ & $\mathrm{DM} / \mathrm{a}$ & \\
\hline Anbauschaufe & & 506,00 & $\mathrm{DM} / \mathrm{a}$ & 0,30 & $\mathrm{DM} / \mathrm{m}^{3}$ & $17.729,41$ & $m^{3} / a$ & $5.824,82$ & $\mathrm{DM} / \mathrm{a}$ & \\
\hline Mietenumsetz & & $3.600,00$ & $\mathrm{DM} / \mathrm{a}$ & 28,00 & $\mathrm{DM} / \mathrm{h}$ & 97,09 & $h / a$ & $6.318,45$ & $\mathrm{DM} / \mathrm{a}$ & \\
\hline & & & & & & Summe (Neuk & bau) & $71.198,30$ & $\mathrm{DM} / \mathrm{a}$ & \\
\hline & & & & & & Summe (Umn & lutzung) & $73.780,40$ & $\mathrm{DM} / \mathrm{a}$ & \\
\hline PERSONA & LOSTEN & & & & & & & & & \\
\hline & Std.-Lohn inkl & I.Lohn-NK & Arbeitsstd. pro & o Jahr & Personal-Einz & zelkosten & & & & \\
\hline Neubau & 26,00 & $D M / h$ & 869,96 & $\mathrm{~h} / \mathrm{a}$ & $22.618,89$ & $\mathrm{DM} / \mathrm{a}$ & & & & \\
\hline Umnutzung & 26,00 & $D M / h$ & 910,59 & $\mathrm{~h} / \mathrm{a}$ & $23.675,29$ & DM/a & & & & \\
\hline
\end{tabular}




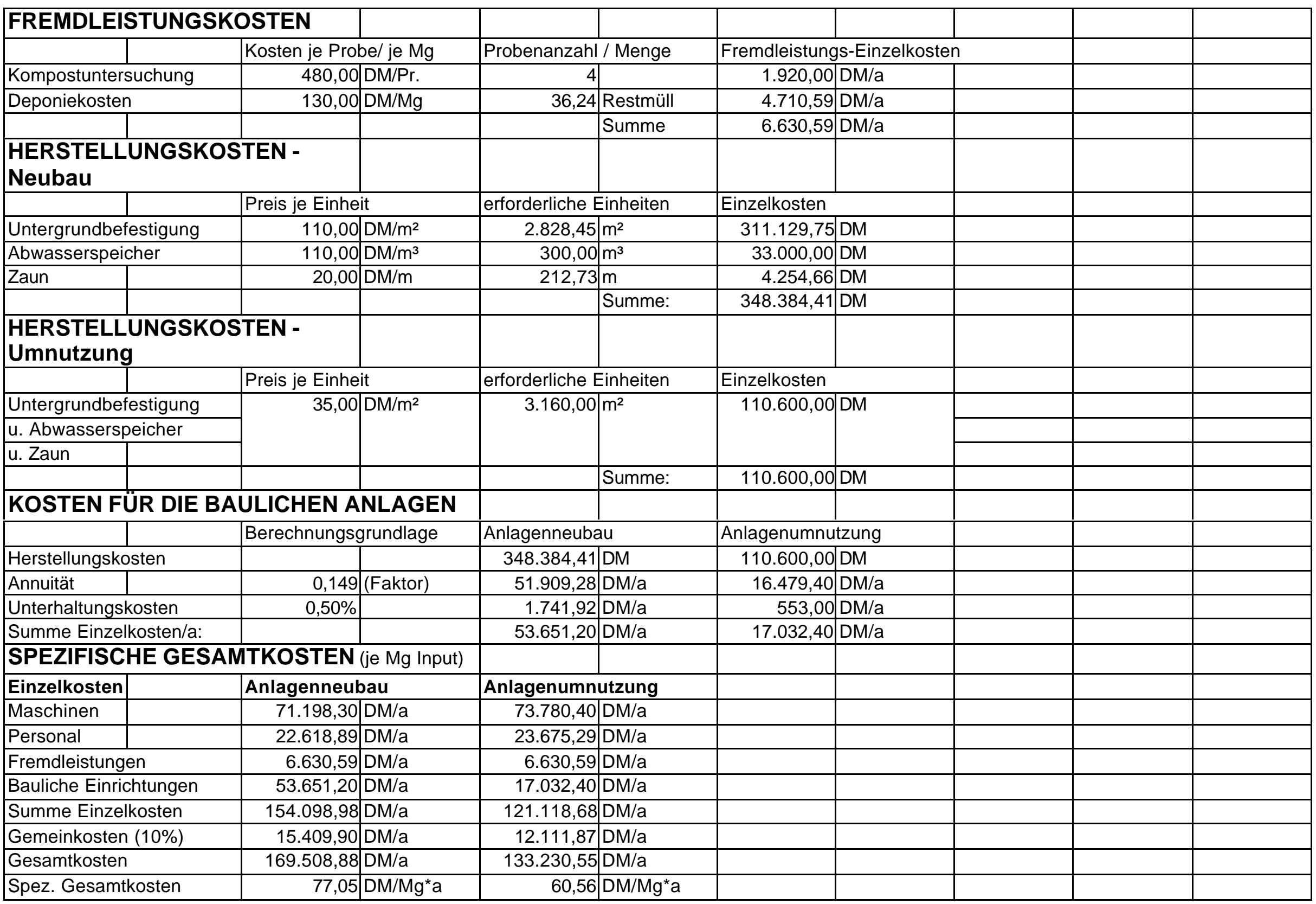


Kostenvariante B11

\section{MATERIAL}

Jahresinputmenge

Zusammensetzung

\begin{tabular}{|l|l|}
\hline & \\
\hline Dichte & \\
\hline & \\
\hline & \\
\hline & \\
\hline & \\
\hline & \\
\hline & \\
\hline & \\
\hline &
\end{tabular}

Gewichtsanteil

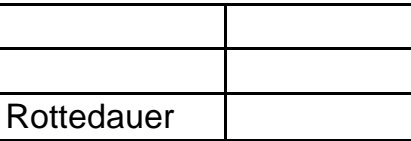

durchschnittliches

Monatsaufkommen

maximaler Monatsanfall

TS-Gehalt (Fertigkompost)

Mietenhöhe

Mietenbasisbreite

\section{ANLAGENDIMENSIONIERUNG}

\section{Anlagenteil}

Anlieferungsfläche

Rottefläche

Rangierfläche

Zwischenlager für

Strukturmaterial

Kompostlager

Anlagenfläche (gesamt)

zu verwertende

Abwassermenge

\section{|}

+

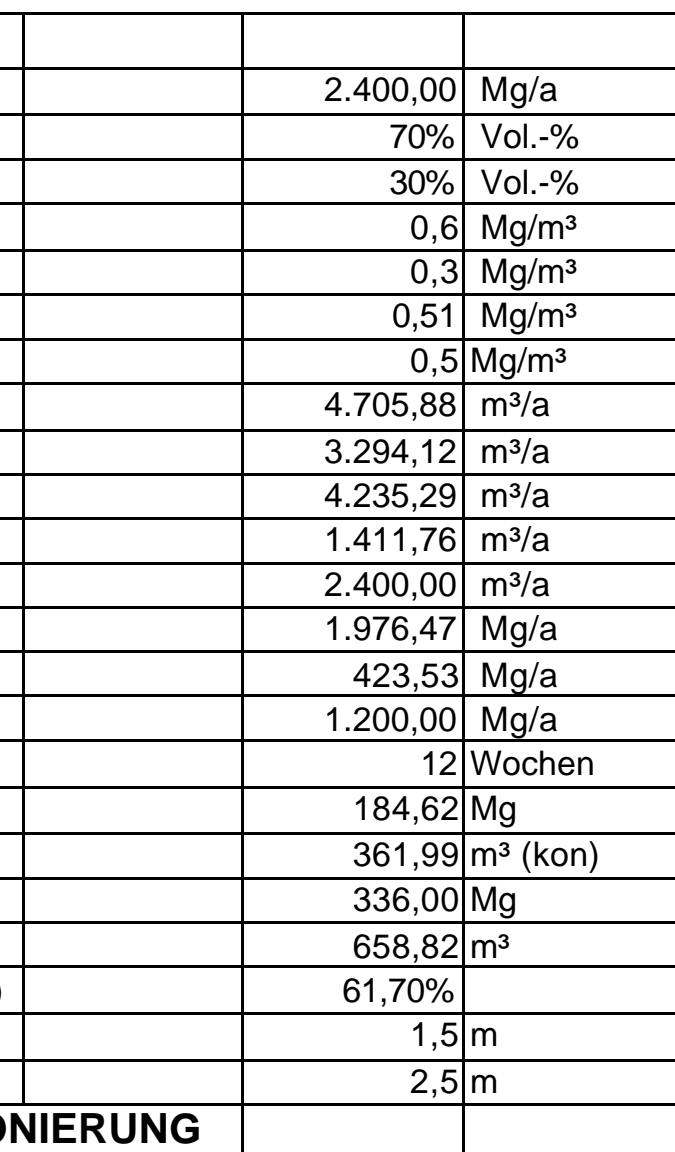

Berechnungsgrundlage

$5 \%$ vom Input in Mg/a, ausgedrückt in $\mathrm{m}^{2}$

$1,33 \mathrm{~m}^{2} / \mathrm{m}^{3}$ Rottematerial bei max.M.-Anfall

$40 \%$ der Rottefläche

der Rottefläche

$10 \%$ der Rottefläche

\begin{tabular}{l|l}
0,2 & $\mathrm{~m}^{3} / \mathrm{m}^{2 \star} \mathrm{a}$
\end{tabular}

Grüngut

\begin{tabular}{|c|c|c|}
\hline ax.M.-Anfall & 1853,49 & $\mathrm{~m}^{2}$ \\
\hline & 741,40 & $\mathrm{~m}^{2}$ \\
\hline & & $\mathrm{m}^{2}$ \\
\hline & 185,35 & \\
\hline & 185,35 & $m^{2}$ \\
\hline & 3085,58 & $\mathrm{~m}^{2}$ \\
\hline & 617,12 & $m^{3} / a$ \\
\hline
\end{tabular}

Bioabfälle aus Haushalten

gehäckseltes Grüngut

Bioabfälle aus Haushalten

gehäckseltes Grüngut

konditioniertes Material

Fertigkompost

konditioniertes Material

Bioabfälle aus Haushalten

angeliefertes Grüngut

gehäckseltes Grüngut

Fertigkompost

Bioabfälle aus Haushalten

Fertigkompost

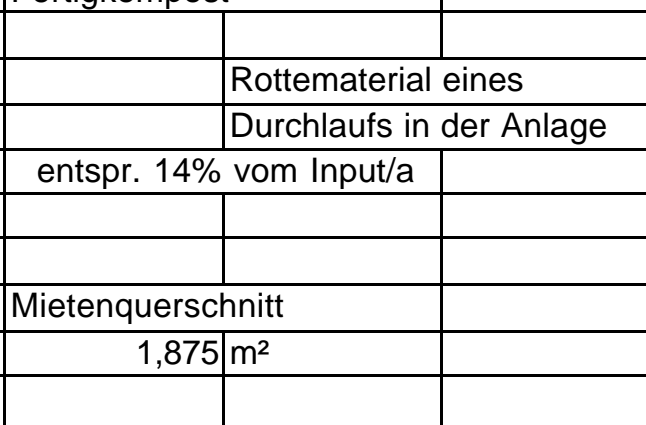

Anlagenneubau

\section{Anlagenumnutzung}

$850,00 \mathrm{~m}^{2}$

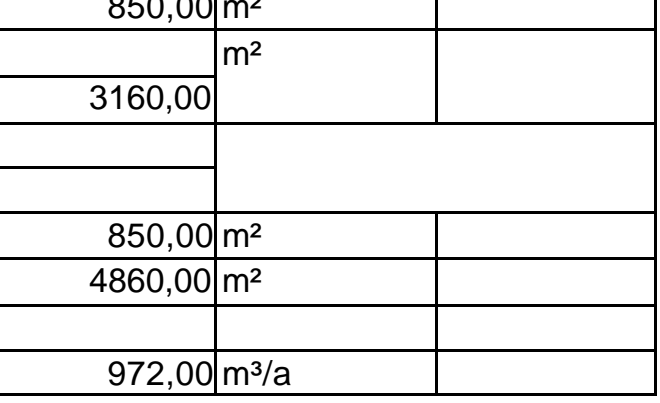




\begin{tabular}{|c|c|c|c|c|c|c|c|c|c|c|}
\hline ZEITEN & & & & & & & & & & \\
\hline Arbeitsgang & & & eingesetzte $\mathrm{M}$ & Maschinen & Zeitbedarf/Ei & inheit & geleistete Ein & nheiten & Zeitbedarf/Ja & ahr \\
\hline Materialannah & ime & & & & 4,000 & h/Woche & 52,000 & Wochen/a & 208,000 & $h / a$ \\
\hline Manuelle Stör & stoffauslese & & & & 1,000 & $h / 100 m^{3}(\ln )$ & 7.529,412 & $\mathrm{m}^{3} / \mathrm{a}$ & 75,294 & $h / a$ \\
\hline Zerkleinerung & von Strukturm & naterial & TL, SZ, Schr. & & 1,000 & $h / 50 m^{3}(\operatorname{In})$ & $4.235,294$ & $\mathrm{~m}^{3} / \mathrm{a}$ & 84,706 & $h / a$ \\
\hline Aufsetzen ein & er Matte aus S & Strukturmat. & TL, AS & & 0,300 & $\mathrm{~h} / 100 \mathrm{~m}^{3}$ (kon) & $4.705,882$ & $\mathrm{~m}^{3} / \mathrm{a}$ & 14,118 & $\mathrm{~h} / \mathrm{a}$ \\
\hline Aufsetzen der & Dreiecksmiete & & TL, AS & & 1,000 & $\mathrm{~h} / 20 \mathrm{~m}^{3}$ (kon) & $4.705,882$ & $\mathrm{~m}^{3} / \mathrm{a}$ & 235,294 & $h / a$ \\
\hline Umsetzen der & Dreiecksmiete & & Schl., MU & & 0,005 & $\mathrm{~h} / \mathrm{m}$ (Mietenl.) & $21.182,745$ & $\mathrm{~m} / \mathrm{a}$ & 105,914 & $h / a$ \\
\hline Reinigung der & Annahmefläch & & TL, AS & & 0,500 & $h / 150 m^{3}(\ln )$ & $7.529,412$ & $\mathrm{~m}^{3} / \mathrm{a}$ & 25,098 & $\mathrm{~h} / \mathrm{a}$ \\
\hline Sieben & & & TL, AS, Sieb & & 1,000 & $\mathrm{~h} / 20 \mathrm{~m}^{3}(\mathrm{kom})$ & $2.400,000$ & $\mathrm{~m}^{3} / \mathrm{a}$ & 120,000 & $h / a$ \\
\hline Abw.-Ausbring & gung bei Neub & & Schl.,PT & & 1,000 & $\mathrm{~h} / 10 \mathrm{~m}^{3}(\mathrm{Abw})$ & 617,117 & $\mathrm{~m}^{3} / \mathrm{a}$ & 61,712 & $h / a$ \\
\hline Abw.-Ausbring & gung bei Umnu & utzung & Schl., PT & & 1,000 & $\mathrm{~h} / 10 \mathrm{~m}^{3}(\mathrm{Abw})$ & 972,000 & $\mathrm{~m}^{3} / \mathrm{a}$ & 97,200 & $h / a$ \\
\hline Abkürzungen & für die eingese & etzten Maschin & nen: & & & & & & & \\
\hline TL - Teleskop & lader & & Schl. - Schlepp & per & & & & & & \\
\hline MU- Mietenum & nsetzer & & Schr. - Schred & dder & & & & & & \\
\hline SZ - Silozange & & & PT - Pumpenta & tankwagen & & & & & & \\
\hline AS - Anbausc & haufel & & & & & & & & & \\
\hline MASCHINE & ENKOSTEN & & & & & & & & & \\
\hline Maschine / G & erät & Fixkosten & & Variable Kost & ten & Einheiten/a & & Maschinen-Ei & inzelkosten & \\
\hline Traktor (Neub & au) & 0,00 & $\mathrm{DM} / \mathrm{a}$ & 33,55 & $D M / h$ & 167,63 & $\mathrm{~h} / \mathrm{a}$ & $5.623,83$ & $\mathrm{DM} / \mathrm{a}$ & \\
\hline Traktor (Umnu & itzung) & 0,00 & $\mathrm{DM} / \mathrm{a}$ & 33,55 & $D M / h$ & 203,11 & $\mathrm{~h} / \mathrm{a}$ & $6.814,47$ & $\mathrm{DM} / \mathrm{a}$ & \\
\hline Teleskoplader & & 0,00 & $D M / a$ & 66,50 & $\mathrm{DM} / \mathrm{h}$ & 479,22 & $h / a$ & $31.867,84$ & $\mathrm{DM} / \mathrm{a}$ & \\
\hline Schredder & & 0,00 & DM/a & 7,50 & $\mathrm{DM} / \mathrm{m}^{3}$ (Out) & $1.411,76$ & $\mathrm{~m}^{3} / \mathrm{a}$ & $10.588,24$ & $\mathrm{DM} / \mathrm{a}$ & \\
\hline Trommelsieb & & 0,00 & $D M / a$ & 5,00 & $\mathrm{DM} / \mathrm{m}^{3}(\mathrm{Kom})$ & $2.400,00$ & $m^{3} / a$ & $12.000,00$ & $\mathrm{DM} / \mathrm{a}$ & \\
\hline PumpenTW ( & Veubau) & 0,00 & $\mathrm{DM} / \mathrm{a}$ & 30,00 & $\mathrm{DM} / \mathrm{h}$ & 61,71 & $\mathrm{~h} / \mathrm{a}$ & $1.851,35$ & $\mathrm{DM} / \mathrm{a}$ & \\
\hline PumpenTW (L & Jmnutzung) & 0,00 & $D M / a$ & 30,00 & $D M / h$ & 97,20 & $h / a$ & $2.916,00$ & $\mathrm{DM} / \mathrm{a}$ & \\
\hline Silozange & & $1.120,00$ & DM/a & 0,30 & $\mathrm{DM} / \mathrm{m}^{3}$ & $4.235,29$ & $\mathrm{~m}^{3} / \mathrm{a}$ & $2.390,59$ & $\mathrm{DM} / \mathrm{a}$ & \\
\hline Anbauschaufe & & 506,00 & $\mathrm{DM} / \mathrm{a}$ & 0,30 & $\mathrm{DM} / \mathrm{m}^{3}$ & $19.341,18$ & $\mathrm{~m}^{3} / \mathrm{a}$ & $6.308,35$ & $\mathrm{DM} / \mathrm{a}$ & \\
\hline Mietenumsetz & & $3.600,00$ & $\mathrm{DM} / \mathrm{a}$ & 28,00 & $\mathrm{DM} / \mathrm{h}$ & 105,91 & $\mathrm{~h} / \mathrm{a}$ & $6.565,58$ & $\mathrm{DM} / \mathrm{a}$ & \\
\hline & & & & & & Summe (Neuk & bau) & $77.195,79$ & $\mathrm{DM} / \mathrm{a}$ & \\
\hline & & & & & & Summe (Umn & hutzung) & $79.451,07$ & $\mathrm{DM} / \mathrm{a}$ & \\
\hline PERSONA & LOSTEN & & & & & & & & & \\
\hline & Std.-Lohn inkl & I.Lohn-NK & Arbeitsstd. pro & o Jahr & Personal-Einz & zelkosten & & & & \\
\hline Neubau & 26,00 & $D M / h$ & 930,14 & $\mathrm{~h} / \mathrm{a}$ & $24.183,52$ & $D M / a$ & & & & \\
\hline Umnutzung & 26,00 & $\mathrm{DM} / \mathrm{h}$ & 965,62 & $\mathrm{~h} / \mathrm{a}$ & $25.106,21$ & $\mathrm{DM} / \mathrm{a}$ & & & & \\
\hline
\end{tabular}




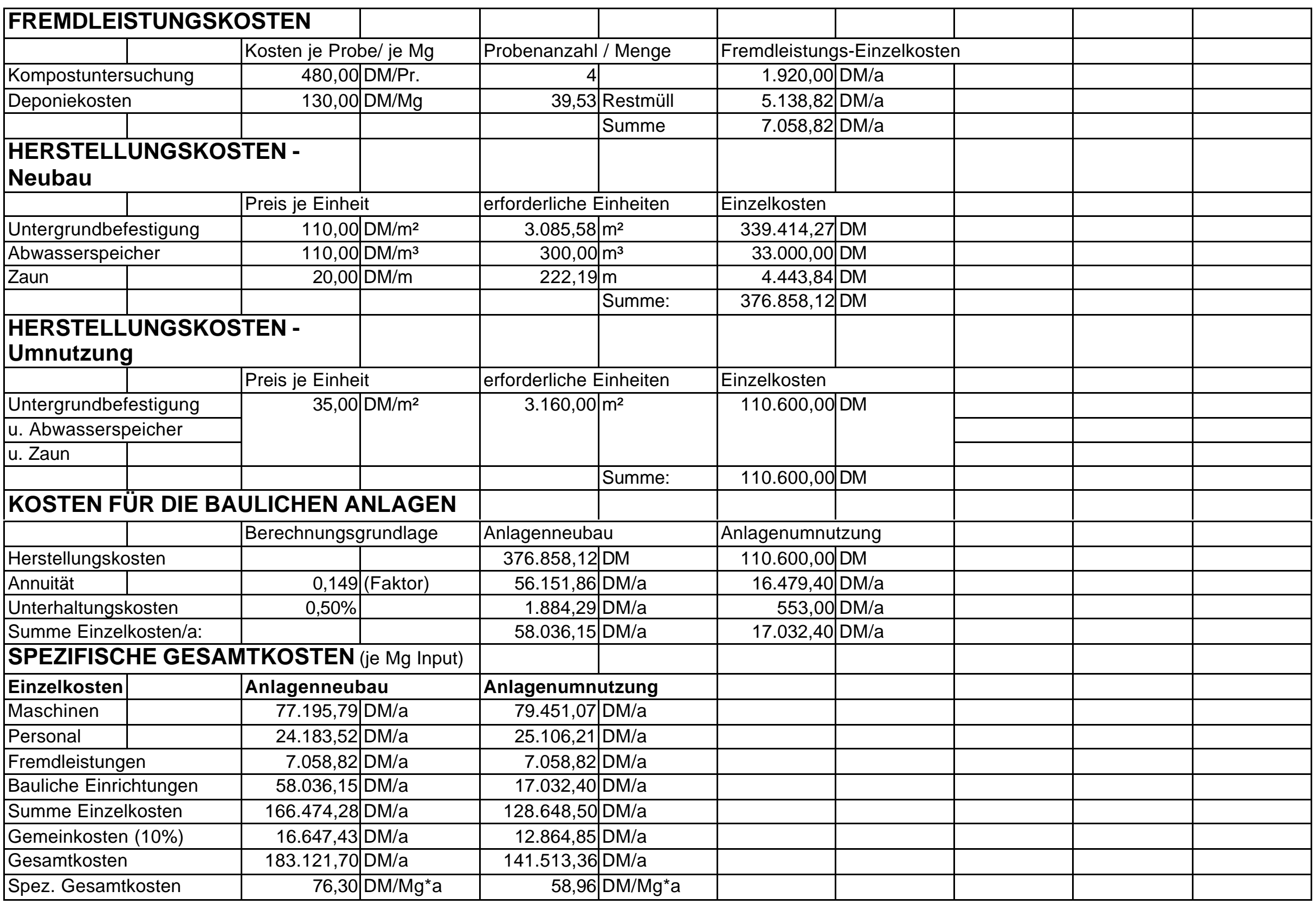


Kostenvariante B12

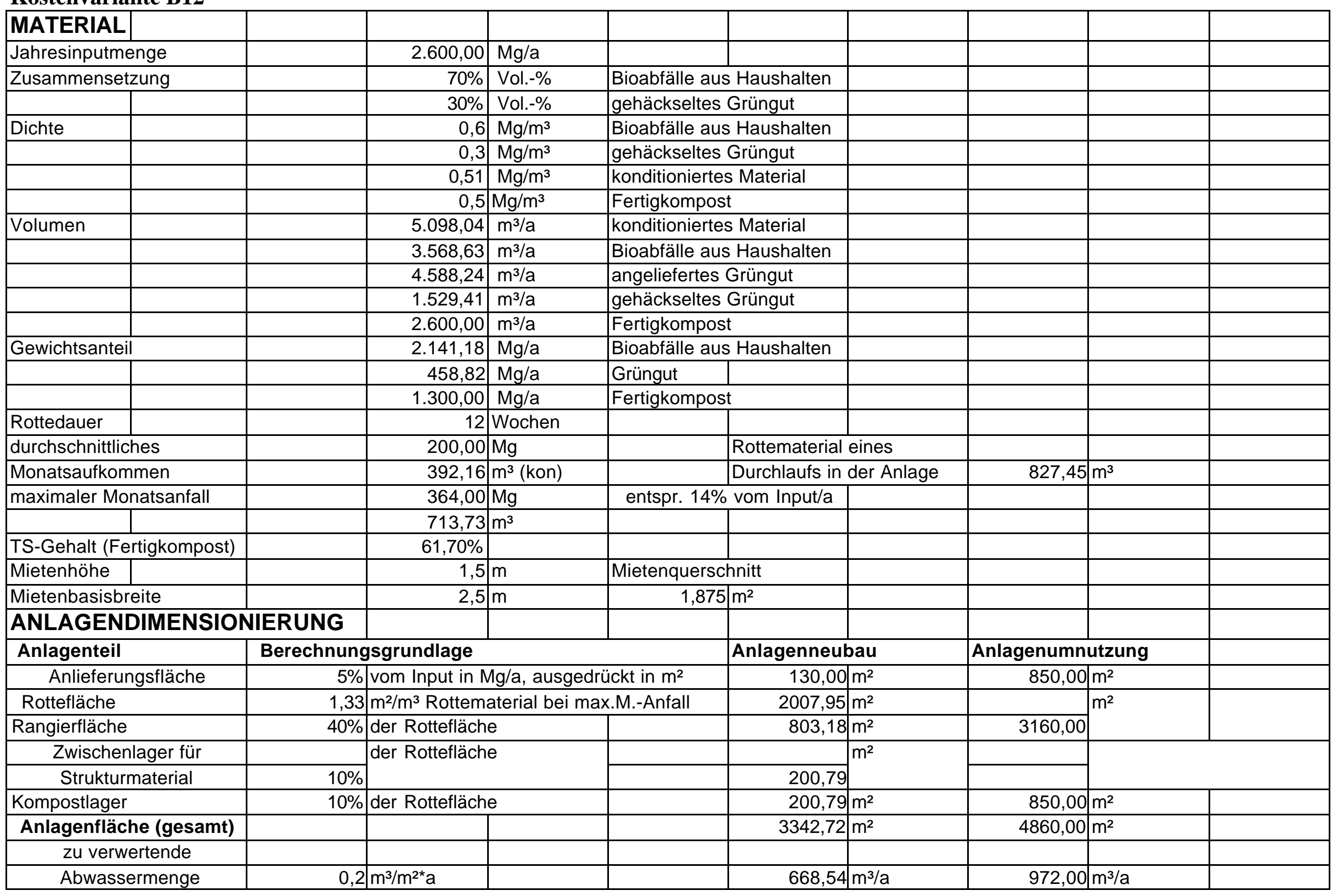




\begin{tabular}{|c|c|c|c|c|c|c|c|c|c|c|}
\hline \multicolumn{11}{|l|}{ ZEITEN } \\
\hline \multicolumn{3}{|l|}{ Arbeitsgang } & \multicolumn{2}{|c|}{ eingesetzte Maschinen } & \multicolumn{2}{|c|}{ Zeitbedarf/Einheit } & \multicolumn{2}{|c|}{ geleistete Einheiten } & \multicolumn{2}{|c|}{ Zeitbedarf/Jahr } \\
\hline \multicolumn{3}{|c|}{ Materialannahme } & & & 4,000 & h/Woche & 52,000 & Wochen/a & 208,000 & $h / a$ \\
\hline \multicolumn{3}{|c|}{ Manuelle Störstoffauslese } & & & 1,000 & $h / 100 m^{3}(\operatorname{In})$ & $8.156,863$ & $\mathrm{~m}^{3} / \mathrm{a}$ & 81,569 & $\mathrm{~h} / \mathrm{a}$ \\
\hline \multicolumn{3}{|c|}{ Zerkleinerung von Strukturmaterial } & TL, SZ, Schr. & & 1,000 & $h / 50 m^{3}(\ln )$ & $4.588,235$ & $\mathrm{~m}^{3} / \mathrm{a}$ & 91,765 & $h / a$ \\
\hline \multicolumn{3}{|c|}{ Aufsetzen einer Matte aus Strukturmat. } & TL, AS & & 0,300 & $\mathrm{~h} / 100 \mathrm{~m}^{3}$ (kon) & $5.098,039$ & $\mathrm{~m}^{3} / \mathrm{a}$ & 15,294 & $\mathrm{~h} / \mathrm{a}$ \\
\hline \multicolumn{3}{|c|}{ Aufsetzen der Dreiecksmieten } & TL, AS & & 1,000 & $\mathrm{~h} / 20 \mathrm{~m}^{3}$ (kon) & $5.098,039$ & $\mathrm{~m}^{3} / \mathrm{a}$ & 254,902 & $h / a$ \\
\hline \multicolumn{3}{|c|}{ Umsetzen der Dreiecksmieten } & Schl., MU & & 0,005 & $\mathrm{~h} / \mathrm{m}$ (Mietenl.) & $22.947,974$ & $\mathrm{~m} / \mathrm{a}$ & 114,740 & $h / a$ \\
\hline \multicolumn{3}{|c|}{ Reinigung der Annahmefläche } & TL, AS & & 0,500 & $h / 150 m^{3}(\ln )$ & $8.156,863$ & $\mathrm{~m}^{3} / \mathrm{a}$ & 27,190 & $h / a$ \\
\hline \multicolumn{3}{|l|}{ Sieben } & TL, AS, Sieb & & 1,000 & $\mathrm{~h} / 20 \mathrm{~m}^{3}(\mathrm{kom})$ & $2.600,000$ & $\mathrm{~m}^{3} / \mathrm{a}$ & 130,000 & $\mathrm{~h} / \mathrm{a}$ \\
\hline \multicolumn{3}{|c|}{ Abw.-Ausbringung bei Neubau } & Schl.,PT & & 1,000 & $\mathrm{~h} / 10 \mathrm{~m}^{3}(\mathrm{Abw})$ & 668,543 & $\mathrm{~m}^{3} / \mathrm{a}$ & 66,854 & $h / a$ \\
\hline \multicolumn{3}{|c|}{ Abw.-Ausbringung bei Umnutzung } & Schl., PT & & 1,000 & $\mathrm{~h} / 10 \mathrm{~m}^{3}(\mathrm{Abw})$ & 972,000 & $\mathrm{~m}^{3} / \mathrm{a}$ & 97,200 & $h / a$ \\
\hline \multicolumn{11}{|c|}{ Abkürzungen für die eingesetzten Maschinen: } \\
\hline \multicolumn{2}{|c|}{ TL - Teleskoplader } & & \multicolumn{2}{|c|}{ Schl. - Schlepper } & & & & & & \\
\hline \multicolumn{2}{|c|}{\begin{tabular}{|l} 
MU- Mietenumsetzer \\
\end{tabular}} & & Schr. - Schred & dder & & & & & & \\
\hline \multicolumn{2}{|c|}{ SZ - Silozange } & & PT - Pumpenta & tankwagen & & & & & & \\
\hline \multicolumn{11}{|c|}{ AS - Anbauschaufel } \\
\hline \multicolumn{11}{|c|}{ MASCHINENKOSTEN } \\
\hline \multicolumn{2}{|c|}{ Maschine / Gerät } & Fixkosten & & \multicolumn{2}{|c|}{ Variable Kosten } & Einheiten/a & & \multicolumn{2}{|c|}{ Maschinen-Einzelkosten } & \\
\hline Traktor (Neub & au) & 0,00 & $\mathrm{DM} / \mathrm{a}$ & 33,55 & $\mathrm{DM} / \mathrm{h}$ & 181,59 & $h / a$ & $6.092,49$ & $\mathrm{DM} / \mathrm{a}$ & \\
\hline Traktor (Umnı & itzung) & 0,00 & $\mathrm{DM} / \mathrm{a}$ & 33,55 & $\mathrm{DM} / \mathrm{h}$ & 211,94 & $\mathrm{~h} / \mathrm{a}$ & $7.110,58$ & $\mathrm{DM} / \mathrm{a}$ & \\
\hline Teleskoplader & & 0,00 & $\mathrm{DM} / \mathrm{a}$ & 66,50 & $\mathrm{DM} / \mathrm{h}$ & 519,15 & $h / a$ & $34.523,50$ & $\mathrm{DM} / \mathrm{a}$ & \\
\hline Schredder & & 0,00 & $\mathrm{DM} / \mathrm{a}$ & 7,50 & $\mathrm{DM} / \mathrm{m}^{3}$ (Out) & $1.529,41$ & $\mathrm{~m}^{3} / \mathrm{a}$ & $11.470,59$ & $\mathrm{DM} / \mathrm{a}$ & \\
\hline Trommelsieb & & 0,00 & $\mathrm{DM} / \mathrm{a}$ & 5,00 & $\mathrm{DM} / \mathrm{m}^{3}(\mathrm{Kom})$ & $2.600,00$ & $m^{3} / a$ & $13.000,00$ & $\mathrm{DM} / \mathrm{a}$ & \\
\hline PumpenTW (I & Veubau) & 0,00 & $\mathrm{DM} / \mathrm{a}$ & 30,00 & $\mathrm{DM} / \mathrm{h}$ & 66,85 & $\mathrm{~h} / \mathrm{a}$ & $2.005,63$ & $\mathrm{DM} / \mathrm{a}$ & \\
\hline PumpenTW (L & Jmnutzung) & 0,00 & $D M / a$ & 30,00 & $D M / h$ & 97,20 & $h / a$ & $2.916,00$ & $\mathrm{DM} / \mathrm{a}$ & \\
\hline Silozange & & $1.120,00$ & DM/a & 0,30 & $\mathrm{DM} / \mathrm{m}^{3}$ & $4.588,24$ & $\mathrm{~m}^{3} / \mathrm{a}$ & $2.496,47$ & $\mathrm{DM} / \mathrm{a}$ & \\
\hline Anbauschaufe & & 506,00 & $\mathrm{DM} / \mathrm{a}$ & 0,30 & $\mathrm{DM} / \mathrm{m}^{3}$ & $20.952,94$ & $\mathrm{~m}^{3} / \mathrm{a}$ & $6.791,88$ & $\mathrm{DM} / \mathrm{a}$ & \\
\hline Mietenumsetz & & $3.600,00$ & $\mathrm{DM} / \mathrm{a}$ & 28,00 & $\mathrm{DM} / \mathrm{h}$ & 114,74 & $\mathrm{~h} / \mathrm{a}$ & $6.812,72$ & $\mathrm{DM} / \mathrm{a}$ & \\
\hline & & & & & & Summe (Neuk & bau) & $83.193,27$ & $\mathrm{DM} / \mathrm{a}$ & \\
\hline & & & & & & Summe (Umn & uutzung) & $85.121,74$ & $\mathrm{DM} / \mathrm{a}$ & \\
\hline PERSONA & LOSTEN & & & & & & & & & \\
\hline & Std.-Lohn inkl & I.Lohn-NK & Arbeitsstd. pro & o Jahr & Personal-Einz & zelkosten & & & & \\
\hline Neubau & 26,00 & $D M / h$ & 990,31 & $\mathrm{~h} / \mathrm{a}$ & $25.748,14$ & $D M / a$ & & & & \\
\hline Umnutzung & 26,00 & $D M / h$ & $1.020,66$ & $h / a$ & $26.537,13$ & DM/a & & & & \\
\hline
\end{tabular}




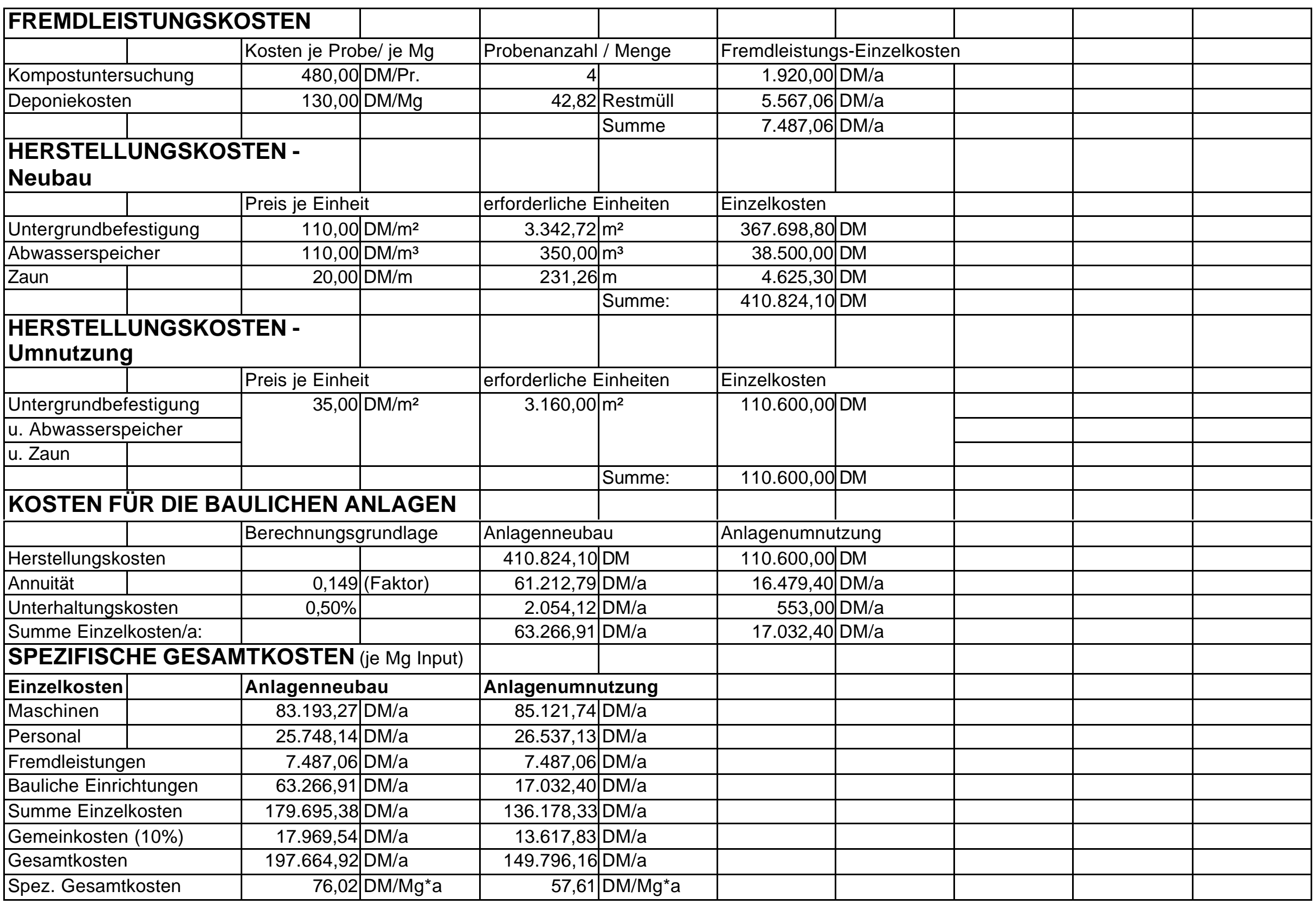


Kostenvariante B13

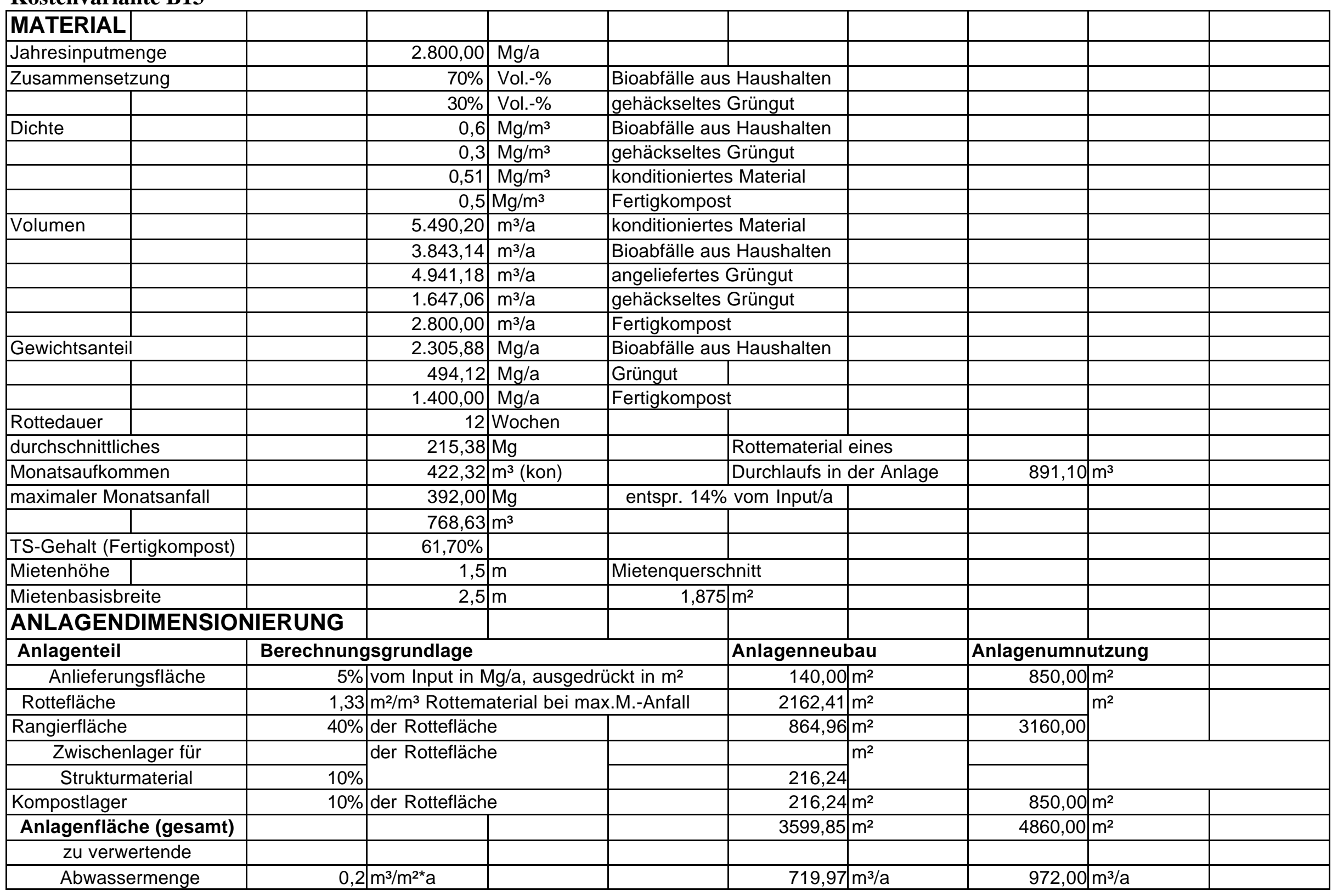




\begin{tabular}{|c|c|c|c|c|c|c|c|c|c|c|}
\hline \multicolumn{11}{|l|}{ ZEITEN } \\
\hline \multicolumn{3}{|l|}{ Arbeitsgang } & \multicolumn{2}{|c|}{ eingesetzte Maschinen } & \multicolumn{2}{|c|}{ Zeitbedarf/Einheit } & \multicolumn{2}{|c|}{ geleistete Einheiten } & \multicolumn{2}{|c|}{ Zeitbedarf/Jahr } \\
\hline \multicolumn{3}{|c|}{ Materialannahme } & & & 4,000 & h/Woche & 52,000 & Wochen/a & 208,000 & $h / a$ \\
\hline \multicolumn{3}{|c|}{ Manuelle Störstoffauslese } & & & 1,000 & $h / 100 m^{3}(\operatorname{In})$ & $8.784,314$ & $\mathrm{~m}^{3} / \mathrm{a}$ & 87,843 & $\mathrm{~h} / \mathrm{a}$ \\
\hline \multicolumn{3}{|c|}{ Zerkleinerung von Strukturmaterial } & TL, SZ, Schr. & & 1,000 & $h / 50 m^{3}(\ln )$ & $4.941,176$ & $\mathrm{~m}^{3} / \mathrm{a}$ & 98,824 & $h / a$ \\
\hline \multicolumn{3}{|c|}{ Aufsetzen einer Matte aus Strukturmat. } & TL, AS & & 0,300 & $\mathrm{~h} / 100 \mathrm{~m}^{3}$ (kon) & $5.490,196$ & $\mathrm{~m}^{3} / \mathrm{a}$ & 16,471 & $\mathrm{~h} / \mathrm{a}$ \\
\hline \multicolumn{3}{|c|}{ Aufsetzen der Dreiecksmieten } & TL, AS & & 1,000 & $\mathrm{~h} / 20 \mathrm{~m}^{3}$ (kon) & $5.490,196$ & $\mathrm{~m}^{3} / \mathrm{a}$ & 274,510 & $h / a$ \\
\hline \multicolumn{3}{|c|}{ Umsetzen der Dreiecksmieten } & Schl., MU & & 0,005 & $\mathrm{~h} / \mathrm{m}$ (Mietenl.) & $24.713,203$ & $\mathrm{~m} / \mathrm{a}$ & 123,566 & $\mathrm{~h} / \mathrm{a}$ \\
\hline \multicolumn{3}{|c|}{ Reinigung der Annahmefläche } & TL, AS & & 0,500 & $\mathrm{~h} / 150 \mathrm{~m}^{3}(\ln )$ & $8.784,314$ & $\mathrm{~m}^{3} / \mathrm{a}$ & 29,281 & $\mathrm{~h} / \mathrm{a}$ \\
\hline \multicolumn{3}{|l|}{ Sieben } & TL, AS, Sieb & & 1,000 & $\mathrm{~h} / 20 \mathrm{~m}^{3}(\mathrm{kom})$ & $2.800,000$ & $\mathrm{~m}^{3} / \mathrm{a}$ & 140,000 & $\mathrm{~h} / \mathrm{a}$ \\
\hline \multicolumn{3}{|c|}{ Abw.-Ausbringung bei Neubau } & Schl.,PT & & 1,000 & $\mathrm{~h} / 10 \mathrm{~m}^{3}(\mathrm{Abw})$ & 719,970 & $\mathrm{~m}^{3} / \mathrm{a}$ & 71,997 & $h / a$ \\
\hline \multicolumn{3}{|c|}{ Abw.-Ausbringung bei Umnutzung } & Schl., PT & & 1,000 & $\mathrm{~h} / 10 \mathrm{~m}^{3}(\mathrm{Abw})$ & 972,000 & $\mathrm{~m}^{3} / \mathrm{a}$ & 97,200 & $h / a$ \\
\hline \multicolumn{11}{|c|}{ Abkürzungen für die eingesetzten Maschinen: } \\
\hline \multicolumn{2}{|c|}{ TL - Teleskoplader } & & \multicolumn{2}{|c|}{ Schl. - Schlepper } & & & & & & \\
\hline \multicolumn{2}{|c|}{\begin{tabular}{|l} 
MU- Mietenumsetzer \\
\end{tabular}} & & Schr. - Schred & dder & & & & & & \\
\hline \multicolumn{2}{|c|}{ SZ - Silozange } & & PT - Pumpenta & tankwagen & & & & & & \\
\hline \multicolumn{11}{|c|}{ AS - Anbauschaufel } \\
\hline \multicolumn{11}{|c|}{ MASCHINENKOSTEN } \\
\hline \multicolumn{2}{|c|}{ Maschine / Gerät } & Fixkosten & & \multicolumn{2}{|c|}{ Variable Kosten } & Einheiten/a & & \multicolumn{2}{|c|}{ Maschinen-Einzelkosten } & \\
\hline Traktor (Neub & au) & 0,00 & $\mathrm{DM} / \mathrm{a}$ & 33,55 & $\mathrm{DM} / \mathrm{h}$ & 195,56 & $\mathrm{~h} / \mathrm{a}$ & $6.561,14$ & $\mathrm{DM} / \mathrm{a}$ & \\
\hline Traktor (Umnı & itzung) & 0,00 & $\mathrm{DM} / \mathrm{a}$ & 33,55 & $\mathrm{DM} / \mathrm{h}$ & 220,77 & $\mathrm{~h} / \mathrm{a}$ & $7.406,70$ & $\mathrm{DM} / \mathrm{a}$ & \\
\hline Teleskoplader & & 0,00 & $\mathrm{DM} / \mathrm{a}$ & 66,50 & $\mathrm{DM} / \mathrm{h}$ & 559,08 & $\mathrm{~h} / \mathrm{a}$ & $37.179,15$ & $\mathrm{DM} / \mathrm{a}$ & \\
\hline Schredder & & 0,00 & $\mathrm{DM} / \mathrm{a}$ & 7,50 & $\mathrm{DM} / \mathrm{m}^{3}$ (Out) & $1.647,06$ & $\mathrm{~m}^{3} / \mathrm{a}$ & $12.352,94$ & $\mathrm{DM} / \mathrm{a}$ & \\
\hline Trommelsieb & & 0,00 & $\mathrm{DM} / \mathrm{a}$ & 5,00 & $\mathrm{DM} / \mathrm{m}^{3}(\mathrm{Kom})$ & $2.800,00$ & $\mathrm{~m}^{3} / \mathrm{a}$ & $14.000,00$ & $\mathrm{DM} / \mathrm{a}$ & \\
\hline PumpenTW (I & Veubau) & 0,00 & $\mathrm{DM} / \mathrm{a}$ & 30,00 & $\mathrm{DM} / \mathrm{h}$ & 72,00 & $\mathrm{~h} / \mathrm{a}$ & $2.159,91$ & $\mathrm{DM} / \mathrm{a}$ & \\
\hline PumpenTW (L & Jmnutzung) & 0,00 & $D M / a$ & 30,00 & $D M / h$ & 97,20 & $\mathrm{~h} / \mathrm{a}$ & $2.916,00$ & $\mathrm{DM} / \mathrm{a}$ & \\
\hline Silozange & & $1.120,00$ & DM/a & 0,30 & $\mathrm{DM} / \mathrm{m}^{3}$ & $4.941,18$ & $\mathrm{~m}^{3} / \mathrm{a}$ & $2.602,35$ & $\mathrm{DM} / \mathrm{a}$ & \\
\hline Anbauschaufe & & 506,00 & $\mathrm{DM} / \mathrm{a}$ & 0,30 & $\mathrm{DM} / \mathrm{m}^{3}$ & $22.564,71$ & $\mathrm{~m}^{3} / \mathrm{a}$ & $7.275,41$ & $\mathrm{DM} / \mathrm{a}$ & \\
\hline Mietenumsetz & & $3.600,00$ & $\mathrm{DM} / \mathrm{a}$ & 28,00 & $\mathrm{DM} / \mathrm{h}$ & 123,57 & $\mathrm{~h} / \mathrm{a}$ & $7.059,85$ & $\mathrm{DM} / \mathrm{a}$ & \\
\hline & & & & & & Summe (Neub & bau) & $89.190,75$ & $\mathrm{DM} / \mathrm{a}$ & \\
\hline & & & & & & Summe (Umn & uutzung) & $90.792,40$ & $\mathrm{DM} / \mathrm{a}$ & \\
\hline PERSONAI & LOSTEN & & & & & & & & & \\
\hline & Std.-Lohn inkl & I.Lohn-NK & Arbeitsstd. pro & o Jahr & Personal-Einz & zelkosten & & & & \\
\hline Neubau & 26,00 & $D M / h$ & $1.050,49$ & $\mathrm{~h} / \mathrm{a}$ & $27.312,77$ & $D M / a$ & & & & \\
\hline Umnutzung & 26,00 & $D M / h$ & $1.075,69$ & $h / a$ & $27.968,05$ & $D M / a$ & & & & \\
\hline
\end{tabular}




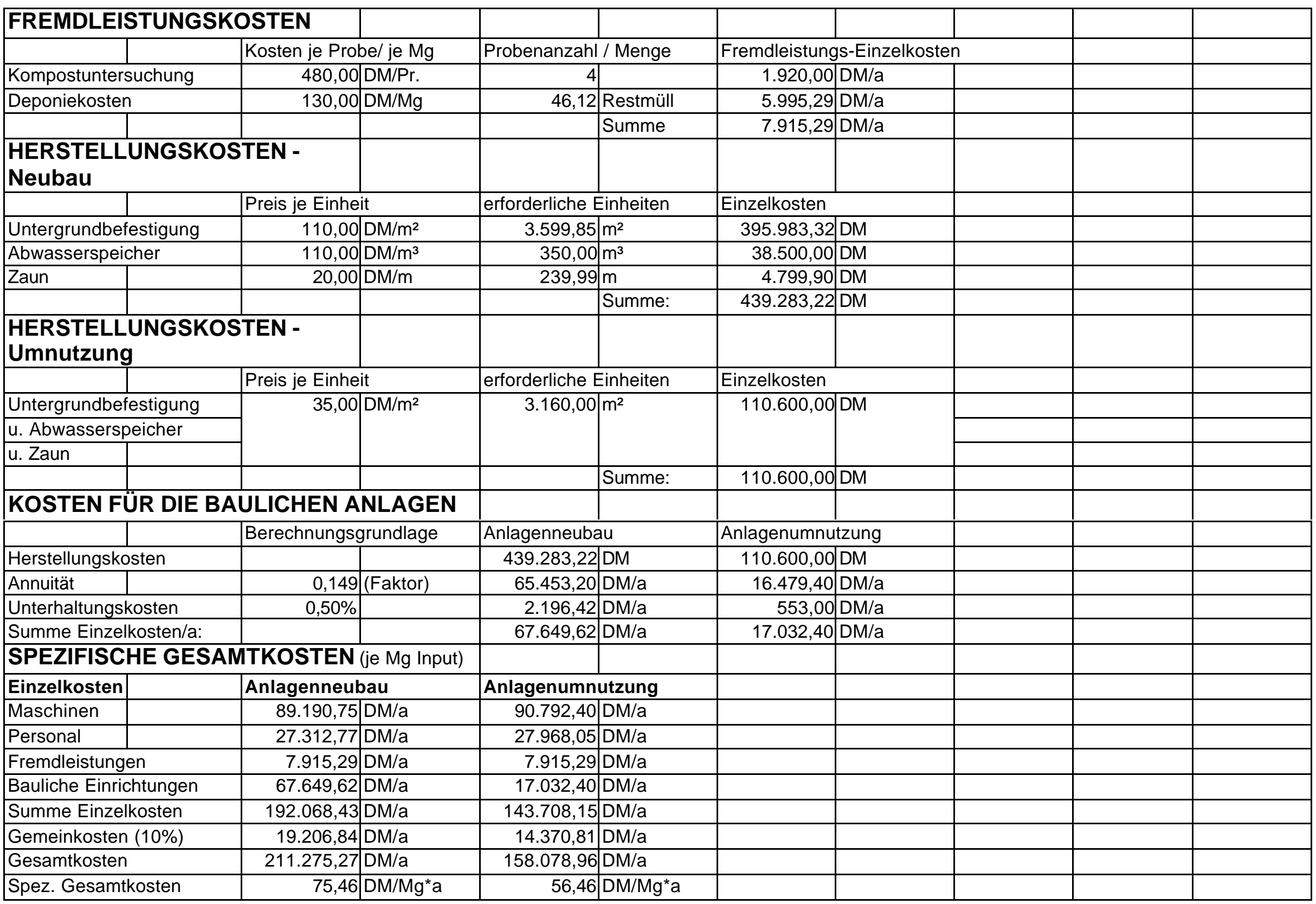


Kostenvariante C1

\section{MATERIAL}

Jahresinputmenge

Zusammensetzung

\begin{tabular}{|l|l|}
\hline & \\
\hline Dichte & \\
\hline & \\
\hline & \\
\hline & \\
\hline Volumen & \\
\hline & \\
\hline & \\
\hline & \\
\hline & \\
\hline
\end{tabular}

Gewichtsanteil

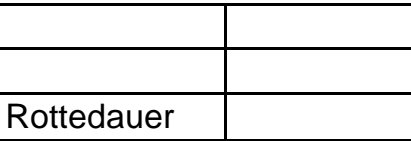

durchschnittliches

Monatsaufkommen

maximaler Monatsanfall

\begin{tabular}{l|l} 
& \\
\hline TS-Gehalt (Fertigkompost)
\end{tabular}

Mietenhöhe

Mietenbasisbreite

\section{ANLAGENDIMENSIONIERUNG}

\section{Anlagenteil}

Anlieferungsfläche

Rottefläche

Rangierfläche

Zwischenlager für

Strukturmaterial

Kompostlager

Anlagenfläche (gesamt)

zu verwertende

Abwassermenge

\section{|}

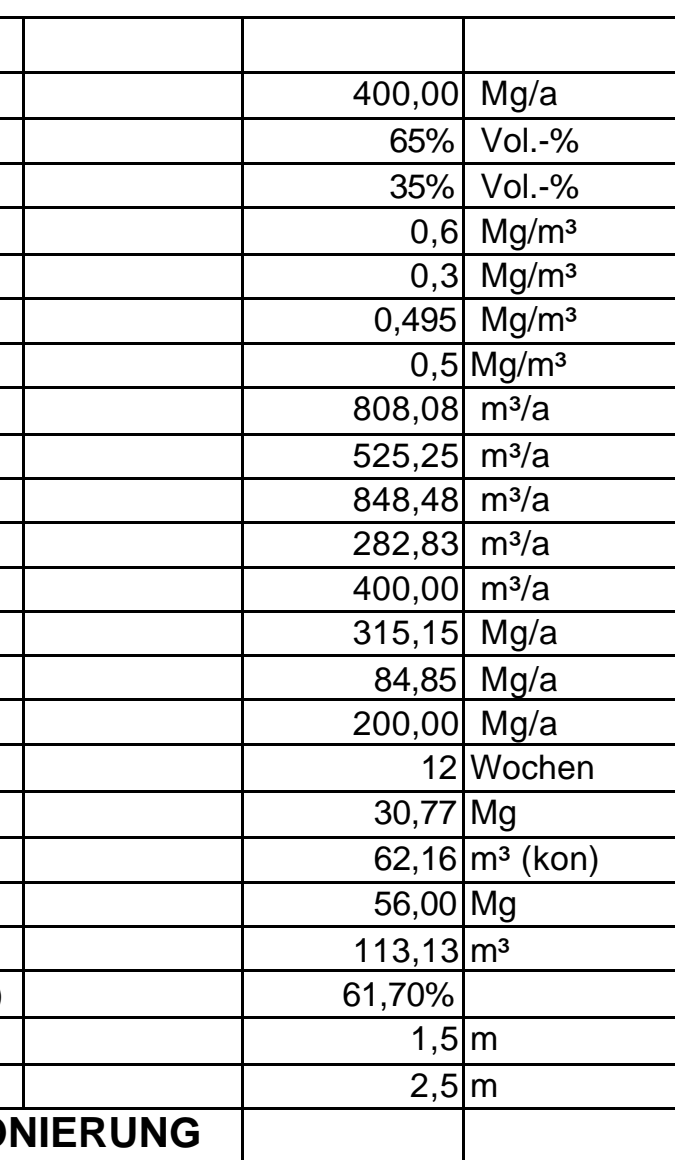

Berechnungsgrundlage

$5 \%$ vom Input in Mg/a, ausgedrückt in $\mathrm{m}^{2}$

$1,33 \mathrm{~m}^{2} / \mathrm{m}^{3}$ Rottematerial bei max.M.-Anfall

$40 \%$ der Rottefläche

der Rottefläche

$10 \%$ der Rottefläche

$+$

$0,2 \mathrm{~m}^{3} / \mathrm{m}^{2 \star} \mathrm{a}$

Grüngut

\begin{tabular}{|c|c|c|}
\hline ax.M.-Anfall & 316,01 & $\mathrm{~m}^{2}$ \\
\hline & 126,41 & $m^{2}$ \\
\hline & & $\mathrm{m}^{2}$ \\
\hline & 31,60 & \\
\hline & 31,60 & $\mathrm{~m}^{2}$ \\
\hline & 525,62 & $\mathrm{~m}^{2}$ \\
\hline & 105,12 & $m^{3} / a$ \\
\hline
\end{tabular}

Bioabfälle aus Haushalten

gehäckseltes Grüngut

Bioabfälle aus Haushalten

gehäckseltes Grüngut

konditioniertes Material

Fertigkompost

konditioniertes Material

Bioabfälle aus Haushalten

angeliefertes Grüngut

gehäckseltes Grüngut

Fertigkompost

Bioabfälle aus Haushalten

Fertigkompost

\begin{tabular}{l|l|l}
\hline & & \\
\hline & Rottematerial eines
\end{tabular}

entspr. 14\% vom Input/a

Mietenquerschnitt

\begin{tabular}{|r|l|l}
\hline $1,875 \mathrm{~m}^{2}$ & \\
\hline & &
\end{tabular}

Anlagenneubau

Anlagenumnutzung

\begin{tabular}{|c|c|c|}
\hline 400,00 & $\mathrm{~m}^{2}$ & \\
\hline & $\mathrm{m}^{2}$ & \\
\hline 1525,00 & & \\
\hline & $m^{2}(r$ & ert) \\
\hline 600,00 & & \\
\hline 400,00 & $\mathrm{~m}^{2}$ & \\
\hline 2325,00 & $\mathrm{~m}^{2}$ & \\
\hline & & \\
\hline 465,00 & $\mathrm{~m}^{3} / \mathrm{a}$ & \\
\hline
\end{tabular}




\begin{tabular}{|c|c|c|c|c|c|c|c|c|c|c|}
\hline ZEITEN & & & & & & & & & & \\
\hline Arbeitsgang & & & eingesetzte $\mathrm{M}$ & Maschinen & Zeitbedarf/Ei & inheit & geleistete Ein & nheiten & Zeitbedarf/Ja & ahr \\
\hline Materialannah & ime & & & & 4,000 & h/Woche & 52,000 & Wochen/a & 208,000 & $h / a$ \\
\hline Manuelle Stör & stoffauslese & & & & 1,000 & $h / 100 m^{3}(\ln )$ & $1.373,737$ & $\mathrm{~m}^{3} / \mathrm{a}$ & 13,737 & $\mathrm{~h} / \mathrm{a}$ \\
\hline Zerkleinerung & von Strukturm & naterial & TL, SZ, Schr. & & 1,000 & $h / 50 m^{3}(\operatorname{In})$ & 848,485 & $\mathrm{~m}^{3} / \mathrm{a}$ & 16,970 & $h / a$ \\
\hline Aufsetzen ein & er Matte aus S & Strukturmat. & TL, AS & & 0,300 & $\mathrm{~h} / 100 \mathrm{~m}^{3}$ (kon) & 808,081 & $\mathrm{~m}^{3} / \mathrm{a}$ & 2,424 & $h / a$ \\
\hline Aufsetzen der & Dreiecksmiete & & TL, AS & & 1,000 & $\mathrm{~h} / 20 \mathrm{~m}^{3}$ (kon) & 808,081 & $\mathrm{~m}^{3} / \mathrm{a}$ & 40,404 & $\mathrm{~h} / \mathrm{a}$ \\
\hline Umsetzen der & Dreiecksmiete & & Schl., MU & & 0,005 & $\mathrm{~h} / \mathrm{m}$ (Mietenl.) & $3.611,582$ & $\mathrm{~m} / \mathrm{a}$ & 18,058 & $\mathrm{~h} / \mathrm{a}$ \\
\hline Reinigung der & Annahmefläch & & TL, AS & & 0,500 & $h / 150 m^{3}(\ln )$ & $1.373,737$ & $\mathrm{~m}^{3} / \mathrm{a}$ & 4,579 & $h / a$ \\
\hline Sieben & & & TL, AS, Sieb & & 1,000 & $\mathrm{~h} / 20 \mathrm{~m}^{3}(\mathrm{kom})$ & 400,000 & $\mathrm{~m}^{3} / \mathrm{a}$ & 20,000 & $h / a$ \\
\hline Abw.-Ausbring & gung bei Neub & & Schl.,PT & & 1,000 & $\mathrm{~h} / 10 \mathrm{~m}^{3}(\mathrm{Abw})$ & 105,124 & $\mathrm{~m}^{3} / \mathrm{a}$ & 10,512 & $h / a$ \\
\hline Abw.-Ausbring & gung bei Umnu & utzung & Schl., PT & & 1,000 & $\mathrm{~h} / 10 \mathrm{~m}^{3}(\mathrm{Abw})$ & 465,000 & $\mathrm{~m}^{3} / \mathrm{a}$ & 46,500 & $h / a$ \\
\hline Abkürzungen & für die eingese & etzten Maschin & nen: & & & & & & & \\
\hline TL - Teleskop & lader & & Schl. - Schlepp & per & & & & & & \\
\hline MU- Mietenum & nsetzer & & Schr. - Schred & dder & & & & & & \\
\hline SZ - Silozange & & & PT - Pumpenta & tankwagen & & & & & & \\
\hline AS - Anbausc & haufel & & & & & & & & & \\
\hline MASCHINE & ENKOSTEN & & & & & & & & & \\
\hline Maschine / G & erät & Fixkosten & & Variable Kost & ten & Einheiten/a & & Maschinen-Ei & inzelkosten & \\
\hline Traktor (Neub & au) & 0,00 & $\mathrm{DM} / \mathrm{a}$ & 33,55 & $D M / h$ & 28,57 & $h / a$ & 958,54 & $D M / a$ & \\
\hline Traktor (Umnu & itzung) & 0,00 & $\mathrm{DM} / \mathrm{a}$ & 33,55 & $D M / h$ & 64,56 & $\mathrm{~h} / \mathrm{a}$ & $2.165,92$ & $\mathrm{DM} / \mathrm{a}$ & \\
\hline Teleskoplader & & 0,00 & $D M / a$ & 66,50 & $\mathrm{DM} / \mathrm{h}$ & 84,38 & $\mathrm{~h} / \mathrm{a}$ & $5.611,08$ & $\mathrm{DM} / \mathrm{a}$ & \\
\hline Schredder & & 0,00 & DM/a & 7,50 & $\mathrm{DM} / \mathrm{m}^{3}$ (Out) & 282,83 & $\mathrm{~m}^{3} / \mathrm{a}$ & $2.121,21$ & $\mathrm{DM} / \mathrm{a}$ & \\
\hline Trommelsieb & & 0,00 & $D M / a$ & 5,00 & $\mathrm{DM} / \mathrm{m}^{3}(\mathrm{Kom})$ & 400,00 & $\mathrm{~m}^{3} / \mathrm{a}$ & $2.000,00$ & $\mathrm{DM} / \mathrm{a}$ & \\
\hline PumpenTW ( & Veubau) & 0,00 & $\mathrm{DM} / \mathrm{a}$ & 30,00 & $\mathrm{DM} / \mathrm{h}$ & 10,51 & $\mathrm{~h} / \mathrm{a}$ & 315,37 & $\mathrm{DM} / \mathrm{a}$ & \\
\hline PumpenTW (L & Jmnutzung) & 0,00 & $D M / a$ & 30,00 & $D M / h$ & 46,50 & $h / a$ & $1.395,00$ & $\mathrm{DM} / \mathrm{a}$ & \\
\hline Silozange & & $1.120,00$ & DM/a & 0,30 & $\mathrm{DM} / \mathrm{m}^{3}$ & 848,48 & $\mathrm{~m}^{3} / \mathrm{a}$ & $1.374,55$ & $\mathrm{DM} / \mathrm{a}$ & \\
\hline Anbauschaufe & & 506,00 & $\mathrm{DM} / \mathrm{a}$ & 0,30 & $\mathrm{DM} / \mathrm{m}^{3}$ & $3.389,90$ & $m^{3} / a$ & $1.522,97$ & $\mathrm{DM} / \mathrm{a}$ & \\
\hline Mietenumsetz & & $3.600,00$ & $\mathrm{DM} / \mathrm{a}$ & 28,00 & $\mathrm{DM} / \mathrm{h}$ & 18,06 & $h / a$ & $4.105,62$ & $\mathrm{DM} / \mathrm{a}$ & \\
\hline & & & & & & Summe (Neuk & bau) & $18.009,33$ & $\mathrm{DM} / \mathrm{a}$ & \\
\hline & & & & & & Summe (Umn & hutzung) & $20.296,34$ & $\mathrm{DM} / \mathrm{a}$ & \\
\hline PERSONA & LOSTEN & & & & & & & & & \\
\hline & Std.-Lohn inkl & I.Lohn-NK & Arbeitsstd. pro & o Jahr & Personal-Einz & zelkosten & & & & \\
\hline Neubau & 26,00 & $D M / h$ & 334,68 & $\mathrm{~h} / \mathrm{a}$ & $8.701,81$ & $\mathrm{DM} / \mathrm{a}$ & & & & \\
\hline Umnutzung & 26,00 & $D M / h$ & 370,67 & $\mathrm{~h} / \mathrm{a}$ & $9.637,48$ & $D M / a$ & & & & \\
\hline
\end{tabular}




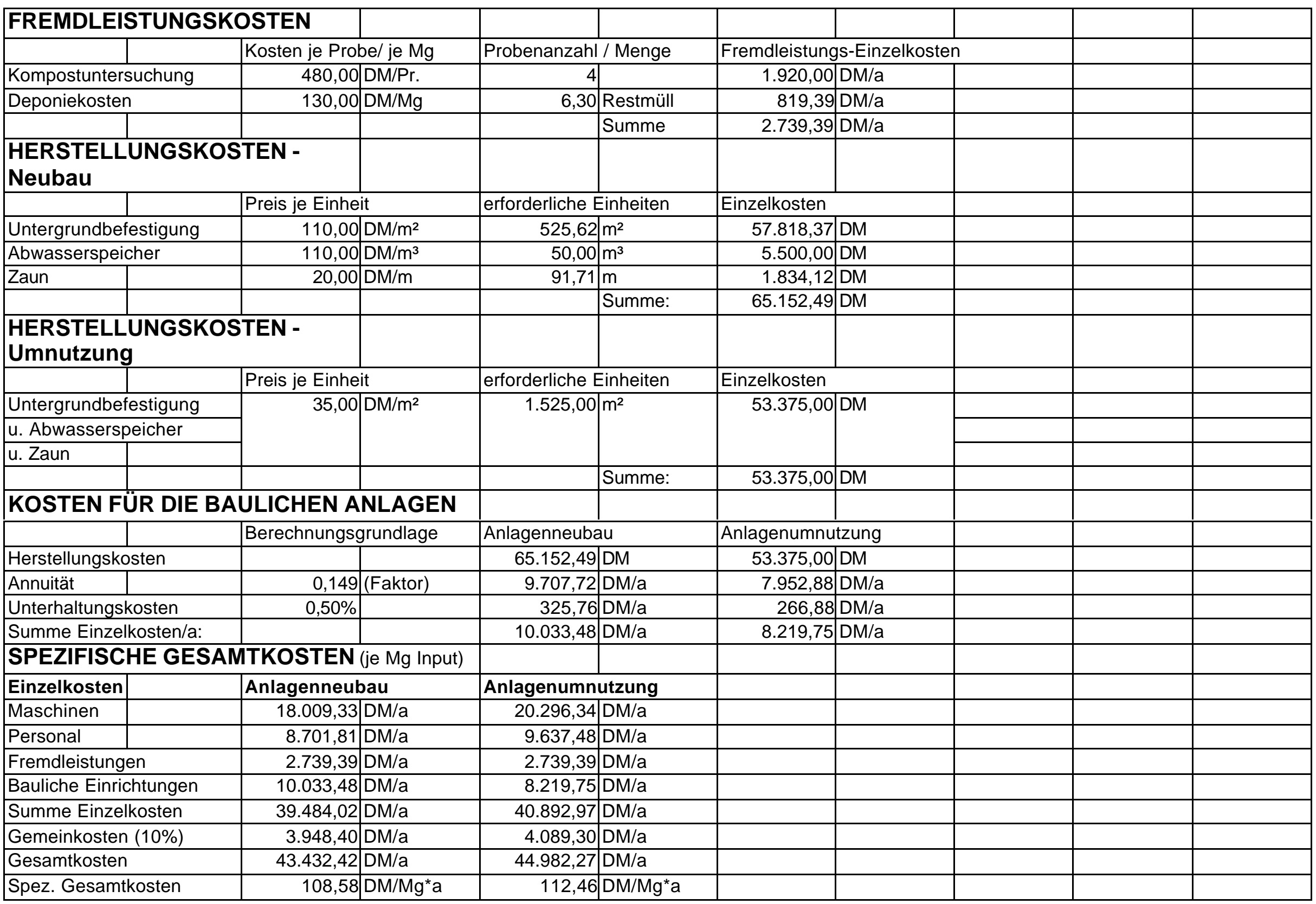


Kostenvariante C2

\section{MATERIAL}

Jahresinputmenge

Zusammensetzung

\begin{tabular}{|l|l|}
\hline & \\
\hline Dichte & \\
\hline & \\
\hline & \\
\hline & \\
\hline & \\
\hline & \\
\hline & \\
\hline & \\
\hline &
\end{tabular}

Gewichtsanteil

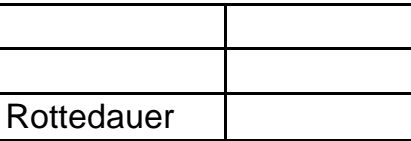

durchschnittliches

Monatsaufkommen

maximaler Monatsanfall

\begin{tabular}{l|} 
\\
\hline TS-Gehalt (Fertigkompost)
\end{tabular}

Mietenhöhe

Mietenbasisbreite

\section{ANLAGENDIMENSIONIERUNG}

\section{Anlagenteil}

Anlieferungsfläche

Rottefläche

Rangierfläche

Zwischenlager für

Strukturmaterial

Kompostlager

Anlagenfläche (gesamt)

zu verwertende

Abwassermenge

|

+

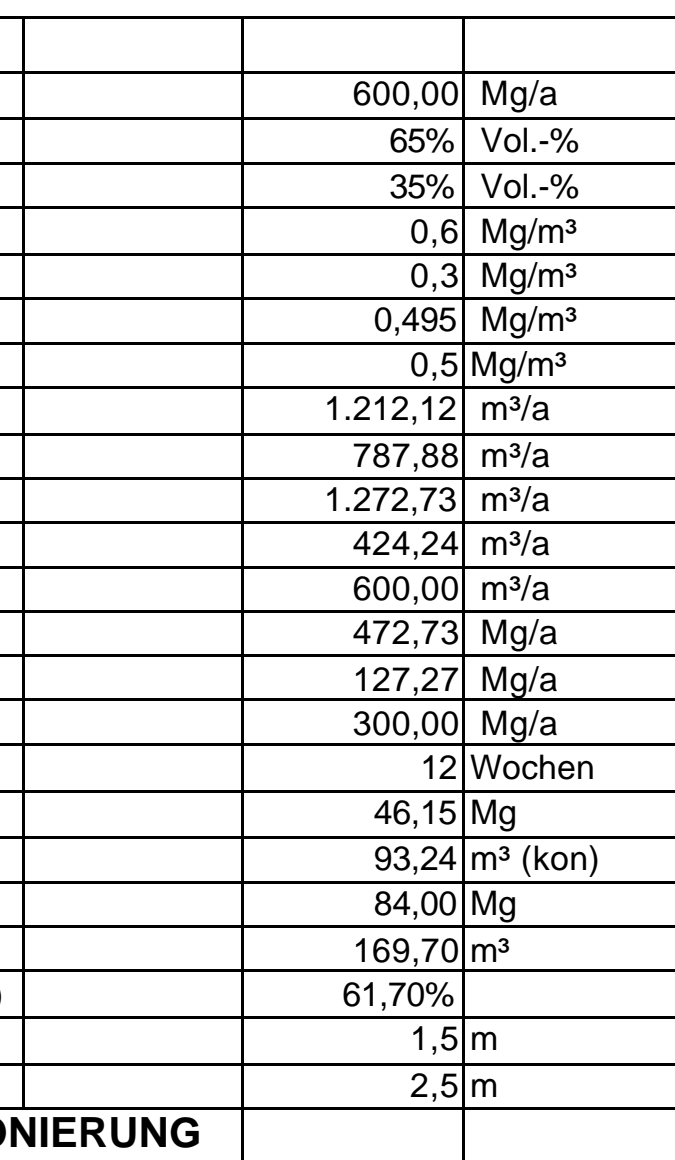

Berechnungsgrundlage

$5 \%$ vom Input in Mg/a, ausgedrückt in $\mathrm{m}^{2}$

$1,33 \mathrm{~m}^{2} / \mathrm{m}^{3}$ Rottematerial bei max.M.-Anfall

$40 \%$ der Rottefläche

der Rottefläche

$10 \%$ der Rottefläche

$0,2 \mathrm{~m}^{3} / \mathrm{m}^{2 \star} \mathrm{a}$

Grüngut

he

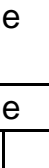

\begin{tabular}{l|l|}
\hline \\
\hline
\end{tabular}

\begin{tabular}{|c|c|c|}
\hline ax.M.-Anfall & 474,02 & $\mathrm{~m}^{2}$ \\
\hline & 189,61 & $\mathrm{~m}^{2}$ \\
\hline & & $\mathrm{m}^{2}$ \\
\hline & 47,40 & \\
\hline & 47,40 & $\mathrm{~m}^{2}$ \\
\hline & 788,43 & $\mathrm{~m}^{2}$ \\
\hline & & \\
\hline & 157,69 & $\mathrm{~m}^{3} / \mathrm{a}$ \\
\hline
\end{tabular}

Bioabfälle aus Haushalten

gehäckseltes Grüngut

Bioabfälle aus Haushalten

gehäckseltes Grüngut

konditioniertes Material

Fertigkompost

konditioniertes Material

Bioabfälle aus Haushalten

angeliefertes Grüngut

gehäckseltes Grüngut

Fertigkompost

Bioabfälle aus Haushalten

Fertigkompost

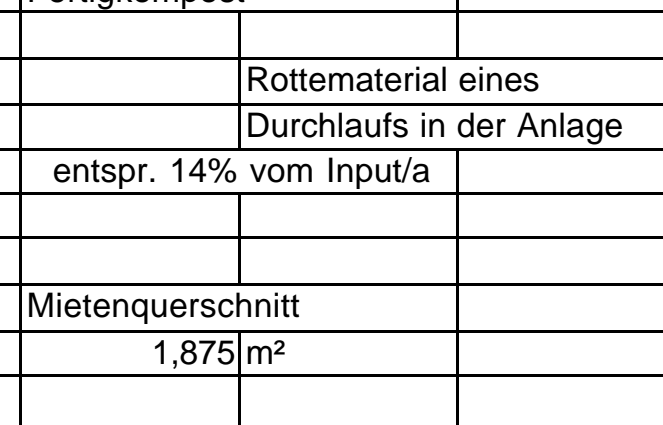

Anlagenneubau

$30,00 \mathrm{~m}^{2}$

$474,02 \mathrm{~m}^{2}$

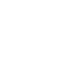

Anlagenumnutzung

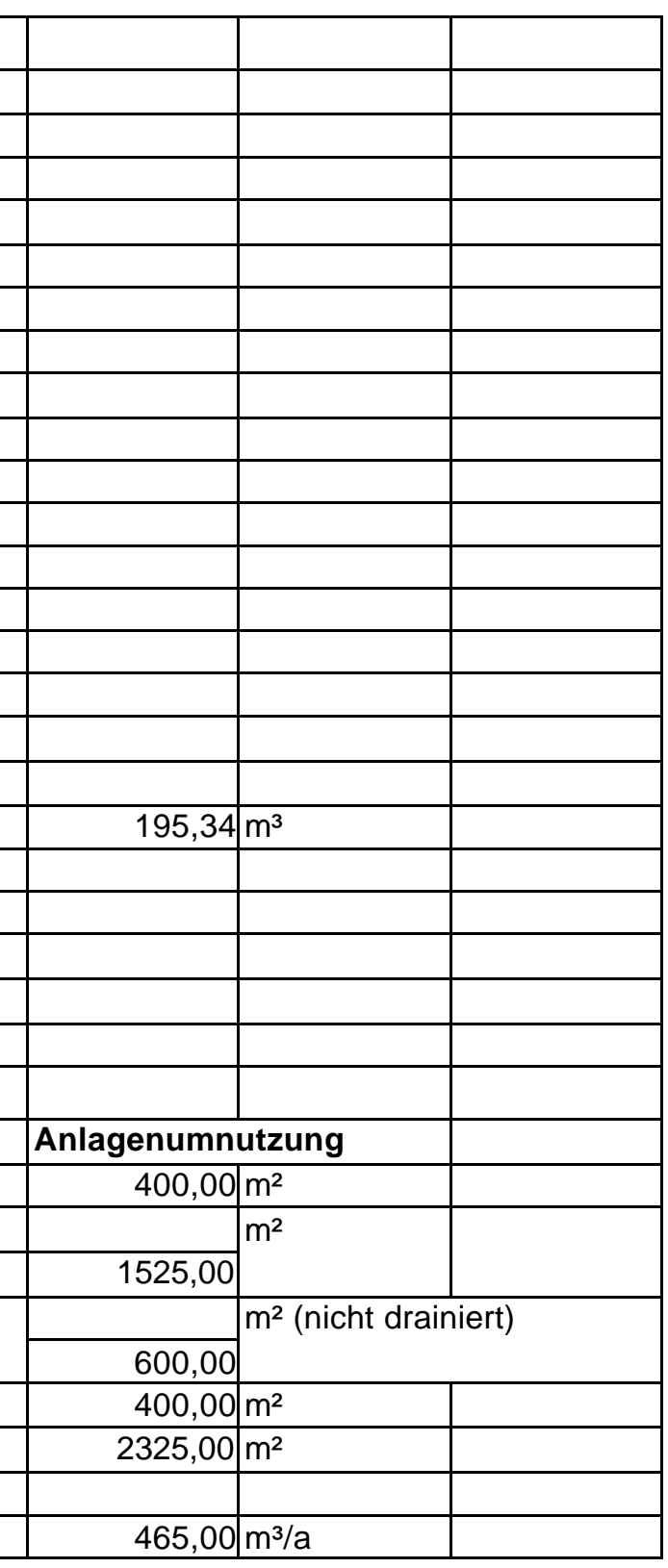




\begin{tabular}{|c|c|c|c|c|c|c|c|c|c|c|}
\hline ZEITEN & & & & & & & & & & \\
\hline Arbeitsgang & & & eingesetzte $\mathrm{M}$ & Maschinen & Zeitbedarf/Ei & nheit & geleistete Ein & nheiten & Zeitbedarf/Ja & ahr \\
\hline Materialannah & ime & & & & 4,000 & h/Woche & 52,000 & Wochen/a & 208,000 & $h / a$ \\
\hline Manuelle Stör & stoffauslese & & & & 1,000 & $\mathrm{~h} / 100 \mathrm{~m}^{3}(\mathrm{In})$ & $2.060,606$ & $\mathrm{~m}^{3} / \mathrm{a}$ & 20,606 & $h / a$ \\
\hline Zerkleinerung & von Strukturm & naterial & TL, SZ, Schr. & & 1,000 & $\mathrm{~h} / 50 \mathrm{~m}^{3}(\mathrm{In})$ & $1.272,727$ & $\mathrm{~m}^{3} / \mathrm{a}$ & 25,455 & $h / a$ \\
\hline Aufsetzen ein & er Matte aus S & Strukturmat. & TL, AS & & 0,300 & $\mathrm{~h} / 100 \mathrm{~m}^{3}$ (kon) & $1.212,121$ & $\mathrm{~m}^{3} / \mathrm{a}$ & 3,636 & $h / a$ \\
\hline Aufsetzen der & Dreiecksmiete & & TL, AS & & 1,000 & $\mathrm{~h} / 20 \mathrm{~m}^{3}$ (kon) & $1.212,121$ & $\mathrm{~m}^{3} / \mathrm{a}$ & 60,606 & $h / a$ \\
\hline Umsetzen der & Dreiecksmiete & & Schl., MU & & 0,005 & h/m(Mietenl.) & $5.417,374$ & $\mathrm{~m} / \mathrm{a}$ & 27,087 & $\mathrm{~h} / \mathrm{a}$ \\
\hline Reinigung der & Annahmefläch & & TL, AS & & 0,500 & $\mathrm{~h} / 150 \mathrm{~m}^{3}(\ln )$ & $2.060,606$ & $\mathrm{~m}^{3} / \mathrm{a}$ & 6,869 & $h / a$ \\
\hline Sieben & & & TL, AS, Sieb & & 1,000 & $\mathrm{~h} / 20 \mathrm{~m}^{3}$ (kom) & 600,000 & $\mathrm{~m}^{3} / \mathrm{a}$ & 30,000 & $h / a$ \\
\hline Abw.-Ausbring & gung bei Neub & & Schl.,PT & & 1,000 & $\mathrm{~h} / 10 \mathrm{~m}^{3}(\mathrm{Abw})$ & 157,686 & $\mathrm{~m}^{3} / \mathrm{a}$ & 15,769 & $h / a$ \\
\hline Abw.-Ausbring & gung bei Umnu & utzung & Schl., PT & & 1,000 & $\mathrm{~h} / 10 \mathrm{~m}^{3}(\mathrm{Abw})$ & 465,000 & $\mathrm{~m}^{3} / \mathrm{a}$ & 46,500 & $h / a$ \\
\hline Abkürzungen & für die eingese & etzten Maschin & nen: & & & & & & & \\
\hline TL - Teleskop & lader & & Schl. - Schlepp & per & & & & & & \\
\hline MU- Mietenum & nsetzer & & Schr. - Schred & dder & & & & & & \\
\hline SZ - Silozange & & & PT - Pumpenta & tankwagen & & & & & & \\
\hline AS - Anbausc & haufel & & & & & & & & & \\
\hline MASCHINE & ENKOSTEN & & & & & & & & & \\
\hline Maschine / G & erät & Fixkosten & & Variable Kost & ten & Einheiten/a & & Maschinen-Ei & inzelkosten & \\
\hline Traktor (Neub & au) & 0,00 & $\mathrm{DM} / \mathrm{a}$ & 33,55 & $\mathrm{DM} / \mathrm{h}$ & 42,86 & $h / a$ & $1.437,80$ & $\mathrm{DM} / \mathrm{a}$ & \\
\hline Traktor (Umnu & itzung) & 0,00 & $\mathrm{DM} / \mathrm{a}$ & 33,55 & $\mathrm{DM} / \mathrm{h}$ & 73,59 & $\mathrm{~h} / \mathrm{a}$ & $2.468,84$ & $\mathrm{DM} / \mathrm{a}$ & \\
\hline Teleskoplader & & 0,00 & DM/a & 66,50 & $\mathrm{DM} / \mathrm{h}$ & 126,57 & $\mathrm{~h} / \mathrm{a}$ & $8.416,62$ & $\mathrm{DM} / \mathrm{a}$ & \\
\hline Schredder & & 0,00 & DM/a & 7,50 & $\mathrm{DM} / \mathrm{m}^{3}$ (Out) & 424,24 & $\mathrm{~m}^{3} / \mathrm{a}$ & $3.181,82$ & $\mathrm{DM} / \mathrm{a}$ & \\
\hline Trommelsieb & & 0,00 & $D M / a$ & 5,00 & $\mathrm{DM} / \mathrm{m}^{3}(\mathrm{Kom})$ & 600,00 & $\mathrm{~m}^{3} / \mathrm{a}$ & $3.000,00$ & $\mathrm{DM} / \mathrm{a}$ & \\
\hline PumpenTW ( & Veubau) & 0,00 & $\mathrm{DM} / \mathrm{a}$ & 30,00 & $\mathrm{DM} / \mathrm{h}$ & 15,77 & $\mathrm{~h} / \mathrm{a}$ & 473,06 & $\mathrm{DM} / \mathrm{a}$ & \\
\hline PumpenTW (L & Jmnutzung) & 0,00 & $\mathrm{DM} / \mathrm{a}$ & 30,00 & $\mathrm{DM} / \mathrm{h}$ & 46,50 & $h / a$ & $1.395,00$ & $\mathrm{DM} / \mathrm{a}$ & \\
\hline Silozange & & $1.120,00$ & DM/a & 0,30 & $\mathrm{DM} / \mathrm{m}^{3}$ & $1.272,73$ & $\mathrm{~m}^{3} / \mathrm{a}$ & $1.501,82$ & $D M / a$ & \\
\hline Anbauschaufe & & 506,00 & $\mathrm{DM} / \mathrm{a}$ & 0,30 & $\mathrm{DM} / \mathrm{m}^{3}$ & $5.084,85$ & $\mathrm{~m}^{3} / \mathrm{a}$ & $2.031,45$ & $\mathrm{DM} / \mathrm{a}$ & \\
\hline Mietenumsetz & & $3.600,00$ & $\mathrm{DM} / \mathrm{a}$ & 28,00 & $\mathrm{DM} / \mathrm{h}$ & 27,09 & $h / a$ & $4.358,43$ & $\mathrm{DM} / \mathrm{a}$ & \\
\hline & & & & & & Summe (Neub & bau) & $24.401,00$ & $\mathrm{DM} / \mathrm{a}$ & \\
\hline & & & & & & Summe (Umn & hutzung) & $26.353,98$ & $\mathrm{DM} / \mathrm{a}$ & \\
\hline PERSONA & LKOSTEN & & & & & & & & & \\
\hline & Std.-Lohn inkl & I.Lohn-NK & Arbeitsstd. pro & o Jahr & Personal-Einze & elkosten & & & & \\
\hline Neubau & 26,00 & $D M / h$ & 398,03 & $\mathrm{~h} / \mathrm{a}$ & $10.348,71$ & $\mathrm{DM} / \mathrm{a}$ & & & & \\
\hline Umnutzung & 26,00 & $D M / h$ & 428,76 & $\mathrm{~h} / \mathrm{a}$ & $11.147,72$ & $\mathrm{DM} / \mathrm{a}$ & & & & \\
\hline
\end{tabular}




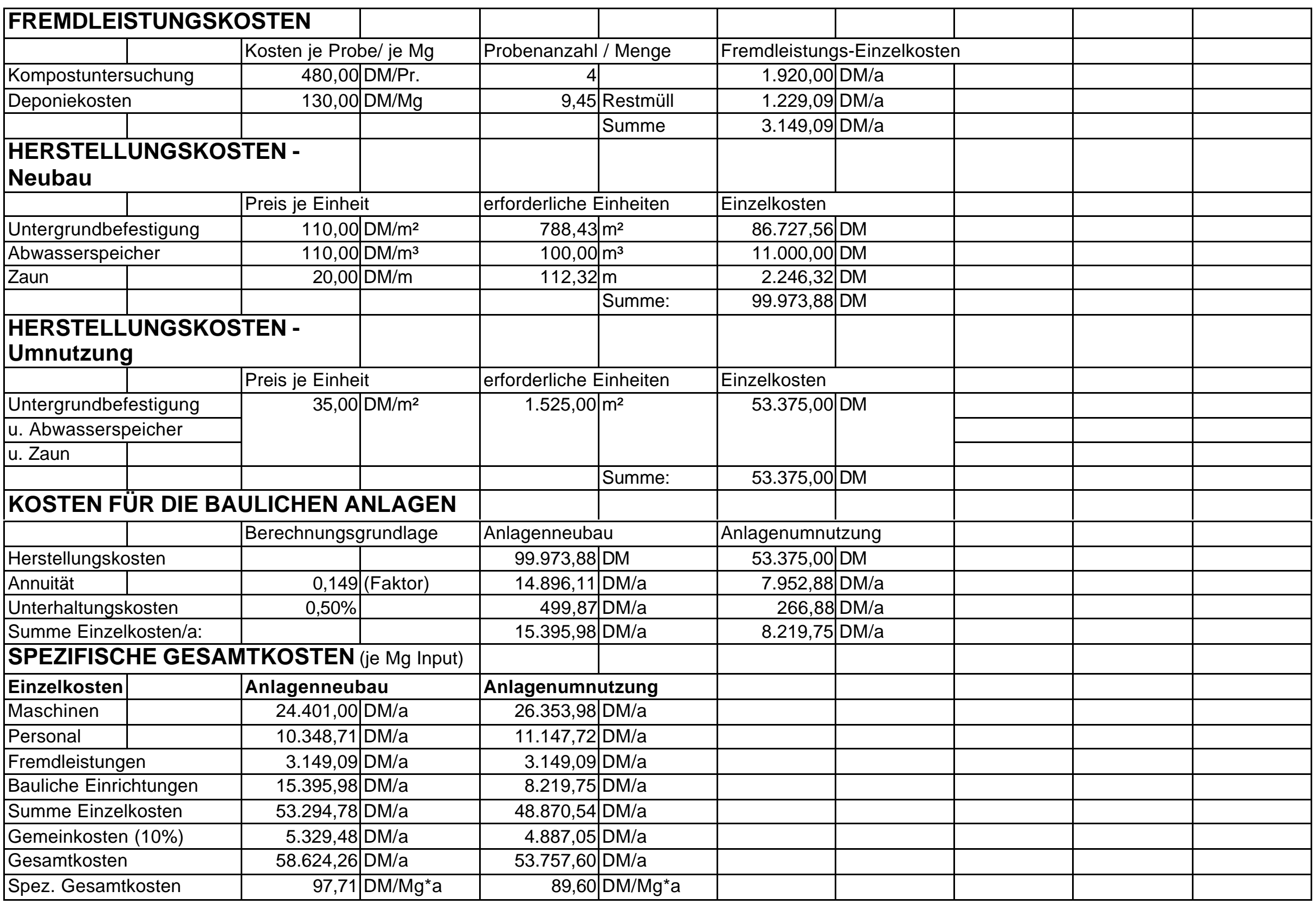


Kostenvariante C3

\begin{tabular}{|c|c|c|c|c|c|c|c|c|c|c|}
\hline MATERIA & & & & & & & & & & \\
\hline Jahresinput & & & 800,00 & $\mathrm{Mg} / \mathrm{a}$ & & & & & & \\
\hline Zusammens & & & $65 \%$ & Vol.-\% & Bioabfälle & Haushalten & & & & \\
\hline & & & $35 \%$ & Vol.-\% & gehäckselt & Grüngut & & & & \\
\hline Dichte & & & 0,6 & $\mathrm{Mg} / \mathrm{m}^{3}$ & Bioabfälle & Haushalten & & & & \\
\hline & & & 0,3 & $\mathrm{Mg} / \mathrm{m}^{3}$ & gehäckselt & Grüngut & & & & \\
\hline & & & 0,495 & $\mathrm{Mg} / \mathrm{m}^{3}$ & konditionie & 5 Material & & & & \\
\hline & & & 0,5 & $\mathrm{Mg} / \mathrm{m}^{3}$ & Fertigkomp & & & & & \\
\hline Volumen & & & $1.616,16$ & $\mathrm{~m}^{3} / \mathrm{a}$ & konditionie & s Material & & & & \\
\hline & & & $1.050,51$ & $\mathrm{~m}^{3} / \mathrm{a}$ & Bioabfälle & Haushalten & & & & \\
\hline & & & $1.696,97$ & $\mathrm{~m}^{3} / \mathrm{a}$ & angeliefert & Grüngut & & & & \\
\hline & & & 565,66 & $\mathrm{~m}^{3} / \mathrm{a}$ & gehäckselt & Grüngut & & & & \\
\hline & & & 800,00 & $\mathrm{~m}^{3} / \mathrm{a}$ & Fertigkomp & & & & & \\
\hline Gewichtsan & & & 630,30 & $\mathrm{Mg} / \mathrm{a}$ & Bioabfälle & Haushalten & & & & \\
\hline & & & 169,70 & $\mathrm{Mg} / \mathrm{a}$ & Grüngut & & & & & \\
\hline & & & 400,00 & $\mathrm{Mg} / \mathrm{a}$ & Fertigkomp & & & & & \\
\hline Rottedauer & & & 12 & Wochen & & & & & & \\
\hline durchschnit & & & 61,54 & $\mathrm{Mg}$ & & Rottematerial & eines & & & \\
\hline Monatsaufk & & & 124,32 & $m^{3}$ (kon) & & Durchlaufs in & der Anlage & 260,45 & $\mathrm{~m}^{3}$ & \\
\hline maximaler I & atsanfall & & 112,00 & $\mathrm{Mg}$ & entspr. 12 & vom Input/a & & & & \\
\hline & & & 226,26 & $\mathrm{~m}^{3}$ & & & & & & \\
\hline TS-Gehalt & igkompost) & & $61,70 \%$ & & & & & & & \\
\hline Mietenhöhe & & & 1,5 & $\mathrm{~m}$ & Mietenquer & hnitt & & & & \\
\hline Mietenbasis & & & 2,5 & $\mathrm{~m}$ & $\overline{1,8}$ & $\mathrm{~m}^{2}$ & & & & \\
\hline ANLAGE & IMENSIO & IIERUNG & & & & & & & & \\
\hline Anlagent & & Berechnung & gsgrundlage & & & Anlagenneub & bau & Anlagenumn & utzung & \\
\hline Anliefe & sfläche & $5 \%$ & vom Input in I & hg/a, ausg & ickt in $\mathrm{m}^{2}$ & 40,00 & $\mathrm{~m}^{2}$ & 400,00 & $\mathrm{~m}^{2}$ & \\
\hline Rottefläcr & & 1,33 & $\mathrm{~m}^{2} / \mathrm{m}^{3}$ Rottem & aterial bei & M.-Anfall & 632,03 & $\mathrm{~m}^{2}$ & & $m^{2}$ & \\
\hline Rangierfläc & & $40 \%$ & der Rottefläch & & & 252,81 & $m^{2}$ & 1525,00 & & \\
\hline Zwisch & ger für & & der Rottefläch & & & & $\mathrm{m}^{2}$ & & $\mathrm{~m}^{2}$ (nich & niert) \\
\hline Strukt & aterial & $10 \%$ & & & & 63,20 & & 600,00 & & \\
\hline Kompostla & & $10 \%$ & der Rottefläch & & & 63,20 & $\mathrm{~m}^{2}$ & 400,00 & $\mathrm{~m}^{2}$ & \\
\hline Anlagenfl & (gesamt) & & & & & 1051,24 & $\mathrm{~m}^{2}$ & 2325,00 & $\mathrm{~m}^{2}$ & \\
\hline zu ve & tende & & & & & & & & & \\
\hline Abwa & menge & 0,2 & $m^{3} / m^{2 \star} a$ & & & 210,25 & $\mathrm{~m}^{3} / \mathrm{a}$ & 465,00 & $\mathrm{~m}^{3} / \mathrm{a}$ & \\
\hline
\end{tabular}




\begin{tabular}{|c|c|c|c|c|c|c|c|c|c|c|}
\hline \multicolumn{11}{|l|}{ ZEITEN } \\
\hline \multicolumn{3}{|l|}{ Arbeitsgang } & \multicolumn{2}{|c|}{ eingesetzte Maschinen } & \multicolumn{2}{|c|}{ Zeitbedarf/Einheit } & \multicolumn{2}{|c|}{ geleistete Einheiten } & \multicolumn{2}{|c|}{ Zeitbedarf/Jahr } \\
\hline \multicolumn{3}{|c|}{ Materialannahme } & & & 4,000 & h/Woche & 52,000 & Wochen/a & 208,000 & $h / a$ \\
\hline \multicolumn{3}{|c|}{ Manuelle Störstoffauslese } & & & 1,000 & $h / 100 m^{3}(\operatorname{In})$ & $2.747,475$ & $\mathrm{~m}^{3} / \mathrm{a}$ & 27,475 & $\mathrm{~h} / \mathrm{a}$ \\
\hline \multicolumn{3}{|c|}{ Zerkleinerung von Strukturmaterial } & \multicolumn{2}{|l|}{ TL, SZ, Schr. } & 1,000 & $h / 50 m^{3}(\ln )$ & $1.696,970$ & $\mathrm{~m}^{3} / \mathrm{a}$ & 33,939 & $h / a$ \\
\hline \multicolumn{3}{|c|}{ Aufsetzen einer Matte aus Strukturmat. } & \multicolumn{2}{|l|}{$\mathrm{TL}, \mathrm{AS}$} & 0,300 & $\mathrm{~h} / 100 \mathrm{~m}^{3}$ (kon) & $1.616,162$ & $\mathrm{~m}^{3} / \mathrm{a}$ & 4,848 & $\mathrm{~h} / \mathrm{a}$ \\
\hline \multicolumn{3}{|c|}{ Aufsetzen der Dreiecksmieten } & \multicolumn{2}{|l|}{ TL, AS } & 1,000 & $\mathrm{~h} / 20 \mathrm{~m}^{3}$ (kon) & $1.616,162$ & $\mathrm{~m}^{3} / \mathrm{a}$ & 80,808 & $\mathrm{~h} / \mathrm{a}$ \\
\hline \multicolumn{3}{|c|}{ Umsetzen der Dreiecksmieten } & \multicolumn{2}{|l|}{ Schl., MU } & 0,005 & $\mathrm{~h} / \mathrm{m}$ (Mietenl.) & $7.223,165$ & $\mathrm{~m} / \mathrm{a}$ & 36,116 & $h / a$ \\
\hline \multicolumn{3}{|c|}{ Reinigung der Annahmefläche } & \multicolumn{2}{|l|}{ TL, AS } & 0,500 & $h / 150 m^{3}(\ln )$ & $2.747,475$ & $\mathrm{~m}^{3} / \mathrm{a}$ & 9,158 & $\mathrm{~h} / \mathrm{a}$ \\
\hline \multicolumn{3}{|l|}{ Sieben } & \multicolumn{2}{|l|}{ TL, AS, Sieb } & 1,000 & $\mathrm{~h} / 20 \mathrm{~m}^{3}(\mathrm{kom})$ & 800,000 & $\mathrm{~m}^{3} / \mathrm{a}$ & 40,000 & $\mathrm{~h} / \mathrm{a}$ \\
\hline \multicolumn{3}{|c|}{ Abw.-Ausbringung bei Neubau } & \multicolumn{2}{|l|}{ Schl.,PT } & 1,000 & $\mathrm{~h} / 10 \mathrm{~m}^{3}(\mathrm{Abw})$ & 210,249 & $\mathrm{~m}^{3} / \mathrm{a}$ & 21,025 & $h / a$ \\
\hline \multicolumn{3}{|c|}{ Abw.-Ausbringung bei Umnutzung } & \multicolumn{2}{|l|}{ Schl., PT } & 1,000 & $\mathrm{~h} / 10 \mathrm{~m}^{3}(\mathrm{Abw})$ & 465,000 & $\mathrm{~m}^{3} / \mathrm{a}$ & 46,500 & $h / a$ \\
\hline \multicolumn{11}{|c|}{ Abkürzungen für die eingesetzten Maschinen: } \\
\hline \multicolumn{3}{|c|}{\begin{tabular}{|l|l|} 
TL - Teleskoplader & \\
\end{tabular}} & Schl. - Schlepp & per & & & & & & \\
\hline MU- Mietenum & etzer & & Schr. - Schred & dder & & & & & & \\
\hline SZ - Silozange & & & PT - Pumpenta & tankwagen & & & & & & \\
\hline AS - Anbausc & aufel & & & & & & & & & \\
\hline MASCHINE & NKOSTEN & & & & & & & & & \\
\hline Maschine / G & & Fixkosten & & Variable Kost & ten & Einheiten/a & & Maschinen-Ei & inzelkosten & \\
\hline Traktor (Neub & & 0,00 & $D M / a$ & 33,55 & $D M / h$ & 57,14 & $h / a$ & $1.917,07$ & $\mathrm{DM} / \mathrm{a}$ & \\
\hline Traktor (Umnu & zung) & 0,00 & $\mathrm{DM} / \mathrm{a}$ & 33,55 & $D M / h$ & 82,62 & $h / a$ & $2.771,76$ & $\mathrm{DM} / \mathrm{a}$ & \\
\hline Teleskoplader & & 0,00 & $D M / a$ & 66,50 & $\mathrm{DM} / \mathrm{h}$ & 168,75 & $h / a$ & $11.222,15$ & $\mathrm{DM} / \mathrm{a}$ & \\
\hline Schredder & & 0,00 & DM/a & 7,50 & $\mathrm{DM} / \mathrm{m}^{3}$ (Out) & 565,66 & $\mathrm{~m}^{3} / \mathrm{a}$ & $4.242,42$ & $\mathrm{DM} / \mathrm{a}$ & \\
\hline Trommelsieb & & 0,00 & $\mathrm{DM} / \mathrm{a}$ & 5,00 & $\mathrm{DM} / \mathrm{m}^{3}(\mathrm{Kom})$ & 800,00 & $\mathrm{~m}^{3} / \mathrm{a}$ & $4.000,00$ & $D M / a$ & \\
\hline PumpenTW ( & abau) & 0,00 & $\mathrm{DM} / \mathrm{a}$ & 30,00 & $\mathrm{DM} / \mathrm{h}$ & 21,02 & $h / a$ & 630,75 & $\mathrm{DM} / \mathrm{a}$ & \\
\hline PumpenTW (L & nnutzung) & 0,00 & $D M / a$ & 30,00 & $D M / h$ & 46,50 & $h / a$ & $1.395,00$ & $\mathrm{DM} / \mathrm{a}$ & \\
\hline Silozange & & $1.120,00$ & DM/a & 0,30 & $\mathrm{DM} / \mathrm{m}^{3}$ & $1.696,97$ & $\mathrm{~m}^{3} / \mathrm{a}$ & $1.629,09$ & $\mathrm{DM} / \mathrm{a}$ & \\
\hline Anbauschaufe & & 506,00 & $\mathrm{DM} / \mathrm{a}$ & 0,30 & $\mathrm{DM} / \mathrm{m}^{3}$ & $6.779,80$ & $m^{3} / a$ & $2.539,94$ & $\mathrm{DM} / \mathrm{a}$ & \\
\hline Mietenumsetz & & $3.600,00$ & $\mathrm{DM} / \mathrm{a}$ & 28,00 & $\mathrm{DM} / \mathrm{h}$ & 36,12 & $h / a$ & $4.611,24$ & $\mathrm{DM} / \mathrm{a}$ & \\
\hline & & & & & & Summe (Neuk & bau) & $30.792,67$ & $\mathrm{DM} / \mathrm{a}$ & \\
\hline & & & & & & Summe (Umn & futzung) & $32.411,61$ & $\mathrm{DM} / \mathrm{a}$ & \\
\hline PERSONA & KOSTEN & & & & & & & & & \\
\hline & Std.-Lohn in & kl.Lohn-NK & Arbeitsstd. pro & o Jahr & Personal-Einz & zelkosten & & & & \\
\hline Neubau & 26,00 & $\mathrm{DM} / \mathrm{h}$ & 461,37 & $\mathrm{~h} / \mathrm{a}$ & 11.995,61 & $\mathrm{DM} / \mathrm{a}$ & & & & \\
\hline Umnutzung & 26,00 & DM/h & 486,84 & $h / a$ & $12.657,96$ & $D M / a$ & & & & \\
\hline
\end{tabular}




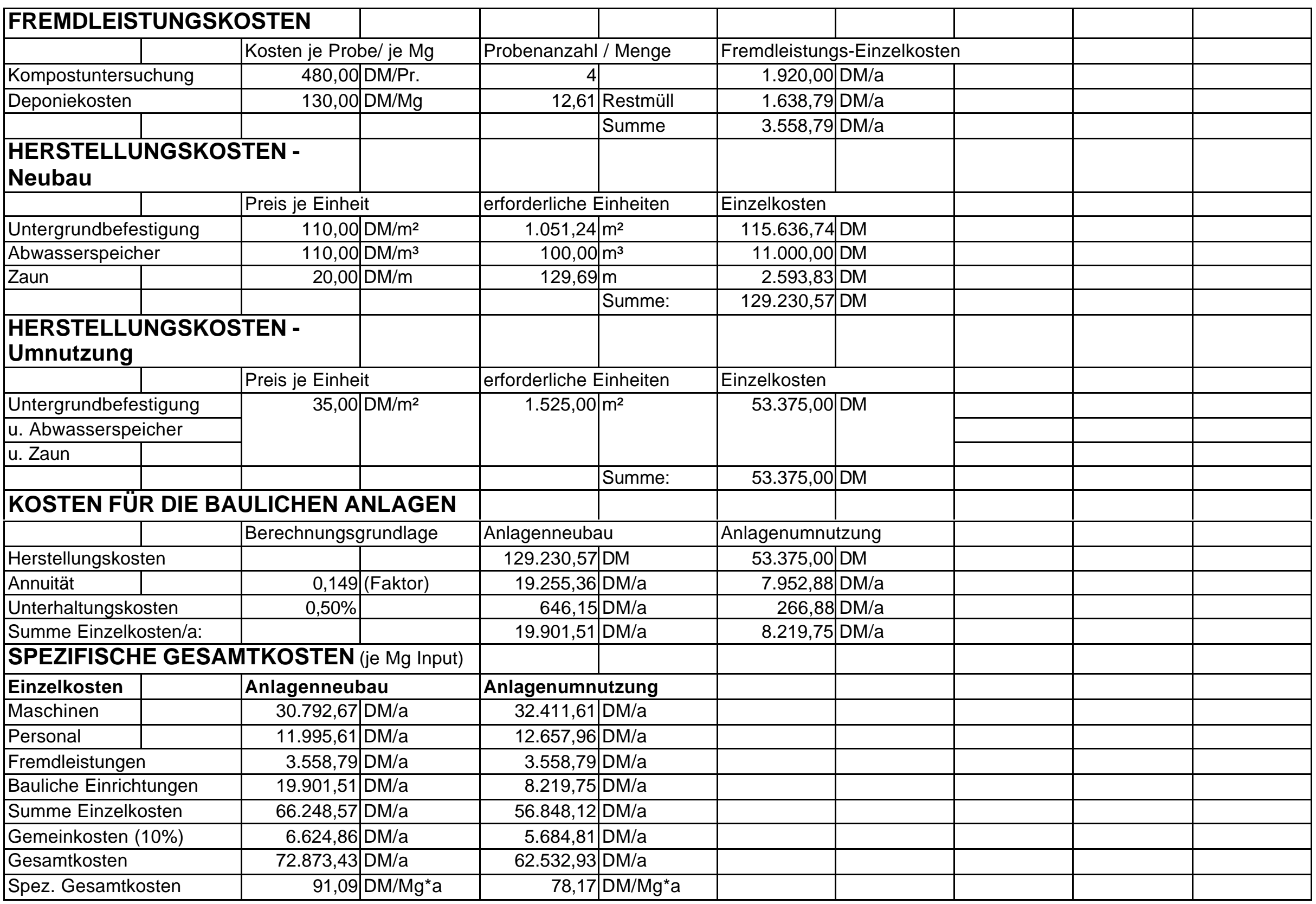


Kostenvariante C4

\begin{tabular}{|c|c|c|c|c|c|c|c|c|c|c|}
\hline MATERIA & & & & & & & & & & \\
\hline Jahresinput & & & $1.000,00$ & $\mathrm{Mg} / \mathrm{a}$ & & & & & & \\
\hline Zusammens & & & $65 \%$ & Vol.-\% & Bioabfälle & Haushalten & & & & \\
\hline & & & $35 \%$ & Vol.-\% & gehäckselt & Grüngut & & & & \\
\hline Dichte & & & 0,6 & $\mathrm{Mg} / \mathrm{m}^{3}$ & Bioabfälle & Haushalten & & & & \\
\hline & & & 0,3 & $\mathrm{Mg} / \mathrm{m}^{3}$ & gehäckselt & Grüngut & & & & \\
\hline & & & 0,495 & $\mathrm{Mg} / \mathrm{m}^{3}$ & konditionie & 5 Material & & & & \\
\hline & & & 0,5 & $\mathrm{Mg} / \mathrm{m}^{3}$ & Fertigkomp & & & & & \\
\hline Volumen & & & $2.020,20$ & $\mathrm{~m}^{3} / \mathrm{a}$ & konditionie & s Material & & & & \\
\hline & & & $1.313,13$ & $\mathrm{~m}^{3} / \mathrm{a}$ & Bioabfälle & Haushalten & & & & \\
\hline & & & $2.121,21$ & $\mathrm{~m}^{3} / \mathrm{a}$ & angeliefert & Grüngut & & & & \\
\hline & & & 707,07 & $\mathrm{~m}^{3} / \mathrm{a}$ & gehäckselt & Grüngut & & & & \\
\hline & & & $1.000,00$ & $\mathrm{~m}^{3} / \mathrm{a}$ & Fertigkomp & & & & & \\
\hline Gewichtsan & & & 787,88 & $\mathrm{Mg} / \mathrm{a}$ & Bioabfälle c & Haushalten & & & & \\
\hline & & & 212,12 & $\mathrm{Mg} / \mathrm{a}$ & Grüngut & & & & & \\
\hline & & & 500,00 & $\mathrm{Mg} / \mathrm{a}$ & Fertigkomp & & & & & \\
\hline Rottedauer & & & 12 & Wochen & & & & & & \\
\hline durchschnit & & & 76,92 & $\mathrm{Mg}$ & & Rottematerial & eines & & & \\
\hline Monatsaufk & & & 155,40 & $m^{3}$ (kon) & & Durchlaufs in & der Anlage & 325,56 & $\mathrm{~m}^{3}$ & \\
\hline maximaler I & atsanfall & & 140,00 & $\mathrm{Mg}$ & entspr. 12 & vom Input/a & & & & \\
\hline & & & 282,83 & $\mathrm{~m}^{3}$ & & & & & & \\
\hline TS-Gehalt & igkompost) & & $61,70 \%$ & & & & & & & \\
\hline Mietenhöhe & & & 1,5 & $\mathrm{~m}$ & Mietenquer & hnitt & & & & \\
\hline Mietenbasis & & & 2,5 & $\mathrm{~m}$ & $\overline{1,8}$ & $\mathrm{~m}^{2}$ & & & & \\
\hline ANLAGE & IMENSIO & IIERUNG & & & & & & & & \\
\hline Anlagent & & Berechnung & gsgrundlage & & & Anlagenneub & bau & Anlagenumn & utzung & \\
\hline Anliefe & sfläche & $5 \%$ & vom Input in I & hg/a, ausg & ickt in $\mathrm{m}^{2}$ & 50,00 & $\mathrm{~m}^{2}$ & 400,00 & $\mathrm{~m}^{2}$ & \\
\hline Rottefläcl & & 1,33 & $\mathrm{~m}^{2} / \mathrm{m}^{3}$ Rottem & aterial bei & M.-Anfall & 790,03 & $\mathrm{~m}^{2}$ & & $m^{2}$ & \\
\hline Rangierflä & & $40 \%$ & der Rottefläch & & & 316,01 & $m^{2}$ & 1525,00 & & \\
\hline Zwisch & ger für & & der Rottefläch & & & & $\mathrm{m}^{2}$ & & $\mathrm{~m}^{2}$ (nich & niert) \\
\hline Struk & aterial & $10 \%$ & & & & 79,00 & & 600,00 & & \\
\hline Kompostla & & $10 \%$ & der Rottefläch & & & 79,00 & $\mathrm{~m}^{2}$ & 400,00 & $\mathrm{~m}^{2}$ & \\
\hline Anlagenfl & (gesamt) & & & & & 1314,05 & $\mathrm{~m}^{2}$ & 2325,00 & $m^{2}$ & \\
\hline zu ve & tende & & & & & & & & & \\
\hline Abwa & menge & 0,2 & $m^{3} / m^{2 \star} a$ & & & 262,81 & $\mathrm{~m}^{3} / \mathrm{a}$ & 465,00 & $m^{3} / a$ & \\
\hline
\end{tabular}




\begin{tabular}{|c|c|c|c|c|c|c|c|c|c|c|}
\hline \multicolumn{11}{|l|}{ ZEITEN } \\
\hline \multicolumn{3}{|l|}{ Arbeitsgang } & \multicolumn{2}{|c|}{ eingesetzte Maschinen } & \multicolumn{2}{|c|}{ Zeitbedarf/Einheit } & \multicolumn{2}{|c|}{ geleistete Einheiten } & \multicolumn{2}{|c|}{ Zeitbedarf/Jahr } \\
\hline \multicolumn{3}{|c|}{ Materialannahme } & & & 4,000 & h/Woche & 52,000 & Wochen/a & 208,000 & $h / a$ \\
\hline \multicolumn{3}{|c|}{ Manuelle Störstoffauslese } & & & 1,000 & $h / 100 m^{3}(\operatorname{In})$ & $3.434,343$ & $\mathrm{~m}^{3} / \mathrm{a}$ & 34,343 & $\mathrm{~h} / \mathrm{a}$ \\
\hline \multicolumn{3}{|c|}{ Zerkleinerung von Strukturmaterial } & \multicolumn{2}{|l|}{ TL, SZ, Schr. } & 1,000 & $h / 50 m^{3}(\ln )$ & $2.121,212$ & $\mathrm{~m}^{3} / \mathrm{a}$ & 42,424 & $h / a$ \\
\hline \multicolumn{3}{|c|}{ Aufsetzen einer Matte aus Strukturmat. } & \multicolumn{2}{|l|}{ TL, AS } & 0,300 & $\mathrm{~h} / 100 \mathrm{~m}^{3}$ (kon) & $2.020,202$ & $\mathrm{~m}^{3} / \mathrm{a}$ & 6,061 & $\mathrm{~h} / \mathrm{a}$ \\
\hline \multicolumn{3}{|c|}{ Aufsetzen der Dreiecksmieten } & \multicolumn{2}{|l|}{ TL, AS } & 1,000 & $\mathrm{~h} / 20 \mathrm{~m}^{3}$ (kon) & $2.020,202$ & $\mathrm{~m}^{3} / \mathrm{a}$ & 101,010 & $h / a$ \\
\hline \multicolumn{3}{|c|}{ Umsetzen der Dreiecksmieten } & \multicolumn{2}{|l|}{ Schl., MU } & 0,005 & $\mathrm{~h} / \mathrm{m}$ (Mietenl.) & $9.028,956$ & $\mathrm{~m} / \mathrm{a}$ & 45,145 & $\mathrm{~h} / \mathrm{a}$ \\
\hline \multicolumn{3}{|c|}{ Reinigung der Annahmefläche } & \multicolumn{2}{|l|}{ TL, AS } & 0,500 & $h / 150 m^{3}(\ln )$ & $3.434,343$ & $\mathrm{~m}^{3} / \mathrm{a}$ & 11,448 & $\mathrm{~h} / \mathrm{a}$ \\
\hline \multicolumn{3}{|l|}{ Sieben } & \multicolumn{2}{|l|}{ TL, AS, Sieb } & 1,000 & $\mathrm{~h} / 20 \mathrm{~m}^{3}(\mathrm{kom})$ & $1.000,000$ & $\mathrm{~m}^{3} / \mathrm{a}$ & 50,000 & $\mathrm{~h} / \mathrm{a}$ \\
\hline \multicolumn{3}{|c|}{ Abw.-Ausbringung bei Neubau } & \multicolumn{2}{|l|}{ Schl.,PT } & 1,000 & $\mathrm{~h} / 10 \mathrm{~m}^{3}(\mathrm{Abw})$ & 262,811 & $\mathrm{~m}^{3} / \mathrm{a}$ & 26,281 & $\mathrm{~h} / \mathrm{a}$ \\
\hline \multicolumn{3}{|c|}{ Abw.-Ausbringung bei Umnutzung } & \multicolumn{2}{|l|}{ Schl., PT } & 1,000 & $\mathrm{~h} / 10 \mathrm{~m}^{3}(\mathrm{Abw})$ & 465,000 & $\mathrm{~m}^{3} / \mathrm{a}$ & 46,500 & $h / a$ \\
\hline \multicolumn{11}{|c|}{ Abkürzungen für die eingesetzten Maschinen: } \\
\hline \multicolumn{3}{|c|}{\begin{tabular}{|l|l|} 
TL - Teleskoplader & \\
\end{tabular}} & Schl. - Schlepp & per & & & & & & \\
\hline MU- Mietenum & etzer & & Schr. - Schred & dder & & & & & & \\
\hline SZ - Silozange & & & PT - Pumpenta & tankwagen & & & & & & \\
\hline AS - Anbausc & aufel & & & & & & & & & \\
\hline MASCHINE & NKOSTEN & & & & & & & & & \\
\hline Maschine / G & & Fixkosten & & Variable Kost & ten & Einheiten/a & & Maschinen-Ei & inzelkosten & \\
\hline Traktor (Neub & & 0,00 & $D M / a$ & 33,55 & $D M / h$ & 71,43 & $\mathrm{~h} / \mathrm{a}$ & $2.396,34$ & $D M / a$ & \\
\hline Traktor (Umnu & zung) & 0,00 & $\mathrm{DM} / \mathrm{a}$ & 33,55 & $D M / h$ & 91,64 & $\mathrm{~h} / \mathrm{a}$ & $3.074,68$ & $\mathrm{DM} / \mathrm{a}$ & \\
\hline Teleskoplader & & 0,00 & $D M / a$ & 66,50 & $\mathrm{DM} / \mathrm{h}$ & 210,94 & $\mathrm{~h} / \mathrm{a}$ & $14.027,69$ & $\mathrm{DM} / \mathrm{a}$ & \\
\hline Schredder & & 0,00 & DM/a & 7,50 & $\mathrm{DM} / \mathrm{m}^{3}$ (Out) & 707,07 & $\mathrm{~m}^{3} / \mathrm{a}$ & $5.303,03$ & $\mathrm{DM} / \mathrm{a}$ & \\
\hline Trommelsieb & & 0,00 & $\mathrm{DM} / \mathrm{a}$ & 5,00 & $\mathrm{DM} / \mathrm{m}^{3}(\mathrm{Kom})$ & $1.000,00$ & $m^{3} / a$ & $5.000,00$ & $D M / a$ & \\
\hline PumpenTW ( & abau) & 0,00 & $\mathrm{DM} / \mathrm{a}$ & 30,00 & $\mathrm{DM} / \mathrm{h}$ & 26,28 & $\mathrm{~h} / \mathrm{a}$ & 788,43 & $\mathrm{DM} / \mathrm{a}$ & \\
\hline PumpenTW (L & nnutzung) & 0,00 & $D M / a$ & 30,00 & $D M / h$ & 46,50 & $h / a$ & $1.395,00$ & $\mathrm{DM} / \mathrm{a}$ & \\
\hline Silozange & & $1.120,00$ & DM/a & 0,30 & $\mathrm{DM} / \mathrm{m}^{3}$ & $2.121,21$ & $\mathrm{~m}^{3} / \mathrm{a}$ & $1.756,36$ & $\mathrm{DM} / \mathrm{a}$ & \\
\hline Anbauschaufe & & 506,00 & $\mathrm{DM} / \mathrm{a}$ & 0,30 & $\mathrm{DM} / \mathrm{m}^{3}$ & $8.474,75$ & $\mathrm{~m}^{3} / \mathrm{a}$ & $3.048,42$ & $\mathrm{DM} / \mathrm{a}$ & \\
\hline Mietenumsetz & & $3.600,00$ & $\mathrm{DM} / \mathrm{a}$ & 28,00 & $\mathrm{DM} / \mathrm{h}$ & 45,14 & $\mathrm{~h} / \mathrm{a}$ & $4.864,05$ & $\mathrm{DM} / \mathrm{a}$ & \\
\hline & & & & & & Summe (Neuk & bau) & $37.184,34$ & $\mathrm{DM} / \mathrm{a}$ & \\
\hline & & & & & & Summe (Umn & hutzung) & $38.469,25$ & $\mathrm{DM} / \mathrm{a}$ & \\
\hline PERSONA & KOSTEN & & & & & & & & & \\
\hline & Std.-Lohn in & kl.Lohn-NK & Arbeitsstd. pro & o Jahr & Personal-Einz & zelkosten & & & & \\
\hline Neubau & 26,00 & $\mathrm{DM} / \mathrm{h}$ & 524,71 & $\mathrm{~h} / \mathrm{a}$ & 13.642,51 & $\mathrm{DM} / \mathrm{a}$ & & & & \\
\hline Umnutzung & 26,00 & DM/h & 544,93 & $h / a$ & $14.168,21$ & $\mathrm{DM} / \mathrm{a}$ & & & & \\
\hline
\end{tabular}




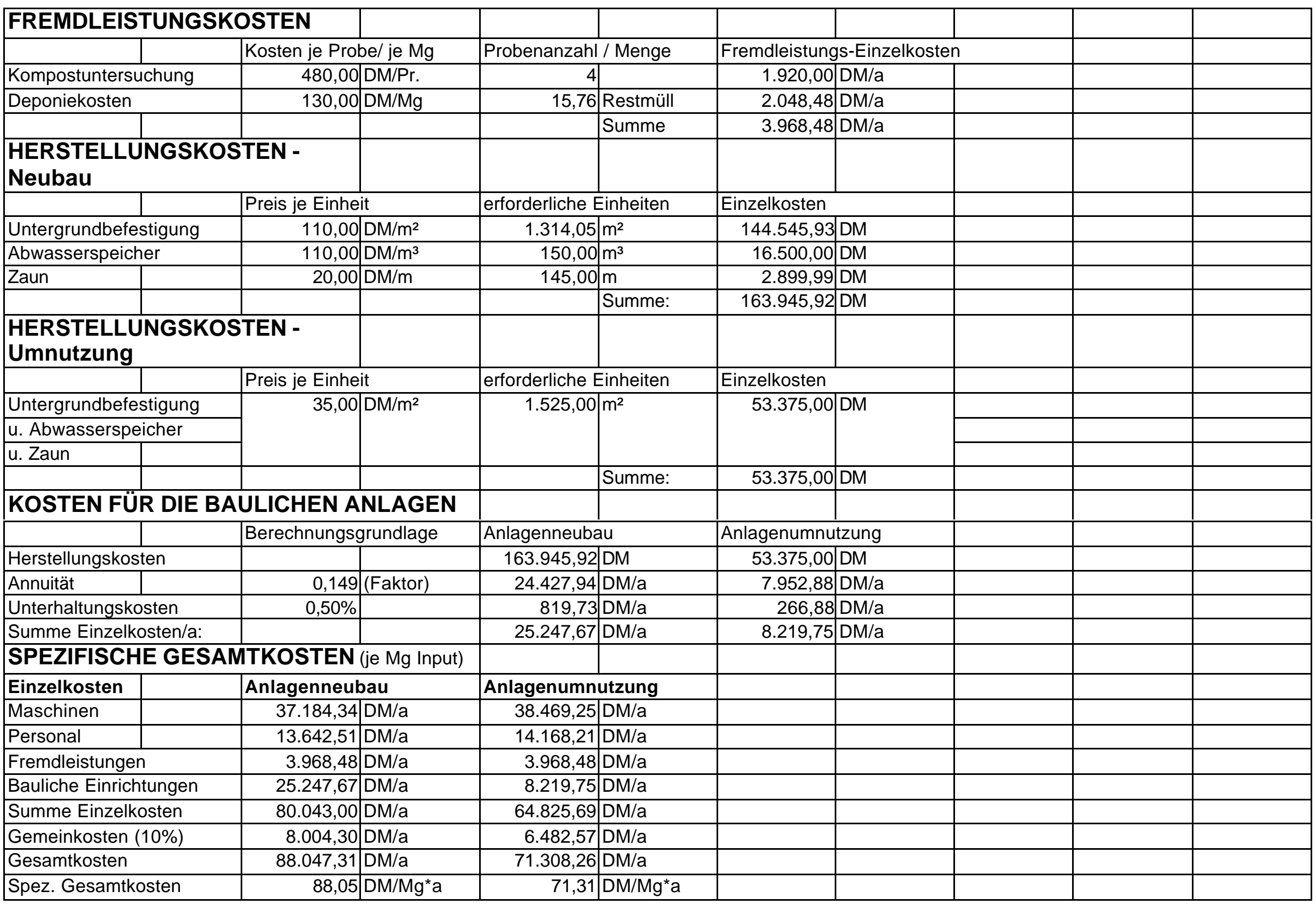


Kostenvariante C5

\begin{tabular}{|c|c|c|c|c|c|c|c|c|c|c|}
\hline MATERIA & & & & & & & & & & \\
\hline Jahresinput & & & $1.200,00$ & $\mathrm{Mg} / \mathrm{a}$ & & & & & & \\
\hline Zusammens & & & $65 \%$ & Vol.-\% & Bioabfälle & Haushalten & & & & \\
\hline & & & $35 \%$ & Vol.-\% & gehäckselt & Grüngut & & & & \\
\hline Dichte & & & 0,6 & $\mathrm{Mg} / \mathrm{m}^{3}$ & Bioabfälle & Haushalten & & & & \\
\hline & & & 0,3 & $\mathrm{Mg} / \mathrm{m}^{3}$ & gehäckselt & Grüngut & & & & \\
\hline & & & 0,495 & $\mathrm{Mg} / \mathrm{m}^{3}$ & konditionie & 5 Material & & & & \\
\hline & & & 0,5 & $\mathrm{Mg} / \mathrm{m}^{3}$ & Fertigkomp & & & & & \\
\hline Volumen & & & $2.424,24$ & $\mathrm{~m}^{3} / \mathrm{a}$ & konditionie & s Material & & & & \\
\hline & & & $1.575,76$ & $\mathrm{~m}^{3} / \mathrm{a}$ & Bioabfälle & Haushalten & & & & \\
\hline & & & $2.545,45$ & $\mathrm{~m}^{3} / \mathrm{a}$ & angeliefert & Grüngut & & & & \\
\hline & & & 848,48 & $\mathrm{~m}^{3} / \mathrm{a}$ & gehäckselt & Grüngut & & & & \\
\hline & & & $1.200,00$ & $\mathrm{~m}^{3} / \mathrm{a}$ & Fertigkomp & & & & & \\
\hline Gewichtsan & & & 945,45 & $\mathrm{Mg} / \mathrm{a}$ & Bioabfälle c & Haushalten & & & & \\
\hline & & & 254,55 & $\mathrm{Mg} / \mathrm{a}$ & Grüngut & & & & & \\
\hline & & & 600,00 & $\mathrm{Mg} / \mathrm{a}$ & Fertigkomp & & & & & \\
\hline Rottedauer & & & 12 & Wochen & & & & & & \\
\hline durchschnit & & & 92,31 & $\mathrm{Mg}$ & & Rottematerial & eines & & & \\
\hline Monatsaufk & & & 186,48 & $m^{3}$ (kon) & & Durchlaufs in & der Anlage & 390,68 & $\mathrm{~m}^{3}$ & \\
\hline maximaler I & atsanfall & & 168,00 & $\mathrm{Mg}$ & entspr. 12 & vom Input/a & & & & \\
\hline & & & 339,39 & $\mathrm{~m}^{3}$ & & & & & & \\
\hline TS-Gehalt & igkompost) & & $61,70 \%$ & & & & & & & \\
\hline Mietenhöhe & & & 1,5 & $\mathrm{~m}$ & Mietenquer & hnitt & & & & \\
\hline Mietenbasis & & & 2,5 & $\mathrm{~m}$ & $\overline{1,8}$ & $\mathrm{~m}^{2}$ & & & & \\
\hline ANLAGE & IMENSIO & IIERUNG & & & & & & & & \\
\hline Anlagent & & Berechnung & gsgrundlage & & & Anlagenneul & bau & Anlagenumn & utzung & \\
\hline Anliefe & sfläche & $5 \%$ & vom Input in I & hg/a, ausg & ickt in $\mathrm{m}^{2}$ & 60,00 & $\mathrm{~m}^{2}$ & 400,00 & $\mathrm{~m}^{2}$ & \\
\hline Rottefläcr & & 1,33 & $\mathrm{~m}^{2} / \mathrm{m}^{3}$ Rottem & aterial bei & M.-Anfall & 948,04 & $\mathrm{~m}^{2}$ & & $m^{2}$ & \\
\hline Rangierfläc & & $40 \%$ & der Rottefläch & & & 379,22 & $m^{2}$ & 1525,00 & & \\
\hline Zwisch & ger für & & der Rottefläch & & & & $\mathrm{m}^{2}$ & & $\mathrm{~m}^{2}$ (nich & niert) \\
\hline Strukt & aterial & $10 \%$ & & & & 94,80 & & 600,00 & & \\
\hline Kompostla & & $10 \%$ & der Rottefläch & & & 94,80 & $\mathrm{~m}^{2}$ & 400,00 & $\mathrm{~m}^{2}$ & \\
\hline Anlagenfl & (gesamt) & & & & & 1576,86 & $\mathrm{~m}^{2}$ & 2325,00 & $m^{2}$ & \\
\hline zu ve & tende & & & & & & & & & \\
\hline Abwa & menge & 0,2 & $m^{3} / m^{2 \star} a$ & & & 315,37 & $\mathrm{~m}^{3} / \mathrm{a}$ & 465,00 & $m^{3} / a$ & \\
\hline
\end{tabular}




\begin{tabular}{|c|c|c|c|c|c|c|c|c|c|c|}
\hline \multicolumn{11}{|l|}{ ZEITEN } \\
\hline \multicolumn{3}{|l|}{ Arbeitsgang } & \multicolumn{2}{|c|}{ eingesetzte Maschinen } & \multicolumn{2}{|c|}{ Zeitbedarf/Einheit } & \multicolumn{2}{|c|}{ geleistete Einheiten } & \multicolumn{2}{|c|}{ Zeitbedarf/Jahr } \\
\hline \multicolumn{3}{|c|}{ Materialannahme } & & & 4,000 & h/Woche & 52,000 & Wochen/a & 208,000 & $h / a$ \\
\hline \multicolumn{3}{|c|}{ Manuelle Störstoffauslese } & & & 1,000 & $h / 100 m^{3}(\operatorname{In})$ & $4.121,212$ & $\mathrm{~m}^{3} / \mathrm{a}$ & 41,212 & $h / a$ \\
\hline \multicolumn{3}{|c|}{ Zerkleinerung von Strukturmaterial } & \multicolumn{2}{|l|}{ TL, SZ, Schr. } & 1,000 & $h / 50 m^{3}(\ln )$ & $2.545,455$ & $\mathrm{~m}^{3} / \mathrm{a}$ & 50,909 & $h / a$ \\
\hline \multicolumn{3}{|c|}{ Aufsetzen einer Matte aus Strukturmat. } & \multicolumn{2}{|l|}{ TL, AS } & 0,300 & $\mathrm{~h} / 100 \mathrm{~m}^{3}$ (kon) & $2.424,242$ & $\mathrm{~m}^{3} / \mathrm{a}$ & 7,273 & $\mathrm{~h} / \mathrm{a}$ \\
\hline \multicolumn{3}{|c|}{ Aufsetzen der Dreiecksmieten } & \multicolumn{2}{|l|}{ TL, AS } & 1,000 & $\mathrm{~h} / 20 \mathrm{~m}^{3}$ (kon) & $2.424,242$ & $\mathrm{~m}^{3} / \mathrm{a}$ & 121,212 & $h / a$ \\
\hline \multicolumn{3}{|c|}{ Umsetzen der Dreiecksmieten } & \multicolumn{2}{|l|}{ Schl., MU } & 0,005 & $\mathrm{~h} / \mathrm{m}$ (Mietenl.) & $10.834,747$ & $\mathrm{~m} / \mathrm{a}$ & 54,174 & $\mathrm{~h} / \mathrm{a}$ \\
\hline \multicolumn{3}{|c|}{ Reinigung der Annahmefläche } & \multicolumn{2}{|l|}{ TL, AS } & 0,500 & $h / 150 m^{3}(\ln )$ & $4.121,212$ & $\mathrm{~m}^{3} / \mathrm{a}$ & 13,737 & $\mathrm{~h} / \mathrm{a}$ \\
\hline \multicolumn{3}{|l|}{ Sieben } & \multicolumn{2}{|l|}{ TL, AS, Sieb } & 1,000 & $\mathrm{~h} / 20 \mathrm{~m}^{3}(\mathrm{kom})$ & $1.200,000$ & $\mathrm{~m}^{3} / \mathrm{a}$ & 60,000 & $\mathrm{~h} / \mathrm{a}$ \\
\hline \multicolumn{3}{|c|}{ Abw.-Ausbringung bei Neubau } & \multicolumn{2}{|l|}{ Schl.,PT } & 1,000 & $\mathrm{~h} / 10 \mathrm{~m}^{3}(\mathrm{Abw})$ & 315,373 & $\mathrm{~m}^{3} / \mathrm{a}$ & 31,537 & $h / a$ \\
\hline \multicolumn{3}{|c|}{ Abw.-Ausbringung bei Umnutzung } & \multicolumn{2}{|l|}{ Schl., PT } & 1,000 & $\mathrm{~h} / 10 \mathrm{~m}^{3}(\mathrm{Abw})$ & 465,000 & $\mathrm{~m}^{3} / \mathrm{a}$ & 46,500 & $h / a$ \\
\hline \multicolumn{11}{|c|}{ Abkürzungen für die eingesetzten Maschinen: } \\
\hline \multicolumn{3}{|c|}{\begin{tabular}{|l|l|} 
TL - Teleskoplader & \\
\end{tabular}} & Schl. - Schlepp & per & & & & & & \\
\hline MU- Mietenum & etzer & & Schr. - Schred & dder & & & & & & \\
\hline SZ - Silozange & & & PT - Pumpenta & tankwagen & & & & & & \\
\hline AS - Anbausc & aufel & & & & & & & & & \\
\hline MASCHINE & NKOSTEN & & & & & & & & & \\
\hline Maschine / G & & Fixkosten & & Variable Kost & ten & Einheiten/a & & Maschinen-Ei & inzelkosten & \\
\hline Traktor (Neub & & 0,00 & $D M / a$ & 33,55 & $D M / h$ & 85,71 & $\mathrm{~h} / \mathrm{a}$ & $2.875,61$ & $\mathrm{DM} / \mathrm{a}$ & \\
\hline Traktor (Umnu & zung) & 0,00 & $\mathrm{DM} / \mathrm{a}$ & 33,55 & $D M / h$ & 100,67 & $\mathrm{~h} / \mathrm{a}$ & $3.377,60$ & $\mathrm{DM} / \mathrm{a}$ & \\
\hline Teleskoplader & & 0,00 & $D M / a$ & 66,50 & $\mathrm{DM} / \mathrm{h}$ & 253,13 & $\mathrm{~h} / \mathrm{a}$ & $16.833,23$ & $\mathrm{DM} / \mathrm{a}$ & \\
\hline Schredder & & 0,00 & DM/a & 7,50 & $\mathrm{DM} / \mathrm{m}^{3}$ (Out) & 848,48 & $\mathrm{~m}^{3} / \mathrm{a}$ & $6.363,64$ & $\mathrm{DM} / \mathrm{a}$ & \\
\hline Trommelsieb & & 0,00 & $\mathrm{DM} / \mathrm{a}$ & 5,00 & $\mathrm{DM} / \mathrm{m}^{3}(\mathrm{Kom})$ & $1.200,00$ & $\mathrm{~m}^{3} / \mathrm{a}$ & $6.000,00$ & $\mathrm{DM} / \mathrm{a}$ & \\
\hline PumpenTW ( & abau) & 0,00 & $\mathrm{DM} / \mathrm{a}$ & 30,00 & $\mathrm{DM} / \mathrm{h}$ & 31,54 & $\mathrm{~h} / \mathrm{a}$ & 946,12 & $\mathrm{DM} / \mathrm{a}$ & \\
\hline PumpenTW (L & nnutzung) & 0,00 & $D M / a$ & 30,00 & $D M / h$ & 46,50 & $h / a$ & $1.395,00$ & $\mathrm{DM} / \mathrm{a}$ & \\
\hline Silozange & & $1.120,00$ & DM/a & 0,30 & $\mathrm{DM} / \mathrm{m}^{3}$ & $2.545,45$ & $\mathrm{~m}^{3} / \mathrm{a}$ & $1.883,64$ & $\mathrm{DM} / \mathrm{a}$ & \\
\hline Anbauschaufe & & 506,00 & $\mathrm{DM} / \mathrm{a}$ & 0,30 & $\mathrm{DM} / \mathrm{m}^{3}$ & $10.169,70$ & $m^{3} / a$ & $3.556,91$ & $\mathrm{DM} / \mathrm{a}$ & \\
\hline Mietenumsetz & & $3.600,00$ & $\mathrm{DM} / \mathrm{a}$ & 28,00 & $\mathrm{DM} / \mathrm{h}$ & 54,17 & $\mathrm{~h} / \mathrm{a}$ & $5.116,86$ & $\mathrm{DM} / \mathrm{a}$ & \\
\hline & & & & & & Summe (Neuk & bau) & $43.576,00$ & $\mathrm{DM} / \mathrm{a}$ & \\
\hline & & & & & & Summe (Umn & hutzung) & $44.526,88$ & $\mathrm{DM} / \mathrm{a}$ & \\
\hline PERSONA & KOSTEN & & & & & & & & & \\
\hline & Std.-Lohn in & kl.Lohn-NK & Arbeitsstd. pro & Jahr & Personal-Einz & zelkosten & & & & \\
\hline Neubau & 26,00 & $\mathrm{DM} / \mathrm{h}$ & 588,05 & $\mathrm{~h} / \mathrm{a}$ & $15.289,42$ & $D M / a$ & & & & \\
\hline Umnutzung & 26,00 & DM/h & 603,02 & $h / a$ & $15.678,45$ & $D M / a$ & & & & \\
\hline
\end{tabular}




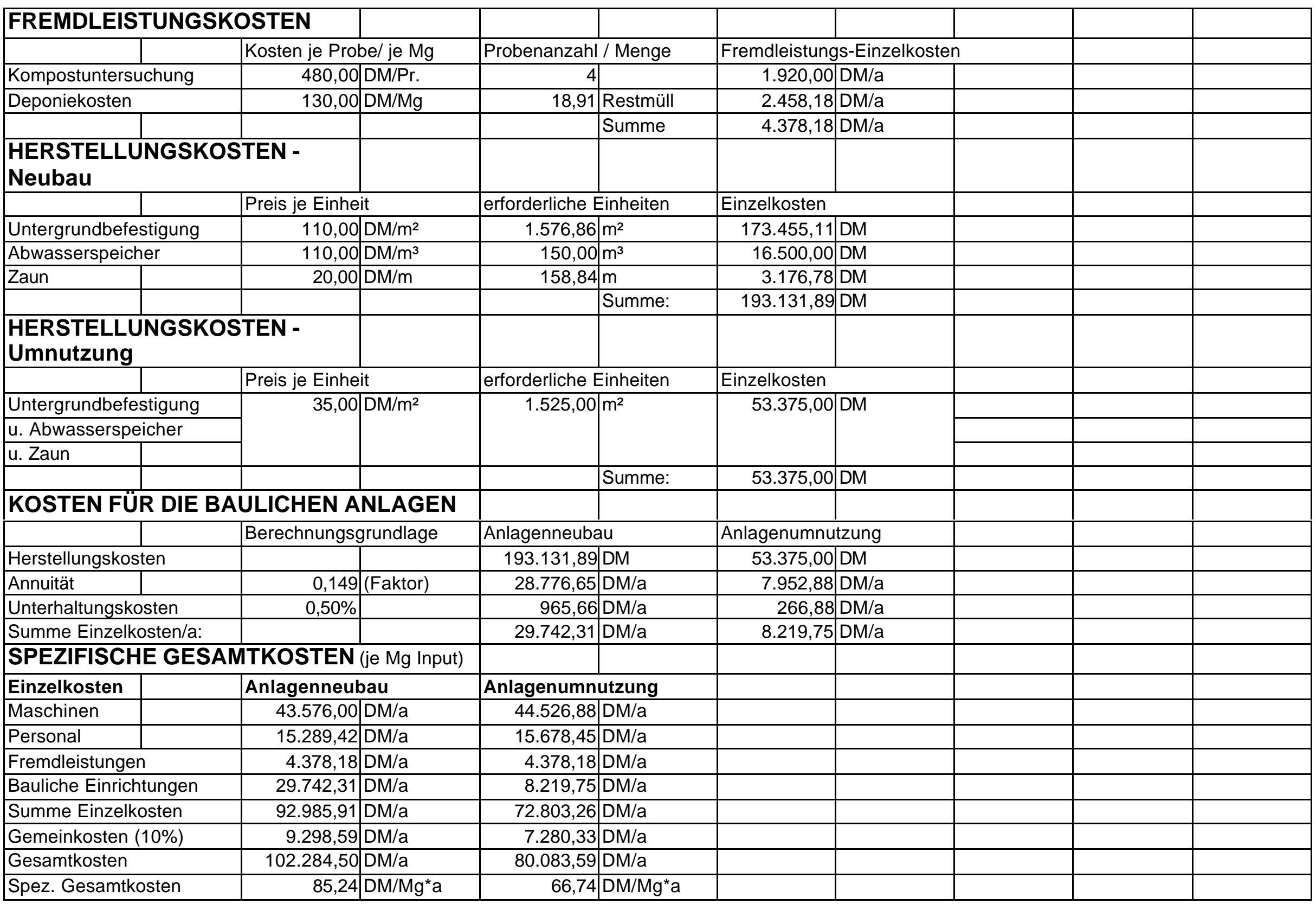


Kostenvariante C6

\begin{tabular}{|c|c|c|c|c|c|c|c|c|c|c|}
\hline MATERIA & & & & & & & & & & \\
\hline Jahresinput & & & $1.400,00$ & $\mathrm{Mg} / \mathrm{a}$ & & & & & & \\
\hline Zusammens & & & $65 \%$ & Vol.-\% & Bioabfälle & Haushalten & & & & \\
\hline & & & $35 \%$ & Vol.-\% & gehäckselt & Grüngut & & & & \\
\hline Dichte & & & 0,6 & $\mathrm{Mg} / \mathrm{m}^{3}$ & Bioabfälle & Haushalten & & & & \\
\hline & & & 0,3 & $\mathrm{Mg} / \mathrm{m}^{3}$ & gehäckselt & Grüngut & & & & \\
\hline & & & 0,495 & $\mathrm{Mg} / \mathrm{m}^{3}$ & konditionie & 5 Material & & & & \\
\hline & & & 0,5 & $\mathrm{Mg} / \mathrm{m}^{3}$ & Fertigkomp & & & & & \\
\hline Volumen & & & $2.828,28$ & $\mathrm{~m}^{3} / \mathrm{a}$ & konditionie & s Material & & & & \\
\hline & & & $1.838,38$ & $\mathrm{~m}^{3} / \mathrm{a}$ & Bioabfälle & Haushalten & & & & \\
\hline & & & $2.969,70$ & $\mathrm{~m}^{3} / \mathrm{a}$ & angeliefert & Grüngut & & & & \\
\hline & & & 989,90 & $\mathrm{~m}^{3} / \mathrm{a}$ & gehäckselt & Grüngut & & & & \\
\hline & & & $1.400,00$ & $\mathrm{~m}^{3} / \mathrm{a}$ & Fertigkomp & & & & & \\
\hline Gewichtsan & & & $1.103,03$ & $\mathrm{Mg} / \mathrm{a}$ & Bioabfälle c & Haushalten & & & & \\
\hline & & & 296,97 & $\mathrm{Mg} / \mathrm{a}$ & Grüngut & & & & & \\
\hline & & & 700,00 & $\mathrm{Mg} / \mathrm{a}$ & Fertigkomp & & & & & \\
\hline Rottedauer & & & 12 & Wochen & & & & & & \\
\hline durchschnit & & & 107,69 & $\mathrm{Mg}$ & & Rottematerial & eines & & & \\
\hline Monatsaufk & & & 217,56 & $m^{3}$ (kon) & & Durchlaufs in & der Anlage & 455,79 & $\mathrm{~m}^{3}$ & \\
\hline maximaler I & atsanfall & & 196,00 & $\mathrm{Mg}$ & entspr. 12 & vom Input/a & & & & \\
\hline & & & 395,96 & $\mathrm{~m}^{3}$ & & & & & & \\
\hline TS-Gehalt & igkompost) & & $61,70 \%$ & & & & & & & \\
\hline Mietenhöhe & & & 1,5 & $\mathrm{~m}$ & Mietenquer & hnitt & & & & \\
\hline Mietenbasis & & & 2,5 & $\mathrm{~m}$ & $\overline{1,8}$ & $\mathrm{~m}^{2}$ & & & & \\
\hline ANLAGE & IMENSIO & IIERUNG & & & & & & & & \\
\hline Anlagent & & Berechnung & gsgrundlage & & & Anlagenneub & bau & Anlagenumn & utzung & \\
\hline Anliefe & sfläche & $5 \%$ & vom Input in I & hg/a, ausg & ickt in $\mathrm{m}^{2}$ & 70,00 & $\mathrm{~m}^{2}$ & 400,00 & $\mathrm{~m}^{2}$ & \\
\hline Rottefläch & & 1,33 & $\mathrm{~m}^{2} / \mathrm{m}^{3}$ Rottem & aterial bei & M.-Anfall & 1106,05 & $\mathrm{~m}^{2}$ & & $m^{2}$ & \\
\hline Rangierfläc & & $40 \%$ & der Rottefläch & & & 442,42 & $\mathrm{~m}^{2}$ & 1525,00 & & \\
\hline Zwisch & ger für & & der Rottefläch & & & & $m^{2}$ & & $\mathrm{~m}^{2}$ (nich & niert) \\
\hline Strukt & aterial & $10 \%$ & & & & 110,60 & & 600,00 & & \\
\hline Kompostla & & $10 \%$ & der Rottefläch & & & 110,60 & $m^{2}$ & 400,00 & $\mathrm{~m}^{2}$ & \\
\hline Anlagenfl & (gesamt) & & & & & 1839,68 & $\mathrm{~m}^{2}$ & 2325,00 & $m^{2}$ & \\
\hline zu ve & tende & & & & & & & & & \\
\hline Abwa & menge & 0,2 & $m^{3} / m^{2 \star} a$ & & & 367,94 & $m^{3} / a$ & 465,00 & $m^{3} / a$ & \\
\hline
\end{tabular}




\begin{tabular}{|c|c|c|c|c|c|c|c|c|c|c|}
\hline ZEITEN & & & & & & & & & & \\
\hline Arbeitsgang & & & eingesetzte $\mathrm{M}$ & Maschinen & Zeitbedarf/Ei & inheit & geleistete Ein & nheiten & Zeitbedarf/Ja & ahr \\
\hline Materialannah & & & & & 4,000 & h/Woche & 52,000 & Wochen/a & 208,000 & $h / a$ \\
\hline Manuelle Stör & offauslese & & & & 1,000 & $h / 100 m^{3}(\ln )$ & $4.808,081$ & $\mathrm{~m}^{3} / \mathrm{a}$ & 48,081 & $h / a$ \\
\hline Zerkleinerung & on Strukturm & iaterial & TL, SZ, Schr. & & 1,000 & $h / 50 m^{3}(\operatorname{In})$ & $2.969,697$ & $\mathrm{~m}^{3} / \mathrm{a}$ & 59,394 & $h / a$ \\
\hline Aufsetzen ein & Matte aus S & trukturmat. & TL, AS & & 0,300 & $\mathrm{~h} / 100 \mathrm{~m}^{3}$ (kon) & $2.828,283$ & $\mathrm{~m}^{3} / \mathrm{a}$ & 8,485 & $h / a$ \\
\hline Aufsetzen der & Jreiecksmiete & & TL, AS & & 1,000 & $\mathrm{~h} / 20 \mathrm{~m}^{3}$ (kon) & $2.828,283$ & $\mathrm{~m}^{3} / \mathrm{a}$ & 141,414 & $h / a$ \\
\hline Umsetzen der & Jreiecksmiete & & Schl., MU & & 0,005 & $\mathrm{~h} / \mathrm{m}$ (Mietenl.) & $12.640,539$ & $\mathrm{~m} / \mathrm{a}$ & 63,203 & $\mathrm{~h} / \mathrm{a}$ \\
\hline Reinigung der & Annahmefläch & & TL, AS & & 0,500 & $h / 150 m^{3}(\ln )$ & $4.808,081$ & $\mathrm{~m}^{3} / \mathrm{a}$ & 16,027 & $\mathrm{~h} / \mathrm{a}$ \\
\hline Sieben & & & TL, AS, Sieb & & 1,000 & $\mathrm{~h} / 20 \mathrm{~m}^{3}(\mathrm{kom})$ & $1.400,000$ & $\mathrm{~m}^{3} / \mathrm{a}$ & 70,000 & $h / a$ \\
\hline Abw.-Ausbring & Ing bei Neub & & Schl.,PT & & 1,000 & $\mathrm{~h} / 10 \mathrm{~m}^{3}(\mathrm{Abw})$ & 367,935 & $\mathrm{~m}^{3} / \mathrm{a}$ & 36,794 & $h / a$ \\
\hline Abw.-Ausbring & Ing bei Umnu & utzung & Schl., PT & & 1,000 & $\mathrm{~h} / 10 \mathrm{~m}^{3}(\mathrm{Abw})$ & 465,000 & $\mathrm{~m}^{3} / \mathrm{a}$ & 46,500 & $h / a$ \\
\hline Abkürzungen & Ir die eingese & tzten Maschin & nen: & & & & & & & \\
\hline TL - Teleskop & der & & Schl. - Schlepp & per & & & & & & \\
\hline MU- Mietenum & etzer & & Schr. - Schred & dder & & & & & & \\
\hline SZ - Silozange & & & PT - Pumpenta & tankwagen & & & & & & \\
\hline AS - Anbausc & aufel & & & & & & & & & \\
\hline MASCHINE & NKOSTEN & & & & & & & & & \\
\hline Maschine / G & & Fixkosten & & Variable Kost & ten & Einheiten/a & & Maschinen-Ei & inzelkosten & \\
\hline Traktor (Neub & & 0,00 & $\mathrm{DM} / \mathrm{a}$ & 33,55 & $D M / h$ & 100,00 & $h / a$ & $3.354,87$ & $\mathrm{DM} / \mathrm{a}$ & \\
\hline Traktor (Umnu & zung) & 0,00 & $\mathrm{DM} / \mathrm{a}$ & 33,55 & $D M / h$ & 109,70 & $\mathrm{~h} / \mathrm{a}$ & $3.680,53$ & $\mathrm{DM} / \mathrm{a}$ & \\
\hline Teleskoplader & & 0,00 & $D M / a$ & 66,50 & $\mathrm{DM} / \mathrm{h}$ & 295,32 & $h / a$ & $19.638,77$ & $\mathrm{DM} / \mathrm{a}$ & \\
\hline Schredder & & 0,00 & DM/a & 7,50 & $\mathrm{DM} / \mathrm{m}^{3}$ (Out) & 989,90 & $\mathrm{~m}^{3} / \mathrm{a}$ & $7.424,24$ & $\mathrm{DM} / \mathrm{a}$ & \\
\hline Trommelsieb & & 0,00 & DM/a & 5,00 & $\mathrm{DM} / \mathrm{m}^{3}(\mathrm{Kom})$ & $1.400,00$ & $m^{3} / a$ & $7.000,00$ & $\mathrm{DM} / \mathrm{a}$ & \\
\hline PumpenTW ( & abau) & 0,00 & $\mathrm{DM} / \mathrm{a}$ & 30,00 & $\mathrm{DM} / \mathrm{h}$ & 36,79 & $\mathrm{~h} / \mathrm{a}$ & $1.103,81$ & $\mathrm{DM} / \mathrm{a}$ & \\
\hline PumpenTW (L & nnutzung) & 0,00 & $D M / a$ & 30,00 & $D M / h$ & 46,50 & $h / a$ & $1.395,00$ & $\mathrm{DM} / \mathrm{a}$ & \\
\hline Silozange & & $1.120,00$ & DM/a & 0,30 & $\mathrm{DM} / \mathrm{m}^{3}$ & $2.969,70$ & $\mathrm{~m}^{3} / \mathrm{a}$ & $2.010,91$ & $\mathrm{DM} / \mathrm{a}$ & \\
\hline Anbauschaufe & & 506,00 & $\mathrm{DM} / \mathrm{a}$ & 0,30 & $\mathrm{DM} / \mathrm{m}^{3}$ & $11.864,65$ & $\mathrm{~m}^{3} / \mathrm{a}$ & $4.065,39$ & $\mathrm{DM} / \mathrm{a}$ & \\
\hline Mietenumsetz & & $3.600,00$ & $\mathrm{DM} / \mathrm{a}$ & 28,00 & $D M / h$ & 63,20 & $h / a$ & $5.369,68$ & $\mathrm{DM} / \mathrm{a}$ & \\
\hline & & & & & & Summe (Neuk & bau) & $49.967,67$ & $\mathrm{DM} / \mathrm{a}$ & \\
\hline & & & & & & Summe (Umn & hutzung) & $50.584,52$ & $\mathrm{DM} / \mathrm{a}$ & \\
\hline PERSONA & KOSTEN & & & & & & & & & \\
\hline & Std.-Lohn in & kl.Lohn-NK & Arbeitsstd. pro & o Jahr & Personal-Einz & zelkosten & & & & \\
\hline Neubau & 26,00 & $\mathrm{DM} / \mathrm{h}$ & 651,40 & $\mathrm{~h} / \mathrm{a}$ & $16.936,32$ & $D M / a$ & & & & \\
\hline Umnutzung & 26,00 & $\mathrm{DM} / \mathrm{h}$ & 661,10 & $\mathrm{~h} / \mathrm{a}$ & $17.188,69$ & DM/a & & & & \\
\hline
\end{tabular}




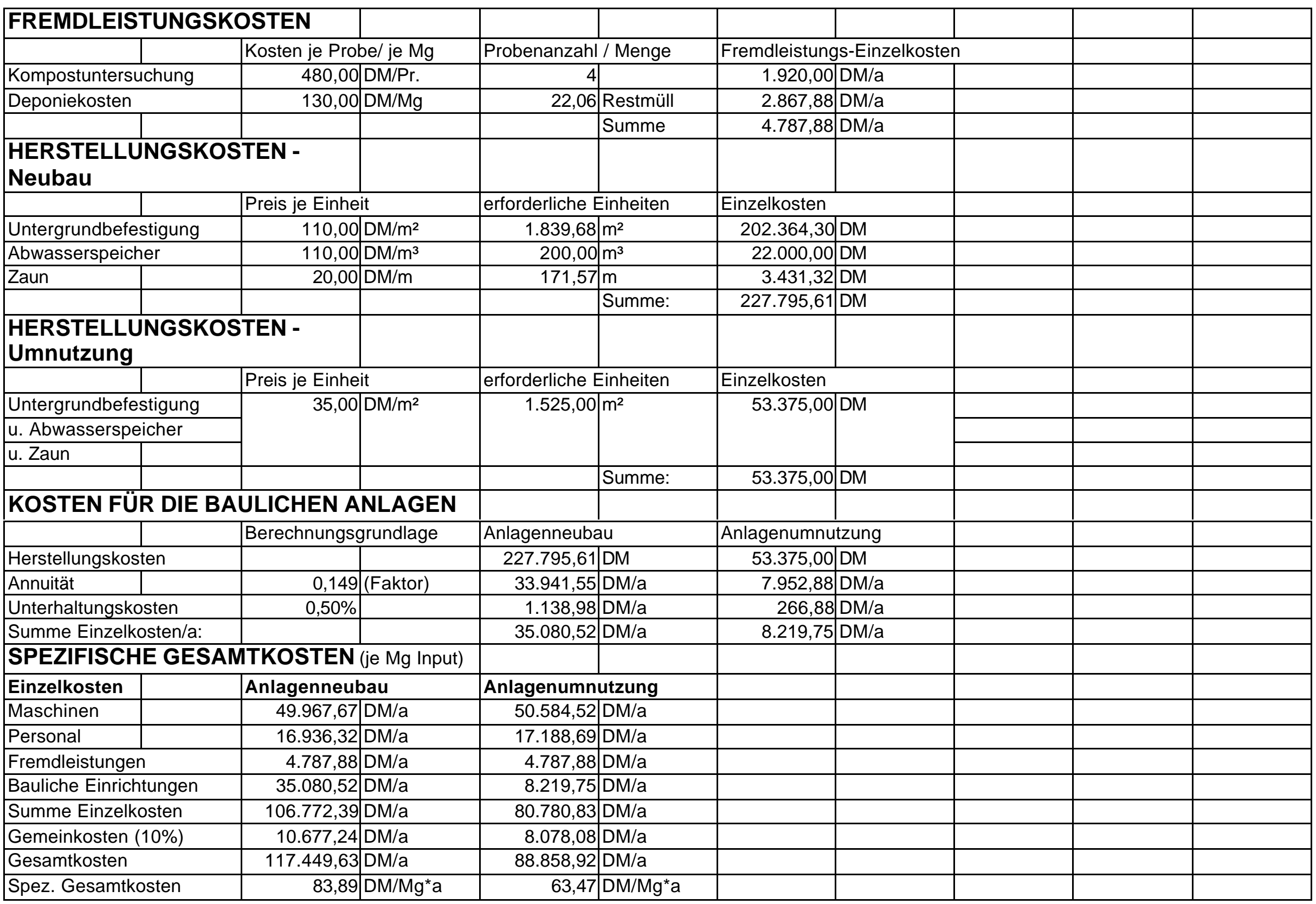


Kostenvariante C7

\begin{tabular}{|c|c|c|c|c|c|c|c|c|c|c|}
\hline MATERIA & & & & & & & & & & \\
\hline Jahresinput & & & $1.600,00$ & $\mathrm{Mg} / \mathrm{a}$ & & & & & & \\
\hline Zusammens & & & $65 \%$ & Vol.-\% & Bioabfälle & Haushalten & & & & \\
\hline & & & $35 \%$ & Vol.-\% & gehäckselt & Grüngut & & & & \\
\hline Dichte & & & 0,6 & $\mathrm{Mg} / \mathrm{m}^{3}$ & Bioabfälle & Haushalten & & & & \\
\hline & & & 0,3 & $\mathrm{Mg} / \mathrm{m}^{3}$ & gehäckselt & Grüngut & & & & \\
\hline & & & 0,495 & $\mathrm{Mg} / \mathrm{m}^{3}$ & konditionie & s Material & & & & \\
\hline & & & 0,5 & $\mathrm{Mg} / \mathrm{m}^{3}$ & Fertigkomp & & & & & \\
\hline Volumen & & & $3.232,32$ & $\mathrm{~m}^{3} / \mathrm{a}$ & konditionie & s Material & & & & \\
\hline & & & $2.101,01$ & $\mathrm{~m}^{3} / \mathrm{a}$ & Bioabfälle & Haushalten & & & & \\
\hline & & & $3.393,94$ & $\mathrm{~m}^{3} / \mathrm{a}$ & angeliefert & Grüngut & & & & \\
\hline & & & $1.131,31$ & $\mathrm{~m}^{3} / \mathrm{a}$ & gehäckselt & Grüngut & & & & \\
\hline & & & $1.600,00$ & $\mathrm{~m}^{3} / \mathrm{a}$ & Fertigkomp & & & & & \\
\hline Gewichtsan & & & $1.260,61$ & $\mathrm{Mg} / \mathrm{a}$ & Bioabfälle & Haushalten & & & & \\
\hline & & & 339,39 & $\mathrm{Mg} / \mathrm{a}$ & Grüngut & & & & & \\
\hline & & & 800,00 & $\mathrm{Mg} / \mathrm{a}$ & Fertigkomp & & & & & \\
\hline Rottedauer & & & 12 & Wochen & & & & & & \\
\hline durchschnit & & & 123,08 & $\mathrm{Mg}$ & & Rottematerial & eines & & & \\
\hline Monatsaufk & & & 248,64 & $m^{3}$ (kon) & & Durchlaufs in & der Anlage & 520,90 & $\mathrm{~m}^{3}$ & \\
\hline maximaler I & atsanfall & & 224,00 & $\mathrm{Mg}$ & entspr. 1 & vom Input/a & & & & \\
\hline & & & 452,53 & $\mathrm{~m}^{3}$ & & & & & & \\
\hline TS-Gehalt & igkompost) & & $61,70 \%$ & & & & & & & \\
\hline Mietenhöhe & & & 1,5 & $\mathrm{~m}$ & Mietenquer & hnitt & & & & \\
\hline Mietenbasis & & & 2,5 & $\mathrm{~m}$ & $\overline{1,8}$ & $\mathrm{~m}^{2}$ & & & & \\
\hline ANLAGE & IMENSIO & IIERUNG & & & & & & & & \\
\hline Anlagent & & Berechnung & gsgrundlage & & & Anlagenneub & bau & Anlagenumn & utzung & \\
\hline Anliefe & sfläche & $5 \%$ & vom Input in 1 & $\mathrm{Mg} / \mathrm{a}$, ausg & ickt in $\mathrm{m}^{2}$ & 80,00 & $\mathrm{~m}^{2}$ & 850,00 & $\mathrm{~m}^{2}$ & \\
\hline Rottefläch & & 1,33 & $\mathrm{~m}^{2} / \mathrm{m}^{3}$ Rottem & aterial bei & M.-Anfall & 1264,05 & $\mathrm{~m}^{2}$ & & $m^{2}$ & \\
\hline Rangierfläc & & $40 \%$ & der Rottefläch & & & 505,62 & $\mathrm{~m}^{2}$ & 3160,00 & & \\
\hline Zwisch & iger für & & der Rottefläch & & & & $m^{2}$ & & & \\
\hline Strukt & aterial & $10 \%$ & & & & 126,41 & & & & \\
\hline Kompostla & & $10 \%$ & der Rottefläch & & & 126,41 & $\mathrm{~m}^{2}$ & 850,00 & $\mathrm{~m}^{2}$ & \\
\hline Anlagenfl & (gesamt) & & & & & 2102,49 & $\mathrm{~m}^{2}$ & 4860,00 & $m^{2}$ & \\
\hline zu ve & tende & & & & & & & & & \\
\hline Abwa & menge & 0,2 & $m^{3} / m^{2 \star} a$ & & & 420,50 & $m^{3} / a$ & 972,00 & $\mathrm{~m}^{3} / \mathrm{a}$ & \\
\hline
\end{tabular}




\begin{tabular}{|c|c|c|c|c|c|c|c|c|c|c|}
\hline \multicolumn{11}{|l|}{ ZEITEN } \\
\hline \multicolumn{3}{|l|}{ Arbeitsgang } & \multicolumn{2}{|c|}{ eingesetzte Maschinen } & \multicolumn{2}{|c|}{ Zeitbedarf/Einheit } & \multicolumn{2}{|c|}{ geleistete Einheiten } & \multicolumn{2}{|c|}{ Zeitbedarf/Jahr } \\
\hline \multicolumn{3}{|c|}{ Materialannahme } & & & 4,000 & h/Woche & 52,000 & Wochen/a & 208,000 & $h / a$ \\
\hline \multicolumn{3}{|c|}{ Manuelle Störstoffauslese } & & & 1,000 & $h / 100 m^{3}(\operatorname{In})$ & $5.494,949$ & $\mathrm{~m}^{3} / \mathrm{a}$ & 54,949 & $\mathrm{~h} / \mathrm{a}$ \\
\hline \multicolumn{3}{|c|}{ Zerkleinerung von Strukturmaterial } & \multicolumn{2}{|l|}{ TL, SZ, Schr. } & 1,000 & $h / 50 m^{3}(\ln )$ & $3.393,939$ & $\mathrm{~m}^{3} / \mathrm{a}$ & 67,879 & $h / a$ \\
\hline \multicolumn{3}{|c|}{ Aufsetzen einer Matte aus Strukturmat. } & \multicolumn{2}{|l|}{$\mathrm{TL}, \mathrm{AS}$} & 0,300 & $\mathrm{~h} / 100 \mathrm{~m}^{3}$ (kon) & $3.232,323$ & $\mathrm{~m}^{3} / \mathrm{a}$ & 9,697 & $h / a$ \\
\hline \multicolumn{3}{|c|}{ Aufsetzen der Dreiecksmieten } & \multicolumn{2}{|l|}{ TL, AS } & 1,000 & $\mathrm{~h} / 20 \mathrm{~m}^{3}$ (kon) & $3.232,323$ & $\mathrm{~m}^{3} / \mathrm{a}$ & 161,616 & $\mathrm{~h} / \mathrm{a}$ \\
\hline \multicolumn{3}{|c|}{ Umsetzen der Dreiecksmieten } & \multicolumn{2}{|l|}{ Schl., MU } & 0,005 & $\mathrm{~h} / \mathrm{m}$ (Mietenl.) & $14.446,330$ & $\mathrm{~m} / \mathrm{a}$ & 72,232 & $h / a$ \\
\hline \multicolumn{3}{|c|}{ Reinigung der Annahmefläche } & \multicolumn{2}{|l|}{ TL, AS } & 0,500 & $h / 150 m^{3}(\ln )$ & $5.494,949$ & $\mathrm{~m}^{3} / \mathrm{a}$ & 18,316 & $h / a$ \\
\hline \multicolumn{3}{|l|}{ Sieben } & \multicolumn{2}{|l|}{ TL, AS, Sieb } & 1,000 & $\mathrm{~h} / 20 \mathrm{~m}^{3}(\mathrm{kom})$ & $1.600,000$ & $\mathrm{~m}^{3} / \mathrm{a}$ & 80,000 & $\mathrm{~h} / \mathrm{a}$ \\
\hline \multicolumn{3}{|c|}{ Abw.-Ausbringung bei Neubau } & \multicolumn{2}{|l|}{ Schl.,PT } & 1,000 & $\mathrm{~h} / 10 \mathrm{~m}^{3}(\mathrm{Abw})$ & 420,497 & $\mathrm{~m}^{3} / \mathrm{a}$ & 42,050 & $h / a$ \\
\hline \multicolumn{3}{|c|}{ Abw.-Ausbringung bei Umnutzung } & \multicolumn{2}{|l|}{ Schl., PT } & 1,000 & $\mathrm{~h} / 10 \mathrm{~m}^{3}(\mathrm{Abw})$ & 972,000 & $\mathrm{~m}^{3} / \mathrm{a}$ & 97,200 & $h / a$ \\
\hline \multicolumn{11}{|c|}{ Abkürzungen für die eingesetzten Maschinen: } \\
\hline \multicolumn{3}{|c|}{\begin{tabular}{|l|l|} 
TL - Teleskoplader & \\
\end{tabular}} & Schl. - Schlepp & per & & & & & & \\
\hline MU- Mietenum & etzer & & Schr. - Schred & dder & & & & & & \\
\hline SZ - Silozange & & & PT - Pumpenta & tankwagen & & & & & & \\
\hline AS - Anbausc & aufel & & & & & & & & & \\
\hline MASCHINE & NKOSTEN & & & & & & & & & \\
\hline Maschine / G & & Fixkosten & & Variable Kost & ten & Einheiten/a & & Maschinen-Ei & inzelkosten & \\
\hline Traktor (Neub & & 0,00 & $D M / a$ & 33,55 & $D M / h$ & 114,28 & $\mathrm{~h} / \mathrm{a}$ & $3.834,14$ & $D M / a$ & \\
\hline Traktor (Umnu & zung) & 0,00 & $\mathrm{DM} / \mathrm{a}$ & 33,55 & $D M / h$ & 169,43 & $\mathrm{~h} / \mathrm{a}$ & $5.684,43$ & $\mathrm{DM} / \mathrm{a}$ & \\
\hline Teleskoplader & & 0,00 & $D M / a$ & 66,50 & $\mathrm{DM} / \mathrm{h}$ & 337,51 & $h / a$ & $22.444,31$ & $\mathrm{DM} / \mathrm{a}$ & \\
\hline Schredder & & 0,00 & DM/a & 7,50 & $\mathrm{DM} / \mathrm{m}^{3}$ (Out) & $1.131,31$ & $\mathrm{~m}^{3} / \mathrm{a}$ & $8.484,85$ & $\mathrm{DM} / \mathrm{a}$ & \\
\hline Trommelsieb & & 0,00 & $\mathrm{DM} / \mathrm{a}$ & 5,00 & $\mathrm{DM} / \mathrm{m}^{3}(\mathrm{Kom})$ & $1.600,00$ & $\mathrm{~m}^{3} / \mathrm{a}$ & $8.000,00$ & $\mathrm{DM} / \mathrm{a}$ & \\
\hline PumpenTW ( & abau) & 0,00 & $\mathrm{DM} / \mathrm{a}$ & 30,00 & $\mathrm{DM} / \mathrm{h}$ & 42,05 & $\mathrm{~h} / \mathrm{a}$ & $1.261,49$ & $\mathrm{DM} / \mathrm{a}$ & \\
\hline PumpenTW (L & nnutzung) & 0,00 & $D M / a$ & 30,00 & $D M / h$ & 97,20 & $h / a$ & $2.916,00$ & $\mathrm{DM} / \mathrm{a}$ & \\
\hline Silozange & & $1.120,00$ & DM/a & 0,30 & $\mathrm{DM} / \mathrm{m}^{3}$ & $3.393,94$ & $\mathrm{~m}^{3} / \mathrm{a}$ & $2.138,18$ & $\mathrm{DM} / \mathrm{a}$ & \\
\hline Anbauschaufe & & 506,00 & $\mathrm{DM} / \mathrm{a}$ & 0,30 & $\mathrm{DM} / \mathrm{m}^{3}$ & $13.559,60$ & $m^{3} / a$ & $4.573,88$ & $\mathrm{DM} / \mathrm{a}$ & \\
\hline Mietenumsetz & & $3.600,00$ & $\mathrm{DM} / \mathrm{a}$ & 28,00 & $\mathrm{DM} / \mathrm{h}$ & 72,23 & $\mathrm{~h} / \mathrm{a}$ & $5.622,49$ & $\mathrm{DM} / \mathrm{a}$ & \\
\hline & & & & & & Summe (Neuk & bau) & $56.359,34$ & $\mathrm{DM} / \mathrm{a}$ & \\
\hline & & & & & & Summe (Umn & hutzung) & $59.864,14$ & $\mathrm{DM} / \mathrm{a}$ & \\
\hline PERSONA & KOSTEN & & & & & & & & & \\
\hline & Std.-Lohn in & kl.Lohn-NK & Arbeitsstd. pro & o Jahr & Personal-Einz & zelkosten & & & & \\
\hline Neubau & 26,00 & $\mathrm{DM} / \mathrm{h}$ & 714,74 & $\mathrm{~h} / \mathrm{a}$ & $18.583,22$ & $D M / a$ & & & & \\
\hline Umnutzung & 26,00 & $\mathrm{DM} / \mathrm{h}$ & 769,89 & $\mathrm{~h} / \mathrm{a}$ & $20.017,13$ & DM/a & & & & \\
\hline
\end{tabular}




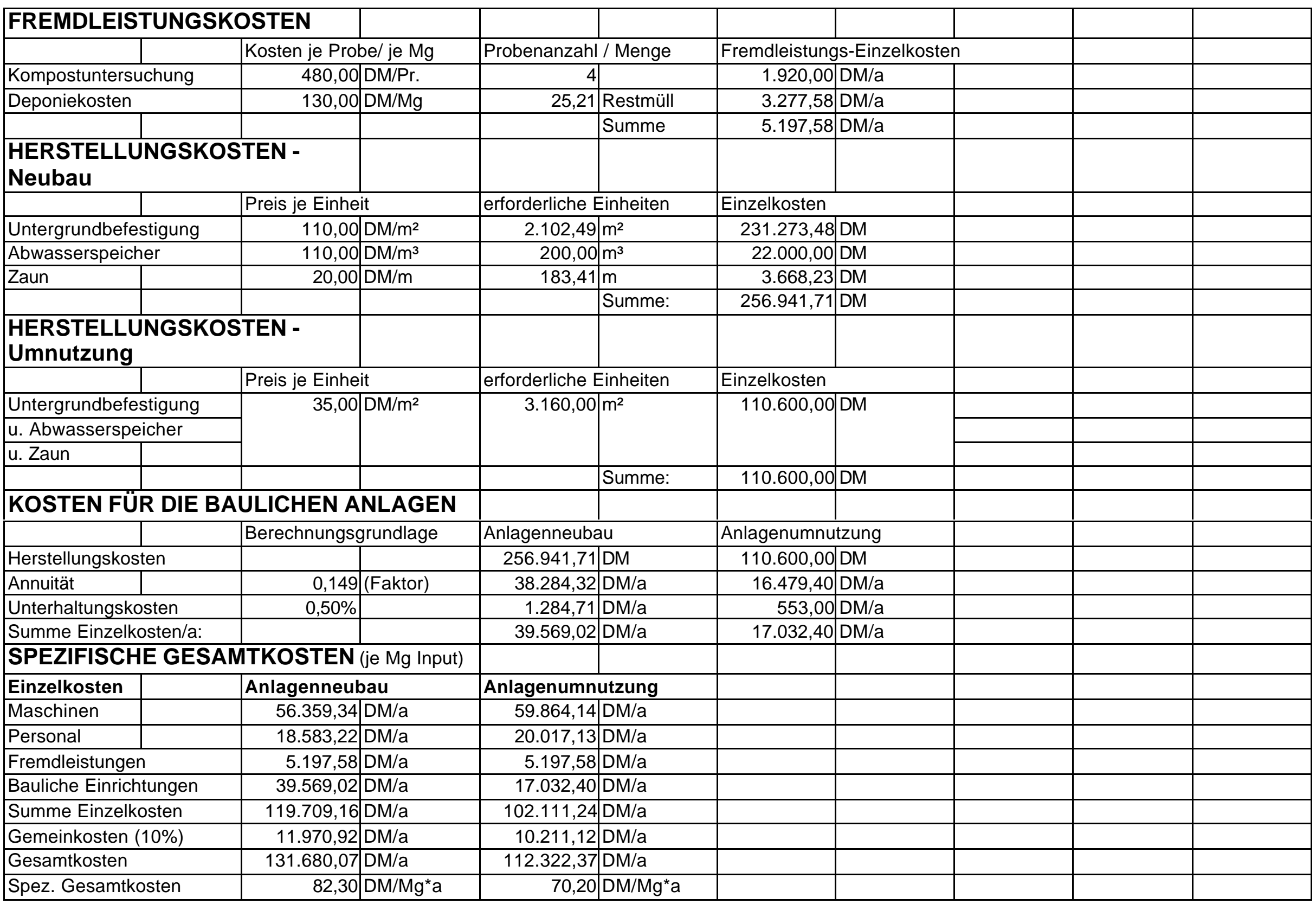


Kostenvariante C8

\begin{tabular}{|c|c|c|c|c|c|c|c|c|c|c|}
\hline MATERIA & & & & & & & & & & \\
\hline Jahresinput & & & $1.800,00$ & $\mathrm{Mg} / \mathrm{a}$ & & & & & & \\
\hline Zusammens & & & $65 \%$ & Vol.-\% & Bioabfälle & Haushalten & & & & \\
\hline & & & $35 \%$ & Vol.-\% & gehäckselt & Grüngut & & & & \\
\hline Dichte & & & 0,6 & $\mathrm{Mg} / \mathrm{m}^{3}$ & Bioabfälle & Haushalten & & & & \\
\hline & & & 0,3 & $\mathrm{Mg} / \mathrm{m}^{3}$ & gehäckselt & Grüngut & & & & \\
\hline & & & 0,495 & $\mathrm{Mg} / \mathrm{m}^{3}$ & konditionie & s Material & & & & \\
\hline & & & 0,5 & $\mathrm{Mg} / \mathrm{m}^{3}$ & Fertigkomp & & & & & \\
\hline Volumen & & & $3.636,36$ & $\mathrm{~m}^{3} / \mathrm{a}$ & konditionie & s Material & & & & \\
\hline & & & $2.363,64$ & $\mathrm{~m}^{3} / \mathrm{a}$ & Bioabfälle & Haushalten & & & & \\
\hline & & & $3.818,18$ & $\mathrm{~m}^{3} / \mathrm{a}$ & angeliefert & Grüngut & & & & \\
\hline & & & $1.272,73$ & $\mathrm{~m}^{3} / \mathrm{a}$ & gehäckselt & Grüngut & & & & \\
\hline & & & $1.800,00$ & $\mathrm{~m}^{3} / \mathrm{a}$ & Fertigkomp & & & & & \\
\hline Gewichtsan & & & $1.418,18$ & $\mathrm{Mg} / \mathrm{a}$ & Bioabfälle c & Haushalten & & & & \\
\hline & & & 381,82 & $\mathrm{Mg} / \mathrm{a}$ & Grüngut & & & & & \\
\hline & & & 900,00 & $\mathrm{Mg} / \mathrm{a}$ & Fertigkomp & & & & & \\
\hline Rottedauer & & & 12 & Wochen & & & & & & \\
\hline durchschnit & & & 138,46 & $\mathrm{Mg}$ & & Rottematerial & eines & & & \\
\hline Monatsaufk & & & 279,72 & $m^{3}$ (kon) & & Durchlaufs in & der Anlage & 586,01 & $\mathrm{~m}^{3}$ & \\
\hline maximaler I & atsanfall & & 252,00 & $\mathrm{Mg}$ & entspr. 1 & vom Input/a & & & & \\
\hline & & & 509,09 & $\mathrm{~m}^{3}$ & & & & & & \\
\hline TS-Gehalt & igkompost) & & $61,70 \%$ & & & & & & & \\
\hline Mietenhöhe & & & 1,5 & $\mathrm{~m}$ & Mietenquer & hnitt & & & & \\
\hline Mietenbasis & & & 2,5 & $\mathrm{~m}$ & $\overline{1,8}$ & $\mathrm{~m}^{2}$ & & & & \\
\hline ANLAGE & IMENSIO & IIERUNG & & & & & & & & \\
\hline Anlagent & & Berechnung & gsgrundlage & & & Anlagenneub & bau & Anlagenumn & utzung & \\
\hline Anliefe & sfläche & $5 \%$ & vom Input in I & hg/a, ausg & ickt in $\mathrm{m}^{2}$ & 90,00 & $\mathrm{~m}^{2}$ & 850,00 & $\mathrm{~m}^{2}$ & \\
\hline Rottefläch & & 1,33 & $\mathrm{~m}^{2} / \mathrm{m}^{3}$ Rottem & aterial bei & M.-Anfall & 1422,06 & $\mathrm{~m}^{2}$ & & $m^{2}$ & \\
\hline Rangierfläc & & $40 \%$ & der Rottefläch & & & 568,82 & $\mathrm{~m}^{2}$ & 3160,00 & & \\
\hline Zwisch & iger für & & der Rottefläch & & & & $m^{2}$ & & & \\
\hline Strukt & aterial & $10 \%$ & & & & 142,21 & & & & \\
\hline Kompostla & & $10 \%$ & der Rottefläch & & & 142,21 & $\mathrm{~m}^{2}$ & 850,00 & $\mathrm{~m}^{2}$ & \\
\hline Anlagenfl & (gesamt) & & & & & 2365,30 & $\mathrm{~m}^{2}$ & 4860,00 & $m^{2}$ & \\
\hline zu ve & tende & & & & & & & & & \\
\hline Abwa & menge & 0,2 & $m^{3} / m^{2 \star} a$ & & & 473,06 & $\mathrm{~m}^{3} / \mathrm{a}$ & 972,00 & $\mathrm{~m}^{3} / \mathrm{a}$ & \\
\hline
\end{tabular}




\begin{tabular}{|c|c|c|c|c|c|c|c|c|c|c|}
\hline \multicolumn{11}{|l|}{ ZEITEN } \\
\hline \multicolumn{3}{|l|}{ Arbeitsgang } & \multicolumn{2}{|c|}{ eingesetzte Maschinen } & \multicolumn{2}{|c|}{ Zeitbedarf/Einheit } & \multicolumn{2}{|c|}{ geleistete Einheiten } & \multicolumn{2}{|c|}{ Zeitbedarf/Jahr } \\
\hline \multicolumn{3}{|c|}{ Materialannahme } & & & 4,000 & h/Woche & 52,000 & Wochen/a & 208,000 & $h / a$ \\
\hline \multicolumn{3}{|c|}{ Manuelle Störstoffauslese } & & & 1,000 & $h / 100 m^{3}(\operatorname{In})$ & $6.181,818$ & $m^{3} / a$ & 61,818 & $\mathrm{~h} / \mathrm{a}$ \\
\hline \multicolumn{3}{|c|}{ Zerkleinerung von Strukturmaterial } & \multicolumn{2}{|l|}{ TL, SZ, Schr. } & 1,000 & $h / 50 m^{3}(\ln )$ & $3.818,182$ & $\mathrm{~m}^{3} / \mathrm{a}$ & 76,364 & $h / a$ \\
\hline \multicolumn{3}{|c|}{ Aufsetzen einer Matte aus Strukturmat. } & \multicolumn{2}{|l|}{$\mathrm{TL}, \mathrm{AS}$} & 0,300 & $\mathrm{~h} / 100 \mathrm{~m}^{3}$ (kon) & $3.636,364$ & $\mathrm{~m}^{3} / \mathrm{a}$ & 10,909 & $\mathrm{~h} / \mathrm{a}$ \\
\hline \multicolumn{3}{|c|}{ Aufsetzen der Dreiecksmieten } & \multicolumn{2}{|l|}{ TL, AS } & 1,000 & $\mathrm{~h} / 20 \mathrm{~m}^{3}$ (kon) & $3.636,364$ & $\mathrm{~m}^{3} / \mathrm{a}$ & 181,818 & $\mathrm{~h} / \mathrm{a}$ \\
\hline \multicolumn{3}{|c|}{ Umsetzen der Dreiecksmieten } & \multicolumn{2}{|l|}{ Schl., MU } & 0,005 & $\mathrm{~h} / \mathrm{m}$ (Mietenl.) & $16.252,121$ & $\mathrm{~m} / \mathrm{a}$ & 81,261 & $\mathrm{~h} / \mathrm{a}$ \\
\hline \multicolumn{3}{|c|}{ Reinigung der Annahmefläche } & \multicolumn{2}{|l|}{ TL, AS } & 0,500 & $h / 150 m^{3}(\ln )$ & $6.181,818$ & $\mathrm{~m}^{3} / \mathrm{a}$ & 20,606 & $h / a$ \\
\hline \multicolumn{3}{|l|}{ Sieben } & \multicolumn{2}{|l|}{ TL, AS, Sieb } & 1,000 & $\mathrm{~h} / 20 \mathrm{~m}^{3}(\mathrm{kom})$ & $1.800,000$ & $\mathrm{~m}^{3} / \mathrm{a}$ & 90,000 & $\mathrm{~h} / \mathrm{a}$ \\
\hline \multicolumn{3}{|c|}{ Abw.-Ausbringung bei Neubau } & \multicolumn{2}{|l|}{ Schl.,PT } & 1,000 & $\mathrm{~h} / 10 \mathrm{~m}^{3}(\mathrm{Abw})$ & 473,059 & $\mathrm{~m}^{3} / \mathrm{a}$ & 47,306 & $h / a$ \\
\hline \multicolumn{3}{|c|}{ Abw.-Ausbringung bei Umnutzung } & \multicolumn{2}{|l|}{ Schl., PT } & 1,000 & $\mathrm{~h} / 10 \mathrm{~m}^{3}(\mathrm{Abw})$ & 972,000 & $\mathrm{~m}^{3} / \mathrm{a}$ & 97,200 & $h / a$ \\
\hline \multicolumn{11}{|c|}{ Abkürzungen für die eingesetzten Maschinen: } \\
\hline \multicolumn{3}{|c|}{\begin{tabular}{|l|l|} 
TL - Teleskoplader & \\
\end{tabular}} & Schl. - Schlepp & per & & & & & & \\
\hline MU- Mietenum & etzer & & Schr. - Schred & dder & & & & & & \\
\hline SZ - Silozange & & & PT - Pumpenta & tankwagen & & & & & & \\
\hline AS - Anbausc & aufel & & & & & & & & & \\
\hline MASCHINE & NKOSTEN & & & & & & & & & \\
\hline Maschine / G & & Fixkosten & & Variable Kost & ten & Einheiten/a & & Maschinen-Ei & inzelkosten & \\
\hline Traktor (Neub & & 0,00 & $D M / a$ & 33,55 & $D M / h$ & 128,57 & $h / a$ & $4.313,41$ & $\mathrm{DM} / \mathrm{a}$ & \\
\hline Traktor (Umnu & zung) & 0,00 & $\mathrm{DM} / \mathrm{a}$ & 33,55 & $D M / h$ & 178,46 & $\mathrm{~h} / \mathrm{a}$ & $5.987,35$ & $\mathrm{DM} / \mathrm{a}$ & \\
\hline Teleskoplader & & 0,00 & $D M / a$ & 66,50 & $\mathrm{DM} / \mathrm{h}$ & 379,70 & $h / a$ & $25.249,85$ & $\mathrm{DM} / \mathrm{a}$ & \\
\hline Schredder & & 0,00 & DM/a & 7,50 & $\mathrm{DM} / \mathrm{m}^{3}$ (Out) & $1.272,73$ & $\mathrm{~m}^{3} / \mathrm{a}$ & $9.545,45$ & $\mathrm{DM} / \mathrm{a}$ & \\
\hline Trommelsieb & & 0,00 & $\mathrm{DM} / \mathrm{a}$ & 5,00 & $\mathrm{DM} / \mathrm{m}^{3}(\mathrm{Kom})$ & $1.800,00$ & $m^{3} / a$ & $9.000,00$ & $D M / a$ & \\
\hline PumpenTW ( & abau) & 0,00 & $\mathrm{DM} / \mathrm{a}$ & 30,00 & $\mathrm{DM} / \mathrm{h}$ & 47,31 & $\mathrm{~h} / \mathrm{a}$ & $1.419,18$ & $\mathrm{DM} / \mathrm{a}$ & \\
\hline PumpenTW (L & nnutzung) & 0,00 & $D M / a$ & 30,00 & $D M / h$ & 97,20 & $h / a$ & $2.916,00$ & $\mathrm{DM} / \mathrm{a}$ & \\
\hline Silozange & & $1.120,00$ & DM/a & 0,30 & $\mathrm{DM} / \mathrm{m}^{3}$ & $3.818,18$ & $\mathrm{~m}^{3} / \mathrm{a}$ & $2.265,45$ & $\mathrm{DM} / \mathrm{a}$ & \\
\hline Anbauschaufe & & 506,00 & $\mathrm{DM} / \mathrm{a}$ & 0,30 & $\mathrm{DM} / \mathrm{m}^{3}$ & $15.254,55$ & $\mathrm{~m}^{3} / \mathrm{a}$ & $5.082,36$ & $\mathrm{DM} / \mathrm{a}$ & \\
\hline Mietenumsetz & & $3.600,00$ & $\mathrm{DM} / \mathrm{a}$ & 28,00 & $\mathrm{DM} / \mathrm{h}$ & 81,26 & $\mathrm{~h} / \mathrm{a}$ & $5.875,30$ & $\mathrm{DM} / \mathrm{a}$ & \\
\hline & & & & & & Summe (Neuk & bau) & $62.751,00$ & $\mathrm{DM} / \mathrm{a}$ & \\
\hline & & & & & & Summe (Umn & hutzung) & $65.921,77$ & $\mathrm{DM} / \mathrm{a}$ & \\
\hline PERSONA & KOSTEN & & & & & & & & & \\
\hline & Std.-Lohn in & kl.Lohn-NK & Arbeitsstd. pro & o Jahr & Personal-Einz & zelkosten & & & & \\
\hline Neubau & 26,00 & $\mathrm{DM} / \mathrm{h}$ & 778,08 & $\mathrm{~h} / \mathrm{a}$ & $20.230,12$ & $D M / a$ & & & & \\
\hline Umnutzung & 26,00 & DM/h & 827,98 & $h / a$ & $21.527,37$ & DM/a & & & & \\
\hline
\end{tabular}




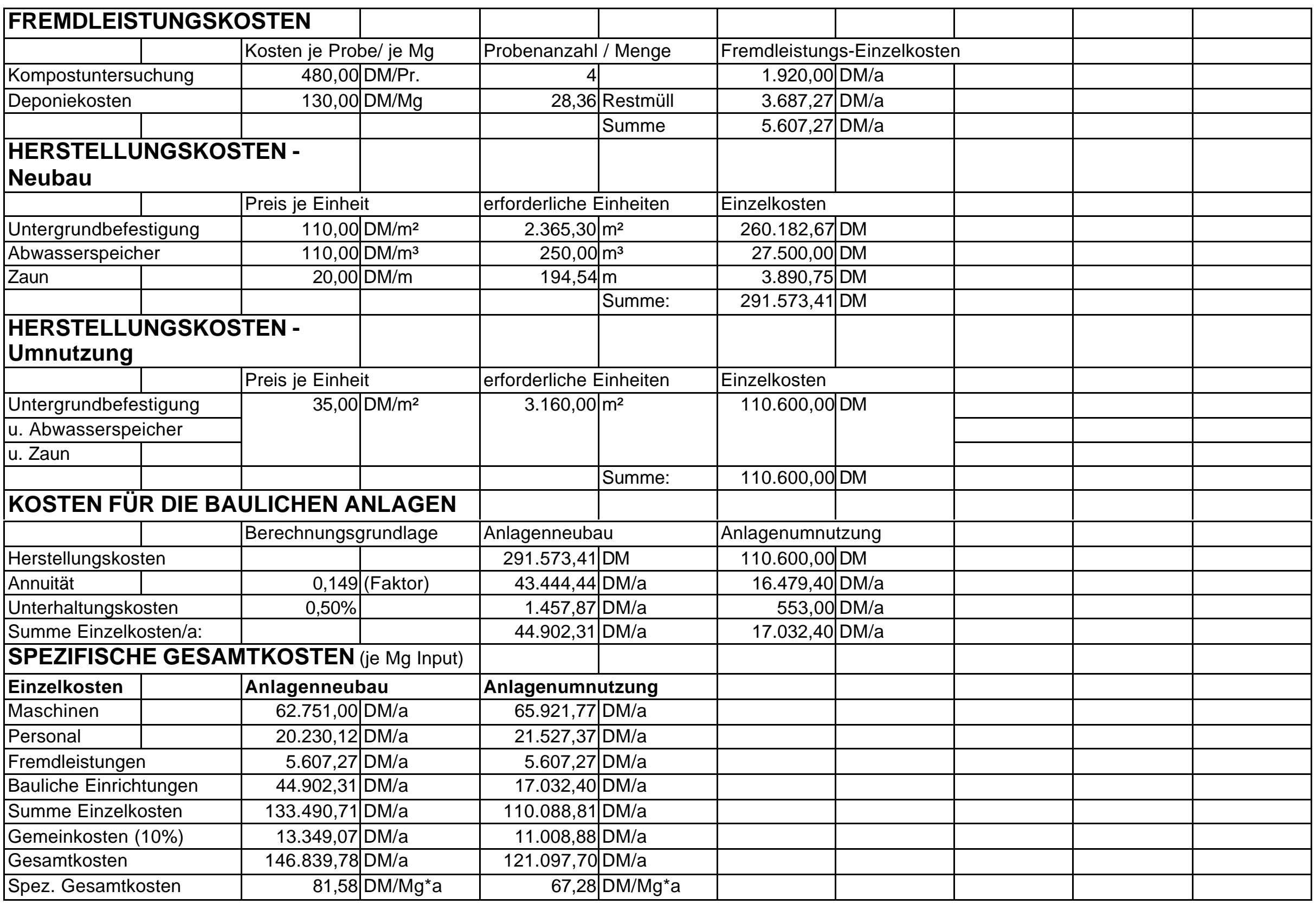


Kostenvariante C9

\begin{tabular}{|c|c|c|c|c|c|c|c|c|c|c|}
\hline MATERIA & & & & & & & & & & \\
\hline Jahresinput & & & $2.000,00$ & $\mathrm{Mg} / \mathrm{a}$ & & & & & & \\
\hline Zusammens & & & $65 \%$ & Vol.-\% & Bioabfälle & Haushalten & & & & \\
\hline & & & $35 \%$ & Vol.-\% & gehäckselt & Grüngut & & & & \\
\hline Dichte & & & 0,6 & $\mathrm{Mg} / \mathrm{m}^{3}$ & Bioabfälle & Haushalten & & & & \\
\hline & & & 0,3 & $\mathrm{Mg} / \mathrm{m}^{3}$ & gehäckselt & Grüngut & & & & \\
\hline & & & 0,495 & $\mathrm{Mg} / \mathrm{m}^{3}$ & konditionie & s Material & & & & \\
\hline & & & 0,5 & $\mathrm{Mg} / \mathrm{m}^{3}$ & Fertigkomp & & & & & \\
\hline Volumen & & & $4.040,40$ & $\mathrm{~m}^{3} / \mathrm{a}$ & konditionie & s Material & & & & \\
\hline & & & $2.626,26$ & $\mathrm{~m}^{3} / \mathrm{a}$ & Bioabfälle & Haushalten & & & & \\
\hline & & & $4.242,42$ & $\mathrm{~m}^{3} / \mathrm{a}$ & angeliefert & Grüngut & & & & \\
\hline & & & $1.414,14$ & $\mathrm{~m}^{3} / \mathrm{a}$ & gehäckselt & Grüngut & & & & \\
\hline & & & $2.000,00$ & $\mathrm{~m}^{3} / \mathrm{a}$ & Fertigkomp & & & & & \\
\hline Gewichtsan & & & $1.575,76$ & $\mathrm{Mg} / \mathrm{a}$ & Bioabfälle c & Haushalten & & & & \\
\hline & & & 424,24 & $\mathrm{Mg} / \mathrm{a}$ & Grüngut & & & & & \\
\hline & & & $1.000,00$ & $\mathrm{Mg} / \mathrm{a}$ & Fertigkomp & & & & & \\
\hline Rottedauer & & & 12 & Wochen & & & & & & \\
\hline durchschnit & & & 153,85 & $\mathrm{Mg}$ & & Rottematerial & eines & & & \\
\hline Monatsaufk & & & 310,80 & $m^{3}$ (kon) & & Durchlaufs in & der Anlage & 651,13 & $\mathrm{~m}^{3}$ & \\
\hline maximaler I & atsanfall & & 280,00 & $\mathrm{Mg}$ & entspr. 1 & vom Input/a & & & & \\
\hline & & & 565,66 & $\mathrm{~m}^{3}$ & & & & & & \\
\hline TS-Gehalt & igkompost) & & $61,70 \%$ & & & & & & & \\
\hline Mietenhöhe & & & 1,5 & $\mathrm{~m}$ & Mietenquer & hnitt & & & & \\
\hline Mietenbasis & & & 2,5 & $\mathrm{~m}$ & $\overline{1,8}$ & $\mathrm{~m}^{2}$ & & & & \\
\hline ANLAGE & IMENSIO & IIERUNG & & & & & & & & \\
\hline Anlagent & & Berechnung & gsgrundlage & & & Anlagenneub & bau & Anlagenumn & utzung & \\
\hline Anliefe & sfläche & $5 \%$ & vom Input in I & hg/a, ausg & ickt in $\mathrm{m}^{2}$ & 100,00 & $\mathrm{~m}^{2}$ & 850,00 & $\mathrm{~m}^{2}$ & \\
\hline Rottefläch & & 1,33 & $\mathrm{~m}^{2} / \mathrm{m}^{3}$ Rottem & aterial bei & M.-Anfall & 1580,07 & $\mathrm{~m}^{2}$ & & $m^{2}$ & \\
\hline Rangierfläc & & $40 \%$ & der Rottefläch & & & 632,03 & $\mathrm{~m}^{2}$ & 3160,00 & & \\
\hline Zwisch & iger für & & der Rottefläch & & & & $m^{2}$ & & & \\
\hline Strukt & aterial & $10 \%$ & & & & 158,01 & & & & \\
\hline Kompostla & & $10 \%$ & der Rottefläch & & & 158,01 & $\mathrm{~m}^{2}$ & 850,00 & $\mathrm{~m}^{2}$ & \\
\hline Anlagenfl & (gesamt) & & & & & 2628,11 & $\mathrm{~m}^{2}$ & 4860,00 & $m^{2}$ & \\
\hline zu ve & tende & & & & & & & & & \\
\hline Abwa & menge & 0,2 & $m^{3} / m^{2 *} a$ & & & 525,62 & $\mathrm{~m}^{3} / \mathrm{a}$ & 972,00 & $\mathrm{~m}^{3} / \mathrm{a}$ & \\
\hline
\end{tabular}




\begin{tabular}{|c|c|c|c|c|c|c|c|c|c|c|}
\hline \multicolumn{11}{|l|}{ ZEITEN } \\
\hline \multicolumn{3}{|l|}{ Arbeitsgang } & \multicolumn{2}{|c|}{ eingesetzte Maschinen } & \multicolumn{2}{|c|}{ Zeitbedarf/Einheit } & \multicolumn{2}{|c|}{ geleistete Einheiten } & \multicolumn{2}{|c|}{ Zeitbedarf/Jahr } \\
\hline \multicolumn{3}{|c|}{ Materialannahme } & & & 4,000 & h/Woche & 52,000 & Wochen/a & 208,000 & $h / a$ \\
\hline \multicolumn{3}{|c|}{ Manuelle Störstoffauslese } & & & 1,000 & $h / 100 m^{3}(\operatorname{In})$ & $6.868,687$ & $\mathrm{~m}^{3} / \mathrm{a}$ & 68,687 & $\mathrm{~h} / \mathrm{a}$ \\
\hline \multicolumn{3}{|c|}{ Zerkleinerung von Strukturmaterial } & \multicolumn{2}{|l|}{ TL, SZ, Schr. } & 1,000 & $h / 50 m^{3}(\ln )$ & $4.242,424$ & $\mathrm{~m}^{3} / \mathrm{a}$ & 84,848 & $h / a$ \\
\hline \multicolumn{3}{|c|}{ Aufsetzen einer Matte aus Strukturmat. } & \multicolumn{2}{|l|}{ TL, AS } & 0,300 & $\mathrm{~h} / 100 \mathrm{~m}^{3}$ (kon) & $4.040,404$ & $\mathrm{~m}^{3} / \mathrm{a}$ & 12,121 & $\mathrm{~h} / \mathrm{a}$ \\
\hline \multicolumn{3}{|c|}{ Aufsetzen der Dreiecksmieten } & \multicolumn{2}{|l|}{ TL, AS } & 1,000 & $\mathrm{~h} / 20 \mathrm{~m}^{3}$ (kon) & $4.040,404$ & $\mathrm{~m}^{3} / \mathrm{a}$ & 202,020 & $h / a$ \\
\hline \multicolumn{3}{|c|}{ Umsetzen der Dreiecksmieten } & \multicolumn{2}{|l|}{ Schl., MU } & 0,005 & $\mathrm{~h} / \mathrm{m}$ (Mietenl.) & $18.057,912$ & $\mathrm{~m} / \mathrm{a}$ & 90,290 & $h / a$ \\
\hline \multicolumn{3}{|c|}{ Reinigung der Annahmefläche } & \multicolumn{2}{|l|}{ TL, AS } & 0,500 & $h / 150 m^{3}(\ln )$ & $6.868,687$ & $\mathrm{~m}^{3} / \mathrm{a}$ & 22,896 & $h / a$ \\
\hline \multicolumn{3}{|l|}{ Sieben } & \multicolumn{2}{|l|}{ TL, AS, Sieb } & 1,000 & $\mathrm{~h} / 20 \mathrm{~m}^{3}(\mathrm{kom})$ & $2.000,000$ & $\mathrm{~m}^{3} / \mathrm{a}$ & 100,000 & $\mathrm{~h} / \mathrm{a}$ \\
\hline \multicolumn{3}{|c|}{ Abw.-Ausbringung bei Neubau } & \multicolumn{2}{|l|}{ Schl.,PT } & 1,000 & $\mathrm{~h} / 10 \mathrm{~m}^{3}(\mathrm{Abw})$ & 525,622 & $\mathrm{~m}^{3} / \mathrm{a}$ & 52,562 & $h / a$ \\
\hline \multicolumn{3}{|c|}{ Abw.-Ausbringung bei Umnutzung } & \multicolumn{2}{|l|}{ Schl., PT } & 1,000 & $\mathrm{~h} / 10 \mathrm{~m}^{3}(\mathrm{Abw})$ & 972,000 & $\mathrm{~m}^{3} / \mathrm{a}$ & 97,200 & $h / a$ \\
\hline \multicolumn{11}{|c|}{ Abkürzungen für die eingesetzten Maschinen: } \\
\hline \multicolumn{3}{|c|}{\begin{tabular}{|l|l|} 
TL - Teleskoplader & \\
\end{tabular}} & Schl. - Schlepp & per & & & & & & \\
\hline MU- Mietenum & etzer & & Schr. - Schred & dder & & & & & & \\
\hline SZ - Silozange & & & PT - Pumpenta & tankwagen & & & & & & \\
\hline AS - Anbausc & aufel & & & & & & & & & \\
\hline MASCHINE & NKOSTEN & & & & & & & & & \\
\hline Maschine / G & & Fixkosten & & Variable Kost & ten & Einheiten/a & & Maschinen-Ei & inzelkosten & \\
\hline Traktor (Neub & & 0,00 & $D M / a$ & 33,55 & $D M / h$ & 142,85 & $h / a$ & $4.792,68$ & $\mathrm{DM} / \mathrm{a}$ & \\
\hline Traktor (Umnu & zung) & 0,00 & $\mathrm{DM} / \mathrm{a}$ & 33,55 & $D M / h$ & 187,49 & $\mathrm{~h} / \mathrm{a}$ & $6.290,27$ & $\mathrm{DM} / \mathrm{a}$ & \\
\hline Teleskoplader & & 0,00 & $D M / a$ & 66,50 & $\mathrm{DM} / \mathrm{h}$ & 421,89 & $h / a$ & $28.055,39$ & $\mathrm{DM} / \mathrm{a}$ & \\
\hline Schredder & & 0,00 & DM/a & 7,50 & $\mathrm{DM} / \mathrm{m}^{3}$ (Out) & $1.414,14$ & $\mathrm{~m}^{3} / \mathrm{a}$ & $10.606,06$ & $\mathrm{DM} / \mathrm{a}$ & \\
\hline Trommelsieb & & 0,00 & $\mathrm{DM} / \mathrm{a}$ & 5,00 & $\mathrm{DM} / \mathrm{m}^{3}(\mathrm{Kom})$ & $2.000,00$ & $m^{3} / a$ & $10.000,00$ & $\mathrm{DM} / \mathrm{a}$ & \\
\hline PumpenTW ( & abau) & 0,00 & $\mathrm{DM} / \mathrm{a}$ & 30,00 & $\mathrm{DM} / \mathrm{h}$ & 52,56 & $h / a$ & $1.576,86$ & $\mathrm{DM} / \mathrm{a}$ & \\
\hline PumpenTW (L & nnutzung) & 0,00 & $D M / a$ & 30,00 & $D M / h$ & 97,20 & $h / a$ & $2.916,00$ & $\mathrm{DM} / \mathrm{a}$ & \\
\hline Silozange & & $1.120,00$ & DM/a & 0,30 & $\mathrm{DM} / \mathrm{m}^{3}$ & $4.242,42$ & $m^{3} / a$ & $2.392,73$ & $\mathrm{DM} / \mathrm{a}$ & \\
\hline Anbauschaufe & & 506,00 & $\mathrm{DM} / \mathrm{a}$ & 0,30 & $\mathrm{DM} / \mathrm{m}^{3}$ & $16.949,49$ & $\mathrm{~m}^{3} / \mathrm{a}$ & $5.590,85$ & $\mathrm{DM} / \mathrm{a}$ & \\
\hline Mietenumsetz & & $3.600,00$ & $\mathrm{DM} / \mathrm{a}$ & 28,00 & $\mathrm{DM} / \mathrm{h}$ & 90,29 & $h / a$ & $6.128,11$ & $\mathrm{DM} / \mathrm{a}$ & \\
\hline & & & & & & Summe (Neuk & bau) & $69.142,67$ & $\mathrm{DM} / \mathrm{a}$ & \\
\hline & & & & & & Summe (Umn & hutzung) & $71.979,41$ & $\mathrm{DM} / \mathrm{a}$ & \\
\hline PERSONA & KOSTEN & & & & & & & & & \\
\hline & Std.-Lohn in & kl.Lohn-NK & Arbeitsstd. pro & Jahr & Personal-Einz & zelkosten & & & & \\
\hline Neubau & 26,00 & $\mathrm{DM} / \mathrm{h}$ & 841,42 & $\mathrm{~h} / \mathrm{a}$ & $21.877,03$ & $D M / a$ & & & & \\
\hline Umnutzung & 26,00 & DM/h & 886,06 & $h / a$ & $23.037,61$ & $\mathrm{DM} / \mathrm{a}$ & & & & \\
\hline
\end{tabular}




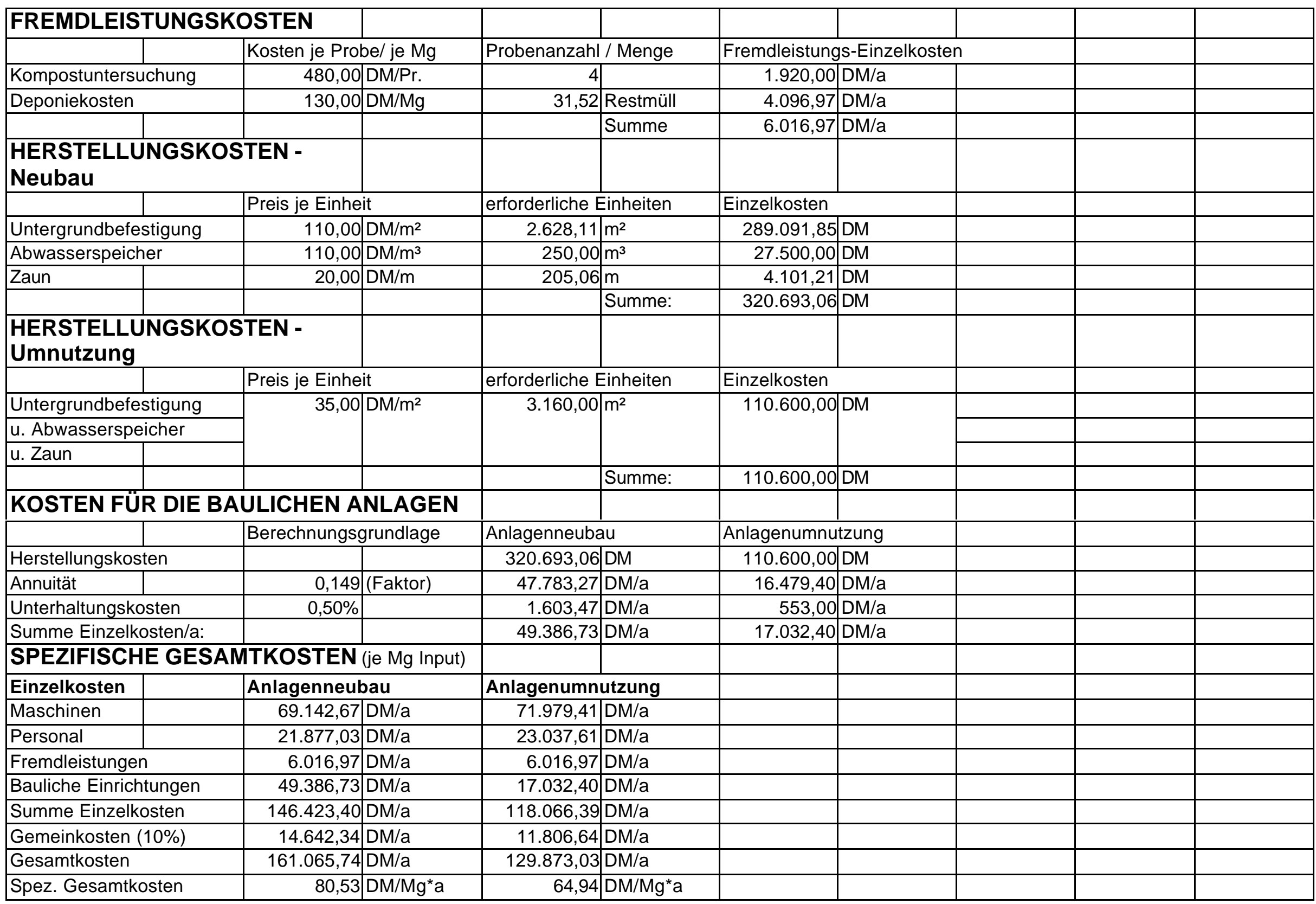


Kostenvariante C10

\begin{tabular}{|c|c|c|c|c|c|c|c|c|c|c|}
\hline MATERIA & & & & & & & & & & \\
\hline Jahresinput & & & $2.200,00$ & $\mathrm{Mg} / \mathrm{a}$ & & & & & & \\
\hline Zusammens & & & $65 \%$ & Vol.-\% & Bioabfälle & Haushalten & & & & \\
\hline & & & $35 \%$ & Vol.-\% & gehäckselt & Grüngut & & & & \\
\hline Dichte & & & 0,6 & $\mathrm{Mg} / \mathrm{m}^{3}$ & Bioabfälle & Haushalten & & & & \\
\hline & & & 0,3 & $\mathrm{Mg} / \mathrm{m}^{3}$ & gehäckselt & Grüngut & & & & \\
\hline & & & 0,495 & $\mathrm{Mg} / \mathrm{m}^{3}$ & konditionie & s Material & & & & \\
\hline & & & 0,5 & $\mathrm{Mg} / \mathrm{m}^{3}$ & Fertigkomp & & & & & \\
\hline Volumen & & & $4.444,44$ & $\mathrm{~m}^{3} / \mathrm{a}$ & konditionie & s Material & & & & \\
\hline & & & $2.888,89$ & $\mathrm{~m}^{3} / \mathrm{a}$ & Bioabfälle & Haushalten & & & & \\
\hline & & & $4.666,67$ & $\mathrm{~m}^{3} / \mathrm{a}$ & angeliefert & Grüngut & & & & \\
\hline & & & $1.555,56$ & $\mathrm{~m}^{3} / \mathrm{a}$ & gehäckselt & Grüngut & & & & \\
\hline & & & $2.200,00$ & $\mathrm{~m}^{3} / \mathrm{a}$ & Fertigkomp & & & & & \\
\hline Gewichtsan & & & $1.733,33$ & $\mathrm{Mg} / \mathrm{a}$ & Bioabfälle c & Haushalten & & & & \\
\hline & & & 466,67 & $\mathrm{Mg} / \mathrm{a}$ & Grüngut & & & & & \\
\hline & & & $1.100,00$ & $\mathrm{Mg} / \mathrm{a}$ & Fertigkomp & & & & & \\
\hline Rottedauer & & & 12 & Wochen & & & & & & \\
\hline durchschnit & & & 169,23 & $\mathrm{Mg}$ & & Rottematerial & eines & & & \\
\hline Monatsaufk & & & 341,88 & $m^{3}$ (kon) & & Durchlaufs in & der Anlage & 716,24 & $\mathrm{~m}^{3}$ & \\
\hline maximaler I & atsanfall & & 308,00 & $\mathrm{Mg}$ & entspr. 1 & vom Input/a & & & & \\
\hline & & & 622,22 & $\mathrm{~m}^{3}$ & & & & & & \\
\hline TS-Gehalt & igkompost) & & $61,70 \%$ & & & & & & & \\
\hline Mietenhöhe & & & 1,5 & $\mathrm{~m}$ & Mietenquer & hnitt & & & & \\
\hline Mietenbasis & & & 2,5 & $\mathrm{~m}$ & $\overline{1,8}$ & $\mathrm{~m}^{2}$ & & & & \\
\hline ANLAGE & IMENSIO & IIERUNG & & & & & & & & \\
\hline Anlagent & & Berechnung & gsgrundlage & & & Anlagenneub & bau & Anlagenumn & utzung & \\
\hline Anliefe & sfläche & $5 \%$ & vom Input in 1 & $\mathrm{Mg} / \mathrm{a}$, ausg & ickt in $\mathrm{m}^{2}$ & 110,00 & $\mathrm{~m}^{2}$ & 850,00 & $\mathrm{~m}^{2}$ & \\
\hline Rottefläch & & 1,33 & $\mathrm{~m}^{2} / \mathrm{m}^{3}$ Rottem & aterial bei & M.-Anfall & 1738,07 & $\mathrm{~m}^{2}$ & & $m^{2}$ & \\
\hline Rangierfläc & & $40 \%$ & der Rottefläch & & & 695,23 & $\mathrm{~m}^{2}$ & 3160,00 & & \\
\hline Zwisch & iger für & & der Rottefläch & & & & $m^{2}$ & & & \\
\hline Strukt & aterial & $10 \%$ & & & & 173,81 & & & & \\
\hline Kompostla & & $10 \%$ & der Rottefläch & & & 173,81 & $\mathrm{~m}^{2}$ & 850,00 & $\mathrm{~m}^{2}$ & \\
\hline Anlagenfl & (gesamt) & & & & & 2890,92 & $\mathrm{~m}^{2}$ & 4860,00 & $\mathrm{~m}^{2}$ & \\
\hline zu ve & tende & & & & & & & & & \\
\hline Abwa & menge & 0,2 & $m^{3} / m^{2 \star} a$ & & & 578,18 & $\mathrm{~m}^{3} / \mathrm{a}$ & 972,00 & $\mathrm{~m}^{3} / \mathrm{a}$ & \\
\hline
\end{tabular}




\begin{tabular}{|c|c|c|c|c|c|c|c|c|c|c|}
\hline \multicolumn{11}{|l|}{ ZEITEN } \\
\hline \multicolumn{3}{|l|}{ Arbeitsgang } & \multicolumn{2}{|c|}{ eingesetzte Maschinen } & \multicolumn{2}{|c|}{ Zeitbedarf/Einheit } & \multicolumn{2}{|c|}{ geleistete Einheiten } & \multicolumn{2}{|c|}{ Zeitbedarf/Jahr } \\
\hline \multicolumn{3}{|c|}{ Materialannahme } & & & 4,000 & h/Woche & 52,000 & Wochen/a & 208,000 & $h / a$ \\
\hline \multicolumn{3}{|c|}{ Manuelle Störstoffauslese } & & & 1,000 & $h / 100 m^{3}(\operatorname{In})$ & $7.555,556$ & $m^{3} / a$ & 75,556 & $h / a$ \\
\hline \multicolumn{3}{|c|}{ Zerkleinerung von Strukturmaterial } & \multicolumn{2}{|l|}{ TL, SZ, Schr. } & 1,000 & $h / 50 m^{3}(\ln )$ & $4.666,667$ & $\mathrm{~m}^{3} / \mathrm{a}$ & 93,333 & $h / a$ \\
\hline \multicolumn{3}{|c|}{ Aufsetzen einer Matte aus Strukturmat. } & \multicolumn{2}{|l|}{$\mathrm{TL}, \mathrm{AS}$} & 0,300 & $\mathrm{~h} / 100 \mathrm{~m}^{3}$ (kon) & $4.444,444$ & $\mathrm{~m}^{3} / \mathrm{a}$ & 13,333 & $\mathrm{~h} / \mathrm{a}$ \\
\hline \multicolumn{3}{|c|}{ Aufsetzen der Dreiecksmieten } & \multicolumn{2}{|l|}{ TL, AS } & 1,000 & $\mathrm{~h} / 20 \mathrm{~m}^{3}$ (kon) & $4.444,444$ & $\mathrm{~m}^{3} / \mathrm{a}$ & 222,222 & $h / a$ \\
\hline \multicolumn{3}{|c|}{ Umsetzen der Dreiecksmieten } & \multicolumn{2}{|l|}{ Schl., MU } & 0,005 & $\mathrm{~h} / \mathrm{m}$ (Mietenl.) & $19.863,704$ & $\mathrm{~m} / \mathrm{a}$ & 99,319 & $\mathrm{~h} / \mathrm{a}$ \\
\hline \multicolumn{3}{|c|}{ Reinigung der Annahmefläche } & \multicolumn{2}{|l|}{ TL, AS } & 0,500 & $h / 150 m^{3}(\ln )$ & $7.555,556$ & $\mathrm{~m}^{3} / \mathrm{a}$ & 25,185 & $\mathrm{~h} / \mathrm{a}$ \\
\hline \multicolumn{3}{|l|}{ Sieben } & \multicolumn{2}{|l|}{ TL, AS, Sieb } & 1,000 & $\mathrm{~h} / 20 \mathrm{~m}^{3}(\mathrm{kom})$ & $2.200,000$ & $\mathrm{~m}^{3} / \mathrm{a}$ & 110,000 & $\mathrm{~h} / \mathrm{a}$ \\
\hline \multicolumn{3}{|c|}{ Abw.-Ausbringung bei Neubau } & \multicolumn{2}{|l|}{ Schl.,PT } & 1,000 & $\mathrm{~h} / 10 \mathrm{~m}^{3}(\mathrm{Abw})$ & 578,184 & $\mathrm{~m}^{3} / \mathrm{a}$ & 57,818 & $\mathrm{~h} / \mathrm{a}$ \\
\hline \multicolumn{3}{|c|}{ Abw.-Ausbringung bei Umnutzung } & \multicolumn{2}{|l|}{ Schl., PT } & 1,000 & $\mathrm{~h} / 10 \mathrm{~m}^{3}(\mathrm{Abw})$ & 972,000 & $\mathrm{~m}^{3} / \mathrm{a}$ & 97,200 & $h / a$ \\
\hline \multicolumn{11}{|c|}{ Abkürzungen für die eingesetzten Maschinen: } \\
\hline \multicolumn{3}{|c|}{\begin{tabular}{|l|l|} 
TL - Teleskoplader & \\
\end{tabular}} & Schl. - Schlepp & per & & & & & & \\
\hline MU- Mietenum & etzer & & Schr. - Schred & dder & & & & & & \\
\hline SZ - Silozange & & & PT - Pumpenta & tankwagen & & & & & & \\
\hline AS - Anbausc & aufel & & & & & & & & & \\
\hline MASCHINE & NKOSTEN & & & & & & & & & \\
\hline Maschine / G & & Fixkosten & & Variable Kost & ten & Einheiten/a & & Maschinen-Ei & inzelkosten & \\
\hline Traktor (Neub & & 0,00 & $D M / a$ & 33,55 & $D M / h$ & 157,14 & $\mathrm{~h} / \mathrm{a}$ & $5.271,94$ & $D M / a$ & \\
\hline Traktor (Umnu & zung) & 0,00 & $\mathrm{DM} / \mathrm{a}$ & 33,55 & $D M / h$ & 196,52 & $h / a$ & $6.593,20$ & $\mathrm{DM} / \mathrm{a}$ & \\
\hline Teleskoplader & & 0,00 & $D M / a$ & 66,50 & $\mathrm{DM} / \mathrm{h}$ & 464,07 & $\mathrm{~h} / \mathrm{a}$ & $30.860,93$ & $\mathrm{DM} / \mathrm{a}$ & \\
\hline Schredder & & 0,00 & DM/a & 7,50 & $\mathrm{DM} / \mathrm{m}^{3}$ (Out) & $1.555,56$ & $\mathrm{~m}^{3} / \mathrm{a}$ & $11.666,67$ & $\mathrm{DM} / \mathrm{a}$ & \\
\hline Trommelsieb & & 0,00 & $\mathrm{DM} / \mathrm{a}$ & 5,00 & $\mathrm{DM} / \mathrm{m}^{3}(\mathrm{Kom})$ & $2.200,00$ & $\mathrm{~m}^{3} / \mathrm{a}$ & $11.000,00$ & $\mathrm{DM} / \mathrm{a}$ & \\
\hline PumpenTW ( & abau) & 0,00 & $\mathrm{DM} / \mathrm{a}$ & 30,00 & $\mathrm{DM} / \mathrm{h}$ & 57,82 & $h / a$ & $1.734,55$ & $\mathrm{DM} / \mathrm{a}$ & \\
\hline PumpenTW (L & nnutzung) & 0,00 & $D M / a$ & 30,00 & $D M / h$ & 97,20 & $h / a$ & $2.916,00$ & $\mathrm{DM} / \mathrm{a}$ & \\
\hline Silozange & & $1.120,00$ & DM/a & 0,30 & $\mathrm{DM} / \mathrm{m}^{3}$ & $4.666,67$ & $\mathrm{~m}^{3} / \mathrm{a}$ & $2.520,00$ & $\mathrm{DM} / \mathrm{a}$ & \\
\hline Anbauschaufe & & 506,00 & $\mathrm{DM} / \mathrm{a}$ & 0,30 & $\mathrm{DM} / \mathrm{m}^{3}$ & $18.644,44$ & $\mathrm{~m}^{3} / \mathrm{a}$ & $6.099,33$ & $\mathrm{DM} / \mathrm{a}$ & \\
\hline Mietenumsetz & & $3.600,00$ & $\mathrm{DM} / \mathrm{a}$ & 28,00 & $\mathrm{DM} / \mathrm{h}$ & 99,32 & $h / a$ & $6.380,92$ & $\mathrm{DM} / \mathrm{a}$ & \\
\hline & & & & & & Summe (Neuk & bau) & $75.534,34$ & $\mathrm{DM} / \mathrm{a}$ & \\
\hline & & & & & & Summe (Umn & hutzung) & $78.037,04$ & $\mathrm{DM} / \mathrm{a}$ & \\
\hline PERSONA & KOSTEN & & & & & & & & & \\
\hline & Std.-Lohn in & kl.Lohn-NK & Arbeitsstd. pro & Jahr & Personal-Einz & zelkosten & & & & \\
\hline Neubau & 26,00 & $\mathrm{DM} / \mathrm{h}$ & 904,77 & $\mathrm{~h} / \mathrm{a}$ & $23.523,93$ & $D M / a$ & & & & \\
\hline Umnutzung & 26,00 & DM/h & 944,15 & $h / a$ & $24.547,85$ & $D M / a$ & & & & \\
\hline
\end{tabular}




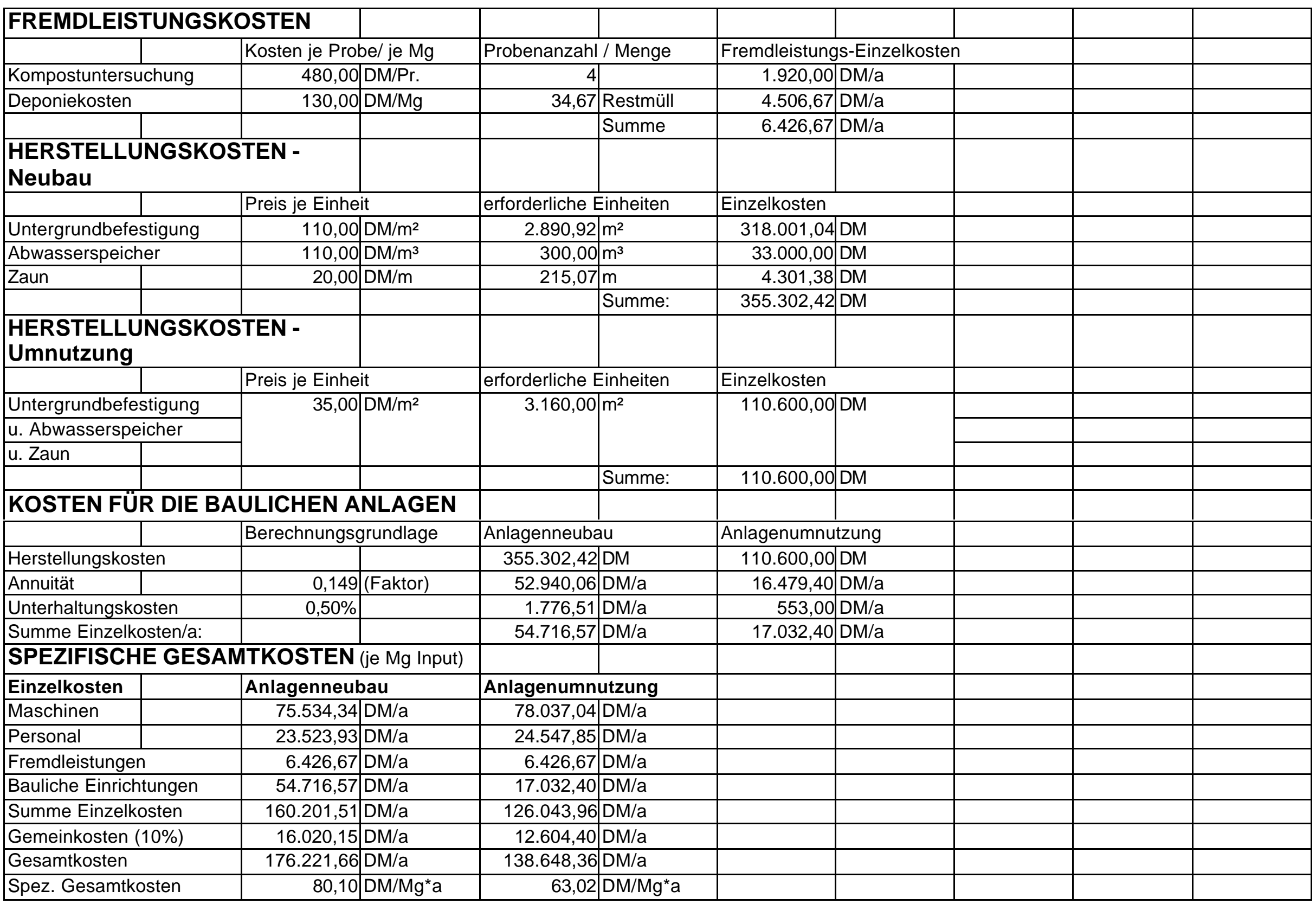


Kostenvariante C11

\begin{tabular}{|c|c|c|c|c|c|c|c|c|c|c|}
\hline MATERIA & & & & & & & & & & \\
\hline Jahresinput & & & $2.400,00$ & $\mathrm{Mg} / \mathrm{a}$ & & & & & & \\
\hline Zusammens & & & $65 \%$ & Vol.-\% & Bioabfälle & Haushalten & & & & \\
\hline & & & $35 \%$ & Vol.-\% & gehäckselt & Grüngut & & & & \\
\hline Dichte & & & 0,6 & $\mathrm{Mg} / \mathrm{m}^{3}$ & Bioabfälle & Haushalten & & & & \\
\hline & & & 0,3 & $\mathrm{Mg} / \mathrm{m}^{3}$ & gehäckselt & Grüngut & & & & \\
\hline & & & 0,495 & $\mathrm{Mg} / \mathrm{m}^{3}$ & konditionie & s Material & & & & \\
\hline & & & 0,5 & $\mathrm{Mg} / \mathrm{m}^{3}$ & Fertigkomp & & & & & \\
\hline Volumen & & & $4.848,48$ & $\mathrm{~m}^{3} / \mathrm{a}$ & konditionie & s Material & & & & \\
\hline & & & $3.151,52$ & $\mathrm{~m}^{3} / \mathrm{a}$ & Bioabfälle & Haushalten & & & & \\
\hline & & & $5.090,91$ & $\mathrm{~m}^{3} / \mathrm{a}$ & angeliefert & Grüngut & & & & \\
\hline & & & $1.696,97$ & $\mathrm{~m}^{3} / \mathrm{a}$ & gehäckselt & Grüngut & & & & \\
\hline & & & $2.400,00$ & $\mathrm{~m}^{3} / \mathrm{a}$ & Fertigkomp & & & & & \\
\hline Gewichtsan & & & $1.890,91$ & $\mathrm{Mg} / \mathrm{a}$ & Bioabfälle c & Haushalten & & & & \\
\hline & & & 509,09 & $\mathrm{Mg} / \mathrm{a}$ & Grüngut & & & & & \\
\hline & & & $1.200,00$ & $\mathrm{Mg} / \mathrm{a}$ & Fertigkomp & & & & & \\
\hline Rottedauer & & & 12 & Wochen & & & & & & \\
\hline durchschnit & & & 184,62 & $\mathrm{Mg}$ & & Rottematerial & eines & & & \\
\hline Monatsaufk & & & 372,96 & $m^{3}$ (kon) & & Durchlaufs in & der Anlage & 781,35 & $\mathrm{~m}^{3}$ & \\
\hline maximaler I & atsanfall & & 336,00 & $\mathrm{Mg}$ & entspr. 1 & vom Input/a & & & & \\
\hline & & & 678,79 & $\mathrm{~m}^{3}$ & & & & & & \\
\hline TS-Gehalt & igkompost) & & $61,70 \%$ & & & & & & & \\
\hline Mietenhöhe & & & 1,5 & $\mathrm{~m}$ & Mietenquer & hnitt & & & & \\
\hline Mietenbasis & & & 2,5 & $\mathrm{~m}$ & $\overline{1,8}$ & $\mathrm{~m}^{2}$ & & & & \\
\hline ANLAGE & IMENSIO & IIERUNG & & & & & & & & \\
\hline Anlagent & & Berechnung & gsgrundlage & & & Anlagenneub & bau & Anlagenumn & utzung & \\
\hline Anliefe & sfläche & $5 \%$ & vom Input in I & hg/a, ausg & ickt in $\mathrm{m}^{2}$ & 120,00 & $\mathrm{~m}^{2}$ & 850,00 & $\mathrm{~m}^{2}$ & \\
\hline Rottefläch & & 1,33 & $\mathrm{~m}^{2} / \mathrm{m}^{3}$ Rottem & aterial bei & M.-Anfall & 1896,08 & $\mathrm{~m}^{2}$ & & $m^{2}$ & \\
\hline Rangierfläc & & $40 \%$ & der Rottefläch & & & 758,43 & $\mathrm{~m}^{2}$ & 3160,00 & & \\
\hline Zwisch & iger für & & der Rottefläch & & & & $m^{2}$ & & & \\
\hline Strukt & aterial & $10 \%$ & & & & 189,61 & & & & \\
\hline Kompostla & & $10 \%$ & der Rottefläch & & & 189,61 & $\mathrm{~m}^{2}$ & 850,00 & $\mathrm{~m}^{2}$ & \\
\hline Anlagenfl & (gesamt) & & & & & 3153,73 & $\mathrm{~m}^{2}$ & 4860,00 & $m^{2}$ & \\
\hline zu ve & tende & & & & & & & & & \\
\hline Abwa & menge & 0,2 & $m^{3} / m^{2 \star} a$ & & & 630,75 & $m^{3} / a$ & 972,00 & $\mathrm{~m}^{3} / \mathrm{a}$ & \\
\hline
\end{tabular}




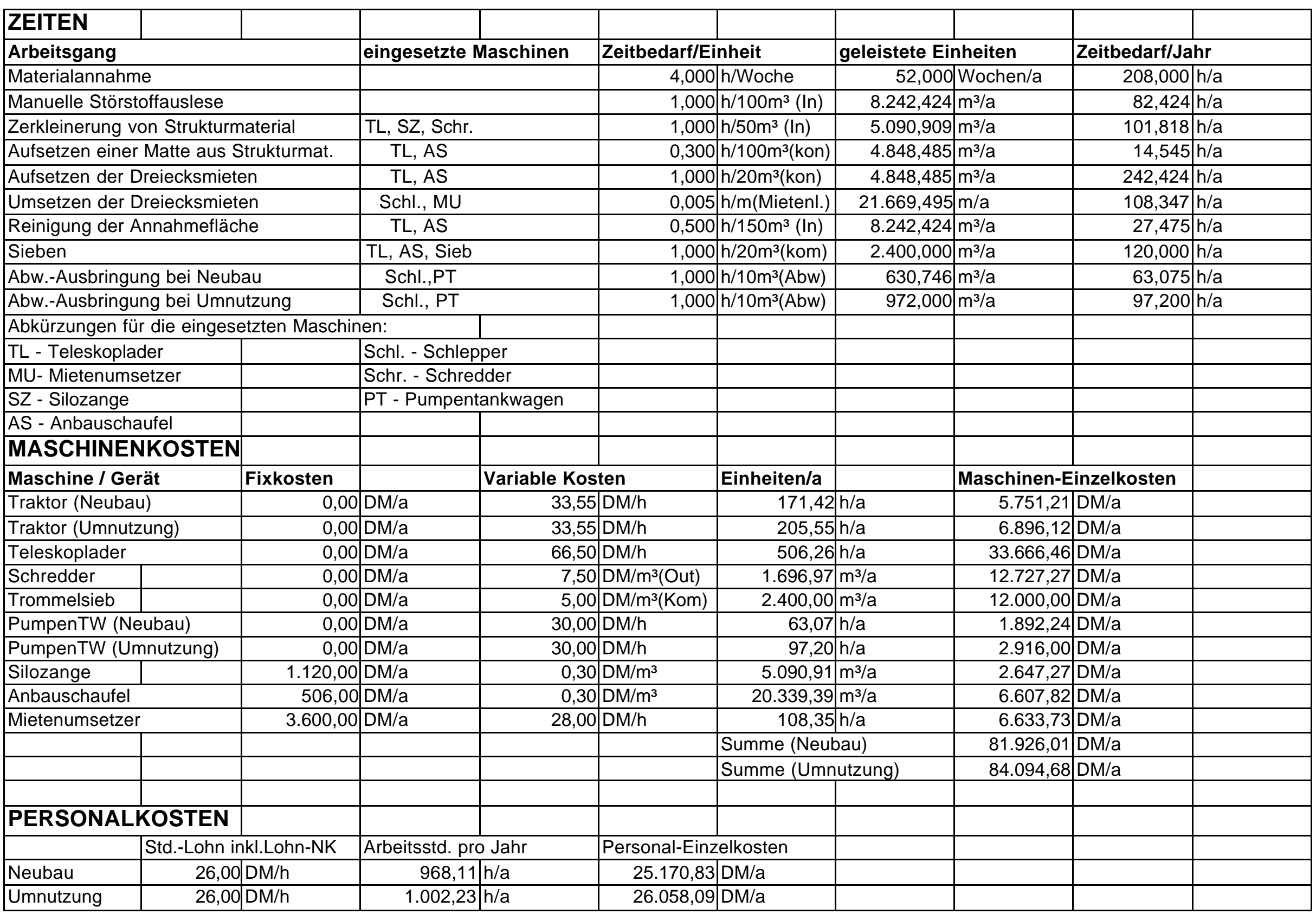




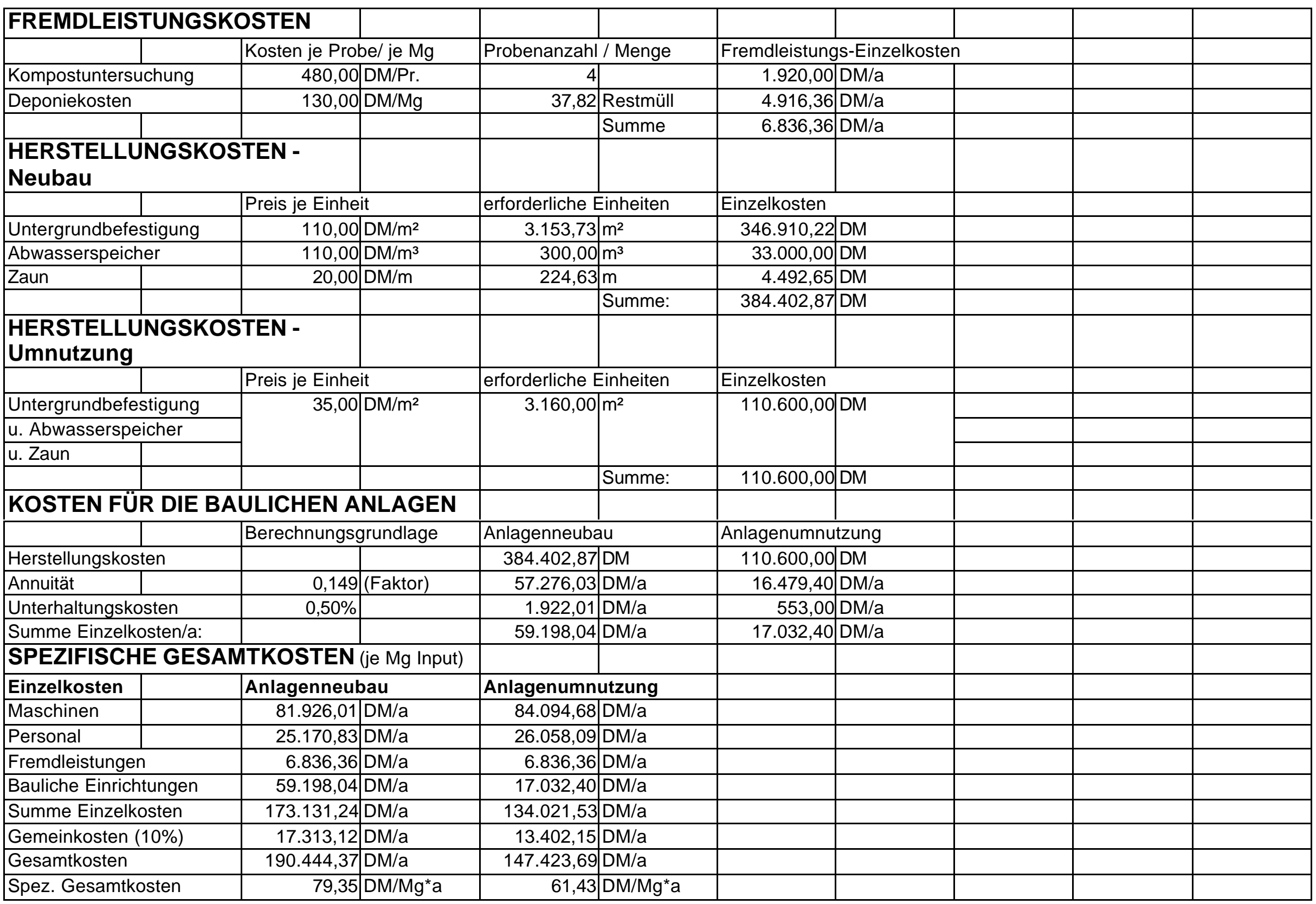


Kostenvariante C12

\begin{tabular}{|c|c|c|c|c|c|c|c|c|c|c|}
\hline MATERIA & & & & & & & & & & \\
\hline Jahresinput & & & $2.600,00$ & $\mathrm{Mg} / \mathrm{a}$ & & & & & & \\
\hline Zusammens & & & $65 \%$ & Vol.-\% & Bioabfälle & Haushalten & & & & \\
\hline & & & $35 \%$ & Vol.-\% & gehäckselt & Grüngut & & & & \\
\hline Dichte & & & 0,6 & $\mathrm{Mg} / \mathrm{m}^{3}$ & Bioabfälle & Haushalten & & & & \\
\hline & & & 0,3 & $\mathrm{Mg} / \mathrm{m}^{3}$ & gehäckselt & Grüngut & & & & \\
\hline & & & 0,495 & $\mathrm{Mg} / \mathrm{m}^{3}$ & konditionie & s Material & & & & \\
\hline & & & 0,5 & $\mathrm{Mg} / \mathrm{m}^{3}$ & Fertigkomp & & & & & \\
\hline Volumen & & & $5.252,53$ & $\mathrm{~m}^{3} / \mathrm{a}$ & konditionie & s Material & & & & \\
\hline & & & $3.414,14$ & $\mathrm{~m}^{3} / \mathrm{a}$ & Bioabfälle & Haushalten & & & & \\
\hline & & & $5.515,15$ & $\mathrm{~m}^{3} / \mathrm{a}$ & angeliefert & Grüngut & & & & \\
\hline & & & $1.838,38$ & $\mathrm{~m}^{3} / \mathrm{a}$ & gehäckselt & Grüngut & & & & \\
\hline & & & $2.600,00$ & $\mathrm{~m}^{3} / \mathrm{a}$ & Fertigkomp & & & & & \\
\hline Gewichtsan & & & $2.048,48$ & $\mathrm{Mg} / \mathrm{a}$ & Bioabfälle c & Haushalten & & & & \\
\hline & & & 551,52 & $\mathrm{Mg} / \mathrm{a}$ & Grüngut & & & & & \\
\hline & & & $1.300,00$ & $\mathrm{Mg} / \mathrm{a}$ & Fertigkomp & & & & & \\
\hline Rottedauer & & & 12 & Wochen & & & & & & \\
\hline durchschnit & & & 200,00 & $\mathrm{Mg}$ & & Rottematerial & eines & & & \\
\hline Monatsaufk & & & 404,04 & $m^{3}$ (kon) & & Durchlaufs in & der Anlage & 846,46 & $\mathrm{~m}^{3}$ & \\
\hline maximaler I & atsanfall & & 364,00 & $\mathrm{Mg}$ & entspr. 1 & vom Input/a & & & & \\
\hline & & & 735,35 & $\mathrm{~m}^{3}$ & & & & & & \\
\hline TS-Gehalt & igkompost) & & $61,70 \%$ & & & & & & & \\
\hline Mietenhöhe & & & 1,5 & $\mathrm{~m}$ & Mietenquer & hnitt & & & & \\
\hline Mietenbasis & & & 2,5 & $\mathrm{~m}$ & $\overline{1,8}$ & $\mathrm{~m}^{2}$ & & & & \\
\hline ANLAGE & IMENSIO & IIERUNG & & & & & & & & \\
\hline Anlagent & & Berechnung & gsgrundlage & & & Anlagenneub & bau & Anlagenumn & utzung & \\
\hline Anliefe & sfläche & $5 \%$ & vom Input in I & hg/a, ausg & ickt in $\mathrm{m}^{2}$ & 130,00 & $\mathrm{~m}^{2}$ & 850,00 & $\mathrm{~m}^{2}$ & \\
\hline Rottefläch & & 1,33 & $\mathrm{~m}^{2} / \mathrm{m}^{3}$ Rottem & aterial bei & M.-Anfall & 2054,09 & $\mathrm{~m}^{2}$ & & $m^{2}$ & \\
\hline Rangierfläc & & $40 \%$ & der Rottefläch & & & 821,64 & $m^{2}$ & 3160,00 & & \\
\hline Zwisch & iger für & & der Rottefläch & & & & $m^{2}$ & & & \\
\hline Strukt & aterial & $10 \%$ & & & & 205,41 & & & & \\
\hline Kompostla & & $10 \%$ & der Rottefläch & & & 205,41 & $\mathrm{~m}^{2}$ & 850,00 & $\mathrm{~m}^{2}$ & \\
\hline Anlagenfl & (gesamt) & & & & & 3416,54 & $m^{2}$ & 4860,00 & $\mathrm{~m}^{2}$ & \\
\hline zu ve & tende & & & & & & & & & \\
\hline Abwa & menge & 0,2 & $m^{3} / m^{2 *} a$ & & & 683,31 & $\mathrm{~m}^{3} / \mathrm{a}$ & 972,00 & $\mathrm{~m}^{3} / \mathrm{a}$ & \\
\hline
\end{tabular}




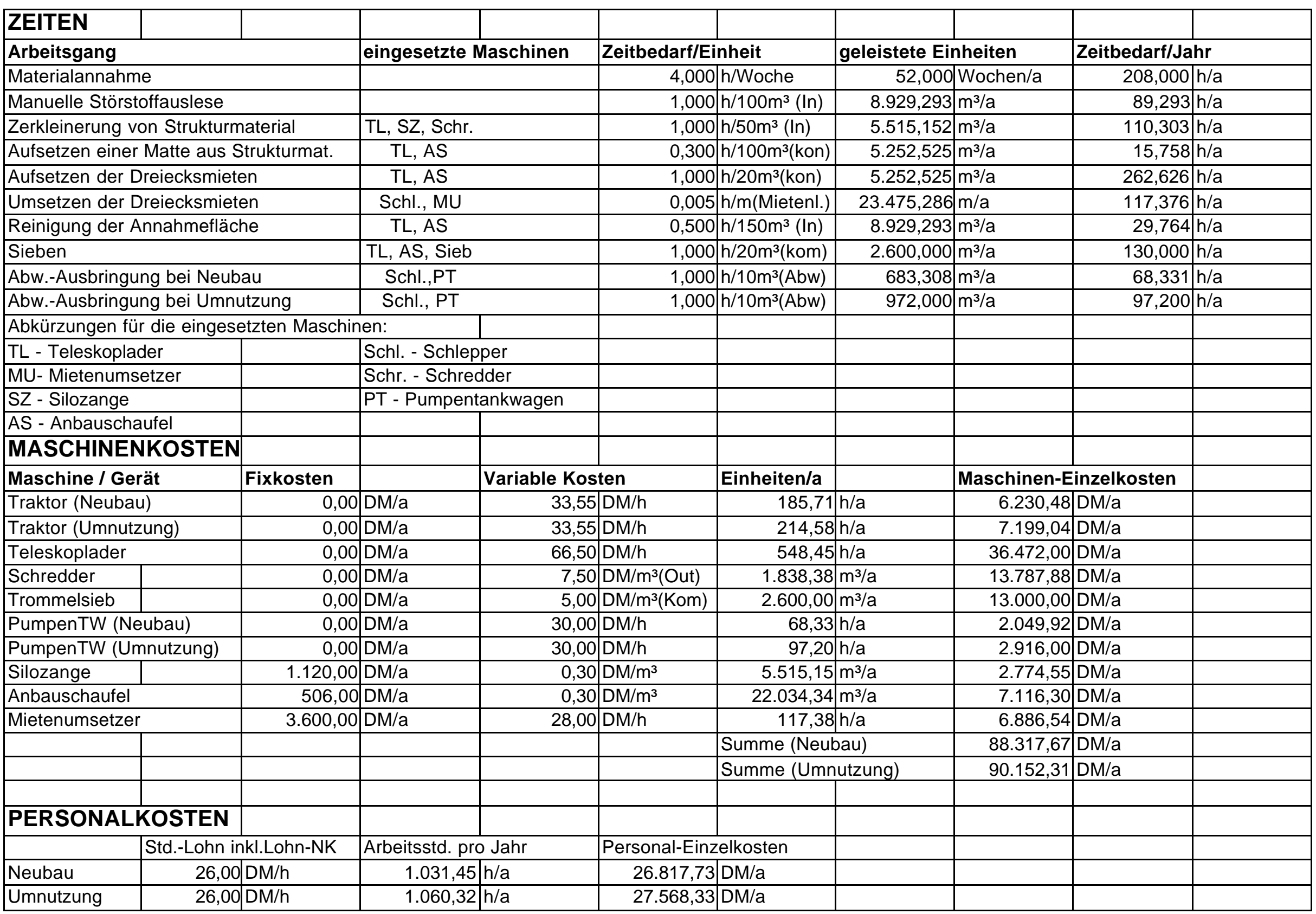




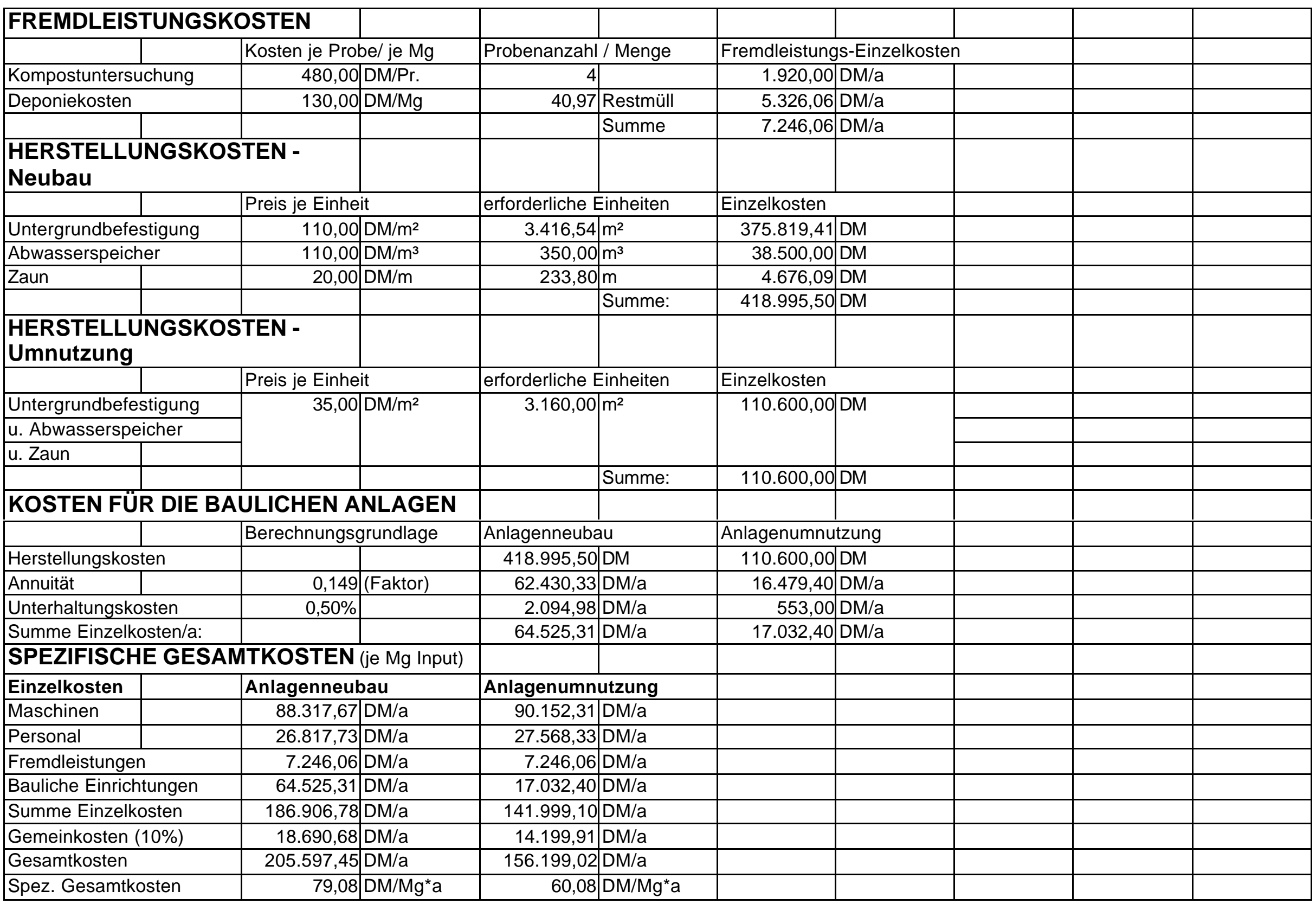


Kostenvariante C13

\begin{tabular}{|c|c|c|c|c|c|c|c|c|c|c|}
\hline MATERIA & & & & & & & & & & \\
\hline Jahresinput & & & $2.800,00$ & $\mathrm{Mg} / \mathrm{a}$ & & & & & & \\
\hline Zusammens & & & $65 \%$ & Vol.-\% & Bioabfälle & Haushalten & & & & \\
\hline & & & $35 \%$ & Vol.-\% & gehäckselt & Grüngut & & & & \\
\hline Dichte & & & 0,6 & $\mathrm{Mg} / \mathrm{m}^{3}$ & Bioabfälle & Haushalten & & & & \\
\hline & & & 0,3 & $\mathrm{Mg} / \mathrm{m}^{3}$ & gehäckselt & Grüngut & & & & \\
\hline & & & 0,495 & $\mathrm{Mg} / \mathrm{m}^{3}$ & konditionie & s Material & & & & \\
\hline & & & 0,5 & $\mathrm{Mg} / \mathrm{m}^{3}$ & Fertigkomp & & & & & \\
\hline Volumen & & & $5.656,57$ & $\mathrm{~m}^{3} / \mathrm{a}$ & konditionie & s Material & & & & \\
\hline & & & $3.676,77$ & $\mathrm{~m}^{3} / \mathrm{a}$ & Bioabfälle & Haushalten & & & & \\
\hline & & & $5.939,39$ & $\mathrm{~m}^{3} / \mathrm{a}$ & angeliefert & Grüngut & & & & \\
\hline & & & $1.979,80$ & $\mathrm{~m}^{3} / \mathrm{a}$ & gehäckselt & Grüngut & & & & \\
\hline & & & $2.800,00$ & $\mathrm{~m}^{3} / \mathrm{a}$ & Fertigkomp & & & & & \\
\hline Gewichtsan & & & $2.206,06$ & $\mathrm{Mg} / \mathrm{a}$ & Bioabfälle c & Haushalten & & & & \\
\hline & & & 593,94 & $\mathrm{Mg} / \mathrm{a}$ & Grüngut & & & & & \\
\hline & & & $1.400,00$ & $\mathrm{Mg} / \mathrm{a}$ & Fertigkomp & & & & & \\
\hline Rottedauer & & & 12 & Wochen & & & & & & \\
\hline durchschnit & & & 215,38 & $\mathrm{Mg}$ & & Rottematerial & eines & & & \\
\hline Monatsaufk & & & 435,12 & $m^{3}$ (kon) & & Durchlaufs in & der Anlage & 911,58 & $\mathrm{~m}^{3}$ & \\
\hline maximaler I & atsanfall & & 392,00 & $\mathrm{Mg}$ & entspr. 1 & vom Input/a & & & & \\
\hline & & & 791,92 & $\mathrm{~m}^{3}$ & & & & & & \\
\hline TS-Gehalt & igkompost) & & $61,70 \%$ & & & & & & & \\
\hline Mietenhöhe & & & 1,5 & $\mathrm{~m}$ & Mietenquer & hnitt & & & & \\
\hline Mietenbasis & & & 2,5 & $\mathrm{~m}$ & $\overline{1,8}$ & $\mathrm{~m}^{2}$ & & & & \\
\hline ANLAGE & IMENSIO & IIERUNG & & & & & & & & \\
\hline Anlagent & & Berechnung & gsgrundlage & & & Anlagenneub & bau & Anlagenumn & utzung & \\
\hline Anliefe & sfläche & $5 \%$ & vom Input in I & hg/a, ausg & ickt in $\mathrm{m}^{2}$ & 140,00 & $\mathrm{~m}^{2}$ & 850,00 & $\mathrm{~m}^{2}$ & \\
\hline Rottefläch & & 1,33 & $\mathrm{~m}^{2} / \mathrm{m}^{3}$ Rottem & aterial bei & M.-Anfall & 2212,09 & $\mathrm{~m}^{2}$ & & $m^{2}$ & \\
\hline Rangierfläc & & $40 \%$ & der Rottefläch & & & 884,84 & $m^{2}$ & 3160,00 & & \\
\hline Zwisch & iger für & & der Rottefläch & & & & $m^{2}$ & & & \\
\hline Strukt & aterial & $10 \%$ & & & & 221,21 & & & & \\
\hline Kompostla & & $10 \%$ & der Rottefläch & & & 221,21 & $\mathrm{~m}^{2}$ & 850,00 & $\mathrm{~m}^{2}$ & \\
\hline Anlagenfl & (gesamt) & & & & & 3679,35 & $\mathrm{~m}^{2}$ & 4860,00 & $m^{2}$ & \\
\hline zu ve & tende & & & & & & & & & \\
\hline Abwa & menge & 0,2 & $m^{3} / m^{2 \star} a$ & & & 735,87 & $\mathrm{~m}^{3} / \mathrm{a}$ & 972,00 & $\mathrm{~m}^{3} / \mathrm{a}$ & \\
\hline
\end{tabular}




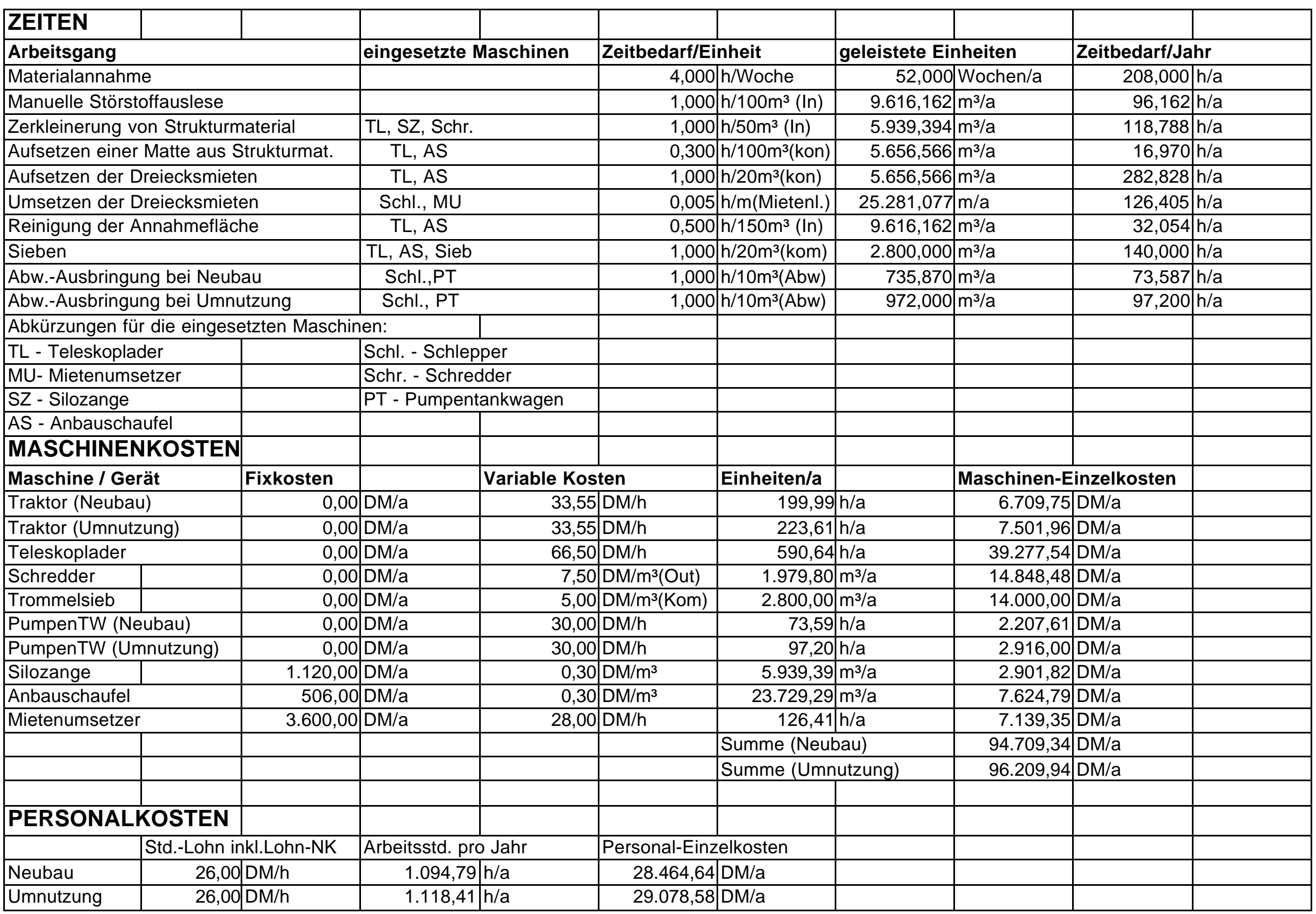




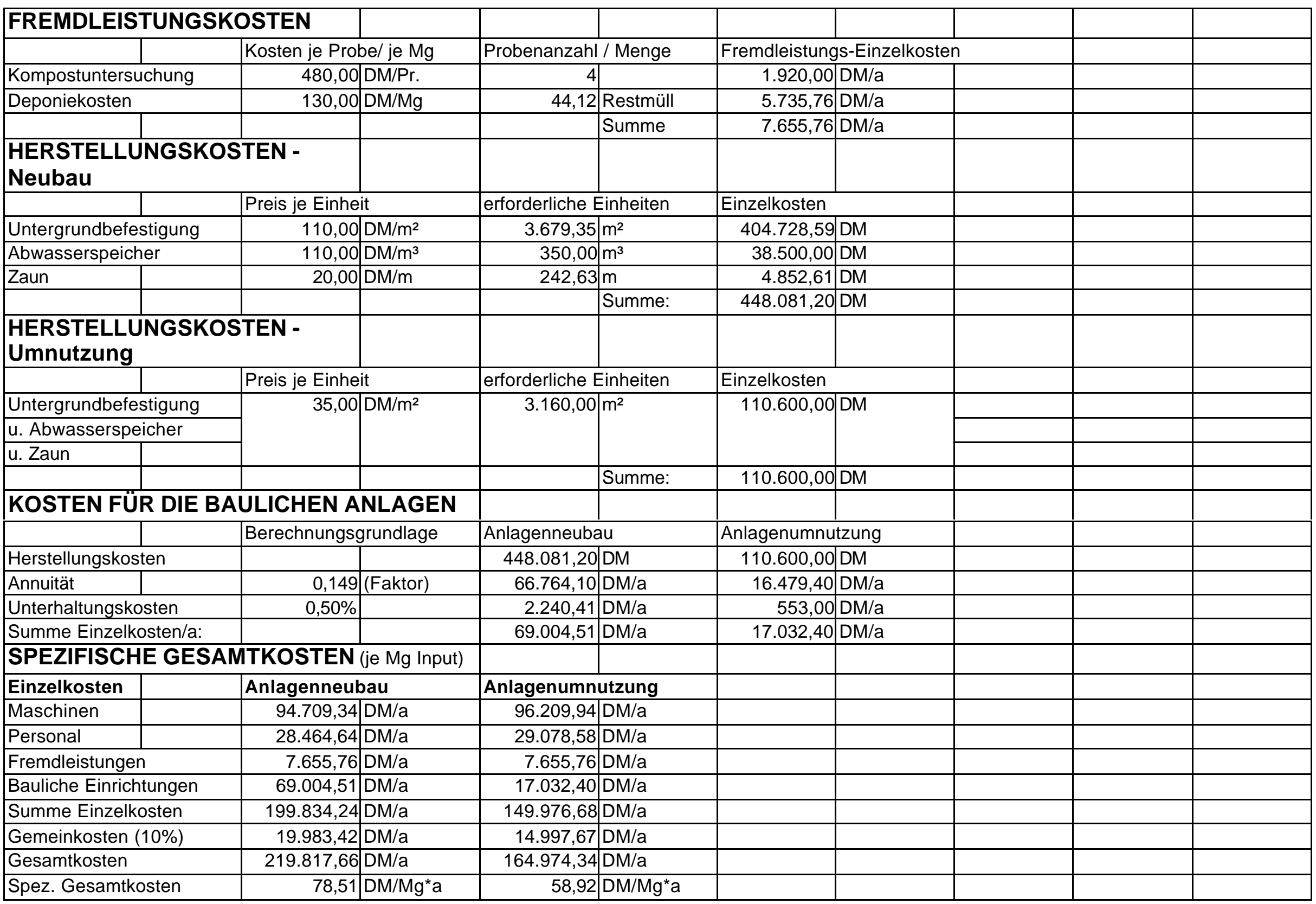


Kostenvariante D1

\section{MATERIAL}

Jahresinputmenge

Zusammensetzung

Dichte

\begin{tabular}{|l|l|}
\hline Dichte & \\
\hline & \\
\hline &
\end{tabular}

\section{Volumen}

\begin{tabular}{|l|l|}
\hline & \\
\hline & \\
\hline & \\
\hline & \\
\hline & \\
\hline
\end{tabular}

Gewichtsanteil

\begin{tabular}{|l|l|}
\hline & \\
\hline Rottedauer & \\
\hline durchschnittliches \\
\hline Monatsaufkommen \\
\hline maximaler Monatsanfall \\
\hline \multicolumn{2}{|l|}{} \\
\hline \multicolumn{2}{|l|}{ TS-Gehalt (Fertigkompost) } \\
\hline
\end{tabular}

TS-Gehalt (Fertigkompost)

Mietenhöhe

Mietenbasisbreite

\section{ANLAGENDIMENSIONIERUNG}

\section{Anlagenteil $\quad$ Berechnungsgrundlage}

Anlieferungsfläche

Rottefläche

Rangierfläche

Zwischenlager für

Strukturmaterial

Kompostlager

Anlagenfläche (gesamt)

zu verwertende

Abwassermenge

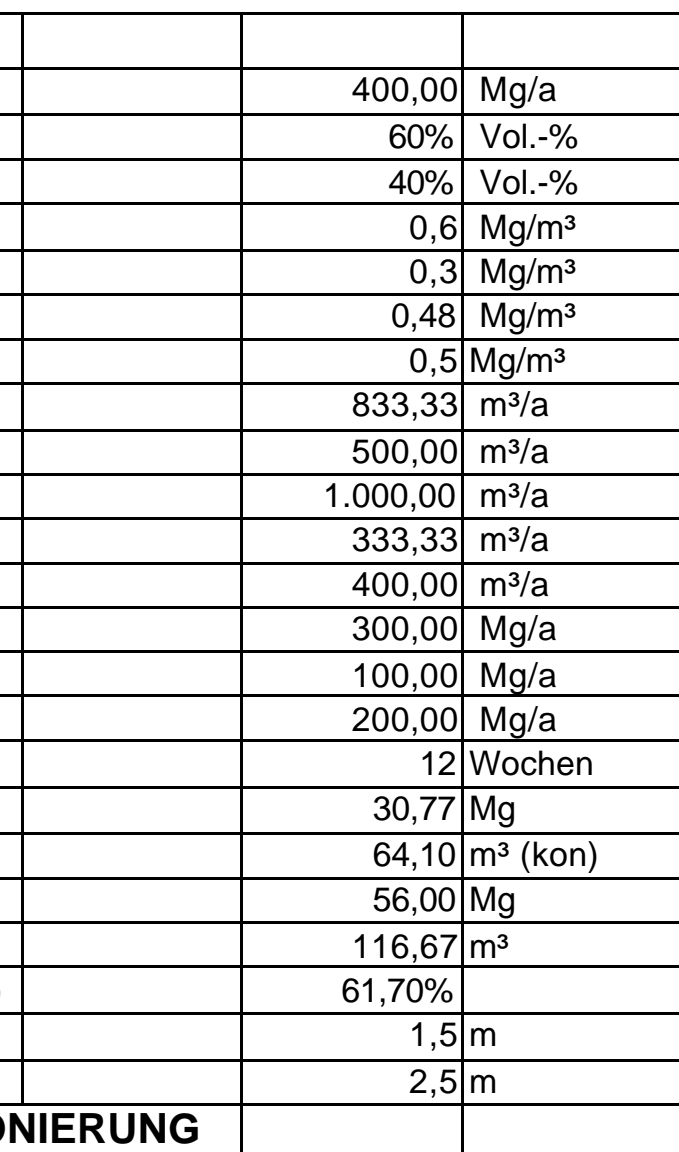

$5 \%$ vom Input in Mg/a, ausgedrückt in $\mathrm{m}^{2}$

$1,33 \mathrm{~m}^{2} / \mathrm{m}^{3}$ Rottematerial bei max.M.-Anfall

$40 \%$ der Rottefläche

der Rottefläche

$10 \%$

$10 \%$ der Rottefläche

\section{|}

$+$

$0,2 \mathrm{~m}^{3} / \mathrm{m}^{2 *} \mathrm{a}$

Grüngut

\begin{tabular}{|c|c|c|}
\hline ax.M.-Anfall & 323,56 & $\mathrm{~m}^{2}$ \\
\hline & 129,42 & $\mathrm{~m}^{2}$ \\
\hline & & $\mathrm{m}^{2}$ \\
\hline & 32,36 & \\
\hline & 32,36 & $\mathrm{~m}^{2}$ \\
\hline & 537,69 & $\mathrm{~m}^{2}$ \\
\hline & & \\
\hline & 107,54 & $\mathrm{~m}^{3} / \mathrm{a}$ \\
\hline
\end{tabular}

Bioabfälle aus Haushalten

gehäckseltes Grüngut

Bioabfälle aus Haushalten

gehäckseltes Grüngut

konditioniertes Material

Fertigkompost

konditioniertes Material

Bioabfälle aus Haushalten

angeliefertes Grüngut

gehäckseltes Grüngut

Fertigkompost

Bioabfälle aus Haushalten

Fertigkompost

\begin{tabular}{l|l}
\hline & \\
\hline & Rottematerial eines
\end{tabular}

entspr. 14\% vom Input/a

Mietenquerschnitt

\begin{tabular}{|r|l|l}
\hline $1,875 \mathrm{~m}^{2}$ & \\
& &
\end{tabular}

Anlagenneubau

Anlagenumnutzung

$400,00 \mathrm{~m}^{2}$

\begin{tabular}{|r|l|l|}
\hline 1525,00 & & \\
\cline { 1 - 2 } & \multicolumn{2}{|l|}{$\mathrm{m}^{2}$ (nicht drainiert) } \\
\hline 600,00 & & \\
\hline 400,00 & $\mathrm{~m}^{2}$ & \\
\hline 2325,00 & $\mathrm{~m}^{2}$ & \\
\hline 465,00 & $\mathrm{~m}^{3} / \mathrm{a}$ & \\
\hline
\end{tabular}




\begin{tabular}{|c|c|c|c|c|c|c|c|c|c|c|}
\hline \multicolumn{11}{|l|}{ ZEITEN } \\
\hline \multicolumn{3}{|l|}{ Arbeitsgang } & \multicolumn{2}{|c|}{ eingesetzte Maschinen } & \multicolumn{2}{|c|}{ Zeitbedarf/Einheit } & \multicolumn{2}{|c|}{ geleistete Einheiten } & \multicolumn{2}{|c|}{ Zeitbedarf/Jahr } \\
\hline \multicolumn{3}{|c|}{ Materialannahme } & & & 4,000 & h/Woche & 52,000 & Wochen/a & 208,000 & $h / a$ \\
\hline \multicolumn{3}{|c|}{ Manuelle Störstoffauslese } & & & 1,000 & $h / 100 m^{3}(\operatorname{In})$ & $1.500,000$ & $\mathrm{~m}^{3} / \mathrm{a}$ & 15,000 & $h / a$ \\
\hline \multicolumn{3}{|c|}{ Zerkleinerung von Strukturmaterial } & \multicolumn{2}{|l|}{ TL, SZ, Schr. } & 1,000 & $h / 50 m^{3}(\ln )$ & $1.000,000$ & $\mathrm{~m}^{3} / \mathrm{a}$ & 20,000 & $h / a$ \\
\hline \multicolumn{3}{|c|}{ Aufsetzen einer Matte aus Strukturmat. } & \multicolumn{2}{|l|}{ TL, AS } & 0,300 & $\mathrm{~h} / 100 \mathrm{~m}^{3}$ (kon) & 833,333 & $\mathrm{~m}^{3} / \mathrm{a}$ & 2,500 & $h / a$ \\
\hline \multicolumn{3}{|c|}{ Aufsetzen der Dreiecksmieten } & \multicolumn{2}{|l|}{ TL, AS } & 1,000 & $\mathrm{~h} / 20 \mathrm{~m}^{3}$ (kon) & 833,333 & $\mathrm{~m}^{3} / \mathrm{a}$ & 41,667 & $\mathrm{~h} / \mathrm{a}$ \\
\hline \multicolumn{3}{|c|}{ Umsetzen der Dreiecksmieten } & \multicolumn{2}{|l|}{ Schl., MU } & 0,005 & $\mathrm{~h} / \mathrm{m}$ (Mietenl.) & $3.697,778$ & $\mathrm{~m} / \mathrm{a}$ & 18,489 & $\mathrm{~h} / \mathrm{a}$ \\
\hline \multicolumn{3}{|c|}{ Reinigung der Annahmefläche } & \multicolumn{2}{|l|}{ TL, AS } & 0,500 & $h / 150 m^{3}(\ln )$ & $1.500,000$ & $\mathrm{~m}^{3} / \mathrm{a}$ & 5,000 & $h / a$ \\
\hline \multicolumn{3}{|l|}{ Sieben } & \multicolumn{2}{|l|}{ TL, AS, Sieb } & 1,000 & $\mathrm{~h} / 20 \mathrm{~m}^{3}(\mathrm{kom})$ & 400,000 & $\mathrm{~m}^{3} / \mathrm{a}$ & 20,000 & $\mathrm{~h} / \mathrm{a}$ \\
\hline \multicolumn{3}{|c|}{ Abw.-Ausbringung bei Neubau } & \multicolumn{2}{|l|}{ Schl.,PT } & 1,000 & $\mathrm{~h} / 10 \mathrm{~m}^{3}(\mathrm{Abw})$ & 107,538 & $\mathrm{~m}^{3} / \mathrm{a}$ & 10,754 & $h / a$ \\
\hline \multicolumn{3}{|c|}{ Abw.-Ausbringung bei Umnutzung } & \multicolumn{2}{|l|}{ Schl., PT } & 1,000 & $\mathrm{~h} / 10 \mathrm{~m}^{3}(\mathrm{Abw})$ & 465,000 & $\mathrm{~m}^{3} / \mathrm{a}$ & 46,500 & $h / a$ \\
\hline \multicolumn{11}{|c|}{ Abkürzungen für die eingesetzten Maschinen: } \\
\hline \multicolumn{3}{|c|}{\begin{tabular}{|l|l|} 
TL - Teleskoplader & \\
\end{tabular}} & Schl. - Schlepp & per & & & & & & \\
\hline MU- Mietenum & etzer & & Schr. - Schred & dder & & & & & & \\
\hline SZ - Silozange & & & PT - Pumpenta & tankwagen & & & & & & \\
\hline AS - Anbausc & aufel & & & & & & & & & \\
\hline MASCHINE & NKOSTEN & & & & & & & & & \\
\hline Maschine / G & & Fixkosten & & Variable Kost & ten & Einheiten/a & & Maschinen-Ei & inzelkosten & \\
\hline Traktor (Neub & & 0,00 & $D M / a$ & 33,55 & $D M / h$ & 29,24 & $h / a$ & 981,09 & $\mathrm{DM} / \mathrm{a}$ & \\
\hline Traktor (Umnu & zung) & 0,00 & $\mathrm{DM} / \mathrm{a}$ & 33,55 & $D M / h$ & 64,99 & $\mathrm{~h} / \mathrm{a}$ & $2.180,38$ & $\mathrm{DM} / \mathrm{a}$ & \\
\hline Teleskoplader & & 0,00 & $D M / a$ & 66,50 & $\mathrm{DM} / \mathrm{h}$ & 89,17 & $\mathrm{~h} / \mathrm{a}$ & $5.929,58$ & $\mathrm{DM} / \mathrm{a}$ & \\
\hline Schredder & & 0,00 & DM/a & 7,50 & $\mathrm{DM} / \mathrm{m}^{3}$ (Out) & 333,33 & $\mathrm{~m}^{3} / \mathrm{a}$ & $2.500,00$ & $\mathrm{DM} / \mathrm{a}$ & \\
\hline Trommelsieb & & 0,00 & $\mathrm{DM} / \mathrm{a}$ & 5,00 & $\mathrm{DM} / \mathrm{m}^{3}(\mathrm{Kom})$ & 400,00 & $\mathrm{~m}^{3} / \mathrm{a}$ & $2.000,00$ & $D M / a$ & \\
\hline PumpenTW ( & abau) & 0,00 & $\mathrm{DM} / \mathrm{a}$ & 30,00 & $\mathrm{DM} / \mathrm{h}$ & 10,75 & $\mathrm{~h} / \mathrm{a}$ & 322,61 & $\mathrm{DM} / \mathrm{a}$ & \\
\hline PumpenTW (L & nnutzung) & 0,00 & $D M / a$ & 30,00 & $D M / h$ & 46,50 & $h / a$ & $1.395,00$ & $\mathrm{DM} / \mathrm{a}$ & \\
\hline Silozange & & $1.120,00$ & DM/a & 0,30 & $\mathrm{DM} / \mathrm{m}^{3}$ & $1.000,00$ & $m^{3} / a$ & $1.420,00$ & $\mathrm{DM} / \mathrm{a}$ & \\
\hline Anbauschaufe & & 506,00 & $\mathrm{DM} / \mathrm{a}$ & 0,30 & $\mathrm{DM} / \mathrm{m}^{3}$ & $3.566,67$ & $\mathrm{~m}^{3} / \mathrm{a}$ & $1.576,00$ & $\mathrm{DM} / \mathrm{a}$ & \\
\hline Mietenumsetz & & $3.600,00$ & $\mathrm{DM} / \mathrm{a}$ & 28,00 & $\mathrm{DM} / \mathrm{h}$ & 18,49 & $h / a$ & $4.117,69$ & $\mathrm{DM} / \mathrm{a}$ & \\
\hline & & & & & & Summe (Neuk & bau) & $18.846,98$ & $\mathrm{DM} / \mathrm{a}$ & \\
\hline & & & & & & Summe (Umn & futzung) & $21.118,65$ & $\mathrm{DM} / \mathrm{a}$ & \\
\hline PERSONA & KOSTEN & & & & & & & & & \\
\hline & Std.-Lohn in & kl.Lohn-NK & Arbeitsstd. pro & o Jahr & Personal-Einz & zelkosten & & & & \\
\hline Neubau & 26,00 & $\mathrm{DM} / \mathrm{h}$ & 341,41 & $\mathrm{~h} / \mathrm{a}$ & $8.876,64$ & $D M / a$ & & & & \\
\hline Umnutzung & 26,00 & DM/h & 377,16 & $h / a$ & $9.806,04$ & $D M / a$ & & & & \\
\hline
\end{tabular}




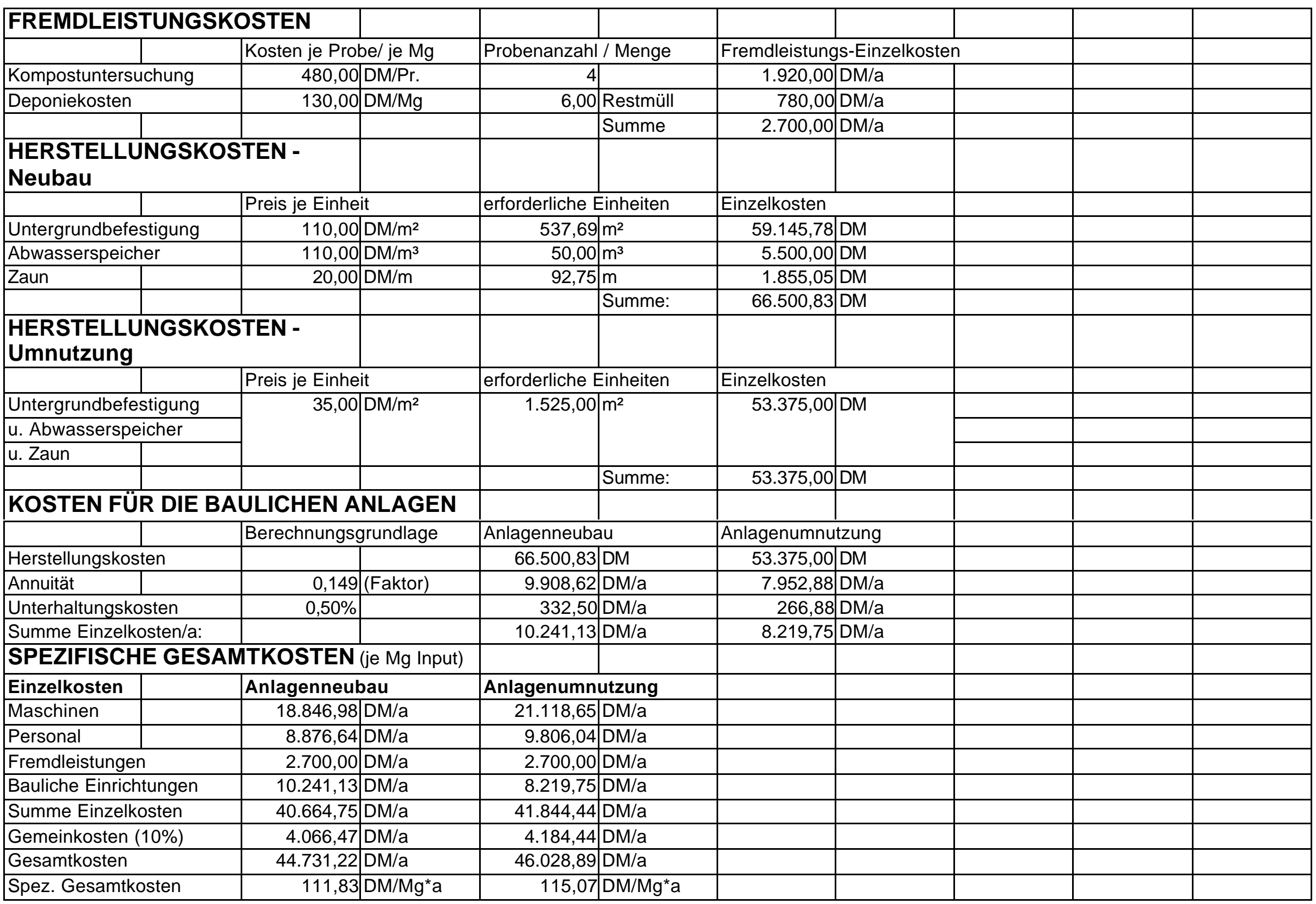


Kostenvariante D2

\section{MATERIAL}

Jahresinputmenge

Zusammensetzung

Dichte

\begin{tabular}{|l|l|}
\hline Dichte & \\
\hline & \\
\hline & \\
\hline Volumen & \\
\hline & \\
\hline & \\
\hline & \\
\hline & \\
\hline
\end{tabular}

Gewichtsanteil

\begin{tabular}{|l|l|}
\hline & \\
\hline & \\
\hline Rottedauer & \\
\hline durchschnittliches \\
\hline \multicolumn{2}{|l|}{ Monatsaufkommen } \\
\hline \multicolumn{2}{|l|}{ maximaler Monatsanfall } \\
\hline \multicolumn{2}{|l|}{} \\
\hline
\end{tabular}

TS-Gehalt (Fertigkompost)

Mietenhöhe

Mietenbasisbreite

\section{ANLAGENDIMENSIONIERUNG}

\section{Anlagenteil $\quad$ Berechnungsgrundlage}

Anlieferungsfläche

Rottefläche

Rangierfläche

Zwischenlager für

Strukturmaterial

Kompostlager

Anlagenfläche (gesamt)

zu verwertende

Abwassermenge

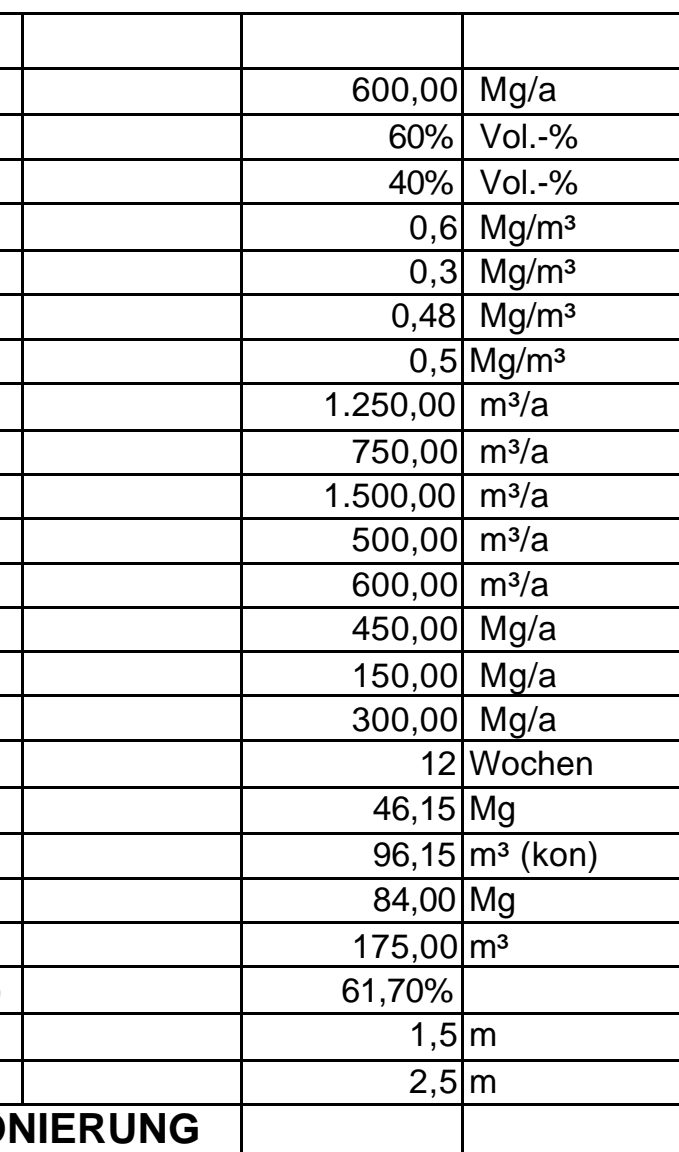

$5 \%$ vom Input in $\mathrm{Mg} / \mathrm{a}$, ausgedrückt in $\mathrm{m}^{2}$

$1,33 \mathrm{~m}^{2} / \mathrm{m}^{3}$ Rottematerial bei max.M.-Anfall

$40 \%$ der Rottefläche

der Rottefläche

$10 \%$ der Rottefläche

\section{|}

+

$0,2 \mathrm{~m}^{3} / \mathrm{m}^{2 \star} \mathrm{a}$

Grüngut

\begin{tabular}{|c|c|c|}
\hline ax.M.-Anfall & 485,33 & $\mathrm{~m}^{2}$ \\
\hline & 194,13 & $\mathrm{~m}^{2}$ \\
\hline & & $\mathrm{m}^{2}$ \\
\hline & 48,53 & \\
\hline & 48,53 & $\mathrm{~m}^{2}$ \\
\hline & 806,53 & $\mathrm{~m}^{2}$ \\
\hline & & \\
\hline & 161,31 & $\mathrm{~m}^{3} / \mathrm{a}$ \\
\hline
\end{tabular}

Bioabfälle aus Haushalten

gehäckseltes Grüngut

Bioabfälle aus Haushalten

gehäckseltes Grüngut

konditioniertes Material

Fertigkompost

konditioniertes Material

Bioabfälle aus Haushalten

angeliefertes Grüngut

gehäckseltes Grüngut

Fertigkompost

Bioabfälle aus Haushalten

Fertigkompost

\begin{tabular}{l|l|l}
\hline & & \\
\hline & Rottematerial eines
\end{tabular}

entspr. 14\% vom Input/a

Mietenquerschnitt

\begin{tabular}{|r|l|l}
\hline $1,875 \mathrm{~m}^{2}$ & \\
& &
\end{tabular}

Anlagenneubau

Anlagenumnutzung

$400,00 \mathrm{~m}^{2}$

\begin{tabular}{|r|l|l|}
\hline 1525,00 & & \\
\cline { 1 - 2 } & \multicolumn{2}{|l|}{$\mathrm{m}^{2}$ (nicht drainiert) } \\
\hline 600,00 & & \\
\hline 400,00 & $\mathrm{~m}^{2}$ & \\
\hline 2325,00 & $\mathrm{~m}^{2}$ & \\
\hline 465,00 & $\mathrm{~m}^{3} / \mathrm{a}$ & \\
\hline
\end{tabular}




\begin{tabular}{|c|c|c|c|c|c|c|c|c|c|c|}
\hline \multicolumn{11}{|l|}{ ZEITEN } \\
\hline \multicolumn{3}{|l|}{ Arbeitsgang } & \multicolumn{2}{|c|}{ eingesetzte Maschinen } & \multicolumn{2}{|c|}{ Zeitbedarf/Einheit } & \multicolumn{2}{|c|}{ geleistete Einheiten } & \multicolumn{2}{|c|}{ Zeitbedarf/Jahr } \\
\hline \multicolumn{3}{|c|}{ Materialannahme } & & & 4,000 & h/Woche & 52,000 & Wochen/a & 208,000 & $h / a$ \\
\hline \multicolumn{3}{|c|}{ Manuelle Störstoffauslese } & & & 1,000 & $h / 100 m^{3}(\operatorname{In})$ & $2.250,000$ & $\mathrm{~m}^{3} / \mathrm{a}$ & 22,500 & $h / a$ \\
\hline \multicolumn{3}{|c|}{ Zerkleinerung von Strukturmaterial } & \multicolumn{2}{|l|}{ TL, SZ, Schr. } & 1,000 & $h / 50 m^{3}(\ln )$ & $1.500,000$ & $\mathrm{~m}^{3} / \mathrm{a}$ & 30,000 & $h / a$ \\
\hline \multicolumn{3}{|c|}{ Aufsetzen einer Matte aus Strukturmat. } & \multicolumn{2}{|l|}{$\mathrm{TL}, \mathrm{AS}$} & 0,300 & $\mathrm{~h} / 100 \mathrm{~m}^{3}$ (kon) & $1.250,000$ & $\mathrm{~m}^{3} / \mathrm{a}$ & 3,750 & $h / a$ \\
\hline \multicolumn{3}{|c|}{ Aufsetzen der Dreiecksmieten } & \multicolumn{2}{|l|}{ TL, AS } & 1,000 & $\mathrm{~h} / 20 \mathrm{~m}^{3}$ (kon) & $1.250,000$ & $\mathrm{~m}^{3} / \mathrm{a}$ & 62,500 & $h / a$ \\
\hline \multicolumn{3}{|c|}{ Umsetzen der Dreiecksmieten } & \multicolumn{2}{|l|}{ Schl., MU } & 0,005 & $\mathrm{~h} / \mathrm{m}$ (Mietenl.) & $5.546,667$ & $\mathrm{~m} / \mathrm{a}$ & 27,733 & $\mathrm{~h} / \mathrm{a}$ \\
\hline \multicolumn{3}{|c|}{ Reinigung der Annahmefläche } & \multicolumn{2}{|l|}{ TL, AS } & 0,500 & $h / 150 m^{3}(\ln )$ & $2.250,000$ & $\mathrm{~m}^{3} / \mathrm{a}$ & 7,500 & $h / a$ \\
\hline \multicolumn{3}{|l|}{ Sieben } & \multicolumn{2}{|l|}{ TL, AS, Sieb } & 1,000 & $\mathrm{~h} / 20 \mathrm{~m}^{3}(\mathrm{kom})$ & 600,000 & $\mathrm{~m}^{3} / \mathrm{a}$ & 30,000 & $\mathrm{~h} / \mathrm{a}$ \\
\hline \multicolumn{3}{|c|}{ Abw.-Ausbringung bei Neubau } & \multicolumn{2}{|l|}{ Schl.,PT } & 1,000 & $\mathrm{~h} / 10 \mathrm{~m}^{3}(\mathrm{Abw})$ & 161,307 & $\mathrm{~m}^{3} / \mathrm{a}$ & 16,131 & $\mathrm{~h} / \mathrm{a}$ \\
\hline \multicolumn{3}{|c|}{ Abw.-Ausbringung bei Umnutzung } & \multicolumn{2}{|l|}{ Schl., PT } & 1,000 & $\mathrm{~h} / 10 \mathrm{~m}^{3}(\mathrm{Abw})$ & 465,000 & $\mathrm{~m}^{3} / \mathrm{a}$ & 46,500 & $h / a$ \\
\hline \multicolumn{11}{|c|}{ Abkürzungen für die eingesetzten Maschinen: } \\
\hline \multicolumn{3}{|c|}{\begin{tabular}{|l|l|} 
TL - Teleskoplader & \\
\end{tabular}} & Schl. - Schlepp & per & & & & & & \\
\hline MU- Mietenum & etzer & & Schr. - Schred & dder & & & & & & \\
\hline SZ - Silozange & & & PT - Pumpenta & tankwagen & & & & & & \\
\hline AS - Anbausc & uffel & & & & & & & & & \\
\hline MASCHINE & IKOSTEN & & & & & & & & & \\
\hline Maschine / G & & Fixkosten & & Variable Kost & ten & Einheiten/a & & Maschinen-Ei & inzelkosten & \\
\hline Traktor (Neub & & 0,00 & $D M / a$ & 33,55 & $D M / h$ & 43,86 & $h / a$ & $1.471,64$ & $D M / a$ & \\
\hline Traktor (Umnu & ung) & 0,00 & $\mathrm{DM} / \mathrm{a}$ & 33,55 & $D M / h$ & 74,23 & $\mathrm{~h} / \mathrm{a}$ & $2.490,53$ & $\mathrm{DM} / \mathrm{a}$ & \\
\hline Teleskoplader & & 0,00 & $D M / a$ & 66,50 & $\mathrm{DM} / \mathrm{h}$ & 133,75 & $h / a$ & $8.894,38$ & $\mathrm{DM} / \mathrm{a}$ & \\
\hline Schredder & & 0,00 & DM/a & 7,50 & $\mathrm{DM} / \mathrm{m}^{3}$ (Out) & 500,00 & $\mathrm{~m}^{3} / \mathrm{a}$ & $3.750,00$ & $\mathrm{DM} / \mathrm{a}$ & \\
\hline Trommelsieb & & 0,00 & $D M / a$ & 5,00 & $\mathrm{DM} / \mathrm{m}^{3}(\mathrm{Kom})$ & 600,00 & $\mathrm{~m}^{3} / \mathrm{a}$ & $3.000,00$ & $\mathrm{DM} / \mathrm{a}$ & \\
\hline PumpenTW ( & ubau) & 0,00 & $\mathrm{DM} / \mathrm{a}$ & 30,00 & $\mathrm{DM} / \mathrm{h}$ & 16,13 & $\mathrm{~h} / \mathrm{a}$ & 483,92 & $\mathrm{DM} / \mathrm{a}$ & \\
\hline PumpenTW (L & nnutzung) & 0,00 & $D M / a$ & 30,00 & $D M / h$ & 46,50 & $h / a$ & $1.395,00$ & $\mathrm{DM} / \mathrm{a}$ & \\
\hline Silozange & & $1.120,00$ & DM/a & 0,30 & $\mathrm{DM} / \mathrm{m}^{3}$ & $1.500,00$ & $\mathrm{~m}^{3} / \mathrm{a}$ & $1.570,00$ & $\mathrm{DM} / \mathrm{a}$ & \\
\hline Anbauschaufe & & 506,00 & $\mathrm{DM} / \mathrm{a}$ & 0,30 & $\mathrm{DM} / \mathrm{m}^{3}$ & $5.350,00$ & $m^{3} / a$ & $2.111,00$ & $\mathrm{DM} / \mathrm{a}$ & \\
\hline Mietenumsetz & & $3.600,00$ & $\mathrm{DM} / \mathrm{a}$ & 28,00 & $\mathrm{DM} / \mathrm{h}$ & 27,73 & $\mathrm{~h} / \mathrm{a}$ & $4.376,53$ & $\mathrm{DM} / \mathrm{a}$ & \\
\hline & & & & & & Summe (Neuk & bau) & $25.657,47$ & $\mathrm{DM} / \mathrm{a}$ & \\
\hline & & & & & & Summe (Umn & hutzung) & $27.587,44$ & $\mathrm{DM} / \mathrm{a}$ & \\
\hline PERSONA & KOSTEN & & & & & & & & & \\
\hline & Std.-Lohn in & nkl.Lohn-NK & Arbeitsstd. pro & o Jahr & Personal-Einz & zelkosten & & & & \\
\hline Neubau & 26,00 & $D M / h$ & 408,11 & $\mathrm{~h} / \mathrm{a}$ & $10.610,96$ & $D M / a$ & & & & \\
\hline Umnutzung & 26,00 & $D M / h$ & 438,48 & $h / a$ & $11.400,57$ & DM/a & & & & \\
\hline
\end{tabular}




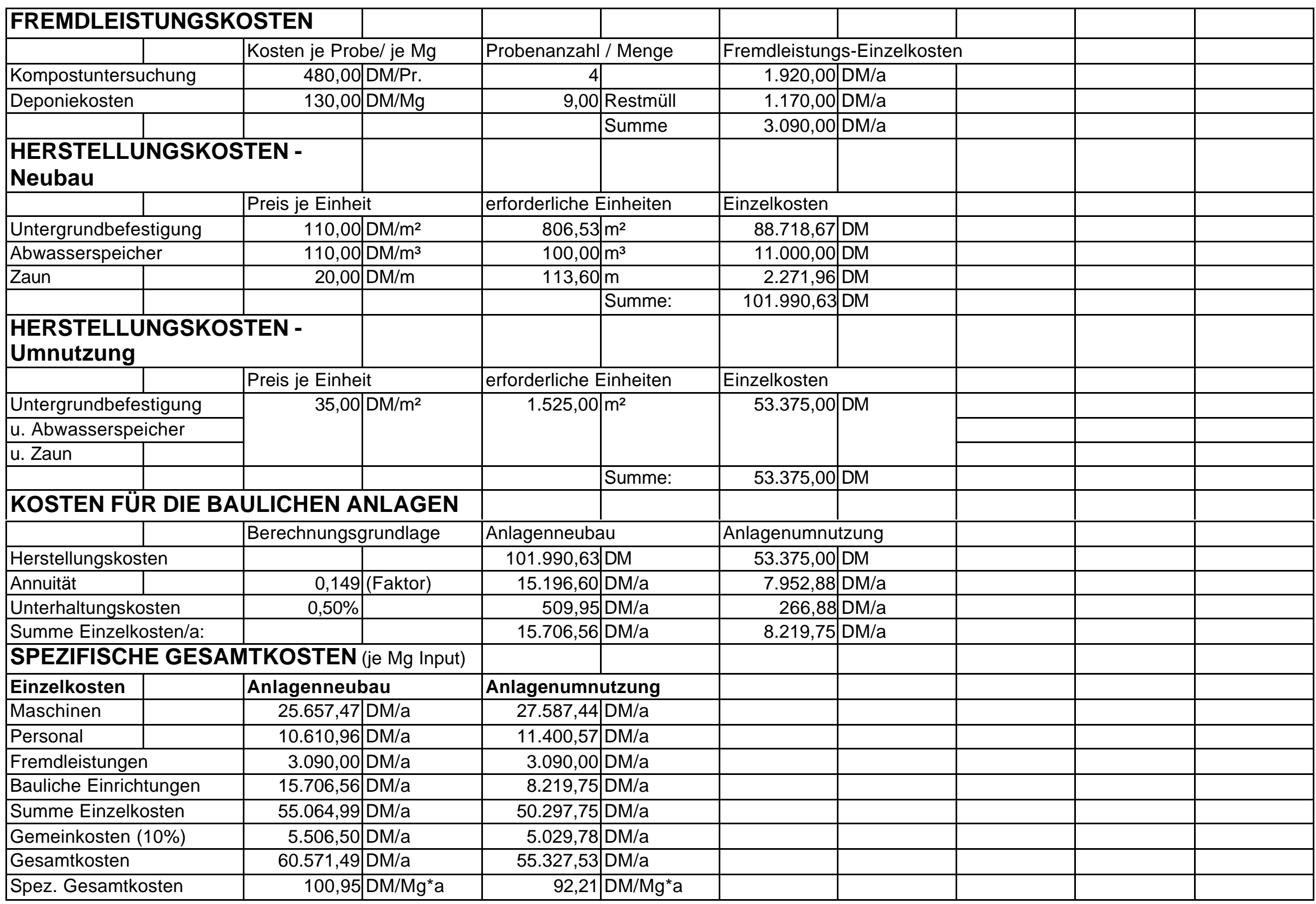


Kostenvariante D3

\section{MATERIAL}

Jahresinputmenge

Zusammensetzung

Dichte

\begin{tabular}{|l|l|}
\hline Dichte & \\
\hline & \\
\hline & \\
\hline Volumen & \\
\hline & \\
\hline & \\
\hline & \\
\hline & \\
\hline
\end{tabular}

Gewichtsanteil

\begin{tabular}{|l|l|}
\hline & \\
\hline & \\
\hline Rottedauer & \\
\hline durchschnittliches \\
\hline \multicolumn{2}{|l|}{ Monatsaufkommen } \\
\hline \multicolumn{2}{|l|}{ maximaler Monatsanfall } \\
\hline \multicolumn{2}{|l|}{} \\
\hline
\end{tabular}

TS-Gehalt (Fertigkompost)

Mietenhöhe

Mietenbasisbreite

\section{ANLAGENDIMENSIONIERUNG}

\section{Anlagenteil $\quad$ Berechnungsgrundlage}

Anlieferungsfläche

Rottefläche

Rangierfläche

Zwischenlager für

Strukturmaterial

Kompostlager

Anlagenfläche (gesamt)

zu verwertende

Abwassermenge

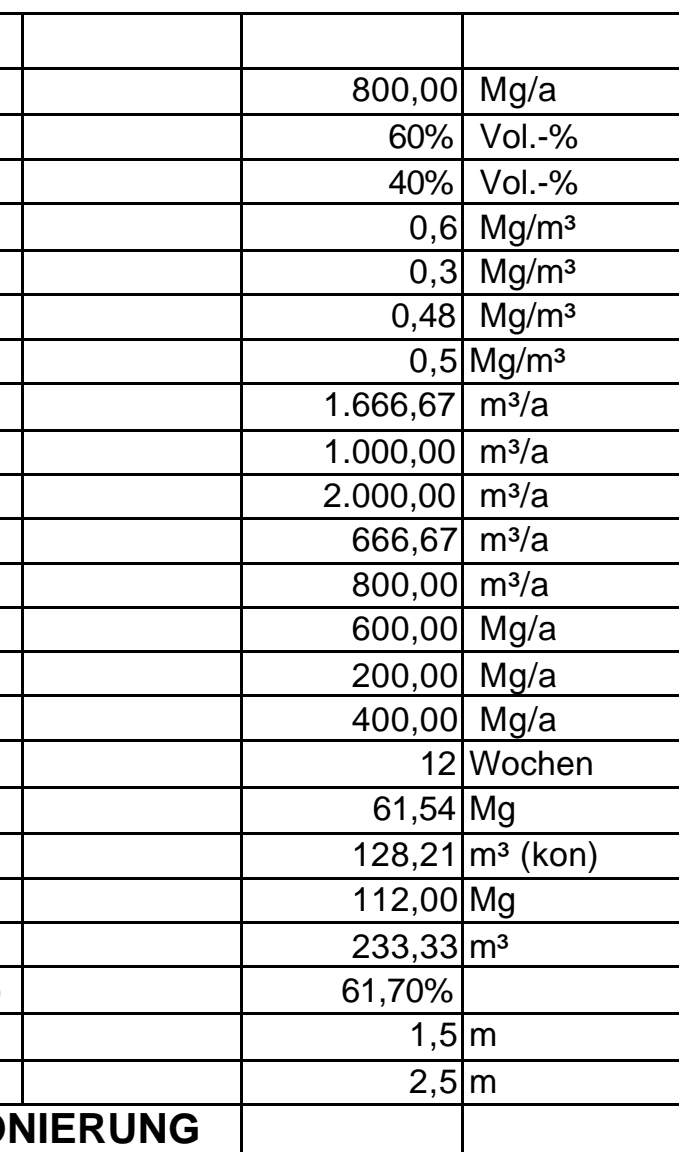

$5 \%$ vom Input in Mg/a, ausgedrückt in $\mathrm{m}^{2}$

$1,33 \mathrm{~m}^{2} / \mathrm{m}^{3}$ Rottematerial bei max.M.-Anfall

$40 \%$ der Rottefläche

der Rottefläche

$10 \%$ der Rottefläche

\section{|}

+

$0,2 \mathrm{~m}^{3} / \mathrm{m}^{2 \star} \mathrm{a}$

Grüngut

\begin{tabular}{|c|c|c|}
\hline ax.M.-Anfall & 647,11 & $\mathrm{~m}^{2}$ \\
\hline & 258,84 & $\mathrm{~m}^{2}$ \\
\hline & & $\mathrm{m}^{2}$ \\
\hline & 64,71 & \\
\hline & 64,71 & $\mathrm{~m}^{2}$ \\
\hline & 1075,38 & $\mathrm{~m}^{2}$ \\
\hline & & \\
\hline & 215,08 & $\mathrm{~m}^{3} / \mathrm{a}$ \\
\hline
\end{tabular}

Bioabfälle aus Haushalten

gehäckseltes Grüngut

Bioabfälle aus Haushalten

gehäckseltes Grüngut

konditioniertes Material

Fertigkompost

konditioniertes Material

Bioabfälle aus Haushalten

angeliefertes Grüngut

gehäckseltes Grüngut

Fertigkompost

Bioabfälle aus Haushalten

Fertigkompost

\begin{tabular}{l|l}
\hline & \\
\hline & Rottematerial eines
\end{tabular}

entspr. 14\% vom Input/a

Mietenquerschnitt

\begin{tabular}{|r|l|l}
\hline $1,875 \mathrm{~m}^{2}$ & \\
& &
\end{tabular}

Anlagenneubau

Anlagenumnutzung

\begin{tabular}{r|l|l|l|}
\hline 400,00 & $\mathrm{~m}^{2}$ & \\
\cline { 1 - 2 } & $\mathrm{m}^{2}$ & \\
\cline { 1 - 2 } & $\mathrm{m}^{2}$ (nicht drainiert) \\
\hline 600,00 & & \\
\hline 400,00 & $\mathrm{~m}^{2}$ & \\
\hline 2325,00 & $\mathrm{~m}^{2}$ & \\
\hline 465,00 & $\mathrm{~m}^{3} / \mathrm{a}$ & \\
\hline
\end{tabular}




\begin{tabular}{|c|c|c|c|c|c|c|c|c|c|c|}
\hline \multicolumn{11}{|l|}{ ZEITEN } \\
\hline \multicolumn{3}{|l|}{ Arbeitsgang } & \multicolumn{2}{|c|}{ eingesetzte Maschinen } & \multicolumn{2}{|c|}{ Zeitbedarf/Einheit } & \multicolumn{2}{|c|}{ geleistete Einheiten } & \multicolumn{2}{|c|}{ Zeitbedarf/Jahr } \\
\hline \multicolumn{3}{|c|}{ Materialannahme } & & & 4,000 & h/Woche & 52,000 & Wochen/a & 208,000 & $h / a$ \\
\hline \multicolumn{3}{|c|}{ Manuelle Störstoffauslese } & & & 1,000 & $h / 100 m^{3}(\operatorname{In})$ & $3.000,000$ & $\mathrm{~m}^{3} / \mathrm{a}$ & 30,000 & $h / a$ \\
\hline \multicolumn{3}{|c|}{ Zerkleinerung von Strukturmaterial } & \multicolumn{2}{|l|}{ TL, SZ, Schr. } & 1,000 & $h / 50 m^{3}(\ln )$ & $2.000,000$ & $\mathrm{~m}^{3} / \mathrm{a}$ & 40,000 & $h / a$ \\
\hline \multicolumn{3}{|c|}{ Aufsetzen einer Matte aus Strukturmat. } & \multicolumn{2}{|l|}{$\mathrm{TL}, \mathrm{AS}$} & 0,300 & $\mathrm{~h} / 100 \mathrm{~m}^{3}$ (kon) & $1.666,667$ & $\mathrm{~m}^{3} / \mathrm{a}$ & 5,000 & $h / a$ \\
\hline \multicolumn{3}{|c|}{ Aufsetzen der Dreiecksmieten } & \multicolumn{2}{|l|}{ TL, AS } & 1,000 & $\mathrm{~h} / 20 \mathrm{~m}^{3}$ (kon) & $1.666,667$ & $\mathrm{~m}^{3} / \mathrm{a}$ & 83,333 & $\mathrm{~h} / \mathrm{a}$ \\
\hline \multicolumn{3}{|c|}{ Umsetzen der Dreiecksmieten } & \multicolumn{2}{|l|}{ Schl., MU } & 0,005 & $\mathrm{~h} / \mathrm{m}$ (Mietenl.) & $7.395,556$ & $\mathrm{~m} / \mathrm{a}$ & 36,978 & $\mathrm{~h} / \mathrm{a}$ \\
\hline \multicolumn{3}{|c|}{ Reinigung der Annahmefläche } & \multicolumn{2}{|l|}{ TL, AS } & 0,500 & $h / 150 m^{3}(\ln )$ & $3.000,000$ & $\mathrm{~m}^{3} / \mathrm{a}$ & 10,000 & $h / a$ \\
\hline \multicolumn{3}{|l|}{ Sieben } & \multicolumn{2}{|l|}{ TL, AS, Sieb } & 1,000 & $\mathrm{~h} / 20 \mathrm{~m}^{3}(\mathrm{kom})$ & 800,000 & $\mathrm{~m}^{3} / \mathrm{a}$ & 40,000 & $\mathrm{~h} / \mathrm{a}$ \\
\hline \multicolumn{3}{|c|}{ Abw.-Ausbringung bei Neubau } & \multicolumn{2}{|l|}{ Schl.,PT } & 1,000 & $\mathrm{~h} / 10 \mathrm{~m}^{3}(\mathrm{Abw})$ & 215,076 & $\mathrm{~m}^{3} / \mathrm{a}$ & 21,508 & $\mathrm{~h} / \mathrm{a}$ \\
\hline \multicolumn{3}{|c|}{ Abw.-Ausbringung bei Umnutzung } & \multicolumn{2}{|l|}{ Schl., PT } & 1,000 & $\mathrm{~h} / 10 \mathrm{~m}^{3}(\mathrm{Abw})$ & 465,000 & $\mathrm{~m}^{3} / \mathrm{a}$ & 46,500 & $h / a$ \\
\hline \multicolumn{11}{|c|}{ Abkürzungen für die eingesetzten Maschinen: } \\
\hline \multicolumn{3}{|c|}{\begin{tabular}{|l|l|} 
TL - Teleskoplader & \\
\end{tabular}} & Schl. - Schlepp & per & & & & & & \\
\hline MU- Mietenum & etzer & & Schr. - Schred & dder & & & & & & \\
\hline SZ - Silozange & & & PT - Pumpenta & tankwagen & & & & & & \\
\hline AS - Anbausc & aufel & & & & & & & & & \\
\hline MASCHINE & NKOSTEN & & & & & & & & & \\
\hline Maschine / G & & Fixkosten & & Variable Kost & ten & Einheiten/a & & Maschinen-Ei & inzelkosten & \\
\hline Traktor (Neub & & 0,00 & $D M / a$ & 33,55 & $D M / h$ & 58,49 & $h / a$ & $1.962,18$ & $\mathrm{DM} / \mathrm{a}$ & \\
\hline Traktor (Umnu & zung) & 0,00 & $\mathrm{DM} / \mathrm{a}$ & 33,55 & $D M / h$ & 83,48 & $\mathrm{~h} / \mathrm{a}$ & $2.800,68$ & $\mathrm{DM} / \mathrm{a}$ & \\
\hline Teleskoplader & & 0,00 & $D M / a$ & 66,50 & $\mathrm{DM} / \mathrm{h}$ & 178,33 & $\mathrm{~h} / \mathrm{a}$ & $11.859,17$ & $\mathrm{DM} / \mathrm{a}$ & \\
\hline Schredder & & 0,00 & DM/a & 7,50 & $\mathrm{DM} / \mathrm{m}^{3}$ (Out) & 666,67 & $\mathrm{~m}^{3} / \mathrm{a}$ & $5.000,00$ & $\mathrm{DM} / \mathrm{a}$ & \\
\hline Trommelsieb & & 0,00 & $D M / a$ & 5,00 & $\mathrm{DM} / \mathrm{m}^{3}(\mathrm{Kom})$ & 800,00 & $\mathrm{~m}^{3} / \mathrm{a}$ & $4.000,00$ & $\mathrm{DM} / \mathrm{a}$ & \\
\hline PumpenTW ( & abau) & 0,00 & $\mathrm{DM} / \mathrm{a}$ & 30,00 & $\mathrm{DM} / \mathrm{h}$ & 21,51 & $\mathrm{~h} / \mathrm{a}$ & 645,23 & $\mathrm{DM} / \mathrm{a}$ & \\
\hline PumpenTW (L & nnutzung) & 0,00 & $D M / a$ & 30,00 & $D M / h$ & 46,50 & $h / a$ & $1.395,00$ & $\mathrm{DM} / \mathrm{a}$ & \\
\hline Silozange & & $1.120,00$ & DM/a & 0,30 & $\mathrm{DM} / \mathrm{m}^{3}$ & $2.000,00$ & $\mathrm{~m}^{3} / \mathrm{a}$ & $1.720,00$ & $\mathrm{DM} / \mathrm{a}$ & \\
\hline Anbauschaufe & & 506,00 & $\mathrm{DM} / \mathrm{a}$ & 0,30 & $\mathrm{DM} / \mathrm{m}^{3}$ & $7.133,33$ & $\mathrm{~m}^{3} / \mathrm{a}$ & $2.646,00$ & $\mathrm{DM} / \mathrm{a}$ & \\
\hline Mietenumsetz & & $3.600,00$ & $\mathrm{DM} / \mathrm{a}$ & 28,00 & $\mathrm{DM} / \mathrm{h}$ & 36,98 & $\mathrm{~h} / \mathrm{a}$ & $4.635,38$ & $\mathrm{DM} / \mathrm{a}$ & \\
\hline & & & & & & Summe (Neuk & bau) & $32.467,95$ & $\mathrm{DM} / \mathrm{a}$ & \\
\hline & & & & & & Summe (Umn & hutzung) & $34.056,22$ & $\mathrm{DM} / \mathrm{a}$ & \\
\hline PERSONA & KOSTEN & & & & & & & & & \\
\hline & Std.-Lohn in & kl.Lohn-NK & Arbeitsstd. pro & o Jahr & Personal-Einz & zelkosten & & & & \\
\hline Neubau & 26,00 & $\mathrm{DM} / \mathrm{h}$ & 474,82 & $\mathrm{~h} / \mathrm{a}$ & $12.345,29$ & $\mathrm{DM} / \mathrm{a}$ & & & & \\
\hline Umnutzung & 26,00 & DM/h & 499,81 & $h / a$ & $12.995,09$ & DM/a & & & & \\
\hline
\end{tabular}




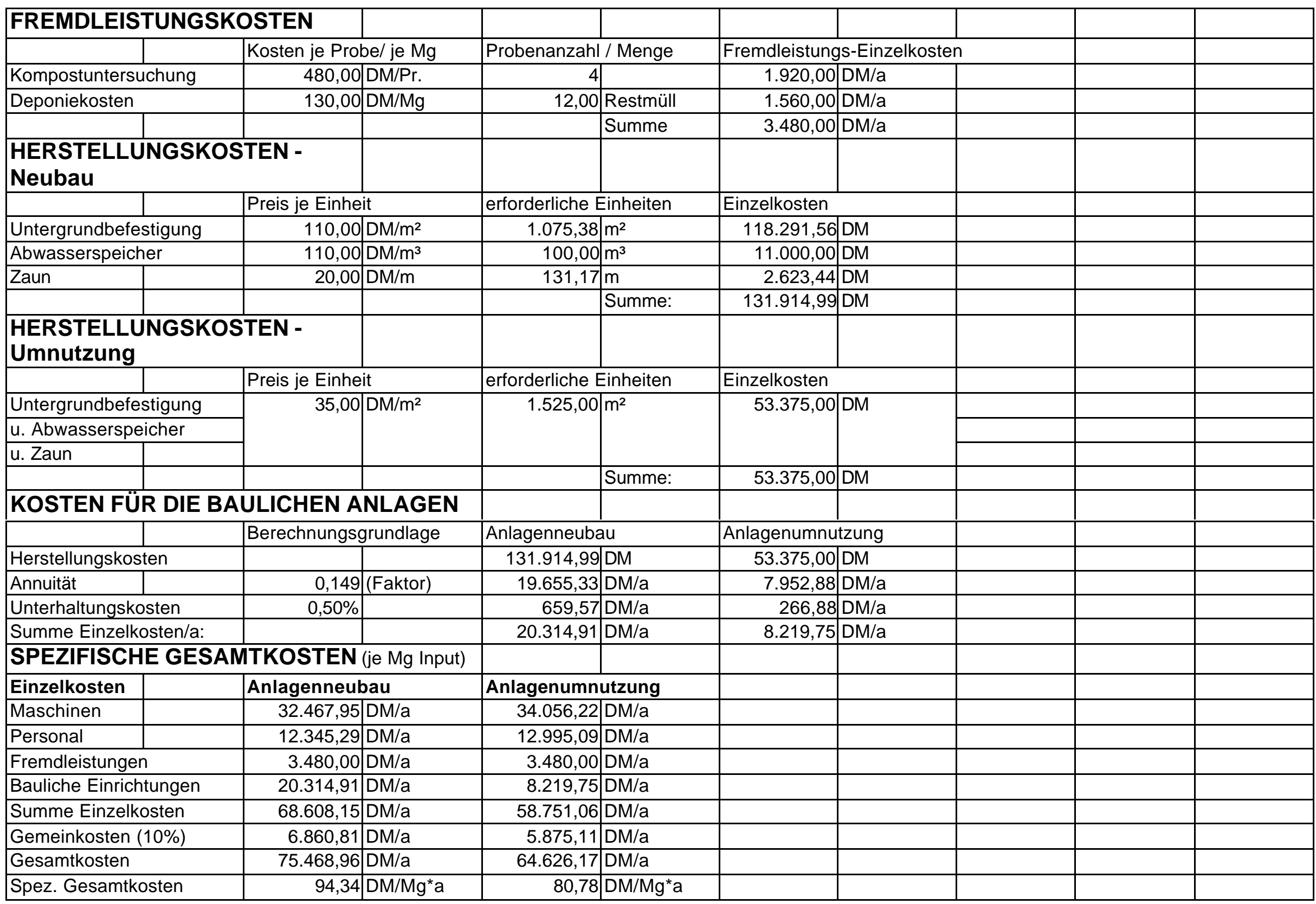


Kostenvariante D4

\section{MATERIAL}

Jahresinputmenge

Zusammensetzung

Dichte

\begin{tabular}{|l|l|}
\hline Dichte & \\
\hline & \\
\hline & \\
\hline Volumen & \\
\hline & \\
\hline & \\
\hline & \\
\hline & \\
\hline
\end{tabular}

Gewichtsanteil

\begin{tabular}{|l|l|}
\hline & \\
\hline Rottedauer & \\
\hline durchschnittliches \\
\hline \multicolumn{2}{|l|}{ Monatsaufkommen } \\
\hline \multicolumn{2}{|l|}{ maximaler Monatsanfall } \\
\hline
\end{tabular}

TS-Gehalt (Fertigkompost)

Mietenhöhe

Mietenbasisbreite

\section{ANLAGENDIMENSIONIERUNG}

\section{Anlagenteil $\quad$ Berechnungsgrundlage}

Anlieferungsfläche

Rottefläche

Rangierfläche

Zwischenlager für

Strukturmaterial

Kompostlager

Anlagenfläche (gesamt)

zu verwertende

Abwassermenge

$0,2 \mathrm{~m}^{3} / \mathrm{m}^{2 *} \mathrm{a}$

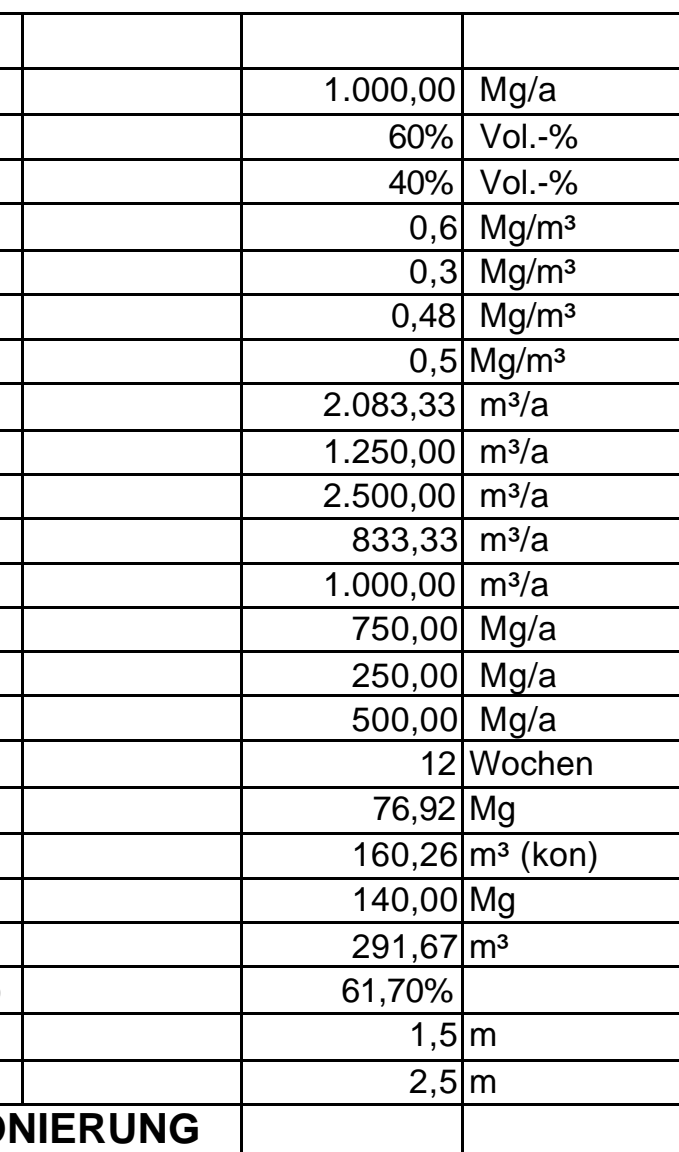

$5 \%$ vom Input in Mg/a, ausgedrückt in $\mathrm{m}^{2}$

$1,33 \mathrm{~m}^{2} / \mathrm{m}^{3}$ Rottematerial bei max.M.-Anfall

$40 \%$ der Rottefläche

der Rottefläche

$10 \%$ der Rottefläche

)

Grüngut

\begin{tabular}{|c|c|c|}
\hline ax.M.-Anfall & 808,89 & $\mathrm{~m}^{2}$ \\
\hline & 323,56 & $\mathrm{~m}^{2}$ \\
\hline & & $\mathrm{m}^{2}$ \\
\hline & 80,89 & \\
\hline & 80,89 & $\mathrm{~m}^{2}$ \\
\hline & 1344,22 & $\mathrm{~m}^{2}$ \\
\hline & & \\
\hline & 268,84 & $\mathrm{~m}^{3} / \mathrm{a}$ \\
\hline
\end{tabular}

Bioabfälle aus Haushalten

gehäckseltes Grüngut

Bioabfälle aus Haushalten

gehäckseltes Grüngut

konditioniertes Material

Fertigkompost

konditioniertes Material

Bioabfälle aus Haushalten

angeliefertes Grüngut

gehäckseltes Grüngut

Fertigkompost

Bioabfälle aus Haushalten

Fertigkompost

\begin{tabular}{l|l|l}
\hline & & \\
\hline & Rottematerial eines
\end{tabular}

entspr. 14\% vom Input/a

Mietenquerschnitt

\begin{tabular}{|r|l|l}
\hline $1,875 \mathrm{~m}^{2}$ & \\
\hline & &
\end{tabular}

Anlagenneubau

Anlagenumnutzung

$400,00 \mathrm{~m}^{2}$

\begin{tabular}{|r|l|l|}
\hline 1525,00 & & \\
\cline { 1 - 2 } & \multicolumn{2}{|l|}{$\mathrm{m}^{2}$ (nicht drainiert) } \\
\hline 600,00 & & \\
\hline 400,00 & $\mathrm{~m}^{2}$ & \\
\hline 2325,00 & $\mathrm{~m}^{2}$ & \\
\hline 465,00 & $\mathrm{~m}^{3} / \mathrm{a}$ & \\
\hline
\end{tabular}




\begin{tabular}{|c|c|c|c|c|c|c|c|c|c|c|}
\hline \multicolumn{11}{|l|}{ ZEITEN } \\
\hline \multicolumn{3}{|l|}{ Arbeitsgang } & \multicolumn{2}{|c|}{ eingesetzte Maschinen } & \multicolumn{2}{|c|}{ Zeitbedarf/Einheit } & \multicolumn{2}{|c|}{ geleistete Einheiten } & \multicolumn{2}{|c|}{ Zeitbedarf/Jahr } \\
\hline \multicolumn{3}{|c|}{ Materialannahme } & & & 4,000 & h/Woche & 52,000 & Wochen/a & 208,000 & $h / a$ \\
\hline \multicolumn{3}{|c|}{ Manuelle Störstoffauslese } & & & 1,000 & $h / 100 m^{3}(\operatorname{In})$ & $3.750,000$ & $\mathrm{~m}^{3} / \mathrm{a}$ & 37,500 & $h / a$ \\
\hline \multicolumn{3}{|c|}{ Zerkleinerung von Strukturmaterial } & \multicolumn{2}{|l|}{ TL, SZ, Schr. } & 1,000 & $h / 50 m^{3}(\ln )$ & $2.500,000$ & $\mathrm{~m}^{3} / \mathrm{a}$ & 50,000 & $h / a$ \\
\hline \multicolumn{3}{|c|}{ Aufsetzen einer Matte aus Strukturmat. } & \multicolumn{2}{|l|}{ TL, AS } & 0,300 & $\mathrm{~h} / 100 \mathrm{~m}^{3}$ (kon) & $2.083,333$ & $\mathrm{~m}^{3} / \mathrm{a}$ & 6,250 & $h / a$ \\
\hline \multicolumn{3}{|c|}{ Aufsetzen der Dreiecksmieten } & \multicolumn{2}{|l|}{ TL, AS } & 1,000 & $\mathrm{~h} / 20 \mathrm{~m}^{3}$ (kon) & $2.083,333$ & $\mathrm{~m}^{3} / \mathrm{a}$ & 104,167 & $\mathrm{~h} / \mathrm{a}$ \\
\hline \multicolumn{3}{|c|}{ Umsetzen der Dreiecksmieten } & \multicolumn{2}{|l|}{ Schl., MU } & 0,005 & $\mathrm{~h} / \mathrm{m}$ (Mietenl.) & $9.244,444$ & $\mathrm{~m} / \mathrm{a}$ & 46,222 & $h / a$ \\
\hline \multicolumn{3}{|c|}{ Reinigung der Annahmefläche } & \multicolumn{2}{|l|}{ TL, AS } & 0,500 & $h / 150 m^{3}(\ln )$ & $3.750,000$ & $\mathrm{~m}^{3} / \mathrm{a}$ & 12,500 & $h / a$ \\
\hline \multicolumn{3}{|l|}{ Sieben } & \multicolumn{2}{|l|}{ TL, AS, Sieb } & 1,000 & $\mathrm{~h} / 20 \mathrm{~m}^{3}(\mathrm{kom})$ & $1.000,000$ & $\mathrm{~m}^{3} / \mathrm{a}$ & 50,000 & $\mathrm{~h} / \mathrm{a}$ \\
\hline \multicolumn{3}{|c|}{ Abw.-Ausbringung bei Neubau } & \multicolumn{2}{|l|}{ Schl.,PT } & 1,000 & $\mathrm{~h} / 10 \mathrm{~m}^{3}(\mathrm{Abw})$ & 268,844 & $\mathrm{~m}^{3} / \mathrm{a}$ & 26,884 & $h / a$ \\
\hline \multicolumn{3}{|c|}{ Abw.-Ausbringung bei Umnutzung } & \multicolumn{2}{|l|}{ Schl., PT } & 1,000 & $\mathrm{~h} / 10 \mathrm{~m}^{3}(\mathrm{Abw})$ & 465,000 & $\mathrm{~m}^{3} / \mathrm{a}$ & 46,500 & $h / a$ \\
\hline \multicolumn{11}{|c|}{ Abkürzungen für die eingesetzten Maschinen: } \\
\hline \multicolumn{3}{|c|}{\begin{tabular}{|l|l|} 
TL - Teleskoplader & \\
\end{tabular}} & Schl. - Schlepp & per & & & & & & \\
\hline MU- Mietenum & etzer & & Schr. - Schred & dder & & & & & & \\
\hline SZ - Silozange & & & PT - Pumpenta & tankwagen & & & & & & \\
\hline AS - Anbausc & aufel & & & & & & & & & \\
\hline MASCHINE & NKOSTEN & & & & & & & & & \\
\hline Maschine / G & & Fixkosten & & Variable Kost & ten & Einheiten/a & & Maschinen-Ei & inzelkosten & \\
\hline Traktor (Neub & & 0,00 & $D M / a$ & 33,55 & $D M / h$ & 73,11 & $\mathrm{~h} / \mathrm{a}$ & $2.452,73$ & $\mathrm{DM} / \mathrm{a}$ & \\
\hline Traktor (Umnu & zung) & 0,00 & $\mathrm{DM} / \mathrm{a}$ & 33,55 & $D M / h$ & 92,72 & $h / a$ & $3.110,83$ & $\mathrm{DM} / \mathrm{a}$ & \\
\hline Teleskoplader & & 0,00 & $D M / a$ & 66,50 & $\mathrm{DM} / \mathrm{h}$ & 222,92 & $h / a$ & $14.823,96$ & $\mathrm{DM} / \mathrm{a}$ & \\
\hline Schredder & & 0,00 & DM/a & 7,50 & $\mathrm{DM} / \mathrm{m}^{3}$ (Out) & 833,33 & $\mathrm{~m}^{3} / \mathrm{a}$ & $6.250,00$ & $\mathrm{DM} / \mathrm{a}$ & \\
\hline Trommelsieb & & 0,00 & $D M / a$ & 5,00 & $\mathrm{DM} / \mathrm{m}^{3}(\mathrm{Kom})$ & $1.000,00$ & $m^{3} / a$ & $5.000,00$ & $\mathrm{DM} / \mathrm{a}$ & \\
\hline PumpenTW ( & abau) & 0,00 & $\mathrm{DM} / \mathrm{a}$ & 30,00 & $\mathrm{DM} / \mathrm{h}$ & 26,88 & $\mathrm{~h} / \mathrm{a}$ & 806,53 & $\mathrm{DM} / \mathrm{a}$ & \\
\hline PumpenTW (L & nnutzung) & 0,00 & $D M / a$ & 30,00 & $D M / h$ & 46,50 & $h / a$ & $1.395,00$ & $\mathrm{DM} / \mathrm{a}$ & \\
\hline Silozange & & $1.120,00$ & DM/a & 0,30 & $\mathrm{DM} / \mathrm{m}^{3}$ & $2.500,00$ & $\mathrm{~m}^{3} / \mathrm{a}$ & $1.870,00$ & $\mathrm{DM} / \mathrm{a}$ & \\
\hline Anbauschaufe & & 506,00 & $\mathrm{DM} / \mathrm{a}$ & 0,30 & $\mathrm{DM} / \mathrm{m}^{3}$ & $8.916,67$ & $\mathrm{~m}^{3} / \mathrm{a}$ & $3.181,00$ & $\mathrm{DM} / \mathrm{a}$ & \\
\hline Mietenumsetz & & $3.600,00$ & $\mathrm{DM} / \mathrm{a}$ & 28,00 & $\mathrm{DM} / \mathrm{h}$ & 46,22 & $h / a$ & $4.894,22$ & $\mathrm{DM} / \mathrm{a}$ & \\
\hline & & & & & & Summe (Neuk & bau) & $39.278,44$ & $\mathrm{DM} / \mathrm{a}$ & \\
\hline & & & & & & Summe (Umn & hutzung) & $40.525,01$ & $\mathrm{DM} / \mathrm{a}$ & \\
\hline PERSONA & KOSTEN & & & & & & & & & \\
\hline & Std.-Lohn in & kl.Lohn-NK & Arbeitsstd. pro & o Jahr & Personal-Einz & zelkosten & & & & \\
\hline Neubau & 26,00 & $\mathrm{DM} / \mathrm{h}$ & 541,52 & $\mathrm{~h} / \mathrm{a}$ & $14.079,61$ & $\mathrm{DM} / \mathrm{a}$ & & & & \\
\hline Umnutzung & 26,00 & DM/h & 561,14 & $h / a$ & $14.589,61$ & $\mathrm{DM} / \mathrm{a}$ & & & & \\
\hline
\end{tabular}




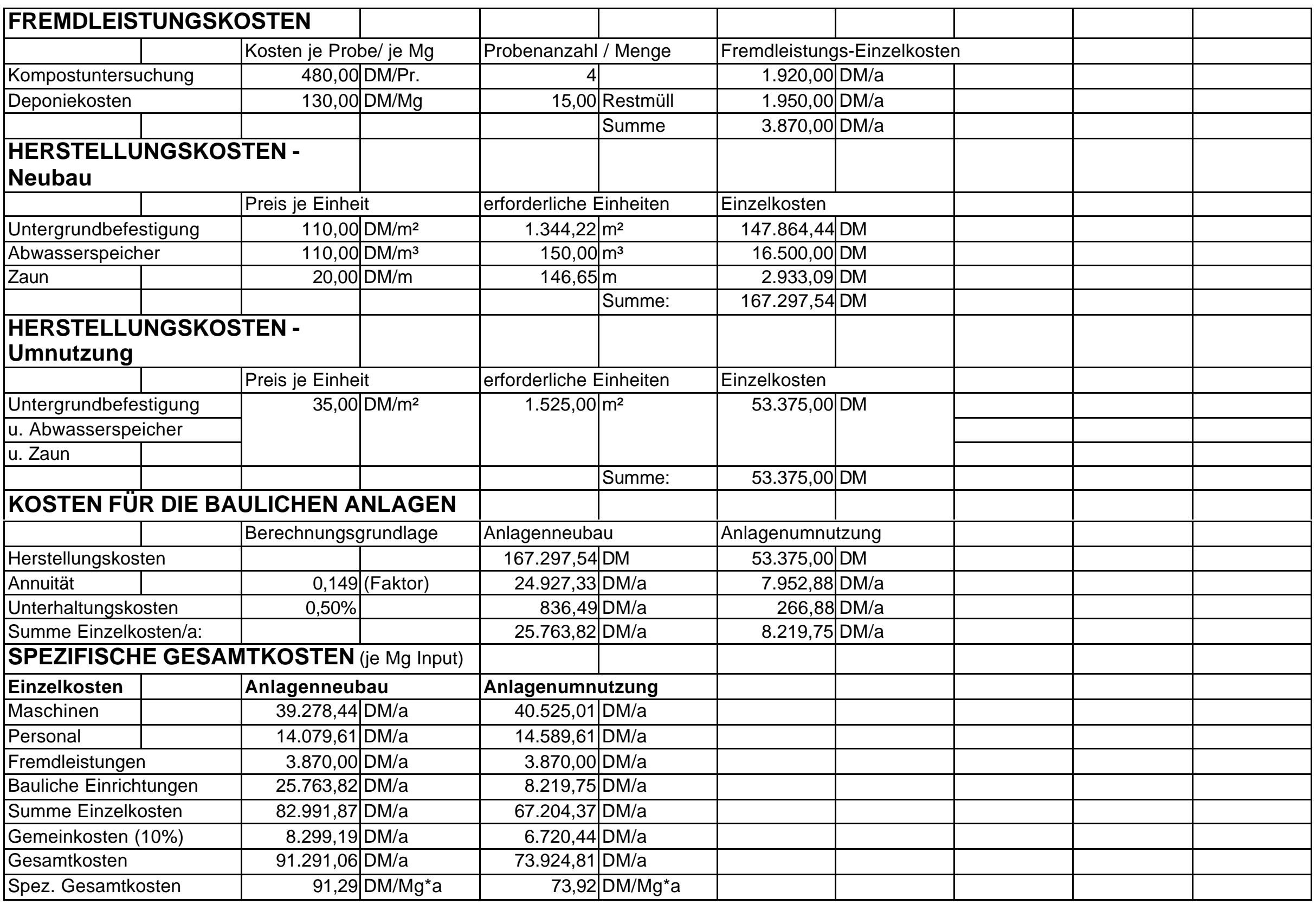


Kostenvariante D5

\section{MATERIAL}

Jahresinputmenge

Zusammensetzung

Dichte

\begin{tabular}{|l|l|}
\hline Dichte & \\
\hline & \\
\hline & \\
\hline Volumen & \\
\hline & \\
\hline & \\
\hline & \\
\hline & \\
\hline
\end{tabular}

Gewichtsanteil

\begin{tabular}{|l|l|}
\hline & \\
\hline & \\
\hline Rottedauer & \\
\hline durchschnittliches \\
\hline Monatsaufkommen \\
\hline maximaler Monatsanfall \\
\hline & \\
\hline
\end{tabular}

TS-Gehalt (Fertigkompost)

Mietenhöhe

Mietenbasisbreite

\section{ANLAGENDIMENSIONIERUNG}

\section{Anlagenteil $\quad$ Berechnungsgrundlage}

Anlieferungsfläche

Rottefläche

Rangierfläche

Zwischenlager für

Strukturmaterial

Kompostlager

Anlagenfläche (gesamt)

zu verwertende

Abwassermenge

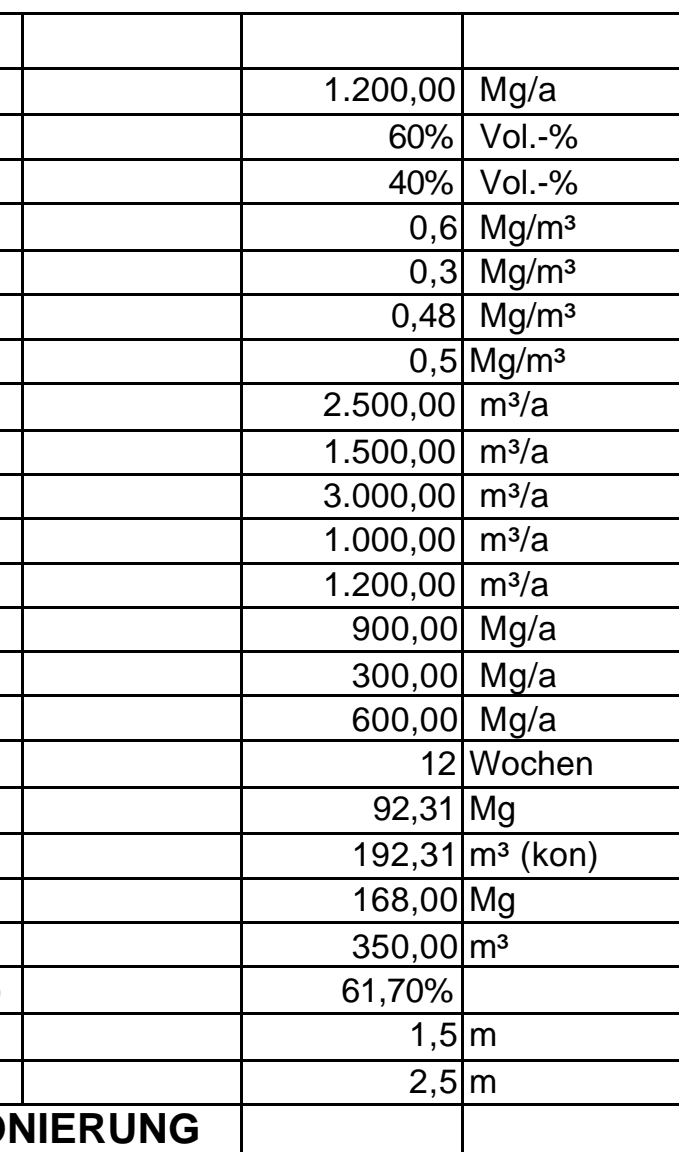

$5 \%$ vom Input in Mg/a, ausgedrückt in $\mathrm{m}^{2}$

$1,33 \mathrm{~m}^{2} / \mathrm{m}^{3}$ Rottematerial bei max.M.-Anfall

$40 \%$ der Rottefläche

der Rottefläche

$10 \%$ der Rottefläche

\section{|}

+

$0,2 \mathrm{~m}^{3} / \mathrm{m}^{2 \star} \mathrm{a}$

Grüngut

\begin{tabular}{|c|c|c|}
\hline ax.M.-Anfall & 970,67 & $\mathrm{~m}^{2}$ \\
\hline & 388,27 & $\mathrm{~m}^{2}$ \\
\hline & & $\mathrm{m}^{2}$ \\
\hline & 97,07 & \\
\hline & 97,07 & $\mathrm{~m}^{2}$ \\
\hline & 1613,07 & $\mathrm{~m}^{2}$ \\
\hline & 322,61 & $\mathrm{~m}^{3} / \mathrm{a}$ \\
\hline
\end{tabular}

Bioabfälle aus Haushalten

gehäckseltes Grüngut

Bioabfälle aus Haushalten

gehäckseltes Grüngut

konditioniertes Material

Fertigkompost

konditioniertes Material

Bioabfälle aus Haushalten

angeliefertes Grüngut

gehäckseltes Grüngut

Fertigkompost

Bioabfälle aus Haushalten

Fertigkompost

\begin{tabular}{l|l|l}
\hline & & \\
\hline & Rottematerial eines
\end{tabular}

entspr. 14\% vom Input/a

Mietenquerschnitt

\begin{tabular}{|r|l|l}
\hline $1,875 \mathrm{~m}^{2}$ & \\
& &
\end{tabular}

Anlagenneubau

Anlagenumnutzung

$400,00 \mathrm{~m}^{2}$

\begin{tabular}{|r|l|l|}
\hline & $\mathrm{m}^{2}$ & \\
& 1525,00 & \multicolumn{2}{|l|}{$\mathrm{m}^{2}$ (nicht drainiert) } \\
\hline 600,00 & & \\
\hline 400,00 & $\mathrm{~m}^{2}$ & \\
\hline 2325,00 & $\mathrm{~m}^{2}$ & \\
\hline & & \\
\hline 465,00 & $\mathrm{~m}^{3} / \mathrm{a}$ & \\
\hline
\end{tabular}




\begin{tabular}{|c|c|c|c|c|c|c|c|c|c|c|}
\hline \multicolumn{11}{|l|}{ ZEITEN } \\
\hline \multicolumn{3}{|l|}{ Arbeitsgang } & \multicolumn{2}{|c|}{ eingesetzte Maschinen } & \multicolumn{2}{|c|}{ Zeitbedarf/Einheit } & \multicolumn{2}{|c|}{ geleistete Einheiten } & \multicolumn{2}{|c|}{ Zeitbedarf/Jahr } \\
\hline \multicolumn{3}{|c|}{ Materialannahme } & & & 4,000 & h/Woche & 52,000 & Wochen/a & 208,000 & $h / a$ \\
\hline \multicolumn{3}{|c|}{ Manuelle Störstoffauslese } & & & 1,000 & $h / 100 m^{3}(\operatorname{In})$ & $4.500,000$ & $\mathrm{~m}^{3} / \mathrm{a}$ & 45,000 & $h / a$ \\
\hline \multicolumn{3}{|c|}{ Zerkleinerung von Strukturmaterial } & \multicolumn{2}{|l|}{ TL, SZ, Schr. } & 1,000 & $h / 50 m^{3}(\ln )$ & $3.000,000$ & $\mathrm{~m}^{3} / \mathrm{a}$ & 60,000 & $h / a$ \\
\hline \multicolumn{3}{|c|}{ Aufsetzen einer Matte aus Strukturmat. } & \multicolumn{2}{|l|}{$\mathrm{TL}, \mathrm{AS}$} & 0,300 & $\mathrm{~h} / 100 \mathrm{~m}^{3}$ (kon) & $2.500,000$ & $\mathrm{~m}^{3} / \mathrm{a}$ & 7,500 & $h / a$ \\
\hline \multicolumn{3}{|c|}{ Aufsetzen der Dreiecksmieten } & \multicolumn{2}{|l|}{ TL, AS } & 1,000 & $\mathrm{~h} / 20 \mathrm{~m}^{3}$ (kon) & $2.500,000$ & $\mathrm{~m}^{3} / \mathrm{a}$ & 125,000 & $h / a$ \\
\hline \multicolumn{3}{|c|}{ Umsetzen der Dreiecksmieten } & \multicolumn{2}{|l|}{ Schl., MU } & 0,005 & $\mathrm{~h} / \mathrm{m}$ (Mietenl.) & $11.093,333$ & $\mathrm{~m} / \mathrm{a}$ & 55,467 & $\mathrm{~h} / \mathrm{a}$ \\
\hline \multicolumn{3}{|c|}{ Reinigung der Annahmefläche } & \multicolumn{2}{|l|}{ TL, AS } & 0,500 & $h / 150 m^{3}(\ln )$ & $4.500,000$ & $\mathrm{~m}^{3} / \mathrm{a}$ & 15,000 & $h / a$ \\
\hline \multicolumn{3}{|l|}{ Sieben } & \multicolumn{2}{|l|}{ TL, AS, Sieb } & 1,000 & $\mathrm{~h} / 20 \mathrm{~m}^{3}(\mathrm{kom})$ & $1.200,000$ & $\mathrm{~m}^{3} / \mathrm{a}$ & 60,000 & $\mathrm{~h} / \mathrm{a}$ \\
\hline \multicolumn{3}{|c|}{ Abw.-Ausbringung bei Neubau } & \multicolumn{2}{|l|}{ Schl.,PT } & 1,000 & $\mathrm{~h} / 10 \mathrm{~m}^{3}(\mathrm{Abw})$ & 322,613 & $\mathrm{~m}^{3} / \mathrm{a}$ & 32,261 & $\mathrm{~h} / \mathrm{a}$ \\
\hline \multicolumn{3}{|c|}{ Abw.-Ausbringung bei Umnutzung } & \multicolumn{2}{|l|}{ Schl., PT } & 1,000 & $\mathrm{~h} / 10 \mathrm{~m}^{3}(\mathrm{Abw})$ & 465,000 & $\mathrm{~m}^{3} / \mathrm{a}$ & 46,500 & $h / a$ \\
\hline \multicolumn{11}{|c|}{ Abkürzungen für die eingesetzten Maschinen: } \\
\hline \multicolumn{3}{|c|}{\begin{tabular}{|l|l|} 
TL - Teleskoplader & \\
\end{tabular}} & Schl. - Schlepp & per & & & & & & \\
\hline MU- Mietenum & etzer & & Schr. - Schred & dder & & & & & & \\
\hline SZ - Silozange & & & PT - Pumpenta & tankwagen & & & & & & \\
\hline AS - Anbausc & aufel & & & & & & & & & \\
\hline MASCHINE & NKOSTEN & & & & & & & & & \\
\hline Maschine / G & & Fixkosten & & Variable Kost & ten & Einheiten/a & & Maschinen-Ei & inzelkosten & \\
\hline Traktor (Neub & & 0,00 & $D M / a$ & 33,55 & $D M / h$ & 87,73 & $\mathrm{~h} / \mathrm{a}$ & $2.943,27$ & $\mathrm{DM} / \mathrm{a}$ & \\
\hline Traktor (Umnu & zung) & 0,00 & $\mathrm{DM} / \mathrm{a}$ & 33,55 & $D M / h$ & 101,97 & $\mathrm{~h} / \mathrm{a}$ & $3.420,98$ & $\mathrm{DM} / \mathrm{a}$ & \\
\hline Teleskoplader & & 0,00 & $D M / a$ & 66,50 & $\mathrm{DM} / \mathrm{h}$ & 267,50 & $h / a$ & $17.788,75$ & $\mathrm{DM} / \mathrm{a}$ & \\
\hline Schredder & & 0,00 & DM/a & 7,50 & $\mathrm{DM} / \mathrm{m}^{3}$ (Out) & $1.000,00$ & $\mathrm{~m}^{3} / \mathrm{a}$ & $7.500,00$ & $\mathrm{DM} / \mathrm{a}$ & \\
\hline Trommelsieb & & 0,00 & $D M / a$ & 5,00 & $\mathrm{DM} / \mathrm{m}^{3}(\mathrm{Kom})$ & $1.200,00$ & $m^{3} / a$ & $6.000,00$ & $\mathrm{DM} / \mathrm{a}$ & \\
\hline PumpenTW ( & abau) & 0,00 & $\mathrm{DM} / \mathrm{a}$ & 30,00 & $\mathrm{DM} / \mathrm{h}$ & 32,26 & $h / a$ & 967,84 & $\mathrm{DM} / \mathrm{a}$ & \\
\hline PumpenTW (L & nnutzung) & 0,00 & $D M / a$ & 30,00 & $D M / h$ & 46,50 & $h / a$ & $1.395,00$ & $\mathrm{DM} / \mathrm{a}$ & \\
\hline Silozange & & $1.120,00$ & DM/a & 0,30 & $\mathrm{DM} / \mathrm{m}^{3}$ & $3.000,00$ & $\mathrm{~m}^{3} / \mathrm{a}$ & $2.020,00$ & $\mathrm{DM} / \mathrm{a}$ & \\
\hline Anbauschaufe & & 506,00 & $\mathrm{DM} / \mathrm{a}$ & 0,30 & $\mathrm{DM} / \mathrm{m}^{3}$ & $10.700,00$ & $m^{3} / a$ & $3.716,00$ & $\mathrm{DM} / \mathrm{a}$ & \\
\hline Mietenumsetz & & $3.600,00$ & $\mathrm{DM} / \mathrm{a}$ & 28,00 & $\mathrm{DM} / \mathrm{h}$ & 55,47 & $\mathrm{~h} / \mathrm{a}$ & $5.153,07$ & $\mathrm{DM} / \mathrm{a}$ & \\
\hline & & & & & & Summe (Neuk & bau) & $46.088,93$ & $\mathrm{DM} / \mathrm{a}$ & \\
\hline & & & & & & Summe (Umn & hutzung) & $46.993,80$ & $\mathrm{DM} / \mathrm{a}$ & \\
\hline PERSONA & KOSTEN & & & & & & & & & \\
\hline & Std.-Lohn in & kl.Lohn-NK & Arbeitsstd. pro & o Jahr & Personal-Einz & zelkosten & & & & \\
\hline Neubau & 26,00 & $\mathrm{DM} / \mathrm{h}$ & 608,23 & $\mathrm{~h} / \mathrm{a}$ & $15.813,93$ & $D M / a$ & & & & \\
\hline Umnutzung & 26,00 & DM/h & 622,47 & $h / a$ & $16.184,13$ & DM/a & & & & \\
\hline
\end{tabular}




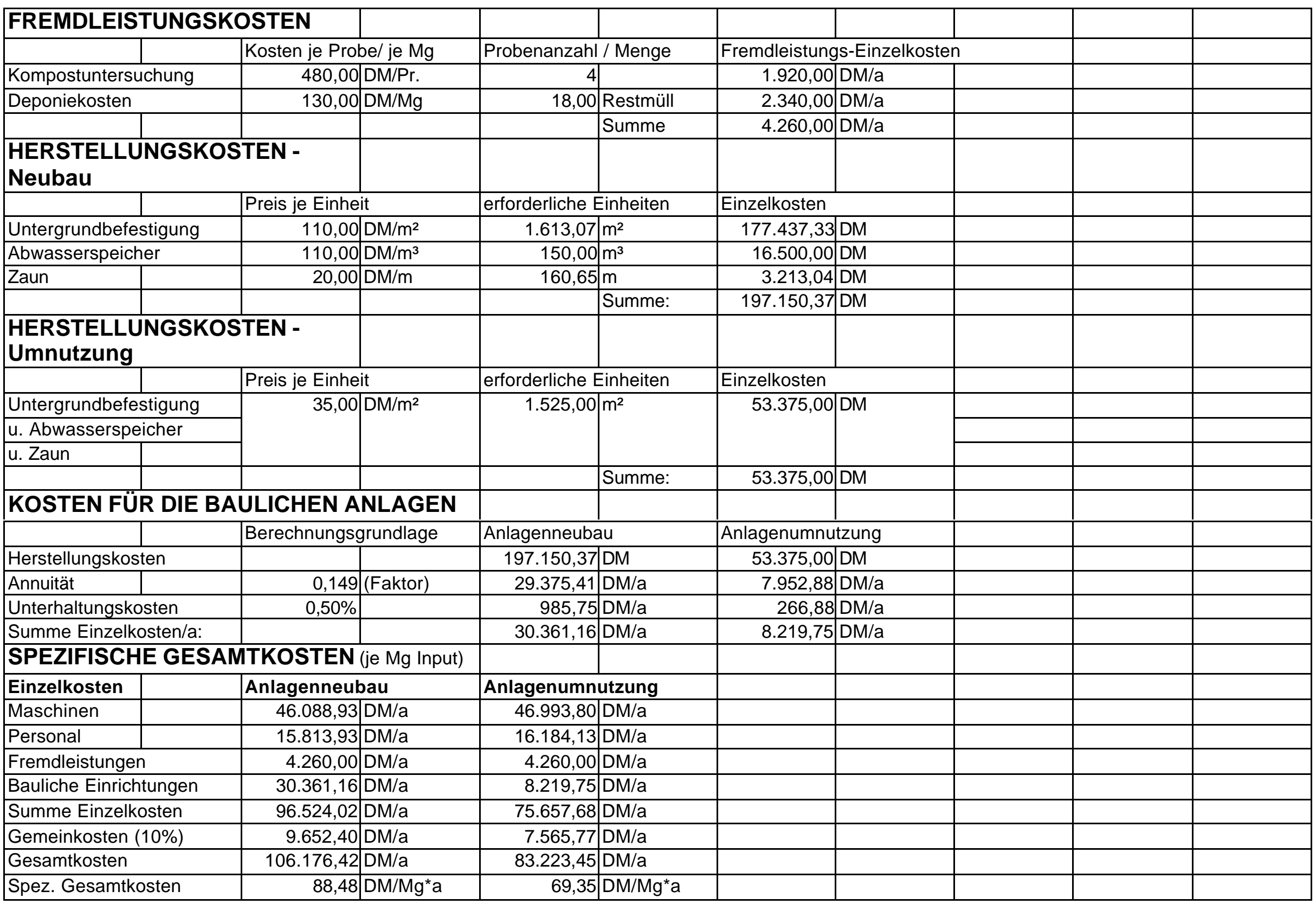


Kostenvariante D6

\section{MATERIAL}

Jahresinputmenge

Zusammensetzung

Dichte

\begin{tabular}{|l|l|}
\hline Dichte & \\
\hline & \\
\hline & \\
\hline Volumen & \\
\hline & \\
\hline & \\
\hline & \\
\hline & \\
\hline
\end{tabular}

Gewichtsanteil

\begin{tabular}{|l|l|}
\hline & \\
\hline & \\
\hline Rottedauer & \\
\hline durchschnittliches \\
\hline Monatsaufkommen \\
\hline maximaler Monatsanfall \\
\hline & \\
\hline
\end{tabular}

TS-Gehalt (Fertigkompost)

Mietenhöhe

Mietenbasisbreite

\section{ANLAGENDIMENSIONIERUNG}

\section{\begin{tabular}{l|l} 
Anlagenteil & Berechnungsgrundlage
\end{tabular}}

Anlieferungsfläche

Rottefläche

Rangierfläche

Zwischenlager für

Strukturmaterial

Kompostlager

Anlagenfläche (gesamt)

zu verwertende

Abwassermenge

$10 \%$

\section{(2)}

+

$0,2 \mathrm{~m}^{3} / \mathrm{m}^{2 *} \mathrm{a}$

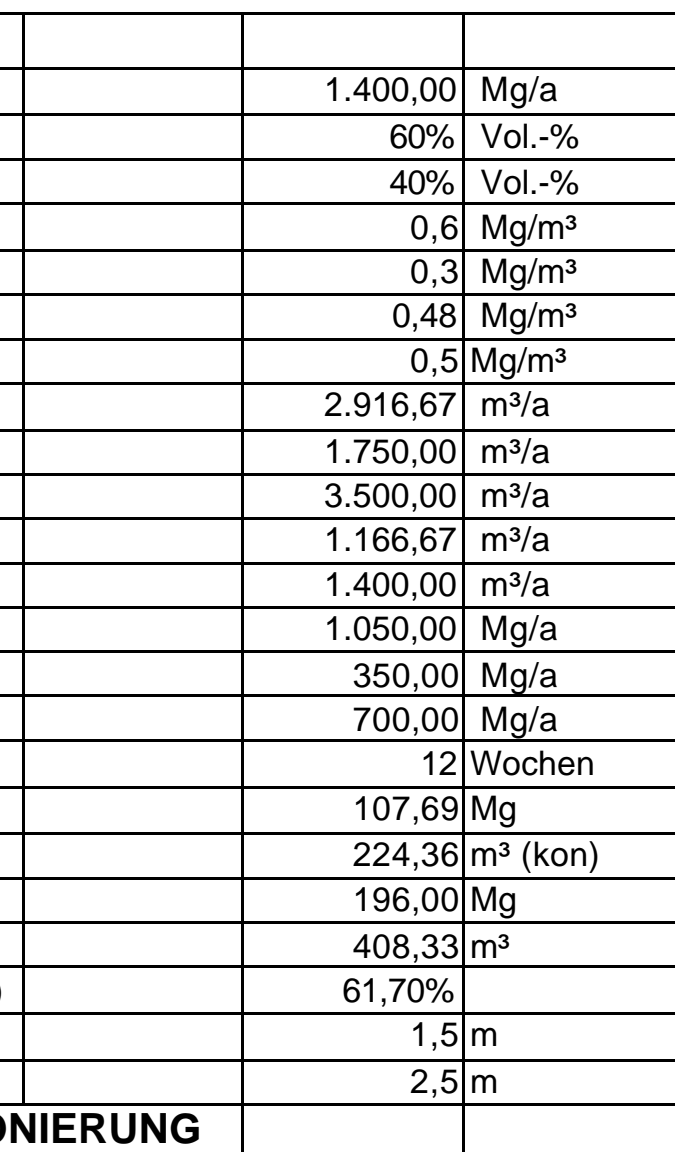

$5 \%$ vom Input in Mg/a, ausgedrückt in $\mathrm{m}^{2}$

$1,33 \mathrm{~m}^{2} / \mathrm{m}^{3}$ Rottematerial bei max.M.-Anfall

$40 \%$ der Rottefläche

der Rottefläche

$10 \%$ der Rottefläche

Grüngut

\begin{tabular}{|c|c|c|}
\hline ax.M.-Anfall & 1132,44 & $\mathrm{~m}^{2}$ \\
\hline & 452,98 & $\mathrm{~m}^{2}$ \\
\hline & & $m^{2}$ \\
\hline & 113,24 & \\
\hline & 113,24 & $\mathrm{~m}^{2}$ \\
\hline & 1881,91 & $\mathrm{~m}^{2}$ \\
\hline & & \\
\hline & 376,38 & $\mathrm{~m}^{3} / \mathrm{a}$ \\
\hline
\end{tabular}

Bioabfälle aus Haushalten

gehäckseltes Grüngut

Bioabfälle aus Haushalten

gehäckseltes Grüngut

konditioniertes Material

Fertigkompost

konditioniertes Material

Bioabfälle aus Haushalten

angeliefertes Grüngut

gehäckseltes Grüngut

Fertigkompost

Bioabfälle aus Haushalten

Fertigkompost

\begin{tabular}{l|l} 
& \\
\hline & Rottematerial eines
\end{tabular}

entspr. 14\% vom Input/a

Mietenquerschnitt

\begin{tabular}{|r|l}
\hline $1,875 \mathrm{~m}^{2}$ & \\
\hline &
\end{tabular}

Anlagenneubau

Anlagenumnutzung

$400,00 \mathrm{~m}^{2}$

\begin{tabular}{|r|l|l|}
\hline 1525,00 & & \\
\cline { 1 - 2 } & \multicolumn{2}{|l|}{$\mathrm{m}^{2}$ (nicht drainiert) } \\
\hline 600,00 & & \\
\hline 400,00 & $\mathrm{~m}^{2}$ & \\
\hline 2325,00 & $\mathrm{~m}^{2}$ & \\
\hline 465,00 & $\mathrm{~m}^{3} / \mathrm{a}$ & \\
\hline
\end{tabular}




\begin{tabular}{|c|c|c|c|c|c|c|c|c|c|c|}
\hline \multicolumn{11}{|l|}{ ZEITEN } \\
\hline \multicolumn{3}{|l|}{ Arbeitsgang } & \multicolumn{2}{|c|}{ eingesetzte Maschinen } & \multicolumn{2}{|c|}{ Zeitbedarf/Einheit } & \multicolumn{2}{|c|}{ geleistete Einheiten } & \multicolumn{2}{|c|}{ Zeitbedarf/Jahr } \\
\hline \multicolumn{3}{|c|}{ Materialannahme } & & & 4,000 & h/Woche & 52,000 & Wochen/a & 208,000 & $h / a$ \\
\hline \multicolumn{3}{|c|}{ Manuelle Störstoffauslese } & & & 1,000 & $h / 100 m^{3}(\operatorname{In})$ & $5.250,000$ & $\mathrm{~m}^{3} / \mathrm{a}$ & 52,500 & $h / a$ \\
\hline \multicolumn{3}{|c|}{ Zerkleinerung von Strukturmaterial } & \multicolumn{2}{|l|}{ TL, SZ, Schr. } & 1,000 & $h / 50 m^{3}(\ln )$ & $3.500,000$ & $\mathrm{~m}^{3} / \mathrm{a}$ & 70,000 & $h / a$ \\
\hline \multicolumn{3}{|c|}{ Aufsetzen einer Matte aus Strukturmat. } & \multicolumn{2}{|l|}{$\mathrm{TL}, \mathrm{AS}$} & 0,300 & $\mathrm{~h} / 100 \mathrm{~m}^{3}$ (kon) & $2.916,667$ & $\mathrm{~m}^{3} / \mathrm{a}$ & 8,750 & $h / a$ \\
\hline \multicolumn{3}{|c|}{ Aufsetzen der Dreiecksmieten } & \multicolumn{2}{|l|}{ TL, AS } & 1,000 & $\mathrm{~h} / 20 \mathrm{~m}^{3}$ (kon) & $2.916,667$ & $\mathrm{~m}^{3} / \mathrm{a}$ & 145,833 & $\mathrm{~h} / \mathrm{a}$ \\
\hline \multicolumn{3}{|c|}{ Umsetzen der Dreiecksmieten } & \multicolumn{2}{|l|}{ Schl., MU } & 0,005 & $\mathrm{~h} / \mathrm{m}$ (Mietenl.) & $12.942,222$ & $\mathrm{~m} / \mathrm{a}$ & 64,711 & $\mathrm{~h} / \mathrm{a}$ \\
\hline \multicolumn{3}{|c|}{ Reinigung der Annahmefläche } & \multicolumn{2}{|l|}{ TL, AS } & 0,500 & $h / 150 m^{3}(\ln )$ & $5.250,000$ & $\mathrm{~m}^{3} / \mathrm{a}$ & 17,500 & $h / a$ \\
\hline \multicolumn{3}{|l|}{ Sieben } & \multicolumn{2}{|l|}{ TL, AS, Sieb } & 1,000 & $\mathrm{~h} / 20 \mathrm{~m}^{3}(\mathrm{kom})$ & $1.400,000$ & $\mathrm{~m}^{3} / \mathrm{a}$ & 70,000 & $\mathrm{~h} / \mathrm{a}$ \\
\hline \multicolumn{3}{|c|}{ Abw.-Ausbringung bei Neubau } & \multicolumn{2}{|l|}{ Schl.,PT } & 1,000 & $\mathrm{~h} / 10 \mathrm{~m}^{3}(\mathrm{Abw})$ & 376,382 & $\mathrm{~m}^{3} / \mathrm{a}$ & 37,638 & $\mathrm{~h} / \mathrm{a}$ \\
\hline \multicolumn{3}{|c|}{ Abw.-Ausbringung bei Umnutzung } & \multicolumn{2}{|l|}{ Schl., PT } & 1,000 & $\mathrm{~h} / 10 \mathrm{~m}^{3}(\mathrm{Abw})$ & 465,000 & $\mathrm{~m}^{3} / \mathrm{a}$ & 46,500 & $h / a$ \\
\hline \multicolumn{11}{|c|}{ Abkürzungen für die eingesetzten Maschinen: } \\
\hline \multicolumn{3}{|c|}{\begin{tabular}{|l|l|} 
TL - Teleskoplader & \\
\end{tabular}} & Schl. - Schlepp & per & & & & & & \\
\hline MU- Mietenum & etzer & & Schr. - Schred & dder & & & & & & \\
\hline SZ - Silozange & & & PT - Pumpenta & tankwagen & & & & & & \\
\hline AS - Anbausc & aufel & & & & & & & & & \\
\hline MASCHINE & NKOSTEN & & & & & & & & & \\
\hline Maschine / G & & Fixkosten & & Variable Kost & ten & Einheiten/a & & Maschinen-Ei & inzelkosten & \\
\hline Traktor (Neub & & 0,00 & $D M / a$ & 33,55 & $D M / h$ & 102,35 & $h / a$ & $3.433,82$ & $\mathrm{DM} / \mathrm{a}$ & \\
\hline Traktor (Umnu & zung) & 0,00 & $\mathrm{DM} / \mathrm{a}$ & 33,55 & $D M / h$ & 111,21 & $\mathrm{~h} / \mathrm{a}$ & $3.731,13$ & $\mathrm{DM} / \mathrm{a}$ & \\
\hline Teleskoplader & & 0,00 & $D M / a$ & 66,50 & $\mathrm{DM} / \mathrm{h}$ & 312,08 & $\mathrm{~h} / \mathrm{a}$ & $20.753,54$ & $\mathrm{DM} / \mathrm{a}$ & \\
\hline Schredder & & 0,00 & DM/a & 7,50 & $\mathrm{DM} / \mathrm{m}^{3}$ (Out) & $1.166,67$ & $\mathrm{~m}^{3} / \mathrm{a}$ & $8.750,00$ & $\mathrm{DM} / \mathrm{a}$ & \\
\hline Trommelsieb & & 0,00 & $D M / a$ & 5,00 & $\mathrm{DM} / \mathrm{m}^{3}(\mathrm{Kom})$ & $1.400,00$ & $m^{3} / a$ & $7.000,00$ & $\mathrm{DM} / \mathrm{a}$ & \\
\hline PumpenTW ( & abau) & 0,00 & $\mathrm{DM} / \mathrm{a}$ & 30,00 & $\mathrm{DM} / \mathrm{h}$ & 37,64 & $\mathrm{~h} / \mathrm{a}$ & $1.129,15$ & $\mathrm{DM} / \mathrm{a}$ & \\
\hline PumpenTW (L & nnutzung) & 0,00 & $D M / a$ & 30,00 & $D M / h$ & 46,50 & $h / a$ & $1.395,00$ & $\mathrm{DM} / \mathrm{a}$ & \\
\hline Silozange & & $1.120,00$ & DM/a & 0,30 & $\mathrm{DM} / \mathrm{m}^{3}$ & $3.500,00$ & $\mathrm{~m}^{3} / \mathrm{a}$ & $2.170,00$ & $\mathrm{DM} / \mathrm{a}$ & \\
\hline Anbauschaufe & & 506,00 & $\mathrm{DM} / \mathrm{a}$ & 0,30 & $\mathrm{DM} / \mathrm{m}^{3}$ & $12.483,33$ & $\mathrm{~m}^{3} / \mathrm{a}$ & $4.251,00$ & $\mathrm{DM} / \mathrm{a}$ & \\
\hline Mietenumsetz & & $3.600,00$ & $\mathrm{DM} / \mathrm{a}$ & 28,00 & $\mathrm{DM} / \mathrm{h}$ & 64,71 & $\mathrm{~h} / \mathrm{a}$ & $5.411,91$ & $\mathrm{DM} / \mathrm{a}$ & \\
\hline & & & & & & Summe (Neuk & bau) & $52.899,42$ & $\mathrm{DM} / \mathrm{a}$ & \\
\hline & & & & & & Summe (Umn & hutzung) & $53.462,59$ & $\mathrm{DM} / \mathrm{a}$ & \\
\hline PERSONA & KOSTEN & & & & & & & & & \\
\hline & Std.-Lohn in & kl.Lohn-NK & Arbeitsstd. pro & o Jahr & Personal-Einz & zelkosten & & & & \\
\hline Neubau & 26,00 & $\mathrm{DM} / \mathrm{h}$ & 674,93 & $\mathrm{~h} / \mathrm{a}$ & $17.548,25$ & $D M / a$ & & & & \\
\hline Umnutzung & 26,00 & DM/h & 683,79 & $h / a$ & $17.778,66$ & $D M / a$ & & & & \\
\hline
\end{tabular}




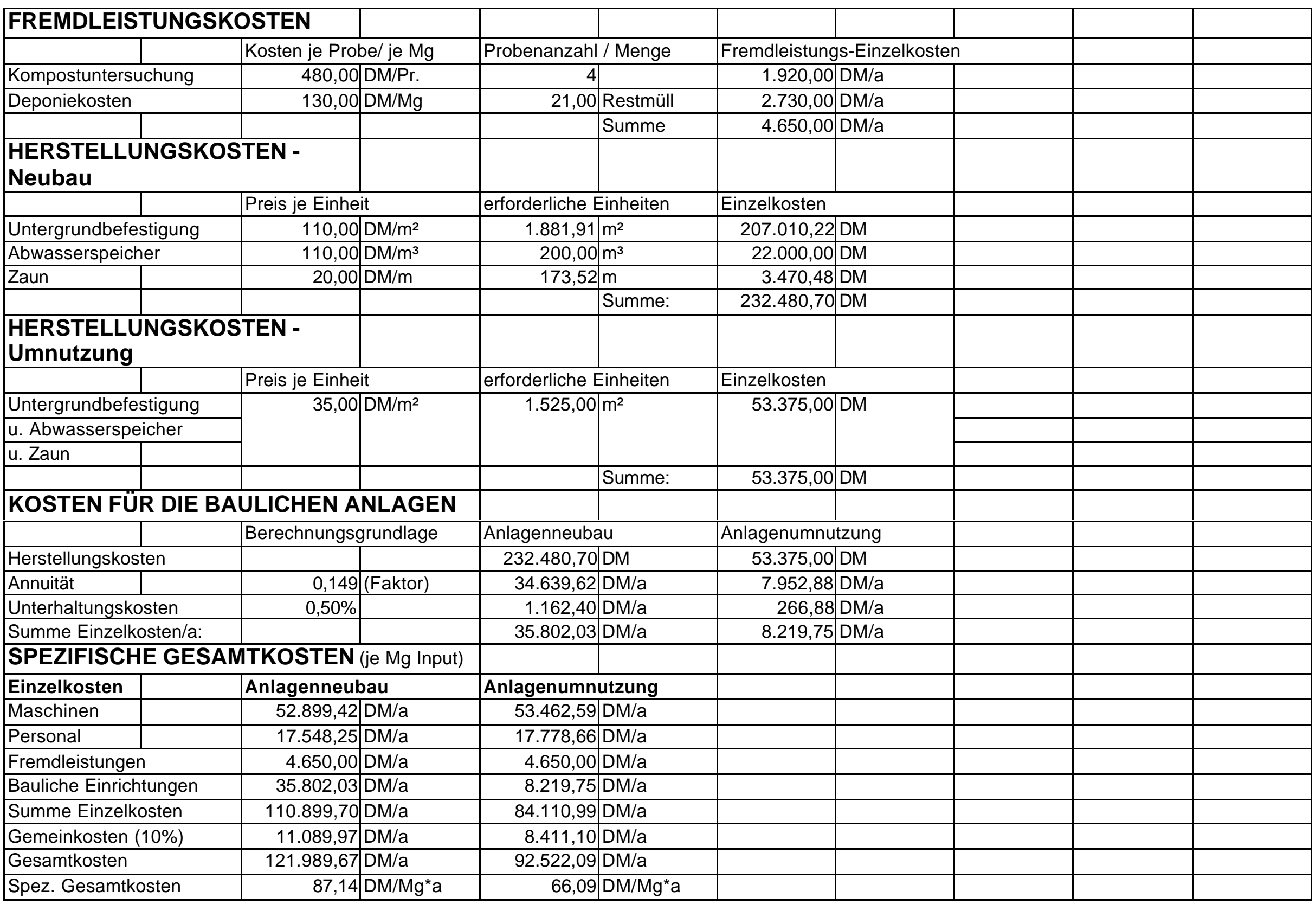


Kostenvariante D7

\section{MATERIAL}

Jahresinputmenge

Zusammensetzung

Dichte

\begin{tabular}{|l|l}
\hline Dichte & \\
\hline & \\
\hline & \\
\hline
\end{tabular}

\section{Volumen}

\begin{tabular}{|l|l|} 
Volumen & \\
\hline & \\
\hline & \\
\hline & \\
\hline & \\
\hline
\end{tabular}

Gewichtsanteil

\begin{tabular}{|l|l|}
\hline & \\
\hline Rottedauer & \\
\hline durchschnittliches \\
\hline Monatsaufkommen \\
\hline maximaler Monatsanfall \\
\hline \multicolumn{2}{|l|}{} \\
\hline \multicolumn{2}{|l|}{ TS-Gehalt (Fertigkompost) } \\
\hline
\end{tabular}

TS-Gehalt (Fertigkompost)

Mietenhöhe

Mietenbasisbreite

\section{ANLAGENDIMENSIONIERUNG}

\section{Anlagenteil $\quad$ Berechnungsgrundlage}

Anlieferungsfläche

Rottefläche

Rangierfläche

Zwischenlager für

Strukturmaterial

Kompostlager

Anlagenfläche (gesamt)

zu verwertende

Abwassermenge

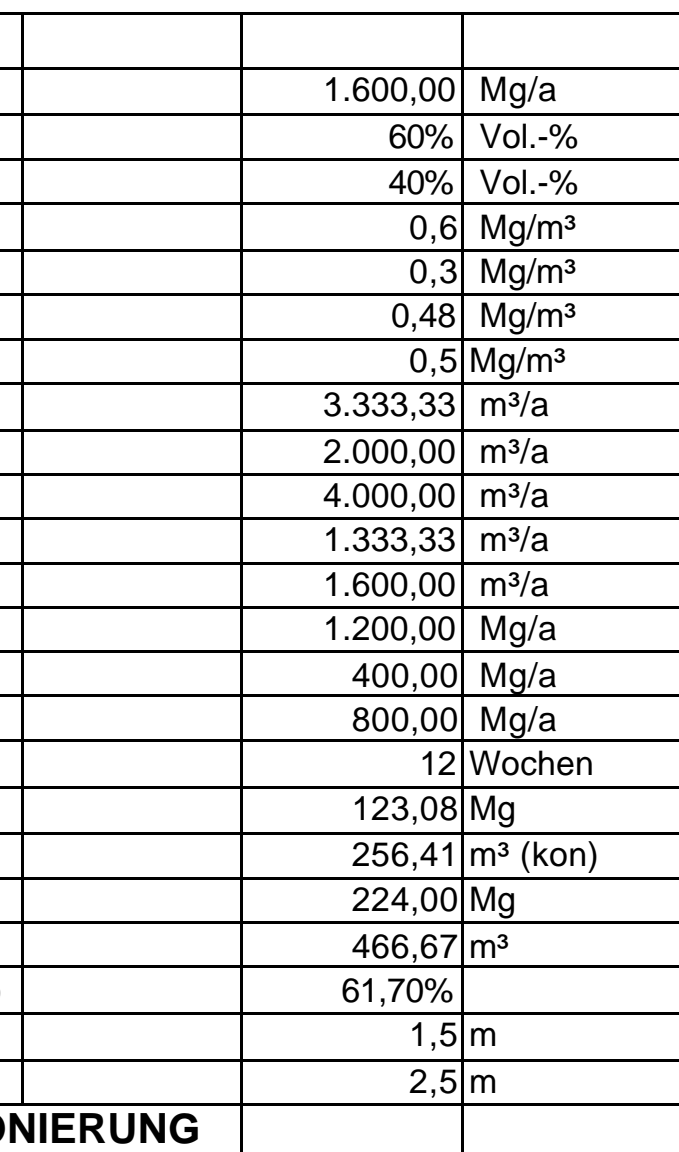

5\% 1 vom Input in Mg/a, ausgedrückt in $\mathrm{m}^{2}$

$1,33 \mathrm{~m}^{2} / \mathrm{m}^{3}$ Rottematerial bei max.M.-Anfall

$40 \%$ der Rottefläche

der Rottefläche

$10 \%$

$10 \%$ der Rottefläche

\begin{tabular}{|r|l|l|l|} 
& $10 \%$ & der Rottefläche \\
\hline & & & \\
\hline & 0,2 & $\mathrm{~m}^{3} / \mathrm{m}^{2 *} \mathrm{a}$ & \\
\hline
\end{tabular}

Grüngut
Bioabfälle aus Haushalten

gehäckseltes Grüngut

Bioabfälle aus Haushalten

gehäckseltes Grüngut

konditioniertes Material

Fertigkompost

konditioniertes Material

Bioabfälle aus Haushalten

angeliefertes Grüngut

gehäckseltes Grüngut

Fertigkompost

Bioabfälle aus Haushalten

Fertigkompost

\begin{tabular}{|c|c|c|}
\hline \\
\hline & & \\
\hline & \multicolumn{2}{|c|}{ Rottematerial eines } \\
\hline & \multicolumn{2}{|c|}{ Durchlaufs in der Anlage } \\
\hline \multicolumn{3}{|c|}{\begin{tabular}{|l|l|} 
entspr. $14 \%$ vom Input/a & \\
\end{tabular}} \\
\hline & & \\
\hline \multirow{2}{*}{\multicolumn{3}{|c|}{ Mietenquerschnitt }} \\
\hline & & \\
\hline 1,875 & $\mathrm{~m}^{2}$ & \\
\hline
\end{tabular}

Anlagenneubau

$80,00 \mathrm{~m}^{2}$

$1294,22 \mathrm{~m}^{2}$

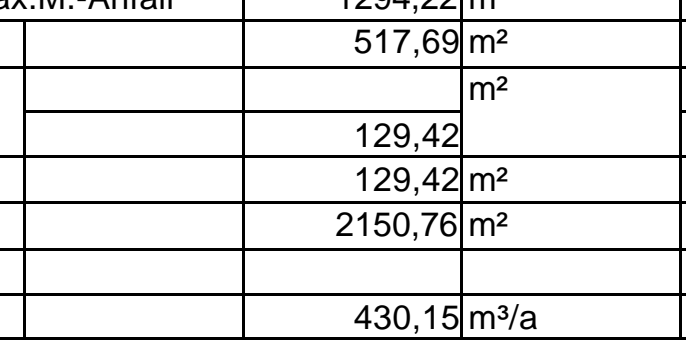

Anlagenumnutzung

$850,00 \mathrm{~m}^{2}$

\begin{tabular}{|r|l|l|}
\hline & $\mathrm{m}^{2}$ & \\
\hline 3160,00 & & \\
\hline & & \\
\cline { 1 - 1 } & & \\
\hline 4850,00 & $\mathrm{~m}^{2}$ & \\
\hline 972,00 & $\mathrm{~m}^{3} / \mathrm{a}$ & \\
\hline
\end{tabular}




\begin{tabular}{|c|c|c|c|c|c|c|c|c|c|c|}
\hline \multicolumn{11}{|l|}{ ZEITEN } \\
\hline \multicolumn{3}{|l|}{ Arbeitsgang } & \multicolumn{2}{|c|}{ eingesetzte Maschinen } & \multicolumn{2}{|c|}{ Zeitbedarf/Einheit } & \multicolumn{2}{|c|}{ geleistete Einheiten } & \multicolumn{2}{|c|}{ Zeitbedarf/Jahr } \\
\hline \multicolumn{3}{|c|}{ Materialannahme } & & & 4,000 & h/Woche & 52,000 & Wochen/a & 208,000 & $h / a$ \\
\hline \multicolumn{3}{|c|}{ Manuelle Störstoffauslese } & & & 1,000 & $h / 100 m^{3}(\operatorname{In})$ & $6.000,000$ & $\mathrm{~m}^{3} / \mathrm{a}$ & 60,000 & $h / a$ \\
\hline \multicolumn{3}{|c|}{ Zerkleinerung von Strukturmaterial } & \multicolumn{2}{|l|}{ TL, SZ, Schr. } & 1,000 & $h / 50 m^{3}(\ln )$ & $4.000,000$ & $\mathrm{~m}^{3} / \mathrm{a}$ & 80,000 & $h / a$ \\
\hline \multicolumn{3}{|c|}{ Aufsetzen einer Matte aus Strukturmat. } & \multicolumn{2}{|l|}{ TL, AS } & 0,300 & $\mathrm{~h} / 100 \mathrm{~m}^{3}$ (kon) & $3.333,333$ & $\mathrm{~m}^{3} / \mathrm{a}$ & 10,000 & $h / a$ \\
\hline \multicolumn{3}{|c|}{ Aufsetzen der Dreiecksmieten } & \multicolumn{2}{|l|}{ TL, AS } & 1,000 & $\mathrm{~h} / 20 \mathrm{~m}^{3}$ (kon) & $3.333,333$ & $\mathrm{~m}^{3} / \mathrm{a}$ & 166,667 & $\mathrm{~h} / \mathrm{a}$ \\
\hline \multicolumn{3}{|c|}{ Umsetzen der Dreiecksmieten } & \multicolumn{2}{|l|}{ Schl., MU } & 0,005 & $\mathrm{~h} / \mathrm{m}$ (Mietenl.) & $14.791,111$ & $\mathrm{~m} / \mathrm{a}$ & 73,956 & $h / a$ \\
\hline \multicolumn{3}{|c|}{ Reinigung der Annahmefläche } & \multicolumn{2}{|l|}{ TL, AS } & 0,500 & $\mathrm{~h} / 150 \mathrm{~m}^{3}(\mathrm{In})$ & $6.000,000$ & $\mathrm{~m}^{3} / \mathrm{a}$ & 20,000 & $h / a$ \\
\hline \multicolumn{3}{|l|}{ Sieben } & \multicolumn{2}{|l|}{ TL, AS, Sieb } & 1,000 & $\mathrm{~h} / 20 \mathrm{~m}^{3}(\mathrm{kom})$ & $1.600,000$ & $\mathrm{~m}^{3} / \mathrm{a}$ & 80,000 & $\mathrm{~h} / \mathrm{a}$ \\
\hline \multicolumn{3}{|c|}{ Abw.-Ausbringung bei Neubau } & \multicolumn{2}{|l|}{ Schl.,PT } & 1,000 & $\mathrm{~h} / 10 \mathrm{~m}^{3}(\mathrm{Abw})$ & 430,151 & $\mathrm{~m}^{3} / \mathrm{a}$ & 43,015 & $h / a$ \\
\hline \multicolumn{3}{|c|}{ Abw.-Ausbringung bei Umnutzung } & \multicolumn{2}{|l|}{ Schl., PT } & 1,000 & $\mathrm{~h} / 10 \mathrm{~m}^{3}(\mathrm{Abw})$ & 972,000 & $\mathrm{~m}^{3} / \mathrm{a}$ & 97,200 & $h / a$ \\
\hline \multicolumn{11}{|c|}{ Abkürzungen für die eingesetzten Maschinen: } \\
\hline \multicolumn{3}{|c|}{\begin{tabular}{|l|l|} 
TL - Teleskoplader & \\
\end{tabular}} & Schl. - Schlepp & per & & & & & & \\
\hline MU- Mietenum & etzer & & Schr. - Schred & dder & & & & & & \\
\hline SZ - Silozange & & & PT - Pumpenta & tankwagen & & & & & & \\
\hline AS - Anbausc & aufel & & & & & & & & & \\
\hline MASCHINE & NKOSTEN & & & & & & & & & \\
\hline Maschine / G & & Fixkosten & & Variable Kost & ten & Einheiten/a & & Maschinen-Ei & inzelkosten & \\
\hline Traktor (Neub & & 0,00 & $D M / a$ & 33,55 & $D M / h$ & 116,97 & $\mathrm{~h} / \mathrm{a}$ & $3.924,37$ & $\mathrm{DM} / \mathrm{a}$ & \\
\hline Traktor (Umnu & zung) & 0,00 & $\mathrm{DM} / \mathrm{a}$ & 33,55 & $D M / h$ & 171,16 & $\mathrm{~h} / \mathrm{a}$ & $5.742,27$ & $\mathrm{DM} / \mathrm{a}$ & \\
\hline Teleskoplader & & 0,00 & $D M / a$ & 66,50 & $\mathrm{DM} / \mathrm{h}$ & 356,67 & $\mathrm{~h} / \mathrm{a}$ & $23.718,33$ & $\mathrm{DM} / \mathrm{a}$ & \\
\hline Schredder & & 0,00 & DM/a & 7,50 & $\mathrm{DM} / \mathrm{m}^{3}$ (Out) & $1.333,33$ & $\mathrm{~m}^{3} / \mathrm{a}$ & $10.000,00$ & $\mathrm{DM} / \mathrm{a}$ & \\
\hline Trommelsieb & & 0,00 & $D M / a$ & 5,00 & $\mathrm{DM} / \mathrm{m}^{3}(\mathrm{Kom})$ & $1.600,00$ & $m^{3} / a$ & $8.000,00$ & $\mathrm{DM} / \mathrm{a}$ & \\
\hline PumpenTW ( & abau) & 0,00 & $\mathrm{DM} / \mathrm{a}$ & 30,00 & $\mathrm{DM} / \mathrm{h}$ & 43,02 & $h / a$ & $1.290,45$ & $\mathrm{DM} / \mathrm{a}$ & \\
\hline PumpenTW (L & nnutzung) & 0,00 & $D M / a$ & 30,00 & $D M / h$ & 97,20 & $h / a$ & $2.916,00$ & $\mathrm{DM} / \mathrm{a}$ & \\
\hline Silozange & & $1.120,00$ & DM/a & 0,30 & $\mathrm{DM} / \mathrm{m}^{3}$ & $4.000,00$ & $\mathrm{~m}^{3} / \mathrm{a}$ & $2.320,00$ & $\mathrm{DM} / \mathrm{a}$ & \\
\hline Anbauschaufe & & 506,00 & $\mathrm{DM} / \mathrm{a}$ & 0,30 & $\mathrm{DM} / \mathrm{m}^{3}$ & $14.266,67$ & $\mathrm{~m}^{3} / \mathrm{a}$ & $4.786,00$ & $\mathrm{DM} / \mathrm{a}$ & \\
\hline Mietenumsetz & & $3.600,00$ & $\mathrm{DM} / \mathrm{a}$ & 28,00 & $\mathrm{DM} / \mathrm{h}$ & 73,96 & $\mathrm{~h} / \mathrm{a}$ & $5.670,76$ & $\mathrm{DM} / \mathrm{a}$ & \\
\hline & & & & & & Summe (Neuk & bau) & $59.709,91$ & $\mathrm{DM} / \mathrm{a}$ & \\
\hline & & & & & & Summe (Umn & hutzung) & $63.153,36$ & $\mathrm{DM} / \mathrm{a}$ & \\
\hline PERSONA & KOSTEN & & & & & & & & & \\
\hline & Std.-Lohn in & kl.Lohn-NK & Arbeitsstd. pro & o Jahr & Personal-Einz & zelkosten & & & & \\
\hline Neubau & 26,00 & $\mathrm{DM} / \mathrm{h}$ & 741,64 & $\mathrm{~h} / \mathrm{a}$ & $19.282,57$ & $D M / a$ & & & & \\
\hline Umnutzung & 26,00 & DM/h & 795,82 & $h / a$ & $20.691,38$ & DM/a & & & & \\
\hline
\end{tabular}




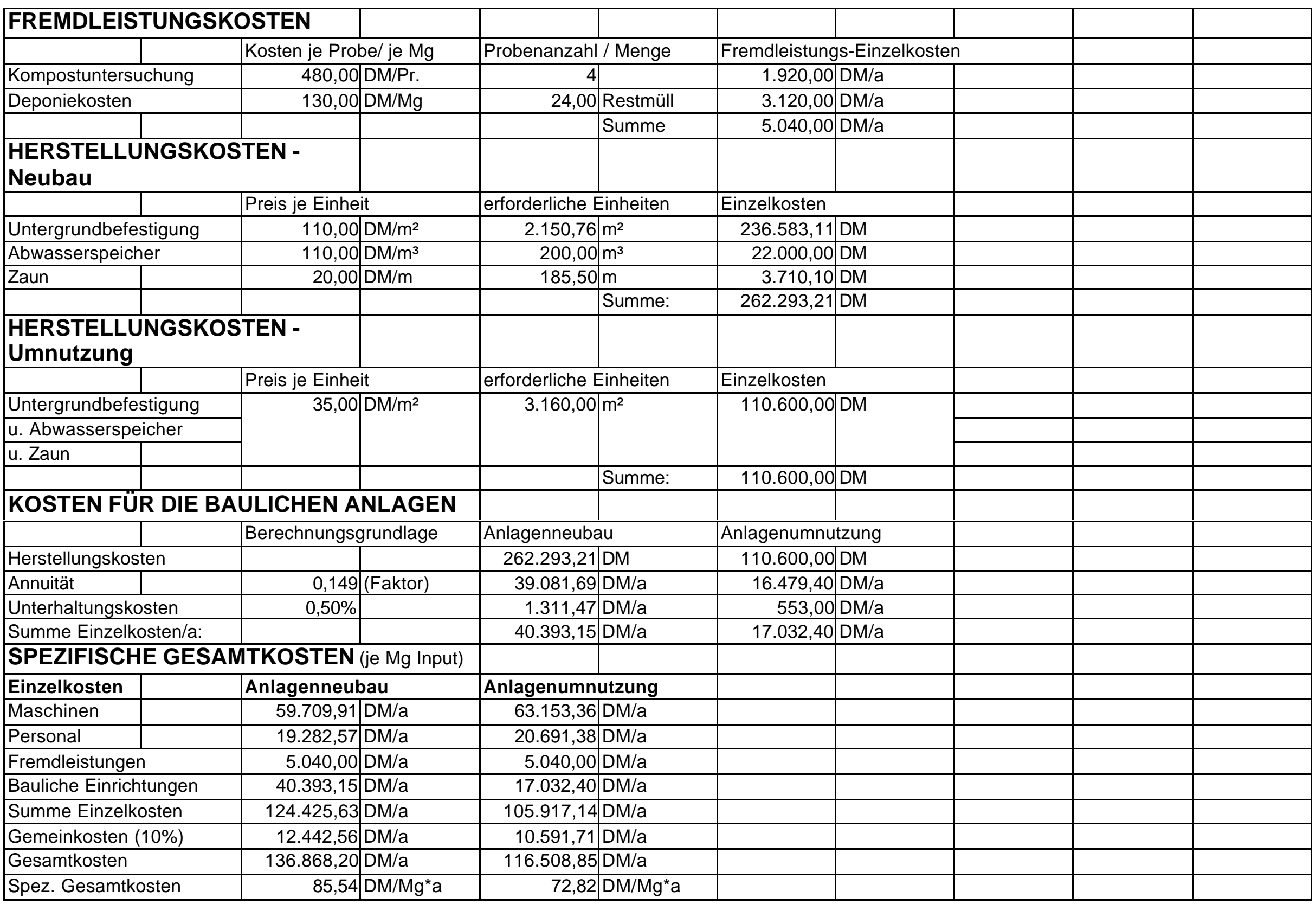


Kostenvariante D8

\section{MATERIAL}

Jahresinputmenge

Zusammensetzung

Dichte

\begin{tabular}{|l|l|}
\hline Dichte & \\
\hline & \\
\hline &
\end{tabular}

\section{Volumen}

\begin{tabular}{|l|l|}
\hline & \\
\hline & \\
\hline & \\
\hline & \\
\hline & \\
\hline
\end{tabular}

Gewichtsanteil

\begin{tabular}{|l|l|}
\hline & \\
\hline Rottedauer & \\
\hline durchschnittliches \\
\hline Monatsaufkommen \\
\hline maximaler Monatsanfall \\
\hline \multicolumn{2}{|l|}{} \\
\hline \multicolumn{2}{|l|}{ TS-Gehalt (Fertigkompost) } \\
\hline
\end{tabular}

TS-Gehalt (Fertigkompost)

Mietenhöhe

Mietenbasisbreite

\section{ANLAGENDIMENSIONIERUNG}

\section{Anlagenteil $\quad$ Berechnungsgrundlage}

Anlieferungsfläche

Rottefläche

Rangierfläche

Zwischenlager für

Strukturmaterial

Kompostlager

Anlagenfläche (gesamt)

zu verwertende

Abwassermenge

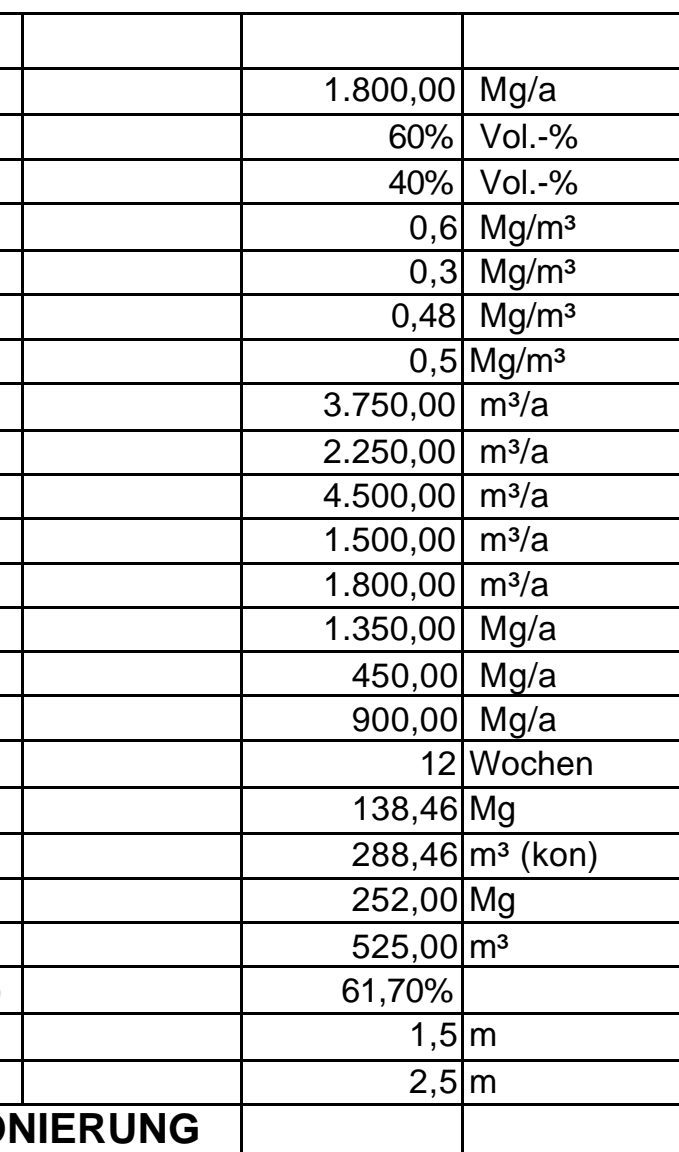

$5 \%$ vom Input in Mg/a, ausgedrückt in $\mathrm{m}^{2}$

$1,33 \mathrm{~m}^{2} / \mathrm{m}^{3}$ Rottematerial bei max.M.-Anfall

$40 \%$ der Rottefläche

der Rottefläche

$10 \%$ der Rottefläche

\section{t)}

$+$

$0,2 \mathrm{~m}^{3} / \mathrm{m}^{2 \star} \mathrm{a}$

Grüngut

\begin{tabular}{|c|c|c|}
\hline ax.M.-Anfall & 1456,00 & $\mathrm{~m}^{2}$ \\
\hline & 582,40 & $m^{2}$ \\
\hline & & $\mathrm{m}^{2}$ \\
\hline & 145,60 & \\
\hline & 145,60 & $\mathrm{~m}^{2}$ \\
\hline & 2419,60 & $\mathrm{~m}^{2}$ \\
\hline & 483,92 & $m^{3} / a$ \\
\hline
\end{tabular}

Bioabfälle aus Haushalten

gehäckseltes Grüngut

Bioabfälle aus Haushalten

gehäckseltes Grüngut

konditioniertes Material

Fertigkompost

konditioniertes Material

Bioabfälle aus Haushalten

angeliefertes Grüngut

gehäckseltes Grüngut

Fertigkompost

Bioabfälle aus Haushalten

Fertigkompost

\begin{tabular}{l|l}
\hline & \\
\hline & Rottematerial eines
\end{tabular}

entspr. 14\% vom Input/a

Mietenquerschnitt

\begin{tabular}{|r|l|l}
\hline $1,875 \mathrm{~m}^{2}$ & \\
\hline & &
\end{tabular}

Anlagenneubau

Anlagenumnutzung

\begin{tabular}{|r|l|l|l|}
\hline 850,00 & $\mathrm{~m}^{2}$ & \\
\hline 3160,00 & & \\
\hline & & \\
\hline & & \\
\hline 850,00 & $\mathrm{~m}^{2}$ & \\
\hline 4860,00 & $\mathrm{~m}^{2}$ & \\
\hline 972,00 & $\mathrm{~m}^{3} / \mathrm{a}$ & \\
\hline
\end{tabular}




\begin{tabular}{|c|c|c|c|c|c|c|c|c|c|c|}
\hline \multicolumn{11}{|l|}{ ZEITEN } \\
\hline \multicolumn{3}{|l|}{ Arbeitsgang } & \multicolumn{2}{|c|}{ eingesetzte Maschinen } & \multicolumn{2}{|c|}{ Zeitbedarf/Einheit } & \multicolumn{2}{|c|}{ geleistete Einheiten } & \multicolumn{2}{|c|}{ Zeitbedarf/Jahr } \\
\hline \multicolumn{3}{|c|}{ Materialannahme } & & & 4,000 & h/Woche & 52,000 & Wochen/a & 208,000 & $h / a$ \\
\hline \multicolumn{3}{|c|}{ Manuelle Störstoffauslese } & & & 1,000 & $h / 100 m^{3}(\operatorname{In})$ & $6.750,000$ & $\mathrm{~m}^{3} / \mathrm{a}$ & 67,500 & $h / a$ \\
\hline \multicolumn{3}{|c|}{ Zerkleinerung von Strukturmaterial } & \multicolumn{2}{|l|}{ TL, SZ, Schr. } & 1,000 & $h / 50 m^{3}(\ln )$ & $4.500,000$ & $\mathrm{~m}^{3} / \mathrm{a}$ & 90,000 & $h / a$ \\
\hline \multicolumn{3}{|c|}{ Aufsetzen einer Matte aus Strukturmat. } & \multicolumn{2}{|l|}{ TL, AS } & 0,300 & $\mathrm{~h} / 100 \mathrm{~m}^{3}$ (kon) & $3.750,000$ & $\mathrm{~m}^{3} / \mathrm{a}$ & 11,250 & $h / a$ \\
\hline \multicolumn{3}{|c|}{ Aufsetzen der Dreiecksmieten } & \multicolumn{2}{|l|}{ TL, AS } & 1,000 & $\mathrm{~h} / 20 \mathrm{~m}^{3}$ (kon) & $3.750,000$ & $\mathrm{~m}^{3} / \mathrm{a}$ & 187,500 & $h / a$ \\
\hline \multicolumn{3}{|c|}{ Umsetzen der Dreiecksmieten } & \multicolumn{2}{|l|}{ Schl., MU } & 0,005 & $\mathrm{~h} / \mathrm{m}$ (Mietenl.) & $16.640,000$ & $\mathrm{~m} / \mathrm{a}$ & 83,200 & $h / a$ \\
\hline \multicolumn{3}{|c|}{ Reinigung der Annahmefläche } & \multicolumn{2}{|l|}{ TL, AS } & 0,500 & $h / 150 m^{3}(\ln )$ & $6.750,000$ & $\mathrm{~m}^{3} / \mathrm{a}$ & 22,500 & $h / a$ \\
\hline \multicolumn{3}{|l|}{ Sieben } & \multicolumn{2}{|l|}{ TL, AS, Sieb } & 1,000 & $\mathrm{~h} / 20 \mathrm{~m}^{3}(\mathrm{kom})$ & $1.800,000$ & $\mathrm{~m}^{3} / \mathrm{a}$ & 90,000 & $\mathrm{~h} / \mathrm{a}$ \\
\hline \multicolumn{3}{|c|}{ Abw.-Ausbringung bei Neubau } & \multicolumn{2}{|l|}{ Schl.,PT } & 1,000 & $\mathrm{~h} / 10 \mathrm{~m}^{3}(\mathrm{Abw})$ & 483,920 & $\mathrm{~m}^{3} / \mathrm{a}$ & 48,392 & $h / a$ \\
\hline \multicolumn{3}{|c|}{ Abw.-Ausbringung bei Umnutzung } & \multicolumn{2}{|l|}{ Schl., PT } & 1,000 & $\mathrm{~h} / 10 \mathrm{~m}^{3}(\mathrm{Abw})$ & 972,000 & $\mathrm{~m}^{3} / \mathrm{a}$ & 97,200 & $h / a$ \\
\hline \multicolumn{11}{|c|}{ Abkürzungen für die eingesetzten Maschinen: } \\
\hline \multicolumn{3}{|c|}{\begin{tabular}{|l|l|} 
TL - Teleskoplader & \\
\end{tabular}} & Schl. - Schlepp & per & & & & & & \\
\hline MU- Mietenum & etzer & & Schr. - Schred & dder & & & & & & \\
\hline SZ - Silozange & & & PT - Pumpenta & tankwagen & & & & & & \\
\hline AS - Anbausc & aufel & & & & & & & & & \\
\hline MASCHINE & NKOSTEN & & & & & & & & & \\
\hline Maschine / G & & Fixkosten & & Variable Kost & ten & Einheiten/a & & Maschinen-Ei & inzelkosten & \\
\hline Traktor (Neub & & 0,00 & $D M / a$ & 33,55 & $D M / h$ & 131,59 & $h / a$ & $4.414,91$ & $\mathrm{DM} / \mathrm{a}$ & \\
\hline Traktor (Umnu & zung) & 0,00 & $\mathrm{DM} / \mathrm{a}$ & 33,55 & $D M / h$ & 180,40 & $\mathrm{~h} / \mathrm{a}$ & $6.052,42$ & $\mathrm{DM} / \mathrm{a}$ & \\
\hline Teleskoplader & & 0,00 & $D M / a$ & 66,50 & $\mathrm{DM} / \mathrm{h}$ & 401,25 & $h / a$ & $26.683,13$ & $\mathrm{DM} / \mathrm{a}$ & \\
\hline Schredder & & 0,00 & DM/a & 7,50 & $\mathrm{DM} / \mathrm{m}^{3}$ (Out) & $1.500,00$ & $\mathrm{~m}^{3} / \mathrm{a}$ & $11.250,00$ & $\mathrm{DM} / \mathrm{a}$ & \\
\hline Trommelsieb & & 0,00 & $\mathrm{DM} / \mathrm{a}$ & 5,00 & $\mathrm{DM} / \mathrm{m}^{3}(\mathrm{Kom})$ & $1.800,00$ & $m^{3} / a$ & $9.000,00$ & $D M / a$ & \\
\hline PumpenTW ( & abau) & 0,00 & $\mathrm{DM} / \mathrm{a}$ & 30,00 & $\mathrm{DM} / \mathrm{h}$ & 48,39 & $h / a$ & $1.451,76$ & $\mathrm{DM} / \mathrm{a}$ & \\
\hline PumpenTW (L & nnutzung) & 0,00 & $D M / a$ & 30,00 & $D M / h$ & 97,20 & $h / a$ & $2.916,00$ & $\mathrm{DM} / \mathrm{a}$ & \\
\hline Silozange & & $1.120,00$ & DM/a & 0,30 & $\mathrm{DM} / \mathrm{m}^{3}$ & $4.500,00$ & $\mathrm{~m}^{3} / \mathrm{a}$ & $2.470,00$ & $\mathrm{DM} / \mathrm{a}$ & \\
\hline Anbauschaufe & & 506,00 & $\mathrm{DM} / \mathrm{a}$ & 0,30 & $\mathrm{DM} / \mathrm{m}^{3}$ & $16.050,00$ & $m^{3} / a$ & $5.321,00$ & $\mathrm{DM} / \mathrm{a}$ & \\
\hline Mietenumsetz & & $3.600,00$ & $\mathrm{DM} / \mathrm{a}$ & 28,00 & $\mathrm{DM} / \mathrm{h}$ & 83,20 & $h / a$ & $5.929,60$ & $\mathrm{DM} / \mathrm{a}$ & \\
\hline & & & & & & Summe (Neuk & bau) & $66.520,40$ & $\mathrm{DM} / \mathrm{a}$ & \\
\hline & & & & & & Summe (Umn & hutzung) & $69.622,15$ & $\mathrm{DM} / \mathrm{a}$ & \\
\hline PERSONA & KOSTEN & & & & & & & & & \\
\hline & Std.-Lohn in & kl.Lohn-NK & Arbeitsstd. pro & Jahr & Personal-Einz & zelkosten & & & & \\
\hline Neubau & 26,00 & $\mathrm{DM} / \mathrm{h}$ & 808,34 & $\mathrm{~h} / \mathrm{a}$ & $21.016,89$ & $\mathrm{DM} / \mathrm{a}$ & & & & \\
\hline Umnutzung & 26,00 & DM/h & 857,15 & $h / a$ & $22.285,90$ & DM/a & & & & \\
\hline
\end{tabular}




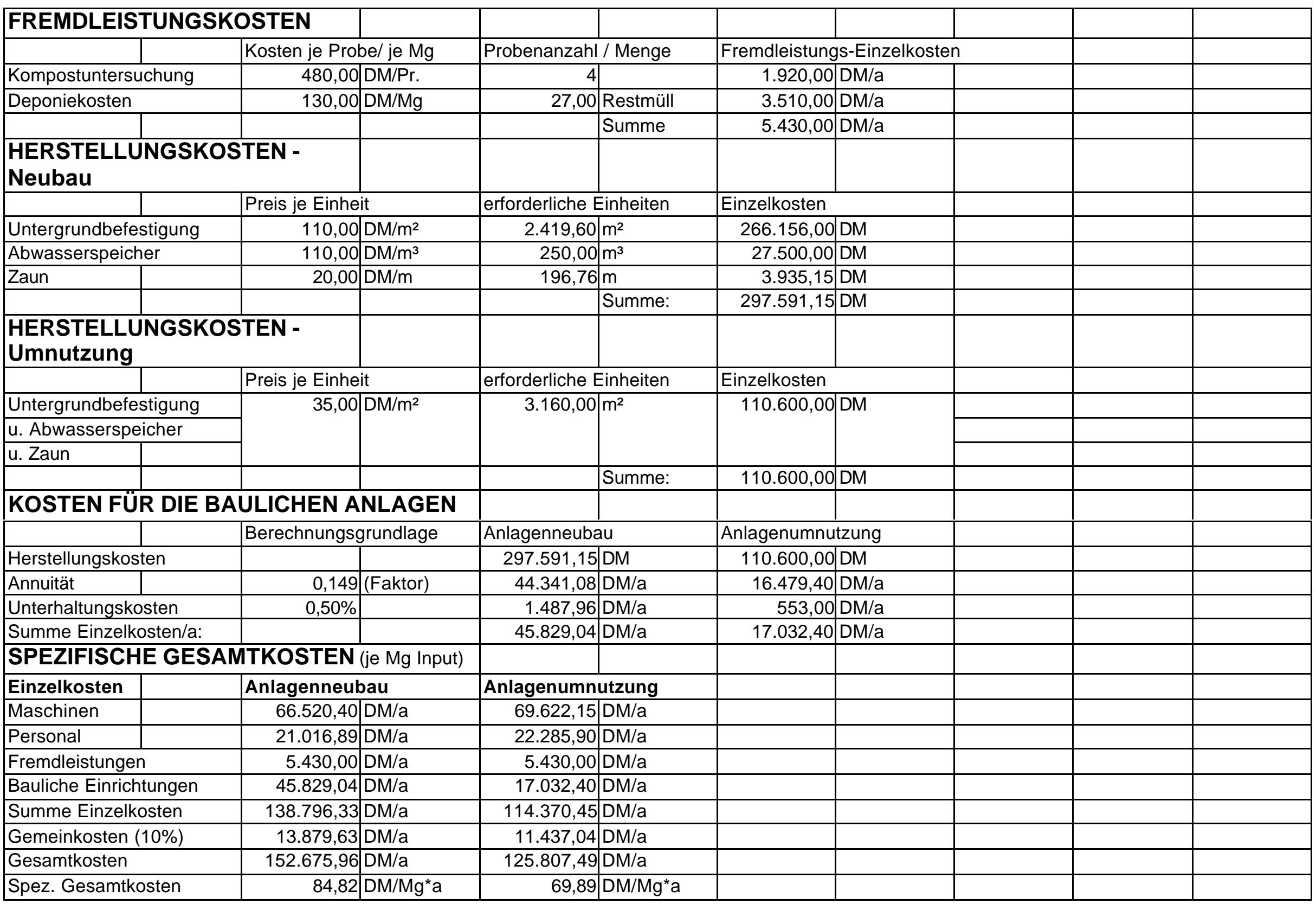


Kostenvariante D9

\section{\begin{tabular}{|l|l|}
\hline MATERIAL \\
\hline Jahresinputmenge
\end{tabular}}

Jahresinputmenge

Zusammensetzung

Dichte

\begin{tabular}{|l|l}
\hline Dichte & \\
\hline & \\
\hline & \\
\hline
\end{tabular}

\section{Volumen}

\begin{tabular}{|l|l|}
\hline & \\
\hline & \\
\hline & \\
\hline & \\
\hline
\end{tabular}

Gewichtsanteil

\begin{tabular}{|l|l|}
\hline & \\
\hline Rottedauer & \\
\hline durchschnittliches \\
\hline Monatsaufkommen \\
\hline maximaler Monatsanfall \\
\hline \multicolumn{2}{|l|}{} \\
\hline \multicolumn{2}{|l|}{ TS-Gehalt (Fertigkompost) } \\
\hline
\end{tabular}

TS-Gehalt (Fertigkompost)

Mietenhöhe

Mietenbasisbreite

\section{ANLAGENDIMENSIONIERUNG}

\section{Anlagenteil $\quad$ Berechnungsgrundlage}

Anlieferungsfläche

Rottefläche

Rangierfläche

Zwischenlager für

Strukturmaterial

Kompostlager

Anlagenfläche (gesamt)

zu verwertende

Abwassermenge

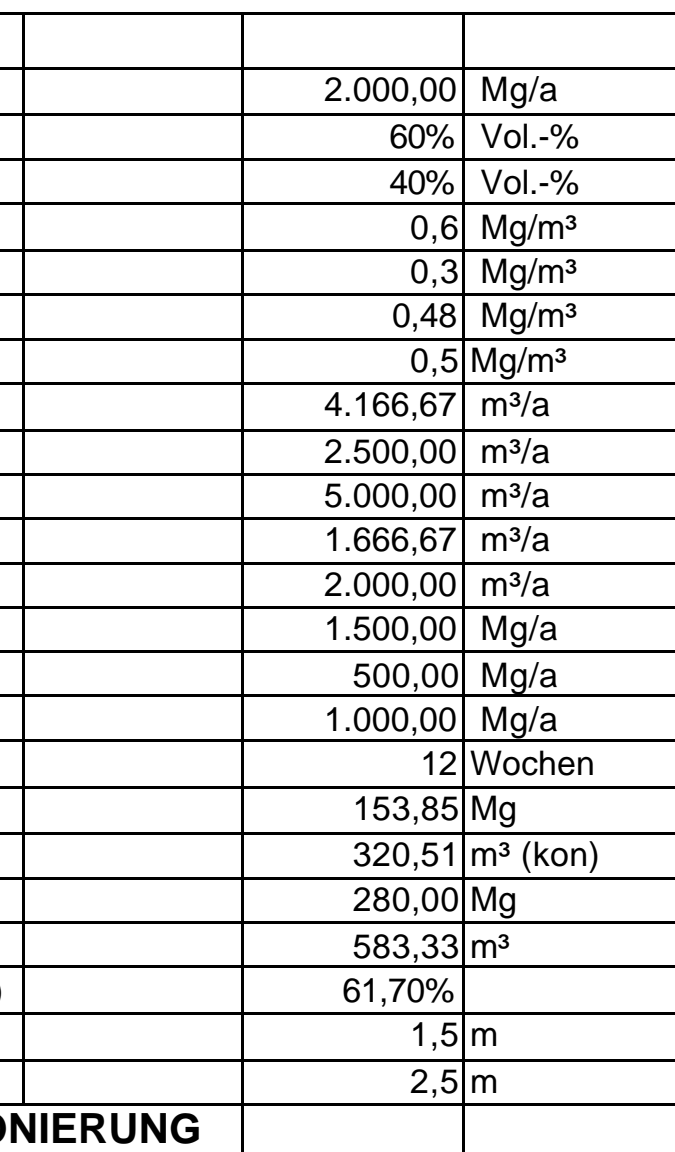

$5 \%$ vom Input in Mg/a, ausgedrückt in $\mathrm{m}^{2}$

$1,33 \mathrm{~m}^{2} / \mathrm{m}^{3}$ Rottematerial bei max.M.-Anfall

$40 \%$ der Rottefläche

der Rottefläche

$10 \%$

$10 \%$ der Rottefläche

\begin{tabular}{|r|l|l|l|} 
& $10 \%$ & der Rottefläche \\
\hline & & & \\
\hline & 0,2 & $\mathrm{~m}^{3} / \mathrm{m}^{2 *} \mathrm{a}$ & \\
\hline
\end{tabular}

Grüngut
Bioabfälle aus Haushalten

gehäckseltes Grüngut

Bioabfälle aus Haushalten

gehäckseltes Grüngut

konditioniertes Material

Fertigkompost

konditioniertes Material

Bioabfälle aus Haushalten

angeliefertes Grüngut

gehäckseltes Grüngut

Fertigkompost

Bioabfälle aus Haushalten

Fertigkompost

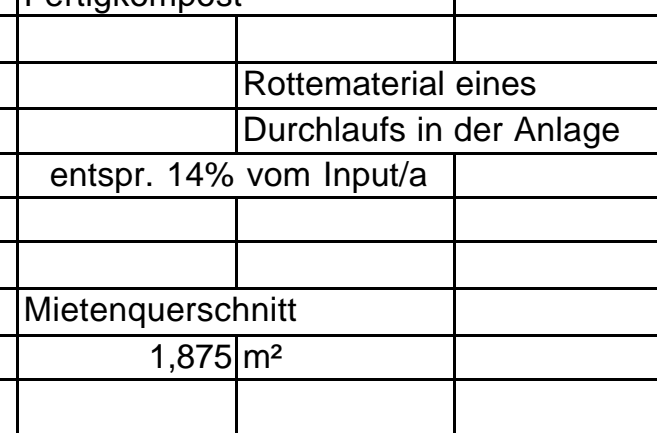

Anlagenneubau

\begin{tabular}{|c|c|c|}
\hline x.M.-Anfall & 1617,78 & $3 \mathrm{~m}^{2}$ \\
\hline & 647,11 & $m^{2}$ \\
\hline & & $\mathrm{m}^{2}$ \\
\hline & 161,78 & \\
\hline & 161,78 & $\mathrm{~m}^{2}$ \\
\hline & 2688,44 & $m^{2}$ \\
\hline & 53769 & $\mathrm{~m}^{3}$ \\
\hline & & Dir/a \\
\hline
\end{tabular}

Anlagenumnutzung

$850,00 \mathrm{~m}^{2}$

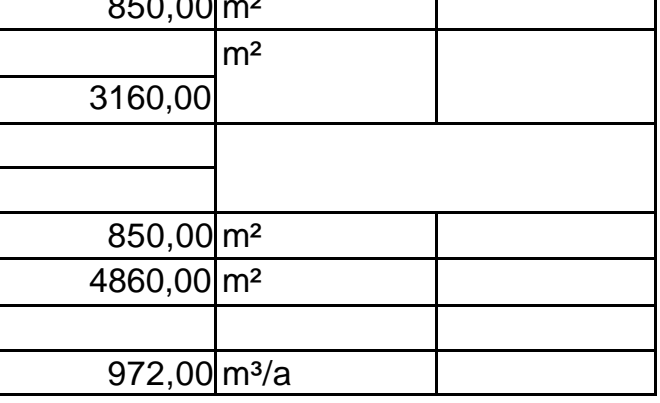




\begin{tabular}{|c|c|c|c|c|c|c|c|c|c|c|}
\hline ZEITEN & & & & & & & & & & \\
\hline Arbeitsgang & & & eingesetzte $\mathrm{M}$ & Maschinen & Zeitbedarf/Ei & inheit & geleistete Ein & nheiten & Zeitbedarf/Ja & ahr \\
\hline Materialannah & & & & & 4,000 & h/Woche & 52,000 & Wochen/a & 208,000 & $h / a$ \\
\hline Manuelle Stör & offauslese & & & & 1,000 & $h / 100 m^{3}(\ln )$ & $7.500,000$ & $\mathrm{~m}^{3} / \mathrm{a}$ & 75,000 & $h / a$ \\
\hline Zerkleinerung & on Strukturm & iaterial & TL, SZ, Schr. & & 1,000 & $h / 50 m^{3}(\operatorname{In})$ & $5.000,000$ & $\mathrm{~m}^{3} / \mathrm{a}$ & 100,000 & $h / a$ \\
\hline Aufsetzen ein & Matte aus S & trukturmat. & TL, AS & & 0,300 & $\mathrm{~h} / 100 \mathrm{~m}^{3}$ (kon) & $4.166,667$ & $\mathrm{~m}^{3} / \mathrm{a}$ & 12,500 & $h / a$ \\
\hline Aufsetzen der & Jreiecksmiete & & TL, AS & & 1,000 & $\mathrm{~h} / 20 \mathrm{~m}^{3}$ (kon) & $4.166,667$ & $\mathrm{~m}^{3} / \mathrm{a}$ & 208,333 & $\mathrm{~h} / \mathrm{a}$ \\
\hline Umsetzen der & Jreiecksmiete & & Schl., MU & & 0,005 & $\mathrm{~h} / \mathrm{m}$ (Mietenl.) & $18.488,889$ & $\mathrm{~m} / \mathrm{a}$ & 92,444 & $\mathrm{~h} / \mathrm{a}$ \\
\hline Reinigung der & Annahmefläch & & TL, AS & & 0,500 & $h / 150 m^{3}(\ln )$ & $7.500,000$ & $\mathrm{~m}^{3} / \mathrm{a}$ & 25,000 & $h / a$ \\
\hline Sieben & & & TL, AS, Sieb & & 1,000 & $\mathrm{~h} / 20 \mathrm{~m}^{3}(\mathrm{kom})$ & $2.000,000$ & $\mathrm{~m}^{3} / \mathrm{a}$ & 100,000 & $h / a$ \\
\hline Abw.-Ausbring & Ing bei Neub & & Schl.,PT & & 1,000 & $\mathrm{~h} / 10 \mathrm{~m}^{3}(\mathrm{Abw})$ & 537,689 & $\mathrm{~m}^{3} / \mathrm{a}$ & 53,769 & $h / a$ \\
\hline Abw.-Ausbring & Ing bei Umnu & utzung & Schl., PT & & 1,000 & $\mathrm{~h} / 10 \mathrm{~m}^{3}(\mathrm{Abw})$ & 972,000 & $\mathrm{~m}^{3} / \mathrm{a}$ & 97,200 & $h / a$ \\
\hline Abkürzungen & Ir die eingese & tzten Maschin & nen: & & & & & & & \\
\hline TL - Teleskop & der & & Schl. - Schlepp & per & & & & & & \\
\hline MU- Mietenum & etzer & & Schr. - Schred & dder & & & & & & \\
\hline SZ - Silozange & & & PT - Pumpenta & tankwagen & & & & & & \\
\hline AS - Anbausc & aufel & & & & & & & & & \\
\hline MASCHINE & NKOSTEN & & & & & & & & & \\
\hline Maschine / G & & Fixkosten & & Variable Kost & ten & Einheiten/a & & Maschinen-Ei & inzelkosten & \\
\hline Traktor (Neub & & 0,00 & $\mathrm{DM} / \mathrm{a}$ & 33,55 & $D M / h$ & 146,21 & $h / a$ & $4.905,46$ & $\mathrm{DM} / \mathrm{a}$ & \\
\hline Traktor (Umnu & zung) & 0,00 & $\mathrm{DM} / \mathrm{a}$ & 33,55 & $D M / h$ & 189,64 & $\mathrm{~h} / \mathrm{a}$ & $6.362,57$ & $\mathrm{DM} / \mathrm{a}$ & \\
\hline Teleskoplader & & 0,00 & $D M / a$ & 66,50 & $\mathrm{DM} / \mathrm{h}$ & 445,83 & $\mathrm{~h} / \mathrm{a}$ & $29.647,92$ & $\mathrm{DM} / \mathrm{a}$ & \\
\hline Schredder & & 0,00 & DM/a & 7,50 & $\mathrm{DM} / \mathrm{m}^{3}$ (Out) & $1.666,67$ & $\mathrm{~m}^{3} / \mathrm{a}$ & $12.500,00$ & $\mathrm{DM} / \mathrm{a}$ & \\
\hline Trommelsieb & & 0,00 & DM/a & 5,00 & $\mathrm{DM} / \mathrm{m}^{3}(\mathrm{Kom})$ & $2.000,00$ & $m^{3} / a$ & $10.000,00$ & $\mathrm{DM} / \mathrm{a}$ & \\
\hline PumpenTW ( & abau) & 0,00 & $\mathrm{DM} / \mathrm{a}$ & 30,00 & $\mathrm{DM} / \mathrm{h}$ & 53,77 & $\mathrm{~h} / \mathrm{a}$ & $1.613,07$ & $\mathrm{DM} / \mathrm{a}$ & \\
\hline PumpenTW (L & nnutzung) & 0,00 & $D M / a$ & 30,00 & $D M / h$ & 97,20 & $h / a$ & $2.916,00$ & $\mathrm{DM} / \mathrm{a}$ & \\
\hline Silozange & & $1.120,00$ & DM/a & 0,30 & $\mathrm{DM} / \mathrm{m}^{3}$ & $5.000,00$ & $\mathrm{~m}^{3} / \mathrm{a}$ & $2.620,00$ & $\mathrm{DM} / \mathrm{a}$ & \\
\hline Anbauschaufe & & 506,00 & $\mathrm{DM} / \mathrm{a}$ & 0,30 & $\mathrm{DM} / \mathrm{m}^{3}$ & $17.833,33$ & $\mathrm{~m}^{3} / \mathrm{a}$ & $5.856,00$ & $\mathrm{DM} / \mathrm{a}$ & \\
\hline Mietenumsetz & & $3.600,00$ & $\mathrm{DM} / \mathrm{a}$ & 28,00 & $D M / h$ & 92,44 & $h / a$ & $6.188,44$ & $\mathrm{DM} / \mathrm{a}$ & \\
\hline & & & & & & Summe (Neuk & bau) & $73.330,89$ & $\mathrm{DM} / \mathrm{a}$ & \\
\hline & & & & & & Summe (Umn & hutzung) & $76.090,93$ & $\mathrm{DM} / \mathrm{a}$ & \\
\hline PERSON/ & OSTEN & & & & & & & & & \\
\hline & Std.-Lohn in & kl.Lohn-NK & Arbeitsstd. pro & Jahr & Personal-Einz & zelkosten & & & & \\
\hline Neubau & 26,00 & $\mathrm{DM} / \mathrm{h}$ & 875,05 & $\mathrm{~h} / \mathrm{a}$ & $22.751,21$ & $\mathrm{DM} / \mathrm{a}$ & & & & \\
\hline Umnutzung & 26,00 & $\mathrm{DM} / \mathrm{h}$ & 918,48 & $\mathrm{~h} / \mathrm{a}$ & $23.880,42$ & $D M / a$ & & & & \\
\hline
\end{tabular}




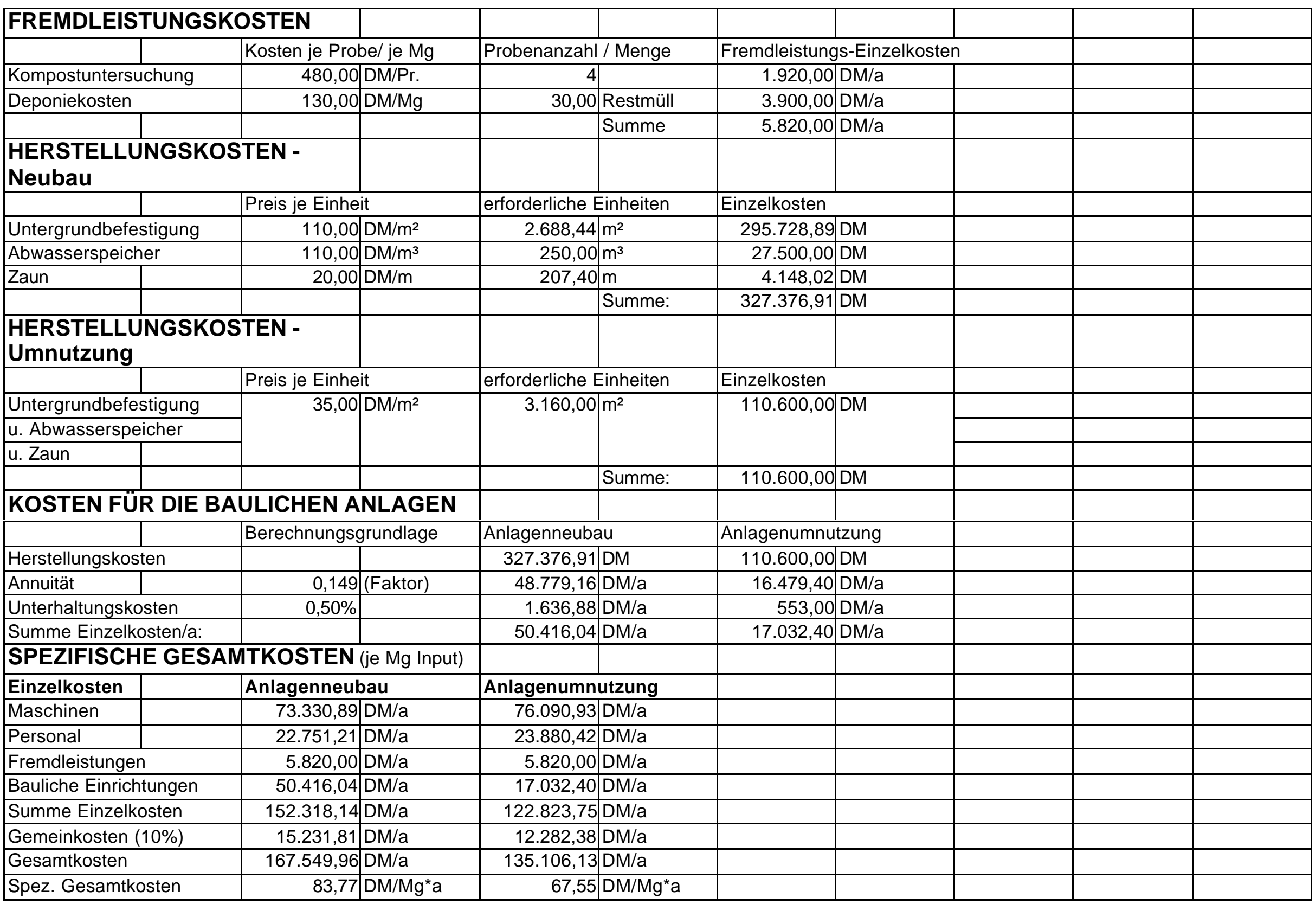


Kostenvariante D10

\section{MATERIAL}

Jahresinputmenge

Zusammensetzung

\begin{tabular}{|l|l|}
\hline & \\
\hline Dichte & \\
\hline & \\
\hline & \\
\hline & \\
\hline Volumen & \\
\hline & \\
\hline & \\
\hline & \\
\hline &
\end{tabular}

Gewichtsanteil

\section{Rottedauer}

durchschnittliches

Monatsaufkommen

maximaler Monatsanfall

\begin{tabular}{|l}
\hline \\
TS-Gehalt (Fertigkompost)
\end{tabular}

Mietenhöhe

Mietenbasisbreite

\section{ANLAGENDIMENSIONIERUNG}

\section{Anlagenteil}

Anlieferungsfläche

Rottefläche

Rangierfläche

Zwischenlager für

Strukturmaterial

Kompostlager

Anlagenfläche (gesamt)

zu verwertende

Abwassermenge

\section{|}

+

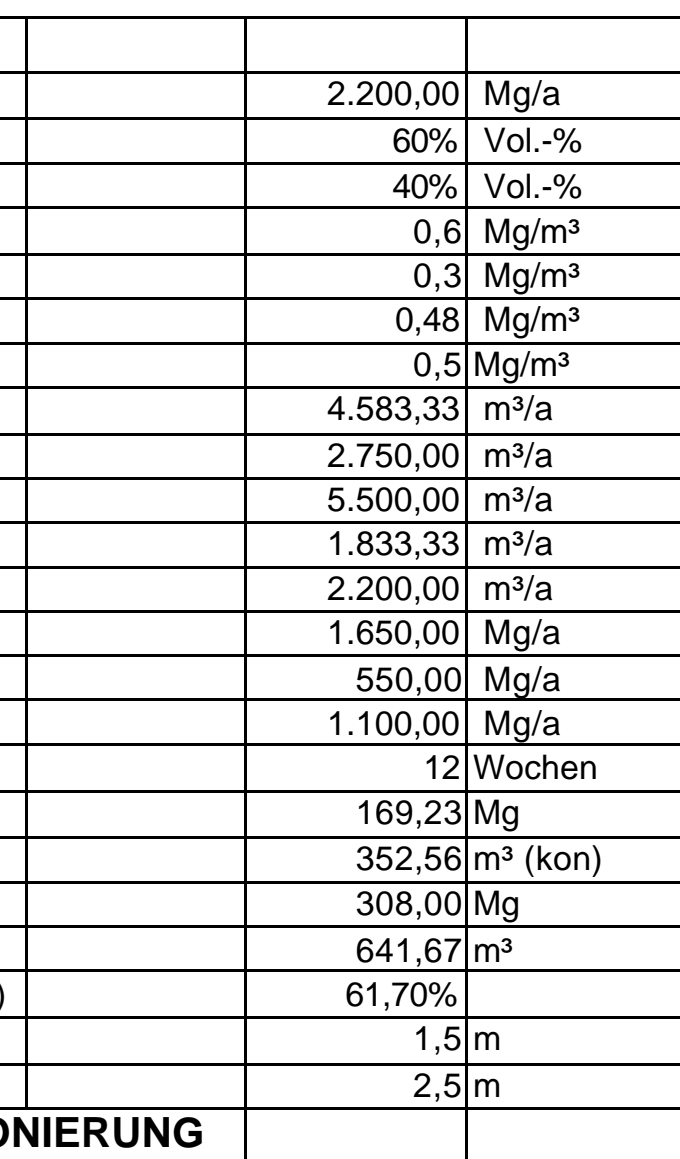

Berechnungsgrundlage

5\% vom Input in Mg/a, ausgedrückt in $\mathrm{m}^{2}$

$1,33 \mathrm{~m}^{2} / \mathrm{m}^{3}$ Rottematerial bei max.M.-Anfall

$40 \%$ der Rottefläche

der Rottefläche

$10 \%$ der Rottefläche

$0,2 \mathrm{~m}^{3} / \mathrm{m}^{2 \star} \mathrm{a}$

Grüngut

\begin{tabular}{|c|c|c|}
\hline ax.M.-Anfall & 1779,56 & $\mathrm{~m}^{2}$ \\
\hline & 711,82 & $\mathrm{~m}^{2}$ \\
\hline & & $m^{2}$ \\
\hline & 177,96 & \\
\hline & 177,96 & $\mathrm{~m}^{2}$ \\
\hline & 2957,29 & $\mathrm{~m}^{2}$ \\
\hline & & \\
\hline & 591,46 & $\mathrm{~m}^{3} / \mathrm{a}$ \\
\hline
\end{tabular}

Bioabfälle aus Haushalten

gehäckseltes Grüngut

Bioabfälle aus Haushalten

gehäckseltes Grüngut

konditioniertes Material

Fertigkompost

konditioniertes Material

Bioabfälle aus Haushalten

angeliefertes Grüngut

gehäckseltes Grüngut

Fertigkompost

Bioabfälle aus Haushalten

Fertigkompost

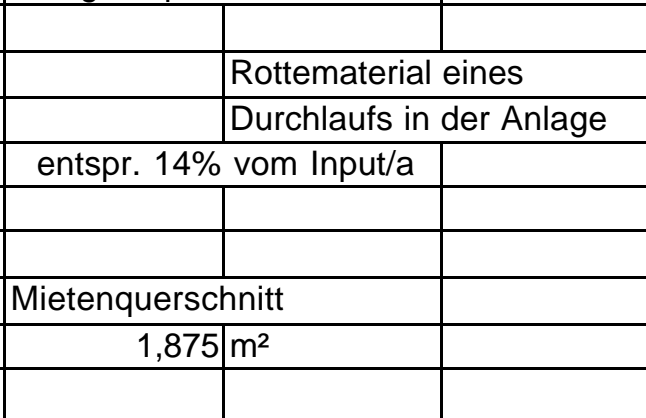

Anlagenneubau

\section{Anlagenumnutzung}

$850,00 \mathrm{~m}^{2}$

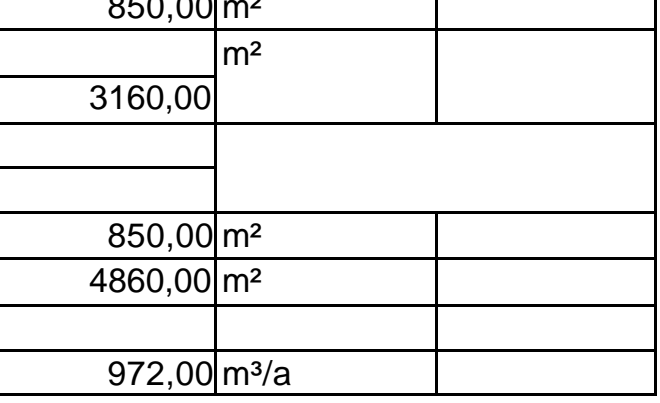




\begin{tabular}{|c|c|c|c|c|c|c|c|c|c|c|}
\hline \multicolumn{11}{|l|}{ ZEITEN } \\
\hline \multicolumn{3}{|l|}{ Arbeitsgang } & \multicolumn{2}{|c|}{ eingesetzte Maschinen } & \multicolumn{2}{|c|}{ Zeitbedarf/Einheit } & \multicolumn{2}{|c|}{ geleistete Einheiten } & \multicolumn{2}{|c|}{ Zeitbedarf/Jahr } \\
\hline \multicolumn{3}{|c|}{ Materialannahme } & & & 4,000 & h/Woche & 52,000 & Wochen/a & 208,000 & $h / a$ \\
\hline \multicolumn{3}{|c|}{ Manuelle Störstoffauslese } & & & 1,000 & $h / 100 m^{3}(\operatorname{In})$ & $8.250,000$ & $\mathrm{~m}^{3} / \mathrm{a}$ & 82,500 & $h / a$ \\
\hline \multicolumn{3}{|c|}{ Zerkleinerung von Strukturmaterial } & TL, SZ, Schr. & & 1,000 & $h / 50 m^{3}(\ln )$ & $5.500,000$ & $\mathrm{~m}^{3} / \mathrm{a}$ & 110,000 & $h / a$ \\
\hline \multicolumn{3}{|c|}{ Aufsetzen einer Matte aus Strukturmat. } & TL, AS & & 0,300 & $\mathrm{~h} / 100 \mathrm{~m}^{3}$ (kon) & $4.583,333$ & $\mathrm{~m}^{3} / \mathrm{a}$ & 13,750 & $h / a$ \\
\hline \multicolumn{3}{|c|}{ Aufsetzen der Dreiecksmieten } & TL, AS & & 1,000 & $\mathrm{~h} / 20 \mathrm{~m}^{3}$ (kon) & $4.583,333$ & $\mathrm{~m}^{3} / \mathrm{a}$ & 229,167 & $\mathrm{~h} / \mathrm{a}$ \\
\hline \multicolumn{3}{|c|}{ Umsetzen der Dreiecksmieten } & Schl., MU & & 0,005 & $\mathrm{~h} / \mathrm{m}$ (Mietenl.) & $20.337,778$ & $\mathrm{~m} / \mathrm{a}$ & 101,689 & $h / a$ \\
\hline \multicolumn{3}{|c|}{ Reinigung der Annahmefläche } & TL, AS & & 0,500 & $h / 150 m^{3}(\ln )$ & $8.250,000$ & $\mathrm{~m}^{3} / \mathrm{a}$ & 27,500 & $h / a$ \\
\hline \multicolumn{3}{|l|}{ Sieben } & TL, AS, Sieb & & 1,000 & $\mathrm{~h} / 20 \mathrm{~m}^{3}(\mathrm{kom})$ & $2.200,000$ & $\mathrm{~m}^{3} / \mathrm{a}$ & 110,000 & $\mathrm{~h} / \mathrm{a}$ \\
\hline \multicolumn{3}{|c|}{ Abw.-Ausbringung bei Neubau } & Schl.,PT & & 1,000 & $\mathrm{~h} / 10 \mathrm{~m}^{3}(\mathrm{Abw})$ & 591,458 & $\mathrm{~m}^{3} / \mathrm{a}$ & 59,146 & $h / a$ \\
\hline \multicolumn{3}{|c|}{ Abw.-Ausbringung bei Umnutzung } & Schl., PT & & 1,000 & $\mathrm{~h} / 10 \mathrm{~m}^{3}(\mathrm{Abw})$ & 972,000 & $\mathrm{~m}^{3} / \mathrm{a}$ & 97,200 & $h / a$ \\
\hline \multicolumn{11}{|c|}{ Abkürzungen für die eingesetzten Maschinen: } \\
\hline \multicolumn{2}{|c|}{ TL - Teleskoplader } & & \multicolumn{2}{|c|}{ Schl. - Schlepper } & & & & & & \\
\hline \multicolumn{2}{|c|}{\begin{tabular}{|l} 
MU- Mietenumsetzer \\
\end{tabular}} & & Schr. - Schred & dder & & & & & & \\
\hline \multicolumn{2}{|c|}{ SZ - Silozange } & & PT - Pumpenta & tankwagen & & & & & & \\
\hline \multicolumn{11}{|c|}{ AS - Anbauschaufel } \\
\hline \multicolumn{11}{|c|}{ MASCHINENKOSTEN } \\
\hline \multicolumn{2}{|c|}{ Maschine / Gerät } & Fixkosten & & \multicolumn{2}{|c|}{ Variable Kosten } & Einheiten/a & & \multicolumn{2}{|c|}{ Maschinen-Einzelkosten } & \\
\hline Traktor (Neub & au) & 0,00 & $\mathrm{DM} / \mathrm{a}$ & 33,55 & $\mathrm{DM} / \mathrm{h}$ & 160,83 & $\mathrm{~h} / \mathrm{a}$ & $5.396,00$ & $\mathrm{DM} / \mathrm{a}$ & \\
\hline Traktor (Umnı & itzung) & 0,00 & $\mathrm{DM} / \mathrm{a}$ & 33,55 & $\mathrm{DM} / \mathrm{h}$ & 198,89 & $\mathrm{~h} / \mathrm{a}$ & $6.672,72$ & $\mathrm{DM} / \mathrm{a}$ & \\
\hline Teleskoplader & & 0,00 & $\mathrm{DM} / \mathrm{a}$ & 66,50 & $\mathrm{DM} / \mathrm{h}$ & 490,42 & $h / a$ & $32.612,71$ & $\mathrm{DM} / \mathrm{a}$ & \\
\hline Schredder & & 0,00 & $\mathrm{DM} / \mathrm{a}$ & 7,50 & $\mathrm{DM} / \mathrm{m}^{3}$ (Out) & $1.833,33$ & $\mathrm{~m}^{3} / \mathrm{a}$ & $13.750,00$ & $\mathrm{DM} / \mathrm{a}$ & \\
\hline Trommelsieb & & 0,00 & $\mathrm{DM} / \mathrm{a}$ & 5,00 & $\mathrm{DM} / \mathrm{m}^{3}(\mathrm{Kom})$ & $2.200,00$ & $\mathrm{~m}^{3} / \mathrm{a}$ & $11.000,00$ & $\mathrm{DM} / \mathrm{a}$ & \\
\hline PumpenTW (I & Veubau) & 0,00 & $\mathrm{DM} / \mathrm{a}$ & 30,00 & $\mathrm{DM} / \mathrm{h}$ & 59,15 & $\mathrm{~h} / \mathrm{a}$ & $1.774,37$ & $\mathrm{DM} / \mathrm{a}$ & \\
\hline PumpenTW (L & Jmnutzung) & 0,00 & $D M / a$ & 30,00 & $D M / h$ & 97,20 & $h / a$ & $2.916,00$ & $\mathrm{DM} / \mathrm{a}$ & \\
\hline Silozange & & $1.120,00$ & DM/a & 0,30 & $\mathrm{DM} / \mathrm{m}^{3}$ & $5.500,00$ & $\mathrm{~m}^{3} / \mathrm{a}$ & $2.770,00$ & $\mathrm{DM} / \mathrm{a}$ & \\
\hline Anbauschaufe & & 506,00 & $\mathrm{DM} / \mathrm{a}$ & 0,30 & $\mathrm{DM} / \mathrm{m}^{3}$ & $19.616,67$ & $\mathrm{~m}^{3} / \mathrm{a}$ & $6.391,00$ & $\mathrm{DM} / \mathrm{a}$ & \\
\hline Mietenumsetz & & $3.600,00$ & $\mathrm{DM} / \mathrm{a}$ & 28,00 & $\mathrm{DM} / \mathrm{h}$ & 101,69 & $\mathrm{~h} / \mathrm{a}$ & $6.447,29$ & $\mathrm{DM} / \mathrm{a}$ & \\
\hline & & & & & & Summe (Neuk & bau) & $80.141,37$ & $\mathrm{DM} / \mathrm{a}$ & \\
\hline & & & & & & Summe (Umn & uutzung) & $82.559,72$ & $\mathrm{DM} / \mathrm{a}$ & \\
\hline PERSONA & LOSTEN & & & & & & & & & \\
\hline & Std.-Lohn inkl & I.Lohn-NK & Arbeitsstd. pro & o Jahr & Personal-Einz & zelkosten & & & & \\
\hline Neubau & 26,00 & $D M / h$ & 941,75 & $\mathrm{~h} / \mathrm{a}$ & $24.485,53$ & $D M / a$ & & & & \\
\hline Umnutzung & 26,00 & $D M / h$ & 979,81 & $h / a$ & $25.474,94$ & $D M / a$ & & & & \\
\hline
\end{tabular}




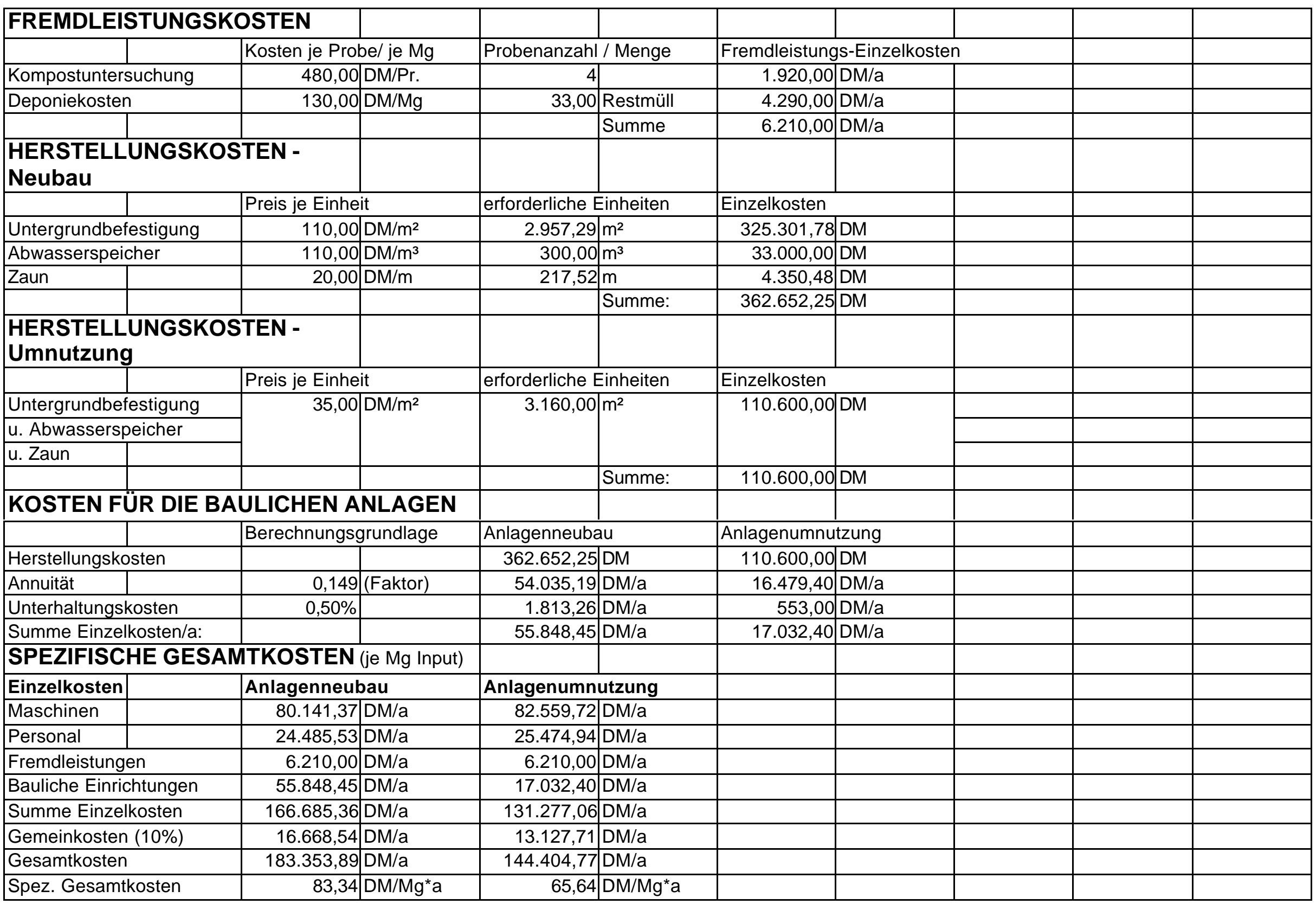


Kostenvariante D11

\begin{tabular}{|c|c|c|c|c|c|c|c|c|c|c|}
\hline MATERIA & & & & & & & & & & \\
\hline Jahresinput & & & $2.400,00$ & $\mathrm{Mg} / \mathrm{a}$ & & & & & & \\
\hline Zusammens & & & $60 \%$ & Vol.-\% & Bioabfälle & Haushalten & & & & \\
\hline & & & $40 \%$ & Vol.-\% & gehäckselt & Grüngut & & & & \\
\hline Dichte & & & 0,6 & $\mathrm{Mg} / \mathrm{m}^{3}$ & Bioabfälle & Haushalten & & & & \\
\hline & & & 0,3 & $\mathrm{Mg} / \mathrm{m}^{3}$ & gehäckselt & Grüngut & & & & \\
\hline & & & 0,48 & $\mathrm{Mg} / \mathrm{m}^{3}$ & konditionie & s Material & & & & \\
\hline & & & 0,5 & $\mathrm{Mg} / \mathrm{m}^{3}$ & Fertigkomp & & & & & \\
\hline Volumen & & & $5.000,00$ & $\mathrm{~m}^{3} / \mathrm{a}$ & konditionie & s Material & & & & \\
\hline & & & $3.000,00$ & $\mathrm{~m}^{3} / \mathrm{a}$ & Bioabfälle & Haushalten & & & & \\
\hline & & & $6.000,00$ & $\mathrm{~m}^{3} / \mathrm{a}$ & angeliefert & Grüngut & & & & \\
\hline & & & $2.000,00$ & $\mathrm{~m}^{3} / \mathrm{a}$ & gehäckselt & Grüngut & & & & \\
\hline & & & $2.400,00$ & $\mathrm{~m}^{3} / \mathrm{a}$ & Fertigkomp & & & & & \\
\hline Gewichtsan & & & $1.800,00$ & $\mathrm{Mg} / \mathrm{a}$ & Bioabfälle c & Haushalten & & & & \\
\hline & & & 600,00 & $\mathrm{Mg} / \mathrm{a}$ & Grüngut & & & & & \\
\hline & & & $1.200,00$ & $\mathrm{Mg} / \mathrm{a}$ & Fertigkomp & & & & & \\
\hline Rottedauer & & & 12 & Wochen & & & & & & \\
\hline durchschnit & & & 184,62 & $\mathrm{Mg}$ & & Rottematerial & eines & & & \\
\hline Monatsaufk & & & 384,62 & $m^{3}$ (kon) & & Durchlaufs in & der Anlage & 800,00 & $\mathrm{~m}^{3}$ & \\
\hline maximaler I & atsanfall & & 336,00 & $\mathrm{Mg}$ & entspr. 1 & vom Input/a & & & & \\
\hline & & & 700,00 & $\mathrm{~m}^{3}$ & & & & & & \\
\hline TS-Gehalt & igkompost) & & $61,70 \%$ & & & & & & & \\
\hline Mietenhöhe & & & 1,5 & $\mathrm{~m}$ & Mietenquer & hnitt & & & & \\
\hline Mietenbasis & & & 2,5 & $\mathrm{~m}$ & $\overline{1,8}$ & $\mathrm{~m}^{2}$ & & & & \\
\hline ANLAGE & IMENSIO & IIERUNG & & & & & & & & \\
\hline Anlagent & & Berechnung & gsgrundlage & & & Anlagenneub & bau & Anlagenumn & utzung & \\
\hline Anliefe & sfläche & $5 \%$ & vom Input in I & hg/a, ausg & ickt in $\mathrm{m}^{2}$ & 120,00 & $\mathrm{~m}^{2}$ & 850,00 & $\mathrm{~m}^{2}$ & \\
\hline Rottefläch & & 1,33 & $\mathrm{~m}^{2} / \mathrm{m}^{3}$ Rottem & aterial bei & M.-Anfall & 1941,33 & $\mathrm{~m}^{2}$ & & $m^{2}$ & \\
\hline Rangierfläc & & $40 \%$ & der Rottefläch & & & 776,53 & $\mathrm{~m}^{2}$ & 3160,00 & & \\
\hline Zwisch & iger für & & der Rottefläch & & & & $m^{2}$ & & & \\
\hline Strukt & aterial & $10 \%$ & & & & 194,13 & & & & \\
\hline Kompostla & & $10 \%$ & der Rottefläch & & & 194,13 & $\mathrm{~m}^{2}$ & 850,00 & $\mathrm{~m}^{2}$ & \\
\hline Anlagenfl & (gesamt) & & & & & 3226,13 & $\mathrm{~m}^{2}$ & 4860,00 & $\mathrm{~m}^{2}$ & \\
\hline zu ve & tende & & & & & & & & & \\
\hline Abwa & menge & 0,2 & $m^{3} / m^{2 *} a$ & & & 645,23 & $\mathrm{~m}^{3} / \mathrm{a}$ & 972,00 & $\mathrm{~m}^{3} / \mathrm{a}$ & \\
\hline
\end{tabular}




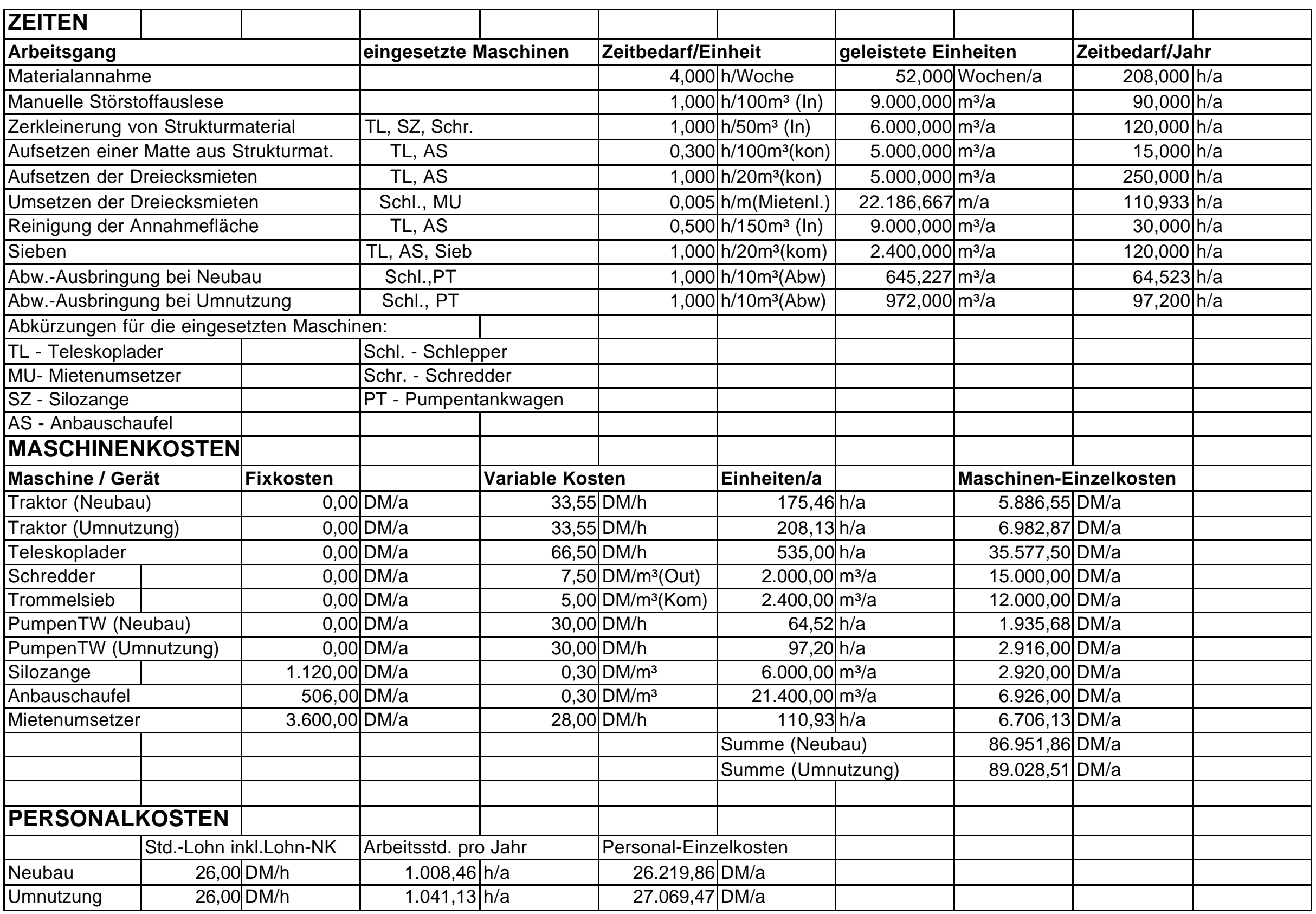




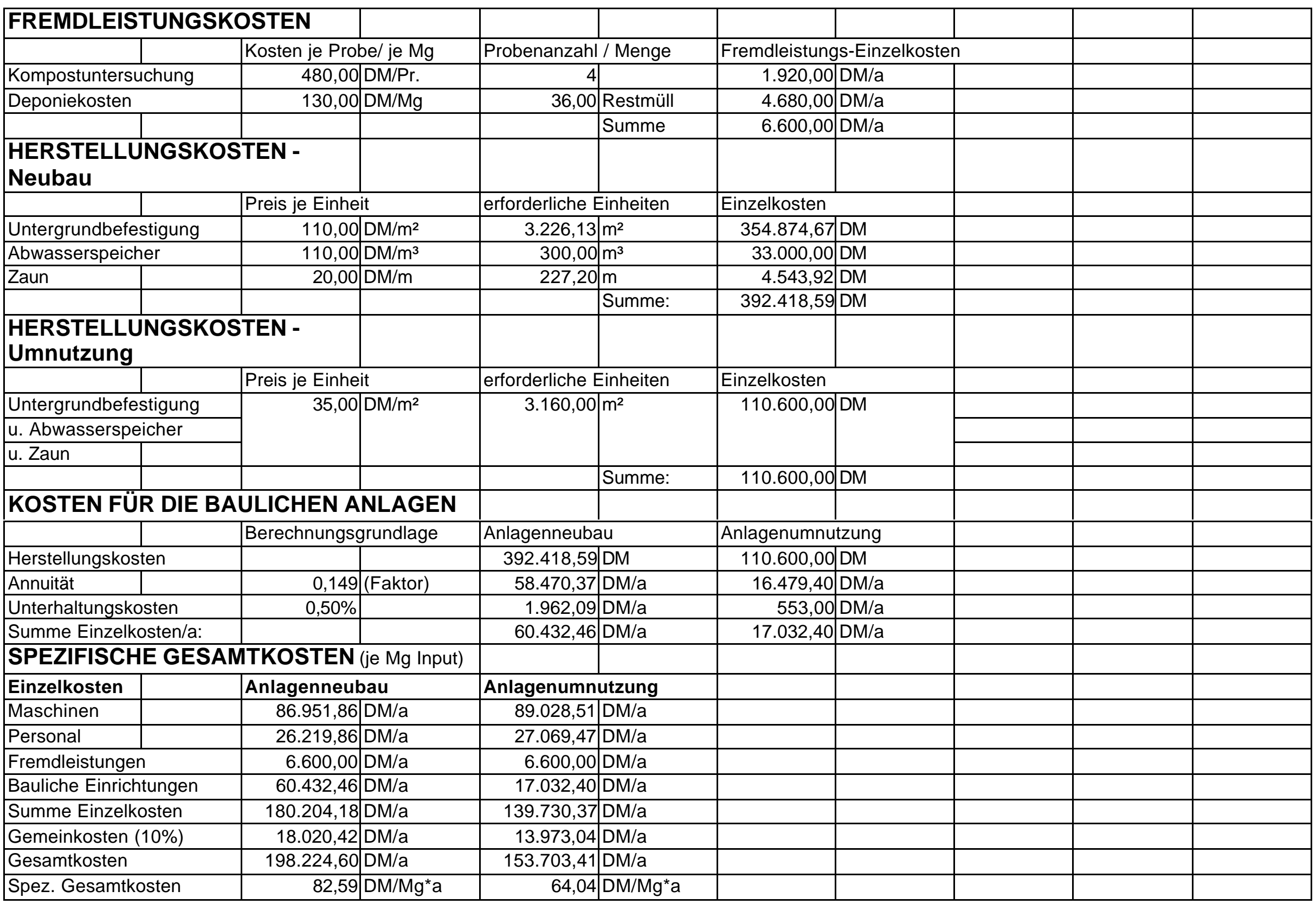


Kostenvariante D12

\begin{tabular}{|c|c|c|c|c|c|c|c|c|c|c|}
\hline MATERIAI & & & & & & & & & & \\
\hline Jahresinputn & nge & & $2.600,00$ & $\mathrm{Mg} / \mathrm{a}$ & & & & & & \\
\hline Zusammense & zung & & $60 \%$ & Vol.-\% & Bioabfälle & Haushalten & & & & \\
\hline & & & $40 \%$ & Vol.-\% & gehäckselt & Grüngut & & & & \\
\hline Dichte & & & 0,6 & $\mathrm{Mg} / \mathrm{m}^{3}$ & Bioabfälle & Haushalten & & & & \\
\hline & & & 0,3 & $\mathrm{Mg} / \mathrm{m}^{3}$ & gehäckselt & Grüngut & & & & \\
\hline & & & 0,48 & $\mathrm{Mg} / \mathrm{m}^{3}$ & konditionie & 5 Material & & & & \\
\hline & & & \begin{tabular}{l|l}
0,5 & 1
\end{tabular} & $\mathrm{Mg} / \mathrm{m}^{3}$ & Fertigkomp & & & & & \\
\hline Volumen & & & $5.416,67$ & $\mathrm{~m}^{3} / \mathrm{a}$ & konditionie & 5 Material & & & & \\
\hline & & & $3.250,00$ & $\mathrm{~m}^{3} / \mathrm{a}$ & Bioabfälle & Haushalten & & & & \\
\hline & & & $6.500,00$ & $\mathrm{~m}^{3} / \mathrm{a}$ & angeliefert & Grüngut & & & & \\
\hline & & & $2.166,67$ & $\mathrm{~m}^{3} / \mathrm{a}$ & gehäckselt & Grüngut & & & & \\
\hline & & & $2.600,00$ & $\mathrm{~m}^{3} / \mathrm{a}$ & Fertigkomp & & & & & \\
\hline Gewichtsant & & & $1.950,00$ & $\mathrm{Mg} / \mathrm{a}$ & Bioabfälle c & Haushalten & & & & \\
\hline & & & 650,00 & $\mathrm{Mg} / \mathrm{a}$ & Grüngut & & & & & \\
\hline & & & $1.300,00$ & $\mathrm{Mg} / \mathrm{a}$ & Fertigkomp & & & & & \\
\hline Rottedauer & & & \begin{tabular}{l|l}
12 & 1 \\
\end{tabular} & Wochen & & & & & & \\
\hline durchschnittl & hes & & 200,00 & $\mathrm{Mg}$ & & Rottematerial & eines & & & \\
\hline Monatsaufko & men & & $416,67 \mathrm{r}$ & $\mathrm{m}^{3}$ (kon) & & Durchlaufs in & der Anlage & 866,67 & $\mathrm{~m}^{3}$ & \\
\hline maximaler M & natsanfall & & 364,00 & $\mathrm{Mg}$ & entspr. 1 & vom Input/a & & & & \\
\hline & & & $\begin{array}{ll}758,33 & r \\
\end{array}$ & $\mathrm{~m}^{3}$ & & & & & & \\
\hline TS-Gehalt (F & rtigkompost) & & $61,70 \%$ & & & & & & & \\
\hline Mietenhöhe & & & $1,5 \mathrm{r}$ & $\mathrm{m}$ & Mietenquer & hnitt & & & & \\
\hline Mietenbasisk & eite & & $2,5 \mathrm{r}$ & $\mathrm{m}$ & $\overline{1,8}$ & $\mathrm{~m}^{2}$ & & & & \\
\hline ANLAGEN & JIMENSIOI & IERUNG & & & & & & & & \\
\hline Anlagentei & & Berechnung & sgrundlage & & & Anlagenneub & bau & Anlagenumnu & utzung & \\
\hline Anliefer & igsfläche & $5 \%$ & vom Input in M & hg/a, ausg & ickt in $\mathrm{m}^{2}$ & 130,00 & $\mathrm{~m}^{2}$ & 850,00 & $\mathrm{~m}^{2}$ & \\
\hline Rottefläche & & 1,33 & $\mathrm{~m}^{2} / \mathrm{m}^{3}$ Rottema & aterial bei & M.-Anfall & 2103,11 & $m^{2}$ & & $m^{2}$ & \\
\hline Rangierfläch & & $40 \%$ & der Rottefläche & & & 841,24 & $m^{2}$ & 3160,00 & & \\
\hline Zwische & lager für & & der Rottefläche & & & & $m^{2}$ & & & \\
\hline Struktu & naterial & $10 \%$ & & & & 210,31 & & & & \\
\hline Kompostlage & & $10 \%$ & der Rottefläche & & & 210,31 & $m^{2}$ & 850,00 & $m^{2}$ & \\
\hline Anlagenflä & he (gesamt) & & & & & 3494,98 & $m^{2}$ & 4860,00 & $m^{2}$ & \\
\hline zu ver & ertende & & & & & & & & & \\
\hline Abwas & rrmenge & 0,2 & $m^{3} / m^{2 *} a$ & & & 699,00 & $m^{3} / a$ & 972,00 & $m^{3} / a$ & \\
\hline
\end{tabular}




\begin{tabular}{|c|c|c|c|c|c|c|c|c|c|c|}
\hline \multicolumn{11}{|l|}{ ZEITEN } \\
\hline \multicolumn{3}{|l|}{ Arbeitsgang } & \multicolumn{2}{|c|}{ eingesetzte Maschinen } & \multicolumn{2}{|c|}{ Zeitbedarf/Einheit } & \multicolumn{2}{|c|}{ geleistete Einheiten } & \multicolumn{2}{|c|}{ Zeitbedarf/Jahr } \\
\hline \multicolumn{3}{|c|}{ Materialannahme } & & & 4,000 & h/Woche & 52,000 & Wochen/a & 208,000 & $h / a$ \\
\hline \multicolumn{3}{|c|}{ Manuelle Störstoffauslese } & & & 1,000 & $h / 100 m^{3}(\operatorname{In})$ & $9.750,000$ & $\mathrm{~m}^{3} / \mathrm{a}$ & 97,500 & $h / a$ \\
\hline \multicolumn{3}{|c|}{ Zerkleinerung von Strukturmaterial } & TL, SZ, Schr. & & 1,000 & $h / 50 m^{3}(\ln )$ & $6.500,000$ & $\mathrm{~m}^{3} / \mathrm{a}$ & 130,000 & $h / a$ \\
\hline \multicolumn{3}{|c|}{ Aufsetzen einer Matte aus Strukturmat. } & TL, AS & & 0,300 & $\mathrm{~h} / 100 \mathrm{~m}^{3}$ (kon) & $5.416,667$ & $\mathrm{~m}^{3} / \mathrm{a}$ & 16,250 & $h / a$ \\
\hline \multicolumn{3}{|c|}{ Aufsetzen der Dreiecksmieten } & TL, AS & & 1,000 & $\mathrm{~h} / 20 \mathrm{~m}^{3}$ (kon) & $5.416,667$ & $\mathrm{~m}^{3} / \mathrm{a}$ & 270,833 & $\mathrm{~h} / \mathrm{a}$ \\
\hline \multicolumn{3}{|c|}{ Umsetzen der Dreiecksmieten } & Schl., MU & & 0,005 & $\mathrm{~h} / \mathrm{m}$ (Mietenl.) & $24.035,556$ & $\mathrm{~m} / \mathrm{a}$ & 120,178 & $\mathrm{~h} / \mathrm{a}$ \\
\hline \multicolumn{3}{|c|}{ Reinigung der Annahmefläche } & TL, AS & & 0,500 & $h / 150 m^{3}(\ln )$ & $9.750,000$ & $\mathrm{~m}^{3} / \mathrm{a}$ & 32,500 & $h / a$ \\
\hline \multicolumn{3}{|l|}{ Sieben } & TL, AS, Sieb & & 1,000 & $\mathrm{~h} / 20 \mathrm{~m}^{3}(\mathrm{kom})$ & $2.600,000$ & $\mathrm{~m}^{3} / \mathrm{a}$ & 130,000 & $\mathrm{~h} / \mathrm{a}$ \\
\hline \multicolumn{3}{|c|}{ Abw.-Ausbringung bei Neubau } & Schl.,PT & & 1,000 & $\mathrm{~h} / 10 \mathrm{~m}^{3}(\mathrm{Abw})$ & 698,996 & $\mathrm{~m}^{3} / \mathrm{a}$ & 69,900 & $h / a$ \\
\hline \multicolumn{3}{|c|}{ Abw.-Ausbringung bei Umnutzung } & Schl., PT & & 1,000 & $\mathrm{~h} / 10 \mathrm{~m}^{3}(\mathrm{Abw})$ & 972,000 & $\mathrm{~m}^{3} / \mathrm{a}$ & 97,200 & $h / a$ \\
\hline \multicolumn{11}{|c|}{ Abkürzungen für die eingesetzten Maschinen: } \\
\hline \multicolumn{2}{|c|}{ TL - Teleskoplader } & & \multicolumn{2}{|c|}{ Schl. - Schlepper } & & & & & & \\
\hline \multicolumn{2}{|c|}{\begin{tabular}{|l} 
MU- Mietenumsetzer \\
\end{tabular}} & & Schr. - Schred & dder & & & & & & \\
\hline \multicolumn{2}{|c|}{ SZ - Silozange } & & PT - Pumpenta & tankwagen & & & & & & \\
\hline \multicolumn{11}{|c|}{ AS - Anbauschaufel } \\
\hline \multicolumn{11}{|c|}{ MASCHINENKOSTEN } \\
\hline \multicolumn{2}{|c|}{ Maschine / Gerät } & Fixkosten & & \multicolumn{2}{|c|}{ Variable Kosten } & Einheiten/a & & \multicolumn{2}{|c|}{ Maschinen-Einzelkosten } & \\
\hline Traktor (Neub & au) & 0,00 & $\mathrm{DM} / \mathrm{a}$ & 33,55 & $\mathrm{DM} / \mathrm{h}$ & 190,08 & $\mathrm{~h} / \mathrm{a}$ & $6.377,09$ & $\mathrm{DM} / \mathrm{a}$ & \\
\hline Traktor (Umnı & itzung) & 0,00 & $\mathrm{DM} / \mathrm{a}$ & 33,55 & $\mathrm{DM} / \mathrm{h}$ & 217,38 & $\mathrm{~h} / \mathrm{a}$ & $7.293,02$ & $\mathrm{DM} / \mathrm{a}$ & \\
\hline Teleskoplader & & 0,00 & $\mathrm{DM} / \mathrm{a}$ & 66,50 & $\mathrm{DM} / \mathrm{h}$ & 579,58 & $\mathrm{~h} / \mathrm{a}$ & $38.542,29$ & $\mathrm{DM} / \mathrm{a}$ & \\
\hline Schredder & & 0,00 & $\mathrm{DM} / \mathrm{a}$ & 7,50 & $\mathrm{DM} / \mathrm{m}^{3}$ (Out) & $2.166,67$ & $\mathrm{~m}^{3} / \mathrm{a}$ & $16.250,00$ & $\mathrm{DM} / \mathrm{a}$ & \\
\hline Trommelsieb & & 0,00 & $\mathrm{DM} / \mathrm{a}$ & 5,00 & $\mathrm{DM} / \mathrm{m}^{3}(\mathrm{Kom})$ & $2.600,00$ & $\mathrm{~m}^{3} / \mathrm{a}$ & $13.000,00$ & $\mathrm{DM} / \mathrm{a}$ & \\
\hline PumpenTW (I & Veubau) & 0,00 & $\mathrm{DM} / \mathrm{a}$ & 30,00 & $\mathrm{DM} / \mathrm{h}$ & 69,90 & $\mathrm{~h} / \mathrm{a}$ & $2.096,99$ & $\mathrm{DM} / \mathrm{a}$ & \\
\hline PumpenTW (L & Jmnutzung) & 0,00 & $D M / a$ & 30,00 & $D M / h$ & 97,20 & $h / a$ & $2.916,00$ & $\mathrm{DM} / \mathrm{a}$ & \\
\hline Silozange & & $1.120,00$ & DM/a & 0,30 & $\mathrm{DM} / \mathrm{m}^{3}$ & $6.500,00$ & $\mathrm{~m}^{3} / \mathrm{a}$ & $3.070,00$ & $\mathrm{DM} / \mathrm{a}$ & \\
\hline Anbauschaufe & & 506,00 & $\mathrm{DM} / \mathrm{a}$ & 0,30 & $\mathrm{DM} / \mathrm{m}^{3}$ & $23.183,33$ & $\mathrm{~m}^{3} / \mathrm{a}$ & $7.461,00$ & $\mathrm{DM} / \mathrm{a}$ & \\
\hline Mietenumsetz & & $3.600,00$ & $\mathrm{DM} / \mathrm{a}$ & 28,00 & $\mathrm{DM} / \mathrm{h}$ & 120,18 & $\mathrm{~h} / \mathrm{a}$ & $6.964,98$ & $\mathrm{DM} / \mathrm{a}$ & \\
\hline & & & & & & Summe (Neuk & bau) & $93.762,35$ & $\mathrm{DM} / \mathrm{a}$ & \\
\hline & & & & & & Summe (Umn & hutzung) & $95.497,29$ & $\mathrm{DM} / \mathrm{a}$ & \\
\hline PERSONA & LOSTEN & & & & & & & & & \\
\hline & Std.-Lohn inkl & I.Lohn-NK & Arbeitsstd. pro & o Jahr & Personal-Einz & zelkosten & & & & \\
\hline Neubau & 26,00 & $D M / h$ & $1.075,16$ & $\mathrm{~h} / \mathrm{a}$ & $27.954,18$ & $D M / a$ & & & & \\
\hline Umnutzung & 26,00 & $D M / h$ & $1.102,46$ & $\mathrm{~h} / \mathrm{a}$ & $28.663,99$ & DM/a & & & & \\
\hline
\end{tabular}




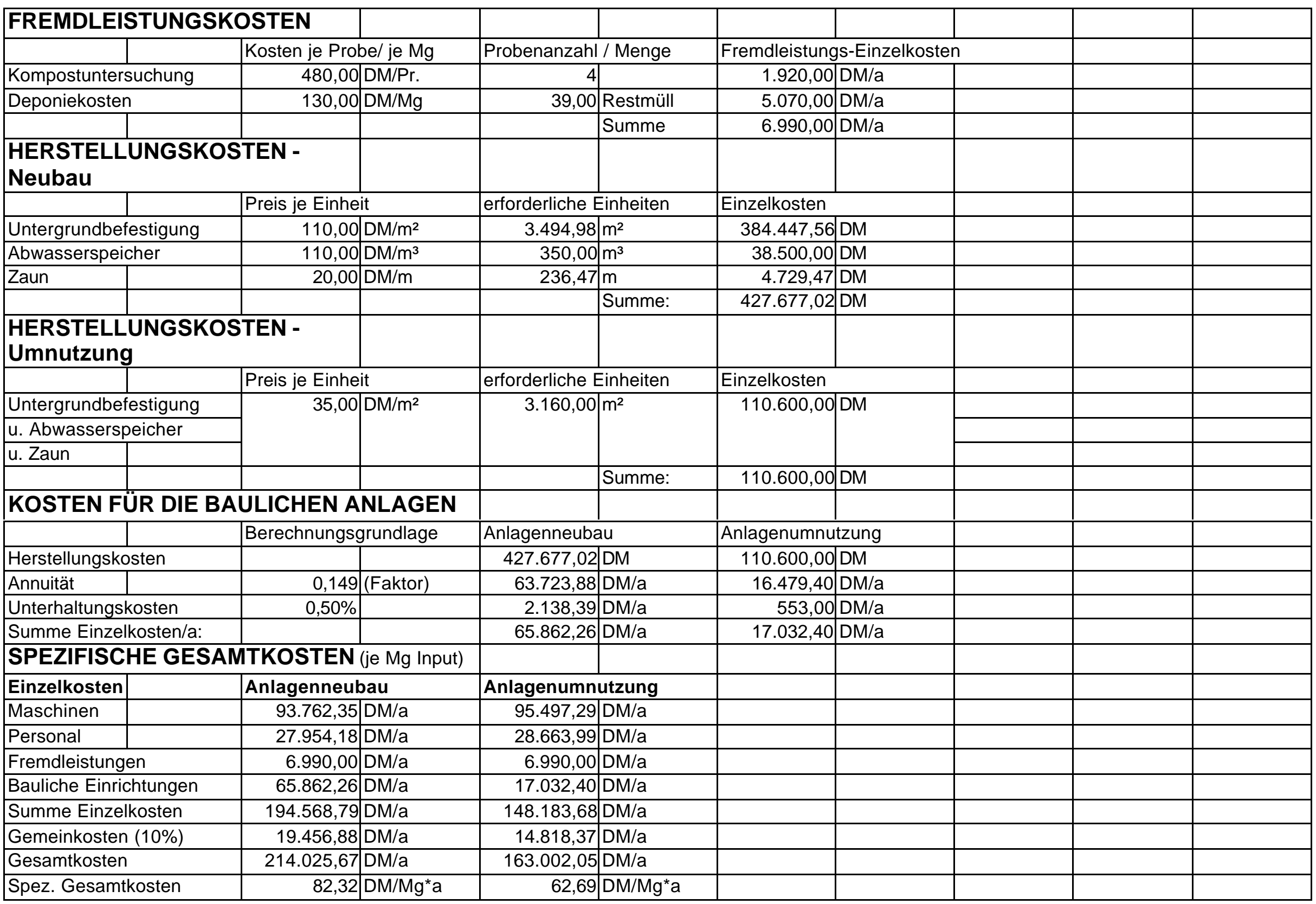


Kostenvariante D13

\begin{tabular}{|c|c|c|c|c|c|c|c|c|c|c|}
\hline MATERIA & & & & & & & & & & \\
\hline Jahresinput & & & $2.800,00$ & $\mathrm{Mg} / \mathrm{a}$ & & & & & & \\
\hline Zusammens & & & $60 \%$ & Vol.-\% & Bioabfälle & s Haushalten & & & & \\
\hline & & & $40 \%$ & Vol.-\% & gehäckselt & Grüngut & & & & \\
\hline Dichte & & & 0,6 & $\mathrm{Mg} / \mathrm{m}^{3}$ & Bioabfälle & s Haushalten & & & & \\
\hline & & & 0,3 & $\mathrm{Mg} / \mathrm{m}^{3}$ & gehäckselt & Grüngut & & & & \\
\hline & & & 0,48 & $\mathrm{Mg} / \mathrm{m}^{3}$ & konditionie & s Material & & & & \\
\hline & & & 0,5 & $\mathrm{Mg} / \mathrm{m}^{3}$ & Fertigkomp & & & & & \\
\hline Volumen & & & $5.833,33$ & $\mathrm{~m}^{3} / \mathrm{a}$ & konditionie & s Material & & & & \\
\hline & & & $3.500,00$ & $\mathrm{~m}^{3} / \mathrm{a}$ & Bioabfälle & s Haushalten & & & & \\
\hline & & & $7.000,00$ & $\mathrm{~m}^{3} / \mathrm{a}$ & angelieferte & Grüngut & & & & \\
\hline & & & $2.333,33$ & $\mathrm{~m}^{3} / \mathrm{a}$ & gehäckselt & Grüngut & & & & \\
\hline & & & $2.800,00$ & $\mathrm{~m}^{3} / \mathrm{a}$ & Fertigkomp & & & & & \\
\hline Gewichtsan & & & $2.100,00$ & $\mathrm{Mg} / \mathrm{a}$ & Bioabfälle c & s Haushalten & & & & \\
\hline & & & 700,00 & $\mathrm{Mg} / \mathrm{a}$ & Grüngut & & & & & \\
\hline & & & $1.400,00$ & $\mathrm{Mg} / \mathrm{a}$ & Fertigkomp & & & & & \\
\hline Rottedauer & & & 12 & Wochen & & & & & & \\
\hline durchschnit & & & 215,38 & $\mathrm{Mg}$ & & Rottematerial & eines & & & \\
\hline Monatsaufk & & & 448,72 & $m^{3}$ (kon) & & Durchlaufs in & der Anlage & 933,33 & $\mathrm{~m}^{3}$ & \\
\hline maximaler 1 & atsanfall & & 392,00 & $\mathrm{Mg}$ & entspr. 1 & vom Input/a & & & & \\
\hline & & & 816,67 & $\mathrm{~m}^{3}$ & & & & & & \\
\hline TS-Gehalt & igkompost) & & $61,70 \%$ & & & & & & & \\
\hline Mietenhöhe & & & 1,5 & $\mathrm{~m}$ & Mietenquer & hnitt & & & & \\
\hline Mietenbasis & & & 2,5 & $m$ & 1,8 & $\mathrm{~m}^{2}$ & & & & \\
\hline ANLAGE & IENSIO & IERUNG & & & & & & & & \\
\hline Anlagent & & Berechnung & gsgrundlage & & & Anlagenneuk & bau & Anlagenumn & utzung & \\
\hline Anliefe & sfläche & $5 \%$ & vom Input in 1 & $\mathrm{Mg} / \mathrm{a}$, ausg & ückt in $\mathrm{m}^{2}$ & 140,00 & $\mathrm{~m}^{2}$ & 850,00 & $\mathrm{~m}^{2}$ & \\
\hline Rottefläch & & 1,33 & $\mathrm{~m}^{2} / \mathrm{m}^{3}$ Rottem & aterial bei & x.M.-Anfall & 2264,89 & $\mathrm{~m}^{2}$ & & $\mathrm{~m}^{2}$ & \\
\hline Rangierfläc & & $40 \%$ & der Rottefläch & & & 905,96 & $\mathrm{~m}^{2}$ & 3160,00 & & \\
\hline Zwisch & gger für & & der Rottefläch & & & & $\mathrm{m}^{2}$ & & & \\
\hline Strukt & aterial & $10 \%$ & & & & 226,49 & & & & \\
\hline Kompostla & & $10 \%$ & der Rottefläch & & & 226,49 & $\mathrm{~m}^{2}$ & 850,00 & $\mathrm{~m}^{2}$ & \\
\hline Anlagenfl & (gesamt) & & & & & 3763,82 & $\mathrm{~m}^{2}$ & 4860,00 & $\mathrm{~m}^{2}$ & \\
\hline zu ve & tende & & & & & & & & & \\
\hline Abwa & menge & 0,2 & $m^{3} / m^{2 *} a$ & & & 752,76 & $\mathrm{~m}^{3} / \mathrm{a}$ & 972,00 & $\mathrm{~m}^{3} / \mathrm{a}$ & \\
\hline
\end{tabular}




\begin{tabular}{|c|c|c|c|c|c|c|c|c|c|c|}
\hline \multicolumn{11}{|l|}{ ZEITEN } \\
\hline \multicolumn{3}{|l|}{ Arbeitsgang } & \multicolumn{2}{|c|}{ eingesetzte Maschinen } & \multicolumn{2}{|c|}{ Zeitbedarf/Einheit } & \multicolumn{2}{|c|}{ geleistete Einheiten } & \multicolumn{2}{|c|}{ Zeitbedarf/Jahr } \\
\hline \multicolumn{3}{|c|}{ Materialannahme } & & & 4,000 & h/Woche & 52,000 & Wochen/a & 208,000 & $h / a$ \\
\hline \multicolumn{3}{|c|}{ Manuelle Störstoffauslese } & & & 1,000 & $h / 100 m^{3}(\operatorname{In})$ & $10.500,000$ & $\mathrm{~m}^{3} / \mathrm{a}$ & 105,000 & $h / a$ \\
\hline \multicolumn{3}{|c|}{ Zerkleinerung von Strukturmaterial } & \multicolumn{2}{|l|}{ TL, SZ, Schr. } & 1,000 & $h / 50 m^{3}(\ln )$ & $7.000,000$ & $\mathrm{~m}^{3} / \mathrm{a}$ & 140,000 & $h / a$ \\
\hline \multicolumn{3}{|c|}{ Aufsetzen einer Matte aus Strukturmat. } & \multicolumn{2}{|l|}{ TL, AS } & 0,300 & $\mathrm{~h} / 100 \mathrm{~m}^{3}$ (kon) & $5.833,333$ & $\mathrm{~m}^{3} / \mathrm{a}$ & 17,500 & $h / a$ \\
\hline \multicolumn{3}{|c|}{ Aufsetzen der Dreiecksmieten } & \multicolumn{2}{|l|}{ TL, AS } & 1,000 & $\mathrm{~h} / 20 \mathrm{~m}^{3}$ (kon) & $5.833,333$ & $\mathrm{~m}^{3} / \mathrm{a}$ & 291,667 & $\mathrm{~h} / \mathrm{a}$ \\
\hline \multicolumn{3}{|c|}{ Umsetzen der Dreiecksmieten } & \multicolumn{2}{|l|}{ Schl., MU } & 0,005 & $\mathrm{~h} / \mathrm{m}$ (Mietenl.) & $25.884,444$ & $\mathrm{~m} / \mathrm{a}$ & 129,422 & $h / a$ \\
\hline \multicolumn{3}{|c|}{ Reinigung der Annahmefläche } & \multicolumn{2}{|l|}{$\mathrm{TL}, \mathrm{AS}$} & 0,500 & $h / 150 m^{3}(\ln )$ & $10.500,000$ & $\mathrm{~m}^{3} / \mathrm{a}$ & 35,000 & $h / a$ \\
\hline \multicolumn{3}{|l|}{ Sieben } & \multicolumn{2}{|l|}{ TL, AS, Sieb } & 1,000 & $\mathrm{~h} / 20 \mathrm{~m}^{3}(\mathrm{kom})$ & $2.800,000$ & $\mathrm{~m}^{3} / \mathrm{a}$ & 140,000 & $\mathrm{~h} / \mathrm{a}$ \\
\hline \multicolumn{3}{|c|}{ Abw.-Ausbringung bei Neubau } & \multicolumn{2}{|l|}{ Schl.,PT } & 1,000 & $\mathrm{~h} / 10 \mathrm{~m}^{3}(\mathrm{Abw})$ & 752,764 & $\mathrm{~m}^{3} / \mathrm{a}$ & 75,276 & $h / a$ \\
\hline \multicolumn{3}{|c|}{ Abw.-Ausbringung bei Umnutzung } & \multicolumn{2}{|l|}{ Schl., PT } & 1,000 & $\mathrm{~h} / 10 \mathrm{~m}^{3}(\mathrm{Abw})$ & 972,000 & $\mathrm{~m}^{3} / \mathrm{a}$ & 97,200 & $h / a$ \\
\hline \multicolumn{11}{|c|}{ Abkürzungen für die eingesetzten Maschinen: } \\
\hline \multicolumn{3}{|c|}{\begin{tabular}{|l|l|} 
TL - Teleskoplader & \\
\end{tabular}} & Schl. - Schlep & oper & & & & & & \\
\hline MU- Mietenum & etzer & & Schr. - Schrec & dder & & & & & & \\
\hline SZ - Silozange & & & PT - Pumpent & tankwagen & & & & & & \\
\hline AS - Anbausc & aufel & & & & & & & & & \\
\hline MASCHINE & NKOSTEN & & & & & & & & & \\
\hline Maschine / G & & Fixkosten & & Variable Kost & ten & Einheiten/a & & Maschinen-Ei & inzelkosten & \\
\hline Traktor (Neub & & 0,00 & $D M / a$ & 33,55 & $D M / h$ & 204,70 & $h / a$ & $6.867,64$ & $D M / a$ & \\
\hline Traktor (Umnu & zung) & 0,00 & $\mathrm{DM} / \mathrm{a}$ & 33,55 & $D M / h$ & 226,62 & $h / a$ & $7.603,18$ & $\mathrm{DM} / \mathrm{a}$ & \\
\hline Teleskoplader & & 0,00 & $D M / a$ & 66,50 & $\mathrm{DM} / \mathrm{h}$ & 624,17 & $\mathrm{~h} / \mathrm{a}$ & $41.507,08$ & $\mathrm{DM} / \mathrm{a}$ & \\
\hline Schredder & & 0,00 & DM/a & 7,50 & $\mathrm{DM} / \mathrm{m}^{3}$ (Out) & $2.333,33$ & $\mathrm{~m}^{3} / \mathrm{a}$ & $17.500,00$ & $\mathrm{DM} / \mathrm{a}$ & \\
\hline Trommelsieb & & 0,00 & $\mathrm{DM} / \mathrm{a}$ & 5,00 & $\mathrm{DM} / \mathrm{m}^{3}(\mathrm{Kom})$ & $2.800,00$ & $m^{3} / a$ & $14.000,00$ & $D M / a$ & \\
\hline PumpenTW ( & abau) & 0,00 & $\mathrm{DM} / \mathrm{a}$ & 30,00 & $\mathrm{DM} / \mathrm{h}$ & 75,28 & $\mathrm{~h} / \mathrm{a}$ & $2.258,29$ & $\mathrm{DM} / \mathrm{a}$ & \\
\hline PumpenTW (L & nnutzung) & 0,00 & $D M / a$ & 30,00 & $D M / h$ & 97,20 & $h / a$ & $2.916,00$ & $\mathrm{DM} / \mathrm{a}$ & \\
\hline Silozange & & $1.120,00$ & DM/a & 0,30 & $\mathrm{DM} / \mathrm{m}^{3}$ & $7.000,00$ & $m^{3} / a$ & $3.220,00$ & $\mathrm{DM} / \mathrm{a}$ & \\
\hline Anbauschaufe & & 506,00 & $\mathrm{DM} / \mathrm{a}$ & 0,30 & $\mathrm{DM} / \mathrm{m}^{3}$ & $24.966,67$ & $\mathrm{~m}^{3} / \mathrm{a}$ & $7.996,00$ & $\mathrm{DM} / \mathrm{a}$ & \\
\hline Mietenumsetz & & $3.600,00$ & $\mathrm{DM} / \mathrm{a}$ & 28,00 & $\mathrm{DM} / \mathrm{h}$ & 129,42 & $h / a$ & $7.223,82$ & $\mathrm{DM} / \mathrm{a}$ & \\
\hline & & & & & & Summe (Neuk & bau) & $100.572,84$ & $D M / a$ & \\
\hline & & & & & & Summe (Umn & hutzung) & $101.966,08$ & $\mathrm{DM} / \mathrm{a}$ & \\
\hline PERSONA & KOSTEN & & & & & & & & & \\
\hline & Std.-Lohn in & kl.Lohn-NK & Arbeitsstd. pre & o Jahr & Personal-Einz & zelkosten & & & & \\
\hline Neubau & 26,00 & $\mathrm{DM} / \mathrm{h}$ & $1.141,87$ & $h / a$ & $29.688,50$ & $\mathrm{DM} / \mathrm{a}$ & & & & \\
\hline Umnutzung & 26,00 & DM/h & $1.163,79$ & $h / a$ & $30.258,51$ & $\mathrm{DM} / \mathrm{a}$ & & & & \\
\hline
\end{tabular}




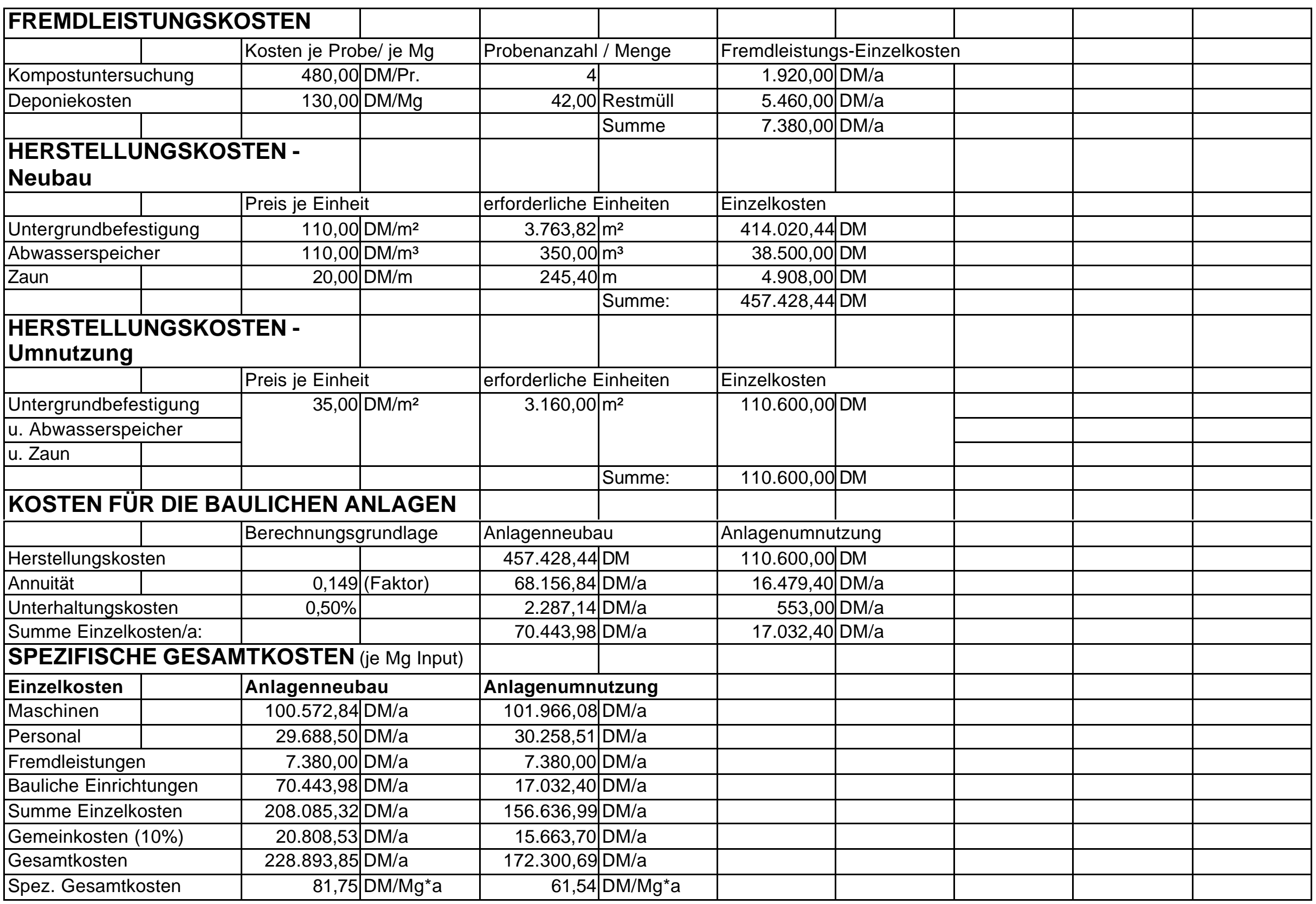




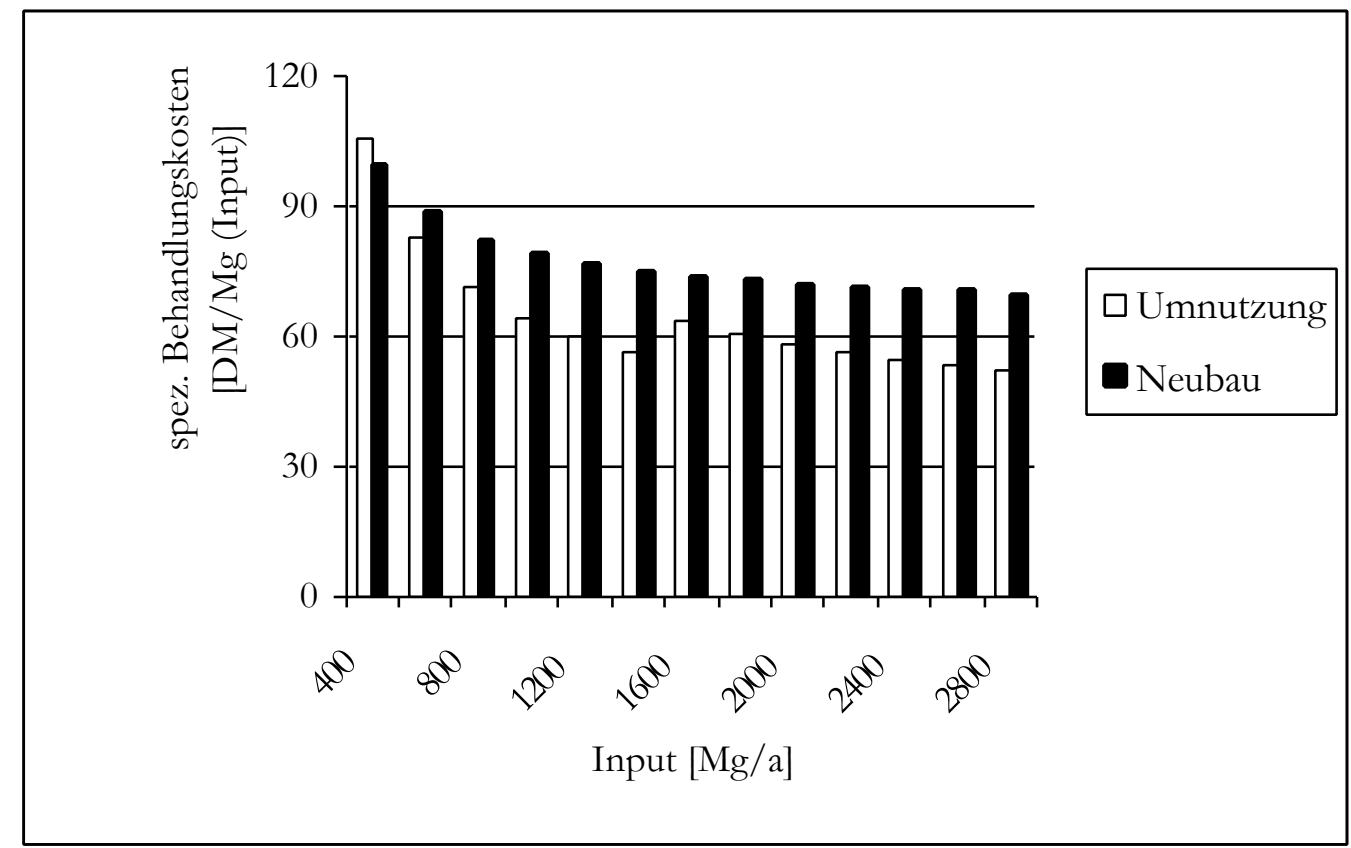

Abb. : Spezifische Behandlungskosten in Abhängigkeit vom Anlagendurchsatz (Strukturmaterialanteil: 20 Vol.-\%)

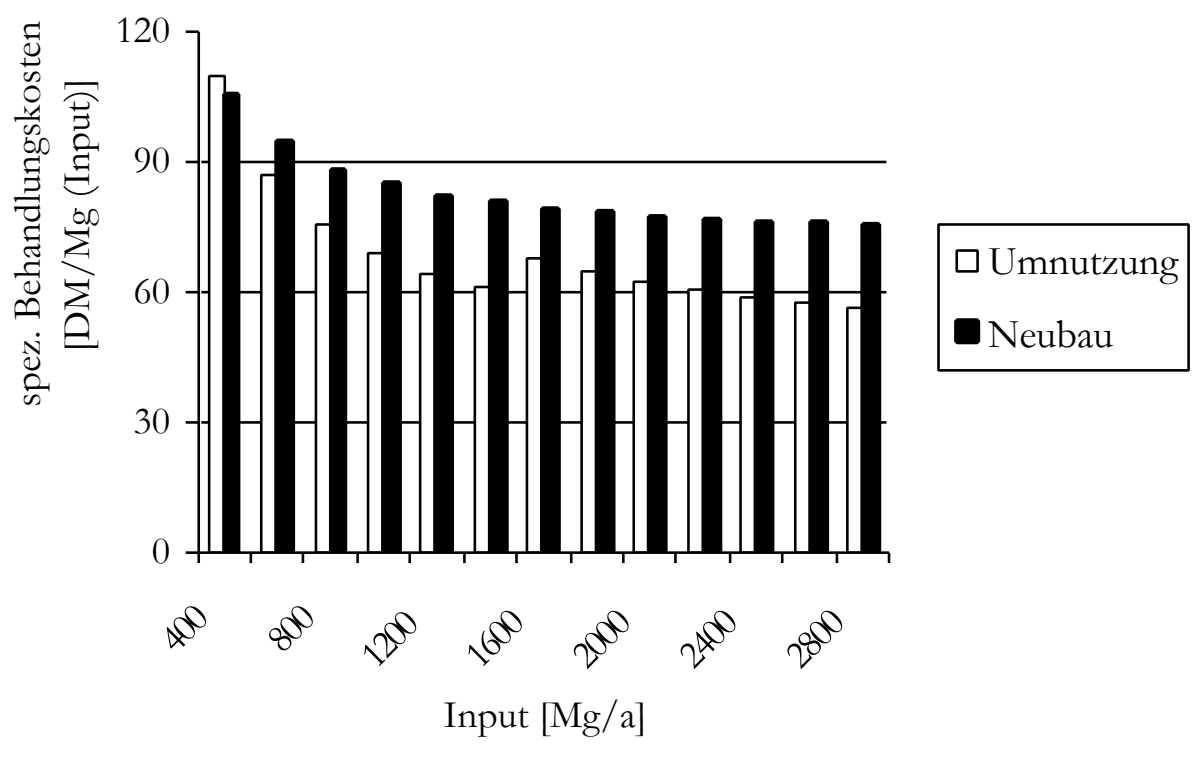

Abb. : Spezifische Behandlungskosten in Abhängigkeit vom Anlagendurchsatz (Strukturmaterialanteil: 30 Vol.-\%) 


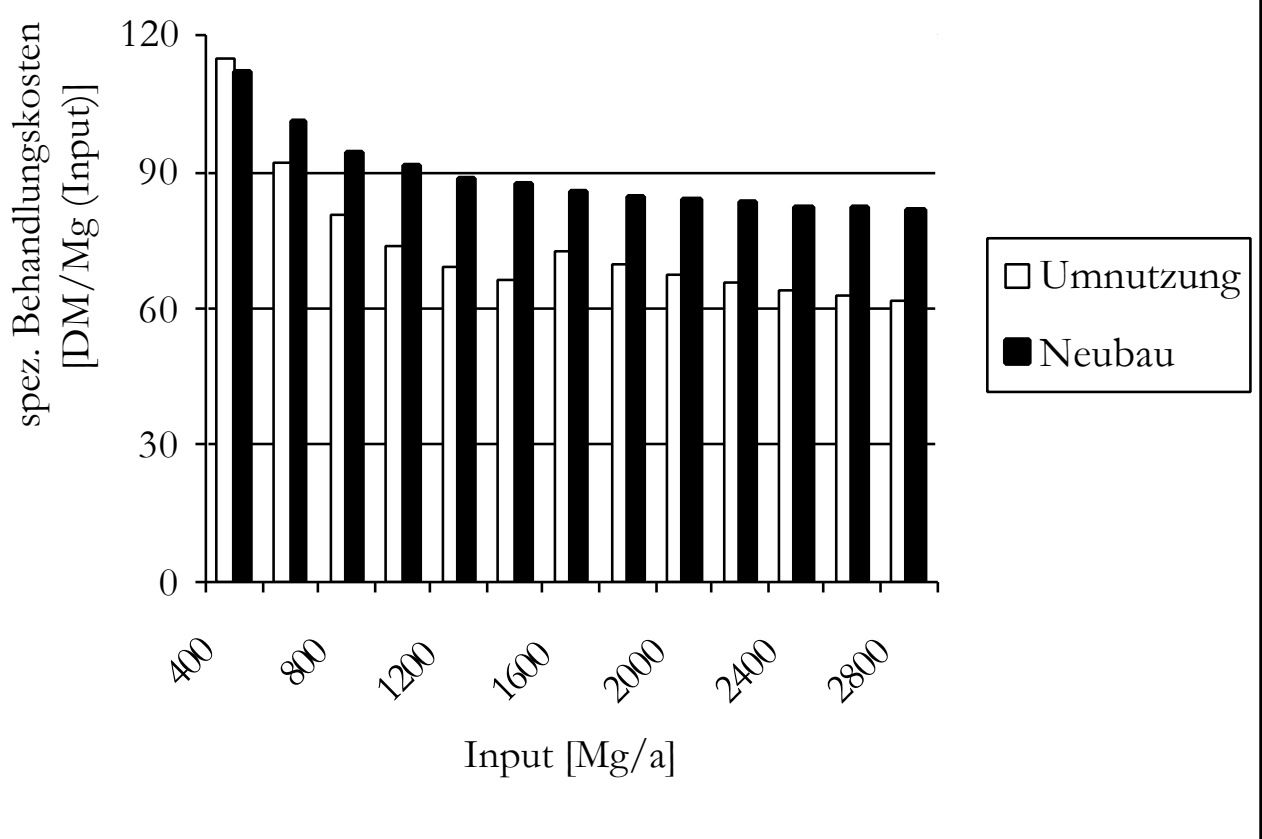

Abb. : Spezifische Behandlungskosten in Abhängigkeit vom Anlagendurchsatz (Strukturmaterialanteil: 40 Vol.-\%) 


\section{Versicherungsgesellschaften:}

Barmenia

Allgemeine VersicherungsAG

42094 Wuppertal

LVM-Versicherungen

Kolde-Ring 21

48126 Münster

$\mathrm{R}+\mathrm{V}$ Allgemeine Versicherung AG

65181 Wiesbaden

Vereinte Versicherung AG

80291 München

Gothaer Versicherungen

50598 Köln

Concordia

Versicherungs-Gesellschaft

30621 Hannover

Transatlantische

Allgemeine Versicherung AG

22357 Hamburg

Albingia Versicherungs AG

20079 Hamburg

Gerling-Konzern

Allgemeine Versicherungs AG

50597 Köln

Itzehoer Versicherung

Hansestraße 10

25521 Itzehoe 
Versicherungsmakler:

GHG Agrarservice GmbH

Hardt 5

92685 Floß

AV-Agrarversicherungsdienst

Ernst-Reuter-Platz 8

10587 Berlin

Gayen \& Berns Homann

Börsenbrücke 6

20457 Hamburg 
Gehalte an löslichen Pflanzennährstoffen in den

Bioabfallkomposten in Tarnow und Borrentin

Nährstoffe lösliche Gehalte [mg/l FM] - Kompost Tarnow

\begin{tabular}{|l|r|rrrr|r|}
\hline Proben-Nr.: & 661 & 220 & 221 & 702 & 1215 & Mittelwert \\
\hline $\mathrm{N}$ & 04.09 .96 & 13.02 .97 & 13.02 .97 & 22.05 .97 & 01.10 .97 & \\
\hline P2O5 & 742 & 57 & 387 & 227 & 616 & 405,80 \\
\hline $\mathrm{K} 2 \mathrm{O}$ & 2665 & 1089 & 1833 & 1393 & 808 & 1557,60 \\
\hline $\mathrm{MgO}$ & 6862 & 4079 & 6578 & 4551 & 444 & 4502,80 \\
\hline
\end{tabular}

Nährstoffe lösliche Gehalte [mg/l FM] - Kompost Borrentin

\begin{tabular}{|l|r|r|r|r|r|r|}
\hline Proben-Nr.: & 846 & 465 & 703 & 244 & 634 & Mittelwert \\
& 01.10 .96 & 17.03 .97 & 22.05 .97 & 26.02 .98 & 15.06 .98 & \\
\hline $\mathrm{N}$ & 95 & 114 & 19 & 22 & 171 & 84,20 \\
\hline $\mathrm{P} 2 \mathrm{O} 5$ & 2054 & 779 & 716 & 1224 & 799 & 1114,40 \\
\hline $\mathrm{K} 2 \mathrm{O}$ & 7579 & 2427 & 2682 & 5511 & 3041 & 4248,00 \\
\hline $\mathrm{MgO}$ & 117 & 130 & 138 & 204 & 164 & 150,60 \\
\hline
\end{tabular}

Nährstoffe lösliche Gehalte [mg/100g TM] - Kompost Tarnow

\begin{tabular}{|l|r|r|r|r|r|r|}
\hline Proben-Nr.: & 661 & 220 & 221 & 702 & 1215 & Mittelwert \\
& 04.09 .96 & 13.02 .97 & 13.02 .97 & 22.05 .97 & 01.10 .97 & \\
\hline $\mathrm{N}$ & 62,5 & 9,61 & 74,58 & 62,52 & 156,96 & 73,23 \\
\hline P2O5 & 224,47 & 183,65 & 353,26 & 383,66 & 205,89 & 270,19 \\
\hline K2O & 577,99 & 687,9 & 1267,73 & 1253,44 & 113,14 & 780,04 \\
\hline MgO & 35,97 & 42,84 & 79,21 & 48,47 & 51,98 & 51,69 \\
\hline
\end{tabular}

Nährstoffe lösliche Gehalte [mg/100g TM] - Kompost Borrentin

\begin{tabular}{|c|c|c|c|c|c|c|}
\hline Proben-Nr.: & 846 & 465 & 703 & 244 & 634 & Mittelwert \\
\hline & 01.10 .96 & 17.03 .97 & 22.05 .97 & 26.02 .98 & 15.06.98 & \\
\hline $\mathrm{N}$ & 21,82 & 32 & 4,31 & 4,37 & 40,48 & 20,60 \\
\hline $\mathrm{P} 2 \mathrm{O5}$ & 471,78 & 218,67 & 162,43 & 242,86 & 189,16 & 256,98 \\
\hline K2O & 1740,8 & 681,28 & 608,44 & 1093,45 & 719,93 & 968,78 \\
\hline $\mathrm{MgO}$ & 26,87 & 36,49 & 31,31 & 40,48 & 38,83 & 34,80 \\
\hline
\end{tabular}


Schwermetallgehalte in den Bioabfallkomposten aus den Anlagen in Tarnow und Borrentin

Schwermetallgehalte - Kompost Tarnow [mg/kg TS]

\begin{tabular}{|l|rrrrr|r|}
\hline Proben-Nr.: & 661 & 220 & 221 & 702 & 1215 & Mittelwert \\
\hline $\mathrm{Pb}$ & 04.09 .96 & 13.02 .97 & 13.02 .97 & 22.05 .97 & 01.10 .97 & \\
$\mathrm{Cd}$ & 59,2 & 47,5 & 39,7 & 70,3 & 35,3 & 50,40 \\
$\mathrm{Cr}$ & 0,41 & 0,21 & 0,34 & 0,34 & 0,35 & 0,33 \\
$\mathrm{Cu}$ & 31,3 & 19,5 & 52,6 & 38,7 & 40,3 & 36,48 \\
$\mathrm{Ni}$ & 14 & 17,8 & 71,5 & 35,5 & 30,6 & 33,88 \\
$\mathrm{Hg}$ & 8,23 & 7,37 & 13,43 & 8,16 & 7,98 & 9,03 \\
$\mathrm{Zn}$ & 0,09 & 0,14 & 0,2 & 0,27 & 0,06 & 0,15 \\
\hline
\end{tabular}

Schwermetallgehalte - Kompost Borrentin [mg/kg TS]

\begin{tabular}{|l|rrrrr|r|}
\hline Proben-Nr.: & 846 & 465 & 703 & 244 & 634 & Mittelwert \\
& 01.10 .96 & 17.03 .97 & 22.05 .97 & 26.02 .98 & 15.06 .98 & \\
\hline $\mathrm{Pb}$ & 40,3 & 33 & 26,5 & 47,7 & 68,5 & 43,20 \\
$\mathrm{Cd}$ & 0,22 & 0,27 & 0,27 & 0,27 & 0,88 & 0,38 \\
$\mathrm{Cr}$ & 43,9 & 84,3 & 34,5 & 29,5 & 46,7 & 47,78 \\
$\mathrm{Cu}$ & 22,1 & 17,9 & 17,2 & 24 & 24,6 & 21,16 \\
$\mathrm{Ni}$ & 5,85 & 6,25 & 5,05 & 6,51 & 5,84 & 5,90 \\
$\mathrm{Hg}$ & 0,2 & 0,3 & 0,26 & 0,12 & 0,09 & 0,19 \\
$\mathrm{Zn}$ & 179 & 111 & 107 & 117 & 236 & 150,00 \\
\hline
\end{tabular}




\section{Tabellenverzeichnis}

Tab.1.1: Ökonomische Aspekte der Bioabfallkompostierung in

landwirtschaftlichen Low-Tech-Anlagen und der landbaulichen

Kompostverwertung

Tab.2.1: Einteilung der Rottegrade entsprechend den Maximaltemperaturen im

Selbsterhitzungsversuch

Tab.3.1: Genehmigungsverfahren für Kompostierungsanlagen

Tab.3.2: Geeignete Inputmaterialien für die Kompostierung gemäß BioAbfV

Tab.4.1: Daten zu den Kompostausbringungsflächen der Verwerterbetriebe im

Tab.5.1: Zeitbedarfswerte für die Arbeitsgänge der offenen Mietenkompostierung

Tab.5.2: Kostenansätze des einzelbetrieblichen Maschineneinsatzes 28

Tab. 5.3: Kostenansätze des überbetrieblichen Maschineneinsatzes 29

Tab. 5.4: Anlagendimensionierung bei der offenen Mietenkompostierung 30

Tab. 5.5: Untersuchte Kostenvarianten der Bioabfallbehandlung 34

Tab.5.6: $\quad$ Spezifische Behandlungskosten der Bioabfallkompostierung in 35 landwirtschaftlichen Low-Tech-Anlagen

Tab. 5.7: Zeitbedarf für die Beladung des Streuers mit Frontlader, Transport zur Kompostausbringungsfläche (mittlere Anlage-Feld-Entfernung: $1 \mathrm{Km}$ ) und Kompostausbringung mit dem Streuer

Tab. 5.8: Kostenansätze der Kompostausbringung

Tab. 5.9: Spezifische Verwertungskosten der Transport- und Ausbringungskette mit einem Stalldungstreuer (Ladekapazität: $5 \mathrm{Mg}$ Kompost) in Abhängigkeit von der auszubringenden Kompostmenge

Tab. 5.10: Spezifische Verwertungskosten der Transport- und Ausbringungskette mit einem Tellerbreitstreuer (Ladekapazität: 6 Mg Kompost) in Abhängigkeit von der auszubringenden Kompostmenge

Tab. 5.11: Spezifische Verwertungskosten der Transport- und Ausbringungskette mit einem Stalldungstreuer (Ladekapazität: $5 \mathrm{Mg}$ Kompost) bzw. einem Tellerbreitstreuer (Ladekapazität: 6 Mg Kompost) in Abhängigkeit vom Anlagendurchsatz

Tab. 6.1: Höchstens zulässige Schwermetallkonzentrationen für landbaulich zu verwertende Komposte nach der Bioabfallverordnung (1998)

Tab. 6.2: Mittlere Schwermetallgehalte in Bioabfallkomposten

Tab. 6.3: Mittlere Schwermetallgehalte von Bioabfallkomposten in Prozent der

Grenzwerte der Bioabfallverordnung für eine zulässige

Kompostausbringungsmenge von höchstens $20 \mathrm{Mg}$ innerhalb von 3

Jahren

Tab. 6.4: Mittlere Schwermetallgehalte von Bioabfallkomposten in Prozent der

Grenzwerte der Bioabfallverordnung für eine zulässige

Kompostausbringungsmenge von höchstens $30 \mathrm{Mg}$ innerhalb von 3 Jahren

Tab. 6.5: Schwermetallgehalte in verschiedenen Wirtschaftsdüngern sowie mittlere Schwermetallgehalte der Bioabfallkomposte aus den Anlagen in Tarnow und Borrentin

Tab. 6.6: $\quad \mathrm{pH}-\mathrm{Wert}$ und Schwermetallgehalte im Abwasser aus offenen Anlagen 
Tab. 6.7: Schwermetallfrachten, die bei einmaliger Ausbringung von

Anlagenabwasser und Kompost in den angegebenen Mengen auf einen

Hektar Ackerfläche gelangen

Tab. 6.8: Bodengrenzwerte für Schwermetallgehalte nach der

Bioabfallverordnung (1998) in Abhängigkeit von der mineralischen

Bodenart

Tab. 6.9: Schwermetallgehalte in Böden

82

Tab.6.10: Durchschnittliche Schwermetallgehalte der Aufbringungsflächen in

Tarnow und Borrentin mit den Grenzwerten der BioAbfV (für die Bodenart Lehm)

Tab.6.11: Mittlere Schwermetallfrachten, die mit 6,67 Mg (TM)

Bioabfallkompost ausgebracht werden

Tab. 6.12: Zeitspannen bis zum Erreichen der Bodengrenzwerte der

Bioabfallverordnung durch landbauliche Kompostverwertung unter

Berücksichtigung der Kompost- und Bodenanalysen für den

Landwirtschaftsbetrieb in Tarnow

Tab. 6.13: Zeitspannen bis zum Erreichen der Bodengrenzwerte der

Bioabfallverordnung durch landbauliche Kompostverwertung unter

Berücksichtigung der Kompost- und Bodenanalysen für den

Landwirtschaftsbetrieb in Borrentin

Tab. 6.14: Zeitspannen bis zum Erreichen der Bodengrenzwerte der

Bioabfallverordnung durch landbauliche Kompostverwertung unter

Berücksichtigung ,normaler“ Schwermetallgehalte im Kompost und im Boden

Tab. 6.15: Zeitspannen bis zum Erreichen der Bodengrenzwerte der

Bioabfallverordnung auf den Kompostausbringungsflächen in Tarnow und Borrentin

Tab. 6.16: Salzgehalte in den Bioabfallkomposten aus den Anlagen in Tarnow und Borrentin

Tab. 6.17: Zeitspannen bis zum Überschreiten eines Bodengrenzwerts der

Bioabfallverordnung in den untersuchten Fällen

Tab. 6.18: Gegenwartswerte der Schadensbeseitigungskosten $K\left(t_{0}\right)$ je Hektar

Ausbringungsfläche bei unterschiedlichen Bodenarten und

Kompostqualitäten für eine zukünftige Schadenshöhe von 1 Mio. DM

Tab. 6.19: Gegenwartswerte der Schadensbeseitigungskosten $K\left(t_{0}\right)$ je Hektar

Ausbringungsfläche bei unterschiedlichen Bodenarten und

Kompostqualitäten für zukünftige Schadenshöhen entsprechend den

Verkehrswerten für Agrarflächen in Mecklenburg-Vorpommern bzw.

den alten Bundesländern

Tab. 6.20: Risikoprämien je Mg (TM) Bioabfallkompost bei zukünftigen

Schadensbeseitigungskosten von $1 \mathrm{Mio}$. DM/ha und einer jährlichen

Kompostausbringungsmenge von $6,67 \mathrm{Mg}(\mathrm{TM}) / \mathrm{ha}$

Tab. 6.21: Risikoprämien je Mg (TM) Bioabfallkompost bei zukünftigen

Schadensbeseitigungskosten entsprechend den Verkehrswerten für

Agrarflächen in Mecklenburg-Vorpommern bzw. den alten

Bundesländern und einer jährlichen Kompostausbringungsmenge von $6,67 \mathrm{Mg}(\mathrm{TM}) / \mathrm{ha}$ 
Tab. 7.1: Gesamtgehalte an Pflanzennährstoffen in den Bioabfallkomposten in Tarnow und Borrentin, angegeben in Prozent der Trockenmasse

Tab. 7.2: Mittlere Gesamtgehalte an Pflanzennährstoffen in den Komposten in Tarnow und Borrentin sowie in zum Vergleich herangezogenen Bioabfallkomposten, angegeben in Prozent der Trockenmasse

Tab. 7.3: Nährstofffrachten durch landbauliche Kompostverwertung je Hektar innerhalb von 3 Jahren

Tab. 7.4: Pflanzenverfügbare Nährstoffgehalte in den Bioabfallkomposten aus den Anlagen in Tarnow und Borrentin sowie in zum Vergleich herangezogenen Bioabfallkomposten

Tab. 7.5: Prozentualer Anteil pflanzenverfügbarer Makronährstoffe in den

Bioabfallkomposten aus den Anlagen in Tarnow und Borrentin in bezug auf deren Gesamtgehalte

Tab. 7.6: Nährstoffgehalte und Preise verschiedener Mineraldüngersorten

Tab. 7.7: Preisansätze für die einzelnen Nährstoffe

Tab. 7.8: Monetäre Bewertung der anrechenbaren Nährstoffgehalte an Phosphor, Kalium, Magnesium und Kalzium für $1 \mathrm{Mg}$ (TM) Bioabfallkompost aus den Anlagen in Tarnow und Borrentin

Tab. 7.9: Monetäre Bewertung der N-Nachlieferungen für den mittleren Gesamtgehalt an Stickstoff für $1 \mathrm{Mg}$ (TM) Bioabfallkompost aus der Anlage in Tarnow

Tab. 7.10: Monetäre Bewertung der N-Nachlieferungen für den mittleren Gesamtgehalt an Stickstoff für $1 \mathrm{Mg}$ (TM) Bioabfallkompost aus der Anlage in Borrentin

Tab. 7.11: Monetäre Bewertung der anrechenbaren Nährstoffgehalte an Stickstoff, Phosphor, Kalium, Magnesium und Kalzium, die in $1 \mathrm{Mg}$ (TM) Bioabfallkompost aus den Anlagen in Tarnow bzw. Borrentin enthalten sind

Tab. 7.12: Wesentliche Einflußbereiche von Humus im Boden

Tab. 7.13: Gehalte an organischer Substanz in Prozent der Trockenmasse (sog. „organische Trockensubstanz“ OTS) in den Bioabfallkomposten in Tarnow und Borrentin

Tab. 7.14: Kalkulation der Kosten einer Kleegrasgemenge-Gründüngung 